International Scientific-Technical and Production Journal

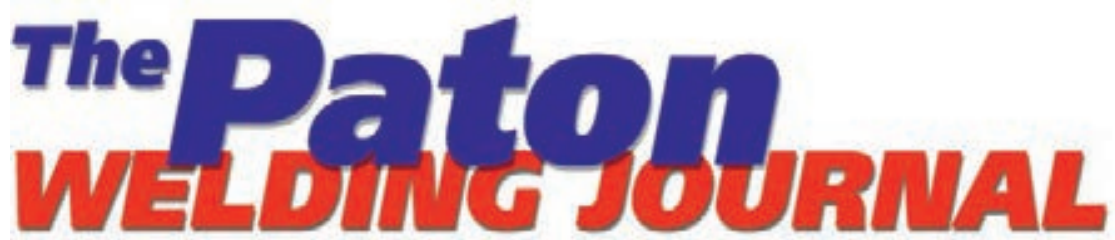

May-June / 2015 Nos. 5-6

Published since 2000

English translation of the monthly «Avtomaticheskaya Svarka» (Automatic Welding) journal published in Russian since 1948

\section{EDITORIAL BOARD}

Editor-in-Chief B.E. Paton Scientists of PWI, Kiev

S.I. Kuchuk-Yatsenko (vice-chief ed.), V.N. Lipodaev (vice-chief ed.),

Yu.S. Borisov, G.M. Grigorenko,

A.T. Zelnichenko, V.V. Knysh,

I.V. Krivtsun, Yu.N. Lankin,

L.M. Lobanov, V.D. Poznyakov,

I.A. Ryabtsev, V.F. Khorunov, K.A. Yushchenko

Scientists of Ukrainian Universities

M.N. Brykov, ZNTSU, Zaporozhie

V.V. Dmitrik, NTU «KhPl», Kharkov

V.F. Kvasnitsky, NUS, Nikolaev

V.D. Kuznetsov, NTUU «KPl», Kiev

Foreign Scientists

N.P. Alyoshin

N.E. Bauman MSTU, Moscow, Russia Guan Qiao

Beijing Aeronautical Institute, China A.S. Zubchenko

DB «Gidropress», Podolsk, Russia M. Zinigrad

College of Judea \& Samaria, Ariel, Israel V.I. Lysak

Volgograd STU, Russia Ya. Pilarczyk

Welding Institute, Gliwice, Poland U. Reisgen

Welding and Joining Institute,

Aachen, Germany O.I. Steklov

Welding Society, Moscow, Russia

G.A. Turichin

St. Petersburg SPU, Russia

Founders
E.O. Paton Electric Welding Institute, NASU

International Association «Welding" Publisher

International Association «Welding" Translators

A.A. Fomin, O.S. Kurochko,

I.N. Kutianova Editor

N.A. Dmitrieva

D.I. Sereda, T.Yu. Snegiryova Address

E.O. Paton Electric Welding Institute International Association «Welding"

11, Bozhenko Str., 03680, Kiev, Ukraine

Tel.: (38044) 20060 16, 2008277

Fax: (38044) 2008277,2008145

E-mail: journal@paton.kiev.ua

www.patonpublishinghouse.com

State Registration Certificate KV 4790 of 09.01 .2001 ISSN 0957-798X

Subscriptions

$\$ 348,12$ issues per year

air postage and packaging included. Back issues available.

All rights reserved.

This publication and each of the articles contained herein are protected by copyright.

Permission to reproduce material contained in this

journal must be obtained in writing from the Publisher.

\section{International Conference «SURFACING SCIENCE. PRODUCTION. PROSPECTS»}

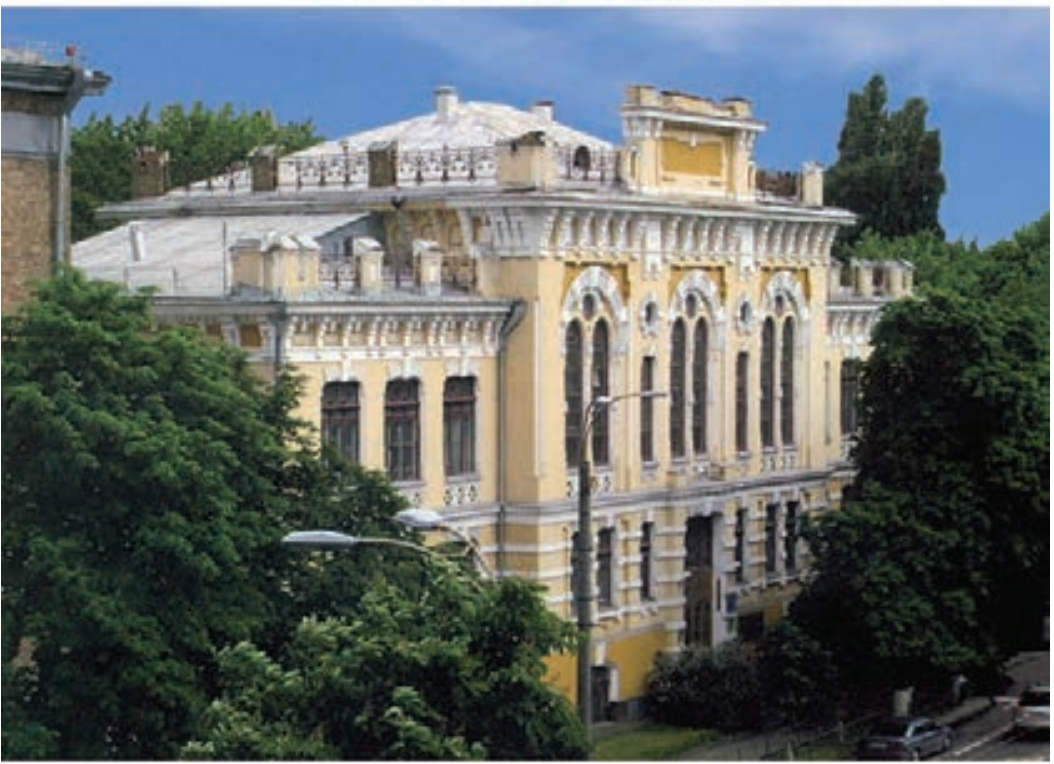

The E.O. Paton Electric Welding Institute of the NAS of Ukraine 15-17 June, 2015

- Modern methods of surfacing, technologies of surfacing and their application

- Surfacing materials. Deposited metal. Composition, structure, properties

- Application of mathematical methods in investigations of surfacing processes

\section{Organizers:}

The E.O. Paton Electric Welding Institute International Association "Welding"

Association «Electrode»

Society of Welders of Ukraine

Russian Welding Society

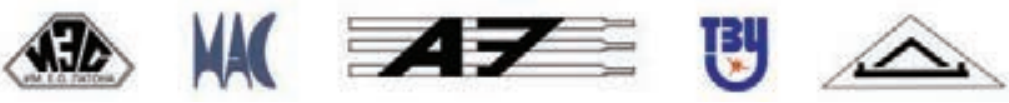




\section{CONTENTS}

«TM. VELTEK Ltd.»: Strategy of development

\section{MODERN METHODS OF SURFACING, TECHNOLOGIES OF SURFACING AND THEIR APPLICATION}

Turyk E. and Rybtsev I.A. Experience in application of the European standards for qualification of surfacing procedures

Pereplyotchikov E.F. Plasma-powder surfacing of nickel and cobalt alloys on copper and its alloys

Yarovitsyn A.V. Energy approach in analysis of microplasma powder surfacing modes

Som A.l. Effect of scheme of powder feeding into arc on its losses and efficiency of plasma-powder surfacing process

Khaskin V.Yu., Shelyagin V.D. and Bernatsky A.V. Modern state and challenges for development of laser and hybrid surfacing technologies (Review)

Kuskov Yu.M., Gordan G.N., Bogajchuk I.L. and Kajda T.V. Electroslag surfacing using discrete materials of different methods of manufacture

Kuzmenko O.G. Peculiarities of heating of stamped billets in non-consumable electrode electroslag surfacing

Majdanchuk T.B., Ilyushenko V.M. and Bondarenko A.N. Improvement of bimetal joint quality in submerged arc surfacing of high-tin bronze on steel

Lendel I.V., Maksimov S.Yu., Lebedev V.A. and Kozyrko O.A. Effect of pulsed electrode wire feeding on formation and wear resistance of deposited bead and losses of electrode metal in $\mathrm{CO}_{2}$ arc surfacing

Peremitko V.V. and Nosov D.G. Optimization of modes of submerged arc surfacing over the layer of alloying charge of caterpillar machine running gear parts

Kuznetsov V.D. and Stepanov D.V. Wear-resistant surfacing with feeding of nanopowders to weld pool .... 47

Bartenev I.A. Peculiarities of fire-cracker plate electrode arc surfacing over alloying charge .................. 52

Grigorenko G.M., Adeeva L.I., Tunik A.Yu., Poleshchuk M.A., Zelenin E.V., Zelenin V.I., Nikityuk Yu.N. and Lukash V.A. Application of friction stir welding method for repair and restoration of worn-out copper plates of MCCB moulds

Pulka Ch.V., Shably O.N., Baranovsky V.N., Senchishin V.S. and Gavrilyuk V.Ya. Ways of updating the technology of induction surfacing of thin steel discs

\section{SURFACING MATERIALS, DEPOSITED METAL. COMPOSITION, STRUCTURE, PROPERTIES}

Mazur A.A., Makovetskaya O.K., Pustovojt S.V. and Brovchenko N.S. Flux-cored wires at the world and regional markets of welding consumables (Review)

Shevchenko S.B., Krivtsun I.V., Golovko L.F., Lutaj A.N. and Slobodyanyuk V.P. Capabilities of laser radiation for improvement of electrode wire quality

Ryabtsev I.A., Panfilov A.I., Babinets A.A., Ryabtsev I.I., Gordan G.N. and Babijchuk I.L. Structure and abrasive wear resistance of deposited metal hardened with carbides of different types

Osin V.V. Flux-cored wires providing deposited metal with high resistance to adhesion wear

Lentyugov I.P. and Ryabtsev I.A. Structure and properties of metal deposited by flux-cored wire with charge of used metal-abrasive wastes

Yushchenko K.A., Kakhovsky Yu.N., Bulat A.V., Samojlenko V.I. and Kakhovsky N.Yu. New electrodes for repair surfacing of damaged lining of impeller chamber of HES hydropower units

Zhudra A.P., Voronchuk A.P., Fomakin A.A. and Veliky S.I. Materials and equipment for surfacing of metal hot cutting knives 
Markashova L.I., Poznyakov V.D., Gajvoronsky A.A., Berdnikova E.N. and Alekseenko T.A. Structure and

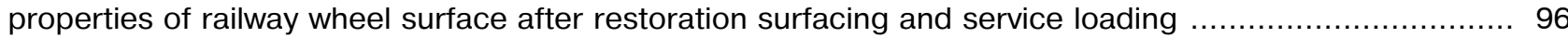

Rosert $R$. Cobalt-based alloys for surfacing 101

Voronchuk A.P., Zhudra A.P., Kochura V.O., Petrov A.V. and Fedosenko V.V. Peculiarities of technology of manufacture and application of flux-cored strips for surfacing

Bely A.I., Zhudra A.P., Roslyakov A.I., Petrov V.V. and Loboda P.I. Effect of alloying on physicomechanical properties of fused tungsten carbides

Sukhovaya E.V. Double-layer surfacing compositions based on filling material of $\mathrm{Cr}-\mathrm{Ti}-\mathrm{C}$ alloying system

Kuskov Yu.M., Gordan G.N., Eremeeva L.T., Bogajchuk I.L. and Kajda T.V. Effect of magnetic-pulsed treatment of filler materials on deposited metal structure

Markashova L.I., Shelyagin V.D., Kushnaryova O.S. and Bernatsky A.V. Effect of technological parameters of laser and laser-plasma alloying on properties of 38KhN3MFA steel layers

\section{APPLICATION OF MATHEMATICAL METHODS IN INVESTIGATIONS OF SURFACING PROCESSES}

Senchenkov I.K., Ryabtsev I.A. and Turyk E. Structural scheme of procedure for calculation of stress-strain state of parts during surfacing and further service

Senchenkov I.K., Chervinko O.P. and Ryabtsev I.A. Calculation of fatigue life of cylindrical parts at multilayer surfacing and service cyclic thermomechanical loading

Gopkalo A.P. and Klipachevsky V.V. Effect of surfacing on stress-strain state of rollers of machines for continuous casting of billets

Kushchy A.M. and Vlasov A.F. Modeling of process of melting of electrodes with exothermal mixture in coating during repair welding and surfacing 


\section{«TM. VELTEK Ltd.»: STRATEGY OF DEVELOPMENT}

Manufacture of flux-cored wires is one of the important trends in the field of welding production of Ukraine, which could in the years of independence to preserve to a great extent the positions at the market under conditions of severe competitiveness with leading foreign brands. In this aspect the great efforts were made by the enterprise TM. VELTEK, which products are well known to the customers not only in Ukraine, but also in Russia, Moldavia, Uzbekistan, Belarus, Turkey. At present the TM. VELTEK is the leading producer of flux-cored wires in Ukraine, which are designed for welding, surfacing and spraying. The nomenclature of wires includes above 80 grades of diameter from 1 up to $6 \mathrm{~mm}$, the customers of which are enterprises of such industry branches as metallurgical, machine-building, mining and others. The Editorial Board of «The Paton Welding Journal» considered it useful to get the readers acquainted with the achievements of the TM. VELTEK and specifics of work of this enterprise. Below, the interview with Andrey A. Golyakevich, the Director of Company, is published.

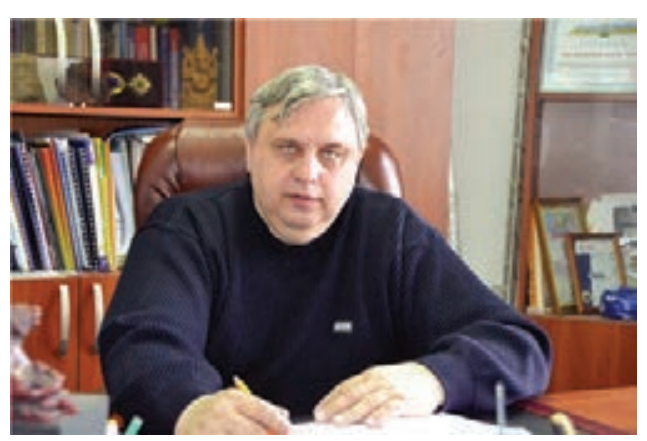

A.A. Golyakevich,

Director of TM. VELTEK Ltd.

Mr. Golyakevich, it is known that You came from the academic sphere. What did stimulate You to organize an independent work, i.e. selection of «free floating»?

Here, there are several reasons. The experience of development of fluxcored wires and organizing of their manufacture and also the experience of implementation in solution of definite industrial problems, which was gained at the E.O. Paton Electric Welding Institute, and, surely, the wish of self-realization.

How did You start? What first steps of You and your company were defined as most important?

The first steps were coming from circumstances, arisen at the beginning of the 1990s, connected with a rupture of trade-economic relations. The delivery of metal strip for flux-cored wire manufacture from Russia to Ukraine was interrupted. Therefore, the Russian-Ukrainian joint venture, «TM. WeldTech», was founded, allowing us to regulate the delivery of strip from Lipetsk Metallurgical Works to Ukraine and to provide at the same time the delivery of flux-cored wires, manufactured at OJSC «Dneprometiz» (DMPO) to the CIS market. All this took place at the conditions of absence of own capacities for manufacture of wires. Team, consisting of specialists of the E.O. Paton Electric Welding Institute, arranged the raw material supply to DMPO, organized research-experimental development of flux-cored wires for the new appeared needs of enterprises, provided marketing and engineering accompanying of the products. This scheme of cooperation of «TM. WeldTech» and DMPO occurred to be very challenging, as it allow us to preserve the production base in DMPO, not to lose the skilled specialists and simultaneously to realize the modernization of capacities for improving the quality of the manufactured products.

What is the further progress of the enterprise?

Having overcome the first difficulties, the further steps became clear for increasing the volumes of production and nomenclature with a continuous improving the quality. It was at this step when the production enterprise TM. VELTEK was distinguished from the joint enterprise. The capacities were rented for manufacture of flux-cored wires (including all the cycle of technological operations) in DMPO. Potential of the enterprise was increased by inviting the young specialists passed the professional training by skilled workers. The systematic work was organized for study of demand for surfacing and welding materials at the enterprises of a number branches of industry. Simultaneously, the work was organized for revision (modernization) of compositions of the earlier manufactured wires taking into account the remarks and requirements of the customers.

What are the strong sides of the enterprise?

It was shown partially in the previous answer. But the main thing is our team, founded this enterprise. All of us were coming from the research department of the E.O. Paton Electric Welding Institute. We have passed the simply fantastic school of Prof. Pokhodnya I.K., which was strict, interesting and effective in different spheres of manufacture of flux-cored wires: scientific, technological, implementing. On the other hand, in the new conditions each of us showed individual abilities more effectively in different sectors of management. This allowed our enterprise to be developed more harmonically and dynamically.

You have modernized the production. What did this give for enterprise?

The modernization of the existing equipment was realized almost at all the operational areas of the production. Installed addition-

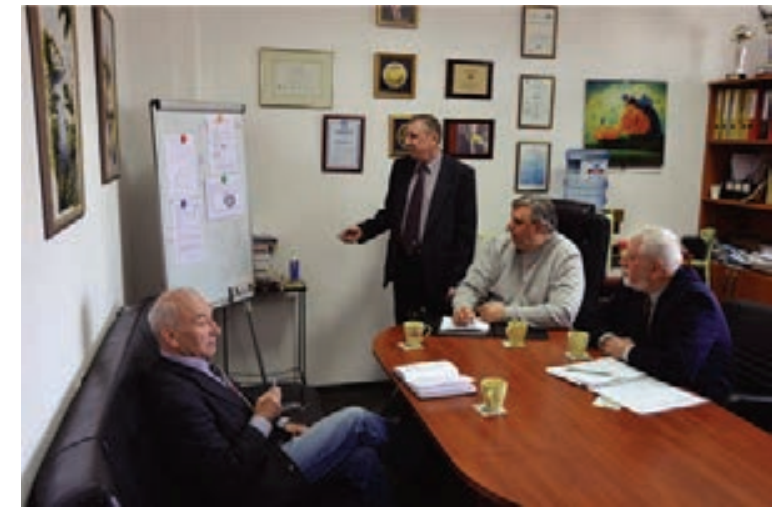

Meeting of Board. From left to right: L.N. Orlov, V.N. Upyr, A.A. Golyakevich, S.P. Giyuk 


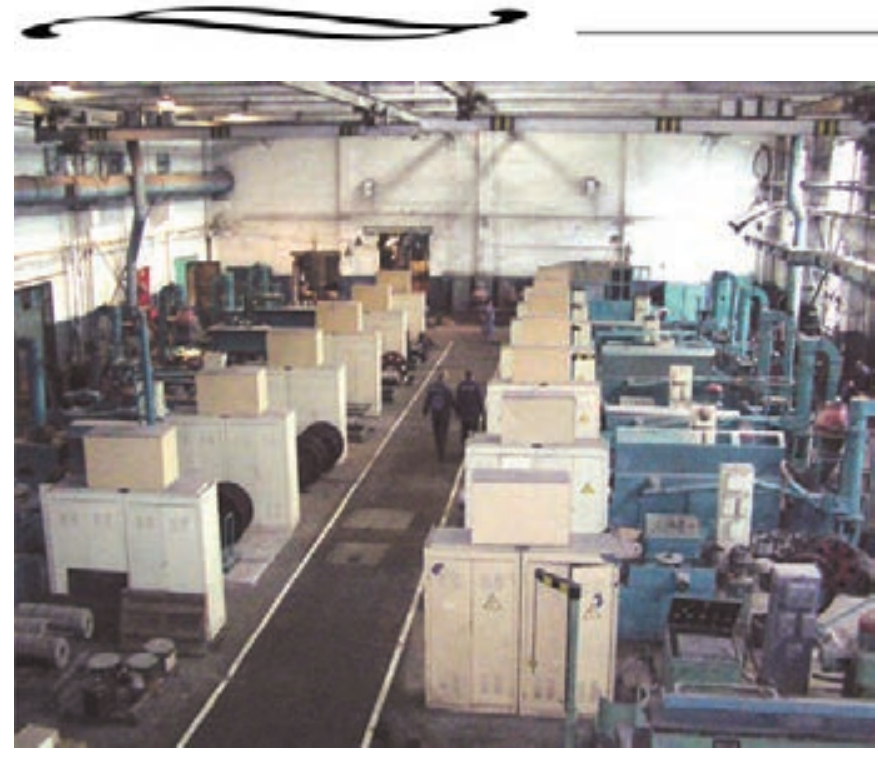

Drawing shop

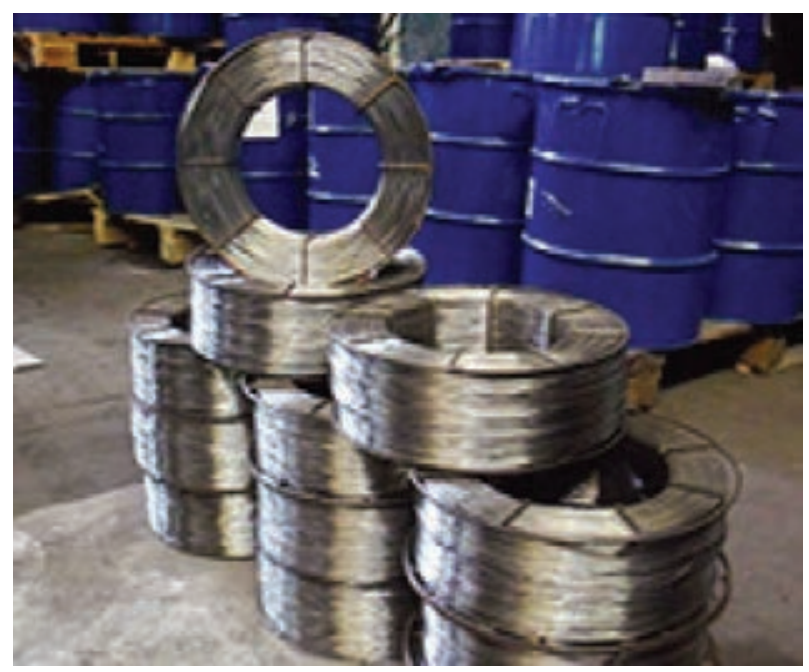

Products of TM. VELTEK

ally were line for strip cleaning, two six-roller mill, several units of crushing and grinding equipment, furnaces for heat treatment of charge materials and ready products, etc. The carrying out of these measures made it possible to widen greatly the nomenclature of manufactured wires, to increase the efficiency of the process of manufacture and, more important, to increase the quality of products.

The company can produce up to 5000 tons of flux-cored wire per year. In fact, the volume of production during recent years is $\mathbf{1 0 0 0}$ tons per year. What are the prospects for increasing the volumes of production?

During recent years many new wires for different branches of industry were developed. As our practical experience show, the time of passing from pilot-industrial types to the mass implementation into production takes from three up to five years. Coming from our capacities we believe to increase the volumes of sale up to 3,000 tons per year, if we have the favorable situation at the market.

To what countries do you deliver the products and what are prospects for widening the geography of delivery?

Except Ukraine our products are supplied to Russia, Belarus, Czechia, Turkey, Baltic countries, countries of Middle Asia and have challenging prospects for coming to the markets of some more countries.

Concerning the quality of products. Do you apply the Quality Management System at the enterprise?

Since 2004 the Quality Management System was implemented and operate successfully, which is in compliance with requirements of ISO 9001:2009, certified by UkrSepro and Russian Maritime Register of Shipping. All the main types of wires were certified by UkrSepro. Wire of TMV-7 grade was certified (and already during 15 years the certificate is confirmed) by Lloyd's Register (Great Britain) and Russian Maritime Register of Shipping. The real characteristic of quality of the manufactured wire is a low share of subquality products (about $0.8-0.9 \%$ ).

What additional services are provided by the Company?

Cutting of strip, crushing and grinding of raw materials. Since 2013 the lines of surfacing and manufacture of oversized metal structures were put into service. In cooperation with partners a specialized surfacing equipment is designed and manufactured.

What are the terms of orders fulfillment?

This depends on volume of delivery and complications in products manufacture. We are shipping from $5 \mathrm{~kg}$ up to railway cars. We can produce up to 7 tons of wires, simultaneously up to 5 grades of diameter from 1 up to 6 mm per one working shift.

What are the prospects of cooperation with the PWI and other research centers and prospects for production of the more high-tech products?

We have a rather beneficial cooperation for a long time with the PWI Department (moreover, the definite results were obtained both in research and production spheres). We also cooperate effectively with Lvov Physical and Mechanical Institute, Priazovsky State Technical University, Dnepropetrovsk University of Railroad Transport, V.N. Bakul Institute for Superhard Materials of the NAS of Ukraine. We support also relations with a number of foreign institutes. We believe that the further widening of cooperation with PWI will enable us to increase the competiveness of products, manufactured by the TM. VELTEK, in improving their quality, development of new grades of wires, that in its turn will guarantee the significant increase in volume of production, and also widen the markets, including those in countries of Europe and Eurasian Union. 


\title{
EXPERIENCE IN APPLICATION OF THE EUROPEAN STANDARDS FOR QUALIFICATION OF SURFACING PROCEDURES
}

\author{
E. TURYK ${ }^{1}$ and I.A. RYBTSEV ${ }^{2}$ \\ ${ }^{1}$ Institute of Welding \\ 16-18 B. Czeslaw Str., 44100, Gliwice, Poland. E-mail: eugeniusz.turyk@glivice.pl \\ ${ }^{2}$ E.O. Paton Electric Welding Institute, NASU \\ 11 Bozhenko Str., 03680, Kiev, Ukraine. E-mail: office@paton.kiev.ua
}

\begin{abstract}
The experience of application of qualification of surfacing procedure in accordance with the European standards is described. Main terminology, used in standards, is given and explained. Qualification of welding (surfacing) works at the enterprise is carried out by the outside independent expert body with an accredited test laboratory of non-destructive and destructive testing. During qualification the testing of procedures of surfacing on standard test specimens in the form of plates or pipes is carried out preliminary. As an exception the qualification of surfacing procedures is allowed on non-standard test specimens simulating the part being surfaced. The quality of deposited test specimens is checked firstly by using the non-destructive methods of testing. At the positive results of these methods of testing the specimens are subjected to the destructive methods of testing. If after testing the inadmissible defects were not revealed, then the expert body makes a protocol about qualification of surfacing procedure WPQR. 5 Ref., 2 Tables, 8 Figures.
\end{abstract}

Keywords: surfacing procedure, qualification, European standard, reference specimen, non-destructive testing, destructive testing

The need in qualification of procedures of welding (surfacing) appeared due to introducing of the International and European standards of the Quality Management System, in which welding is considered as a special process, i.e. process «in which the confirmation of conformity of the final products is difficult» (ISO 9000:2000). It is written in requirements of standard ISO 9001:2008: «Organization should confirm all the processes of production and maintenance, the results of which cannot be checked by successive monitoring or measurements, due to which their drawbacks become evident only after beginning of products use or after rendering the services». Similar requirements to the quality of welding (surfacing) are specified by the series of standards ISO 3834 on quality assurance in welding production.

To have the better understanding of problems of qualification of procedures of welding (surfacing), it is necessary to get acquainted with terminology, used in these standards. In accordance with GOST R ISO 15607-2009 «Technical requirements and qualification of procedures of welding of metallic materials» the following terminology is introduced:
- welding procedure: specified sequence of actions for welding fulfillment, including the recommendations for the process(es) of welding, equipment, base materials and welding consumables, preparation for welding, preheating (when necessary), method and control of welding, postweld heat treatment (when necessary);

- welding process: processes of welding are used in standard, the list and definition of which are given in ISO 857-1, and system of numeration of welding processes according to EN ISO 4063;

- preliminary welding procedure specifications (pWPS): document, containing the values of parameters of welding procedure, which should be qualified;

- welding procedure specification (WPS): document which was qualified by one of methods and which contains the values of parameters of welding procedure, providing repetition of their fulfillment in production;

- work instruction: document, containing the simplified WSP, suitable for applying in the shop;

- welding procedure qualification record (WPQR): protocol containing all the necessary data for qualification of pWPS.

In principle, all this terminology can be referred to surfacing as a process related to welding process, changing the term «welding» for term «surfacing».

To fulfill the standard requirements to the quality of welding (surfacing) works the manu- 


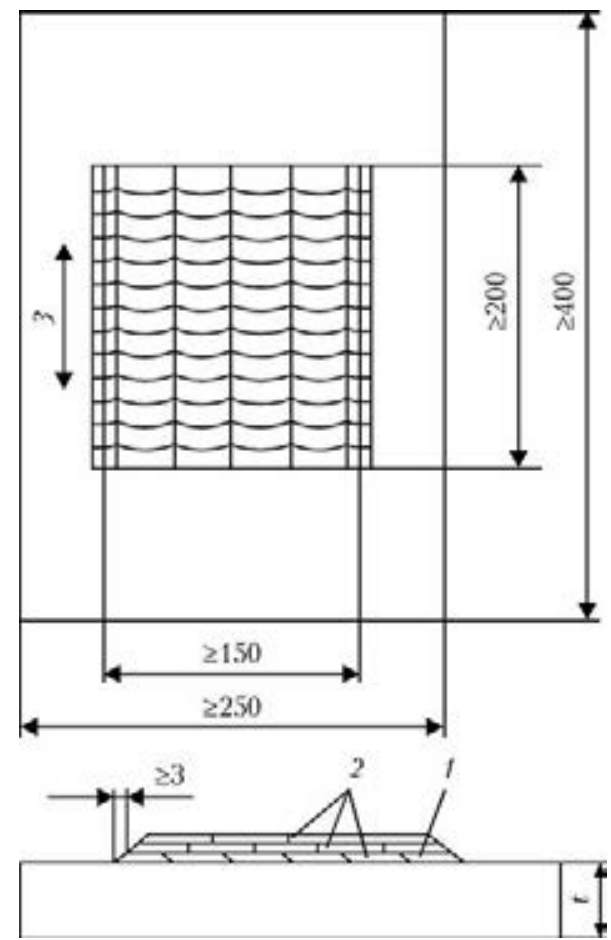

Figure 1. Surfaced test specimen (plate): 1 - buffer layer (sublayer, deposited when necessary); 2 - numbers of layers according to pWPS or total thickness of deposited layer; 3 - direction of surfacing; $t$ - thickness of base metal [1]

facturer should apply the qualified technologies, and method of qualification should correspond to standards for product or technical specifications. The presence of qualified technologies (procedures) of surfacing is the proof of the fact that the industrial technologies are in a complete compliance with the set requirements. Qualification should be made before the fulfillment of welding (surfacing) works at the production facility. It is recommended to carry out qualification of welding (surfacing) works by outside independent expert body with an accredited test laboratory for non-destructive and destructive testing.

Test samples. The obligatory requirement of standard ISO 15614-7 [1] is the conducting of preliminary optimizing of surfacing procedures on standard test specimens in the form of plates or pipes (Figures 1 and 2).

In ISO 15614-7 a regulatory reference to standard ISO 15613 [2] is given, which admits the carrying out of tests of deposited non-standard test specimen, simulating the industrial parts in shape and sizes in that case when their geometry, specific boundary conditions, heat removal, etc. cannot be reproduced by standard specimens. In this case, during qualification, based on the so-called pre-industrial testing, it is necessary to coordinate the details of preparation of nonstandard test specimens, scope of tests and requirements to test results with the expert body. The surfacing of test specimens is performed in accordance with pWPS developed by manufacturer in the presence of expert appointed by the expert body.

Volume of tests and evaluation of results. The tests include the non-destructive and de-

Table 1. Types of tests for surfaced tests specimens [1]

\begin{tabular}{|c|c|c|c|}
\hline Specimen & Type of test & Volume of control & Notes \\
\hline \multirow{9}{*}{$\begin{array}{l}\text { All types of surfacing, } \\
\text { except wear-resistant one }\end{array}$} & Visual inspection & $100 \%$ & - \\
\hline & Ultrasonic flaw detection & $100 \%$ & $a$ \\
\hline & Detection of surface cracks & $100 \%$ & $b$ \\
\hline & Lateral bending & 2 specimens & $c$ \\
\hline & Examination of macrostructure & 1 specimen & - \\
\hline & Examination of microstructure & Same & $d$ \\
\hline & Chemical analysis & $》$ & - \\
\hline & Content of delta-ferrite/ferrite number (FN) & $》$ & $a$ \\
\hline & Hardness measurement & 1 measurement & $d$ \\
\hline \multirow[t]{5}{*}{ Wear-resistant surfacing } & Visual inspection & $100 \%$ & - \\
\hline & Detection of surface cracks & $100 \%$ & $b$ \\
\hline & Examination of macrostructure & 1 specimen & - \\
\hline & Hardness measurement & 1 measurement & - \\
\hline & Examination of microstructure & 1 specimen & $d$ \\
\hline \multicolumn{4}{|c|}{$\begin{array}{l}a-\text { if required by appropriate standards; } \\
b-\text { dye penetrant or magnetic powder flaw detection; } \\
c-\text { bending in transverse direction can be replaced by ultrasonic flaw detection, plus two additional examinations of macrostructure; } \\
d-\text { not required for metal of group } 1 \text { acc. to ISO } 15608 \text { [3]. }\end{array}$} \\
\hline
\end{tabular}



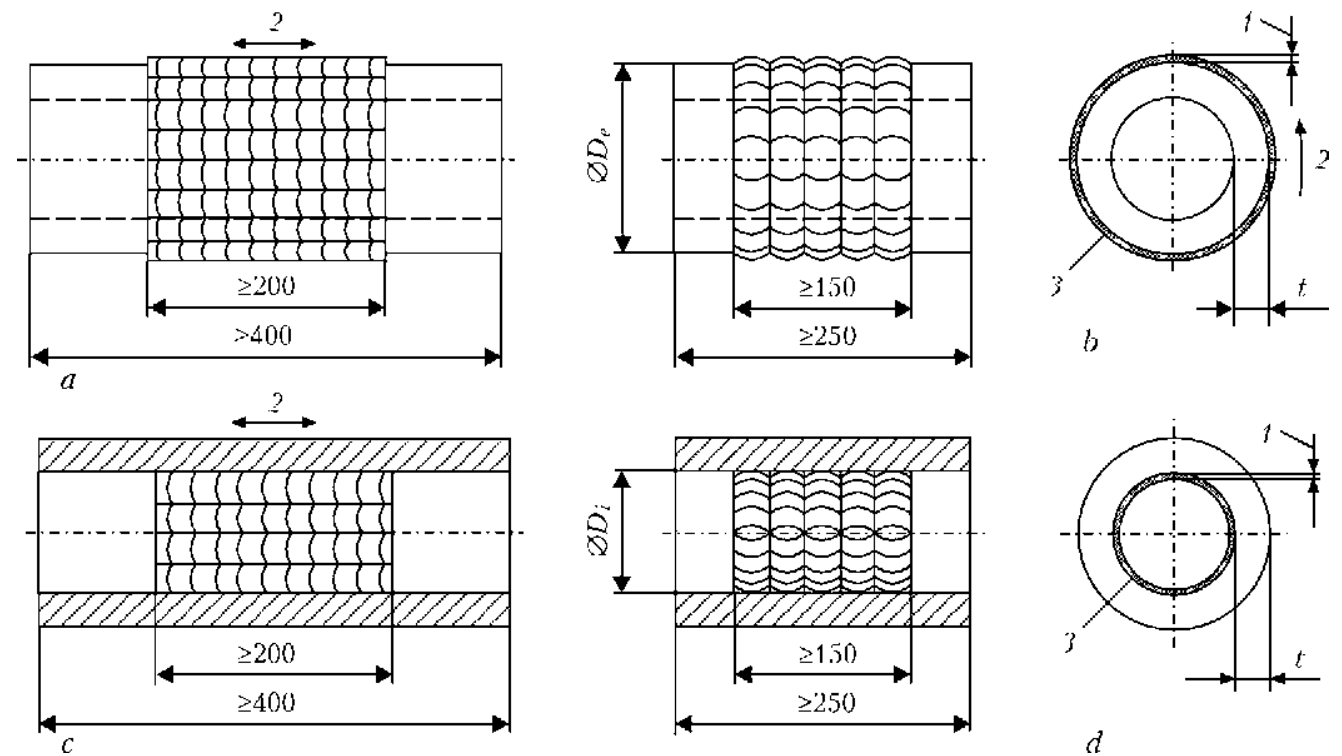

Figure 2. Surfaced test specimen (pipe): $a$ - longitudinal surfacing of external surface; $b$ - circumferential surfacing of external surface; $c$ - longitudinal surfacing of inner surface; $d$ - circumferential surfacing of inner surface; 1 buffer layer (sublayer, deposited when necessary); 2 - direction of surfacing; 3 - numbers of layers according to pWPS or total thickness of deposited layer; $D_{e}-$ external diameter of pipe; $D_{i}-$ inner diameter of pipe; $t-$ thickness of base metal [1]

structive methods in accordance with requirements (Table 1). NDT of test specimens should be made before cutting of specimens for tests. Heat treatment after surfacing, which is preset by the technical specifications, should be carried before the NDT.

If the test specimen satisfies the requirements of visual inspection (cracks and other similar plane defects are inadmissible) and NDT, then the specimens for destructive testing are cut out from it (Figures 3 and 4).

Specimens for examination of macro- and microstructure should be prepared and etched on

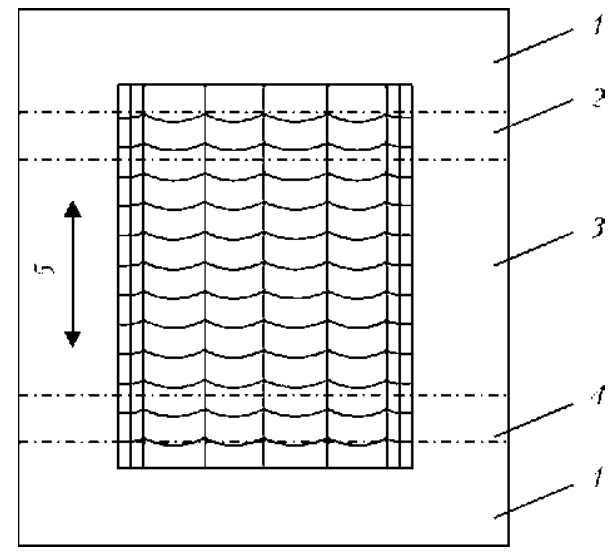

Figure 3. Sequence of specimens cutting out from surfaced plate (test specimen): $1-$ non-controlled zone $\geq 25 \mathrm{~mm}$; 2 - region for specimen cut out for transverse bend tests; 3 - region for specimen cut out for examination of macrostructure, specimen for chemical analysis and determination of delta-ferrite content; specimen for examination of microstructure with hardness measurement; region for cut out of specimens for repeated examinations; 4 - region for specimen cut out for transverse bend tests; 5 - direction of surfacing one side so that to reveal clearly the fusion line, HAZ and deposited layers. Specimens for examination of macrostructure should include a base metal, not touched by a heat effect of surfacing.

Hardness is measured by Vickers method at load $H V 10$ or $H V 5$. Hardness of deposited layer should be measured under angle of about $15^{\circ}$ to the edge surface (Figure 5). In case of wear-resistant surfacing it is necessary to make at least five measurements on polished deposited surface of the test specimen. Hardness is determined as an average value of five measurements.

Hardness of base metal in HAZ should not exceed allowable maximum values, given in $\mathrm{Ta}^{-}$ ble 2. In case of wear-resistant surfacing it is
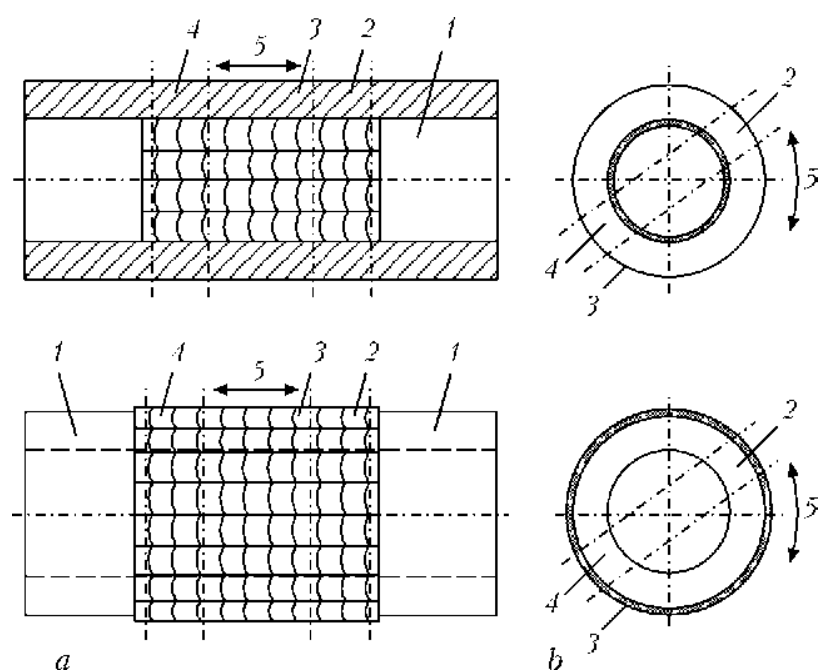

Figure 4. Sequence of cutting out of specimens from pipe (test specimen): $a-$ longitudinal deposited layer; $b-$ circumferential deposited layer (designations are the same as in Figure 3) 


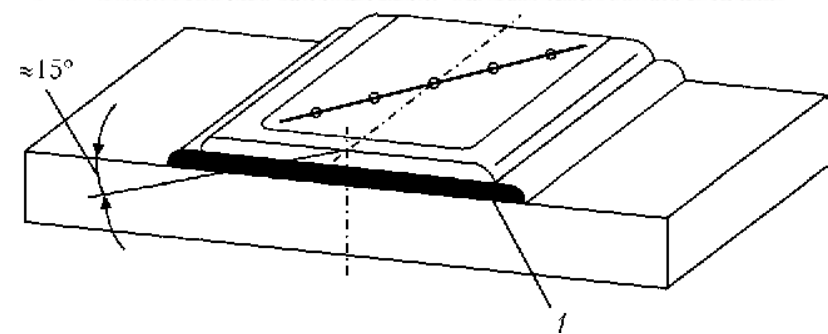

Figure 5. Line of hardness measurement of surfaced specimen: 1 - buffer layer (sublayer)

necessary to determine the maximum value of hardness of the deposited layer. At test for lateral bending the specimen should not have single cracks of length of more than $3 \mathrm{~mm}$ in any direction.

WPQR. If as a result of testing the inadmissible defects were not detected, then the expert body makes a protocol of qualification of surfacing procedure (WPQR). This protocol contains the following data:

- areas, covered by qualification;

- information on technology of surfacing and heat treatment of test specimen;

- results of testing.

It is indicated in the chapter of protocol WPQR, devoted to the areas, covered by qualification:

- process of surfacing according to EN ISO 4063;
- application of surfacing (wear-resistant or another);

- structure of deposited layer (single-layer or multi-layer, number of layers).

In all methods of surfacing, except wear-resistant one, the qualification of single-layer surfacing is valid for the multi-layer one, if the similar technology of surfacing is applied. However, the qualification of the multi-layer is not valid for the single-layer one. In case of the wear-resistant surfacing the qualification of single-layer surfacing is not valid for the multi-layer surfacing. Qualification of the multi-layer surfacing with $N$ layers is valid also to the multi-layer surfacing with number of layers up to $(N+4)$.

Grade, designation and size of electrode (filler) material. Allowance for electrode (filler) material, used in qualification, is valid for other electrode (filler) materials at the conditions that they have equivalent mechanical properties, same type of covering and chemical composition according to designations in a proper standard for electrode (filler) material.

Surfacing current (welding), its kind and polarity. The amount of heat used in surfacing (welding) is determined by EN 1011-1. The upper limit of area of validity of qualification by the amount of heat used for each layer is allowed to

Table 2. Allowable maximum values of HAZ metal hardness $(H V 10)$

\begin{tabular}{|c|c|c|}
\hline Group of steels acc. to ISO/TO 15608 & Without heat treatment & With heat treatment \\
\hline $1^{\mathrm{a}}$ : Unalloyed and fine-grained steels & 380 & 320 \\
\hline 2: Heat-hardened steels & 380 & 320 \\
\hline $3^{\text {b: }}$ Heat-hardened and dispersion-hardened steels & 450 & 380 \\
\hline 4: Low-vanadium $\mathrm{Cr}-\mathrm{Mo}^{-}(\mathrm{Ni})$ steels & 380 & 320 \\
\hline 5: Vanadium-free $\mathrm{Cr}-\mathrm{Mo}$ steels with $\mathrm{C} \leq 0.35 \%$ & 380 & 320 \\
\hline 6: $\mathrm{Cr}-\mathrm{Mo}-\mathrm{Ni}$ steels with increased vanadium content & - & 350 \\
\hline
\end{tabular}
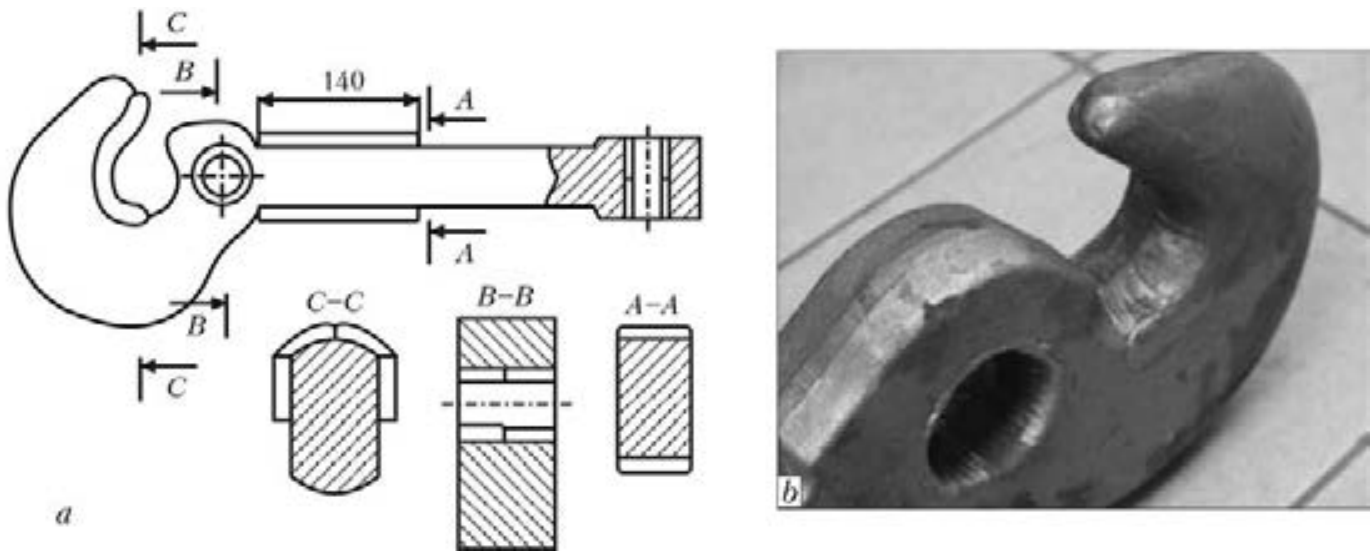

Figure 6. Scheme $(a)$ and appearance of drawhook $(b)$ with deposited layer 4.0-6.2 mm thick 

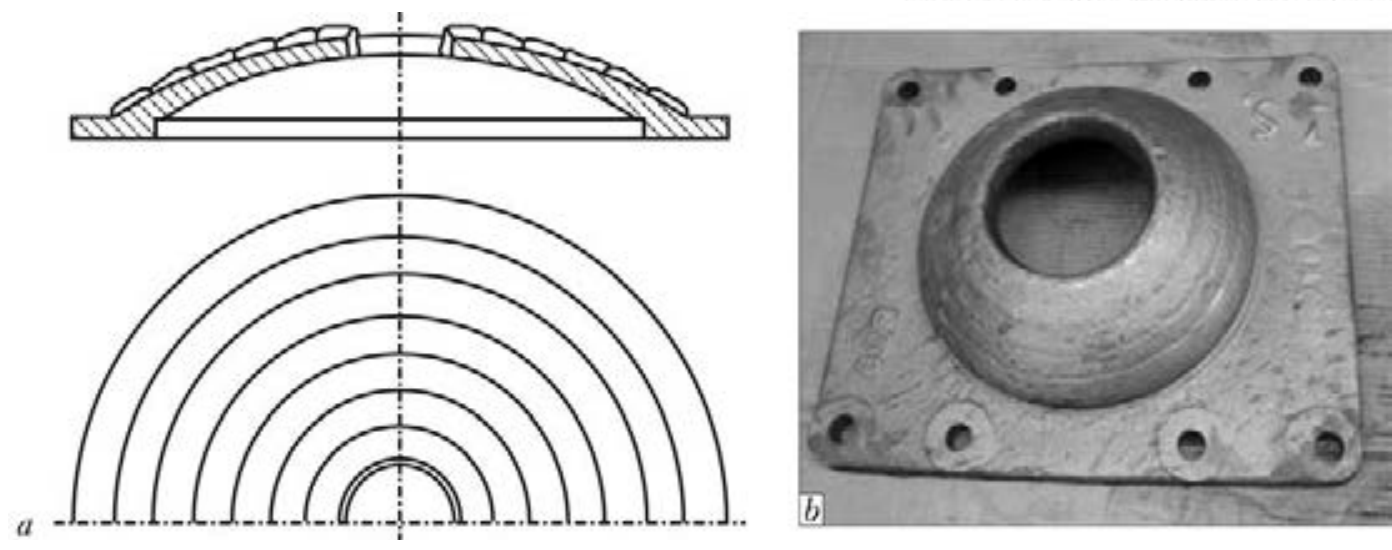

Figure 7. Scheme of cast pivot of steel 45L (with outside diameter of $350 \mathrm{~mm}$, wall thickness of $30 \mathrm{~mm}(a)$, and appearance of surfaced part with deposited layer $4.0-13.8 \mathrm{~mm}$ thick $(b)$
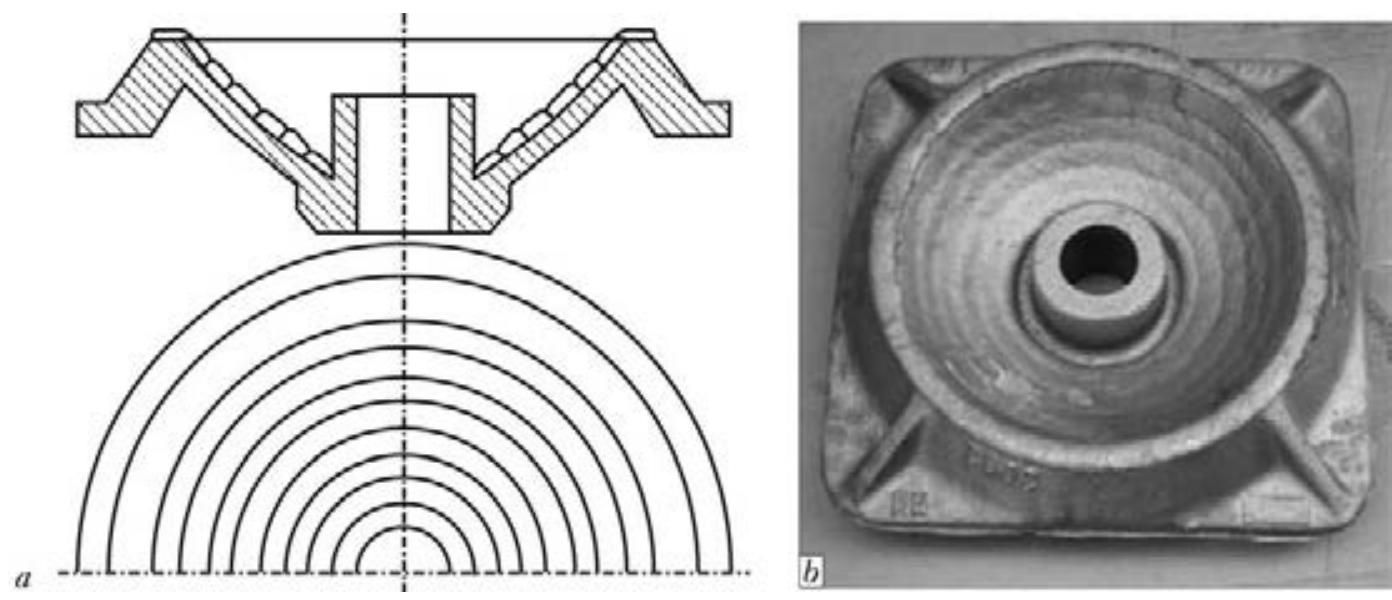

Figure 8. Scheme of cast pivot pocket of steel 45L (with outside diameter of $380 \mathrm{~mm}$, wall thickness of $32 \mathrm{~mm}(a)$, and appearance of surfaced part with deposited layer 9-13 mm thick $(b)$

be set by $25 \%$ higher than the amount of heat supplied for such layer in test specimen surfacing. The lower limit is set by $10 \%$ lower than the amount of heat used in surfacing of the same layer of test specimen.

Position of surfacing. It is allowed to perform surfacing in such a position, at which the surfacing of test specimen was performed.

Temperature of preheating, temperature between passes and heat treatment after surfacing. Adding or refusal of heat treatment after surfacing are not admitted.

Examples of qualification of surfacing procedures. In industrial practice the qualification of procedures of surfacing (welding) is carried out in accordance with ISO 15614-1 [4, 5]. Rods of hydraulic-powered supports are referred to those parts, the technology of surfacing of which was qualified by using this standard, making surfacing of standard test specimens. Qualification of mechanized surfacing with consumable electrode in active gases, under flux and laser surfacing of rods of $38-329 \mathrm{~mm}$ diameter of steel $40 \mathrm{Kh}, 32 \mathrm{KhA}$ and $45 \mathrm{G} 2$ was carried out. The pre-industrial tests of surfaced non-standard test specimens by ISO 15613 taking into account the requirements of ISO 15614-7, were carried out as applied to crane wheels, parts of power stop vales and parts of railway cars (Figures 6-8).

As a result of tests the qualification of procedures of surfacing of all above-mentioned parts in accordance with ISO 15614-7 was carried out. Protocols of qualification of procedure of surfacing (WPQR) were transferred to the enterprises, which are dealing with surfacing of these parts.

1. EN ISO 15614-7:2007: Specification and qualification of welding procedures for metallic materials. Welding procedure test. Pt 7: Overlay welding.

2. EN ISO 15613: Specification and qualification of welding procedures for metallic materials. Qualification based on preproduction test.

3. ISO/TO 15608: Welding. Guidelines on system of grouping of metallic materials.

4. ISO 15614-1:2009: Spefification and qualification of welding procedures for metallic materials. Verification of welding procedure. Pt 1: Arc and gas welding of steels and nickel alloys.

5. Kuzio, T. (2007) Kwalifikowanie technologii spawalniczych przez Instytut Spawalnictwa. Biuletyn Instytutu Spawalnictwa, 2, 50-54.

Received 10.04.2015 


\title{
PLASMA-POWDER SURFACING OF NICKEL AND COBALT ALLOYS ON COPPER AND ITS ALLOYS
}

\author{
E.F. PEREPLYOTCHIKOV \\ E.O. Paton Electric Welding Institute, NASU \\ 11 Bozhenko Str., 03680, Kiev, Ukraine. E-mail: office@paton.kiev.ua
}

\begin{abstract}
The article deals with results of investigation of properties of nickel and cobalt alloys, deposited on copper or its alloys. Investigations of corrosion resistance of these alloys at different types of corrosion (solid, contact, crevice, cavitation-erosion fracture), as well as their antifriction properties and adhesion strength showed that the most acceptable as to the combination of properties are alloys NKh16SR2 and KKh30N6VSR. The technology of automatic plasma-powder surfacing of these alloys on aluminum bronze Br.AZhNMts94-4-1 was developed providing a quality joining of the deposited metal and the base one. The technology and equipment found application in surfacing of parts of ship pipeline fittings. 4 Ref., 1 Table, 6 Figures.
\end{abstract}

$\boldsymbol{K} \boldsymbol{e} \boldsymbol{y} \boldsymbol{w} \boldsymbol{O} \boldsymbol{r} \boldsymbol{d} \boldsymbol{s}:$ plasma-powder surfacing, surfacing on copper, surfacing technology, cobalt- and nickel-based alloys, corrosion, antifriction properties

Surfacing of Ni- and Co-based alloys on copper and its alloys is a rather complicated technical problem since the materials being joined differ greatly by their thermal, mechanical and operational properties. Thus, melting temperature of the mentioned alloys is by $300-350{ }^{\circ} \mathrm{C}$ higher than that of copper and its alloys. The possibility of conducting surfacing itself at the penetration depth of base metal being acceptable for practical purposes becomes problematic. In addition, during solidification process of weld pool metal between an already solidified deposited metal and solid base metal a layer of liquid copper (copper alloy) can remain, which may lead to delamination of the deposited and base metals.

The serious problems in surfacing arise also due to high thermal conductivity of copper and its alloys, i.e. at the beginning of surfacing when a workpiece is cold there is a high risk of lack of fusions; at the end of surfacing (especially when sizes of workpiece are small) the penetration depth of base metal inadmissibly increases. To eliminate these defects it is necessary to change the mode parameters in the surfacing process. The effective thermal capacity of the arc must be adjusted independently of the filler material feed rate.

Iron and cobalt have a limited solubility in copper, and the latter, in its turn, has a limited solubility in iron and cobalt. Therefore, in surfacing of cobalt and iron alloys on copper and copper alloys the problems of metallurgical character occur.

(C) E.F. PEREPLYOTCHIKOV, 2015
As the preliminary investigations showed, these problems can be solved by using plasmapowder surfacing, which is characterized by [1]:

- negligible penetration of base metal;

- lower temperature of weld pool metal and shorter time of contacting molten metal with a solid one at the fusion boundary as compared to the arc surfacing;

- possibility of separate control of heating the base metal and the filler powder feeding that allows taking into account the change in conditions of heat removal from the weld pool at different stages of surfacing process;

- ability to conduct surfacing at direct and reversed polarity at full automation of the process;

- saving consumption of surfacing consumables;

- small allowances for machining of the deposited parts.

Materials and methods of investigations. For investigations as the surfacing materials the powders of alloys based on nickel PR-NKh16SR2 and PR-NKh25S5R, and based on cobalt PRKKh30N6VSR were chosen. Plasma-powder surfacing of specimens was performed on the serial surfacing equipment completed with a plasmatron with distributed side supply of powder into the arc, that provides the widest opportunities for control of filler material heating [1]. All the mentioned powders were produced by spraying the molten metal with nitrogen under the industrial conditions. The fraction of powders was $63-100 \mu \mathrm{m}$. As the base metal, aluminum bronze Br.AZhNMts94-4-1 was selected. The surfacing was carried out in a single layer without preheating; after surfacing the specimens were cooled in air.

According to the conditions of service of parts of pipeline fittings operating in contact with sea 
water, the deposited metal of parts of chemical plants and other equipment must have the high antifriction properties as well as wear and corrosion resistance.

The corrosion resistance of alloys at different types of corrosion (solid, contact, crevice, cavitation-erosion fracture), and also their antifriction properties and adhesion strength with the base metal were investigated.

The tests for continuous and contact corrosion as well as cavitation-erosion fracture were carried out in synthetic sea water at $20{ }^{\circ} \mathrm{C}$ for $2000 \mathrm{~h}$. During testing of the alloys investigated for contact corrosion the ratio of areas of deposited metal and bronze was equal to $1: 1$. In the process of testing the potentials of contacting couple, i.e. deposited metal and bronze, were measured.

The tests for crevice corrosion were carried out in synthetic sea water at $75-80{ }^{\circ} \mathrm{C}$ during $2000 \mathrm{~h}$. The specimens were mounted in the special cells having slots to create a clearance gap between the surface of specimen and material of the cell.

The tests for cavitation-erosion fracture were carried out on the spindle device at $12 \mathrm{~m} / \mathrm{s}$ speed of rotation of specimens. After finishing of corrosion tests the specimens were etched in solution of oxalic-acid aluminum with the purpose of complete removal of corrosion products, washed out, dried and weighed, then the corrosion rate of each material was determined.

Investigation of antifriction properties was performed on the stand simulating the conditions of operation of parts of gate shutter valves. The speed of reciprocating movement was $0.02 \mathrm{~m} / \mathrm{s}$, the number of operating cycles was 2000 at the travel of specimens to one direction for $10 \mathrm{~mm}$. The specific pressure was $400 \mathrm{MPa}$, the lubricant was water. The inspection of specimens was carried out every $5,10,20,50,100,500$ and then every 500 cycles of double travels with registration of operating surfaces condition. The operability of couple and coefficient of friction were determined.

The adhesion strength of deposited metal with bronze was evaluated at rupture tensile testing (Figure 1). The loading rate was $6 \mathrm{~mm} / \mathrm{min}$.

Results of investigations. The rate of continuous corrosion of the tested nickel and cobalt alloys in the environment of sea water does not exceed $0.003 \mathrm{~g} /\left(\mathrm{m}^{2} \cdot \mathrm{h}\right)$, which according to the ten-point scale of corrosion resistance refers to point 1 of GOST 13819-68, and the metal itself is classified as a «highly resistant». In the tests for contact corrosion in all the three cases, the potential of deposited metal is moved to a nega-

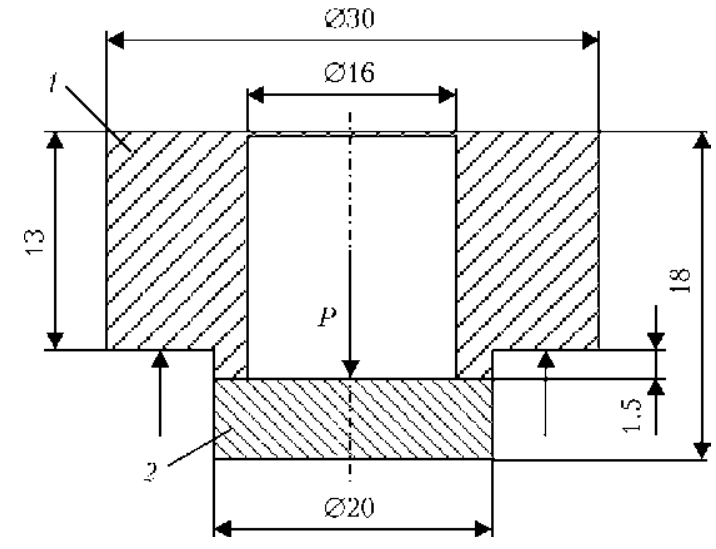

Figure 1. Specimen for rupture tensile test of deposited layer: 1 - base metal; 2 - deposited metal

tive side from the steady value and amounts to $0.15 \mathrm{~V}$. In the slotted gaps the surface of investigated alloys is characterized by negligible corrosion roughness. The bronze in the fusion zone under these conditions was subjected to a selective corrosion. Cavitation-erosion fracture in all the alloys is absent.

During investigation of antifriction properties of the deposited metal on tested specimens with deposits of type NKh25S5R the burrs were revealed after 100 cycles of double travels (see the Table).

As is seen from the Table, the best antifriction properties belong to alloys NKh16SR2 and KKh30N6VSR. In particular, the ability of alloy NKh16SR2 to polish itself during the test determines the lowest coefficient of friction in shear from the place (initiation) and in the movement. Alloys NKh16SR2 and KKh30N6VSR fully meet the requirements specified to stop valves of pipe fittings.

The mechanical and operational properties of bimetal products are largely determined by the properties of fusion boundary. As is seen from the Table, the metal in the fusion zone of cobalt and nickel alloys is characterized by satisfactory

Antifriction properties of deposited metal and its adhesion strength to bronze

\begin{tabular}{||l|c|c|c||}
\hline Grade of powder & $\begin{array}{c}\text { Change in } \\
\text { coefficients of } \\
\text { initiation/ } \\
\text { movement }\end{array}$ & $\begin{array}{c}\text { Number of } \\
\text { cycles before } \\
\text { burr }\end{array}$ & $\begin{array}{c}\text { Adhesion } \\
\text { strength, } \\
\text { MPa }\end{array}$ \\
\hline PR-NKh16SR2 & $\frac{0.218-0.253}{0.168-0.177}$ & 2000 & $\frac{205-367}{294}$ \\
\hline PR-NKh25S5R & $\frac{0.168-0.486}{0.134-0.454}$ & 100 & $\frac{202-298}{261}$ \\
\hline PR-KKh30N6VSR & $\frac{0.219-0.436}{0.185-0.404}$ & 2000 & $\frac{253-410}{334}$ \\
\hline
\end{tabular}

' In numerator the limit values and in denumerator the average values are given according to the test results of 4 specimens. 


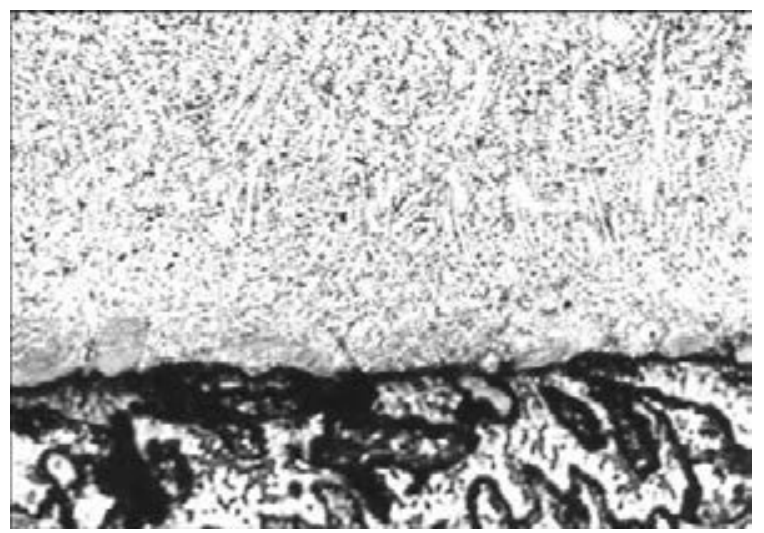

Figure 2. Microstructure $(\times 125)$ of fusion zone of nickel alloy NKh16SR2 with bronze
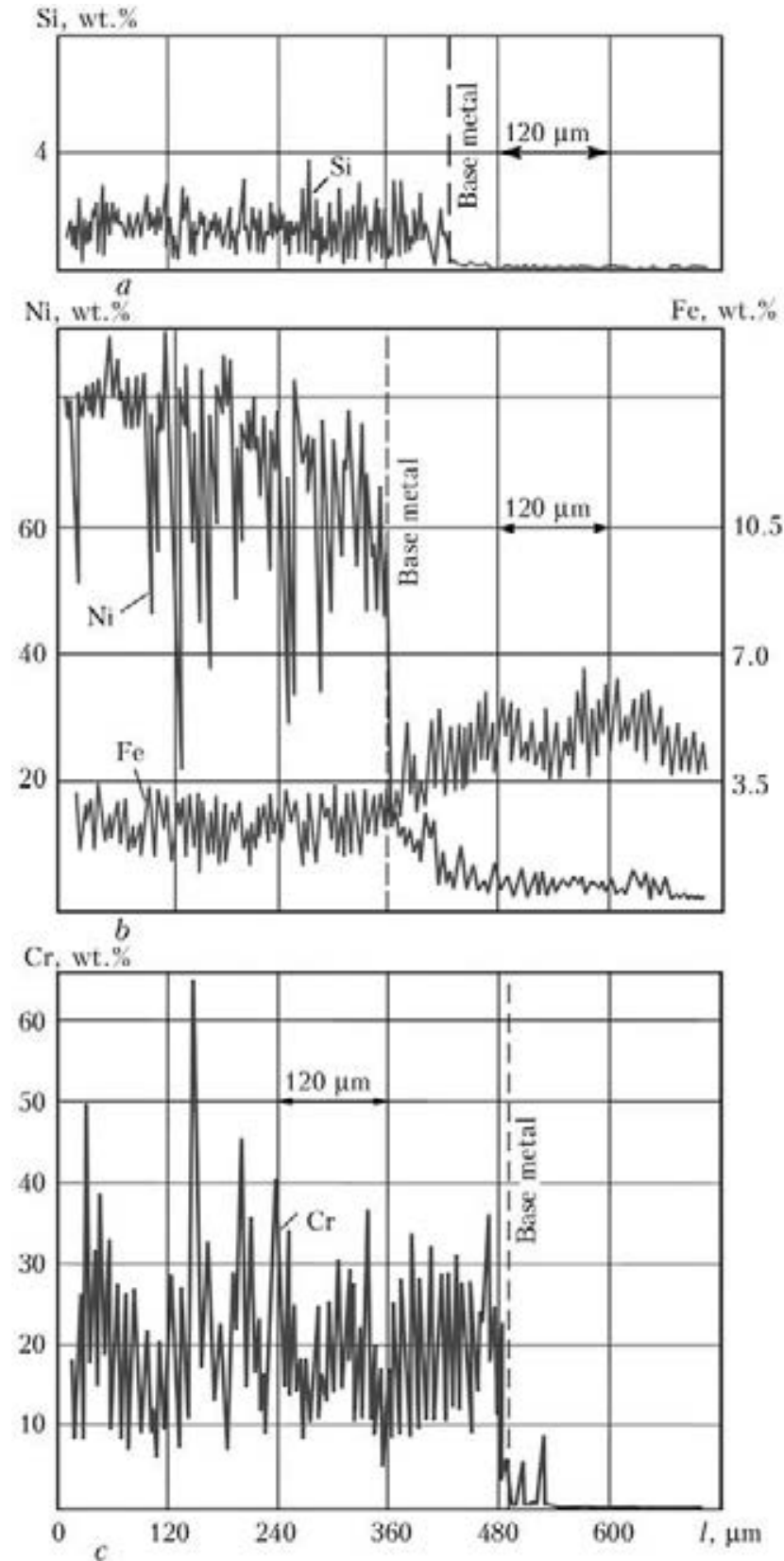

Figure 3. Distribution of alloying elements in the fusion zone of alloy NKh16SR2 with bronze Br.AZhNMts9-4-4-1: $a-$ silicon; $b-$ iron and nickel; $c-$ chromium strength. The fracture of the specimens, deposited by cobalt alloy KKh30N6VSR, during rupture tensile occurs along the base metal. The specimens, deposited by nickel alloys, are fractured along the deposited metal.

Metallographic investigations revealed that in plasma-powder surfacing of nickel and cobalt alloys on aluminum bronze the cracks are absent. The optimal surfacing modes provide reliable $\mathrm{fu}^{-}$ sion of surfacing metal with bronze (Figure 2). In the base and deposited metal near the fusion zone neither depletion nor enrichment by alloying elements are observed. The typical distribution of some elements in the fusion zone of cobalt and nickel alloys with aluminum bronze are illustrated in Figures 3 and 4.

The structure of base metal along the fusion boundary is almost unchanged and typical for aluminum bronze [2]. It consists of dendrites of solid solution, eutectoid and iron component. In surfacing of cobalt and nickel alloys on bronze their structure is somewhat finer than in surfacing on steel. It is evidently affected by a high thermal conductivity of base metal which causes a more rapid cooling of the deposited layer.

Despite the difference in thermal and mechanical properties of base and filler materials, plasmapowder surfacing provides a well-formed deposited layer at a minimum fusion of base metal.

It is known [1] that penetration depth of base metal decreases with increase in arc current and increase in deposition rate, feed rate and fraction of the filler powder. In addition, the shape and dimensions of the deposited product, temperature of its preheating have also a significant influence. During surfacing with oscillations of plasmatron, nonuniformity of penetration depth across the bead width is usually observed, which is connected with different speed of arc movement along the oscillation trajectory. Obtaining uni-

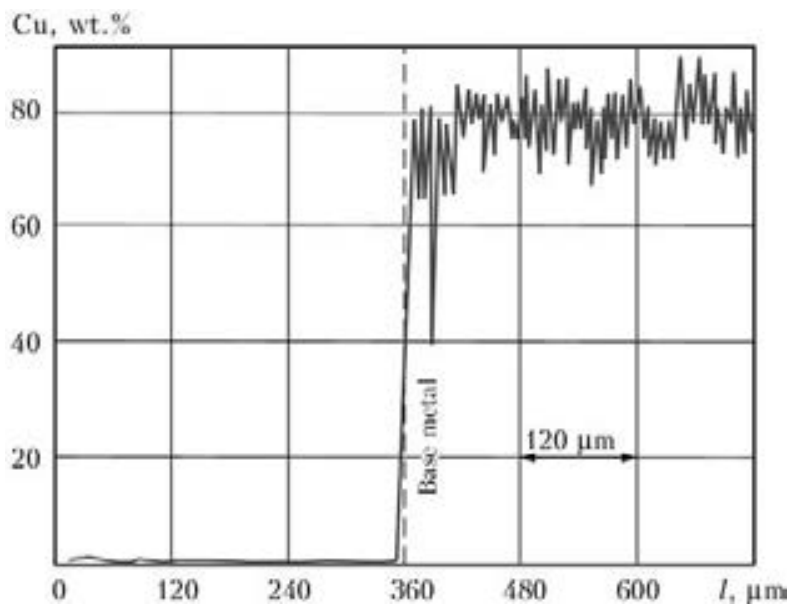

Figure 4. Distribution of copper in the fusion zone of alloy KKh30N6VSR with bronze Br.AZhNMts9-4-4-1 


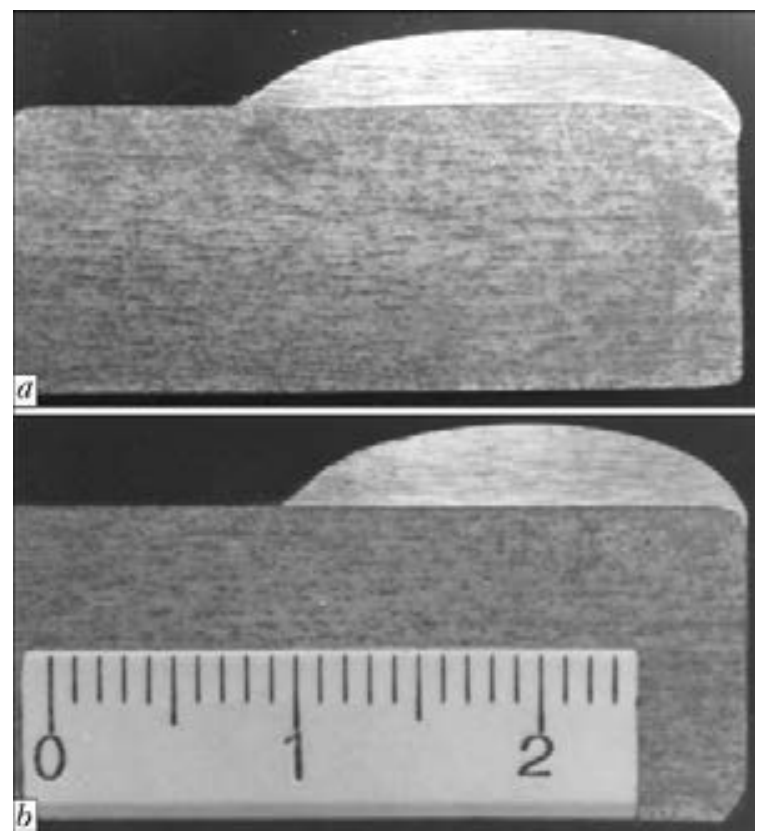

Figure 5. Macrosections of deposited bead: $a-$ without current adjustment; $b$ - with current adjustment across the width of deposited layer

form penetration of base metal is possible by regulating arc current along the trajectory of oscillation (Figure 5). Achieving such technical characteristics of the process is only possible by using computerized equipment. Such equipment provides change in the effective values of arc current and voltage, travel speed of plasmatron, frequency of its oscillations, feed rate of powder and on-line control of these parameters. Change of parameters along the length of deposited bead is preset by a time cyclogram.

Until the recent time at the enterprises for plasma-powder surfacing, universal installations OB 2184 and specialized ones UP-142 were used [3]. The specialized installations were equipped with control system which provides automatic surfacing cycle.

Basing on the experience of operation of such equipment a new control system was developed at the E.O. Paton Electric Welding Institute, providing a full automation of surfacing process and thus optimizing surfacing current and powder feed rate [4]. Using this system the technological algorithms of surfacing were practiced and the discs of bronze Br.AZhNMts9-4-4-1 were deposited (Figure 6). The appearance and macrosection of parts with deposited layer indi-
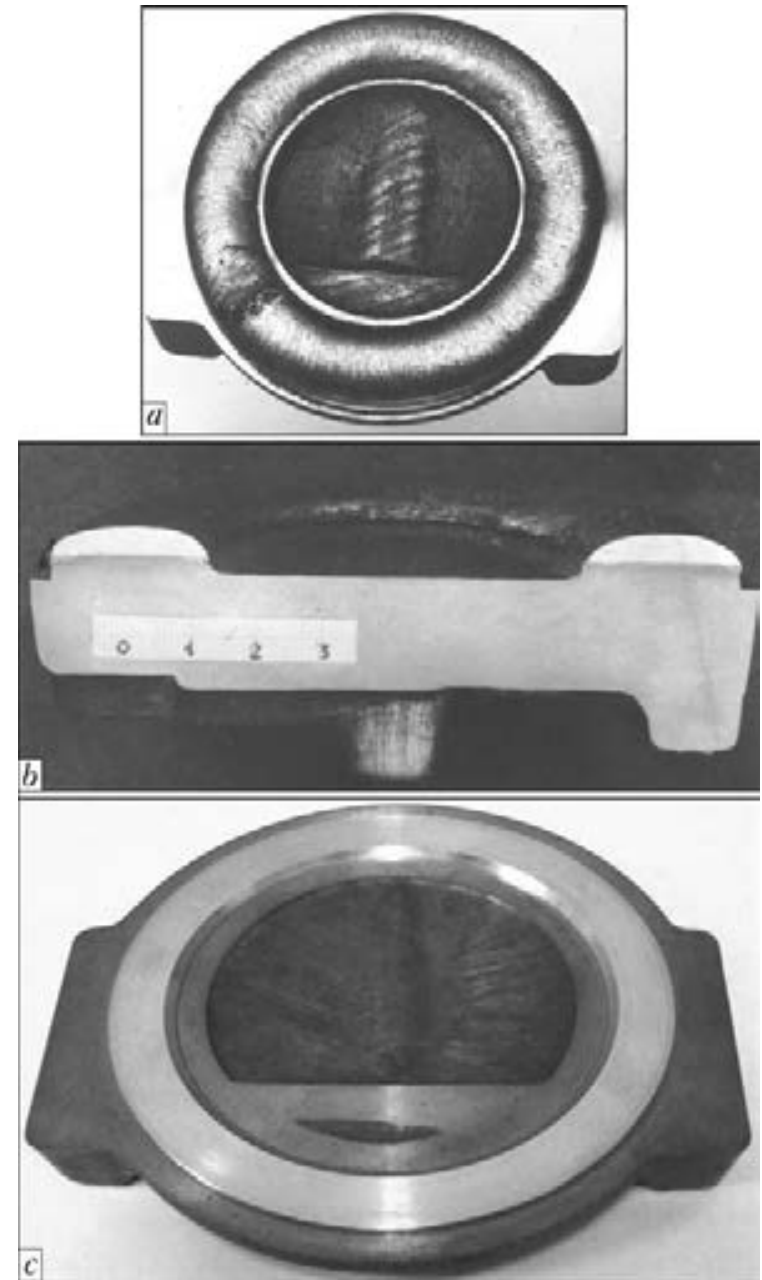

Figure 6. Disc of bronze Br.AZhNMts9-4-4-1 after plasmapowder surfacing using alloy KKh30N6VSR $(a)$, macrosection of this disc $(b)$, and disc after machining $(c)$

cate a good formation of beads. It allows reducing the labor efficiency of machining due to reduction of allowances and obtaining economy of the expensive filler material.

1. Gladky, P.V., Pereplyotchikov, E.F., Ryabtsev, I.A. (2007) Plasma surfacing. Kiev: Ekotekhnologiya.

2. Maltsev, M.V. (1970) Metallography of commercial non-ferrous metals and alloys. Moscow: Metallurgiva.

3. Pereplyotchikov, E.F. (2000) Plasma surfacing. Svarshchik, 2, 8-11.

4. Pereplyotchikov, E.F., Ryabtsev, I.A., Lankin, Yu.N. et al. (2014) Modernization of control system of A1756 machine for plasma-powder surfacing. The $\mathrm{Pa}$ ton Welding J., 12, 41-44. 


\title{
ENERGY APPROACH IN ANALYSIS OF MICROPLASMA POWDER SURFACING MODES
}

\author{
A.V. YAROVITSYN \\ E.O. Paton Electric Welding Institute, NASU \\ 11 Bozhenko Str., 03680, Kiev, Ukraine. E-mail: office@paton.kiev.ua
}

\begin{abstract}
A new procedure for analysis of microplasma powder surfacing modes was proposed on the basis of evaluation of the value of definite integral of welding current magnitude during the time of arc running on the item. It is realized by digital processing of signals from current and voltage sensors with galvanic decoupling from the welding circuit, registered using the analog-digital converter. Its algorithm allows evaluation of the amount of heat applied to the anode for different models of specialized surfacing equipment under the conditions of variation of welding current and of a number of stationary technological parameters, and correlating this value with micro- or macrocracking susceptibility of items from high-temperature nickel alloys in fusion welding. It is established that at limited welding current overall heat input of micropalsma arc into the anode is proportional to weld pool volume and surfacing efficiency. In the case of multilayer surfacing of airfoil edge of GTE blade from JS32 and JS26 alloys it is shown that optimization of the total amount of heat energy allows prevention of microcracking in such a welded joint. 24 Ref., 8 Figures.
\end{abstract}

$\boldsymbol{K} \boldsymbol{e} \boldsymbol{y} \boldsymbol{w} \boldsymbol{o r d} \boldsymbol{s}:$ data acquisition systems, microplasma powder surfacing, high-temperature nickel alloys, amount of heat applied to the anode, susceptibility to microcracking in fusion welding

Measurement, recording and mathematical treatment of electric parameters of the welding arc have been applied for a long time to study the features of arcing, regularities of the process of electrode metal transfer, as well as welding equipment testing [1-10].

At the end of 1980s procedural fundamentals for statistical analysis of oscillograms of electric parameters of reverse polarity welding arcs were developed at PWI under the guidance of Prof. I.K. Pokhodnya [1, 2]. Values of mean root square deviation $\sigma$ and variation coefficient $K_{\mathrm{V}}$ for welding current $I$, voltage $U$ and short-circuiting time $\tau$ were calculated to evaluate their arcing stability in the interval between the shortcircuits. As a rule, oscillographing of arc electric parameters was performed with the frequency of $0.1-20 \mathrm{kHz}$, and sampling dimensions were limited by recording time of $20-40 \mathrm{~s}$, in view of acquisition of sufficient quantity of statistical data. This procedure enabled performance of comparative evaluation [2-4] of:

- technological properties of various models of consumable electrode welding equipment by criterion $K_{\mathrm{V}}^{I}, K_{\mathrm{V}}^{U}, K_{\mathrm{V}}^{\tau} \rightarrow \min$;

- arcing stability for different grades of welding electrodes and wires by $K_{\mathrm{V}}^{U}, \tau \rightarrow$ min criterion;
- stability of running of straight polarity plasma arcs during a continuous time interval.

Data acquisition systems [5-10] have become widely applied recently for recording, processing and analysis of process parameters of the welding arc. These systems allow:

- measuring current and voltage signals using sensors with galvanic decoupling from the welding circuit;

- recording them with discrete frequency of up to $100-200 \mathrm{kHz} /$ channel for practically unlimited time using from 2 to 16 recording channels of analog-digital converters (ADC);

- using specialized programs to perform digital processing and analysis of electric signals, corresponding to process technological parameters: welding current, arc voltage, electrode wire feed rate, welding head displacement, shielding gas flow rate, etc.

Basic methodological support of data acquisition systems [1-4] was complemented by plotting arc dynamic volt-ampere characteristics [5], application of Fourier transforms for frequency analysis of electrode metal mass transfer [5, 6], neural networks for optimization of welding parameters during arcing [7].

At the present stage such systems are hightechnology tools for recording the main parameters of welding processes, which alongside their monitoring [8] and analysis of welding equipment quality [9], also allow optimization of technological control of the welding arc [10].

In welding production, a traditional task is establishing a relationship between weld- 
ing/surfacing parameters and dimensions and quality of welded joints. In a number of cases at nonstationary arcing modes their technological correction is difficult. Objective analysis and optimization of such modes requires establishing specialized criteria for their evaluation. This paper proposes for consideration a procedure for evaluation of mode parameters of nonstationary process of microplasma surfacing, based on application of data acquisition systems.

The process of microplasma powder surfacing $[11,12]$ is used in production in serial repair of aircraft GTE blades [13, 14] from high-temperature nickel alloys with high content of $\gamma^{\prime}$-phase, having limited weldability $[15,16]$. This process is characterized by up to $35 \mathrm{~A}$ welding current, up to $650 \mathrm{~W}$ effective power of microplasma arc, quantity of locally fed disperse filler of up to $9 \mathrm{~g} / \mathrm{min}$. Expansion of its technological capabilities is urgent to include multilayer surfacing and overlapping bead deposition [17]. During surfacing technology optimization, the welded joint can develop macro- or microcracks [14], detected by penetrant testing and/or metallographic examination. Hence the need to optimize both the modes of preliminary and subsequent heat treatment, and those of surfacing proper to ensure the quality and required properties of welded joints.

Depending on narrow substrate width [18] $\delta=0.8-5.0 \mathrm{~mm}$ and required height of the deposited bead, the welding current and amount of powder fed to the weld pool are selected and periodically regulated in the above range [12], proceeding from the technical capabilities of the respective equipment for:

- limiting the penetration depth to less than $2 \mathrm{~mm}$;

- ensuring in the surfacing forefront the wetting angle of base and deposited metal within $20-70^{\circ}$.

Features of welding current variation in a local area are due to successive formation of deposited bead section, and on the whole for the item - to the geometry of restored structural element of the blade (Figure 1). Thus, for this process the main technological factors of its parameter variation are [11-14]:

- kinds and amplitude of welding current variation (continuous, pulsed);

- powder feeding methods (portioned, continuous);

- plasmatron nozzle channel diameters;

- flow rates of plasma, carrier and shielding gases;

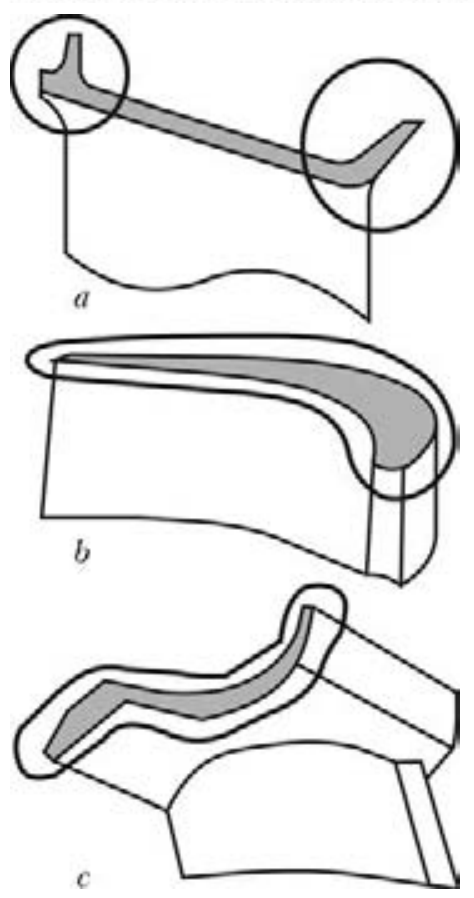

Figure 1. Main types of profiles of surfaced blades of aircraft GTE (on-line correction of surfacing mode is required in marked sections)

- shielding gas compositions (in Ar + 0-10\% $\mathrm{H}_{2}$ system).

All the abovementioned variable factors make it difficult to perform subjective analysis and selection of the possible technological variants of surfacing.

PWI developed and tried out a special procedure for recording and analysis of parameters of microplasma powder surfacing modes, using a data acquisition system. It allows correlation of

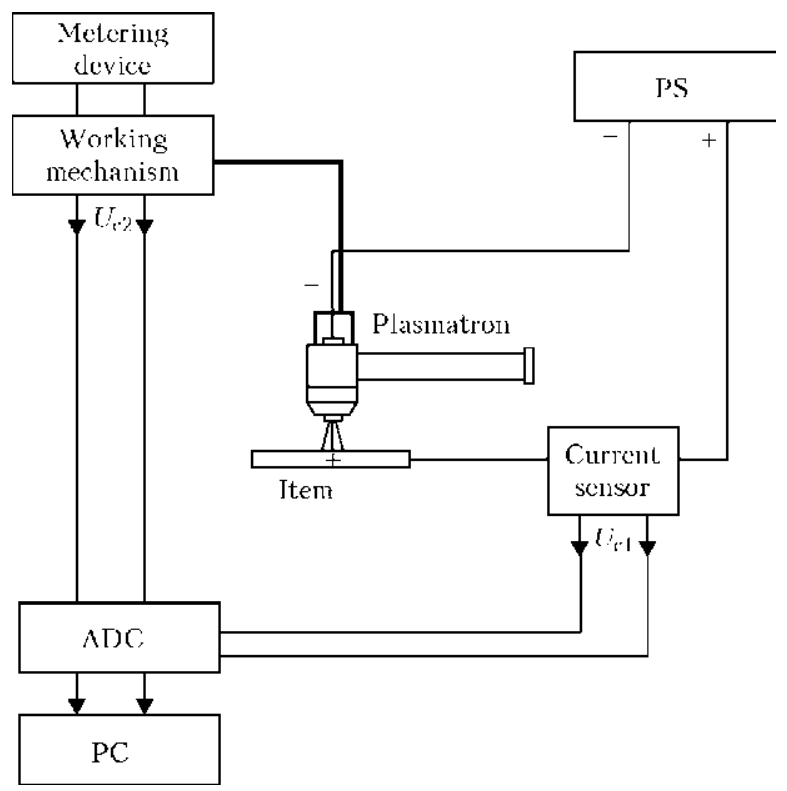

Figure 2. Schematic of measurement and recording of microplasma powder surfacing mode parameters: ADC - analog-digital converter; $\mathrm{PC}-$ personal computer; $U_{\mathrm{c} 1}$, $U_{\mathrm{c} 2}-$ measured signals of voltage from current sensor and powder metering device working mechanism, respectively 


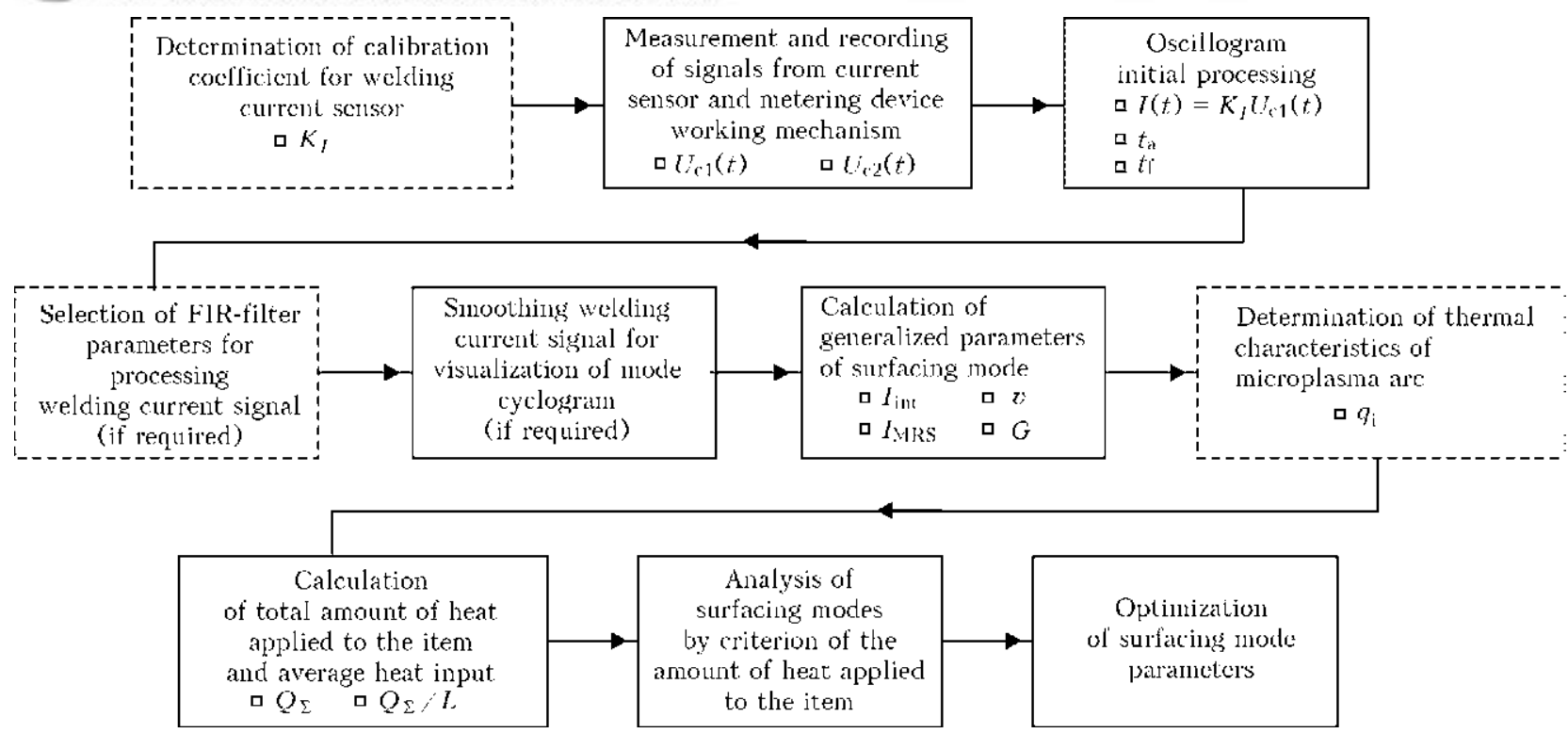

Figure 3. Algorithm for digital processing of signals at analysis and optimization of microplasma powder surfacing modes (dash lines designate preliminary preparation stages)

micro- and macrocracking susceptibility, revealed in the base-deposited metal joint by penetrant testing and metallographic examination, and the amount of heat applied to the item during the surfacing process.

Schematic of measurement and recording of process parameter signals and their digital processing algorithm are given in Figures 2 and 3. The following was used in the data acquisition system:

- ADC, allowing signal recording with 1$10 \mathrm{kHz} /$ channel frequency;

- current sensors of LEM Company designed for measurement of up to 100 A welding current;

- voltage sensor LV-25P for recording $U_{\mathrm{c} 2}$ signal from metering device working mechanism, ensuring disperse filler feeding during surfacing;

- PowerGraph 3.3 software for digital processing and analysis of data.

Shape of $I(t)$ dependence, as well as time of microplasma arc running on the item $t_{\mathrm{a}}$ and time of disperse filler feeding $t_{\mathrm{f}}$ were determined as a result of initial processing of oscillogram signals, measured and recorded in the welding circuit during item surfacing. Appearance of fragments of such welding current oscillograms for various microplasma arc power sources is given in Figure 4.

In the case of recording signals of unstabilized welding current (Figure $4, b$ ) visual analysis of welding current oscillogram is difficult, and further digital processing of the respective signal is required with application of a smoothing digital filter with finite impulse response (FIR-filter) $[19,20]$. Smoothing window size was selected, proceeding from the condition of preservation of the same amplitude and shape of welding current pulses (Figure 4,c). Errors introduced into this signal by digital processing were assessed at computation of mean-root-square value and definite integral for welding current during a fixed time interval:

$$
\begin{gathered}
I_{\mathrm{MRS}}=\sqrt{\frac{1}{N} \sum_{i=1}^{N} I_{i}^{2}}, \\
I_{\mathrm{int}}=\int_{0}^{t} I d t .
\end{gathered}
$$

Error value was determined for signal averaging functions with the following types of weight factors $W_{i}$ [20]: for mean-root-square, triangular and biquadratic windows. Their analysis showed that the integral characteristic of welding current $I_{\text {int }}$ practically does not change at smoothing. Error, introduced into the signal by this kind of digital processing, does not exceed $0.2 \%$. A more significant error of up to $15 \%$ is superposed on the mean-root-square value of welding current $I_{\text {MRS }}$ during digital processing of welding current signal by smoothing. This error can be eliminated by linear correlation.

Surfacing rate $v$ and amount of disperse filler $G$ fed to the plasmatron were calculated, proceeding from the time of micropalsma arc running $t_{\mathrm{a}}$ and functioning of metering device working mechanism $t_{\mathrm{f}}$ determined at initial processing of mode oscillogram:

$$
v=\frac{L}{t_{\mathrm{a}}}
$$

for continuous feeding:

$$
G=G_{0} t_{\mathrm{f}}
$$



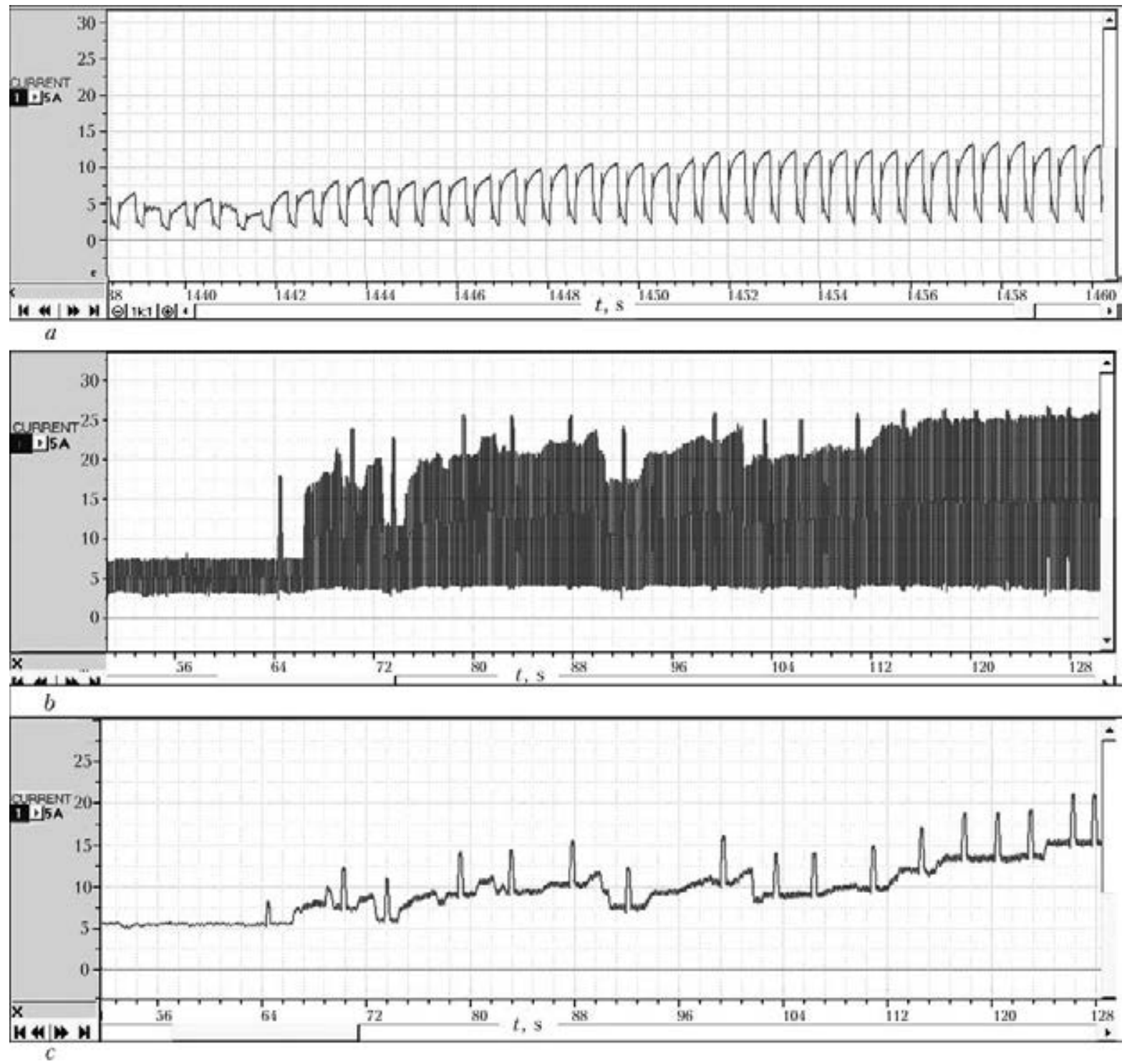

Figure 4. Appearance of fragments of microplasma powder surfacing mode cyclogram $I(t)=U_{\mathrm{c} 1}(t)$ after initial digital processing at signal recording frequency of $2.5 \mathrm{kHz}: a$ - stabilized welding current, Kennametal Stellite system STARWELD PTA $190 \mathrm{H} ; b, c-$ unstabilized welding current, UPNS-304M2/M3 system; welding current pulse frequency of $150 \mathrm{~Hz}$

for portioned feeding:

$$
G=M_{0} N_{\mathrm{mp}},
$$

where $L$ is the deposited bead length; $G_{0}$ is the metering device working efficiency at continuous feeding of filler; $M_{0}$ is the mass of microportion at continuous feeding of disperse filler; $N_{\mathrm{mp}}$ is the number of powder microportions fed to the plasmatron at surfacing during time $t_{\mathrm{f}}$.

The final stage of the proposed algorithm for surfacing mode analysis is determination of the amount of heat $Q_{\Sigma}$, applied to the item. It is known that specific heat input values of welding arcs are characterized by effective power of item heating $q_{\mathrm{i}}$ [21]. In the range of plasmatron optimum thermal load (duty cycle of $100 \%$ ), dependence $q_{\mathrm{i}}(I)$ is linear $[11,12,18]$ and is given by the following equation:

$$
q_{\mathrm{i}}=k_{q} I \pm c_{q},
$$

where $k_{q}$ and $c_{q}$ are the coefficients of linear regression.

Then, allowing for dependencies (2), (6) $Q_{\Sigma}$ value can be determined as follows:

$$
Q_{\Sigma}=\int_{0}^{t_{\mathrm{a}}} q_{\mathrm{i}} d t=k_{q} I_{\mathrm{int}} \pm c_{q} t_{\mathrm{a}},
$$

and mean heat input at bead deposition as $Q_{\Sigma} / L$.

Variation of such stationary technological parameters of the process of microplasma powder surfacing as the ratio of plasmatron nozzle channel diameters, process gas flow rate and shielding gas composition affects microplasma arc thermal characteristics [12], and is preliminarily taken into account at experimental determination of 


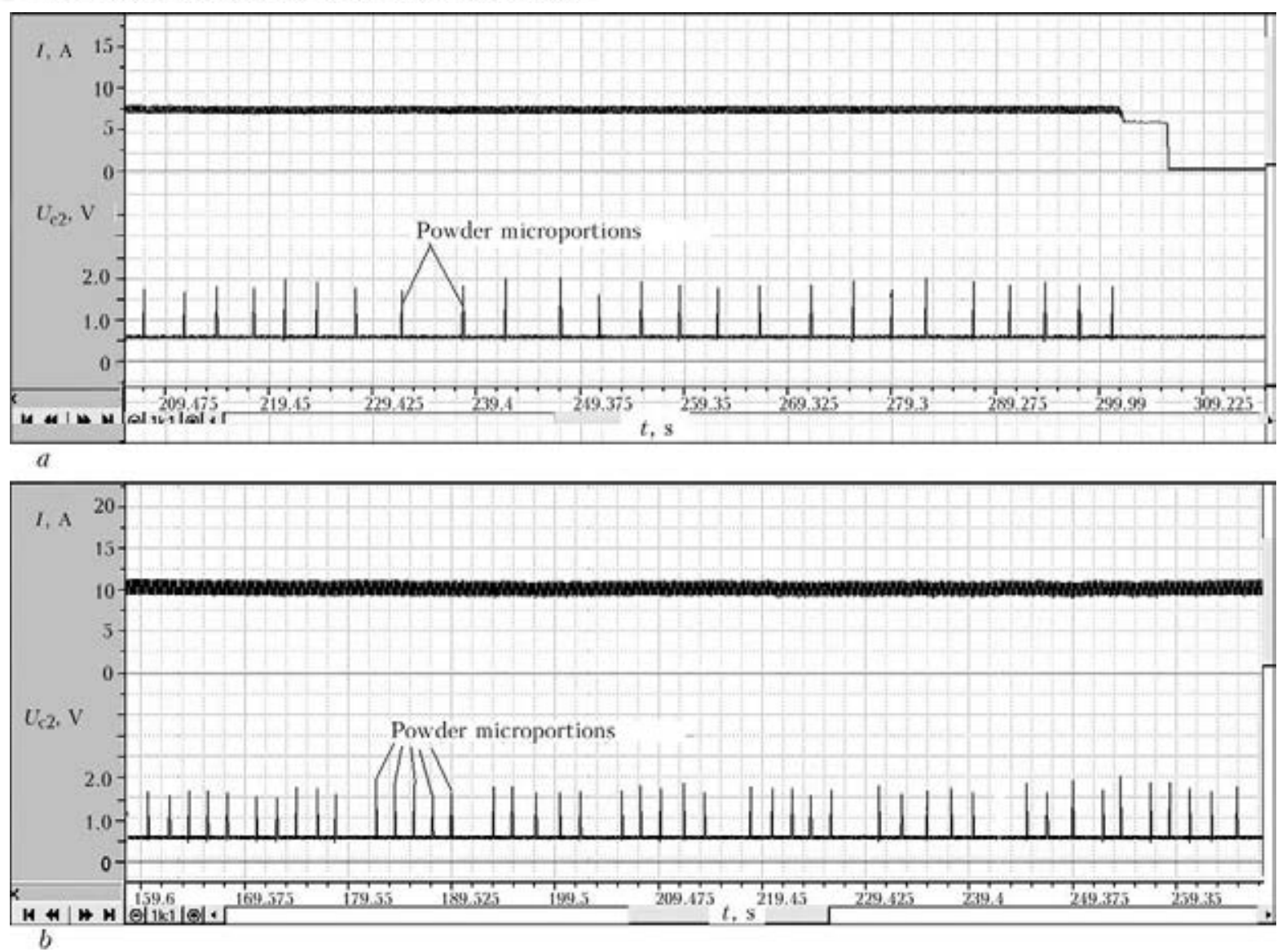

Figure 5. Fragments of oscillgorams of micropasma powder surfacing a narrow substrate $\delta=1.6 \mathrm{~mm}$ with $1(a)$ and 5 (b) disperse filler microportions fed into the weld pool

dependence $q_{\mathrm{i}}(I)$ by the procedure of flow calorimetry $[12,18]$. Note that in view of the mismatch between the conditions of microplasma arc running on a water-cooled copper anode and in real surfacing with weld pool formation, $Q_{\Sigma}$ value determined by us will have a certain systematic error. Its value, according to the data of [22], is roughly estimated as $+7 \%$.

Thus, nonstationary processes of welding current variation during arcing, also for pulsed modes with different principles of their realization, are allowed for through the value of definite integral of welding current magnitude, and most of the possible combinations of stationary process parameters of microplasma arc are determined with acceptable accuracy through application of coefficients $k_{q}$ and $c_{q}$ of linear regression $q_{\mathrm{i}}(I)$ at calculation of heat applied to the anode. Procedure of energy analysis, presented in the paper, allows evaluation of applied amount of heat not only for surfacing the item as a whole, but also at any of its local areas (right up to weld pool dimensions). In combination with determination of deposited metal mass by weighing and measurement of base metal penetration depth, it further allows, at portioned feeding of filler, evalu- ation of a number of parameters given below that characterize weld pool dimensions and pool energy.

Volume of deposited metal in the weld pool is

$$
V_{\text {wpd }}=\frac{M_{\mathrm{d}}}{\rho\left(N_{\mathrm{mp}} / N_{0}-k_{n}\right)},
$$

where $M_{\mathrm{d}}$ is the deposited metal mass; $\rho$ is the deposited material density; $N_{0}$ is the number of filler microportions in one series of weld pool filling; $k_{n}=1$ is the coefficient, allowing for the correction for initial stage of bead formation.

Length of weld pool region in the base metal is

$$
L_{0}=\frac{L k_{0}}{\left(N_{\mathrm{mp}} / N_{0}-k_{n}\right)},
$$

where $L$ is the deposited bead length; $k_{0}=2$ is the coefficient, allowing for overlapping of molten metal volumes at weld pool displacement.

Volume of base metal being remelted is

$$
V_{\text {bmp }}=L_{0} h_{0} \delta,
$$

where $h_{0}$ is the base metal penetration depth; $\delta$ is the narrow substrate width.

Total weld pool volume is

$$
V_{\mathrm{wp}}=V_{\mathrm{wpd}}+V_{\mathrm{bmp}} \text {. }
$$


Thermal efficiency [21] for deposited metal is

$$
\eta_{\mathrm{d}}=\frac{M_{\mathrm{d}} H_{\mathrm{d}}}{q_{\mathrm{i}}},
$$

where $H_{\mathrm{d}}$ is the specific enthalpy of $1 \mathrm{~g}$ of deposited metal.

To reveal the general regularities of the change of heat energy applied to the item depending on microplasma arc power and weld pool dimensions, a series of experiments were performed on bead deposition on a narrow substrate from austenitic stainless steel of width $\delta=1.6 \mathrm{~mm}$ at $I=6-13$ A. Powder of JS32 alloy with $63-160 \mu \mathrm{m}$ particle size was used as disperse filler. Weld pool volume in different experiments was successively increased due to addition of series of filler microportions from 1 up to 6 (see Figure 5). Frequency of portioned powder feed and welding current magnitude in the above-mentioned range were selected so as to ensure at surfacing forefront the wetting angle of base and deposited metal of $30-60^{\circ}$ and limit base metal penetration depth within $2 \mathrm{~mm}$.

In this case in the range of welding currents $I=6-13$ A and effective power of item heating $q_{\mathrm{i}}=140-260 \mathrm{~W}$, this procedure enabled more precise determination of the region of optimum surfacing modes, which corresponds to welding current of 9-10 A and deposited bead height of 3.0 to $3.5 \mathrm{~mm}$ (determined as the distance from fusion line with base metal to bead upper boundary) (Figure 6). In the other cases, increase of heat input into the item is observed, which is due to lowering of surfacing speed below 0.85$0.90 \mathrm{~m} / \mathrm{h}$, as a result of increase of time of:

- sample heating by microplasma arc in the intervals between feeding the powder microportions (up to 6-8 s), required for stable formation of the deposited bead;

- required for feeding into the weld pool 4-6 microportions of disperse filler at further increase of deposited bead volume (up to 12-18 s).

Calculations performed by dependencies (8)(12) for deposited metal JS32 $\left(H_{\mathrm{d}}=861.2 \mathrm{~J}\right.$ calculated on the basis of $[18,23,24])$ allowed analyzing the regularities of variation of effective heating power of the item $q_{\mathrm{i}}$, thermal efficiency for deposited metal $\eta_{d}$ and base metal fraction $\gamma_{\mathrm{bm}}$, depending on weld pool volume for a series of experiments described above. They demonstrate that (Figure 7) beginning from a $q_{\mathrm{i}}$ certain value, somewhat greater than the minimum possible value for the start of a stable surfacing process, weld pool volume can increase 5-6 times, due to feeding disperse filler into it. Here, specific heat input into the anode, and base metal
$Q_{2} / L, J / m m$

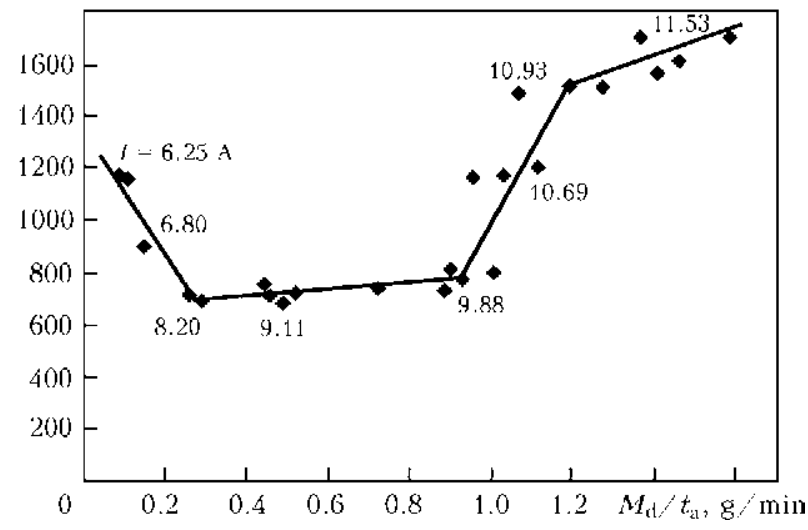

Figure 6. Dependence of heat input $Q_{\Sigma} / L$ on efficiency $M_{\mathrm{d}} / t_{\mathrm{a}}$ and change of welding current average value at surfacing a narrow substrate $1.6 \mathrm{~mm}$ wide

fraction in the weld pool do not change significantly. Under the conditions of limited arc power, bead deposition duration depends on the time of weld pool metal staying in the molten state, which is, in its turn, determined by the duration of the series of portioned filler feeding (see Figure 5). Therefore, amount of heat applied to the item is proportional to bead deposition time, and to pool volume and deposited metal mass, respectively. In view of the known dependence of weld pool metal staying in the molten state on heat input magnitude [21], the modes of microplasma powder surfacing may require op-
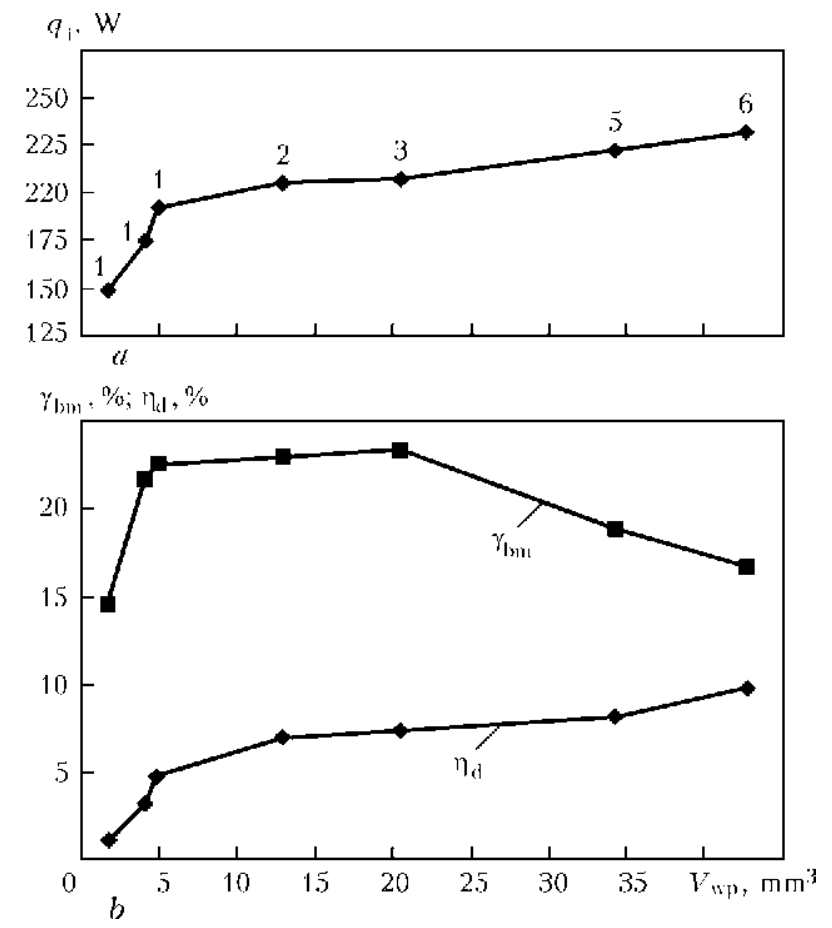

Figure 7. Dependence of effective power of item heating $q_{\mathrm{i}}$ (a), base metal fraction $\gamma \mathrm{bm}$ and thermal efficiency for deposited metal $\eta_{\mathrm{d}}(b)$ on weld pool volume $V_{\text {wp }}$ at deposition on narrow substrate $1.6 \mathrm{~mm}$ wide: $1-6-$ quantity of disperse filler microportions fed into the weld pool 

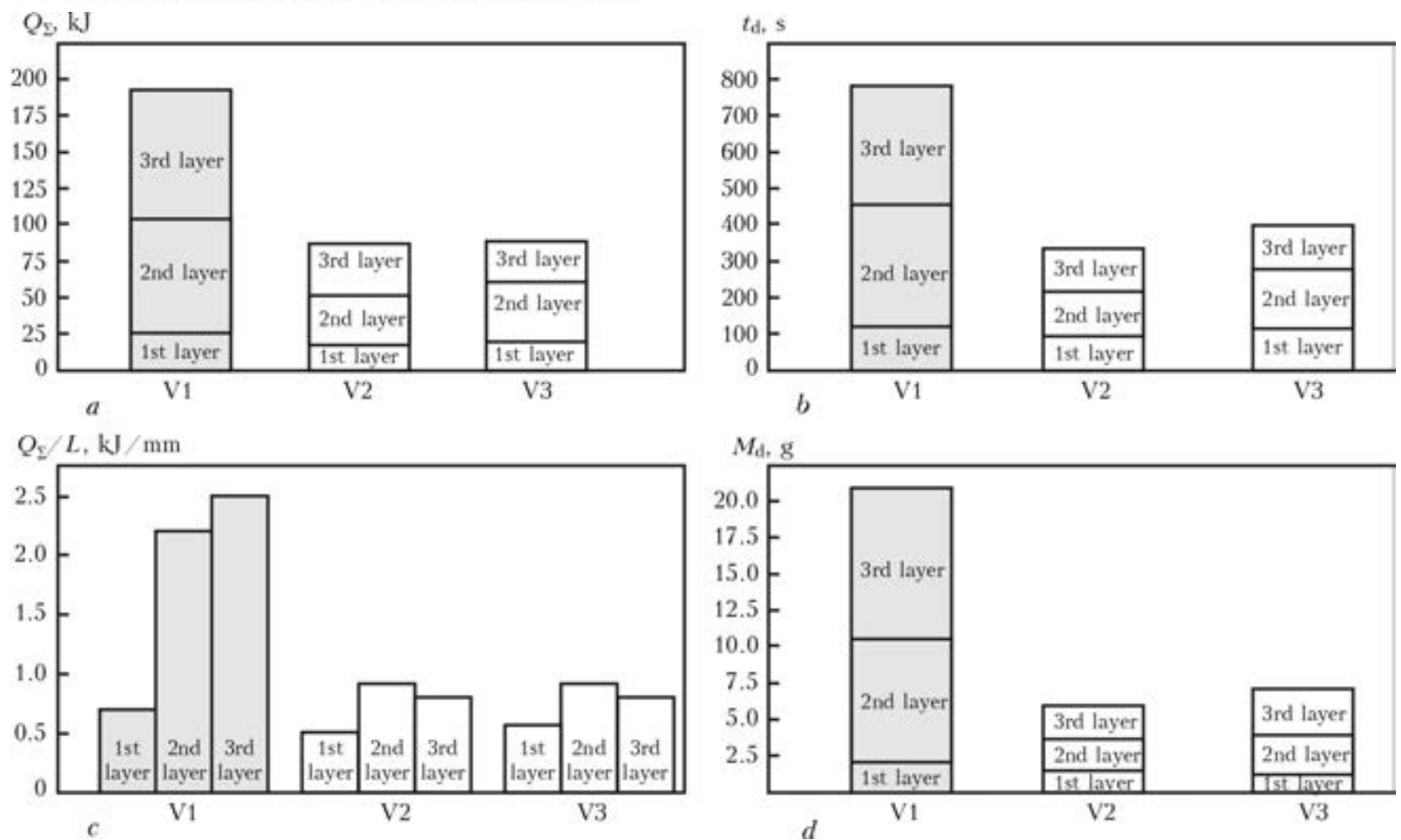

Figure 8. Regularities of variation of amount of heat $Q_{\Sigma}$ applied to the item, surfacing time $t_{\mathrm{d}}$ and average value of welding current at correction of the modes of deposition on a narrow substrate of width $\delta=2.5-6.0 \mathrm{~mm}$ : V1 UPNS-304M2/M3 system, shielding gas $\mathrm{Ar}+10 \% \mathrm{H}_{2}$ : V2 - UPNS-304M2/M3 system, shielding gas Ar $+5 \% \mathrm{H}_{2}$; V3 - STARWELD PTA $190 \mathrm{H}$ system, shielding gas is Ar (filler powder is JS32 alloy; dark colour marks surfacing mode, where microcracking susceptibility is manifested)

timization of their parameters by the criterion of weld pool volume (deposited metal mass).

The above approach was applied for analysis of the modes of multilayer microplasma powder surfacing of airfoil edge of hollow shroudless blades from JS32 and JS26 alloys (see Figure 1, $b)$. At the stage of technology verification, it will allow optimizing the heat input into the item at average welding current of 11-16 A, due to limitation of weld pool dimensions, deposited metal mass and layer deposition duration by the criterion of average heat input $Q_{\Sigma} / L<1 \mathrm{~kJ} / \mathrm{mm}$ (Figure 8, technological variants V2 and V3). By the results of metallographic examination this enabled prevention of microcracks (see Figure 8, V1) at 3-layer deposition of JS32 alloy on a narrow substrate $\delta=2.5-6.0 \mathrm{~mm}$. Modes were corrected in two types of specialized equipment with different principles of pulsed mode formation (see Figure 4, $a, b$ ) and disperse filler feeding.

\section{Conclusions}

In the case of analysis of the modes of surfacing a narrow substrate of $1.6 \mathrm{~mm}$ width it was established that starting with a certain value of microplasma arc effective power, somewhat greater than the minimum possible value for the start of a stable process, weld pool volume can increase 5 to 6 times without any significant in- crease of arc power, due to increase of the amount of added disperse filler. As total heat input into the item is proportional to weld pool dimensions and surfacing efficiency, optimization of the modes of microplasma surfacing by the criteria of deposited metal mass and heat input may be required.

Application of the developed procedure of evaluation and analysis of the amount of heat, applied to the item, allowed at the stage of technology verification eliminating microcracking in the deposited metal at 3-layer surfacing of airfoil edge $2.5-6.0 \mathrm{~mm}$ wide for hollow shroudless blades from JS32 and JS26 alloys. Optimization of total heat inputs into the anode by $Q_{\Sigma} / L<$ $<1 \mathrm{~kJ} / \mathrm{mm}$ and $M_{\mathrm{d}}<3 \mathrm{~g}$ criteria was realized in two types of specialized equipment with different principles of pulsed welding current formation and disperse filler feeding method.

1. (1988) Statistic assessment of metal transfer and stability of welding arcing: Procedural recommendations. Kiev: PWI

2. Pokhodnya, I.K., Zaruba, I.I., Ponomaryov, V.E. et al. (1989) Criteria of evaluation of stability of DC arc welding process. Avtomatich. Svarka, 8, 1-4.

3. Pokhodnya, I.K., Zaruba, I.I., Ponomaryov, V.E. et al. (1990) Methods of comparative evaluation of technological properties of welding equipment and materials. Ibid., 5, 1-5.

4. Kirevsky, I.E., Amosov, A.P., Popov, V.V. (1997) Disturbance of stability of constricted arc running. Svarochn. Proizvodstvo, 4, 23-24. 
5. Pirumov, A.E., Skachkov, I.O., Suprun, S.A. et al (2007) Specialized complex for welding process monitoring. PiKAD, 4, 18-19.

6. Akinci, T.C. (2010) Time-frequency analysis of the current measurement by Hall effect sensors for electric arc welding machine. Mechanica, 85(5), 66-71.

7. Akinci, T.C., Nogay, H.S., Gokmen, G. (2011) Determination of optimum operation cases in electric arc welding machine using neural network. J. Mechanical Sci. and Technol., 25(4), 1003-1010.

8. Lebar, A., Selak, L., Vrabic, R. et al. (2012) Online monitoring, analysis and remote recording of welding parameters to welding diary. J. Mechanical Eng., $58(7 / 8), 444-452$.

9. Paton, B.E., Korotynsky, A.E., Skopyuk, M.I. et al. (2002) System of in-process quality control of welding equipment during its manufacturing. The Paton Welding J., 5, 25-27.

10. Lankin, Yu.N., Ryabtsev, I.A., Soloviov, V.G. et al. (2014) Effect of electric parameters of arc surfacing using flux-cored wire on process stability and base metal penetration. Ibid., 9, 25-29.

11. Yarovitsyn, A.V., Yushchenko, K.A., Nakonechny, A.A. et al. (2009) Peculiarities of low-amperage argon-arc and microplasma powder cladding on narrow substrate. Ibid., 6, 31-35.

12. Yarovytsyn, O.V. (2009) Microplasma powder cladding of high-temperature nickel alloys with $\gamma^{\prime}$-phase content of 45-65\%: Syn. of Thesis for Cand. of Techn. Sci. Degree. Kyiv: PWI

13. (2010) Technological Seminar of Deloro Stellite in Saporozhie. The Paton Welding J., 1, 46-49.

14. Yushchenko, K.A., Savchenko, V.S., Yarovitsyn, A.V. (2010) Development of the technology for repair by microplasma powder cladding of flange platform faces of aircraft engine high-pressure turbine blades. Ibid., 8, 21-24.
15. Sorokin, L.I., Lukin, V.I., Bagdasarov, Yu.S. (1997) Weldability of cast high-temperature alloys of JS6 type. Svarochn. Proizvodstvo, 6, 12-17.

16. Sorokin, L.I. (1999) Stresses and cracks in welding and heat treatment of high-temperature nickel alloys. Ibid., 12, 11-17.

17. Yushchenko, K.A., Yarovitsyn, A.V. (2012) Improvement of technology for repair of upper flange platform face of aircraft gas-turbine engine blades. In: Transact. of NAS of Ukraine on Problems of resource and service safety of building and machine structures: Results of 2010-2012, 506-509. Kiev: PWI.

18. Gladky, P.V., Pereplyotchikov, E.F., Ryabtsev, I.A. (2007) Plasma surfacing. Kiev: Ekotekhnologiya.

19. Kester, W. (2010) Design of systems of digital and miscellaneous signal processing. Moscow: Tekhnosfera.

20. Izmajlov, D.Yu. (2009) PowerGraph: Handbook on signal processing functions, Pt 2. PiKAD, 2, 26-28.

21. Petrov, G.L., Tumarev, A.S. (1967) Theory of welding processes (with fundamentals of physical chemistry). Moscow: Vysshaya Shkola.

22. Yarovitsyn, A.V., Novikov, S.V. (2009) Methodological support of immersion calorimetry of low-amperage arcs. In: Proc. of 5th All-Ukrain. Sci.-Techn. Conf. of Young Scientists and Specialists on Welding and Related Technologies (Kiev, Ukraine, 27-29 May, 2009). Kiev: PWI.

23. Zhiguo Gao, Ojo, O.A. (2012) Modeling analysis of hybrid laser-arc welding of single-crystal nickel-base superalloys. Acta Mater., 60, 3153-3167.

24. Frumin, I.I. (1961) Automatic electric arc surfacing. Kharkov: Metallurgizdat.

Received 15.04.2015 


\title{
EFFECT OF SCHEME OF POWDER FEEDING INTO ARC ON ITS LOSSES AND EFFICIENCY OF PLASMA-POWDER SURFACING PROCESS
}

\author{
A.I. SOM \\ «Plasma-Master Ltd.» Company \\ 3 Krzhizhanovsky Str., 03680, Kiev, Ukraine. E-mail: info@plasma-master.com
}

\begin{abstract}
Area of investigation was powder losses in plasma-powder surfacing using plasmatrons with internal and external schemes of its feeding into arc. Dependence of powder losses on its fraction, geometry of deposited bead and surfacing efficiency was shown. It is determined that losses of powder from steel 10Kh18N10T are 4-5 times lower at internal scheme of feeding, due to its more effective heating in the arc than at external one and do not exceed 1-2 \% under favorable conditions. Practical recommendations on efficient application of plasmatrons with different systems of powder feeding are given. 4 Ref., 1 Table, 6 Figures.
\end{abstract}

Keywords: plasma-powder surfacing, powder losses, plasmatron, scheme of powder feeding, heating efficiency, particle flying path, bead formation

Efficiency of process of plasma-powder surfacing (PPS) mainly depends on heating efficiency and melting of filler powder in arc. The better powder heating in the arc is, the less its losses and the higher surfacing productivity are under the same process parameters. Besides, base metal penetration is lower and formation of deposited bead is better.

It is well-known fact [1] that efficiency of powder heating in PPS depends to significant extent on scheme and parameters of its feeding in arc. They determine flaying path and velocity of particles as well as time of their staying in the arc. Details on process of powder heating and melting in the arc are given in works [2, 3]. Practical recommendations of these investigations made a basis for development of current plasmatrons [4].

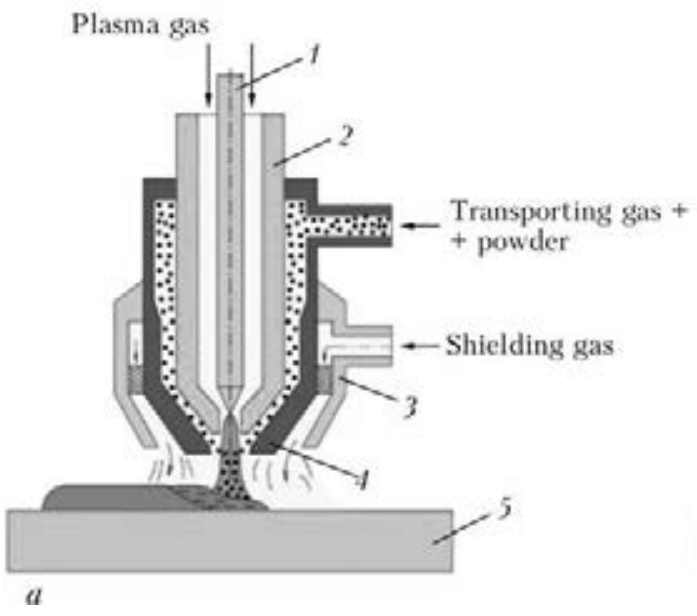

Figure 1. Internal $(a)$ and external $(b)$ scheme of powder feeding in arc: 1 - electrode; $2-4$ - plasma-shaping, protective and focusing nozzle, respectively; 5 - part
Today internal and external schemes of powder feeding in arc $[3,4]$ are the most widely used for PPS. In the first case (Figure 1, $a$ ), powder is fed in the arc inside the plasmatron in form of uniformly distributed on circumference flow of particles through cone slot formed by plasma and focusing nozzles. In the second one (Figure 1, $b$ ), it takes place outside the plasmatron through one or several holes at the end of plasma-shaping nozzle. Focusing nozzle is absent in this case.

Aim of the present work is providing quantitative evaluation to these schemes from point of view of powder losses, efficiency and safety of surfacing process and, based on mentioned above, make a proposal on practical recommendations of their reasonable application.

Powder losses were investigated in surfacing of beads of various width and thickness with different efficiency over flat samples from steel 20 . Bead width was varied in $5-30 \mathrm{~mm}$ range,

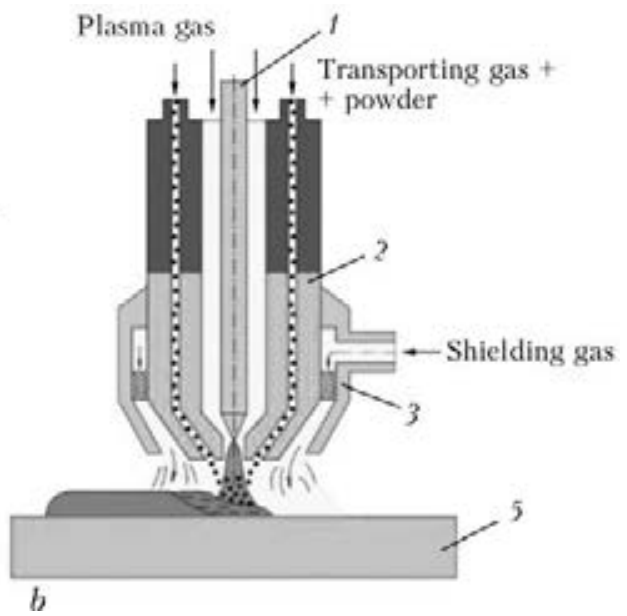


variation of thickness made 1-5 $\mathrm{mm}$ and efficiency $10-50 \mathrm{~g} / \mathrm{min}$. Stainless steel powder of $10 \mathrm{Kh} 18 \mathrm{~N} 10 \mathrm{~T}$ type (analog AISI 321) of two fractions $63-100$ and $100-200 \mu \mathrm{m}$ were used as filler material. As indicated in work [3], the dependencies of movement and heating of this type of powder in the arc are typical for majority of powders used for PPS. Besides, it is relatively refractory and has short pool in surfacing that is very important in powder loss investigation.

The investigations were carried out on PlasmaMaster Ltd. equipment using PP-6-01 plasmatron [4], which has internal system of powder feeding, and experimental plasmatron with external powder feeding system, similar to applied in plasmatrons of leading world manufacturers Castolin, Deloro Stellite, Commersald etc.

Powder in PP-6-01 plasmatron firstly enters a special distribution chamber through inlet connection, where it is uniformly distributed around the circumference, and then being fed in the arc via a system of slots, evenly located on conical surface of plasma-shaping nozzle. The slots guide the powder particles directly in the central most heated part of the arc. Focus point of powder particles is at $3 \mathrm{~mm}$ distance from the end of focusing nozzle. Diameters of plasma-shaping and focusing nozzles in these experiments equaled 5 and $8 \mathrm{~mm}$, respectively.

Filler powder in the experimental plasmatron is preliminary divided on two similar flows and being fed in the arc directly through two holes of $1.4 \mathrm{~mm}$ diameter made in diametric opposition to each other at the end of plasma-shaping nozzle. Angel of powder feeding in arc relatively to vertical axis makes $35^{\circ}$, the same as in PP-6-01 plasmatron. Focus point of powder particles is at $8 \mathrm{~mm}$ distance from the end of plasma-shaping nozzle, diameter of which equaled $5 \mathrm{~mm}$ in experiments. Plasmatron in surfacing was oriented in such a way that powder feeding takes place in plane normal to axis of deposited bead. In both cases plasmatron distance to surface being deposited was $10 \mathrm{~mm}$.

Figure 2 shows plumes of powder flowing from PP-6-01 plasmatron (Figure 2, $a$ ) and experi-

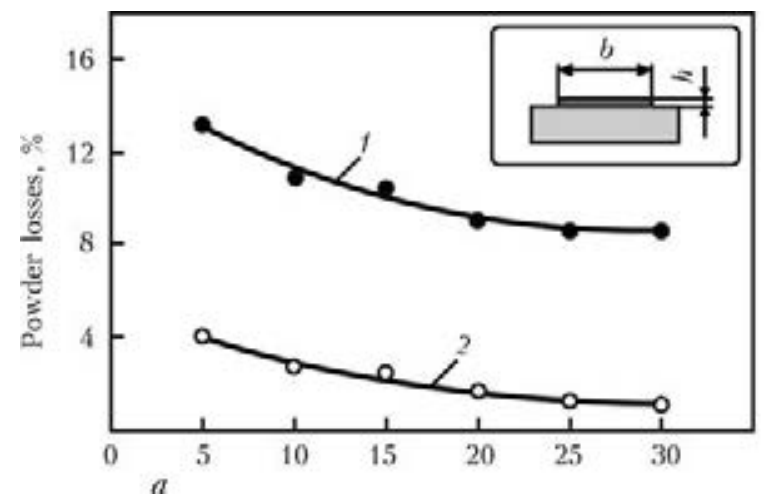

Figure 3. Dependence of powder loss on width of deposited bead at external (1) and internal (2) schemes of its feeding in arc: $a-63-100 \mu \mathrm{m}$ powder fraction; $b-100-200 \mu \mathrm{m}$

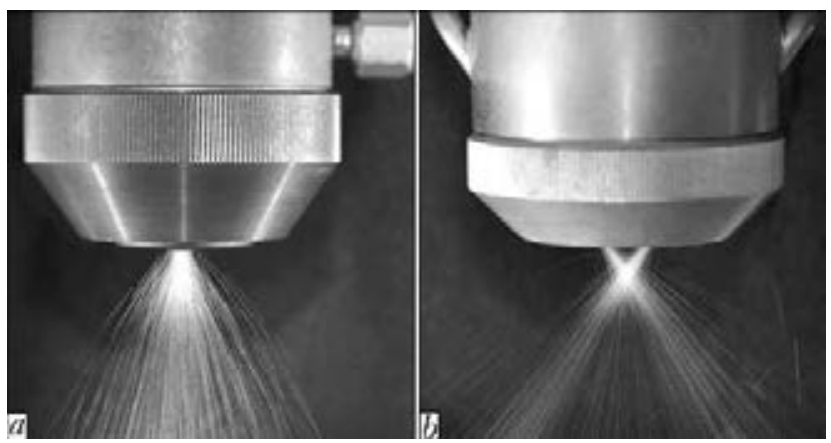

Figure 2. Plumes of powder outflow from PP-6-01 plasmatron $(a)$ and experimental plasmatron $(b)$

mental plasmatron (Figure 2, b) at $50 \mathrm{~g} / \mathrm{min}$ feeding. Consumption of transporting gas in both cases was minimum for elimination of powder blockage in the channels of plasmatrons and made $21 / \mathrm{min}$. At that, initial velocity of particle flight at the moment of their entrance in the arc equaled $1.0-1.5 \mathrm{~m} / \mathrm{s}$ for PP-6-01 plasmatron and 2$3 \mathrm{~m} / \mathrm{s}$ for experimental one. Such variations are caused by different resistance of channels for powder feeding in these systems.

Powder loss was determined as difference between general consumption of powder supplied by feeder and mass of metal deposited for the same time. Mass of deposited metal was determined by means of weighting of the sample before and after surfacing. Surfacing distance made $200 \mathrm{~mm}$. Weighing of the samples was carried out using laboratory scales of up to $0.05 \mathrm{~g}$ accuracy.

Experiments showed that the largest powder losses were observed with external scheme of its feeding in the arc. Particularly, it becomes apparent in deposition of narrow and thin beads using coarse-grain powder. They achieve $20 \%$ (Figures $3, b$ and $4, b$ ) in such cases. Increase of width and thickness of the beads provides for significant reduction of powder loss due to more favorable conditions for powder entering into the weld pool. Using of finer powder promotes more significant decrease of losses, however, they are still large enough and make $8-10 \%$ (Figures 3 , $a$ and $4, a$ ).

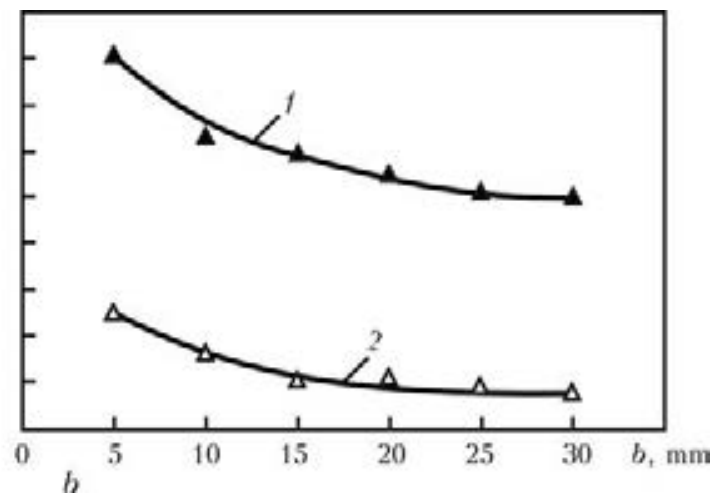



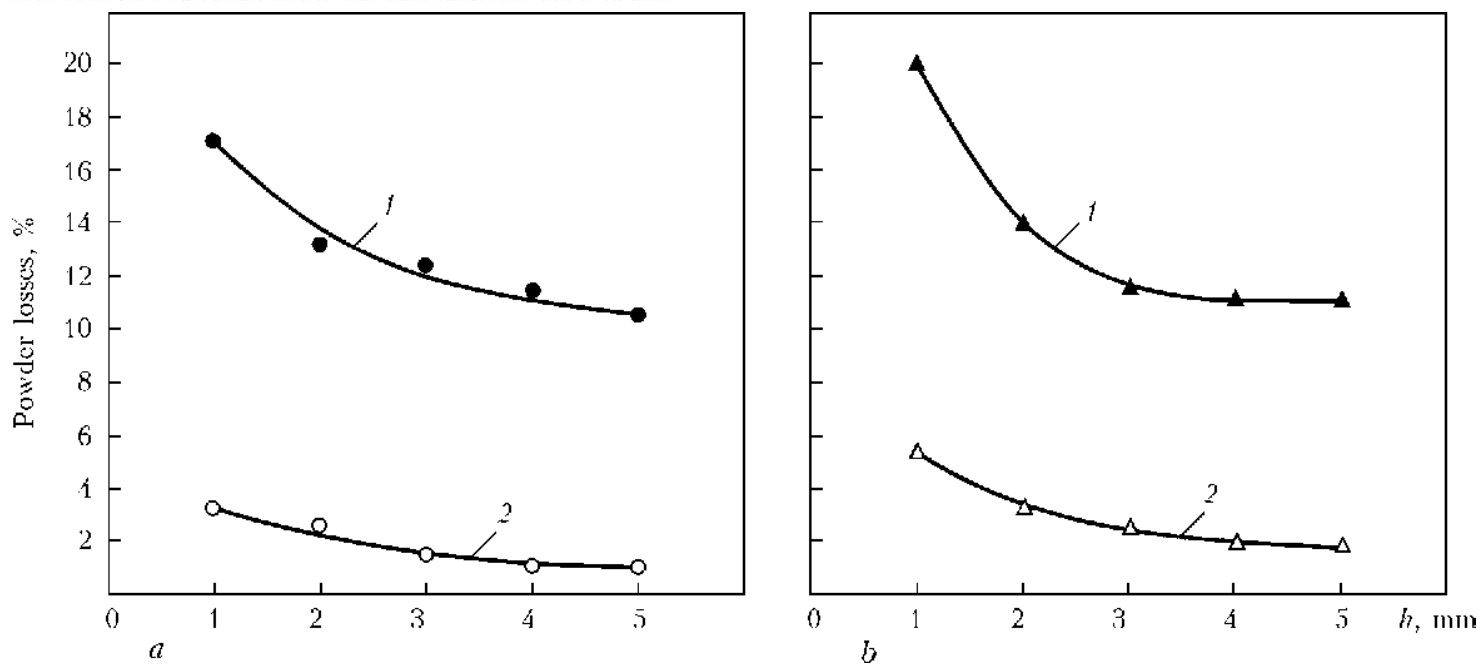

Figure 4. Dependence of powder losses on height of deposited bead at external (1) and internal (2) schemes of its feeding in arc: $a-63-100 \mu \mathrm{m}$ powder fraction; $b-100-200 \mu \mathrm{m}$

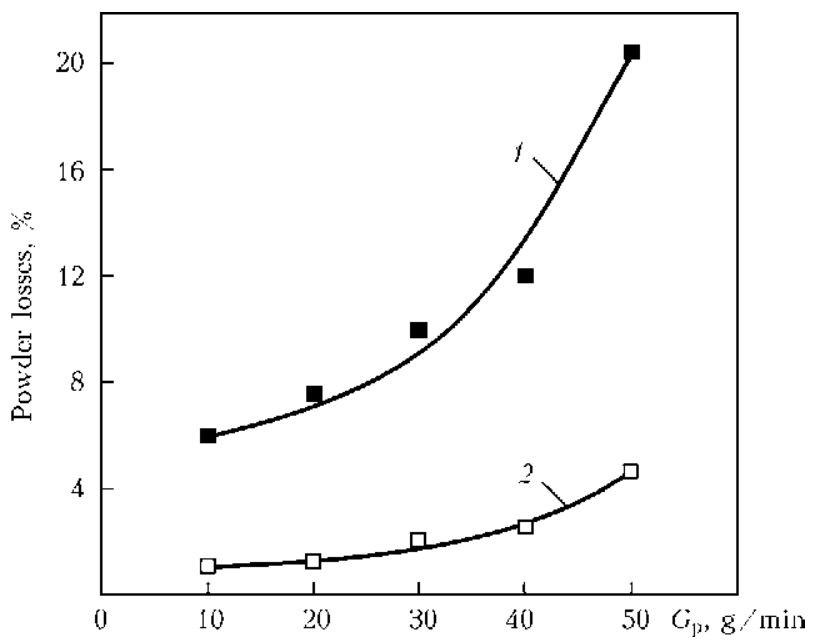

Figure 5. Dependence of powder losses on value of feeding at different schemes of its feeding in arc: 1 - external; 2 - internal (63-200 $\mu \mathrm{m}$ powder fraction, bead width of $20 \mathrm{~mm}$, height of $3 \mathrm{~mm}$ )

Such significant powder losses at external feeding scheme are firts of all caused by unfavorable conditions of its heating in the arc. Time of powder staying and heating in the arc is limited due to low position of point for powder feeding and large initial particle velocity. Moreover, local jets of cold transporting gas deform arc column and reduce plasma temperature in heating zone. Calculation data of work [3] show that only particles finer than $50 \mu \mathrm{m}$ can be heated to melting temperature of $10 \mathrm{Kh} 18 \mathrm{~N} 10 \mathrm{~T}$ steel at such feeding scheme. Larger particles, which did not come into weld pool, flew past and got lost.

Significantly better results are observed at internal powder feeding. Regardless the fact that dependencies are in general close, the level of powder losses here is considerably lower. Also, the difference between fine and coarse fractions is not large. Under the most unfavorable conditions powder losses do not exceed $5 \%$ versus $20 \%$ at external feeding. Powder losses make only $1-2 \%$ (see Figures 3, $a$ and $4, a$ ) in surfacing of wide and full beads.

It was noted during the experiment that powder losses depend not only on geometry of deposited bead, but on productivity of process performance as well. Increase of powder feeding promotes for also increase of loss, in particular, at external feeding (Figure 5).

It can be explained by the fact that increase of powder feeding provides for rise of particle density in the arc and possibility of their elastic collision between themselves at the moment of entering in the arc is increased, as a result of which they fly off from the arc and get lost. Probability of particle collision is significantly more at external feeding due to the fact that powder is fed in the arc by more concentrated flows towards each other. The important indices of surfacing efficiency in addition to powder loss are also formation of layer,

Optimum values of current at deposition of different geometry beads

\begin{tabular}{|c|c|c|c|c|c|}
\hline \multirow{2}{*}{ Geometry of beads, mm } & \multirow{2}{*}{$\begin{array}{l}\text { Surfacing speed, } \\
\mathrm{mm} / \mathrm{min}\end{array}$} & \multirow{2}{*}{$\begin{array}{l}\text { Powder feeding rate, } \\
\qquad \mathrm{g} / \mathrm{min}\end{array}$} & \multirow{2}{*}{ Powder fraction, $\mu \mathrm{m}$} & \multicolumn{2}{|c|}{ Surfacing current, A } \\
\hline & & & & Internal feeding & External feeding \\
\hline \multirow{2}{*}{$\begin{array}{c}b=10 \\
h=3\end{array}$} & \multirow[t]{2}{*}{140} & \multirow[t]{2}{*}{26} & $63-100$ & 170 & 190 \\
\hline & & & $100-200$ & 180 & 205 \\
\hline \multirow{2}{*}{$\begin{array}{c}b=20 \\
h=3\end{array}$} & \multirow[t]{2}{*}{70} & \multirow[t]{2}{*}{34} & $63-100$ & 175 & 200 \\
\hline & & & $100-200$ & 180 & 210 \\
\hline \multirow{2}{*}{$\begin{array}{c}b=30 \\
h=3\end{array}$} & \multirow[t]{2}{*}{50} & \multirow[t]{2}{*}{38} & $63-100$ & 180 & 220 \\
\hline & & & $100-200$ & 190 & 230 \\
\hline
\end{tabular}




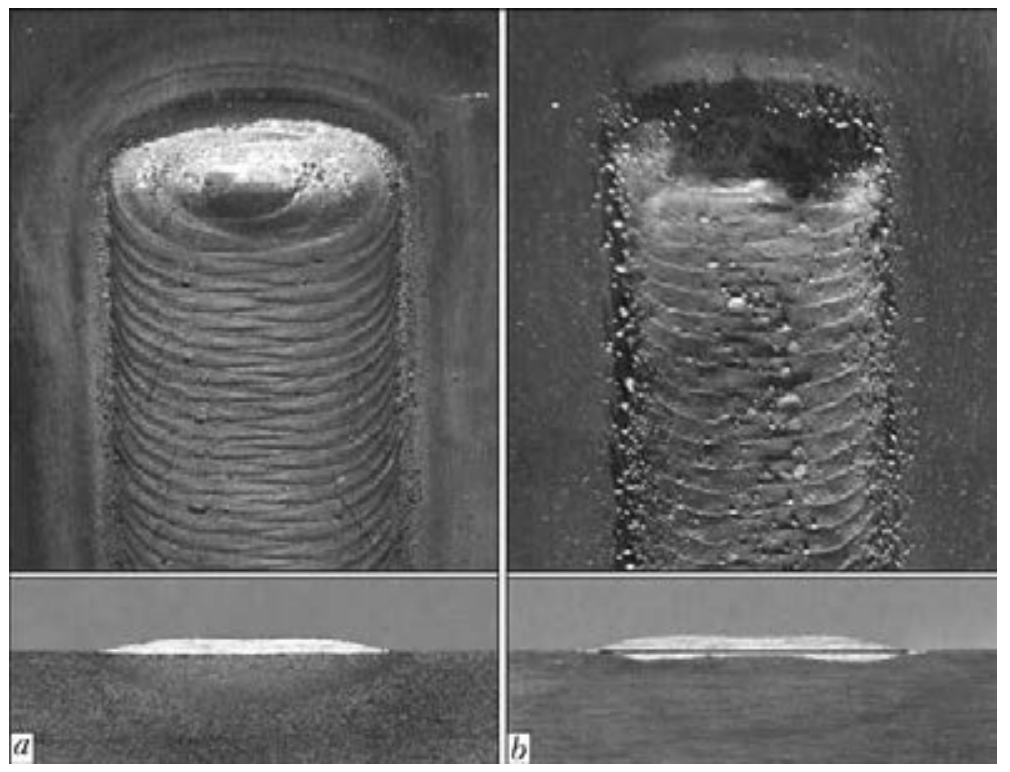

Figure 6. View and macrosections of beads at internal $(a)$ and external $(b)$ schemes of powder feeding in arc

penetration of base metal and specific consumption of energy. Here, internal scheme of powder feeding also has obvious advantages, in particular at fine layer surfacing.

Figure 6 shows view and macrosections of cross section of $20 \mathrm{~mm}$ width and $1 \mathrm{~mm}$ height deposited beads. It can be seen that formation of bead deposited at internal powder feeding is significantly better, and base metal penetration is obviously lower than at external one. It is achieved due to better heating of powder in the arc and larger factor of its use. In this case, energy distribution of plasma arc is so that its larger part is consumed for powder heating, not for part, i.e. heat input in the part is significantly lower. Flow of transporting gas uniformly distributed around the circumference provides for additional stabilizing effect on arc and also promotes improvement of bead formation. The result of common effect of these factors shows that surfacing with internal powder feeding is more energetically profitable than at external one. Surfacing current necessary in this case is $10-15 \%$ lower at the same efficiency.

The Table shows for example the optimum values of arc current in surfacing of different geometry beads using both schemes of powder feeding in arc.

Carried investigations showed that internal scheme of powder feeding provides for significantly better indices of surfacing than external one. However, appearance of drops of liquid metal at the output of focusing nozzle was observed at long-term surfacing of powder fraction of less than $100 \mu \mathrm{m}$ with large productivity. It resulted in deterioration of process stability and degradation of deposited bead formation. Reduction of productivity and, respectively, surfacing current significantly decreases droplets appearance. They were completely absent at less than 150 A cur- rent. No droplets were also observed in use of coarse fraction powder of more than $100 \mu \mathrm{m}$ at current up to $300 \mathrm{~A}$. External scheme of powder feeding in arc did not show such an effect in all investigated range of currents $(50-300 \mathrm{~A})$. It should be taken into account in practice, particularly, in surfacing of fusible self-fluxing nickelbased powders.

\section{Conclusions}

1. Powder losses are significantly less at internal scheme of its feeding in arc than at external one, and under favorable conditions do not exceed $2 \%$.

2. Internal scheme of powder feeding in the arc in general more efficient in comparison with external one. It provides for smaller powder losses, lower penetration of base metal and better formation of deposited bead at decreased energy consumption.

3. Increase of surfacing efficiency using of plasmatrons with external powder feeding requires application of powders with finer fraction of less than $100 \mu \mathrm{m}$, and more than $100 \mu \mathrm{m}$ for plasmatrons with internal feeding.

4. In order to reduce losses of powder in surfacing by plasmatron with external powder feeding the process should be carried at small productivity of less than $30 \mathrm{~g} / \mathrm{min}$.

1. Gladky, P.V., Pavlenko, A.V., Zelnichenko, A.T. (1989) Mathematical modeling of powder heating in arc during plasma surfacing. Avtomatich. Svarka, 11, $17-21,54$

2. Pavlenko, A.V., Gladky, P.V. (1989) Peculiarities of filler powder heating in arc during surfacing. Ibid., 11, 33-37

3. Gladky, P.V., Pereplyotchikov, E.F., Ryabtsev, I.A. (2007) Plasma surfacing. Kiev: Ekotekhnologiya.

4. Som, A.I. (1999) New plasmatrons for plasma-powder surfacing. Avtomatich. Svarka, 7, 44-48.

Received 15.04.2015 


\title{
MODERN STATE AND CHALLENGES FOR DEVELOPMENT OF LASER AND HYBRID SURFACING TECHNOLOGIES (Review)
}

\author{
V.Yu. KHASKIN, V.D. SHELYAGIN and A.V. BERNATSKY \\ E.O. Paton Electric Welding Institute, NASU \\ 11 Bozhenko Str., 03680, Kiev, Ukraine. E-mail: office@paton.kiev.ua
}

\begin{abstract}
The paper deals with development of the processes of laser and combined (for instance, laser-plasma) surfacing. It is shown that in these processes feeding the surfacing material (mainly, in the form of powder, less often - as wire) into the zone of impact of laser radiation focused into a spot of 1-5 mm diameter results in formation of a deposited layer of a certain height with the specified physico-chemical characteristics on the treated surface. The considered processes have a number of advantages and disadvantages. The advantages include: possibility of deposition of layers of $0.1-3.0 \mathrm{~mm}$ height with specified properties; considerable weakening of the effect of redistribution of components from base material into the deposited layer, promoting an increase of the accuracy of forecasting the results and making the deposited layer properties as close as possible to initial properties of the material being surfaced; producing equiaxed fine-crystalline (highly-dispersed) structures of the deposited metal and small (up to 0.1-0.5 mm) heataffected zone; minimizing the allowance for finish machining to values of $0.3-0.5 \mathrm{~mm}$ to the side due to low roughness (up to $R a 200-300 \mu \mathrm{m}$ ) of the deposited surfaces. The disadvantages include: presence of transverse initial cold microcracks in the deposited layers, appearance of which is the result of relaxation of high internal tensile stresses; possibility of formation of both internal and external pores associated with non-metallic inclusions and residual humidity of the surfacing powder, as well as presence of treated surface contamination; relatively high cost of the process associated with comparatively high cost of laser equipment. It is shown that the main tendencies in development of laser surfacing technology in industrialized countries are as follows: producing corrosion- and wear-resistant coatings with improved physico-mechanical properties; synthesis of 3D objects; producing thin deposited layers with special properties. The prospects for further development of laser and laser-plasma (laser-arc) surfacing processes are associated with the ability to eliminate the drawbacks inherent to each of the components separately, due to interaction of these components. 16 Ref., 3 Figures.
\end{abstract}

$\boldsymbol{K} \boldsymbol{e} \boldsymbol{y} \boldsymbol{w} \boldsymbol{o} \boldsymbol{r} \boldsymbol{d} \boldsymbol{s}:$ laser technologies, hybrid and combined processes, commercial application, equipment, materials, prospects

Laser surfacing as a method of coating deposition, appeared at the end of $1970 \mathrm{~s}-$ beginning of 1980s. In the case of surfacing, feeding of surfacing material (predominantly in the form of powder, more seldom - as wire) into the zone of impact of laser beam focused into a 1-5 mm diameter spot on the surface being treated results in deposition of a coating of a certain height with specified physico-chemical properties (Figure 1) [1, 2 ]. Variants of laser surfacing over layers of surfacing material applied onto the surface before the process are also possible. These layers are applied by thermal spraying or as a mixture, consisting of surfacing powder with binder, and then they are remelted by laser radiation. Surfacing with pre-spraying of the layers is usually called laser remelting. The produced coating is bonded to the base material through a transition layer of comparatively small size (usually, from 5-10 up to $50-200 \mu \mathrm{m}$ ). Strength of coating adhesion to the base metal is quite high and is close to the strength values of the latter.

One of the most important moments in surfacing technology is the method of feeding the surfacing material to the substrate. Studying the technologies of laser welding and surfacing showed that while the processes with wire feeding realize the advantage of treatment performance practically in any position in space, the advantage of powder materials consists in more effective absorption of laser radiation [3]. Downhand surfacing can be performed by preliminary spreading of powder over the surface being treated. Application of powder materials in other positions in space usually requires preliminary application of coatings by such methods as flame spraying, plasma spraying or furnace drying of 

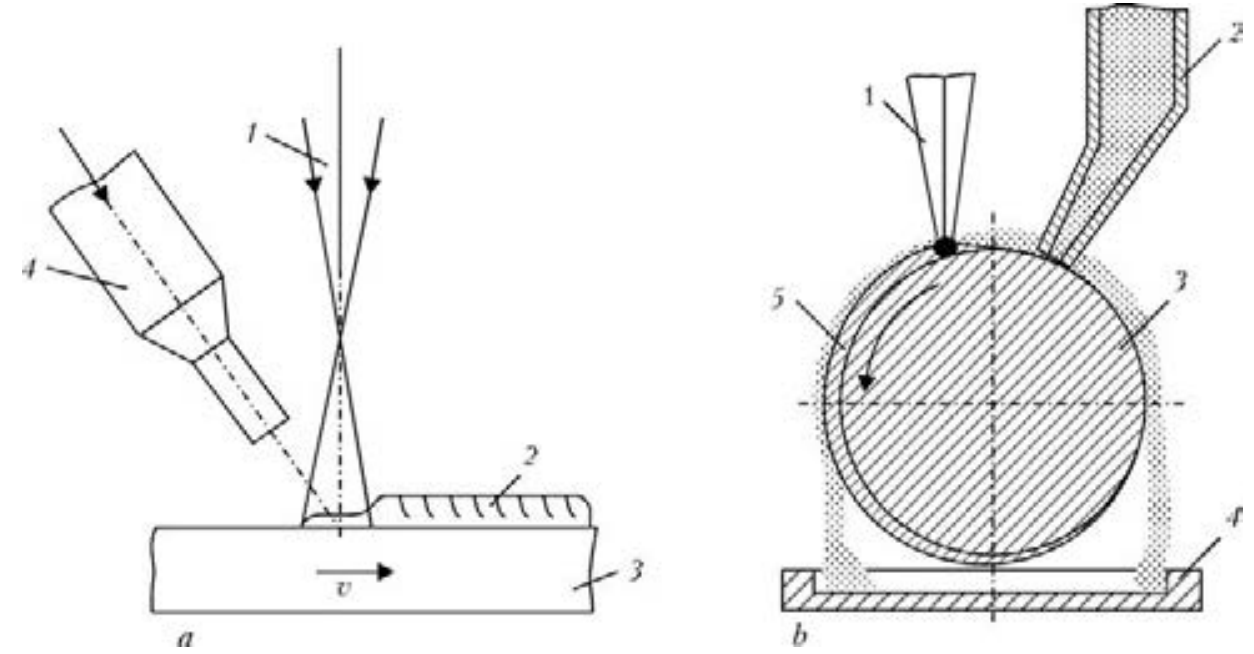

Figure 1. Schematic of processes of laser surfacing of parts of arbitrary geometry $(a): 1$ - laser radiation; $2-$ deposited bead; 3 - moving sample; 4 - nozzle for feeding the shielding gas and filler powder [1], and cylindrical parts $(b)$ : 1 - laser radiation; 2 - feeding tube of powder metering device; 3 - surfaced sample; 4 - nonused powder tray; 5 - deposited metal [2]

coating paste. If the powder cannot be distributed over the surface in advance, it is fed by special metering devices. At present, laser surfacing method became the most widely accepted, which uses filler powder materials, fed directly into the zone of laser radiation impact using special powder metering devices of various designs [4].

Advantages of laser surfacing include [1]: possibility of applying layers of $0.1-3.0 \mathrm{~mm}$ height with specified properties; considerable weakening of the effect of redistribution of components from base material into the deposited layer, promoting an improvement of the accuracy of forecasting the results and achieving deposited layer properties maximum close to those of the surfaced material; producing equiaxed fine-crystalline (highly-dispersed) structures of the deposited metal and small (up to $0.1-0.5 \mathrm{~mm}$ ) HAZ; minimizing the allowance for finish machining up to values of about $0.3-0.5 \mathrm{~mm}$ to the side due to small roughness (up to $R a 200-300 \mu \mathrm{m}$ ) of the deposited metal surfaces. Alongside the abovementioned, laser surfacing advantages further include also those of heat treatment and alloying, associated with the features of laser radiation as a heat source.

The disadvantages of laser surfacing are as follows: presence of transverse cold microcracks in the deposited layers, formation of which is the result of relaxation of high internal tensile stresses [5]; possibility of formation of both the internal and external pores, associated with nonmetallic inclusions and residual humidity of the surfacing powder, as well as contamination of the material being surfaced; relatively high cost of the process, related to comparatively high cost of laser equipment [1]. Controlling, reduction and complete elimination of cracking in laser surfacing was studied at some time by many authors (for instance, [1, 5]). Comparatively recently, Ukrainian authors suggested a mathematical model of this phenomenon, which allowed correlating the distance between the cracks with mechanical properties of the coatings and their thicknesses [6]. It follows from the above-said that methods, which allow lowering residual thermal stresses in the deposited layers in combination with thorough preparation of surfacing powders and treated surface, can be regarded as promising directions of eliminating the process disadvantages. Such methods include, in particular, changing the welding thermal cycle due to application of an additional heat source (for instance, a combination of the impact of laser radiation with that of a plasma jet).

Laser surfacing is used to produce wear- and corrosion-resistant fine-crystalline, amorphized and amorphous coatings from a rather wide material range. However, in the first half of the 1980s laser surfacing has found wider application as the process of reconditioning worn parts of equipment, exposed to sliding friction, shock loads, abrasive wear, etc. [1]. And even now reconditioning laser surfacing is still urgent even in industrialized countries - it is applied for repair of expensive products, at restoration of comparatively small defective areas with high thermal locality [7]. For instance, such technologies are widely applied in processes of reconditioning turbine blades of aircraft engines, supports of shafts, moulds and other expensive products of complex profile [7-9].

Beginning from the start of the XXI century, hybrid and combined technologies more and more 

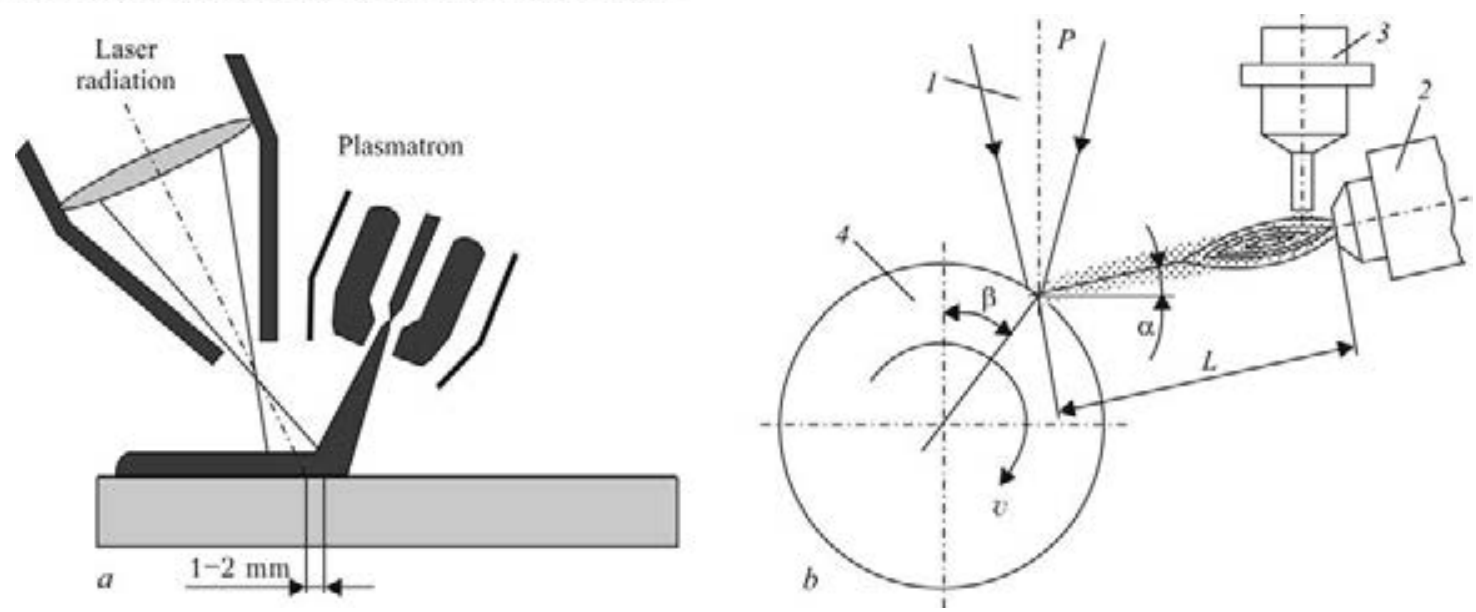

Figure 2. Schematic of processes of powder laser-plasma surfacing using direct- $(a)[10]$ and indirect-action plasmatron $(b): 1$ - radiation; 2 - plasmatron; 3 - powder metering device; 4 - sample; $L, \alpha, \beta$ - surfacing distance and angles [11]

often replace laser technologies. These include laser-plasma processes, which use the simultaneous action of arc plasma and laser energy source. Investigations conducted at the E.O. Paton Electric Welding Institute of the processes of interaction of focused $\mathrm{CO}_{2}$-laser radiation with electric arc column plasma showed that such a system can develop a special type of gas discharge combined laser-arc one [10]. Its properties differ both from those of the electric arc, and from properties of optical discharge maintained by laser radiation. Ability of the combined discharge to generate high-temperature plasma with a high degree of non-equilibrium even at atmospheric

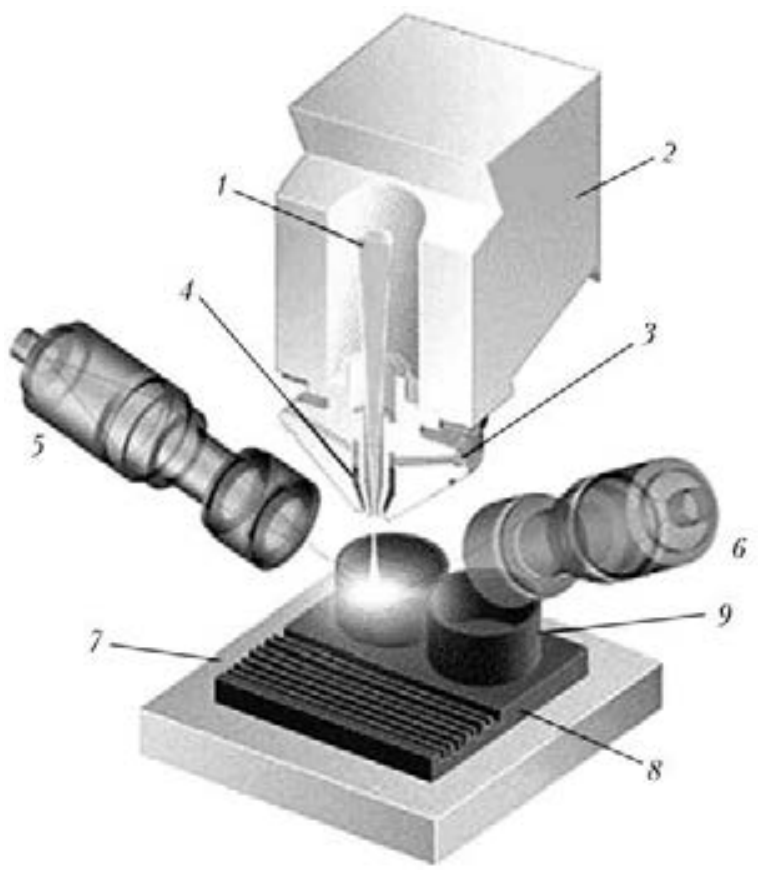

Figure 3. Schematic of process of 3D synthesis of parts by DMD technology: 1 - laser radiation; 2 - focusing optics; 3 - powder feeder; 4 - shielding gas; 5, 6 - sensors of feedback optical system; 7 - platform; 8 - blank (mould); 9 - created object pressure of ambient gas makes it attractive for application in plasma-chemical technologies (including CVD). Theoretical and experimental investigations conducted at PWI (Profs I.V. Krivtsun, V.S. Gvozdetsky, Yu.S. Borisov et al.) showed that such a discharge can form the basis for designing a new class of plasma devices integrated laser-arc plasmatrons.

Both direct- and indirect action plasmatrons can be applied in the processes of hybrid laserplasma surfacing [11-12]. Powders are mainly used as surfacing materials. The main advantage of application of direct-action plasmatrons is the possibility of additional compression of the plasma arc through application of focused laser radiation (Figure $2, a$ ). The advantage of application of indirect-action plasmatrons is absence of direct impact of electric arc on the base metal that, in particular, improves the thermal locality of the process (Figure 2, b) [13]. In the opinion of the authors of [14] application of pulsed radiation of Nd:YAG lasers is the most promising for this purpose, owing to the possibility of its flexible feeding through optical fibre in an optimized position in space. Laser-plasma surfacing considerably decreases residual stresses in the deposited layers, compared to laser surfacing. However, a considerable thermal impact on the item being surfaced remains to be one of its main disadvantages.

Analysis of the advantages and disadvantages of plasma, laser and laser-plasma surfacing processes suggests the following. In the case of plasma surfacing, the part can be exposed to considerable heating, leading to its residual thermal deformations. Laser and laser-plasma processes allow minimizing the part heating, improving the strength of adhesion of the deposited layers to the substrate, eliminating application of under- 
layers, and simplifying surface preparation. However, laser surfacing processes also have certain disadvantages. These include the stressed state of the deposited layers, presence of pores and microcracks in them. Hybrid (combined) laser-plasma processes allow partially or completely eliminating the above drawbacks, owing to interaction of the components or their simultaneous impact on the treated item. So, compression and stabilization of the plasma arc by laser radiation allows increasing the surfacing process speed and reducing the overall heat input; powder preheating by combined discharge in combination with variation of laser treatment thermal cycle due to addition of the plasma component, allows reducing residual stresses, eliminating pore and crack formation, etc.

Hybrid technologies of laser surfacing and coating have already found their practical application [15, 16]. For instance, developed technology of laser-plasma cementation of loom racks from steel 45 with base hardness $H R C$ 30-32 ensures surface layer hardness $H V 750$ as a result of treatment [15]. The process of surface layer carburizing is based not on diffusion, but on carbon adsorption by the surface and its convective stirring in the melt liquid phase that significantly increases the rate of conducting the technological process of cementation.

Thus, review of the processes of laser and hybrid (combined) surfacing showed that the following main tendencies of development of this area include: producing corrosion- and wear-resistant coatings with improved physico-mechanical characteristics; synthesis of 3D objects and development of thin coatings with special properties. Prospects for further development of laser and laser-plasma (laser-arc) surfacing processes are associated with the ability to eliminate the drawbacks inherent in each of the components taken separately through interaction of these components.

1. Grigoriants, A.G., Safonov, A.N. (1987) Laser engi neering and technology: Manual for higher education institutions. Vol. 3: Methods of surface laser treat- ment. Ed. by A.G. Grigoriants. Moscow: Vyschaya Shkola.

2. Velichko, O.A., Avramchenko, P.F., Molchan, I.V. et al. (1990) Laser powder cladding of cylindrical parts. Avtomatich. Svarka, 1, 59-65.

3. (2007) Laserstrahlschweissen mit pulverfoermigem Schweisszusatz. Edelstahl-Mechanik GmbH. Praktiker, 3, 68-69.

4. Zeng Xaoyan, Zhu Beidi, Tao Zengyi et al. (1993) Automatic powder feeder and technology of laser cladding. Chin. J. Lasers, 20(3), 210-214.

5. Pokhmurska, G.V. (2003) Crack formation in thermal coatings depending on laser remelting conditions. Fizyko-Khimichna Mekhanika Materialiv, 1, 59-62.

6. Chekurin, V.F., Pokhmurska, G.V. (2004) Mathematical model of cracking of laser-modified metal powder coatings. Ibid., 5, 18-22.

7. Hoffman, J. (2001) Reconditioning of exchangeable parts using laser technologies. The Paton Welding J., 12, 33-34.

8. Konyushin, A., Manyak, V., Holz, R. et al. (2009) Technical capabilities of modern solid-state lasers. Fotonika, 2, 22-23.

9. Birger, E.M., Moskvitin, G.V., Polyakov, A.N. et al. (2009) Industrial laser surfacing: State-of-the-art and tendencies. Svarochn. Proizvodstvo, 9, 3-8.

10. Gvozdetsky, V.S., Krivtsun, I.V., Chizhenko, M.I. et al. (1995) Laser-arc discharge: Theory and applications. In: Welding and Surfacing Rev., Vol. 3. Amsterdam: Harwood Acad. Publ.

11. Hai-ou Zhang, Ying-ping Qian, Gui-lan Wang (2006) Study of rapid and direct thick coating deposition by hybrid plasma-laser manufacturing. Surface \& Coatings Technology, 201, 1739-1744.

12. Chashchin, E.A., Fedin, A.V., Mitrofanov, A.A. et al. (2007) Increase of the efficiency of plasma treatment of materials at using of additional power source as laser radiation. In: Proc. of 3 rd Int. Sci.-Pract. Conf. on Study, Development and Application of High Technologies in Industry (14-17 March 2007, St.-Petersburg, Russia), Vol. 8: High technologies, fundamental and applied researche, 119-120. SPb: SPbPU.

13. Shelyagin, V.D., Khaskin, V.Yu., Pereverzev, Yu.N. (2006) Laser-microplasma alloying and coating of steel. The Paton Welding J., 2, 2-5.

14. Wilden, J., Bergman, J.P., Dolles, M. (2005) Riporti superficiali laser: aumento di efficienza e flessibilita tramite processi ibridi. Riv. Ital. Saldatura, 6, 809-816.

15. Zabelin, A.M., Shiganov, I.N. Chirkov, A.M. et al. (2007) Hybrid technologies of laser surfacing: Turorial. Moscow: MGOU.

16. Melyukov, V.V., Chirkov, A.M. (2006) Laser-plasma technologies for surface treatment. In: Proc. of 5 th Int. Conf. on Beam Technologies. Laser Application (23-28 Sept., 2006, St.-Petersburg, Russia), 236240

Received 08.04.2015 


\title{
ELECTROSLAG SURFACING USING DISCRETE MATERIALS OF DIFFERENT METHODS OF MANUFACTURE
}

\author{
Yu.M. KUSKOV, G.N. GORDAN, I.L. BOGAJCHUK and T.V. KAJDA \\ E.O. Paton Electric Welding Institute, NASU \\ 11 Bozhenko Str., 03680, Kiev, Ukraine. E-mail: office@paton.kiev.ua
}

\begin{abstract}
Work studies the possibility of application of waste products forming at shot production as discrete filler material in addition to shot of optimum factional composition. It is determined that surfacing by shot from high-chromium cast iron virtually has no difference on surfacing using tablets formed by powder metallurgy from shot production wastes. Metal, deposited by shot, is characterized by finer structure of structural constituents and lower quantity of austenite. Identity of surfacing results, apparently, can be achieved during optimizing the technology of tablet production, their sizes and mass rate of feeding in slag pool. 4 Ref., 2 Tables, 6 Figures.
\end{abstract}

Key words: electroslag surfacing, current-carrying mold, shot, tablets, microstructure of deposited metal

Technology of electroslag surfacing (ESS) and re-melting in current-carrying mold developed at the E.O. Paton Electric Welding Institute allows melting the compact (wires, strips, rods etc.) as well as discrete (shot, chips, powders etc.) materials in a slag pool [1].

Experience of practical surfacing [2] as well as evaluation of thermal condition of slag pool and process of melting of compact and discrete materials in it [3] allowed making a conclusion on application prospects from technical and economical point of view of electroslag process using discrete filler.

Surfacing consumable in form of shot have found the largest application in surfacing among the big list of discrete fillers. Present study compares results of surfacing made using two types of filler materials, i.e. shot and tablets. The second type is considered due to peculiarities of cast shot production.

Today, metallic shot can be manufactured by different technological schemes. The majority of widely used methods of production include the following general operations: metal melting, its dispersion, separation of scrap metal, drying, sizing for fractions, prepacking and stocking. Production of surfacing shot can additionally include magnetic separation, intersizing and vibratory cleaning. Fragmentation and sizing operations are to be entered in the case of manufacture of chipped shot.

The cheapest, easiest and widely distributed industrial method of shot manufacture is its pro-

(c) Yu.M. KUSKOV, G.N. GORDAN, I.L. BOGAJCHUK and T.V. KAJDA, 2015 duction by air atomization of molten metals [4]. Physico-Technical Institute of Metals and Alloys of the NAS of Ukraine (former Institute for Cast Problems of AS of USSR) developed technology and equipment complexes of «Grad» model for production of cast metallic shot with 400 to $6000 \mathrm{t}$ per year productivity.

Cast shot produced by this technology was mainly used in recent investigations and surfacing on practice. Wide spectrum of fractions is received in air atomization of molten metal. Thus, dispersion of jet of high-chromium cast iron, which is the most wide-spread wear-resistant surfacing material, promotes for formation of granules of the following fractional composition:

$\begin{array}{lccccc}\text { Size of granules, mm } & <0.5 & 0.5-1 & 1-3 & 3-5 & >0.5 \\ \text { Quantity of granules, \% } & 10.1 & 5.8 & 51.6 & 21.5 & 11.0\end{array}$

Relationship of fractions can be changed depending on chemical composition of material and dispersion parameters. In any case, production of shot provides for formation of large quantity of fractions which can not be used in surfacing. This is related with the fact that obtaining the quality surfacing requires application of shot with sufficiently narrow range of fractional composition. In particular, these boundaries for relatively fusible material, i.e. high-chromium cast iron, make $0.8-2.5 \mathrm{~mm}$.

Using chromium shot of $>0.8 \mathrm{~mm}$ fraction complicates its feeding in slag pool volume. Surface tension forces of molten slag pool prevents entering the fine shot particles through the slag surface film. At that, the particles are accumulated on the slag surface and form conglomerates. When mass of conglomerate exceeds resistance 


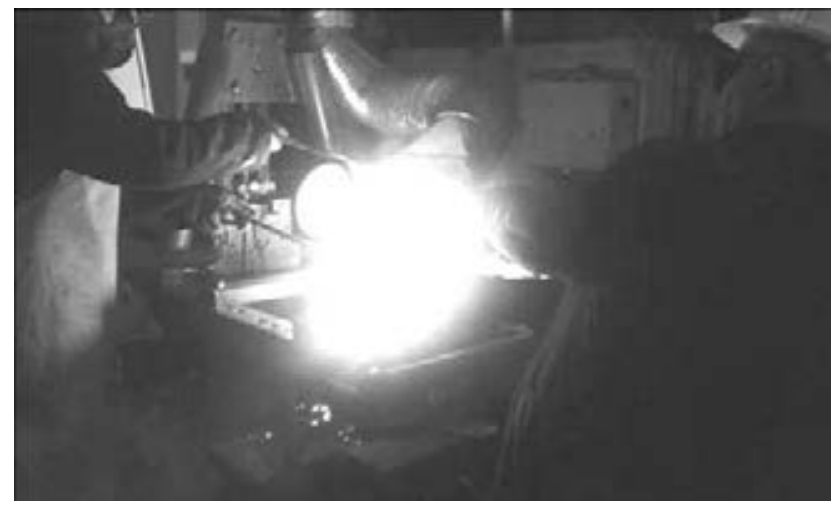

Figure 1. Filling of molten metal in current-carrying mold (using molten slag)

of surface tension forces, it penetrates in the slag volume and further in the metal pool. In this case, depending on mode of surfacing and temperature of the slag pool, it has enough time for melting or promotes formation of defects in form of pores, slag inclusions, unmelted particles of filler material.

Deposited metal can include completely unmelted granules as well as partially melted ones which form composite structure of the deposited metal in feeding to slag pool surface of particles of more than $2.5 \mathrm{~mm}$ fraction in the case of surfacing at increased mass rate of filler feeding. Such particles can also promote for formation of slag inclusions in the liquid metal.

Powder metallurgy methods can be used for solving these technological as well as economical (application in surfacing of all produced shot) task. In particular, fine fraction part of cast shot as well as coarse fraction one (preliminary transformed in split shot) can be pressed in form of tablets of specific size. Such tablets in surfacing will act as discrete material of the same chemical composition as surfacing shot.

Experimental deposits of 25-35 mm thickness layer were carried out using two types of discrete surfacing high-chromium ( $22-25 \% \mathrm{Cr}$ ) cast irons, i.e. shot and tablets, in current-conducting mold of $180 \mathrm{~mm}$ diameter for investigation of peculiarities of electroslag process and evaluation of surfacing results. Beginning of surfacing process was carried out using molten slag (flux ANF-29).

Figures 1, 2 and 3, respectively, show a moment of mold filling with molten slag, surfacing process itself with feeding of filler in the slag pool (using vibrodosimeter), as well as deposited specimen.

The following technical conditions were selected for used filler materials. The shot produced by air atomization has fractional composition of 0.8-2.5 $\mathrm{mm}$ diameter (Figure 4). The tablets were manufactured from fine fraction wastes of

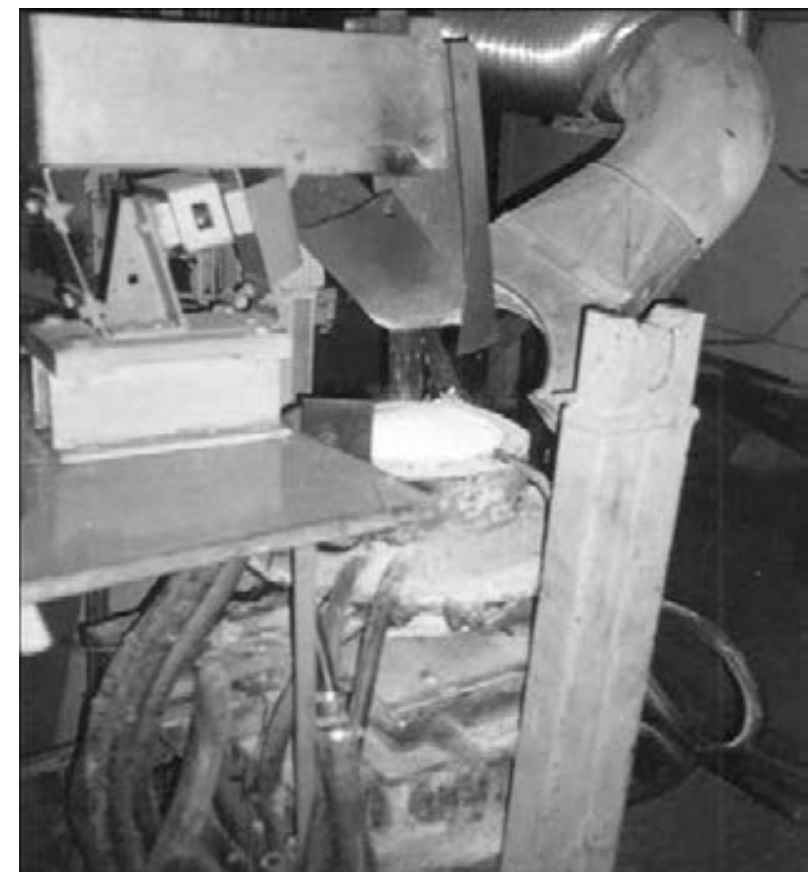

Figure 2. End surfacing of high-chromium cast iron with tablet feeding using vibrodosimeter

atomization of up to $0.4 \mathrm{~mm}$ fractional composition. Transformation of this fraction into the tablets was performed by technology applied at Brovary Plant for Powder Metallurgy (Ukraine). Bakelite lacquer was used as a plasticizing agent. Tablets of $10 \mathrm{~mm}$ diameter and 2.8-3.2 $\mathrm{mm}$ thickness were produced as a result of pressing.

Process of surfacing using both discrete materials was stable. However, some gas emission, related with burning of bakelite lacquer, was observed at tablets feeding in the slag pool. It resulted in appearance of small quantity of pores in metal deposited by tablets. Reduction of level of gas emission or its complete removal is possible at optimum selection of plasticizing agent.

Specimens for optical metallography and Xray spectrum analysis were manufactured from produced bimetallic billets by means of mechanical cutting. Examination of microstrucutres was carried out using «Neophot-32» microscope,

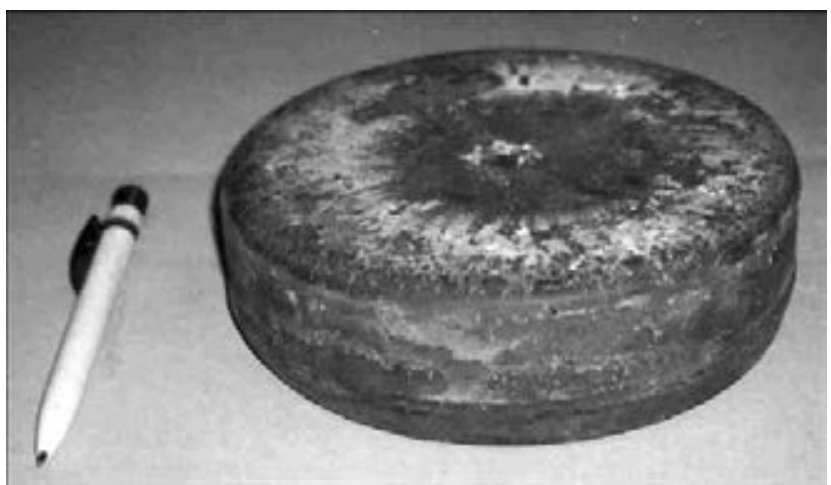

Figure 3. View of billet deposited by tablets 


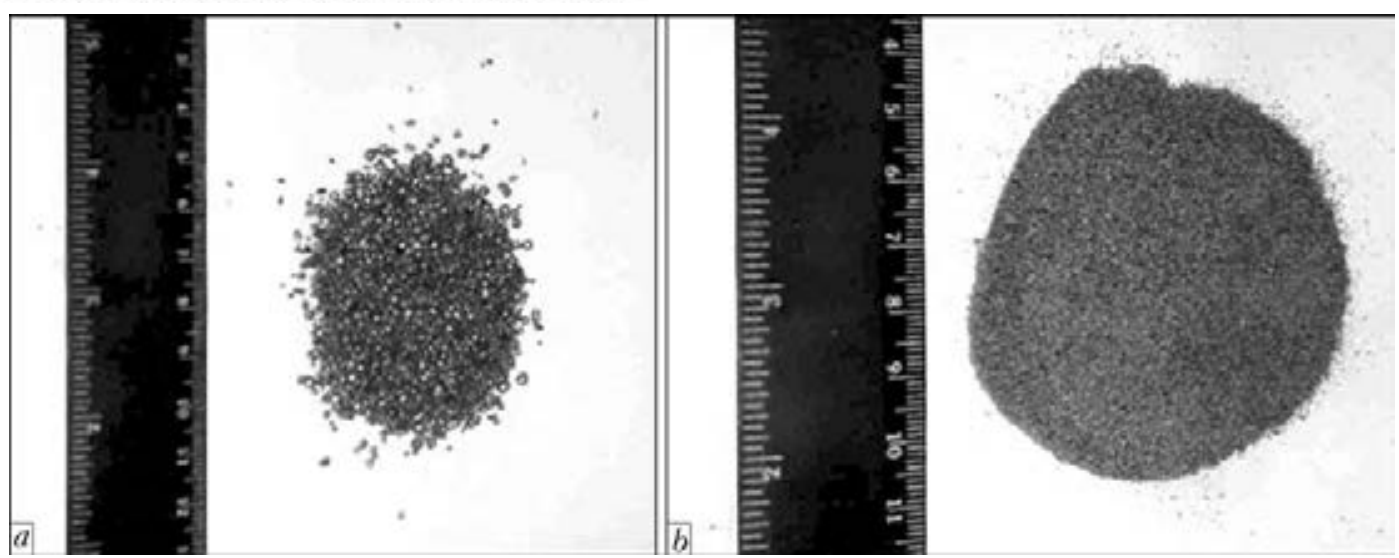

Figure 4. Discrete fillers from high-chromium cast iron: $a$ - shot produced by air atomization; $b$ - fine fraction wastes of atomization

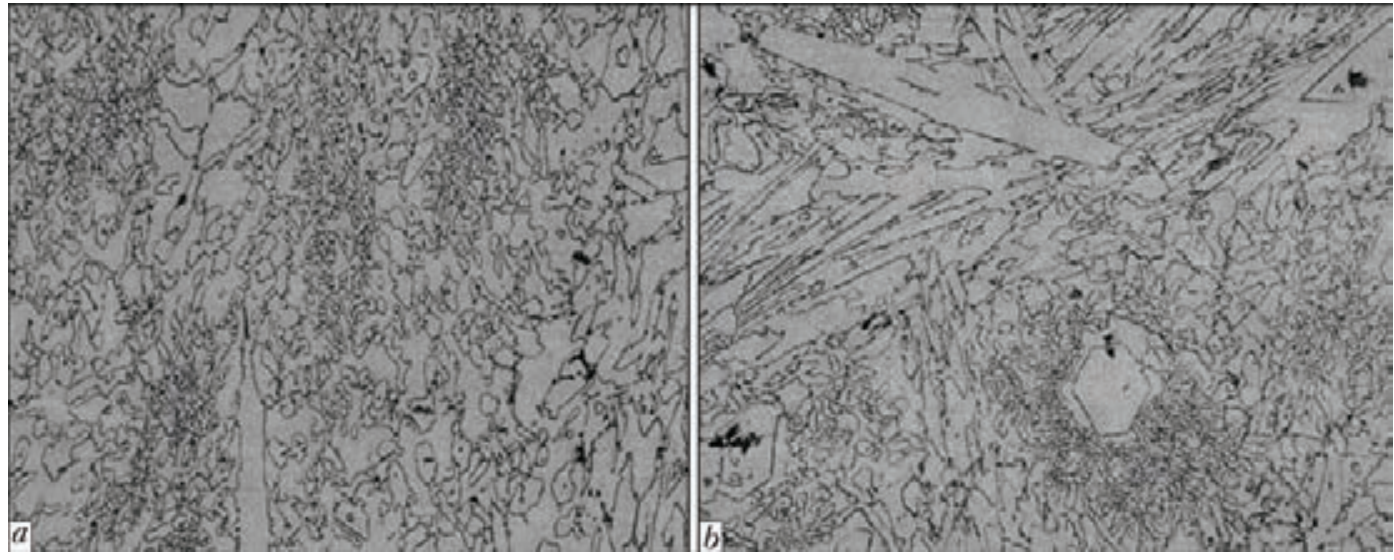

Figure 5. Microstructure $(\times 400)$ of high-chromium cast iron deposited by shot $(a)$ and tablets $(b)$

durometric measurements were performed on the LECO microhardness tester M-400, Camebax SX-50 and DRON TsUM1 were used for X-ray spectrum and X-ray structure examinations, respectively.
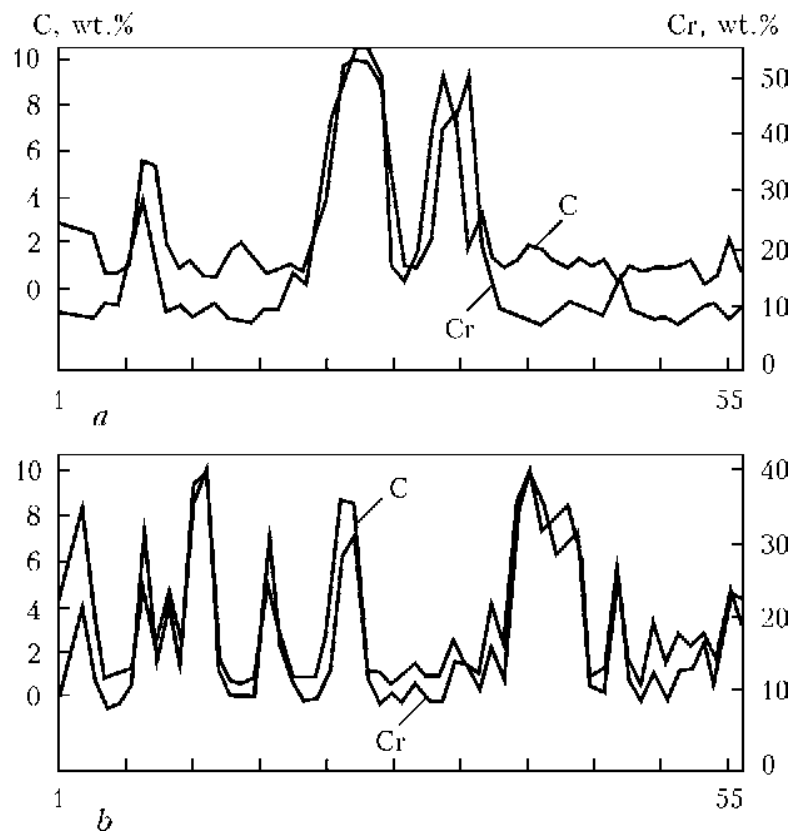

Figure 6. Results of X-ray spectrum analysis of high-chromium cast iron deposited by shot $(a)$ and tablets $(b)$
The following was determined as a result of performed examinations. Metal, deposited by shot, in comparison with metal deposited by tablets, almost does not include coarse carbides of $\mathrm{Cr}_{7} \mathrm{C}_{3}$ type and has structural constituents of

Table 1. Microhardness of structural constituents of metal deposited by shot and tablets

\begin{tabular}{|c|c|c|c|c|}
\hline \multirow{2}{*}{$\begin{array}{l}\text { Discrete } \\
\text { filler }\end{array}$} & \multicolumn{3}{|c|}{ Microhardness, MPa, at $P=0.5 \mathrm{~N}$} & \multirow{2}{*}{$\begin{array}{c}\text { Intergral } \\
\text { hardness, } \\
\mathrm{MPa} \text {, at } \\
P=10 \mathrm{~N}\end{array}$} \\
\hline & $\begin{array}{c}\text { Matrix } \\
\text { (austenite) }\end{array}$ & Carbides & Eutectic & \\
\hline Shot & $4410-5090$ & $11450-12830$ & $6180-6390$ & $5610-5810$ \\
\hline Tablets & 5980 & $12260-13370$ & 6610 & 6130 \\
\hline
\end{tabular}

Table 2. Results of X-ray structural analysis of metal deposited by shot and tablets

\begin{tabular}{|c|c|c|}
\hline \multirow{2}{*}{$\begin{array}{c}\text { Structural } \\
\text { constituents }\end{array}$} & \multicolumn{2}{|c|}{$\begin{array}{c}\text { Content (\%) of structural constituents in metal } \\
\text { deposited by }\end{array}$} \\
\cline { 2 - 3 } & Shot & Tablets \\
\hline$\gamma-\mathrm{Fe}$ & 65.63 & 80.19 \\
\hline$\alpha-\mathrm{Fe}$ & 20.97 & 8.03 \\
\hline$(\mathrm{CrFe})_{7} \mathrm{C}_{3}$ & 13.40 & 11.78 \\
\hline
\end{tabular}


smaller size, in particular, with more dispersed eutectic colonies $\left(d_{\text {shot }}=50-60 \mu \mathrm{m} ; d_{\mathrm{tab}}=80-\right.$ $90 \mu \mathrm{m}$ ) (Figure 5, $a, b$ ).

Microhardness of structural constituents of metal deposited by shot and tablets is represented in Table 1.

The following conclusions can be made based on results of X-ray spectrum analysis (Figure 6, $a, b)$. Metal structure in both cases mainly consists of austenite as well as carbides and chromium-carbide eutectics. Metal, deposited by shot, is characterized by finer atructure of structural constituents and lower amount of austenite, that is verified by results of X-ray structure analysis (Table 2).

It should be noted that observed structural differences in metal, deposited using different types of fillers, can to some extent depend on optimum selection of tablet size. The tablets of comparatively large size can result in different conditions of melting of their various parts, i.e. fusion of external part results in metal solidification similar to that taking place in melting of shots, and internal one, being a particle conglomerate, does not have enough time for melting and developing uniform heat conditions for harmonization of chemical composition in metal volume (kind of cluster). The result of such nonunifor- mity can be, for example, coarse carbide inclusions, located in separate zones of deposited metal (see Figure 5, $b$, upper part).

\section{Conclusions}

1. Experiments proved the technological and economic relevance of application of unconditioned fractions of discrete filler produced by atomization of molten metal.

2. Achievement of identity of metal microstructures deposited by shot and tablets, produced by pressing of fine fraction wastes through atomization of molten metal, requires optimizing of tablet manufacture technology as well as their sizes and, possibly, mass rate of tablet feeding to slag pool surface.

1. Kuskov, Yu.M. (2013) Electroslag surfacing in sectional current-carrying mould. Svarshchik, 3, 21-23.

2. Kuskov, Yu.M., Skorokhodov, V.N., Ryabtsev, I.A. et al. (2001) Electroslag surfacing. Moscow: Nauka i Tekhnologii.

3. Ksyondzyk, G.V., Frumin, I.I., Kuskov, Yu.M. (1977) Electroslag surfacing with grain filler material. In: Theoretical and technological principles of surfacing, 89-95. Ed. by I.I. Frumin. Kiev: PWI.

4. Zatulowsky, S.S., Mudruk, L.A. (1988) Production and application of metal shot. Moscow: Metallurgiya. 


\title{
PECULIARITIES OF HEATING OF STAMPED BILLETS IN NON-CONSUMABLE ELECTRODE ELECTROSLAG SURFACING
}

\author{
O.G. KUZMENKO \\ E.O. Paton Electric Welding Institute, NASU \\ 11 Bozhenko Str., 03680, Kiev, Ukraine. E-mail: office@paton.kiev.ua
}

\begin{abstract}
Peculiarities of heating of stamped billets in non-consumable electrode electroslag surfacing were investigated experimentally and by methods of mathematical modelling. It is determined that fast electroslag heating of billet for further surfacing with relatively low consumption of electric energy and heat saturation of base metal is achieved by specific power maintained at $(150-180) \cdot 10^{4} \mathrm{~W} / \mathrm{m}^{2}$ level. At that, it is necessary to maintain surfacing voltage and depth of slag pool at the possible minimum level. 11 Ref., 8 Figures.
\end{abstract}

$\boldsymbol{K} \boldsymbol{e} \boldsymbol{y} \boldsymbol{w} \boldsymbol{o} \boldsymbol{r} \boldsymbol{s}: \quad$ electroslag surfacing, non-consumable electrodes, specific power, stamps, thermophysical processes

Producing the quality joint of layers in electroslag surfacing (ESS) by liquid metal and noncompact materials requires heating of surface of stamp being deposited up to submelting. At that, uniform submelting of stamp being deposited through the height and area of worn working surface is necessary to be provided.

The practice of electroslag technology application shows that intensity of heat effect of slag pool on base metal depends on current and voltage values as well as slag pool depth [1-7]. If electroslag process is carried out with the help of one non-consumable graphitized electrode at constant power, then reduction of voltage and slag pool depth is accompanied by rise of slag temperature under the electrode and its decrease aside of the electrode at more than $30-60 \mathrm{~mm}$ distance [2, 4]. Works [2, 4] did not consider the effect of these parameters on heating efficiency of the whole surface of billet.

It was necessary to investigate the effect of ESS mode parameters on the next characteristics of electroslag process:

- duration of base metal heating up to its surface burning-off;

- distribution of temperature through the height of heated billet;

- consumption of electric energy and possibilities of rise of its application efficiency.

Several series of experiments were carried out for investigation of main dependencies of electroslag heating of solid metal using non-consumable electrode. The experiments were carried out using AN-15M flux on full-scale specimens from $5 \mathrm{KhNM}$ steel applying temperature measurements by thermocouples installed at different levels through the height of billet being heated, and control of metal state near surface by steel rod. The investigations on full-scale specimens had

(C) O.G. KUZMENKO, 2015 wide combination with calculation of heating parameters by mathematical model described in works $[8,9]$. Figure 1 gives the calculation results on heating of stamp billet of $H=400 \mathrm{~mm}$ height at $q=125 \cdot 10^{4} \mathrm{~W} / \mathrm{m}^{2}$ specific power of heat input in slag pool.

Relatively constant temperature of slag pool $T_{\mathrm{s}}$ is quickly set from the very beginning of the process and formation of skull on the surface of cold metal. Increase of temperature of metal surface $T_{\mathrm{m}}$ provides for reduction of skull thickness $\delta_{\mathrm{sk}}$ and rise of heat transfer coefficient $k_{\mathrm{s}-\mathrm{m}}$, i.e. efficiency of electroslag heating grows. Value of specific heat flow from slag pool in metal $q_{\mathrm{s}-\mathrm{m}}$ at that does not have significant changes - (21.526.9) $10^{4} \mathrm{~W} / \mathrm{m}^{2}$. Coefficient of heat transfer rapidly increases directly up to complete skull melting. Also, rapid rise of heat flow in metal is observed and billet heating is accelerated. Quasiequilibrium between the temperatures of slag pool and metal is set after skull melting, that provokes for their gradual growth and reduction of specific heat flow $q_{\mathrm{s}-\mathrm{m}}$ from $50 \cdot 10^{4}$ to $25.8 \cdot 10^{4} \mathrm{~W} / \mathrm{m}^{2}$.

Experiments determined that rise of ESS specific power reduces time of base metal heating up to submelting of its surface and increases gradient of temperature through its height ( $\mathrm{Fi}^{-}$ gures 2 and 3 ).

The most significant effect of specific power on these characteristics is observed at its relatively low values. This effect is insignificant in the range of high $q$ values (see Figures 2 and 3 ). The reason of this effect lies in stabilizing the temperature of slag pool due to increase of evaporation of slag volatile components and high heat emission from the surface of slag pool. Effect of specific power on heating duration becomes more apparent in melting of billets of larger height. The high value of specific power $\left(150 \cdot 10^{4} \mathrm{~W} / \mathrm{m}^{2}\right.$ and more) allows heating billets of different height up to submetling approximately during the same time (see Figure 2). 


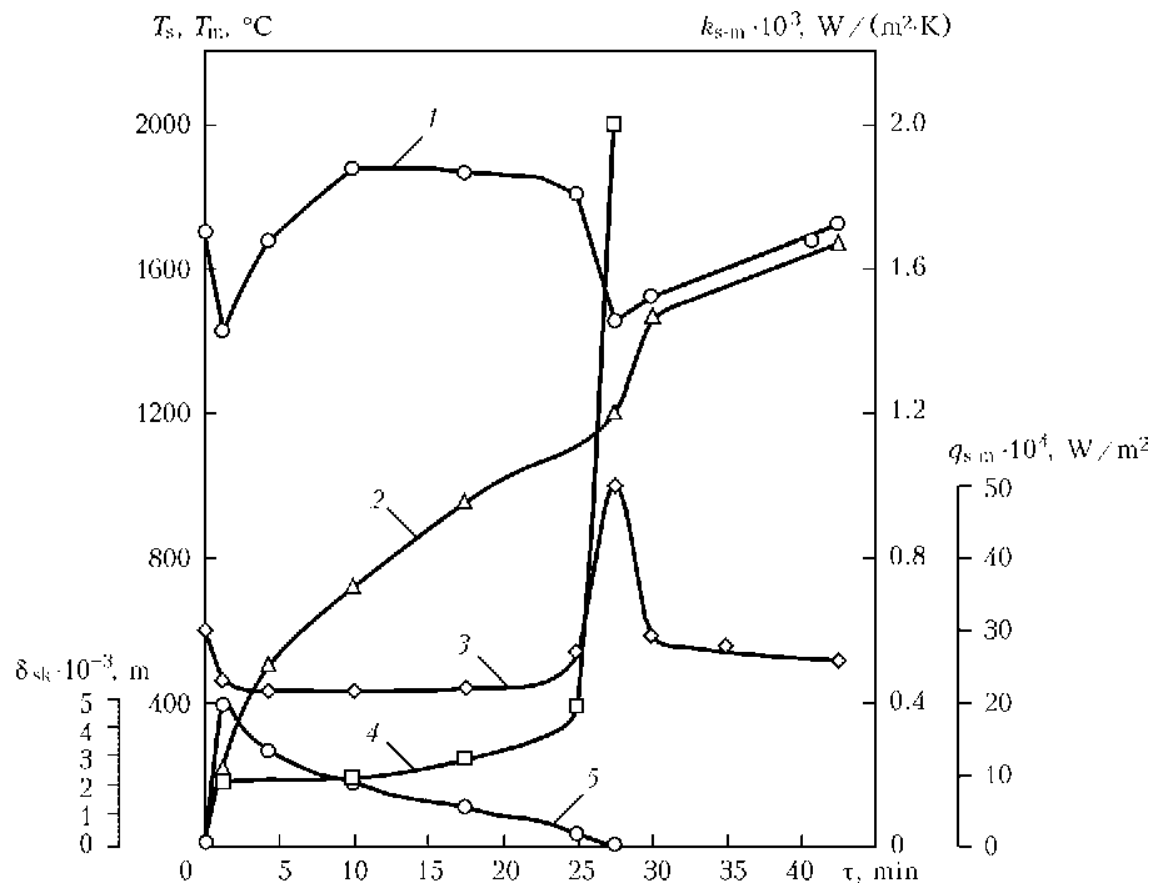

Figure 1. Dependence of temperature of slag pool $T_{\mathrm{S}}(1)$ and surface of billet being surfaced $T_{\mathrm{m}}(2)$, specific heat flow $q_{\mathrm{s}-\mathrm{m}}(3)$, coefficient of heat transfer $k_{\mathrm{S}-\mathrm{m}}$ to metal (4), and skull thicknesses $\delta_{\mathrm{sk}}$ on ESS duration $\tau$ (5)

Figure 4 shows distribution of temperatures through the height of $400 \mathrm{~mm}$ thickness billet depending on duration of its surface heating up to submelting $\left(1510{ }^{\circ} \mathrm{C}\right.$ on the surface).

Quick heating of the surface promotes for reduction of depth and temperature of metal heating-through. The billet is heated up to $200{ }^{\circ} \mathrm{C}$ at $200 \mathrm{~mm}$ depth during $1 \mathrm{~h}$. The experiments also determined that duration of heating of stamped billets of more than $300 \mathrm{~mm}$ height using specific power of ESS of $140 \cdot 10^{4} \mathrm{~W} / \mathrm{m}^{2}$ and more has low dependence on its height (Figure 5).

Application of large specific power of ESS results in intensive heating-through of only upper part of the billet and heat has no time to spread in body of metal being heated. This simplifies the task of heating of the large height stamps.

Effect of voltage on efficiency of electroslag process was evaluated in experimental way. Stamp billet was heated with low specific power $(60-65) \cdot 10^{4} \mathrm{~W} / \mathrm{m}^{2}$ up to setting on the surface of equilibrium temperature, above which the metal is not heated. After that the voltage was

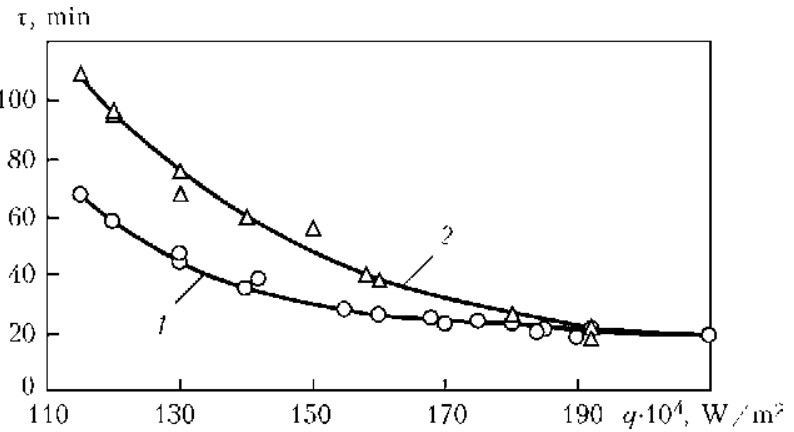

Figure 2. Effect of specific power of ESS on duration of heating of stamped billets up to submelting: $1-180 \mathrm{~mm}$ height; $2-400 \mathrm{~mm}$ changed at stable specific power and temperature of metal being heated was registered.

As can be seen from Figure 6, reduction of voltage provides for higher temperatures on the billet surface. i.e. its heating is intensified.

This can be explained by approaching the zones of active heat emission to metal surface

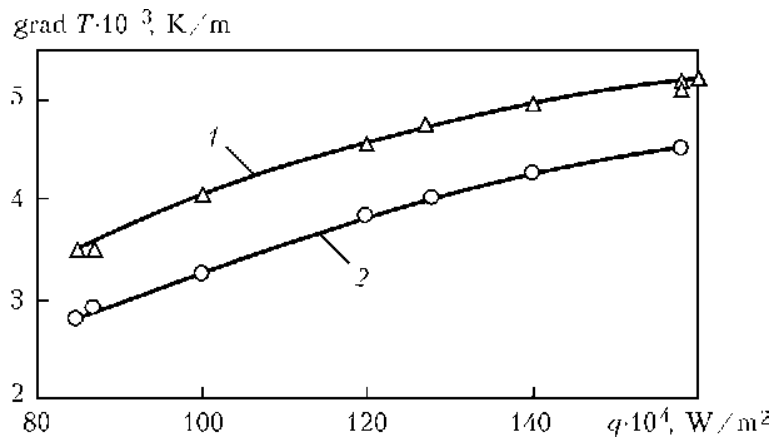

Figure 3. Effect of ESS specific power on temperature gradient through the height $(H=110 \mathrm{~mm})$ of stamped die: 1 - in the upper part of billet; 2 - through the whole billet height

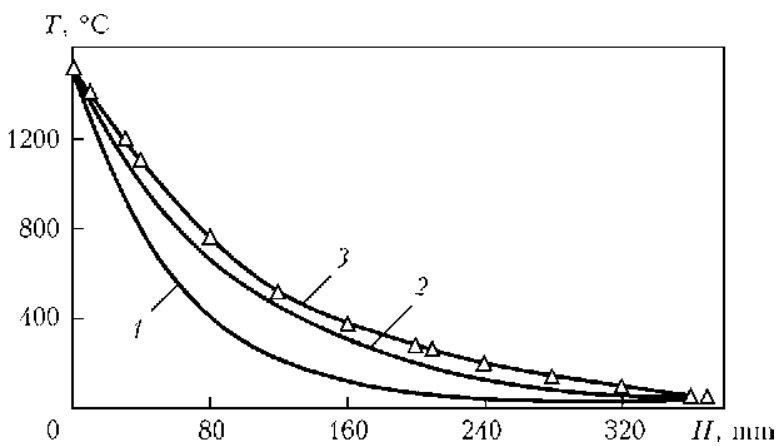

Figure 4. Dependence of temperature distribution through stamped billet height $(H=400 \mathrm{~mm})$ on time of heating: $1-22 ; 2-58 ; 3-68 \mathrm{~min} ; 1,2-$ calculation data; 3 - experimental 


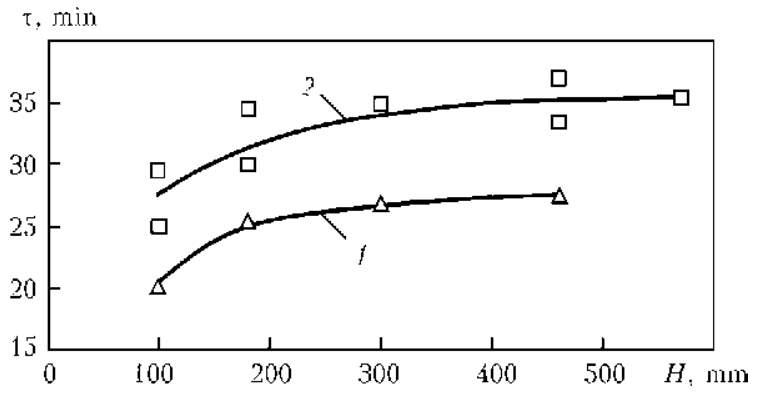

Figure 5. Duration of stamped billet heating of different height: 1 - up to skull melting; 2 - up to metal submelting $\left(q=(140-160) \cdot 10^{4} \mathrm{~W} / \mathrm{m}^{2}\right)$

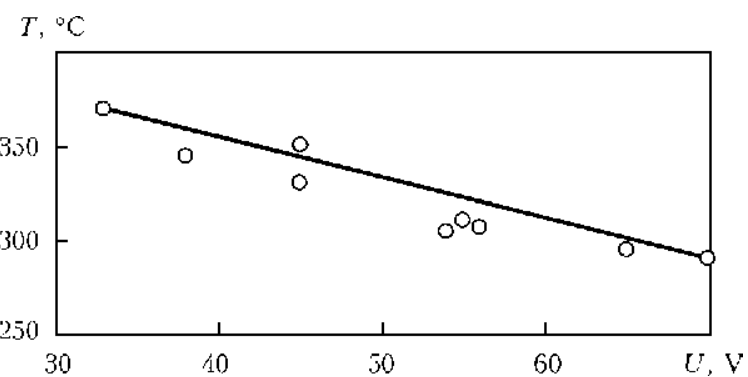

Figure 6. Effect of electroslag process voltage on temperature of stamp surface $\left(H=300 \mathrm{~mm}, q=(60-65) \cdot 10^{4} \mathrm{~W} / \mathrm{m}^{2}\right)$

[8], reduction of heat loss for radiation from slag pool mirror and acceleration of slag pool mixing, that rises the value of heat transfer coefficient $[2,10,11]$

The effect of slag pool depth on intensity of heating of $180 \mathrm{~mm}$ height billet at $150 \cdot 10^{4} \mathrm{~W} / \mathrm{m}^{2}$ specific power was investigated. Moments of skull melting and submelting of billet metal were registered. Received results (Figure 7) indicate reduction of heating duration at decrease of slag pool depth.

Reduction of heating duration in decrease of slag pool depth is explained by approaching the zone of active heat emission to the surface of metal and reduction of heat flow, entering the walls of water-cooled mold. However, its excessive reduction can promote deterioration of stability of electroslag process. Therefore, 50$60 \mathrm{~mm}$ is the optimum depth of slag pool at ESS of stamped billet.

Reduction of heating duration in general results in decrease of electric energy consumption, including at rise of specific power of electroslag process (Figure 8 ).

Energy consumption rises with increase of specific power only in the range of large specific powers, when, as was shown above (see Figure 2), metal heating duration does not depend on this index.

At that, heating of the higher billet in whole requires more electric energy per $1 \mathrm{~m}^{2}$ of the surface. Thus, it was found by investigations that ESS specific power maintained at (150$180) \cdot 10^{4} \mathrm{~W} / \mathrm{m}^{2}$ level provides for fast heating of stamp billet up to surface submelting at relatively small consumption of electric energy and

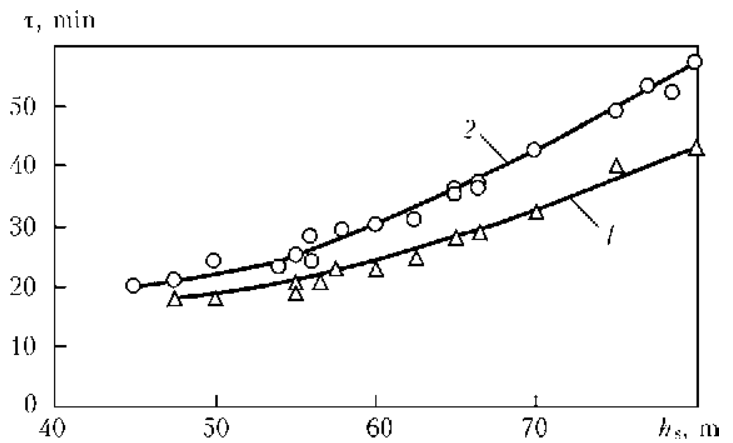

Figure 7. Effect of depth of slag pool $h_{\mathrm{s}}$ on duration of electroslag process: 1 - up to melting of skull; $2-$ up to metal submelting $\left(H=300 \mathrm{~mm}, q=(140-160) \cdot 10^{4} \mathrm{~W} / \mathrm{m}^{2}\right)$

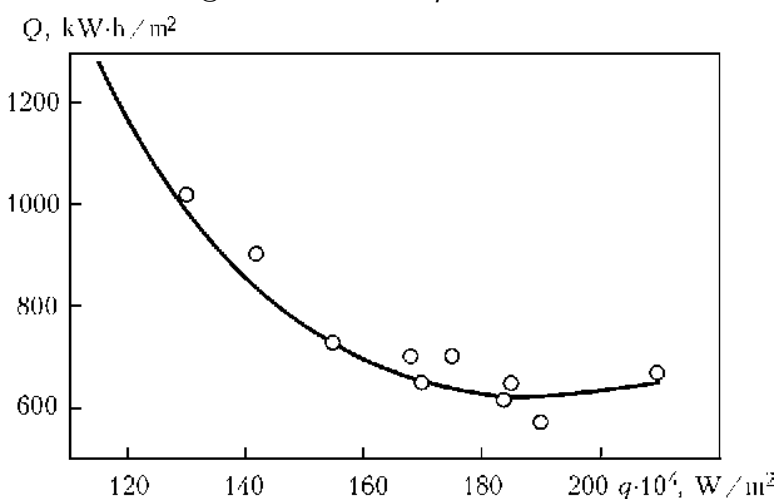

Figure 8. Effect of ESS specific power on electric energy consumption at heating up to submelting of stamps of $180 \mathrm{~mm}$ height

heat saturation of the base metal. At that, voltage and depth of slag pool shall be maintained at the most possible minimum level.

1. (1980) Electroslag welding and surfacing. Ed. by B.E. Paton. Moscow: Mashinostroenie.

2. Lyuty, I.Yu., Latash, Yu.V. (1982) Electroslag melting and refinement of metals. Kiev: Naukova Dumka.

3. Latash, Yu.V., Medovar, B.I. (1965) Electroslag remelting. Kiev: Naukova Dumka.

4. Medovar, B.I., Shevtsov, V.L., Marinsky, G.S. et al. (1978) Thermal processes in electroslag remelting. Kiev: Naukova Dumka.

5. (1974) Technology of fusion electric welding of metals and alloys. Ed. by B.E. Paton. Moscow: Mashinostroenie.

6. Nosatov, V.A. (1982) Investigation and development of electroslag casting technology of bimetal die billets: Syn. of Thesis for Cand. of Techn. Sci. Degree. Kiev: PWI

7. Ksyondzyk, G.V. (1973) Some principles of base metal penetration in circumferential electroslag surfacing. In: Proc. of All-Union Meeting on High-Efficiency Processes of Surfacing and Consumables (Kommunarsk, Sept. 1973), 26-33. Kiev: PWI.

8. Tarasevich, N.I. (1997) Formation of ingots and castings at controlled thermophysical action: Syn. of Thesis for Dr. of Techn. Sci. Degree. Kiev: FTIMS.

9. Demchenko, V.F. (1992) Calculation experiment in thermophysics of technological processes of welding and special electrometallurgy: Syn. of Thesis for Dr. of Techn. Sci. Degree. Kiev: PWI.

10. Baskakov, A.P. (1968) Rapid nonoxidation heating and heat treatment in boiling bed. Moscow: Metallurgiya.

11. Mikheev, M.A., Mikheeva, I.M. (1977) Principles of heat transfer. Moscow: Energiya.

Received 20.04.2015 


\title{
IMPROVEMENT OF BIMETAL JOINT QUALITY IN SUBMERGED ARC SURFACING OF HIGH-TIN BRONZE ON STEEL
}

\author{
T.B. MAJDANCHUK, V.M. ILYUSHENKO and A.N. BONDARENKO \\ E.O. Paton Electric Welding Institute, NASU \\ 11 Bozhenko Str., 03680, Kiev, Ukraine. E-mail: office@paton.kiev.ua
}

\begin{abstract}
It was shown that one of the efficient methods for producing bimetal product steel + high-tin bronze is submerged electric arc surfacing applying flux-cored wires. Analyzed were the causes for formation of different defects, which are possible in surfacing of bronze on steel. Considered were technological and metallurgical measures of eliminating porosity both on the deposited metal as well as along the fusion line of bronze with steel. To provide a minimum penetration of steel and reduction of iron content in bronze the process is performed using «split» electrode (two-electrode surfacing) at the optimum modes. The special attention is paid to study of causes for formation of intercrystalline penetrations of bronze into steel and their influence on quality of bimetal joint. The threshold value of energy input is determined at which the tendency to decrease the formation of intercrystalline penetrations is observed. 10 Ref., 2 Tables, 4 Figures.
\end{abstract}

Keywords: high-tin bronze, submerged arc surfacing, bimetal joint, intercrystalline penetrations

Due to the high antifriction properties and increased hardness, tin-phosphorous bronze of type $\mathrm{Br} . \mathrm{O} 10 \mathrm{~F} 1$ is widely used in manufacture of bearings, gears and bushings for critical purpose, operating at high specific pressures [1]. In order to save deficient nonferrous metals and increase the strength of bearings it is reasonable to replace the cast bronze parts by bimetal ones. One of the effective methods of manufacturing bimetal products, especially large-sized ones with a working layer of tin bronze of grade Br.O10F1, can be submerged electric arc surfacing. Therefore, the challenging problem is the development of material and technology for surfacing of this type of bronze on steel. As many years of experience of the E.O. Paton Electric Welding Institute show, in surfacing of copper alloys on steel the significant metallurgical and technological difficulties are observed, namely: increased tendency to pores formation (both in deposited metal as well as along the fusion line with steel), intercrystalline penetrations of bronze into steel, and possibility to alloy the deposited metal by iron, a high content of which deteriorates operational properties of the deposited bronze.

As far as the high-tin bronze is not treated by pressure and due to its low ductility it can not be used to produce a small-diameter welding wire, therefore, a flux-cored wire can be used as the electrode material. As a sheath of flux-cored wire, a copper strip of grade M1M (GOST 117393) was used. In the core composition a tin in the form of powder of grade PO-1 (GOST 972373) and phosphorus in the form of powder of phosphorous copper of grade MF-9 (GOST 253084) are included. To prevent porosity in surfacing, the powder of marble is added (up to $5 \%$ ) to the flux-cored wire charge. Marble, refining the electrode metal droplets and reducing the time of their existence at the end of electrode, reduces also overheating of the deposited metal, thus reducing the penetration depth of steel [2].

A significant influence on quality of the bimetal joint has a flux, which is used in surfacing. To select the optimum grade of flux, the influence of different fluxes on the stability of surfacing process, formation of the deposited metal, removal of the slag crust and presence of pores were investigated. Figure 1 shows the appearance of deposits made under fluxes of grades AN-60, AN-348A, AN-26S, AN-60SM and fluoride basic flux UV 420 TT of «Bohler Thyssen» (Germany).

It is characteristic that in three-layer surfacing under the investigated fluxes no cracks and pores were found in the deposited metal during visual inspection, a slag is easily separated, here the best results on process stability were observed under fluxes AN-60 and AN-60SM. In surfacing under fluxes AN-348A and AN-26S during investigation of transverse macrosections the fragmentation and pores in the bead upper part were found in the third layer.

Formation of beads in surfacing under flux UV 420 TT (see Figure 1) was unsatisfactory, 


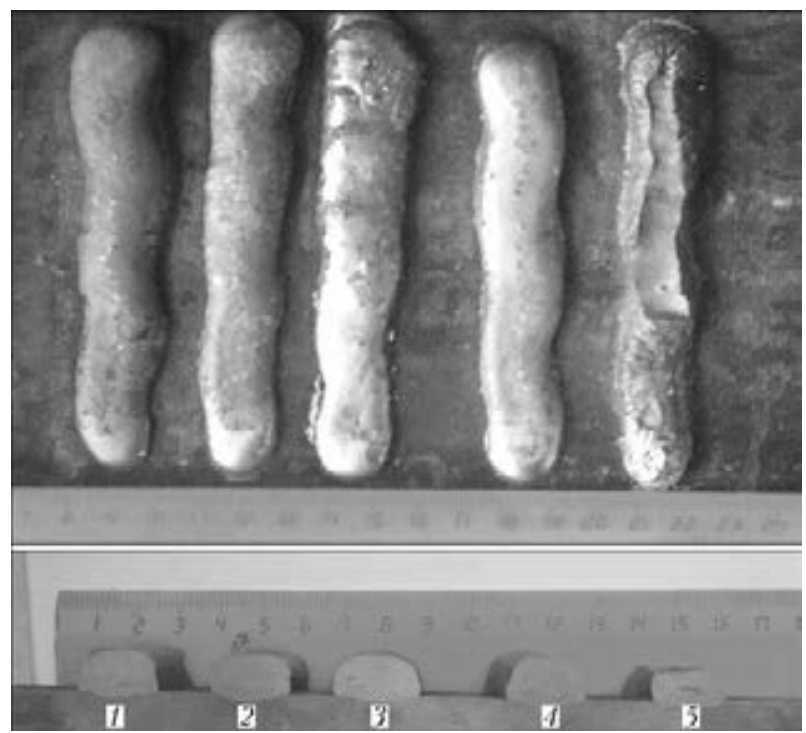

Figure 1. Appearance of deposits made under different fluxes: 1 - AN-60; 2 - AN-348A; 3 - AN-26S; 4 AN-60SM; 5 - UV 420 TT

which may be connected with a high basicity of flux (2.5 points according to Bonishevsky). Therefore, flux AN-60 was used further for surfacing.

In surfacing of copper alloys on steel the pores are often formed along the fusion line. This is connected with a relatively small amount of heat energy, which is introduced in surfacing at the least possible modes to ensure minimization of steel melting, which, on one hand, results in increase of duration of solidification front arrestment and promotes the pores formation [3], and, on the other hand, it results in the volumetric oversaturation of weld pool metal with gases caused by decrease in solubility due to decreasing of metal temperature. In this case, the growth of pores occurs mainly as a result of convective diffusion of gas from the surrounding volumes of metal $[4,5]$. Therefore, the mode of surfacing must be slightly «exceeded» to eliminate this type of defects. At the same time, the increase of mode parameters leads to a large amount of iron, transferred to the deposited metal. It is shown in a number of works $[2,6,7]$ that to reduce penetration of base metal the method of surfacing using split electrode is recommended. The main factor determining penetration depth is the distance between electrodes, i.e. the value of splitting. In order to determine the optimal value of splitting, a single-layer surfacing on lowcarbon steel by flux-cored wire PPBr.OF10-1 at different distance between electrodes was carried out (Figure 2).

The sizes and shape of beads indicate the following. When splitting is less than $6 \mathrm{~mm}$ the common drop of molten metal is formed due to electrodynamic forces during surfacing, which leads to a significant penetration of base metal. In splitting of more than $8 \mathrm{~mm}$ the electrodynamic forces are small, the space between the electrodes is filled with a slag and the arcs begin to burn separately, which results in producing a saddle-shaped deposited metal (see Figure 2) and thus «floating up» of iron-containing particles occurs into the upper part of the bead. The efficiency of the process in surfacing using split electrode is $1.7-2.3$ times increased as compared to a single-electrode surfacing, providing reduction in penetration depth of steel. The decrease in deposition rate from 18 to $10 \mathrm{~m} / \mathrm{h}$, while the other welding parameters are constant, results in up to $5-7 \%$ decrease in iron content in the deposited metal. This is connected with the growth of the layer of molten metal which is leaking under the arc column and thus screening it.

One of the main defects in surfacing of tin bronzes is the intercrystalline penetrations of nonferrous metal into steel. The authors of works $[8,9]$ show that tin bronzes have an increased tendency to intercrystalline penetrations as compared to other copper alloys. At the same time, these defects reduce strength of the joint, they also negatively influence the operation of a product under alternating thermal and dynamic loads.

As metallographic examinations of sections with deposits of tin bronze on steel showed, the

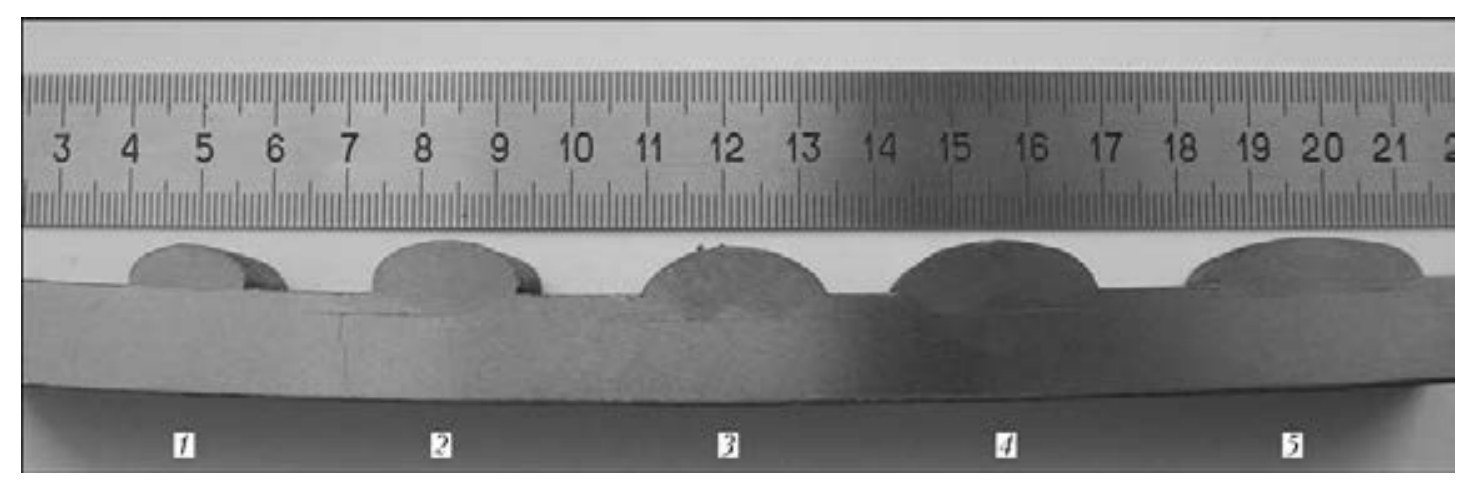

Figure 2. Macrosection of deposits made under flux AN-60 at different distance between the electrodes: $1-1 ; 2-6$; $3-8 ; 4-10.5 ; 5-12 \mathrm{~mm}$ 
Table 1. Effect of surfacing modes on tendency to intercrystalline penetrations of bronze into steel (at $U_{\mathrm{a}}=35 \mathrm{~V}$ )

\begin{tabular}{|c|c|c|c|c|c|c|c|c|}
\hline \multirow{2}{*}{$\begin{array}{l}\text { Number of } \\
\text { deposit }\end{array}$} & \multicolumn{2}{|c|}{ Mode of surfacing } & \multirow{2}{*}{$\begin{array}{l}\text { Energy input, } \\
\mathrm{kJ} / \mathrm{m}\end{array}$} & \multicolumn{3}{|c|}{ Sizes of bead, mm } & \multicolumn{2}{|c|}{ Penetrations } \\
\hline & $I_{\mathrm{s}}, \mathrm{A}$ & $v_{\mathrm{s}}, \mathrm{m} / \mathrm{h}$ & & Width & Height & $\begin{array}{l}\text { Penetration } \\
\text { depth, mm }\end{array}$ & Section I & Section II \\
\hline 1 & 210 & 14 & 496.8 & $14.5-15.5$ & $4.5-5.0$ & $\leq 0.2$ & No & No \\
\hline 2 & 310 & 14 & 669.6 & $20.0-20.5$ & $5.0-5.5$ & $1.5-2.5$ & 2 & No \\
\hline 3 & 390 & 14 & 864 & $24-25$ & $5.3-5.5$ & $1.5-2.5$ & 1 & 2 \\
\hline 4 & 310 & 14 & 478.8 & $14.5-15.0$ & $5.5-6.0$ & $1.0-2.5$ & No & No \\
\hline 5 & 310 & 14 & 576 & $16.5-17.0$ & $5.0-5.5$ & $0.5-1.0$ & No & 2 \\
\hline 6 & 310 & 14 & 669.6 & $19.5-20.0$ & $5.0-5.2$ & $2.5-1.5$ & 2 & No \\
\hline 7 & 310 & 10 & 936 & $20-21$ & $5.0-5.5$ & $\leq 0.5$ & 3 & 2 \\
\hline 8 & 310 & 14 & 669.6 & $19.5-20.0$ & $5.0-5.2$ & $2.5-1.5$ & 2 & No \\
\hline 9 & 310 & 14 & 410.4 & $18.0-18.5$ & $4.0-4.5$ & $\leq 0.5$ & No & No \\
\hline
\end{tabular}

change in concentration in the deposited metal of tin and phosphorus within the limits regulated by GOST 613-79 for the bronze of grade Br.O10F1 (9.0-11.0 \% Sn, 0.4-1.1\% P) has an insignificant effect on amount and extention of intercrystalline penetrations. A more significant influence on presence or absence of penetrations belongs to surfacing modes.

To evaluate the effect of surfacing modes on intercrystalline penetrations the complex of investigations was performed, where in each of the parameters one was changed, and the rest remained unchanged. The surfacing was performed on steel plate of grade St.20 of $12 \mathrm{~mm}$ thickness using split electrode at the distance between axes of $6 \mathrm{~mm}$ using $3 \mathrm{~mm}$ diameter wire PPBr.OF10-1. The templates were cut out of each bead and the presence and nature of intercrystalline penetrations were determined on cross-sections (not less than two sections). The dimensions of bead crosssection as well as penetration depth of base metal

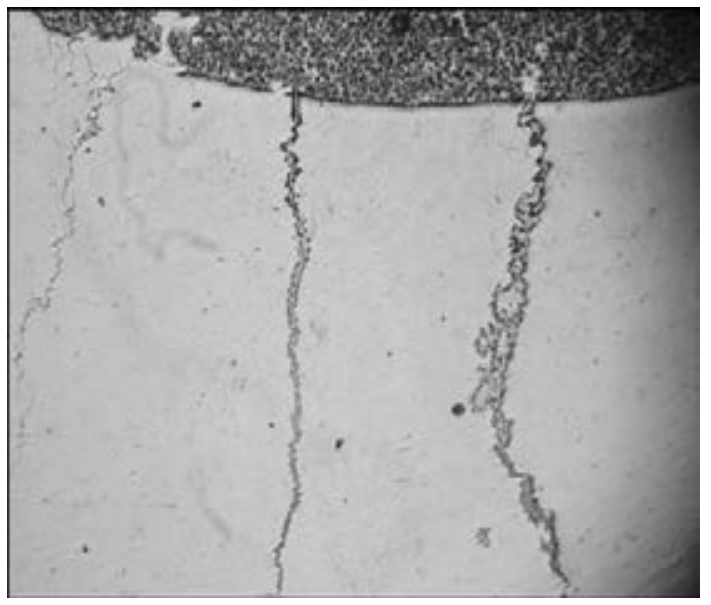

Figure 3. General view of intercrystalline penetration of bronze into steel $(\times 25)$ were recorded. The results of experiments are given in Table. 1.

It is seen from the results given in Table 1 that probability of appearance of intercrystalline penetrations is influenced by all the parameters of welding, but to a greater extent by current and deposition rate than by arc voltage. Moreover, a certain threshold value of heat input exists, below which the intercrystalline penetrations are low probable. For a given method of surfacing it is equal about to $500 \mathrm{~kJ} / \mathrm{m}$.

Any influence of penetration depth on intercrystaline penetrations was not detected. The intercrystalline penetrations are equally probable both during penetration (up to $2.5 \mathrm{~mm}$ ) as well as at almost complete absence of it $(\leq 0.5 \mathrm{~mm})$ i.e. in the samples of deposits 3 and 7 . Heat input in this case is approximately the same. The typical appearance of intercrystalline penetrations is shown in Figure 3.

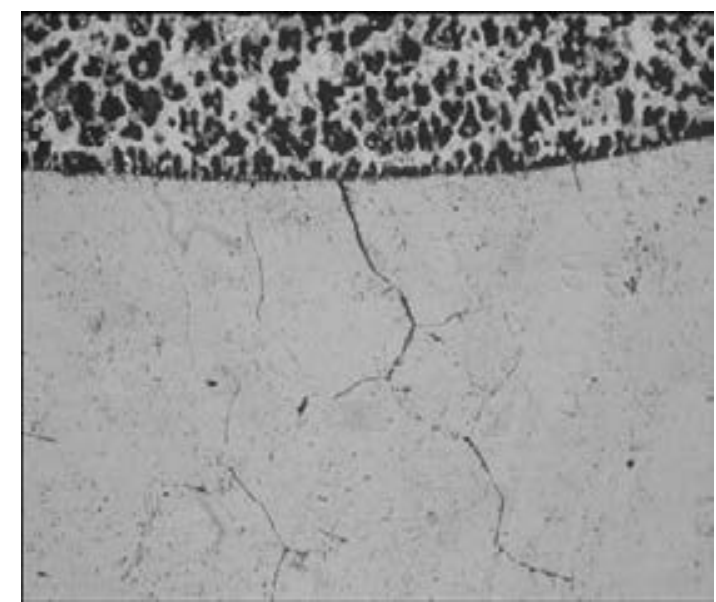

Figure 4. Cracking of steel without filling it with bronze $(\times 156)$ 
Table 2. Chemical composition and mechanical properties of cast and deposited bronzes

\begin{tabular}{|c|c|c|c|c|c|c|c|}
\hline \multirow[b]{2}{*}{ Material } & \multirow[b]{2}{*}{ Sn } & \multirow[b]{2}{*}{$\mathrm{P}$} & \multirow[b]{2}{*}{$\mathrm{Mn}$} & \multirow[b]{2}{*}{$\mathrm{Fe}$} & \multirow[b]{2}{*}{ Hardness $H B$} & \multicolumn{2}{|c|}{ Wear } \\
\hline & & & & & & $\begin{array}{l}\text { Bronze, } \\
\mathrm{mm}^{3} / \mathrm{m}\end{array}$ & $\begin{array}{l}\text { Counterbody, } \\
\mathrm{g} / \mathrm{m}^{*}\end{array}$ \\
\hline Cast bronze of grade Br.O10F1 & $9.0-11.0$ & 0.50 & - & - & $130-140$ & 0.00585 & 0.0013 \\
\hline $\begin{array}{l}\text { Surfacing PPBr.OF10-1 under flux } \\
\text { AN-60 (2nd layer) }\end{array}$ & 9.3 & 0.47 & 0.5 & 2.92 & $150-160$ & 0.0016 & 0.00135 \\
\hline
\end{tabular}

Obviously, the formation of intercrystalline penetration occurs in several stages. At the first stage due to effect of reducing the strength and ductility of steel, which contacts the molten bronze, the fracture occurs at the boundary of steel crystallites (see left side of Figure 3). The presence of initiating crack formations in steel is confirmed by Figure 4, where there is no bronze filling, but separation between the crystallites in steel is clearly seen.

At the next stage the liquid bronze penetrates into the formed crack, which creates an additional pressure on a «wall» of the crack, which leads to its opening. Thus, the crack is opened at a rate of growing to its apex of copper alloy, as even at the end of crack there are no defects such as lack of fusions or voids [10].

The investigations of chemical composition showed that the deposited metal as to its composition corresponds to the cast tin bronze of grade Br.O10F1 (Table 2). Mechanical properties, given in Table 2, indicate that the hardness of deposited metal as compared to the cast one is somewhat higher. In this case wear resistance of the bronze layer deposited under flux is 3-3.5 times higher than that of the cast bronze. It should be noted that the wear of counterbody is almost identical here, from which a conclusion can be made about the same adhesion of steelbronze pairs of friction.

\section{Conclusions}

1. For the surfacing of high-tin bronze on steel the special flux-cored wire was developed providing a high-quality deposited metal of the required composition.
2. In order to reduce iron content in the deposited metal the most effective is to use a split electrode at the optimal surfacing modes.

3. Reduction of tendency to formation of intercrystalline penetrations is achieved due to decrease in heat input.

1. Osintsev, O.E., Fyodorov, V.N. (2004) Copper and copper alloys. Domestic and foreign grades: Refer. Book. Moscow: Mashinostroenie.

2. Ilyushenko, V.M., Lukianchenko, E.P. (2013) Welding and surfacing of copper and copper alloys. Kiev: IAW.

3. Grigorenko, G.M. (1970) To problem of pore formation in welds. Avtomatich. Svarka, 10, 20-29.

4. Pokhodnya, I.K. (1972) Gases in welds. Moscow: Mashinostroenie.

5. Pokhodnya, I.K., Makhnenko, V.I. (1971) On kinetics of pore formation in welds. Avtomatich. Svarka, 7, 20-23.

6. Ilyushenko, V.M., Belov, A.S., Kinovich, A.P. (1985) Efficiency of surfacing of copper alloys on steel with split electrode. In: Surfacing. Experience and efficiency of application, 82-86. Kiev: PWI

7. Ilyushenko, V.M. (1978) Advanced methods of electric arc surfacing of copper alloys on steel. In: Proc. of 1 st All-Union Seminar on Welding and Surfacing of Heavy Nonferrous Metals, 30-32. Kiev: PWI.

8. Vajnerman, A.E., Pichuzhkin, S.A., Chernobaev, S.P. et al. (2012) New welding consumables and technological specifics of welding and surfacing of products of copper alloys and dissimilar metals. In: Proc. of Int. Sci.-Techn. Conf. on Welding Consumables-2012, 141-147.

9. Rybin, V.V., Vajnerman, A.E., Baranov, A.V. at al. (2006) Study of peculiarities and development of welding technologies of copper alloys with steels and surfacing of copper alloys on steel. Voprosy Materialovedeniya, 1, 220-229.

10. Vajnerman, A.E. (1981) Mechanism of intercrystalline penetration in surfacing of copper alloys on steel. Ibid., 6, 22-26. 


\title{
EFFECT OF PULSED ELECTRODE WIRE FEEDING ON FORMATION AND WEAR RESISTANCE OF DEPOSITED BEAD AND LOSSES OF ELECTRODE METAL IN CO2 ARC SURFACING
}

\author{
I.V. LENDEL ${ }^{1}$, S.Yu. MAKSIMOV ${ }^{1}$, V.A. LEBEDEV ${ }^{1}$ and O.A. KOZYRKO ${ }^{2}$ \\ ${ }^{1}$ E.O. Paton Electric Welding Institute, NASU \\ 11 Bozhenko Str., 03680, Kiev, Ukraine. E-mail: office@paton.kiev.ua

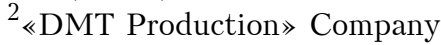 \\ $11 / 2$ Bugsky Bld., 54029, Nikolaev, Ukraine. E-mail: o.kozurko@dmt-wiches.com
}

\begin{abstract}
The work deals with the results of investigations of influence of pulsed electrode wire feed parameters on the conditions of deposited metal bead formation, wear resistance and losses of electrode metal in electric arc surfacing in $\mathrm{CO}_{2}$. The comparative analysis of results was carried out obtained at constant and pulsed electrode wire feed. It was shown that change in electrode wire feed rate at constant power parameters of surfacing process allows efficiently influencing the formation of deposited bead, wear resistance and amount of losses of electrode metal. The given result is achieved due to change of kinematical conditions of electrode metal transfer from the electrode end through the arc gap to the molten metal pool. 11 Ref., 4 Figures.
\end{abstract}

$\boldsymbol{K} \boldsymbol{e} \boldsymbol{y} \boldsymbol{w} \boldsymbol{O} \boldsymbol{r} \boldsymbol{s}:$ deposited metal, electrode wire pulsed feed parameters, geometric parameters of deposited bead, electrode wire feed rate, losses of electrode metal, control of electrode metal transfer

The most important field of the modern welding science and technology is surfacing. The methods of arc surfacing acquired a dominated position in industrial practice. One of the widespread methods remains surfacing in pure $\mathrm{CO}_{2}$. However, this process has a number of disadvantages, the main of which are the following: large penetration depth of base metal; high losses of electrode metal for spattering (from 5 to $15 \%$ ); narrow range of surfacing modes with producing a satisfactory bead formation etc. [1, 2].

The studies, aimed at eliminating disadvantages and improving this technological process, are the subject of numerous works, from which it follows that conditions for formation of deposited metal and manufacturability of arc surfacing in $\mathrm{CO}_{2}$ are determined to a large extent by the possibility of implementation of controllable transfer of molten electrode metal to the weld pool [3, 4].

The effect on electrode metal transfer at constant rate of electrode wire feeding and pulse control of electric parameters of welding arc was realized by such producers like EWM, OTC Daihen, Kemppi, Cloos, ESAB and a number of others. Fronius realized a combined electric mechanical control [5-10].

(c) I.V. LENDEL, S.Yu. MAKSIMOV, V.A. LEBEDEV and O.A. KOZYRKO, 2015
A very scarce information is available in literature on the possibilities of control of molten electrode metal transfer only due to the change in electrode wire feed rate using control circuits of electric parameters of serial sources of welding current.

For these investigations a unique mechanism of pulsed electrode wire feed was designed at the E.O. Paton Electric Welding Institute ( $\mathrm{Fi}^{-}$ gure 1) which allows controlling the electrode metal transfer without using the feedback with welding current source.

The investigations of effect of the pulsed electrode wire feed on geometric sizes of deposited bead were carried out for characteristic ranges of parameters of surfacing in $\mathrm{CO}_{2}$, at which a satisfactory formation of surface of the deposited metal is preserved: surfacing current varied in the range of $80-400 \mathrm{~A}$ and arc voltage was $14-$ $38 \mathrm{~V}$, surfacing speed was $7 \mathrm{~mm} / \mathrm{s}$, electrode stickout was $12 \mathrm{~mm}$, consumption of shielding gas was $0.3 \mathrm{l} / \mathrm{s}$, diameter of nozzle was $20 \mathrm{~mm}$. Power sources Kemppi FastMIG KMS-500 and VDU-506 were applied. The base metal was steel St3. Electrode wires Sv-08G2S and Np-30KhGSA of $1.2 \mathrm{~mm}$ diameter were applied.

The results of carried out investigations show the ability to efficiently influence geometric parameters of bead, to adjust penetration depth of base metal in the frequency range of $10-60 \mathrm{~Hz}$ and pulse duration ratio of $1.25-5$ units (Figure 2). As compared with constant electrode 


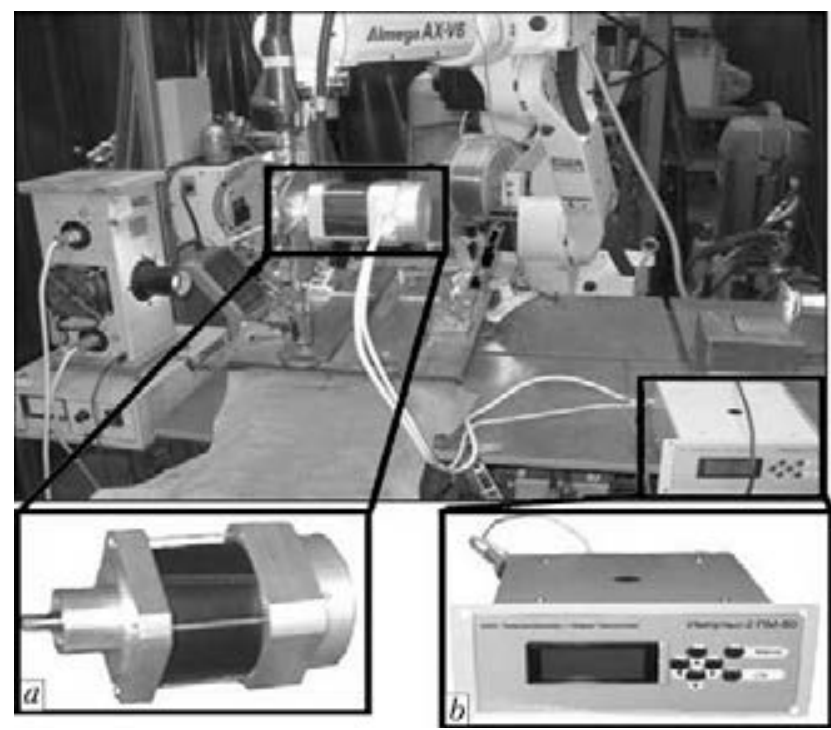

Figure 1. Mechanism of pulsed electrode wire feed installed to the welding robot: $a$ - brushless direct current motor; $b$ - drive control unit

wire rate, it is possible to reduce penetration depth by $1.2-2$ times by using the pulsed feed.

In addition, simultaneously with study of the effect of pulsed wire feed on the geometric parameters of deposited bead, its effect on the loss of electrode metal was studied. The obtained data show that pulsed electrode wire feed allows reducing the loss of electrode metal for spattering by $1.1^{-2}$ times by creating a more favorable conditions for transition of electrode metal drop to the weld pool, which is particularly effective when the frequency of pulses is $20-50 \mathrm{~Hz}$ and pulse duration ratio is 3-5 units (Figure 3 ).

To study the effect of pulsed electrode wire feed on wear resistance of deposited metal the experiments on single- and five-layer surfacing using wire Np-30KhGSA with feeding frequency

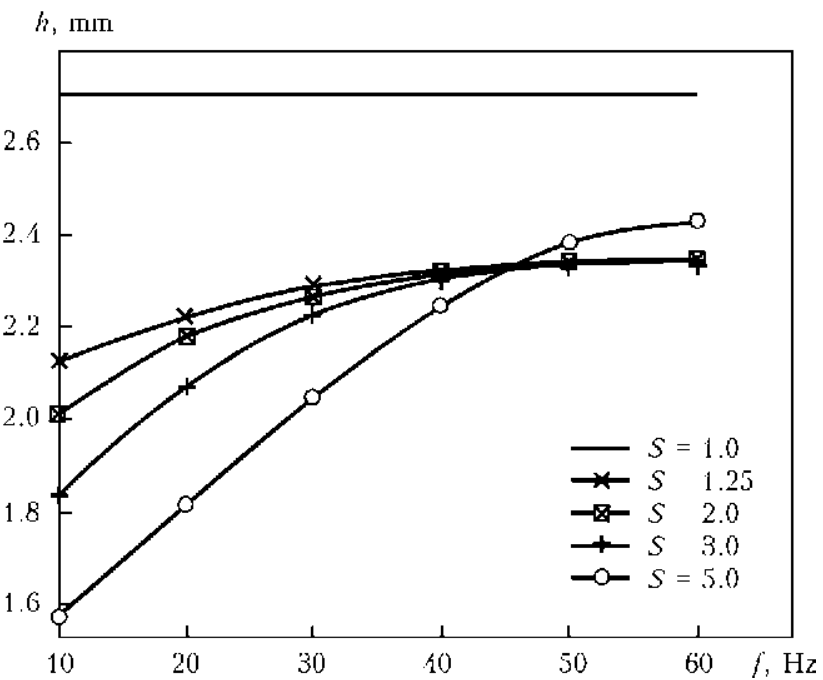

Figure 2. Dependence of penetration depth $h$ on frequency $f$ and pulse duration ratio $S$ of pulsed electrode wire feed at mean current $I=220 \mathrm{~A}$ and voltage $U=26 \mathrm{~V}$ $\psi, \%$

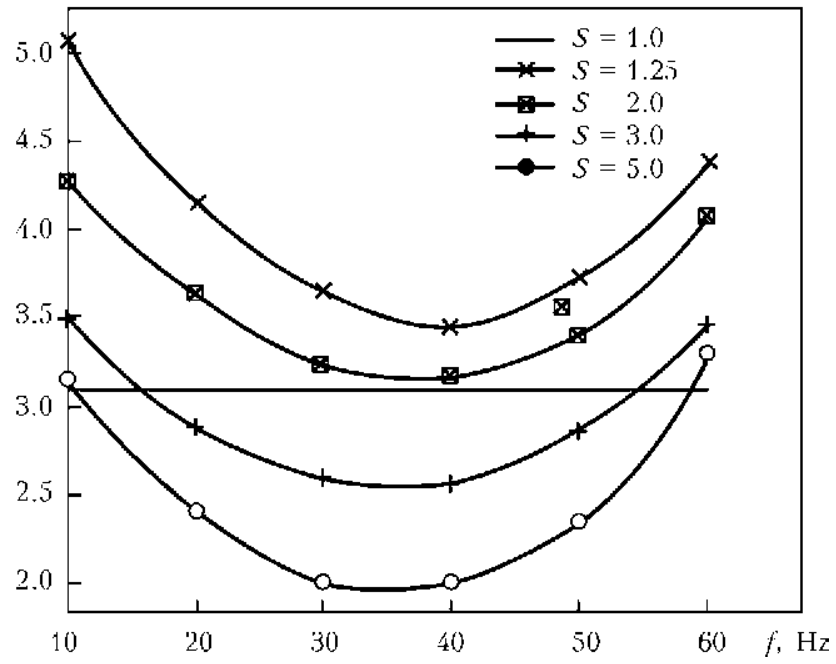

Figure 3. Dependence of losses of electrode metal $\psi$ on frequency $f$ and pulse duration ratio $S$ of pulsed electrode wire feed at mean current $I=220 \mathrm{~A}$ and voltage $U=26 \mathrm{~V}$

of 15,20 and $60 \mathrm{~Hz}$ and pulse duration ratio of 3-5 units were performed.

The tests for wear resistance by friction of metal against metal were carried out at the facility for comprehensive evaluation of deposited metal properties designed at the E.O. Paton Electric Welding Institute [11] under the following conditions: specific pressure at contact point was $100 \mathrm{MPa}$; friction speed was $11-12 \mathrm{~m} / \mathrm{min}$; temperature of ring-counterbody (according to GOST 12423-66) was $23 \pm 2{ }^{\circ} \mathrm{C}$; temperature at the surface of test specimen in contact zone was $30-40{ }^{\circ} \mathrm{C}$; testing time was $1 \mathrm{~h}$. The sizes of ringcounterbody manufactured of hardened steel 45 are as follows: $110 \mathrm{~mm}$ diameter, $30 \mathrm{~mm}$ width, $20 \mathrm{~mm}$ thickness; specimen sizes are $10 \times 20 \times$ $\times 40 \mathrm{~mm}$. For comparison, as a reference the specimens were tested produced at constant electrode wire feed. Wear resistance was evaluated

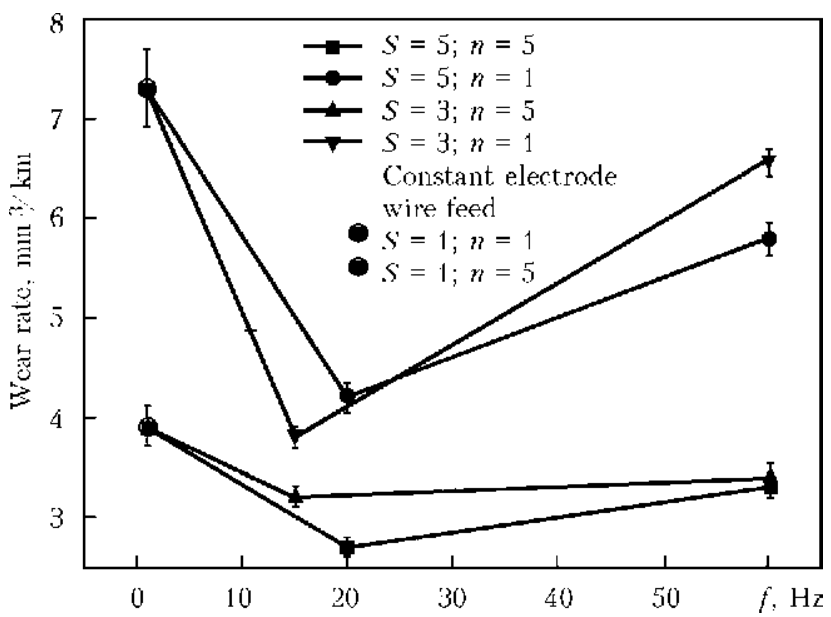

Figure 4. Plot of wear rate of specimens depending on frequency, pulse duration ratio and number $n$ of deposited layers at mean current $I=220 \mathrm{~A}$ and voltage $U=26 \mathrm{~V}$ 
by loss of mass $\Delta G$ of the test specimen and the abrading ring before and after the wear.

The obtained results showed that at pulsed electrode wire feed with low frequency of 15$20 \mathrm{~Hz}$ and pulse duration ratio of 3-5 units, level of wear resistance of fifth deposited layer produced at constant electrode wire feed can be reached already in the first deposited layer, and as compared with a single-layer deposit produced at constant electrode wire feed the wear resistance is almost 2 times higher (Figure 4).

Thus, according to the results of carried out investigations of the effect of pulsed electrode wire feed on formation of deposited bead, wear resistance and losses of electrode metal, the following conclusions were made:

1. The pulsed electrode wire feed allows controlling the geometry of deposited bead. In particular, at current of $220 \mathrm{~A}$ and voltage of $26 \mathrm{~V}$ the penetration depth is 2 times reduced. The increase in frequency from 10 to $60 \mathrm{~Hz}$ results in increase of penetration depth from 1.5 to $2.4 \mathrm{~mm}$, that is closer to the value obtained at constant electrode wire feed.

2. At pulsed electrode wire feed with frequencies of $20-50 \mathrm{~Hz}$ and pulse duration ratio of $3-5$ units the reduction of electrode metal losses is observed. At frequency of $30-40 \mathrm{~Hz}$ and pulse duration ratio of 5 units the minimum losses of electrode metal are provided, that is 2 times lower than those at constant electrode wire feed.
3 . The pulsed electrode wire feed at frequency of pulses of $15-20 \mathrm{~Hz}$ and pulse duration ratio of 3-5 units provides the characteristics of wear resistance even in the first layer similar to those of the fifth deposited layer produced at constant electrode wire feed. Also the improvement of wear resistance by almost 2 times is observed in single-layer surfacing and by 1.5 times - in fivelayer one.

1. Paton, B.E. (1999) Problems of welding at the border of centuries. Avtomatich. Svarka, 1, 4-14.

2. Ryabtsev, I.A., Senchenkov, I.K. (2013) Theory and practice of surfacing works. Kiev: Ekotekhnologiya.

3. Krampit, N.Yu. (2009) Methods of control of electrode metal melting and transfer (Review). Svarochn. Proizvodstvo, 3, 31-35.

4. Zhernosekov, A.M. (2012) Tendencies in development of control of metal transfer processes in shielding gases (Review). The Paton Welding J., 1, 29-33.

5. Goecke, S.F. (2005) Low energy arc joining process for materials sensitive to heat. EWM Hightec Welding $\mathrm{GmbH}$

6. (2013) OTC Daihen Inc. advanced welding and robotic systems. $D P-400 / D P-500 / D M-350 / D M-500$ digital controlled DC inverter arc welding machines: Cat. No. A446C.

7. Uusitalo, J. (2006) Kemppi Pro News 2/2006. FastROOT Process, 4-8.

8. (2008-2009) Kemppi Product Cat. Kemppi Oy. P.O. Box 13. 15801 Lahti, Finland.

9. (2011) Cloos Products, 142. Carl Cloos Schweisstechnik GmbH.

10. (2014/2015) Product Catalogue, 120. Fronius International GmbH, Austria.

11. Ryabtsev, I.I., Chernyak, Ya.P., Osin, V.V. (2004) Block-modular unit for testing of deposited metal. Svarshchik, 1, 18-19. 


\title{
OPTIMIZATION OF MODES OF SUBMERGED ARC SURFACING OVER THE LAYER OF ALLOYING CHARGE OF CATERPILLAR MACHINE RUNNING GEAR PARTS
}

\author{
V.V. PEREMITKO and D.G. NOSOV \\ Dneprodzerzhinsk State Technical University \\ 2 Dneprostroevskaya Str., 51918, Dneprodzerzhinsk, Ukraine. E-mail: science@dstu.dp.ua
}

\begin{abstract}
The optimization of modes of submerged arc surfacing with application of external magnetic field over the layer of alloying charge of caterpillar machine running gear parts was carried out. The influence of external axial magnetic field parameters and powders of silicon carbide $\mathrm{SiC}$ and aerosil $\mathrm{SiO}_{2}$, introduced with the charge, on hardness and microhardness of the deposited metal was studied. During experiments the concentration of silicon compounds in alloying charge, number of deposited layers, deviation in the arrangement of the latter relatively to the arc axis as well as induction of the external magnetic field were changed. The regression dependence of hardness on surfacing mode parameters for two types of charge is presented. The software complex was designed intended to determine the parameters of arc surfacing mode according to the proposed scheme to provide the maximum effect of using external influences. 11 Ref., 1 Table, 3 Figures.
\end{abstract}

$\boldsymbol{K} \boldsymbol{e} \boldsymbol{y} \boldsymbol{w} \boldsymbol{o r d} \boldsymbol{s}:$ arc surfacing, alloying charge, external magnetic field, powders $\mathrm{SiC}$ and $\mathrm{SiO}_{2}$, regression dependences, designing of surfacing technology

Analysis of organization and carrying out of surfacing works shows that for restoration of parts, which at first sight operate approximately under the same conditions, a rather wide range of surfacing materials is commonly proposed differing by degree, and sometimes by alloying system which is not always justified [1-4]. In particular, it is well known from the experience of restoration of running gear parts of caterpillar machines that the requirements to deposited metal depending on conditions of the further operation (operation mode, hardness and granulometric composition of abrasive particles getting to the pairs of friction, etc.) can vary considerably [5].

As a result, for surfacing of the same running gear parts of caterpillar machines (conveyor rollers, rollers, tracks) it becomes necessary to use surfacing materials differing, in the first turn, by hardness, chemical composition and structure. It was established [6] that depending on the mentioned operation conditions the hardness of metal deposited on running gear parts of caterpillar machines should vary in the range of $H V$ 285-435 (HB 283-413), which almost can not be achieved using only one grade of surfacing wire.

It has been shown [7] that changing of hardness of deposited metal in a rather wide range is possible in arc surfacing over the layer of alloying charge previously clad on the surface to be deposited. However, this method has a significant dis-

(C) V.V. PEREMITKO and D.G. NOSOV, 2015 advantage, i.e. during its use the specified composition and good formation of deposited metal can be achieved only in a narrow range of surfacing modes [1]. Improving these parameters is possible due to application of external magnetic field, which, according to some information, has a positive influence on formation of deposited beads and properties of the deposited layers [8, 9].

The aim of these investigations was in optimization of modes of submerged arc surfacing with application of external magnetic field over the layer of alloying charge of running gear parts of caterpillar machines providing a specified hardness of the deposited layer.

To achieve this aim, the experiments on arc surfacing over the layer of alloying charge deposited on the surface of specimens of steel St3 with hardness HB 197-207 were conducted. During surfacing the external axial magnetic field was imposed on welding arc, thus increasing the width of weld pool. This allowed applying filler charge with displacement from the axis of the arc and made it possible to control the process of its melting. As the filler charge the powders of silicon carbides $(\mathrm{SiC})$ and aerosil $\left(\mathrm{SiO}_{2}\right)$ were used mixed with iron powders and binding substances.

Surfacing of specimens was performed using wire $\mathrm{Sv}-08 \mathrm{~A}$ of $3 \mathrm{~mm}$ diameter under flux AN348A in installation UD-209. The surfacing conditions are the following: current $400 \mathrm{~A}$, voltage 32-36 V, wire feed rate $160 \mathrm{~m} / \mathrm{h}$, deposition rate $12-16 \mathrm{~m} / \mathrm{h}$, step of surfacing $6-8 \mathrm{~mm}$, electrode stick-out $30 \mathrm{~mm}$, current was direct, polarity - reversed. The coil, providing axial mag- 
Proportions of mixtures and their consumption per unit of a weld length

\begin{tabular}{||l|c|c||}
\hline \multicolumn{1}{|c|}{ Scheme of layers deposition } & \multicolumn{2}{c||}{ Hardness $H B$} \\
\cline { 2 - 4 } & Deposited layer & HAZ \\
\hline Without additional effects & 243 & 220 \\
\hline With imposition of constant magnetic field, $B_{z}=20 \mathrm{mT}$ & 248 & 229 \\
\hline With imposition of alternating magnetic field, $f=50 \mathrm{~Hz}, B_{z}=20 \mathrm{mT}$ & 277 & 239 \\
\hline With imposition of alternating magnetic field, surfacing along the charge with $\mathrm{SiC}_{2}$ powder & 452 & 227 \\
\hline With imposition of alternating magnetic field, surfacing along the charge with $\mathrm{SiO}_{2}$ powder & 512 & 245 \\
\hline
\end{tabular}

netic field, was attached to the torch so that the nozzle and electrode wire passing through it could serve as an additional ferromagnetic core. The coil was supplied with alternating or direct current. During experiments, the filler charge layers were placed at different distance from the axis of electrode wire, and their width was in the range of $8-10 \mathrm{~mm}$.

To reduce the number of experiments a central planning of decomposition of the second order for the four factors (mixture composition; number of deposited layers of the mixture; eccentricity in the arrangement of alloying charge layer relatively to the axis of electrode wire; induction of external magnetic field) was performed. The experimental data processing was carried out with mathematical package STATISTICA 6.0.

To measure hardness on device TK-2, the plane specimens of $15 \mathrm{~mm}$ thickness were cut out of the deposited plates. The results of hardness measurement show that the effectiveness of supplying alternating magnetic field to the coil is higher than that of the constant one (see the Table).

The regression equation of hardness of deposited metal has the following form:

$$
\begin{gathered}
H B=-19.8459-894.036 A-90.713 N+ \\
+354.479 n+162.6051 B+695.3873 A^{2}- \\
-110.68 N^{2}-975.169 n^{2}-1.08627 B^{2}- \\
-17.2259 A N+286.0339 A n+3.448646 A B+ \\
+958.2996 N n+10.45245 N B-63.9323 n B,
\end{gathered}
$$

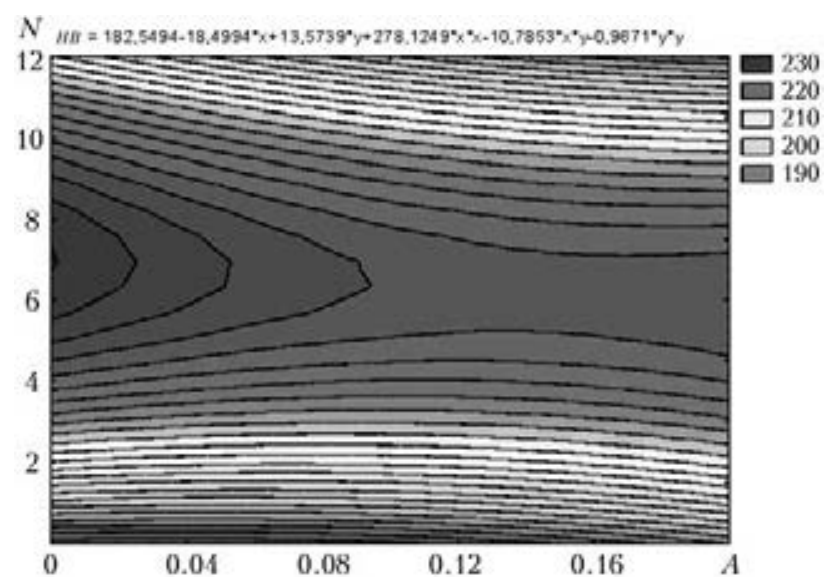

Figure 1. Dependence of hardness $H B$ of deposited metal on distance $N$ between the axis of electrode and layer of charge and concentration $A$ (mass share) of aerosil $\mathrm{SiO}_{2}$ in charge where $N$ is the distance from the axis of electrode to the layer of charge, $\mathrm{mm} ; A$ is the concentration (mass share) of $\mathrm{SiC}$ (up to 0.15 ) or $\mathrm{SiO}_{2}$ (over 0.15 ) in charge; $n$ is the number of layers; $B$ is the magnetic field induction, $\mathrm{mT}$.

As it follows from the obtained data (Figure 1), the optimal is the arrangement of charge layer at 4-10 $\mathrm{mm}$ distance from the axis to the electrode. If the layer is located closer then it melts completely together with refractory particles, if it locates farther, it falls outside the melting zone.

With increase in external magnetic field induction the width of weld pool increases causing a complete remelting of charge and, as a result, a complete melting of dispersed material. As a result, a decrease in hardness (Figure 2, zone $B=$ $=60-80 \mathrm{mTl}$ ) is observed.

To determine the optimum parameters of arc surfacing mode with simultaneous application of external magnetic field providing a maximum benefit from dispersed material introduced in arc surfacing, a software complex was designed ( $\mathrm{Fi}-$ gure 3).

The parameters of surfacing mode, at which the desired hardness of deposited layer is achieved, are determined in the following sequence.

Stage 1 . The user enters the value of necessary hardness $H B$ of deposited layer.

Stage 2. The diameter of electrode wire $d_{\mathrm{e}}$ $(\mathrm{mm})$ is specified and either self entering of basic surfacing modes (current $I_{\mathrm{S}}(\mathrm{A})$, deposition rate

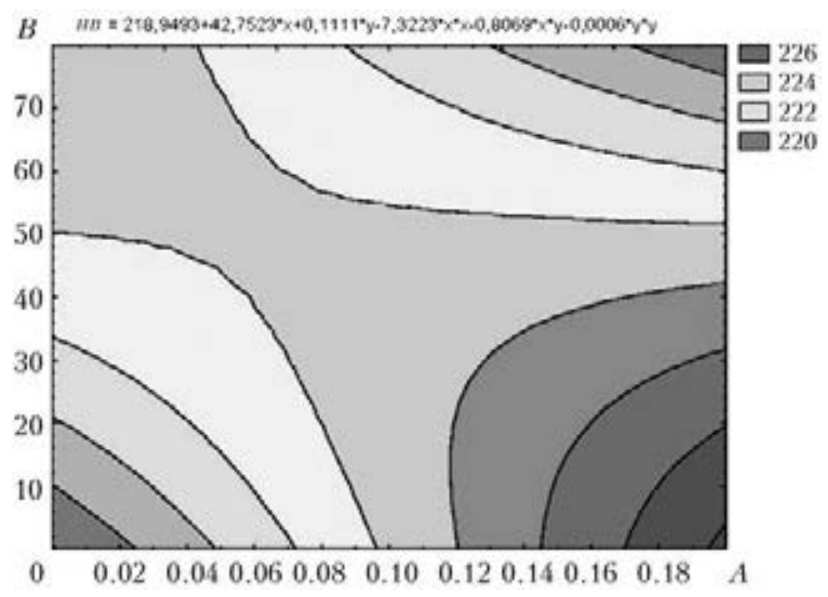

Figure 2. Dependence of hardness $H B$ of deposited metal on magnetic induction $B(\mathrm{mT})$ of external axial field and concentration $A$ (mass share) of aerosil $\mathrm{SiO}_{2}$ in charge 


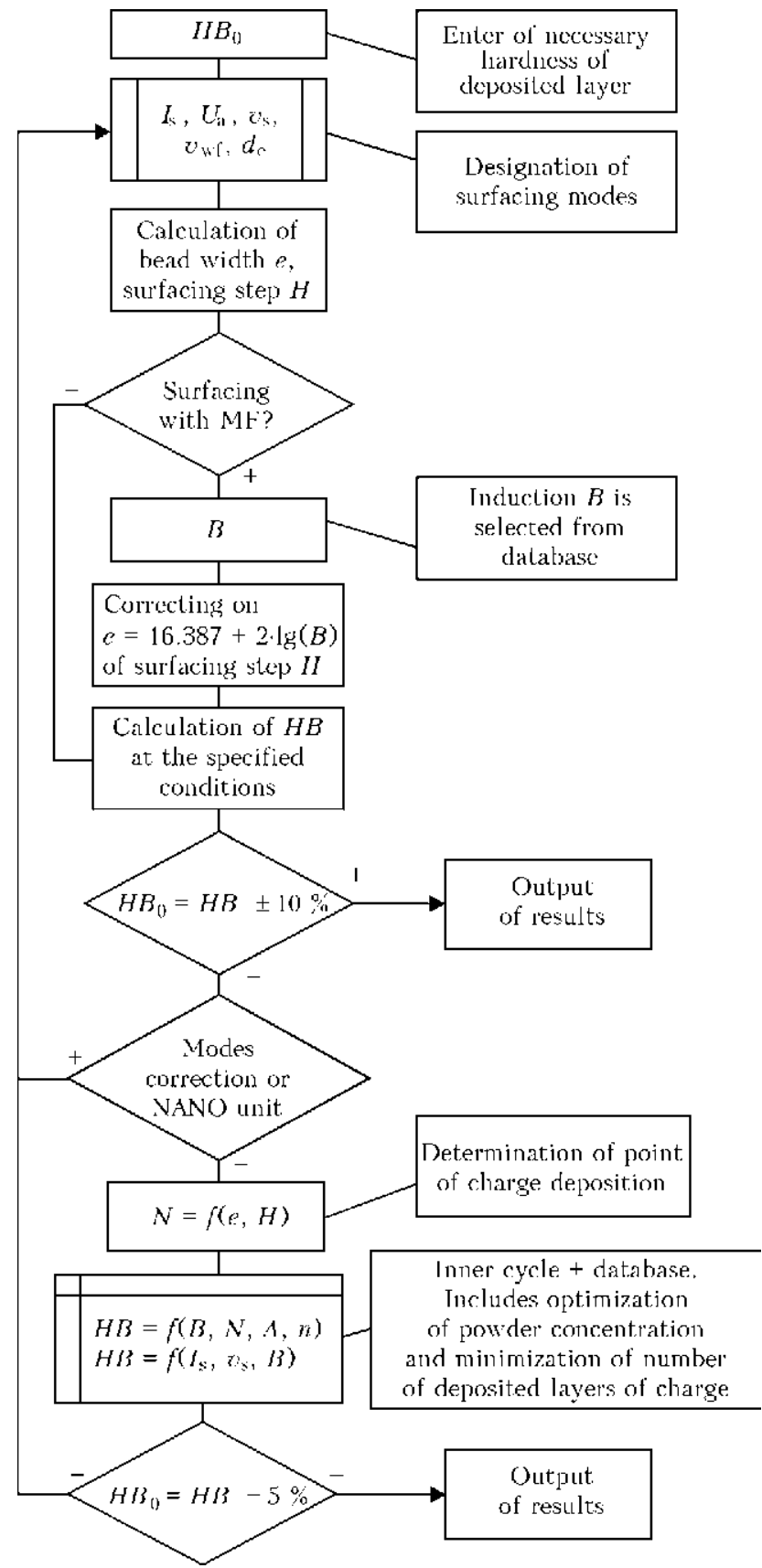

Figure 3. Algorithm for determination of optimum parameters of surfacing mode

$v_{\mathrm{S}}$ and wire feed rate $\left.v_{\mathrm{wf}}(\mathrm{m} / \mathrm{h})\right)$ from the software database or manual entering of the specified modes are offered. The user specifies conditions for the further calculation of surfacing parameters: with use of additional magnetic field (MF) or without it.

Stage 3. Calculation of the width of single deposited bead $e(\mathrm{~mm})$, which is formed under the conditions of surfacing at specified modes and surfacing step $H$. If the surfacing mode with MF was selected, then the program selects MF induction values from the database, correction of width and step of surfacing is performed.

Stage 4. Calculation of hardness of the deposited layer $H B$ in surfacing without use of charge.
Stage 5. Determination of coordinates of charge layer arrangement as function $N=f(e, H)$.

Stage 6. Determination of hardness of deposited metal using available database. It includes optimization of concentration of powder material and minimization of number of deposited layers of charge.

Complex data processing with application of algorithms and models, published in [10,11], is performed.

As the practice of using the program shows, in case of applying automatic correction of surfacing modes, return to the initial unit in manual mode in $95 \%$ of cases is not required.

\section{Conclusions}

1. It was determined that use of alternating magnetic field, imposed on welding arc, causes a greater increase in hardness of the deposited metal than use of constant magnetic field.

2. Analytical dependence for determination of hardness of the deposited layers is offered, which is achieved by additional supply of alloying charge with carbides or oxides of silicon and imposition of external magnetic field.

3. Software complex was developed intended to determine the parameters of arc surfacing providing maximum benefit from the introduced dispersed material and imposition of external magnetic field.

1. Frumin, I.I. (1961) Automatic electric arc surfacing. Kharkov: Metallurgizdat.

2. Livshits, L.S., Grinberg, N.A., Kurkumelli, E.G. (1969) Principles of alloying of deposited metal. Moscow: Mashinostroenie.

3. Khrushchev, M.M., Babichev, M.A., Berkovich, E.S. et al. (1971) Wear resistance and structure of hard deposits. Moscow: Mashinostroenie.

4. Ryabtsev, I.A. (2004) Surfacing of machine and mechanism parts. Kiev: Ekotekhnologiya.

5. Peremitko, V.V., Kuznetsov, V.D. (2014) Account of abrasive granulometric composition in repair surfacing of running gear parts of caterpillar machines. Problemy Tertya ta Znoshuvannya, 64(3), 125-130.

6. Peremitko, V.V., Cherednik, E.A. (2010) Adaptation technology of repair of running gear parts of road machines. Svarshchik, 4, 16-17.

7. Peremitko, V.V. (2014) Wear-resistant arc surfacing over the layer of alloying charge. The Paton Welding J., 8, 54-57.

8. Razmyshlyaev, A.D., Mironova, M.V. (2009) Magnetic control of bead and weld formation in arc surfacing and welding. Mariuopol: PriazovGTU.

9. Ryzhov, R.M., Kuznetsov, V.D. (2010) Magnetic control of welded joint quality. Kiev: Ekotekhnologiya.

10. Nosov, D.G., Peremitko, V.V. (2009) Algorithm of optimization of technological parameters in surfacing of parts of «shaft» type and its realization. Matemat. modelyuv., 20(1), 33-36.

11. Peremitko, V.V., Rejderman, Yu.I., Cherednik, E.A. (2006) Procedure of calculation of optimal surfacing modes. In: Proc. of 10th Interstate Sci.-Method. Conf. on Problems of Mathematical Modeling (DniprodzerzhinskDTU), 84-85. 


\title{
WEAR-RESISTANT SURFACING WITH FEEDING OF NANOPOWDERS TO WELD POOL
}

\author{
V.D. KUZNETSOV and D.V. STEPANOV \\ NTUU «Kiev Polytechnic Institute» \\ 37 Pobeda Ave., 03056, Kiev, Ukraine. E-mail: v.kuznetsov@kpi.ua
}

\begin{abstract}
Experimental studies of wear resistance of deposited metal, produced with feeding of nanooxides to weld pool, are of interest, when searching for new methods to guarantee the high wear resistance of deposited metal for items exposed to friction in service. The paper presents the results of testing wear resistance of deposited metal of 40Kh13, 25KhG2S, 300Kh28M type, modified by aluminium, titanium and silicon nanooxides through the weld pool with different schemes of their feeding. It is shown that nanooxide feeding to weld pool leads to a noticeable increase of deposited metal wear resistance. 13 Ref., 8 Figures.
\end{abstract}

$\boldsymbol{K} \boldsymbol{e} \boldsymbol{y} \boldsymbol{w} \boldsymbol{o} \boldsymbol{r} \boldsymbol{d} \boldsymbol{s}:$ arc surfacing, wear resistance, nanooxides, nonmetallic inclusions, structure

Deposited metal properties are determined by the specified composition of alloying elements and structure. Requirements to metal composition and structure to ensure the required values of its wear resistance are specified, depending on service conditions. The main results of investigations in this area are generalized in [1, 2].

Over the recent years a significant role of nonmetallic inclusions, as a factor controlling cast metal structure and properties, has been noted in publications. The main part of studies was performed for welding low-alloyed steels. Here, precipitation of such inclusions in the form of oxides, carbides and nitrides in weld metal was considered to be the result of chemical bonding of the respective elements during solidification, whereas the inclusions proper, both of up to $1 \mu \mathrm{m}$ size range, and close to nanosize range, were given the role of inoculators [1-6]. In other cases, formation of nonmetallic inclusions was the result of feeding nanooxides or nanocarbides into the weld pool [7-9]. A positive influence of inclusions of a certain composition, dimensions and distribution density on weld structure and properties is noted in all the cases.

Information on their influence on deposited metal wear resistance is limited, although the available experience of applying both nanooxides in plasma surfacing [10] and nanocarbides in electrode coatings [11] points to good prospects for their application in surfacing processes.

The objective of the work was experimental study of deposited metal wear resistance at feeding nanooxides into the weld pool.
Different schemes of nanooxide feeding into the weld pool were used in the experiments. Nanocomponents were added to the weld pool in the form of master alloy after compacting and sintering of a homogeneous mixture of iron powders of $40 \mu \mathrm{m}$ particle size and nanosized powders of aluminium and titanium oxides $(27-41 \mathrm{~nm})$ with specified volume ratio.

Prepared master alloy was used as consumable electrode of a certain length and diameter, inserted into the slot before surfacing. Volume ratios of nanooxides established earlier for low-alloyed steel welding were used in these experiments $[8,9]$.

In other schemes, more readily adaptable to surfacing, the mixtures prepared in specified volume ratios, after their processing in a planetarytype mill, were first fixed by priming to avoid scattering, and were applied in a thin layer across the bead width for the entire length of the deposit. The same scheme was applied for feeding just nanooxide powders into the weld pool with recalculation of their weight fraction to weld pool volume.

For the conditions of metal-to-metal friction tribotechnical testing was performed in friction machine of CMTs-2 type by shaft-block scheme. $20 \mathrm{~mm}$ long and $10 \mathrm{~mm}$ wide samples were used. Disc of $50 \mathrm{~mm}$ diameter from U8 steel of hardness $H B$ 400-450 was applied as the counterbody. Testing conditions were as follows: pressure applied to sample $P=0.1 \mathrm{MPa}$; friction velocity $v=0.8 \mathrm{~m} / \mathrm{s}$; test temperature $T=20{ }^{\circ} \mathrm{C}$; test duration was $2.5 \mathrm{~h}$ with measurements taken every $30 \mathrm{~min}$.

Samples were weighed before and after testing in accurate laboratory scales with $0.001 \mathrm{~g}$ error. Mass wear was determined as the difference of sample mass values before and after testing. 


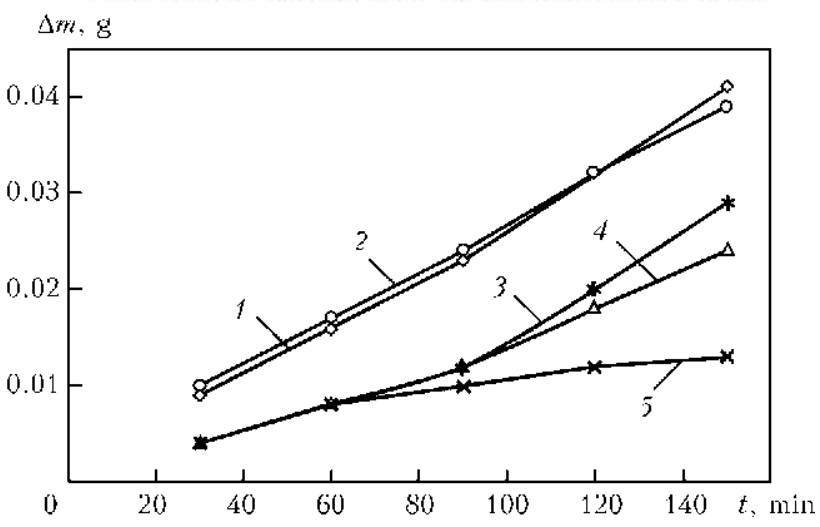

Figure 1. Wear resistance of metal deposited with PP-Np$40 \mathrm{Kh} 13$ wire with feeding nanoadditives through sintered master alloy: 1 - initial bead; 2 - with feeding of $0.5 \% \mathrm{TiO}_{2}$ to the weld pool; 3 - same, with $1 \% \mathrm{TiO}_{2}$; $4-1 \% \mathrm{Al}_{2} \mathrm{O}_{3} ; 5-0.5 \% \mathrm{Al}_{2} \mathrm{O}_{3}$

Testing for abrasive wear was performed in LKI-3 unit by measuring mass losses every $30 \mathrm{~m}$ of friction path. Electrocorundum of $14 \mathrm{~A}$ grade with $0.4-1.0 \mathrm{~mm}$ grain size was used as abrasive. Samples were tested at constant load $P=150 \mathrm{~N}$ along the total friction path of $480 \mathrm{~m}$. After every $30 \mathrm{~m}$ the samples were turned through $90^{\circ}$ to achieve uniform wear, and after every $120 \mathrm{~m}$ they were weighed in the scales to determine the change in mass.

To reveal the general regularities, beads were deposited using different processes and conditions. So, experiments on surfacing with application of $2 \mathrm{~mm}$ flux-cored wire PP-Np-40Kh13, recommended for metal-to-metal friction conditions, were conducted on steel St3, both in the mixture of gases $\mathrm{Ar}+28 \% \mathrm{CO}_{2}$ in semi-automatic machine $\mathrm{KP} 004 \mathrm{U} 3$ at $10.6 \mathrm{~kJ} / \mathrm{cm}$ heat input, and by an open arc in AD-231 automatic machine at $15 \mathrm{~kJ} / \mathrm{cm}$ heat input, and surfacing with $2.2 \mathrm{~mm} 25 \mathrm{KhG} 2 \mathrm{~S}$ wire of $09 \mathrm{G} 2 \mathrm{~S}$ steel was conducted in AD-231 automatic machine at $11.5 \mathrm{~kJ} / \mathrm{cm}$ heat input.

For abrasive wear conditions surfacing of steel St3 with $2.7 \mathrm{~mm}$ flux-cored wire PP-AN-180 (analog of flux-cored strip PL-AN-180) was also performed by automatic machine AD-231 at heat input of $12 \mathrm{~kJ} / \mathrm{cm}$.

Testing of metal deposited in welding in a gas mixture with PP-Np-40Kh13 wire showed ( Figure 1) that at feeding of nanooxides into the weld pool, metal wear resistance is increased at melting of sintered master alloy both in the presence of nanooxides of aluminium and of titanium. Here, mass losses in the case of application of $\mathrm{Al}_{2} \mathrm{O}_{3}$ nanooxide are smaller compared to $\mathrm{TiO}_{2}$ (compare curves 4, 5 and 2, 3). Maximum effect is observed at feeding of $0.5 \% \mathrm{Al}_{2} \mathrm{O}_{3}$ into the pool with mass losses decreasing from $\Delta m=$ $=0.042 \mathrm{~g}$ (initial bead, curve 1$)$ to $\Delta m=0.013 \mathrm{~g}$ $\left(0.5 \% \mathrm{Al}_{2} \mathrm{O}_{3}\right.$, see curve 5$)$, i.e. by more than 3 times. These data confirmed that similar to welding, at surfacing the fed volume ratios of nanooxides influence cast metal properties.

Microhardness measurement showed that at average value of initial bead metal microhardness of $H V$ 530, in the other cases microhardness decreased $\left(0.5 \% \mathrm{TiO}_{2}-H V 478,1 \% \mathrm{TiO}_{2}-\right.$ $\left.H V 460,0.5 \% \mathrm{Al}_{2} \mathrm{O}_{3}-H V 469\right)$, except for $1 \% \mathrm{Al}_{2} \mathrm{O}_{3}(H V 552)$.

Deposited metal microstructure consists of martensite with developed coarse-needle texture characteristic for the initial conditions (Figure 2, a). In the case of surfacing with $0.5 \% \mathrm{Al}_{2} \mathrm{O}_{3}$ nanooxide, a markedly smaller amount of martensite precipitate blocks with less developed needle-like structure (Figure 2, b) is observed. Another characteristic feature also is presence of, possibly, carbides and oxides along grain boundaries, which as a hard component promote an increase of wear resistance of such metal, alongside thinning of martensite precipitates. No correlation between hardness and wear resistance is observed in this case.

At application of surfacing scheme with powder fixing on the plate surface, aerosil (silicon dioxide) was further added, both in the mixture with iron powder, and in its pure form. Aerosil

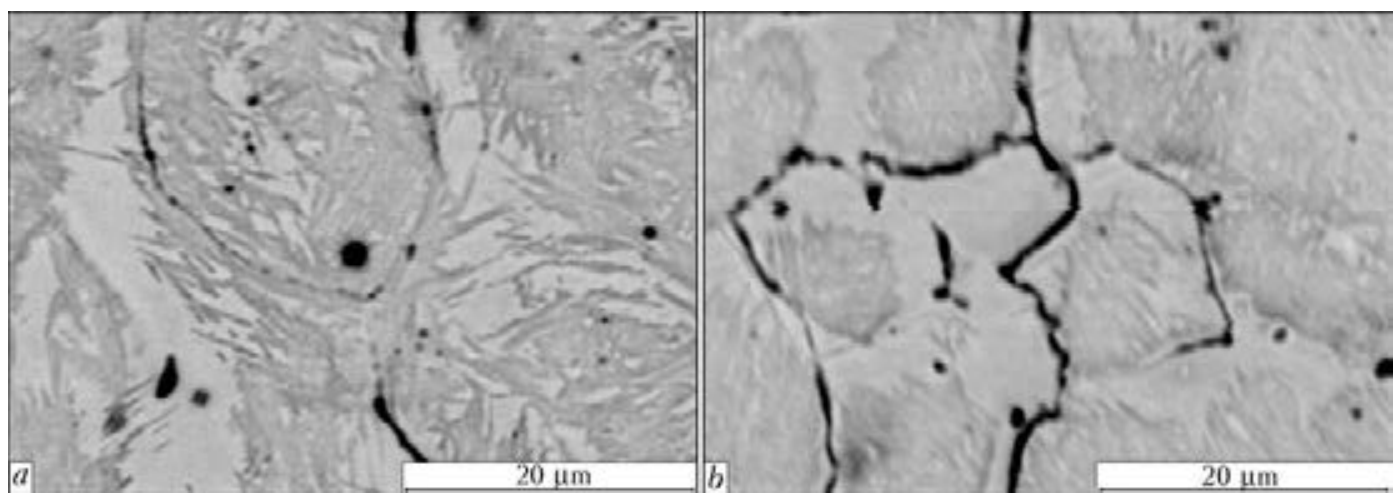

Figure 2. Deposited metal microstructure at nanooxide feeding through master alloy: $a-$ initial bead; $b-$ with $0.5 \% \mathrm{Al}_{2} \mathrm{O}_{3}$ nanooxide 


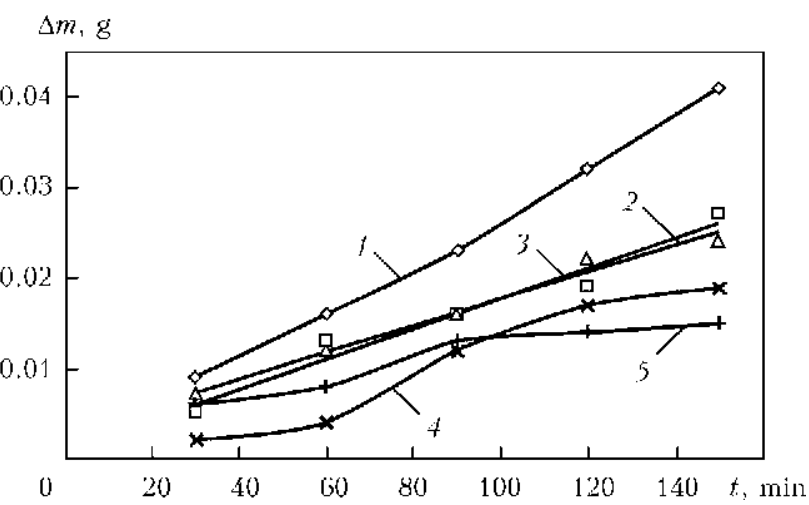

Figure 3. Wear resistance of metal deposited with PP-Np$40 \mathrm{Kh} 13$ wire with feeding nanoadditives through powder materials: $1-$ initial bead; $2-\mathrm{Fe}+0.5 \% \mathrm{Al}_{2} \mathrm{O}_{3} ; 3-$ $\mathrm{Fe}+0.5 \% \mathrm{TiO}_{2} ; 4-\mathrm{Fe}+45 \% \mathrm{SiO}_{2} ; 5-10 \% \mathrm{SiO}_{2}$

is manufactured on the commercial scale for preparation of various lubricants, paints and lacquers, for suspension stabilization. Considering several times lower density of aerosil relative to aluminium and titanium nanooxides, its volume ratios were increased, accordingly.

It is established that aluminium and titanium nanooxides in this case showed lower wear resistance (Figure 3, compare curves 2, 3 and curve 1 for initial bead), compared to feeding through sintered master alloy (see Figure 1) that, apparently, is associated with deviations from percent ratio and their incomplete absorption by the weld pool. Maximum wear resistance is observed in the case of application of powder of just silicon nanooxide. In this case, mass losses decrease from $\Delta m=0.042 \mathrm{~g}$ (Figure 3, curve 1) to $\Delta m=0.015 \mathrm{~g}$ (Figure 3, curve 5), i.e. by 2.8 times.

Testing of metal deposited by open arc with 25KhG2S wire showed (Figure 4) that both aluminium and titanium oxide promote improvement of deposited metal wear resistance (compare curves 2, 3 and curve 1 for initial bead), while mass losses in case of feeding $0.7 \% \mathrm{Al}_{2} \mathrm{O}_{3}$ are reduced 4 times. Maximum wear resistance increase by more than 6 times is observed in the
$\Delta m, \mathrm{~kg} / \mathrm{m}^{2}$

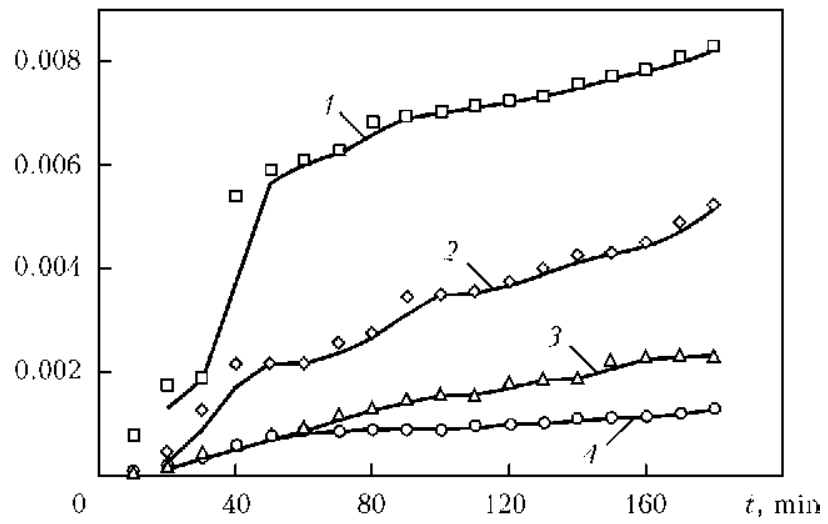

Figure 4. Wear resistance of metal deposited with $25 \mathrm{KhG} 2 \mathrm{~S}$ wire: 1 - initial bead; $2-0.5 \% \mathrm{TiO}_{2} ; 3-0.7 \% \mathrm{Al}_{2} \mathrm{O}_{2}$; $4-90 \% \mathrm{SiO}_{2}$

case of application of silicon dioxide (Figure 4, compare curves 4 and 1 ).

Microhardness measurement showed that at average value for bead initial metal of $H V$ 352, in the other cases microhardness decreased $\left(0.5 \% \mathrm{TiO}_{2}-H V\right.$ 271, $0.7 \% \mathrm{Al}_{2} \mathrm{O}_{3}-$ $H V$ 313), except for $90 \% \mathrm{SiO}_{2}(H V$ 424).

In this case, a correlation between deposited metal hardness and wear resistance is observed. Analysis showed that initial bead metal has bainite structure with a small amount of martensite component (Figure 5, a). Deposited metal with silicon dioxide is characterized by purely martensite structure (Figure 5, b) that, apparently, is exactly what determines wear resistance increase.

Results of analysis of distribution of nonmetallic inclusion quantity revealed that in the initial condition without nanoadditives their volume fraction is equal to $0.25 \%$ and mainly is in the dimensional range of $0.07-0.49 \mu \mathrm{m}$, of which from 12 up to $16 \%$ inclusions correspond to dimensional range of 0.13 to $0.37 \mu \mathrm{m}$.

In the metal of the bead with $0.5 \% \mathrm{TiO}_{2}$ nanooxide the volume fraction of nonmetallic inclusions is somewhat greater and is equal to

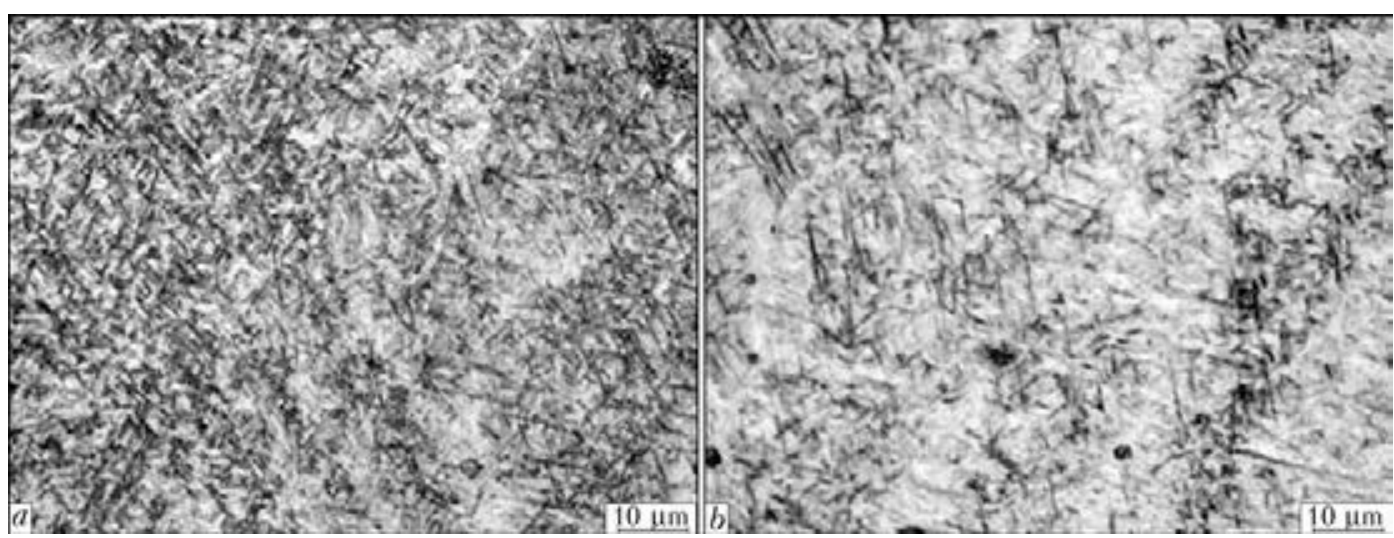

Figure 5. Microstructure of deposited metal without ( $a$ ) and with (b) $\mathrm{SiO}_{2}$ additives 

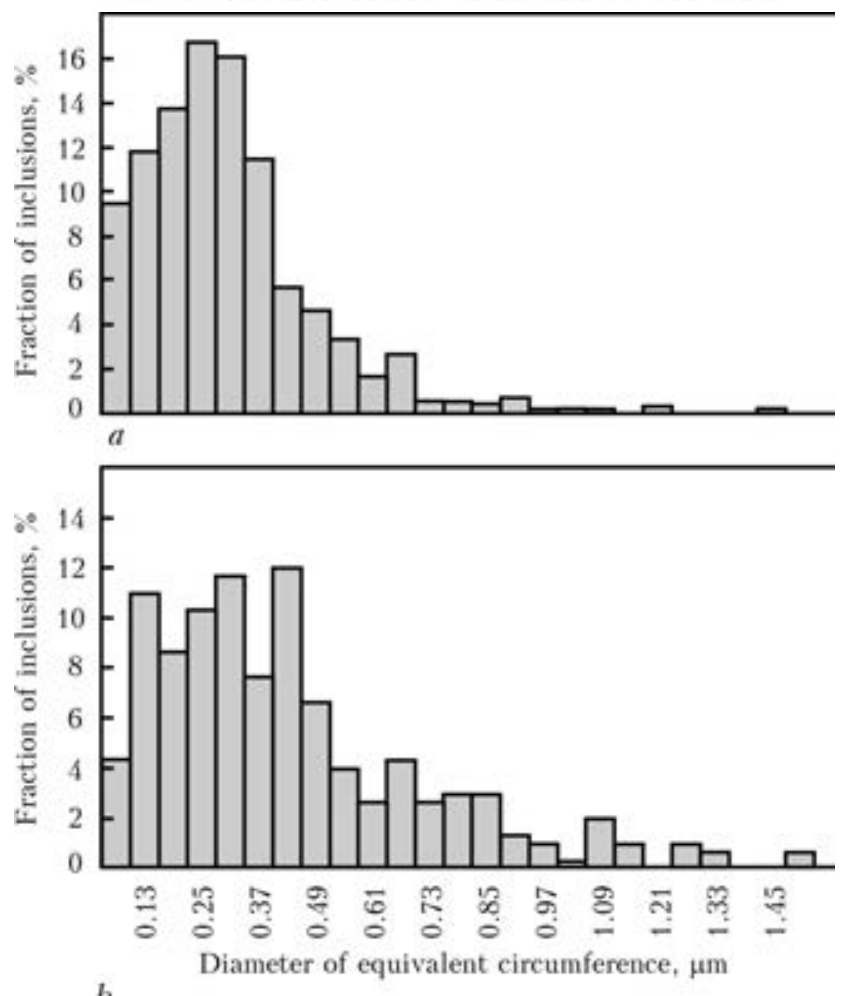

Figure 6. Histogram of inclusion distribution in deposited metal by the parameter of equivalent circumference: $a-$ in the initial condition; $b$ - with $90 \mathrm{vol} . \% \mathrm{SiO}_{2}$ nanooxide

$0.27 \%$, of which from 6 up to $12 \%$ inclusions correspond to dimensional range of $0.07-$ $0.55 \mu \mathrm{m}$.

In the metal of the bead with $0.7 \% \mathrm{Al}_{2} \mathrm{O}_{3}$ nanooxide the volume fraction of nonmetallic inclusions is also greater and is equal to $0.34 \%$, of which from 6 up to $15 \%$ inclusions correspond to dimensional range of 0.07 up to $0.55 \mu \mathrm{m}$.

In the metal of the bead with $90 \% \mathrm{SiO}_{2}$ nanooxide the volume fraction of nonmetallic inclusions is smaller and is equal to $0.2 \%$, of which from 4 up to $12 \%$ inclusions are in the dimensional range of $0.07-0.85 \mu \mathrm{m}$.

Comparative analysis of the data points to an increase of volume fraction of inclusions in the dimensional range of $0.07-0.55 \mu \mathrm{m}$ at feeding nanooxides of both aluminium and titanium and

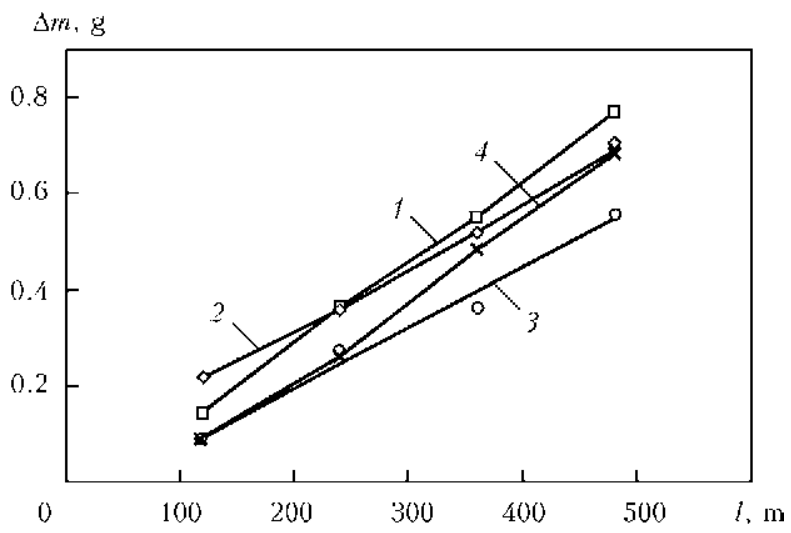

Figure 7. Wear resistance of metal deposited with PP-AN180 wire with feeding nanopowders through powder materials: $1-$ initial bead; $2-\mathrm{Fe}+0.5 \% \mathrm{Al}_{2} \mathrm{O}_{3} ; 3-\mathrm{Fe}+$ $+5 \% \mathrm{Al}_{2} \mathrm{O}_{3} ; 4-\mathrm{Fe}+0.5 \% \mathrm{Al}_{2} \mathrm{O}_{3}$

in greater dimensional range of $0.07-0.85 \mu \mathrm{m}$, respectively, at aerosil feeding, compared to the initial structure.

The established regularities are also confirmed by the results of processing the dimensions of inclusions of just spherical shape by the parameter of equivalent circumference diameter. For instance, Figure 6 gives the histograms by volume fraction and distribution of such inclusions in the weld metal for the initial condition and in the presence of silicon nanooxide.

Processing the dimensions of inclusions of just spherical shape by the parameter of equivalent circumference diameter showed that in the initial condition without nanooxide powder feeding the main part of spherical inclusions from 9 up to $16 \%$ is both in the dimensional range up to $0.3 \mu \mathrm{m}$ and in the ranges of $0.3-0.5 \mu \mathrm{m}$ (Figure $6, a$ ).

At addition of powder of $90 \% \mathrm{SiO}_{2}$ nanooxide, the fraction of spherical inclusions both of up to $0.3 \mu \mathrm{m}$ size and in the range of $0.3-0.5 \mu \mathrm{m}$ rises up to $12 \%$. Here, presence of inclusions of more than $0.8 \mu \mathrm{m}$ size is observed (Figure $6, b$ ). The fact of nonmetallic inclusions coarsening in this case can be associated with increased concentration of aerosil nanoparticles, promoting their coagula-

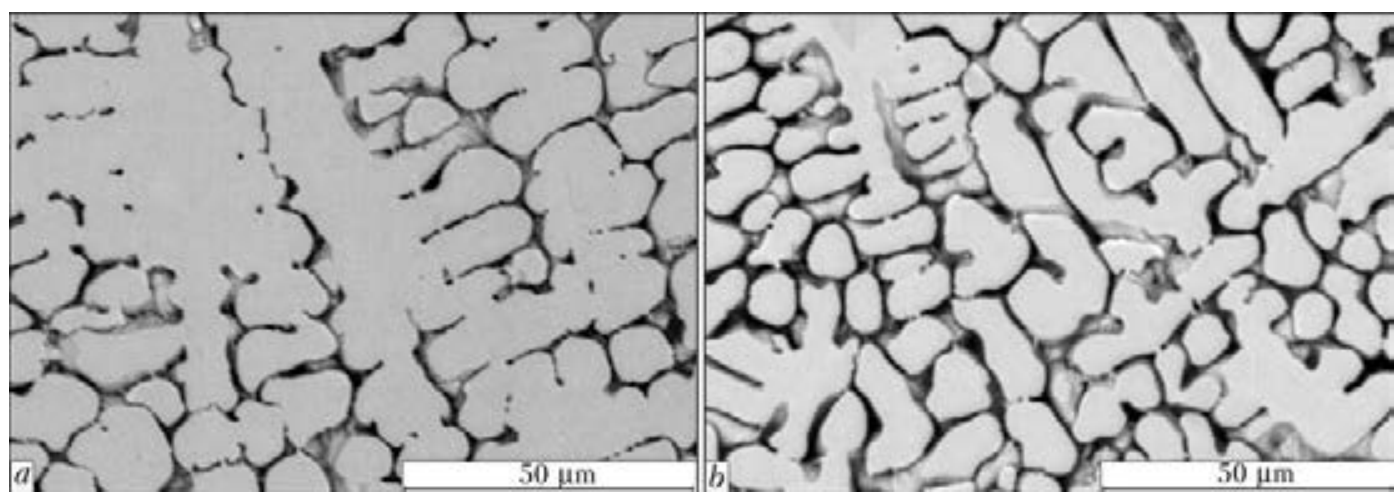

Figure 8. Microstructure of deposited metal without $(a)$ and with $(b) \mathrm{Al}_{2} \mathrm{O}_{3}$ additives 
tion and coalescence with nonmetallic inclusions of material during weld pool solidification.

Testing of the composition of high-chromium cast iron at surfacing with PP-AN-180 flux-cored wire showed that at $0.5 \%$ volume fraction, feeding titanium and aluminium nanooxides has practically the same effect on wear resistance with its slight increase (Figure 7, curves 1, 4, 2). In these experiments wear resistance increase by 1.4 times was observed at feeding $5 \% \mathrm{Al}_{2} \mathrm{O}_{3}$.

Analysis showed that in the initial bead the structure of hypereutectic cast iron is characterized by quite coarse cementite precipitates in the austenitic matrix (Figure 8, $a$ ). In the case of application of $5 \% \mathrm{Al}_{2} \mathrm{O}_{3}$, a significant dispersion of cementite precipitates is observed, that, apparently, is exactly what determines increase of wear resistance of such a structure.

Thus, investigations showed that irrespective of the used alloying systems of surfacing materials or surfacing conditions, the common feature is the positive influence of nanooxides on deposited metal wear resistance. At this research stage it does not seem possible to make unambiguous conclusions on either the mechanism of manifestation of the positive effect of nanooxide application, or their volume fraction for different surfacing conditions, that neccessitates further studies.

\section{Conclusions}

1. Positive influence of volume ratios of aluminium and titanium nanooxides on wear resistance, earlier established for low-alloyed steel welds, was confirmed at deposition of high-chromium compositions with increased carbon content. It is established that silicon nanooxide is a more effective nanoadditive for these compositions.

2. At deposition of medium-alloyed composition, it is further established that silicon dioxide is more effective compared to aluminium and titanium nanooxides, providing a more than 4 times increase of wear resistance.
3. For abrasive wear conditions at deposition of high-chromium cast iron composition, the effect of wear resistance increase is manifested to a smaller degree (by $40 \%$ ), compared to compositions recommended for metal-to-metal friction conditions.

1. Ryabtsev, I.A. (2004) Surfacing of machine and mechanism parts. Kiev: Ekotekhnologiya.

2. Ryabtsev, I.A., Senchenkov, I.K. (2013) Theory and practice of surfacing operations. Kiev: Ekotekhnologiya.

3. Lee, T.K., Kim, H.J., Kang, B.Y. et al. (2000) Effect of inclusion size on the nucleation of acicular ferrite in welds. ISIJ Int., 40, 1260-1268.

4. Golovko, V.V., Grigorenko, G.M., Kostin, V.A. (2011) Effect of nanoinclusions on structure formation of weld metal of ferritic-bainitic steels (Review). Zbirnyk Nauk. Prats NUK, 4, 42-49.

5. Golovko, V.V., Stepanyuk, S.M., Ermolenko, D.Yu. (2012) Investigation of effect of nanoformations in metal on weld microstructure formation and its mechanical properties. In: Building, materials science, machine-building, Issue 64, 155-159.

6. Golovko, V.V., Pokhodnya, I.K. (2013) Effect of non-metallic inclusions on formation of structure of the weld metal in high-strength low-alloy steels. The Paton Welding J., 6, 2-10.

7. Vanovsek, W., Bernhard, C., Fiedler, M. et al. (2013) Influence of aluminium content on the characterization of microstructure and inclusions in highstrength steel welds. Welding in the World, 57(1), 73-83.

8. Junseok Seo, Heejin Kim, Changhee Lee (2013) Effect of $\mathrm{Ti}$ addition on weld microstructure and inclusion characteristics of bainitic GMA welds. ISIJ Int., 53(5), 880-886.

9. Yushchenko, K.A., Ustinov, A.I., Zadery, B.A. et al. (2010) Effect of nanofoil of $\mathrm{Ni}-\mathrm{NbC}$ system on structure of electron beam welds in heat-resistant alloys. The Paton Welding J., 11, 2-7.

10. Kuznetsov, V.D., Smirnov, I.V., Stepanov, D.V. et al. (2013) Effect of modification by oxide nanoparticles on structure formation of low-alloy steel welds. Mizhouz. Zbirnyk Naukovi Notatky, 41, Pt 2, 61-68.

11. Kuzniecow, W., Szapowalow, K. (2014) Effect of nano-oxides on the structure and properties of low-alloy steel weld metal. Biuletyn Institutu Spawalnictwa , 5, 103-108.

12. Knyazkov, K.V., Radchenko, M.V., Smirnov, A.N. et al. (2012) Increase in properties of plasma-powder coatings by their modification with nanosized particles. Polzunovsky Vestnik, 1, 127-130.

13. Sokolov, G.N., Lysak, I.V., Troshkov, A.S. et al. (2009) Modification of deposited metal structure by nanodispersed tungsten carbides. Fizika $i$ Khimiya Obrab. Materialov, 6, 41-47.

Received 12.05.2015 


\title{
PECULIARITIES OF FIRE-CRACKER PLATE ELECTRODE ARC SURFACING OVER ALLOYING CHARGE
}

\author{
I.A. BARTENEV \\ Karaganda State Technical University \\ 56 Mir Bld., 100027, Karaganda, Kazakhstan. E-mail: igor_svar@mail.ru
}

\begin{abstract}
The method of arc surfacing of flat parts using fire-cracker plate electrode over alloying charge was offered. The main factors determining stability of surfacing process are the following: arc voltage $U$, arc current $I$, and electrode sectional area $S$. As a result of experiments the range of surfacing current (300-400 A) was determined providing stability of mode at the start and throughout the whole process of surfacing. It was established that hardness of deposited metal amounted to HRC 47-52, which is higher than that of metal such as steel G13. Metallographic investigations showed that the offered method provides a minimal penetration of base metal, that will allow obtaining the necessary chemical composition of deposited metal in single-layer surfacing. 4 Ref., 2 Tables, 3 Figures.
\end{abstract}

Key words: arc surfacing, alloying charge, plate electrode, hardness of deposited metal, penetration

High-manganese austenitic steels, containing up to $13 \% \mathrm{Mn}$ and known under the grade of Hadfield steel, are widely used in manufacture and restoration of parts operating at abrasive wear with intensive impact loads [1, 2]. In particular, they are used in manufacture of parts of crushing and milling equipment, railroad frogs, excavator bucket teeth, etc. Steels of this type have an ability to cold working under the effect of impact loads, whereby hardness of surface of parts manufactured of these steels increases to $H B$ 450-500, while their core remains tough and its hardness is at the level of $H B$ 220-280.

To restore parts of high-manganese steels the arc surfacing using flux-cored wire gained the widest use in industry $[3,4]$. The chemical composition and hardness of metal deposited by these wires are shown in Table 1.

Comparing chemical compositions of manganese steels and those of standard ferromanganese (Table 2), it can be assumed that in the general weld pool by mixing low-carbon steel and ferromanganese in specific proportions a composition can be provided similar, for example, to steel of G13 type.

To realize this possibility the most appropriate is the method of arc surfacing using fire-cracker plate electrode over the alloying charge in the form of carbon ferromanganese alloy (Figure 1). In this case surfacing is carried out under flux by ignition of arc between the workpiece being surfaced and the plate placed on layer of alloying filler of $3-5 \mathrm{~mm}$ thickness (see Figure 1). The arc at the rate of melting electrode and filler moves along the part, and as a result, a highlyalloyed deposited metal bead is formed on its surface. With a proper preparation the surfacing process is rather stable.

To implement the proposed technology the related experiments were conducted. On the specimen of steel St3 of the size $300 \times 150 \times$ $\times 10 \mathrm{~mm}$ a layer of flux AN-348A of $3 \mathrm{~mm}$ thickness was uniformly poured, with an area corresponding to that of the plate electrode. Atop the flux a plate electrode was horizontally placed, over which the powder alloying filler was poured. In the experiments as alloying filler the alloy of the following composition was used, wt.\%: $1.7 \mathrm{C}$; $86 \mathrm{Mn} ; 2 \mathrm{Si} ; \mathrm{Fe}$ - the rest. Over the alloying

Table 1. Chemical composition and hardness of deposited metal of the type of high-manganese austenite steels

\begin{tabular}{|c|c|c|c|c|c|c||}
\hline \multirow{2}{*}{$\begin{array}{c}\text { Type of deposited } \\
\text { metal }\end{array}$} & \multicolumn{7}{|c||}{ Mass fraction of elements, \% } & \multicolumn{2}{c||}{ Hardness $H B$} \\
\cline { 2 - 7 } & $\mathrm{C}$ & $\mathrm{Si}$ & $\mathrm{Mn}$ & $\mathrm{Cr}$ & $\mathrm{Ni}$ & After surfacing \\
\hline G13 & 1.0 & 0.6 & 13 & - & - & $220-280$ \\
\hline G13N4 & 0.8 & 0.5 & 13 & - & 4 & $170-230$ \\
\hline G13Kh25N3 & 0.8 & 0.4 & 14 & 25 & 3 & $220-320$ \\
\hline
\end{tabular}


Table 2. GOST 4755-91: Ferromanganese. Technical requirements and delivery conditions

\begin{tabular}{|c|c|c|c|c|c|c|c|}
\hline \multirow{4}{*}{ Group of materials } & \multirow{4}{*}{ Grade of alloy base } & \multicolumn{6}{|c|}{ Mass fraction, $\%$} \\
\hline & & \multirow{3}{*}{$\mathrm{Mn}$} & \multirow{2}{*}{$\mathrm{C}$} & \multirow{2}{*}{$\mathrm{Si}$} & \multicolumn{2}{|c|}{$\mathrm{P}$} & \multirow{2}{*}{$\mathrm{S}$} \\
\hline & & & & & $A$ & $B$ & \\
\hline & & & \multicolumn{5}{|c|}{ Not more than } \\
\hline Low-carbon & FMn90 & $\geq 85-95$ & 0.5 & 1.8 & 0.05 & 0.3 & 0.02 \\
\hline Medium-carbon & FMn88 & $\geq 85-95$ & 2.0 & 3.0 & 0.10 & 0.4 & 0.02 \\
\hline \multirow[t]{2}{*}{ High-carbon } & FMn78 & $\geq 75-82$ & 7.0 & 6.0 & 0.05 & 0.7 & 0.02 \\
\hline & FMn70 & $\geq 65-75$ & 7.0 & 6.0 & 0.30 & 0.7 & 0.02 \\
\hline
\end{tabular}

filler the second layer of flux AN-348A of up to $2 \mathrm{~cm}$ height was poured.

The electric arc surfacing was performed in laboratory installation using a «hard» start. As power source, rectifier VDM-1202S with rigid external current-voltage characteristic was used. As plate electrodes the strips of steel St3 were used. Mass of the surfacing powder of manganese alloy varied in the range of $20-50 \mathrm{~g}$.

The greatest problems in implementation of surfacing process arose at the start. It was established that the main factors determining stability of the process at the start are the following: arc voltage $U$, arc current $I$, and electrode sectional area $S$.

During experiments, at the start the parameters of surfacing mode were changed within the following limits: surfacing current from 280 to $350 \mathrm{~A}$, voltage from 28 to $36 \mathrm{~V}$, and section of plate electrode from 50 to $80 \mathrm{~mm}^{2}$. As a result of surfacing the deposited beads of 15-25 mm width and 5-8 $\mathrm{mm}$ height were produced. The specimens were cut out of them to investigate microstructure and determine hardness of deposited layer.

As a result of experiments the range of surfacing current was determined (300-400 A) providing stability of the mode at the start and throughout the whole process of surfacing. At current of less than 300 A a lack of fusion of the

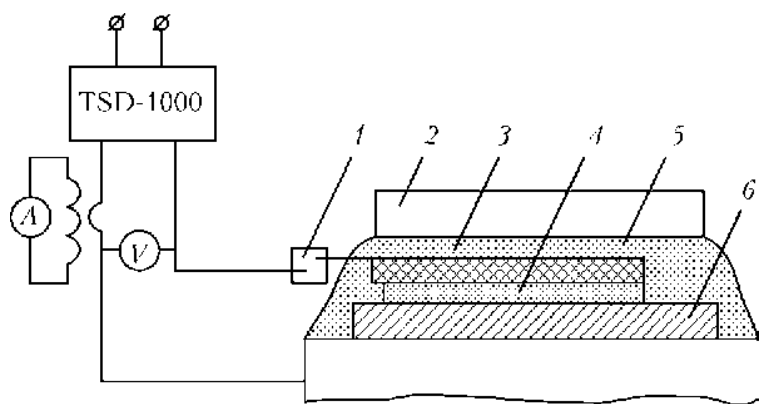

Figure 1. Fire-cracker plate electrode surfacing over the alloying filler layer: 1 - current conductor; 2 - copper plate; 3 - electrode; 4 - alloying filler; 5 - flux; 6 workpiece deposited bead along its edges was observed due to insufficient heat input to the part being surfaced. By increasing current over $400 \mathrm{~A}$ due to high rate of surfacing the process of starting operation was difficult to control, which resulted often in short circuiting of electrode to the part being surfaced.

While conducting experiments it was established that the hardness of deposited metal amounted to $H R C$ 47-52, which is higher than that of metal such as steel G13. Moreover, chemical composition and hardness of the deposited
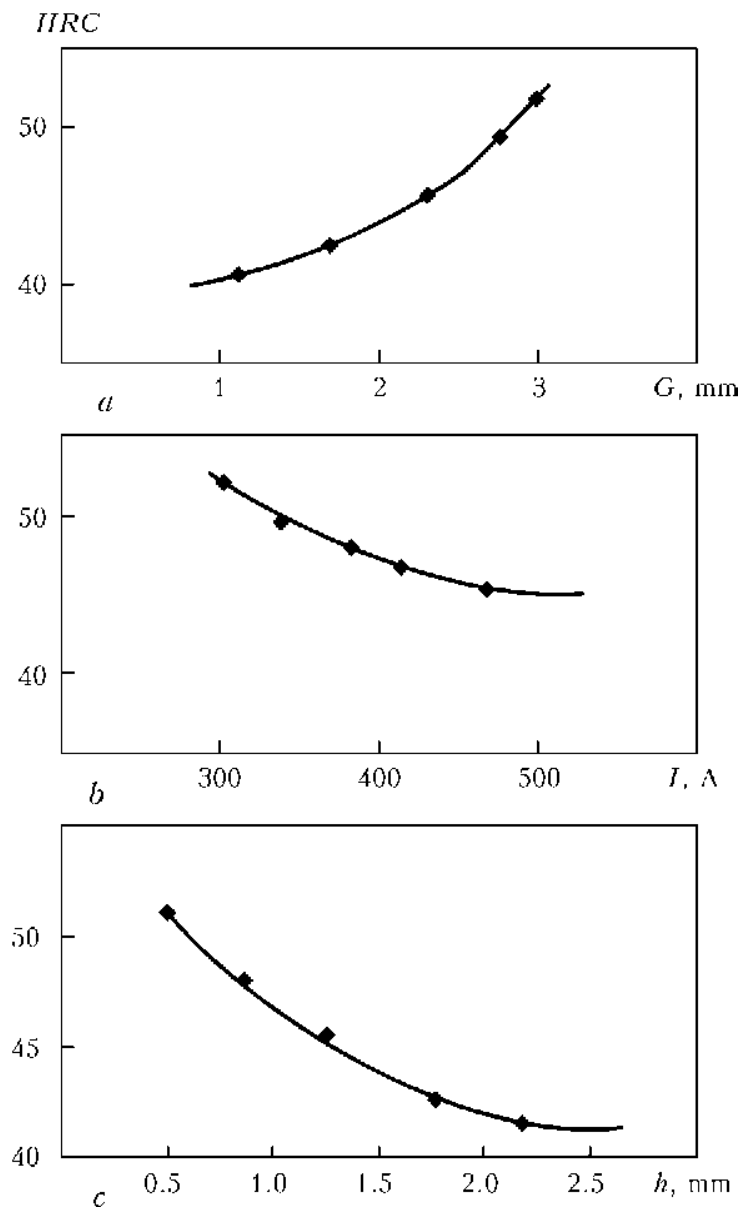

Figure 2. Dependence of deposited metal hardness on thickness of layer $G$ of alloying filler $(a)$, surfacing current $I$ (b) and penetration depth $h(c)$ 


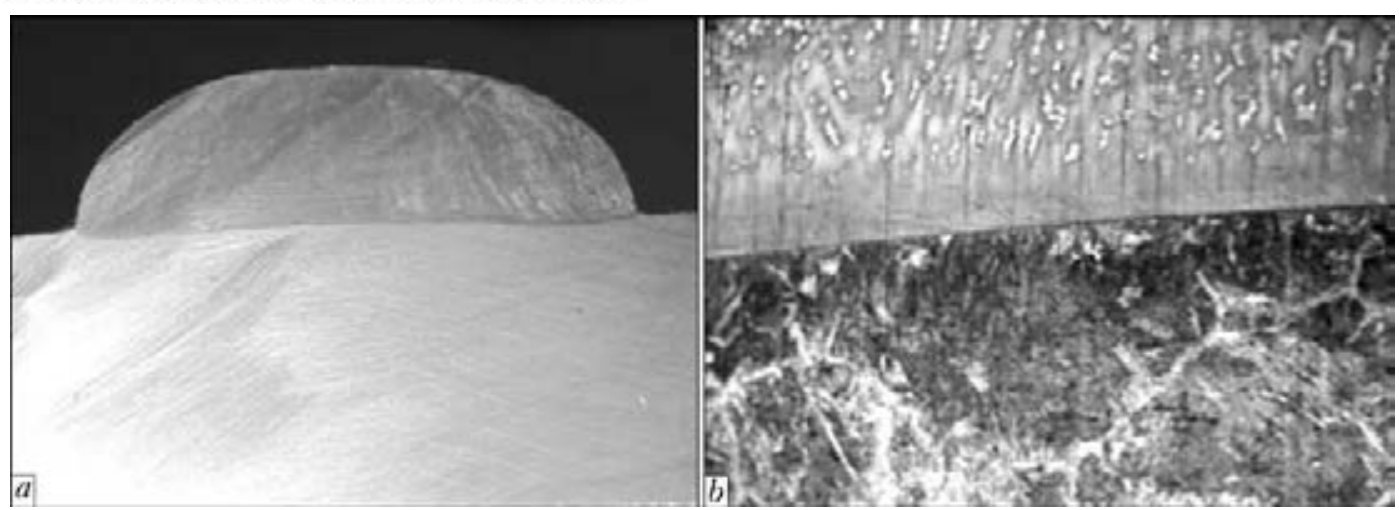

Figure 3. Macrosection $(a)$ and microstructure $(b)$ of deposited specimen

metal are affected by mass, and in this case, by thickness of alloying filler layer per unit of length of deposited bead. With increase in the layer thickness the hardness is increased and during its decrease the latter decreases respectively ( $\mathrm{Fi}$ gure $2, a$ ).

With increase in surfacing current the hardness of deposited metal is reduced (Figure 2, $b$ ). This is explained by increase in current with increase in penetration depth, which leads to increase in the proportion of base metal in the deposited metal and corresponding decrease in hardness of the deposited metal (Figure 2,c).

Metallographic investigations showed that the offered method provides a slight penetration of the workpiece surface. Along the edges of deposited bead the penetration is higher at the clear fusion boundary and minimum fusion in the middle part of bead section (Figure 3, $a$ ).

In the microstructure of deposited metal (Figure $3, b$ ) very fine dendrites are observed grow- ing from the surface of base metal with a high content of austenite and martensite.

Thus, as a result of experiments, the parameters of stable arc surfacing process using firecracker plate electrode over alloying charge were determined. As the alloying filler charge it was proposed to use powder of carbon ferromanganese. The developed process can be used in wearresistant surfacing of flat parts.

1. Vlasov, V.M. (1987) Serviceability of reinforced friction surfaces. Moscow: Mashinostroenie.

2. Livshits, L.S., Grinberg, N.A., Kurkumelli, E.G. (1969) Principles of alloying of deposited metal. Moscow: Mashinostroenie.

3. Frumin, I.I. (1961) Automatic electric arc surfacing. Kharkov: Metallurgizdat.

4. Ryabtsev, I.A., Kondratiev, I.A. (1999) Mechanized electric arc surfacing of metallurgical equipment parts. Kiev: Ekotekhnologiya.

Received 20.04.2015 


\title{
APPLICATION OF FRICTION STIR WELDING METHOD FOR REPAIR AND RESTORATION OF WORN-OUT COPPER PLATES OF MCCB MOULDS
}

\author{
G.M. GRIGORENKO ${ }^{1}$, L.I. ADEEVA ${ }^{1}$, A.Yu. TUNIK ${ }^{1}$, M.A. POLESHCHUK ${ }^{1}$, \\ E.V. ZELENIN ${ }^{1}$, V.I. ZELENIN ${ }^{1}$, Yu.N. NIKITYUK ${ }^{2}$ and V.A. LUKASH ${ }^{3}$ \\ ${ }^{1}$ E.O. Paton Electric Welding Institute, NASU \\ 11 Bozhenko Str., 03680, Kiev, Ukraine. E-mail: office@paton.kiev.ua \\ ${ }^{2}$ Research and Production Company «VISP Ltd» \\ 23 Moskovsky Ave., 04655, Kiev, Ukraine \\ ${ }^{3}$ V.N. Bakul Institute for Superhard Materials, NASU \\ 2 Avtozavodskaya Str., 04074, Kiev, Ukraine
}

\begin{abstract}
The advantages of friction stir welding (FSW) are well known from numerous publications. In this work it was proposed to apply FSW in restoration of sizes of copper plates of machines for continuous casting of billets (MCCB) moulds and for the further surface hardening with nickel or nickel alloys. The microstructure of characteristic zones of joints was studied. Application of FSW provides quality joints with sufficiently high mechanical properties of deposited layer. The structure of copper-copper and copper-nickel joints was studied. It was established that in formation of joints the mechanical stirring of metals plays a leading role, and their mutual diffusion affects them to a much lesser extent. Experimental investigations were laid as the basis for development of restoration technology of copper plates with nickel coating. 14 Ref., 10 Figures.
\end{abstract}

$\boldsymbol{K} \boldsymbol{e} \boldsymbol{y} \boldsymbol{w} \boldsymbol{o} \boldsymbol{r} \boldsymbol{d} \boldsymbol{s}:$ friction stir welding, restoration of copper plates, layer deposition, copper, nickel, structure of joints, working tool

Friction stir welding (FSW), developed by the British Welding Institute (TWI) as the process of joining in solid phase, is characterized by advantages which are not common to conventional methods [1-3].

Other processes of pressure welding differ from it by a method of heating, i.e. by the method of heat input into parts being welded. In FSW the kinetic energy is directly converted into heat energy, moreover generation of heat has a strictly localized character in the thin near-surface layers of metal.
Figure 1 shows installation and scheme of joining of the overlapped type of dissimilar metals using FSW method.

Researchers point out the following advantages of this process as compared to other methods of producing permanent joints [4, 5]: significant preservation of base metal properties in the join area; absence of harmful vapors and ultraviolet radiation during welding; possibility of producing defect-free welds on alloys, which during fusion welding are prone to hot cracking and porosity in weld metal; no need in application of filler material and removal of surface oxides at the edges before welding as well as slag and spat-
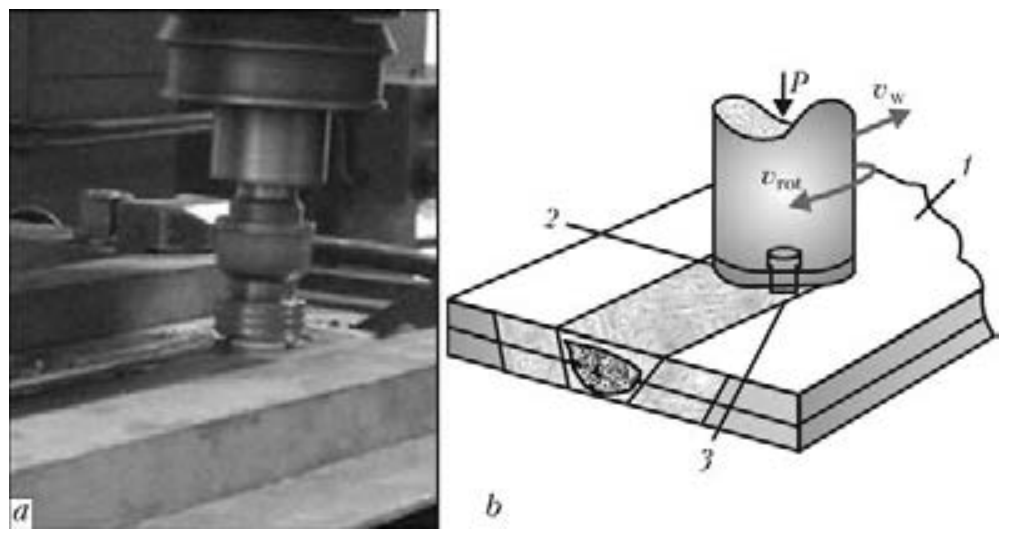

$b$

Figure 1. Installation $(a)$ and scheme of FSW process $(b): 1-$ workpiece; $2-$ shoulder; $3-$ pin tool with special profile 


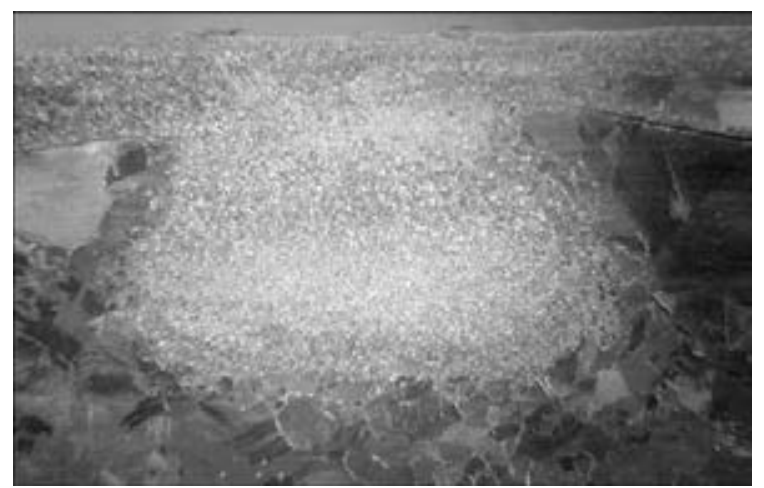

Figure 2. Macrostructure $(\times 5)$ of joint of copper layer with model object of copper of M1 grade produced using FSW

ters after welding; no losses of alloying elements in weld metal.

A great interest represents possibility of applying FSW to join similar and dissimilar metals. In [6-12] the successes in joining dissimilar metals by FSW method are demonstrated. As is shown in these works, weldability of metals is decisively influenced by metallurgical compatibility determined by mutual solubility of metals joined both in liquid as well as in solid states and also formation of brittle chemical compounds (intermetallics).

In this work, using FSW the authors produced and investigated $\mathrm{Cu}-\mathrm{Cu}$ and $\mathrm{Ni}-\mathrm{Cu}$ joints, the elements of which differ by unlimited solubility, with the purpose of using them to restore sizes of copper plates of moulds of machines for continuous casting of billets (MCCB) and their subsequent surface hardening using nickel or nickel alloys.

For the plates of MCCB moulds, a highly pure copper M1 (GOST 859-78) is used. It has a high thermal conductivity, which provides a quick formation of metal crust on the surface of casting. During movement of ingot through the mould a considerable, non-uniform abrasive wear of copper occurs in different areas. By conventional fusion methods it is difficult to restore MCCB moulds, since a high thermal conductivity of copper leads to a strong distortion and its interaction with oxygen, as a result of oxides formation, deteriorates the heat conducting properties of the mould.

The main zones of metal joints were obtained and examined. The macrostructure of base metal

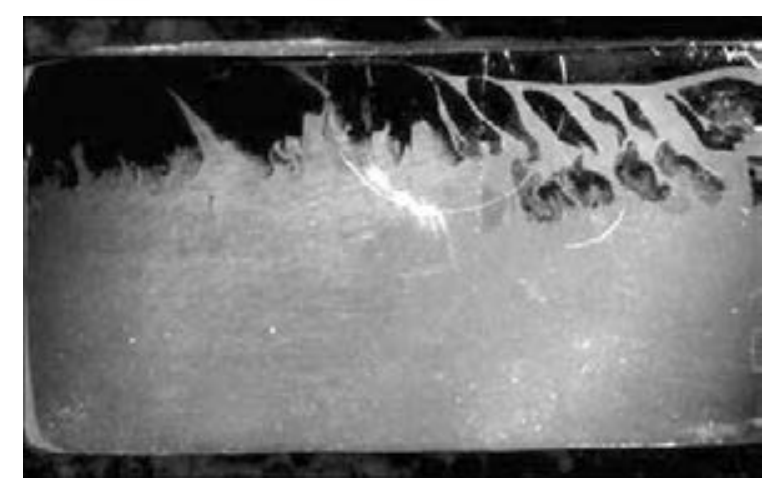

Figure 4. Microsection of copper specimen with nickel coating deposited using FSW method (optical microscope, cross section of the specimen)

with deposited layer is shown in Figure 2. As is seen from the Figure, a quality layer of metal was produced having no defects in the form of pores, cracks, or discontinuities. In the zone of dynamic recrystallization a significant grain refinement is observed. During deposition of copper on the specimen of copper MCCB mould by parallel welds a joint of somewhat different nature was formed, macrostructure of which is shown in Figure 3.

The general view of microsection of copper specimen with deposited layer of nickel is shown in Figure 4 (cross-section). Mechanical stirring of nickel and copper layers without active interaction is observed.

In the area of joining nickel and copper a mutual penetration of these metals to depth down to $3 \mathrm{~mm}$ occurs. The mass transfer of metals is marked in the form of mutually penetrating alternating bands directed towards the movement of pin tool (see Figure 4). Bands of copper and nickel have a different thickness (respectively $0.3-0.6$ and $0.03-0.30 \mathrm{~mm}$ ). Due to recrystallization the structure refinement occurs in these bands. In copper a grain size varies from 5 to 20 , and in nickel - from 5 to $40 \mu \mathrm{m}$. Microhardness of nickel bands is $1270 \pm 40$, and that of copper is $1140 \pm 50 \mathrm{MPa}$.

Using the method of electron microprobe analysis it was established that a slight diffusion of copper into nickel occurs along the grain boundaries. As a result of investigations of joints

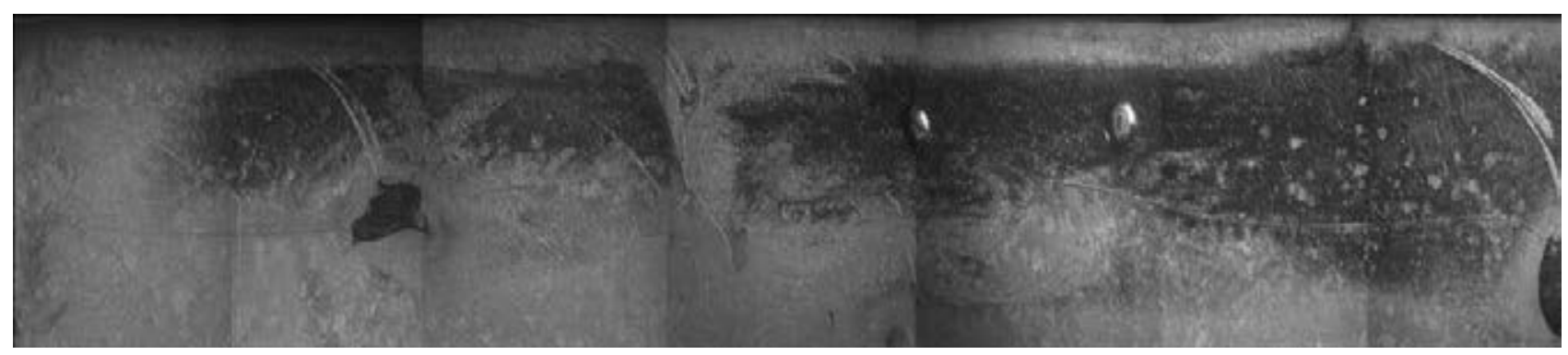

Figure 3. Macrostructure $(\times 10)$ of the M1 copper layer deposited on MCCB mould using FSW method 
of nickel with copper it was established that the mass transfer of metals plays a leading role in FSW process, and their mutual diffusion affects them to a much lesser extent.

The obtained results made it possible to develop a technology for restoration of copper moulds of continuous steel casting by deposition of surface layer of nickel and nickel-chromium coatings on them using FSW method.

In CIS since 2003 at the OJSC «Severstal» the works have been carried out on using slab moulds with slotted cooling channels [13], including those with nickel coatings. They showed their fundamental fitness and advantages over the moulds with drilling channels.

Despite the significant successes in extending the life of copper plates of MCCB moulds with coatings, the problems of their repair remain urgent even today. It was found that among the frequently encountered defects, due to which the moulds are removed from operation, is wear of sidewalls of the bottom part of cooling plates to depth of more than $2.7 \mathrm{~mm}$. Figure 5 shows picture of such a plate.

Figure 6 shows scheme of wear distribution on the working surface of narrow walls of the mould, where each line indicates increase in wear by $0.5 \mathrm{~mm}$ [13]. The presence of such defects makes their further operation unacceptable and requires replacement. The technology of repair of copper plates with the mentioned defects was developed using FSW method. Restoration of plates geometry was performed by the end of the rotating tool with protruding pin, which penetrating through a surfaced (filler) metal and moving, mixed the deposited metal with base metal [14].

To manufacture the tool for FSW a heat resistant and refractory material was selected that allowed operating at the temperatures of up to $1000^{\circ} \mathrm{C}$, at which plasticizing of copper occurs.

The procedure of restoration technology was simply enough. On the repaired segment area of the copper plate, previously milled to a certain level, copper plate of the required composition

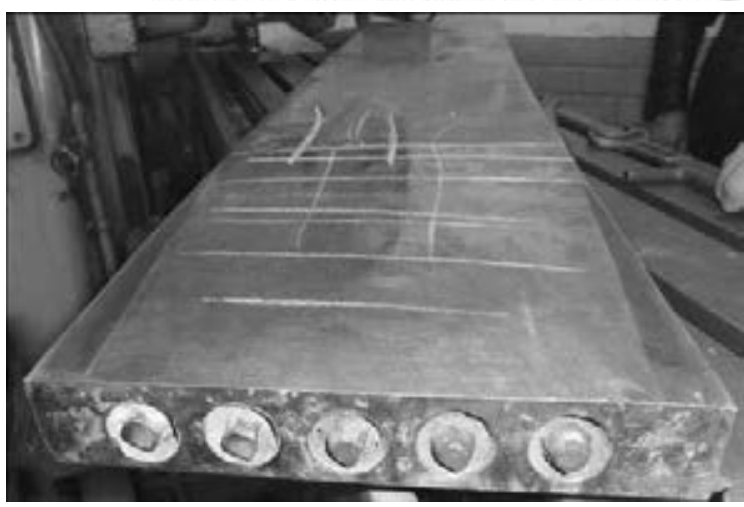

Figure 5. MCCB mould after operation

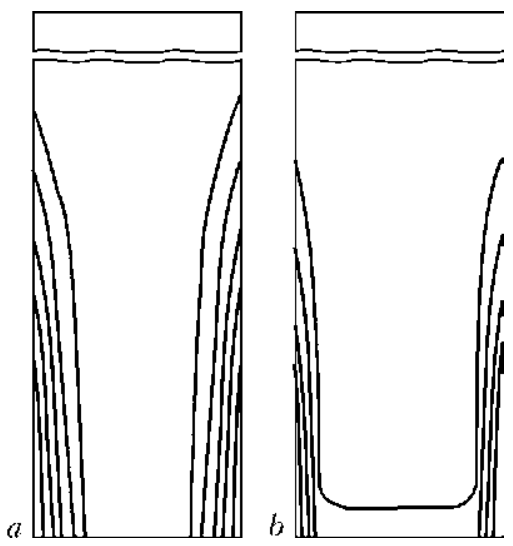

Figure 6. Distribution of wear on working surface of narrow walls of pilot ( $a$ ) and typical $(b)$ moulds (each line indicates increase of wear by $0.5 \mathrm{~mm})[13]$

and shape was placed and firmly fastened by clamps. Then rotating cylindrical tool of hard alloys with protruding pin was introduced into the plate, creating stirring of metal plate with the base metal.

Figure 7 shows steps of copper layer deposition on copper plate. It is seen that the structure of deposited layer of metal is dense, cracks, lacks of penetration and pores are absent. Metallographic examinations confirm this conclusion. Measurements of microhardness of the deposited layer of copper showed identity of its hardness of that of the restored plate. Dissolution of oxygen in the deposited layer was not observed. Similarly, when it was necessary the copper was de-
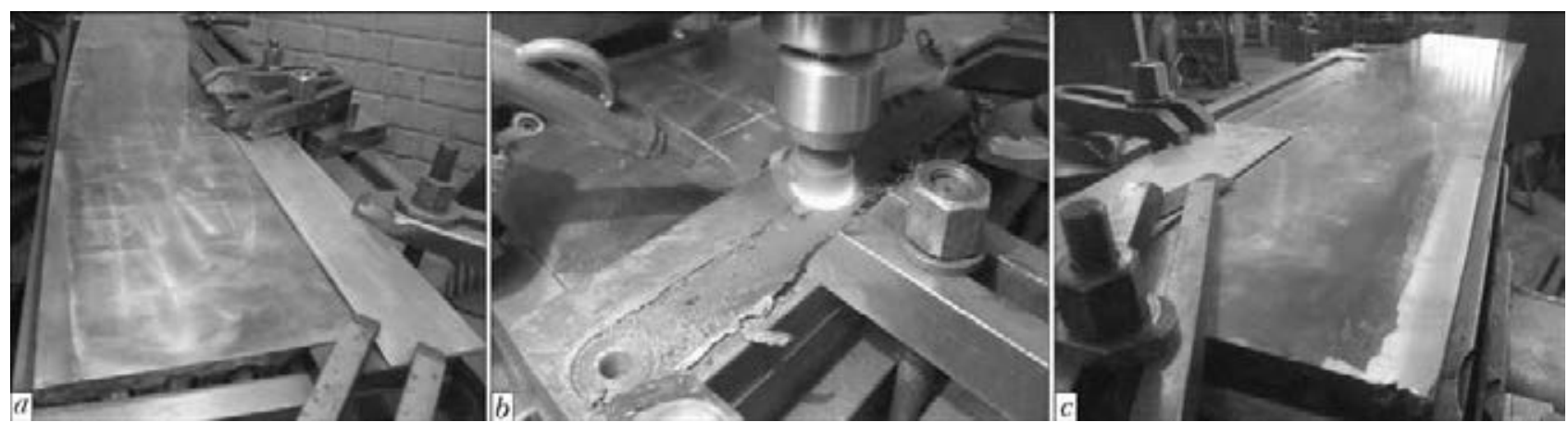

Figure 7. Stages of deposition of copper layer on copper plate: $a-$ plate with thin copper sheet; $b-$ surfacing process; $c-$ appearance of restored plate after grinding 


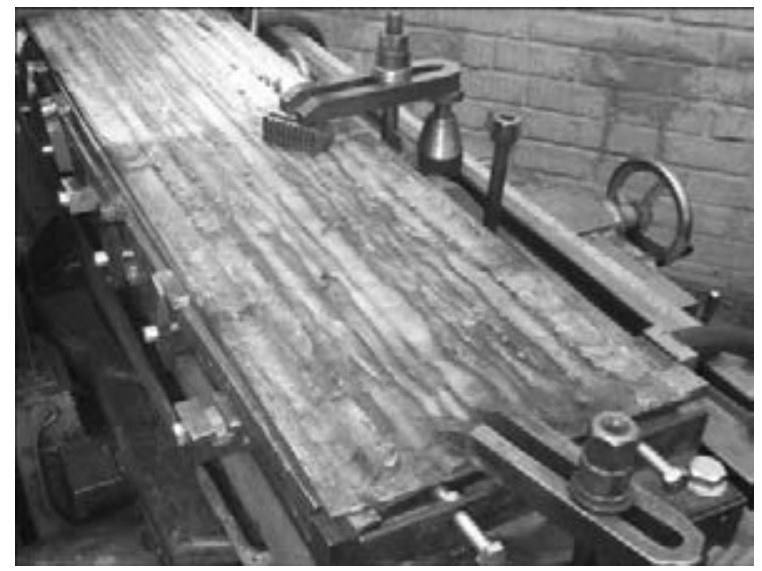

Figure 8. Layer of copper (5 mm) deposited on MCCB plate using FSW method without water cooling

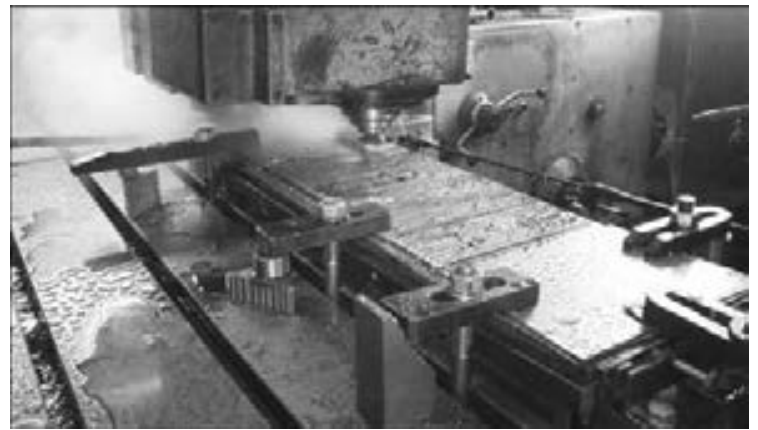

Figure 9. Process of deposition of nickel layer $(3 \mathrm{~mm})$ on copper plate of MCCB using FSW method

posited over the entire surface of the plate ( $\mathrm{Fi}$ gure 8 ). The final stage of restoration of copper plates of the mould is deposition of layer of nickel N1 $(3 \mathrm{~mm})$ using FSW method.

To deposit nickel on copper plate having a higher melting point than copper, it is needed not only to use other materials for the tool, but also to change its design. The best results are shown by hard alloys such as WK, TK and cubic boron nitride.

Such tools have increased strength and heat strength, which allows using them at the temperatures of up to $1000-1200{ }^{\circ} \mathrm{C}$. Surfacing was carried out in the installation for restoration of copper plates. To reduce oxidation of the tool, in the process of operation a cooling inert gas blowout was used (Figure 9).

After deposition of nickel the surface of MCCB plate is polished (Figure 10).

\section{Conclusions}

1. The possibility of deposition of nickel or copper layer on copper plates was shown which can be used during their restoration and strengthening to increase service life.

2. The technology of local and general repair of copper plates of MCCB moulds using FSW was developed.

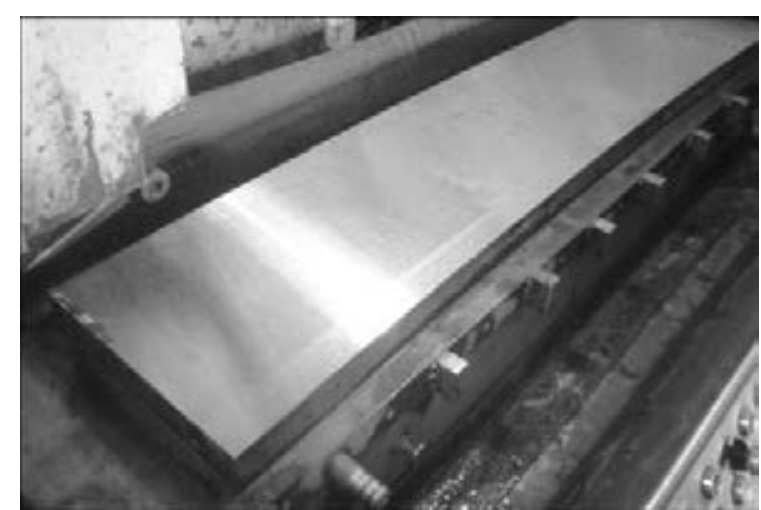

Figure 10. General view of copper plate with FSW-deposited nickel coating after grinding

3. The drawings, shape and composition of materials for the tool as-applied to FSW method were additionally modified.

4. The given technology allowed repairing defects of copper plates and depositing layers of copper and nickel.

1. Thomas, W.M. Friction stir butt welding. Pat. 9125978.8 GB. Int. Cl. PCTrGB92. Publ. 01.12.91.

2. Vill, V.I. (1970) Friction welding of metals. Leningrad: Mashinostroenie.

3. Lebedev, V.K., Chernenko, I.A., Mikhalsky, R. et al. (1987) Friction welding: Refer. Book. Leningrad: Mashinostroenie

4. Okamura, H., Aota, K., Ezumi, M. (2000) Friction stir welding of aluminum alloy and application to welded structure. J. Japan Institute of Light Metals, 50(4), 166-172.

5. Arbegast, W.J. (2006) Friction stir welding. After a decade of development. Welding J., 85(3), 28-35.

6. Watanabe, H., Takayama, H., Yanagisawa, A. (2006) Joining of aluminum alloy to steel by friction stir welding. J. Materials Proc. Techn., 178, 342-349.

7. Hirate, T., Oguri, T., Hagino, H. et al. (2007) Influence of friction stir welding parameters on grain size and formability in 5083 aluminum alloy. Materials Sci. and Eng. A, 456, 344-349.

8. Lee, W.-B., Schmuecker, M., Mercardo, U.A. et al. (2006) Interfacial reaction in steel-aluminum joints made by friction stir welding. Scripta Mater., 55, 355-358.

9. Kosta, A., Coelho, R.S., dos Santos, J. et al. (2000) Microstructure of friction stir welding of aluminium alloy to magnesium alloy. Ibid., 66, 953-956.

10. Kwon, Y.J., Shigematsu, I., Saito, N. (2008) Dissimilar friction stir welding between magnesium and aluminium alloys. Materials Letters, 62, 3827-3829.

11. Xue, P., Ni, D.R., Wang, D. et al. (2011) Effect of friction stir welding parameters on the microstructure and mechanical properties of the dissimilar $\mathrm{Al}-\mathrm{Cu}$ joints. Materials Sci. and Eng., 528, 4683-4689.

12. Saeida, T. Abdollah-Zadehb, A., Sazgarib, B. (2010) Weldability and mechanical properties of dissimilar aluminum-copper lap joints made by friction stir welding. J. Alloys and Compounds, 490, 652-655.

13. Makrushin, A.A., Kuklev, A.V., Ajzin, Yu.M. et al. (2005) Radial slab mould with slot channels and nickel coating of walls, 38-41. Moscow: Metallurgizdat.

14. Grigorenko, G.M., Zelenin, V.I., Kavunenko, P.M. et al. (2012) To problem of hardening of mould copper walls of MCCB. In: Rock cutting and metal-working tool: Technique, technology of its manufacturing and application. Issue 15, 548-552. Kiev: Logos.

Received 10.04.2015 


\title{
WAYS OF UPDATING THE TECHNOLOGY OF INDUCTION SURFACING OF THIN STEEL DISCS
}

\author{
Ch.V. PULKA, O.N. SHABLY, V.N. BARANOVSKY, V.S. SENCHISHIN and V.Ya. GAVRILYUK \\ Ternopol Ivan Puluj National Technical University \\ 56 Russkaya Str., 46011, Ternopol, Ukraine. E-mail: v_gavryliuk@mail.ru
}

\begin{abstract}
Considered are existing technological schemes of induction surfacing of operating elements of agriculture machines. The best results are provided by continuous induction surfacing using double-loop circular inductor, heat and electromagnetic shields, horizontal vibration and rotation of part being surfaced. Application of developed technological schemes and equipment for induction surfacing of thin disks allows increasing productivity, saving electric energy, improving microstructure, increasing wear resistance and stability of thickness of deposited layer as well as reducing residual stresses and deformations of disks. 16 Ref., 6 Figures.
\end{abstract}

\begin{abstract}
Keywords: induction surfacing, surfacing consumables, surfacing technology, double-loop inductor, heat and electromagnetic shield
\end{abstract}

Induction surfacing is based on heating and melting of filler material under the effect of high-frequency currents [1-3]. This is the most technological process for some types of parts due to simple equipment, easy surfacing process and, as a result, absence of necessity in welders with high qualification. In particular, induction surfacing found the widest distribution in surfacing of operating elements of agricultural and road machines and in some other branches of national economy (Figure 1).

Considering increase of industry demands the method of induction surfacing is continuously improved in the following directions: rise of process efficiency and wear resistance of deposited metal, optimization of induction heating modes, improvement of indictor structures and systems of energy saving in surfacing of disks of random diameters and dimensions of surfacing zone.

The aim of present work lies in analyzing the results of researches in directions mentioned above, improvement of induction surfacing process by example of thin profiling disks of top cutters (Figure 1, $f$ ).

Continuous successive surfacing using segment inductor (Figure 2, $a$ ) is used in production for strengthening of top cutters with solid cutting edge. At that, the inductor is fixed to high frequency generator and part being surfaced is rotated relatively to the inductor.

The advantages of this method are technological flexibility and possibility of surfacing of different diameter parts with comparatively small power. However, this technology has relatively low efficiency and large energy consumption. Besides, the part can be deformed in surfacing, that effects stability of thickness of deposited layer and additional alignment operation is necessary for elimination of disk deformation.

The technology of simultaneous induction surfacing over the whole operating surface using surfacing width more than teeth height and double-loop inductor was proposed for increase of surfacing efficiency of top cutters of saw tooth form (Figure $2, b)$. It resulted in $4-5$ times increase of surfacing efficiency.

Loops in the double-loop circular inductor have opposite phase connection on current and magnetic flow between themselves and with generator. Using such a connection provides for formation of electromagnetic field only in surfacing zone and uniform distribution of temperature over the disk surface, where charge is being melted. However, this technology requires significant expenses of electric energy.

Updating the modes of power supply to inductor [4] was carried out in order to save electric energy. It is shown that simultaneous surfacing of disks over the whole operating surface can be carried out using constant specific power at certain time as well as with its change on exponential law (energy saving mode). At that, 15-25\% economy of electric energy is achieved depending on used surfacing consumables. Thus, for example, surfacing with sormite powder PG-S1 provides for $15 \%$ electric energy saving and that makes $23 \%$ in surfacing using PG-AN9 powder.

Work [5] proposed a calculation procedure for double-loop circular inductor which provides 


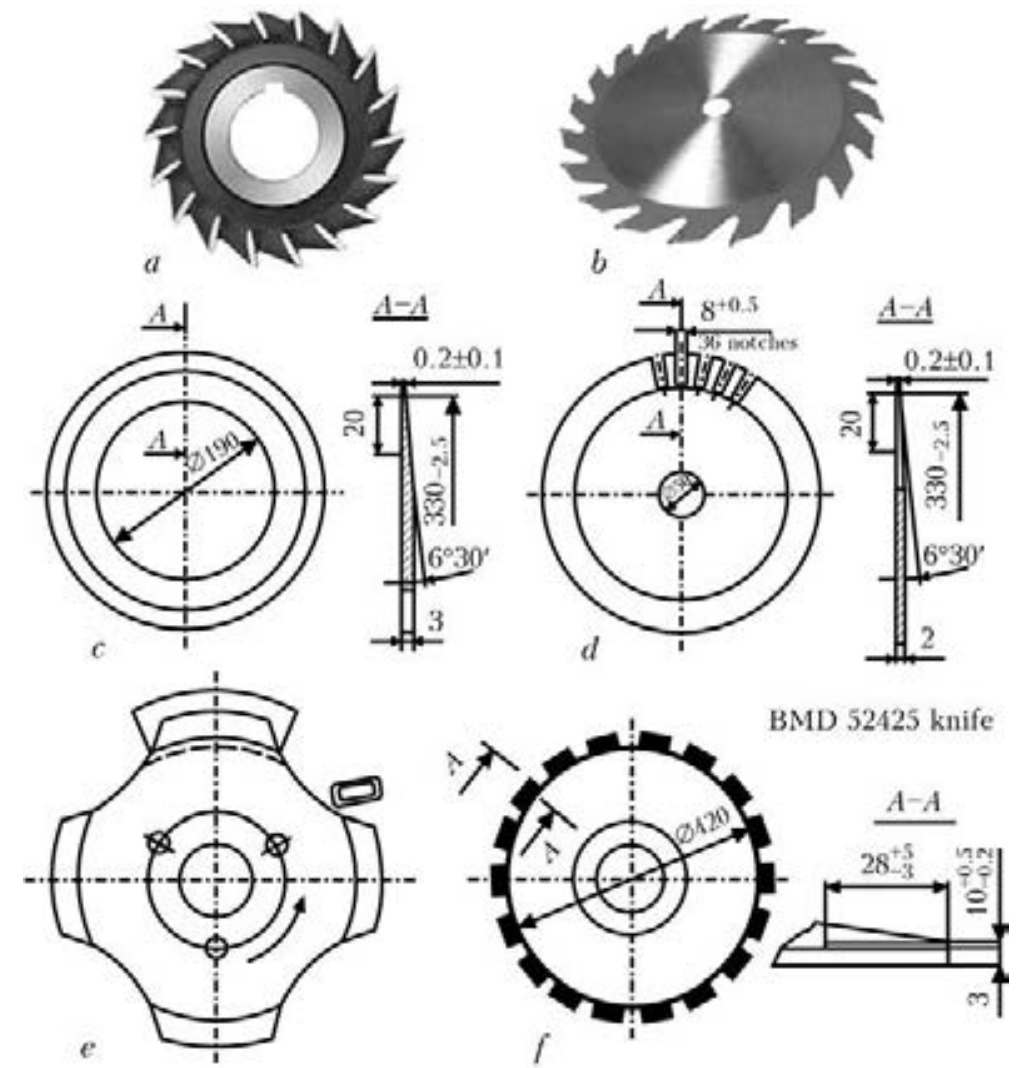

Figure 1. Thin disks subjected to surfacing: $a$ - disk cutter; $b$ - disk saw; $c, d$ - drive and non-drive disks for roofing slate cutting; $e-$ knife for sunflower cutting; $f-$ top cutter BMD 52425

for realizing of methods of simultaneous surfacing of profiling disks of saw tooth form over the whole surface by energy saving mode. A disadvantage of this technology is the fact that it can be used only for disks of specific diameter and surfacing zone width. There are cases on practice when diameters of disks and width of surfacing zone are changed. This requires selecting other structures of inductors or special shields, that is related with large financial and labor expenses.

Investigations and calculations of sizes of inductors and special shields were carried out for different variants of application of these systems, namely, only at inductor use (Figure $3, a$ ); in- ductor and electromagnetic shield (Figure 3, b); inductor, heat and electromagnetic shields ( $\mathrm{Fi}^{-}$ gure $3, c)$ [6-8].

Data received as a result of investigations allowed determining size of inductors and shields as well as current for surfacing of saw tooth disks of random diameter and size of surfacing zone, namely: disks of $210-240 \mathrm{~mm}$ diameter and 2$6 \mathrm{~mm}$ thickness, width and thickness of deposited layer $10-50$ and $1.0-1.5 \mathrm{~mm}$, respectively.

Thus, manufacturing engineer applying one or another heating system of induction surfacing (see Figure 3) selects necessary data graphically or using the tables according to disk diameter,
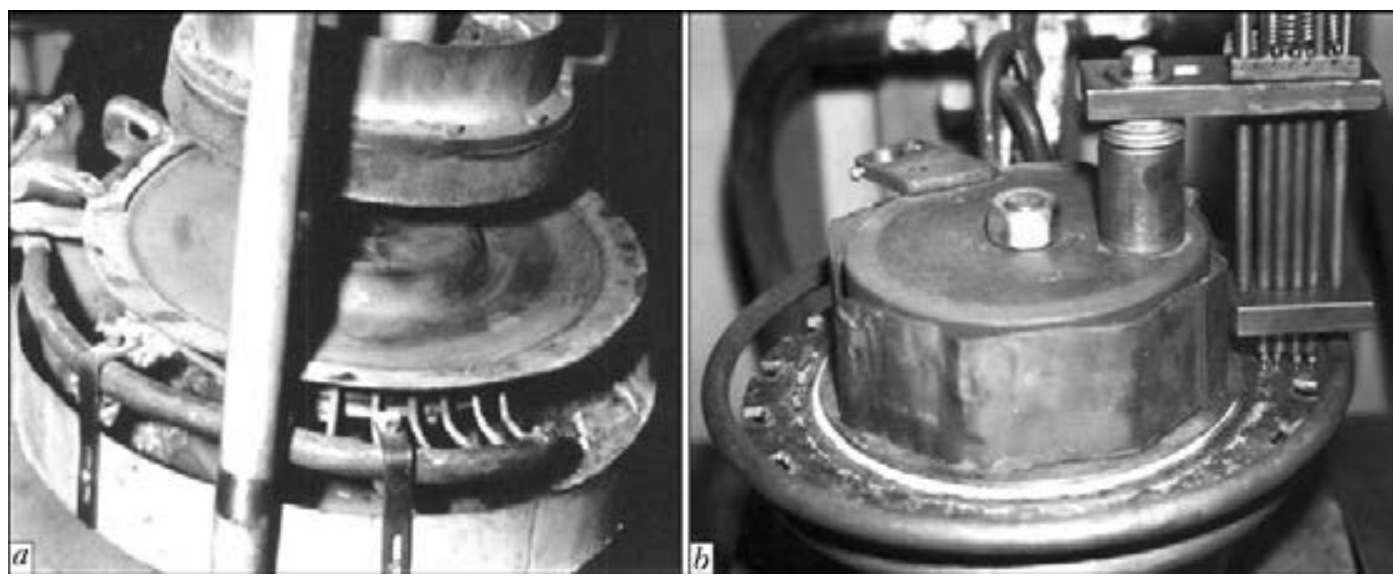

Figure 2. Device for surfacing of all-stamped solid cutter using segment inductor $(a)$ and top cutters of saw tooth form in double-loop circular inductor (b) [3] 

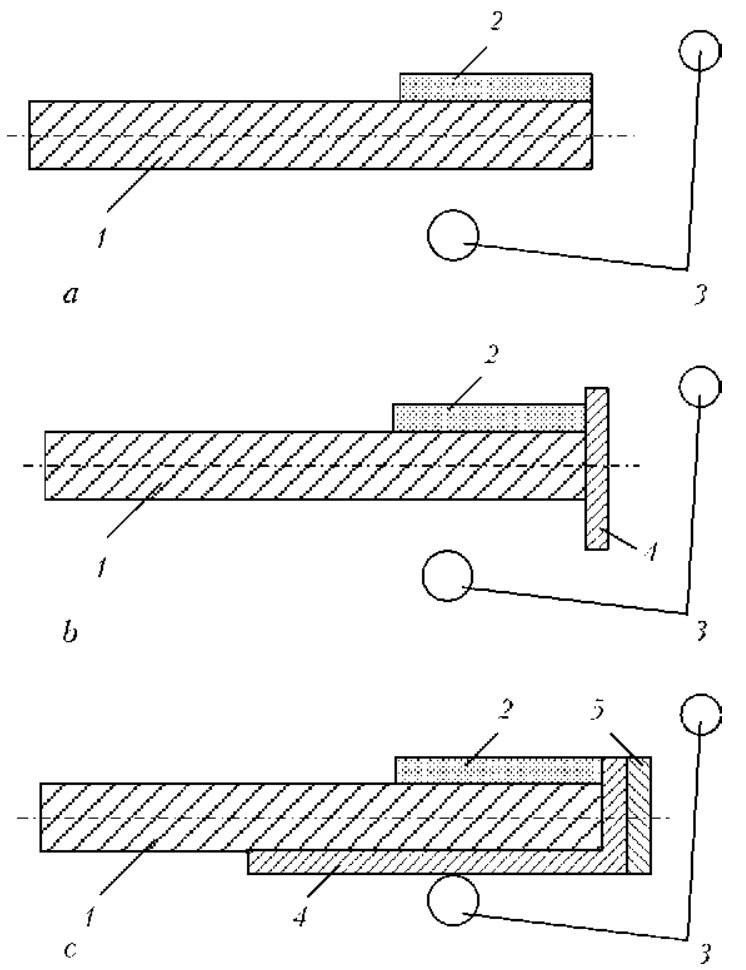

Figure 3. Schemes for positioning inductors and special shields in induction surfacing: $a$ - traditional scheme; $b-$ inductor and electromagnetic shield; $c-$ inductor, heat and electromagnetic shields; 1 - part; 2 - charge; $3-$ double-loop circular indictor; 4 - heat shield; 5 - electromagnetic shield

width and thickness of deposited layer. For example, the first scheme (Figure 3, a) requires entering seven parameters relating inductor structure and its positioning with respect to part, that reduces time and financial expenses for experiment performance and implementation of new technology.

The technology proposed by authors ( $\mathrm{Fi}^{-}$ gure $3, c)$, particularly, allows additional saving of $12-14 \%$ of electric energy, increasing stability of deposited metal by $10-15 \%$ and decreasing disk surfacing time from 32 to $22 \mathrm{~s}$ [9].

Within time a proposal was made about adding new technological operation in induction surfacing process (Figure 4) for further increase of wear resistance of deposited metal. At that, taking into account small thickness of plane disks, significant attention was paid to residual stresses, deformation and displacements which appear after surfacing in zone of operating surface having different width [10-13].

Work [11] represents the results of investigation of effect of additional technological schemes of induction surfacing on stability of deposited layer thickness by four schemes. $90 \%$ of measurements of thickness of deposited layer are in tolerance range at surfacing using scheme in $\mathrm{Fi}$ gure $4, d$, that is $22 \%$ more than in surfacing by
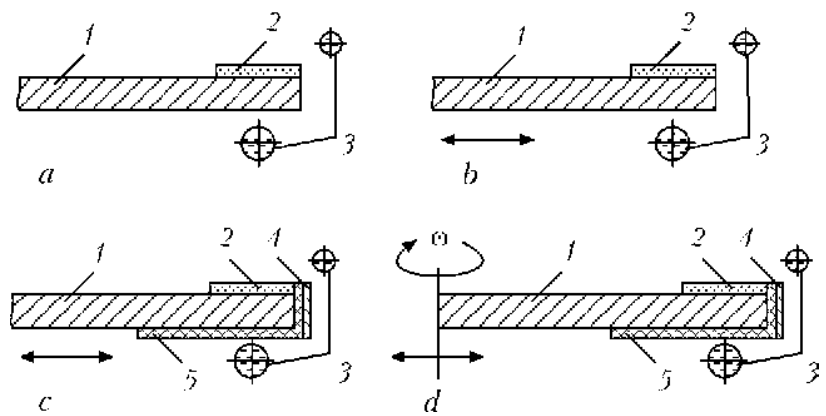

Figure 4. Schemes of induction surfacing used during investigations: $a$ - without vibration of deposited part; $b-$ with horizontal vibration of deposited part; $c-$ with horizontal vibration of deposited part using heat and electromagnetic shields; $d-$ the same, but with additional rotation of deposited part; 1 - part; 2 - deposited layer; 3 circular double-loop inductor; 4,5 - electromagnetic and heat shields, respectively (the arrows show direction of vibration application and disk rotation relatively to vertical axis)

scheme in Figure 4, $a$. In this case more uniform thickness of deposited layer is achieved due to joint application of horizontal vibration, heat and electromagnetic shields as well as centrifugal forces providing uniform distribution of liquid metal in surfacing zone.

The same works show that maximum residual stresses $\sigma_{2}$ appear in the deposited layer directly near the boundary of its joining with the base metal, and $\sigma_{2}=0.54 \sigma_{\mathrm{t}}$ at the boundary with non-surfaced zone at sormite tensile strength $\sigma_{\mathrm{t}} \sim$ $\sim 150 \mathrm{MPa}$ [13].

The developed technology (see Figure 4, $d$ ) allows heating with low level of temperature gradient over disk radius (Figure 5). Horizontal and vertical vibration of the part with corresponding amplitude and frequency directly during surfacing results in deposited metal microstructure optimizing and increasing wear resistance of deposited layer of sormite type (PG-S1 powder) approximately in 1.5 times.

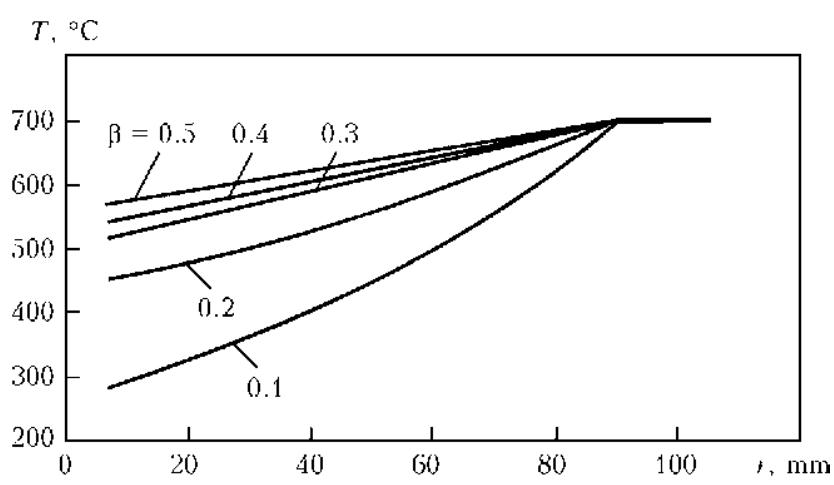

Figure 5. Distribution of temperature over disk radius at the moment of deformation beginning in the base metaldeposited metal system as elastic body at different values of gradient coefficient $\beta$ 


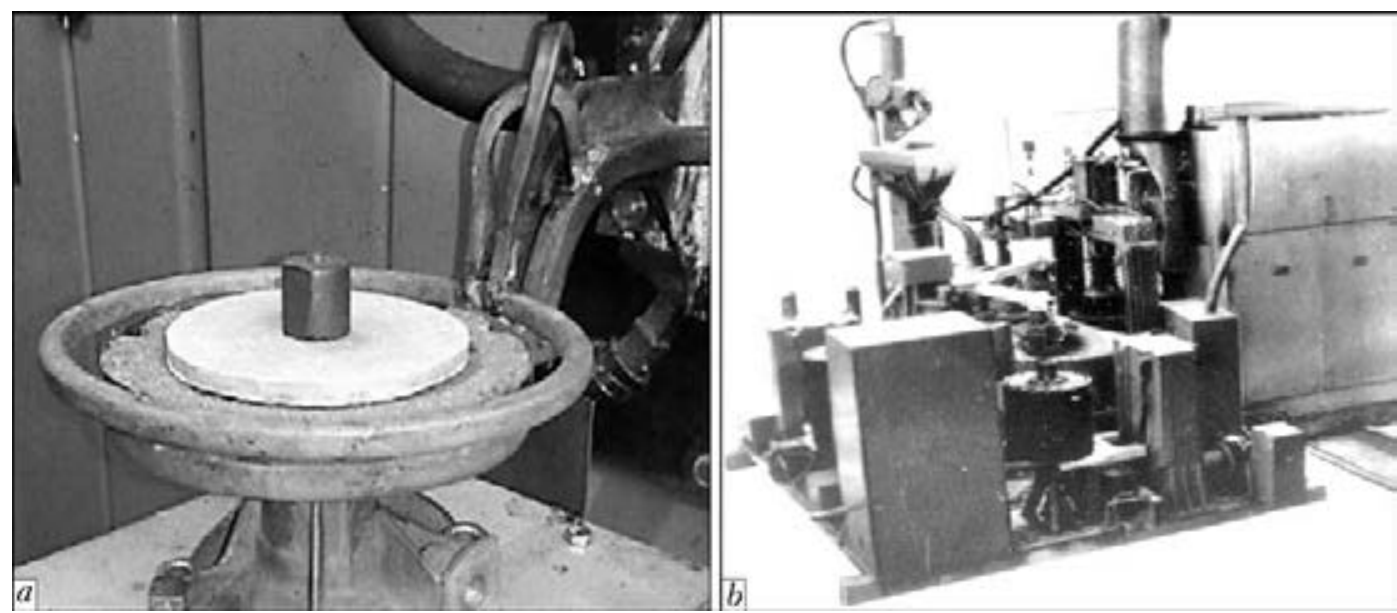

Figure 6. Surfacing unit $(a)$ and automated production system for surfacing of top cutters $(b)$

Automated production system for surfacing of top cutters (Figure 6) [14-16] was developed for realizing these technologies.

High-frequency generators of VChI $63 / 0.44$, VChG 6-60/0.44 and VChG9-60/0.44 of $60 \mathrm{~kW}$ power and $440 \mathrm{kHz}$ frequency were used for induction surfacing since base metal thickness makes $2-6 \mathrm{~mm}$.

Charge consisting of mixture of PG-S1 sormite powder and flux was used as surfacing consumable.

\section{Conclusion}

Application of developed technological schemes and equipment for induction surfacing of thin disks allows increasing efficiency, saving electric energy, improving microstructure, wear resistance and stability of deposited layer as well as decreasing residual stresses and deformations of disks.

1. Tkachev, V.N. (1971) Wear and increase in service life of agricultural machine parts. Moscow: Mashinostroenie.

2. Ryabtsev, I.A., Senchenkov, I.K. (2013) Theory and practice of surfacing works. Kiev: Ekotekhnologiya.

3. Pulka, Ch.V. (2006) Technological and energy effi ciency of induction surfacing of thin steel discs: Syn. of Thesis for Dr. of Techn. Sci. Degree. Kiev.

4. Shably, O.N., Pulka, Ch.V., Budzan, B.P. (1987) Optimization of power inputs in induction surfacing of thin-wall discs. Avtomatich. Svarka, 1, 36-39.

5. Shably, O.N., Pulka, Ch.V., Budzan, B.P. (1988) Ways of energy saving in induction surfacing of thinwall discs. Ibid., 12, 56-58.
6. Shably, O.N., Pulka, Ch.V., Pismenny, A.S. (1997) Optimization of inductor design parameters for induction surfacing of thin steel discs. Ibid., 6, 17-20.

7. Shably, O.N., Pulka, Ch.V., Pismenny, A.S. (2002) Optimization of inductor parameters for uniform heating of discs across the width of hardfacing zone allowing for screening. The Paton Welding J., 11, 23-25.

8. Shably, O.N., Pulka, Ch.V., Pismenny, A.S. (2003) Optimization of induction hardfacing of thin discs allowing for thermal and electromagnetic shielding. Ibid., 9, 20-23.

9. Pulka, Ch.V., Shably, O.N., Pismenny, A.S. (2004) Effect of induction surfacing conditions on structure and properties of deposited metal. Ibid., 10, 15-17.

10. Pulka, Ch.V., Shably, O.N., Senchishin, V.S. et al. (2012) Influence of vibration of parts on structure and properties of metal in surfacing. Ibid., 1, 23-25.

11. Pulka, Ch.V., Senchishin, V.S., Gavrilyuk, V.Ya. et al. (2013) Influence of technological schematics of induction surfacing on stability of deposited layer thickness. Ibid., 4, 61-63.

12. Shably, O.N., Pulka, Ch.V., Pismenny, A.S. et al. (1999) Residual displacements of thin steel discs in induction surfacing with wear-resistant powder-like hard alloys. Avtomatich. Svarka, 9, 55-57.

13. Shably, O.M., Mykhajlyshyn, M.S., Mykhajlyshyn, V.M. et al. (1998) Mathematical modeling of formation of residual stresses, strains and displacements in induction surfacing of thin steel discs. Visnyk TernopilDTU, 3(4), 5-12.

14. Shably, O.N., Pulka, Ch.V. (1994) Technology and equipment for induction surfacing of thin shaped discs. Avtomatich. Svarka, 5/6, 48-50.

15. Pulka, Ch.V., Gavrilyuk, V.Ya., Senchishin, V.S. (2013) Improvement of equipment and technology for induction surfacing. Svarochn. Proizvodstvo, 4, 27-30.

16. Pulka, Ch.V., Gavrylyuk, V.Ya., Senchyshyn, V.S. et al. Automatic production line for surfacing of thin discs. Pat. 94727 UA. Int. Cl. B23K 13/00. Publ. 25.11 .2014

Received 12.03.2015 


\title{
FLUX-CORED WIRES \\ AT THE WORLD AND REGIONAL MARKETS OF WELDING CONSUMABLES (Review)
}

\author{
A.A. MAZUR, O.K. MAKOVETSKAYA, S.V. PUSTOVOJT and N.S. BROVCHENKO \\ E.O. Paton Electric Welding Institute, NASU \\ 11 Bozhenko Str., 03680, Kiev, Ukraine. E-mail: office@paton.kiev.ua
}

\begin{abstract}
Electric arc welding is one of the basic technologies of industrial economy. The industrialized countries are characterized by a sustainable development of welding production and appearance of new technologies, welding equipment, as well as new consumables at the market. The main factors of wide application of welding technologies and surfacing using flux-cored wire in various industries and construction are high quality of welds and efficiency of welding process. The article presents analysis of the world and regional markets of flux-cored wire. In the world a steady growth in using mechanized and automatic welding and surfacing using powder consumables is observed. To meet the rising demand for flux-cored wire at the separate regional markets in a number of countries, new production capacities for its production are created. For example, in China, where rates of development of welding production are far ahead not only the industrialized countries but also certain regions, over the past decade new facilities for production of powder welding and surfacing consumables were put into operation. The level of mechanization and automation of arc welding is increased both in separate countries as well as around the world in general. The production capacities of Ukrainian producers allow completely satisfying the demand for flux-cored wire at the domestic market. 15 Ref., 7 Tables, 7 Figures.
\end{abstract}

$\boldsymbol{K} \boldsymbol{e} \boldsymbol{y} \boldsymbol{w} \boldsymbol{o r d s}:$ welding, welding production, flux cored wire, technology, market, state-of-the-art, prospects

Electric arc welding is the basic technology of creating permanent joints of metals and non-metals in many fields of industry and construction. Therefore, improving its efficiency and quality is one of the main tasks in welding production. The breakthrough in improving electric arc welding processes was creation of technologies and equipment for mechanized and automatic welding and surfacing using flux-cored wires and strips, development of high-quality powder welding and surfacing consumables. Already more than 60 years the significant contribution to the development of new technologies and equipment for mechanized and automatic welding and surfacing, development of welding and surfacing consumables, as well as technologies and equipment for their production is made by the E.O. Paton Electric Welding Institute of the NAS of Ukraine.

World market. Despite a relatively high cost, flux-cored wires are ever more demanded at the world market of welding consumables. In view of wide application of welding technologies and surfacing using flux-cored wires and strips in the economically developed countries their consump- tion in industry and construction is growing every year, despite the short-term recessions during periods of crisis in the world economy. Thus, for example, during the financial crisis of 2008-2009 and the economic crisis caused by it, the market volume of welding consumables dropped by more than $30 \%$ (such tendency was observed at the market of flux-cored wire). However by 2011, the sales of welding consumables reached a precrisis level and in the subsequent years it exceeded it. According to the estimates of leading analytical companies such as BBC Research and Transparency Market Research, the cost volume of welding equipment market in 2013 exceeded 17 billion USD. According to the forecast of these companies the market volume will reach 2425 billion USD by 2020 , and its annual growth in the period of 2014-2020 is expected at 4.5$5.3 \%[1,2]$. Data on the dynamics of cost volume of the world market of welding equipment and its structure in 2010-2012 and forecast of development until 2017 [3] are shown in Figure 1. One of the basic segments of the market of welding technology is the market of welding consumables. In 2013, the cost volume of market of welding consumables reached 8.75 billion USD, which amounts more than a half of the world market. The structure and dynamics of develop- 


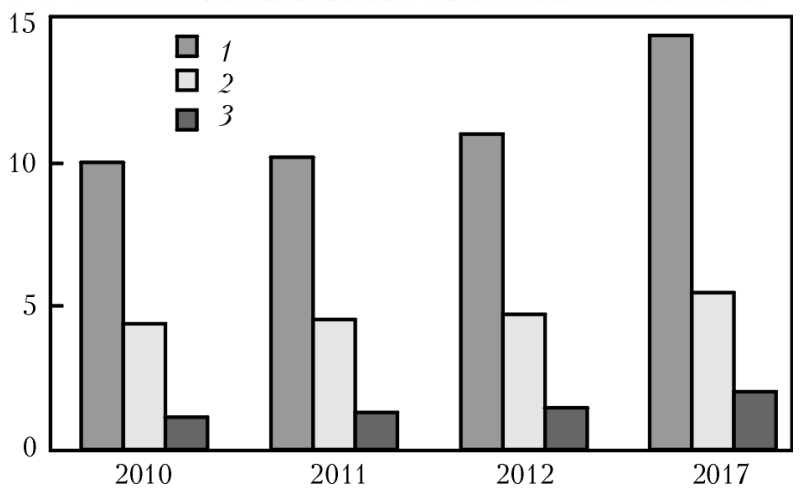

Figure 1. Dynamics of growth of the world welding market in 2010-2017, billion USD: 1 - welding consumables, shielding gas, protection means; 2 - welding equipment; 3 - automatic machines/robots, accessories

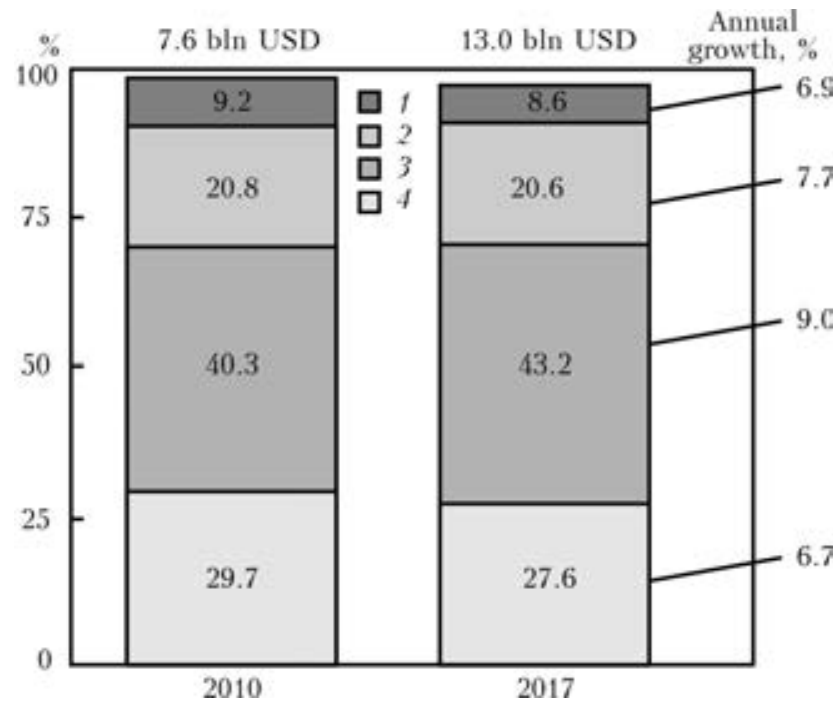

Figure 2. Structure and dynamics of development of the world market of welding consumables categorized by the main product segments (2017 - forecast): 1 - wire and flux (SAW); 2 - flux-cored wire; 3 - solid wire; 4 electrodes
Table 1. The world market of flux-cored wire in 2011-2013

\begin{tabular}{||c|c|c|c||}
\hline \multirow{2}{*}{ Year } & \multicolumn{3}{|c|}{ Market of welding consumables } \\
\cline { 2 - 4 } & $\begin{array}{c}\text { World, in total, } \\
\text { thou t }\end{array}$ & $\begin{array}{c}\text { Flux-cored wire, } \\
\text { thou t }\end{array}$ & $\begin{array}{c}\text { Share of } \\
\text { flux-cored wire, \% }\end{array}$ \\
\hline 2011 & 5945.6 & 748.7 & 12.5 \\
\hline 2012 & 6213.3 & 820.7 & 13.2 \\
\hline 2013 & 6283.6 & 863.7 & 13.8 \\
\hline
\end{tabular}

ment of the world market of welding consumables in 2010-2017 according to the estimates of Frost\&Sullivan [4] is shown in Figure 2.

In terms of cost values in the structure of the world market of welding consumables the fluxcored wire makes a little more than $20 \%$, but the rate of annual growth of its share is inferior only to a solid wire segment. The cost volume of the world market of flux-cored wire for welding and surfacing in 2010 amounted to 1.58 billion USD. In 2012 it amounted to 1.81 billion USD and by 2017 it will reach 2.56 billion USD [5].

In real terms, the world market of welding consumables according to The Japan Welding News for the World in 2013 exceeded 6.2 million tons, of which about $14 \%$ or 864,000 tons is flux-cored wire. Data on the flux-cored wire production in the world in 2011-2013 are shown in Table $1[6,7]$.

In the industrialized countries, in the structure of consumption of welding consumables the share of flux-cored wire amounts to the following values, \%: Korea - 40: Japan - 35.9; North America -22.1 ; EU - 19.1; Taiwan - 18.8.

The main sectors, where welding technologies using powder welding consumables are widely used are, first of all, shipbuilding and construction of offshore structures (platforms, berths,

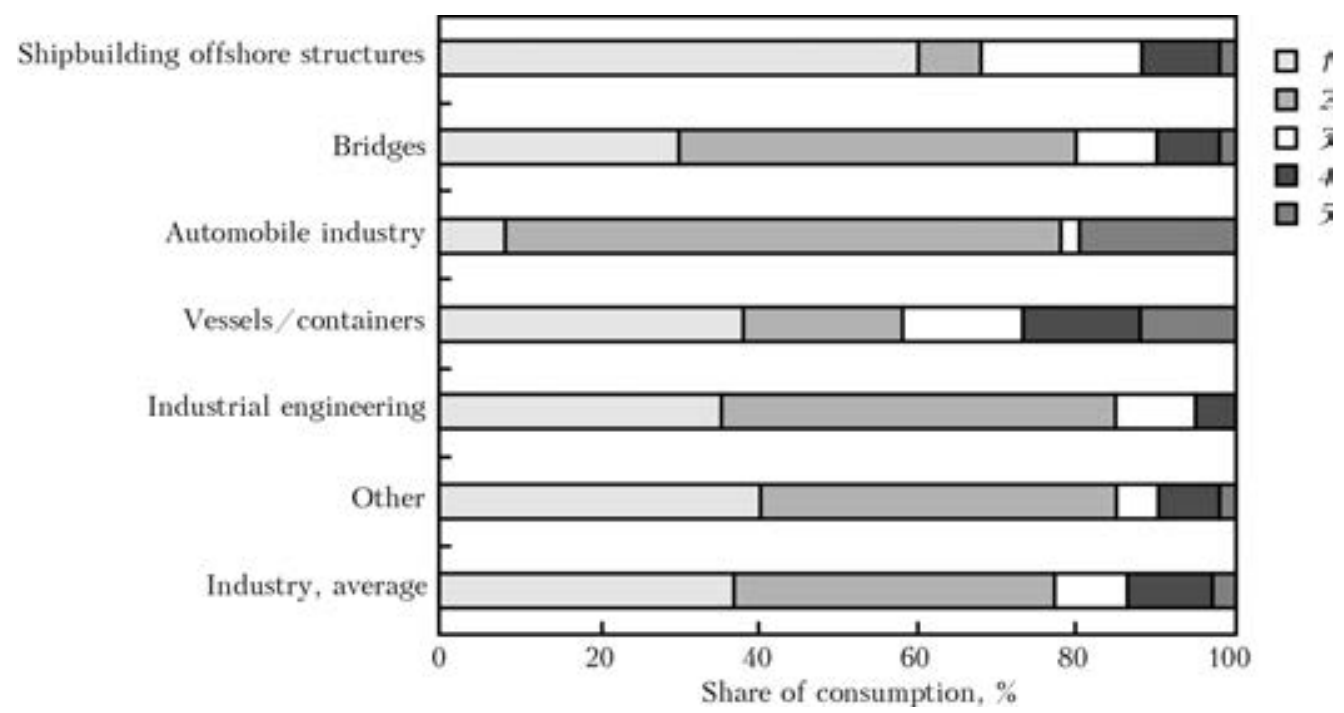

Figure 3. Share of the main types of welding consumables in different branches of industry in Japan: 1 - flux-cored wire; 2 - solid wire; 3 - electrodes; 4 - wire and flux (SAW) 


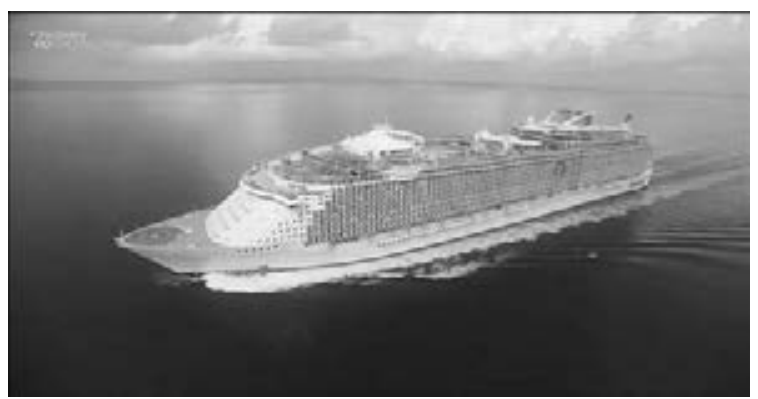

Figure 4. Cruise liner «Oasis of the Seas», 2009

etc.), bridge construction, manufacture of vessels and containers, industrial engineering, power engineering, construction of pipelines. The structure of consumption of the main types of welding consumables in different industries in Japan [8] is shown in Figure 3.

In shipbuilding and oil-and-gas sector the share of mechanized GMAW performed using flux cored-wire amounts almost to $80 \%$. Thus, for example, in Finland during construction of the largest cruise liner «Oasis of the Seas» the length of welds was $2400 \mathrm{~km}$. During construction of the ship more than $1000 \mathrm{~kg}$ of welding consumables was consumed. During assembly and welding of hull structures of the ship, $75 \%$ of welds are produced using flux-cored wire welding technologies, and relatively 15 and $9 \%$ using submerged arc and manual arc welding ( $\mathrm{Fi}-$ gure 4).

Flux-cored wire is widely used also in the construction of various architectural erections of steel building structures. Thus, during construction of the stadium Donbass Arena (Donetsk, Ukraine) the powder welding consumables were used for mechanized welding in shielding gases and submerged arc welding (Figure 5).

A new direction in application of welding consumables for mechanized welding in bridge construction is the refuse from solid wires and implementation of a new generation of metal fluxcored wires specially designed for steel bridge construction. This wire was used in the construction of a unique steel bridge of cable-beam system with an arched pylon across the Moscow River (Figure 6), the bridge across the Zolotoy Rog Bay in Vladivostok (RF), etc.

In the manufacture of offshore platforms and related equipment the seamless flux-cored wires of rutile type with a rapidly solidifying slag crust suitable for welding in all spatial positions were widely applied [9].

Currently, there is an intensive growing demand for welding and surfacing materials applied in the sector of repair and maintenance. Welding, soldering and surface strengthening (deposition), as well as thermal spraying (plasma, gas

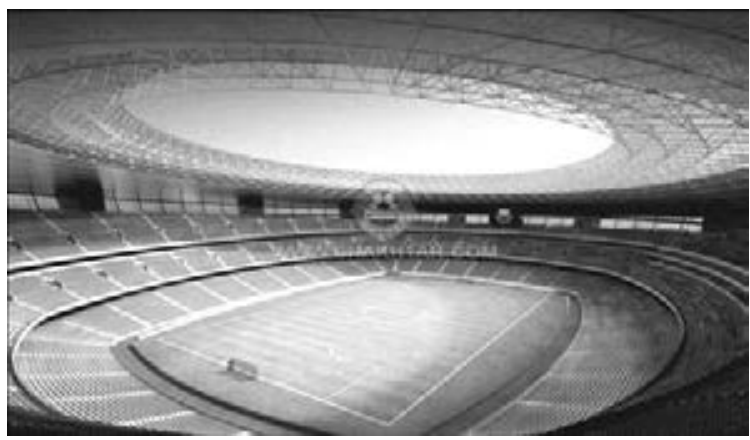

Figure 5. Stadium «Donbass Arena» (Donetsk), 2009

flame, high speed gas flame (HVOF) and arc). The cost volume of the world market of welding consumables for this sector makes about 2 billion USD and by 2017 its annual growth by $4.5 \%$ is expected. The structure of the market of welding consumables for repair and maintenance, according to the data of [10], for the flux-cored wire is $24 \%$, for electrodes is $50 \%$, for solid wire is $24 \%$ and for wire for submerged arc welding is $2 \%$.

Regional markets of flux-cored wire. The large segment of the world market of welding consumables is the Asian region. The market of Asian countries makes more than $70 \%$ of the world market of welding consumables and $68 \%$ of the world market of flux-cored wire. The market share of flux-cored wire in Europe and North America is $12 \%$ each. The data on volume and structure of consumption of the main types of welding consumables in a number of regions of the world are given in Table $2[6,7]$.

At present, China became the leader of the world and regional consumption of welding consumables and, respectively, flux-cored wire. The major share of consumption of welding consumables in China makes up nevertheless covered electrodes $(46 \%)$, but the consumption of fluxcored wire in industry is constantly growing. In 2013, the volume of consumption of flux-cored wire amounted to 330,000 tons or $38.2 \%$ of the world consumption and in the structure of con-

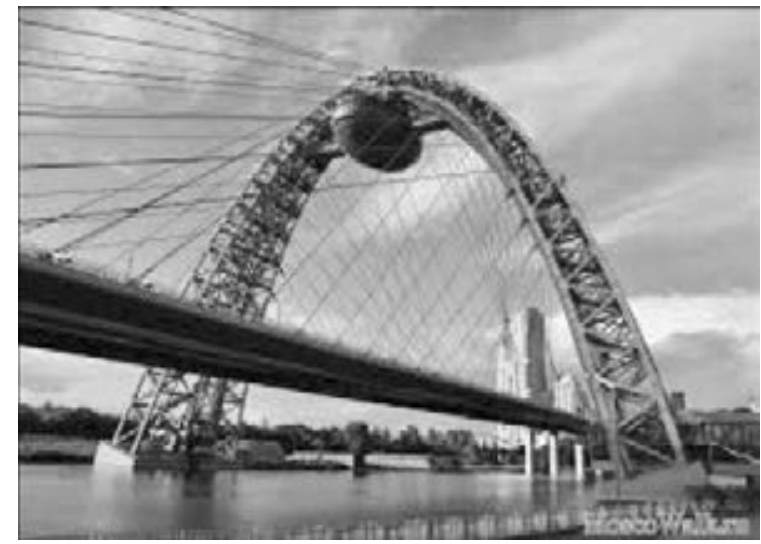

Figure 6. Bridge crossing in Serebryany Bor (Moscow) 
Table 2. Volume and structure of welding consumables consumption in different regions of the world in 2013

\begin{tabular}{|c|c|c|c|c|c|c|c|c|c|c|}
\hline \multirow[t]{2}{*}{ Region } & \multicolumn{2}{|c|}{ Electrodes } & \multicolumn{2}{|c|}{$\begin{array}{l}\text { Wire for SAW } \\
\text { and flux }\end{array}$} & \multicolumn{2}{|c|}{ Solid wire } & \multicolumn{2}{|c|}{ Flux-cored wire } & \multicolumn{2}{|c|}{ In total } \\
\hline & thou $\mathrm{t}$ & $\%$ & thou $\mathrm{t}$ & $\%$ & thou $\mathrm{t}$ & $\%$ & thou $\mathrm{t}$ & $\%$ & thou $\mathrm{t}$ & $\%$ \\
\hline Europe & 58.3 & 11 & 68.9 & 13 & 296.8 & 56 & 106.0 & 20 & 530 & 100 \\
\hline North America & 55.2 & 12 & 46.0 & 10 & 253.0 & 55 & 105.8 & 23 & 460 & 100 \\
\hline Central and South America & 103.4 & 47 & 19.8 & 9 & 79.2 & 36 & 17.6 & 8 & 220 & 100 \\
\hline Russia (the Customs Union) & 105.6 & 48 & 30.8 & 14 & 66.0 & 30 & 17.6 & 8 & 220 & 100 \\
\hline Asia & 1866.3 & 42 & 505.2 & 11 & 1508.5 & 34 & 583.6 & 13 & 4464.6 & 100 \\
\hline Middle East & 95.0 & 50 & 19.0 & 10 & 58.9 & 31 & 17.1 & 9 & 190 & 100 \\
\hline Africa & 82.5 & 55 & 12.0 & 8 & 43.5 & 29 & 12.0 & 8 & 150 & 100 \\
\hline Oceania & 23.0 & 46 & 4.5 & 9 & 18.5 & 37 & 4.0 & 8 & 50 & 100 \\
\hline World, in total & 2389.3 & 38 & 706.2 & 11 & 2324.4 & 37 & 863.7 & 14 & 6283.6 & 100 \\
\hline
\end{tabular}

sumption of welding consumables it had already amounted to $10 \%$.

Despite the growth of production capacities of flux-cored wire in China, a significant increase in its import volume should be noted. If by 2000 the import of flux-cored wire was not higher than $40 \%$ of the domestic production, since 2001 the volume of import of flux-cored wire began to exceed the volumes of its production and currently it amounts to almost $100 \%$ of the volume of flux-cored wire produced in the country.

Figure 7 shows data characterizing the share of consumption of flux-cored wire of the main regions and countries in the world consumption of flux-cored wire and share of consumption of flux-cored wire in the structure of domestic consumption of welding consumables.

China shot up to the leaders of the world production and consumption of flux-cored wire relatively not long ago. As early as in 2002 the volume of production of flux-cored wire in China did not exceed 18,000 tons and the consumption was 35,000 tons. Whereas at that time Japan

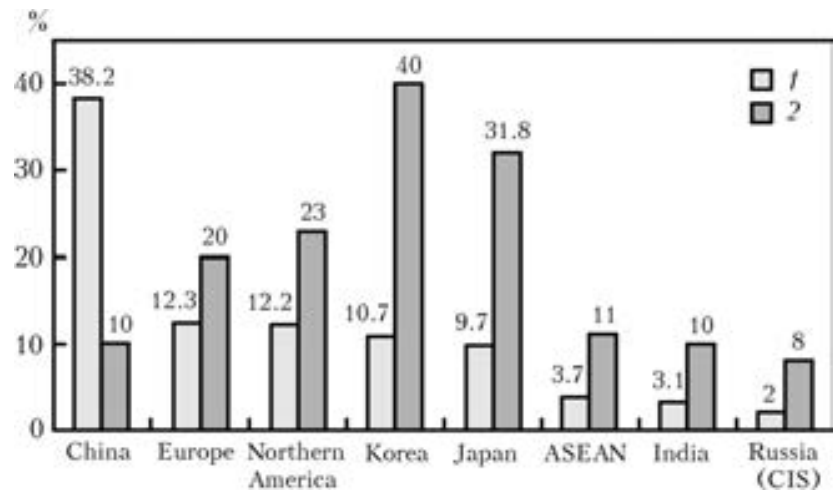

Figure 7. Share of flux-cored wire in the structure of consumption of regions and countries - the world major consumers of flux-cored wire, \%: 1 - in structure of the whole world consumption of flux-cored wire; 2 - in structure of domestic consumption of welding consumables produced already about 90,000 tons of flux-cored wire, of which 16,000 tons were exported. The total production of welding consumables in Japan in 2013 exceeded 280,000 tons and the consumption was 260,000 tons, of which $31.8 \%(83,000$ tons) is a flux-cored wire, $46.7 \%$ is a solid wire.

The recognized leader in production and consumption of flux-cored wire is the Republic of Korea. The country entered the world market of welding consumables relatively not long ago, but its market of welding consumables was developing very dynamically. Thus, over the ten year period from 1995 the quantitative volume of welding consumables in the country increased by 5 times and amounted to about 300,000 tons in 2005. Moreover the domestic consumption amounts to $62 \%$ of produced welding consumables, $38 \%$ of them are exported [11]. More than $70 \%$ of welding consumables produced in the country is the solid and flux-cored wire. The leading manufacturer of welding consumables in Korea - Hyundai Welding Co Ltd. - is among 15 companies the world leaders in production of welding consumables. Its share of sales on the domestic market of welding consumables amounts to $45 \%$.

The volume of the European market of welding consumables in terms of cost value amounts to about 2.1 billion euros and in the recent years tends to decrease. In 2013, the volume of consumption of welding consumables in the European countries amounted to about 530,000 tons, of which $20 \%$ makes flux-cored wire.

The main producers and consumers of welding consumables in Europe are Germany, France and Italy. The volumes of production of the main types of consumables for welding, brazing, thermal spraying in the EU countries are the follow- 
Table 3. Production of welding consumables in Germany in 2011-2013

\begin{tabular}{|c|c|c|c|c|}
\hline \multirow{2}{*}{ Welding and auxiliary materials } & \multicolumn{3}{|c|}{ Volume of production, mln euro } & \multirow{2}{*}{$\begin{array}{c}\text { Change } \\
2013 / 2012, \%\end{array}$} \\
\hline & 2011 & 2012 & 2013 & \\
\hline Welding wire and strip (excluding wire and strip with coating and filling) & 271.5 & 255.3 & 245.6 & -3.8 \\
\hline Covered electrodes for arc welding & 112.1 & 97.9 & 70.2 & -28.2 \\
\hline Flux-cored wire for arc welding & 53.1 & 53.3 & 52.3 & -1.9 \\
\hline Rods with coating for brazing and autogenous welding & 41.8 & 34.7 & 32.9 & -5.2 \\
\hline Auxiliary consumables for welding and brazing of metals & 144.4 & 148.9 & 149.6 & +0.4 \\
\hline In total & 622.9 & 590.1 & 550.7 & -6.7 \\
\hline
\end{tabular}

Table 4. Production of welding consumables in Germany in 2009-2011

\begin{tabular}{|c|c|c|c|c|}
\hline \multirow{2}{*}{ Welding and auxiliary materials } & \multicolumn{3}{|c|}{ Volume of production, thou $\mathrm{t}$} & \multirow{2}{*}{$\begin{array}{c}\text { Change } \\
2009 / 2008, \%\end{array}$} \\
\hline & 2011 & 2012 & 2013 & \\
\hline Welding wire and strip (excluding wire and strip with coating and filling) & 129.2 & 111.0 & 108.8 & -2.0 \\
\hline Covered electrodes for arc welding & 12.6 & 12.3 & 12.0 & -3.0 \\
\hline Flux-cored wire for arc welding & 23.4 & 21.7 & 20.7 & -5.0 \\
\hline Rods with coating for brazing and autogenous welding & 1.5 & 1.3 & 1.2 & -8.0 \\
\hline Auxiliary consumables for welding and brazing of metals & 46.0 & 53.5 & 50.9 & -5.0 \\
\hline In total & 212.7 & 199.7 & 193.6 & -3.0 \\
\hline
\end{tabular}

ing, million euros [12]: Germany - 549; France - 238; Italy - 193; UK - 137; the Netherlands - 73; Czech Republic - 7; others - 830; EU (27) - 2027.

Germany produces about one third of the total volume of production of welding consumables in the EU countries, whereas Germany, France and Italy together produce almost a half of output of all the consumables in the EU.

In the structure of production and application of welding consumables in the EU countries a solid wire (almost $56 \%$ ) is dominated and a flux-cored wire amounts to about $20 \%$.

The data of cost and quantitative volume of production of welding consumables in Germany on the separate product groups, which are presented in Tables 3 and 4, allow evaluating the volume and structure of production of consumables in Europe in 2011-2013. According to the data of these Tables, the volume of production of welding consumables in cost value was reduced almost by $7 \%$ in 2013 and in real terms - by $3 \%$. For the certain types of products, such as for example, covered electrodes, the reduction in cost value terms was $30 \%$ [10].

Basing on the data presented in Tables 3 and 4 and on the fact that Germany produces $30 \%$ of the entire European volume of production of welding consumables, the cost volume of production of welding consumables in the EU countries in 2013 amounted to almost 1.8 billion euros, and about 645,000 tons of welding consumables were produced.

Russia. The volume of production of welding consumables in Russia is constantly decreasing. Since 2001 their production decreased by 3 times, and in 2013 it amounted to about 120,000 tons, of which $80 \%$ were covered electrodes [13].

The volume of production of flux-cored wire is not high. In the best pre-crisis years (2007) it was about 5,000 tons at the total volume of production of welding consumables of 320,000 tons. Currently, according to the evaluation of producers of welded structures in Russia the industrial production of flux-cored wire is established mainly at the enterprise «InterPro» (Oryol region). The main reason for reduction of capacities is lack of quality raw materials and closing of enterprises [14].

Russia increases import of welding consumables, including flux-cored wire. The import of welding consumables in 2001-2014 increased by 5.4 times from 7.3 to 38.6 thou t, including fluxcored wire - by almost 3.6 times from 1.5 to 5.4 thou t. The main suppliers of flux-cored wire are the companies ESAB (China), Lincoln Electric (China), Hyundai (South Korea), Kobelco (Holland) [14].

The share of the CIS countries (including Russia) in the structure of the world market of welding consumables does not exceed $3.5 \%$. According to The Japan Welding News for the World, in 2013 the quantitative volume of market of 
INTERNATIONAL CONFERENCE «SURFACING»

Table 5. Volume of consumption of welding consumables in the world and CIS countries (including Russia) in 2013

\begin{tabular}{|c|c|c|c|c|}
\hline \multirow{2}{*}{ Welding consumables } & \multicolumn{2}{|c|}{ World } & \multicolumn{2}{|c|}{ CIS (including Russia) } \\
\hline & thou $\mathrm{t}$ & $\%$ & thou $\mathrm{t}$ & $\%$ \\
\hline Covered electrodes & 2389.3 & 100 & 105.6 & 4.4 \\
\hline Flux-cored wire & 863.7 & 100 & $17.6^{* *}$ & 2.0 \\
\hline Wire for SAW & 706.2 & 100 & 30.8 & 4.4 \\
\hline Solid wire & 2324.4 & 100 & 66.0 & 2.8 \\
\hline In total & 6283.6 & 100 & $220^{*}$ & 3.5 \\
\hline
\end{tabular}

Table 6. Volume of consumption of welding consumables in CIS countries (including Russia) in 2011-2013.

\begin{tabular}{|c|c|c|c|c|c|c|}
\hline \multirow{2}{*}{ Welding consumables } & \multicolumn{2}{|c|}{2011} & \multicolumn{2}{|c|}{2012} & \multicolumn{2}{|c|}{2013} \\
\hline & thou $\mathrm{t}$ & $\%$ & thou $\mathrm{t}$ & $\%$ & thou $\mathrm{t}$ & $\%$ \\
\hline Covered electrodes & 112.2 & 51 & 112.7 & 49 & 105.6 & 48 \\
\hline Flux cored wire & 13.2 & 6 & 18.4 & 8 & 17.6 & 8 \\
\hline Wire for SAW & 30.8 & 14 & 32.2 & 14 & 30.8 & 14 \\
\hline Solid wire & 63.8 & 29 & 66.7 & 29 & 66.0 & 30 \\
\hline In total & 220 & 100 & 230 & 100 & 220 & 100 \\
\hline
\end{tabular}

welding consumables in the CIS countries (including Russia) amounted to 220,000 tons. In Tables 5 and 6 the data of volume and structure of consumption of welding consumables in the CIS countries in 2011-2013 are given [6, 7].
Within the framework of the program of import substitution being developed today in Russia the works on evaluation of the possibility of increasing domestic production of welding consumables began. However, if in respect of welding electrodes and solid wire the experts note a pos-

Table 7. Apparent consumption of welding and filler materials in Ukraine (according to the State Statistics Service of Ukraine), thou $\mathrm{t}$

\begin{tabular}{|c|c|c|c|c|c|c|}
\hline Description & In total & $\begin{array}{l}\text { Conventional } \\
\text { welding wire }\end{array}$ & $\begin{array}{l}\text { Alloyed welding } \\
\text { wire }\end{array}$ & Flux-cored wire & $\begin{array}{l}\text { Welding } \\
\text { electrodes }\end{array}$ & Welding fluxes \\
\hline & & \multicolumn{5}{|c|}{2011} \\
\hline Production & 86.7 & 8.7 & 11.5 & $0.2^{*}$ & 43.0 & 25.1 \\
\hline Export & 28.1 & - & 2.2 & 0.6 & 8.1 & 17.2 \\
\hline Import & 10.8 & - & 6.4 & 0.6 & 1.1 & 2.7 \\
\hline \multirow[t]{2}{*}{ Apparent consumption } & 69.4 & 8.7 & 15.7 & 0.2 & 36.0 & 10.6 \\
\hline & & \multicolumn{5}{|c|}{2012} \\
\hline Production & 78.2 & 7.7 & 10.0 & 0.2 & 38.6 & 21.7 \\
\hline Export & 25.6 & - & 2.3 & 0.6 & 7.0 & 15.7 \\
\hline Import & 10.2 & - & 7.0 & 0.5 & 1.2 & 1.5 \\
\hline \multirow[t]{2}{*}{ Apparent consumption } & 62.8 & 7.7 & 14.7 & 0.1 & 32.8 & 7.5 \\
\hline & & \multicolumn{5}{|c|}{2013} \\
\hline Production & 77.9 & 7.5 & 10.0 & 0.2 & 40.4 & 19.8 \\
\hline Export & 27.2 & - & 1.6 & 0.3 & 10.5 & 13.9 \\
\hline Import & 12.7 & - & 8.6 & 0.5 & 1.4 & 1.6 \\
\hline Apparent consumption & 63.4 & 7.5 & 17.0 & 0.4 & 31.3 & 7.5 \\
\hline
\end{tabular}


sibility of setting up the production of these types of welding consumables of the required quality, the increase in production of flux-cored wire remains an open question.

Ukraine. Ukraine economy is one of the mostly affected by the crisis in Europe. In the period of 2008-2009 the decline in industrial production exceeded $30 \%$. The general state of the economy was reflected in the volume of production and consumption of welding equipment, including welding consumables. The volume of their production decreased by $40 \%$ in the period of 2008-2009.

In the subsequent years, the volume of production of welding consumables began to recover, but the level of 2007 (111.4 thou t) was not reached. In 2013 the volume of production of welding consumables in Ukraine amounted to 80,000 tons, of which $40 \%$ were welding electrodes and $20 \%$ was flux. The production of flux-cored wire in Ukraine amounts to about $1500 \mathrm{t} /$ year. The volumes of export and import amount to about $600 \mathrm{t} /$ year. In Table 7 the data of the Ukrainian Statistics Committee and the E.O. Paton Electric Welding Institute are presented showing the volumes of production, consumption and trade of the main types of welding consumables in Ukraine in 2011-2013 [15].

The consumption of welding consumables in 2011-2013 years reduced by $28 \%$. The major share of import made a solid alloyed wire, and the major share of export made fused fluxes. It should be noted that despite the significant reduction in production and consumption of welding consumables, during already many years Ukraine has a positive trade balance of welding consumables.

\section{Conclusions}

Welding is the basic technology in many branches of industry and construction. The dynamics of the world production and consumption of structural materials allows making a prediction about increase in volume of the world welding production in the nearest future, despite a temporary crisis in economy of some countries and regions, the demand for welding consumables will grow.
The analysis of the world and regional markets of flux-cored wire showed that in the world a sustainable growth in application of mechanized and automatic welding with powder welding and surfacing materials and increase in their production are observed due to putting into operation of the new production capacities to meet the growing demand.

A high efficiency and quality of welds determine the wide application of welding and surfacing technologies using flux-cored wire in different branches of industry of economically developed and a number of developing countries.

The production capacities available in Ukraine allow completely satisfying the domestic needs in flux-cored wire.

1. (2010) Welding products market is set to reach USD 23.78 billion by 2010. http://www.transparencymarketresearch.com

2. (2013) Victor Technology Group, Inc.: Annual report 2013. http://www.victortechnologies.com

3. Welding equipment and supplies: The global market. http://www.bccresearch.com

4. Sudhakar Ruth Sudhakar. Key growtn accelerators for the global welding consumables market. http://www.frost.com

5. (2013) Multiple benefits to underpin appeal of fluxcored wires. Welding and Cutting, 5, 286.

6. (2014) General description for welding consumables. The Japan Welding News for the World, 67, 4-5.

7. (2012) General description for welding consumables market. Ibid., 59, 5-6.

8. Morimoto, T. (2005) Developments in flux-cored wire for gas-shielded arc welding. Kobelco Techn. Rev., 26, 49-53.

9. Rosert, R., Karasyov, M.V. (2012) Flux-cored wires: Tendencies, development and their industrial application. In: Proc. of Int. Sci.-Techn. Conf. on Welding Consumables (St.-Petersburg), 220-230.

10. Chauhan, A. Welding requirements for repairs and maintenance increased adoption of preventive maintenance leads the market for welding. http://www.frost.com

11. Cho Seon Mook (2005) State-of-the-art of welding materials and instrument in Korea. J. JWS, 74(1), 18-19.

12. (2014) Schweissen und Schneiden 2013 - Keingutes Jahr. Schweissen und Schneiden, 66(9), 500-513.

13. Sidlin, Z.A. (2009) Current status of welding consumables production in Russia. The Paton Welding J., 2, 23-25.

14. (2014) UNCOMTRAD. http://comtrade.un.org 15.

15. Economics review of welding production and market of welding equipment of Ukraine in 1990-2013. Kiev: PWI.

Received 13.05.2015 


\title{
CAPABILITIES OF LASER RADIATION FOR IMPROVEMENT OF ELECTRODE WIRE QUALITY
}

\author{
S.B. SHEVCHENKO ${ }^{1}$, I.V. KRIVTSUN ${ }^{1}$, L.F. GOLOVKO ${ }^{1}$, A.N. LUTAJ ${ }^{1}$ and V.P. SLOBODYANYUK ${ }^{2}$ \\ ${ }^{1}$ NTUU «Kiev Polytechnic Institute» \\ 37 Pobeda Ave., 03056, Kiev, Ukraine. E-mail: leongolovko@gmail.com \\ ${ }^{2} \ll$ PlasmaTec» Company \\ 13/300 Khmelnitskoe Shosse, 20136, Vinnitsa, Ukraine
}

\begin{abstract}
Analysis of the processes of manufacturing wire electrodes for semi-automatic welding was performed, structure, quantitative chemical and phase composition of the wire surface layer before and after copper coating deposition were studied, and geometrical dimensions, location depth and relative quantity of nonmetallic inclusions in the coating were determined. Possibilities of removal of such nonmetallic inclusions by laser radiation with $10.6 \mu \mathrm{m}$ wave length were studied at different treatment parameters. Technology of laser cleaning of welding wire surface was proposed, which is performed before copper coating deposition. An experimental laser process complex was developed to verify development results under conditions close to those in production. 10 Ref., 15 Figures.
\end{abstract}

Keywords: welding wire, nonmetallic inclusions, oxides, laser radiation, absorptance, temperature, simulation, heating, evaporation, residual stresses

Semi-automatic wire electrode welding is widely applied in various industries. Steel wire of $0.8-$ $1.6 \mathrm{~mm}$ diameter with electroplated copper coating is the most often used as welding electrode in this case. The welding process and its quality greatly depend on uniformity of chemical composition of surface layer of the steel wire proper and the resulting quality of the copper coating.

In this connection, the steel wire surface is cleaned by various methods before the copper coating deposition: cleaning from rust and lubrication by metal brushes simultaneously with row winding [1], mechanical cleaning by drawing it through a strand of one or several turns of welding wire proper (loop in the form of figure-ofweight) [2]. The most acceptable is the process of cleaning by repeated drawing through dies, but it significantly increases the wire manufacturing cost - by more than 2 times [1,3]. Moreover, mechanical cleaning leads to instantaneous corrosion of the cleaned surface, higher wear of the guides and tip of the welding machine.

Chemical cleaning also causes corrosion of both the wire proper, and equipment parts contacting it. Used for these purpose is the method of electrolyte-discharge cleaning, which includes cathode processing of welding wire in electrolyte - water solution of sodium chloride or carbonate [4].

During welding wire drawing, dry lubricant based on fatty acid salts is used. Presence of remains of process lubricant on the wire violates the electric contact, leading to arc interruption and welding quality deterioration.

Ultrasound application for welding wire cleaning from remains of process lubrication is known [5]. At wire passing through ultrasonic cleaning bath, the remains of process lubrication and contamination are softened, and washed off by the cleaning solution. At selection of the cleaning solution it should be taken into account that the cleaning media should have high chemical activity, and should effectively loosen, break up or dissolve the remaining contamination. Moreover, ultrasonic cleaning at treatment in liquid media gives rise to cavitation phenomenon, namely collapse of gas bubbles, forming at fluid compression and expansion. Cavitation is accompanied by generation of high dynamic hydrostatic pressures, which tear off the contamination particles sticking to the metal surface. The degree of ultrasonic cleaning of welding wire from remains of process lubrication is influenced by cleaner type, its concentration and temperature and drawing speed. Drawing speed has an important influence directly on the quality of ultrasonic cleaning. At application of one and the same cleaner and the same concentrations and temperatures of working solution, the results of wire cleaning will be different at different speeds - remaining amount of process lubrication will, nonetheless, be the smaller, the lower the wire drawing speed (we are talking about drawing speeds of $2-3 \mathrm{~m} / \mathrm{s}$ ). 
Application of cleaned wire in modern welding equipment allows avoiding violation of electric contact during welding, and, therefore, arc interruption, improving its stability, and reducing the influence of other factors impairing the weld quality.

The above data are indicative of the fact that a whole number of different cleaning methods has been developed so far for welding wire cleaning from various contamination, allowing an only partial reduction of electrode material spattering in welding, but not solving the whole problem.

The problem of improvement of welding wire quality can be solved in several ways: improvement of high-quality copper coating deposition technology, significant reduction of wire surface roughness through application of various kinds of polishing operations, and development of new methods of high-efficient protective coating deposition.

Expensive copper-coated welding wire is mostly used now. The main purpose of the copper coating consists in ensuring good electric contact at supplying welding current to the wire. In terms of ecology, however, application of copper coating on welding wire leads to hazardous contamination of production facilities and environment. Moreover, weld quality is impaired at coppercoated wire application.

As an alternative to copper coating, the leading world manufacturers have mastered production of wire with ground and polished surface. Its cost is $5-8 \%$ higher than that of copper-coated wire. The disadvantage of polished wire is its intensive corrosion in humid air atmosphere.

Plasma-arc and spark methods of surface treatment have been developed. Plasma-arc method allows performing non-polluting, high-quality and comparatively inexpensive cleaning and degassing of welding wire. Its thermovacuum treatment is performed at the same time that even further improves welding quality. The cost of plasma-arc cleaning of welding wire is essentially lower than that of acid or arc cleaning.

Spark method of metal surface cleaning seems promising. This method also is non-polluting and cost-effective.

Analysis of various methods and devices for cleaning the welding wire surface before copper coating deposition, given in [6], showed certain prospects for application of laser treatment of the surface for these purposes that is exactly the objective of this study.

Welding wire, produced by cold drawing of hot-rolled billet from Sv-08G2S steel has become the most widely applied in gas-shielded mechanized welding [7]. The final operation of welding wire manufacturing (before its winding onto cassettes) is deposition of copper coating of thickness $h=0.15-0.60 \mu \mathrm{m}$. The lower thickness limit is determined by formation of a discontinuous (islet) layer, and the upper one - by impact toughness lowering and initiation of solidification cracks at exceeding the limit concentration of copper in welds.

The purpose of copper coating is to protect the welding wire from corrosion in shielding gas atmosphere, lowering the contact resistance of «electrode wire-current-conducing tip» pair, improving the conditions of initial arc excitation and reducing the wear of working channel of copper current-carrying tip.

The abovementioned functional characteristics of copper coating are determined by the degree of layer uniformity and its adhesion. The latter is particularly important at application of various feeding mechanisms in welding, the operation of which largely depends on copper coating adhesion, which, in its turn, determines the arcing stability [8].

PWI studied the copper coating on welding wire, produced by the method of electrolytic deposition in copper sulphate solution [8]. It is found that immediately after deposition the copper layer had considerable concentration of pores and microcracks. Coating deformation in the die with application of lubricant, which was supposed to cover the defects, did not improve the layer quality.

In this connection, at the first stage of this work it is necessary to perform detailed analysis of copper coating defects, reveal the causes for and mechanisms of their formation and develop on this base a highly effective method and equipment for an essential improvement of welding wire quality.

Materials and experimental procedure. Three object types were studied: $1 \mathrm{~mm}$ copper-coated wire after drawing in the last die; 1 and $3 \mathrm{~mm}$ uncoated wire directly after drawing; and $1 \mathrm{~mm}$ wire after polishing.

Investigations were performed in MIM-8 metallographic microscope with application of WEB-camera with 3 Mpix resolution. To detect nonmetallic inclusions, polarized light was used in addition to white light. It is known that in the above-mentioned light nonmetallic inclusions can be seen on micrographs as light regions against a dark background. Two types of surfaces were analyzed - microsection surfaces and wire surfaces without any preparation. Microsections were prepared in the plane, normal to the wire axis, and in the planes forming approximately 


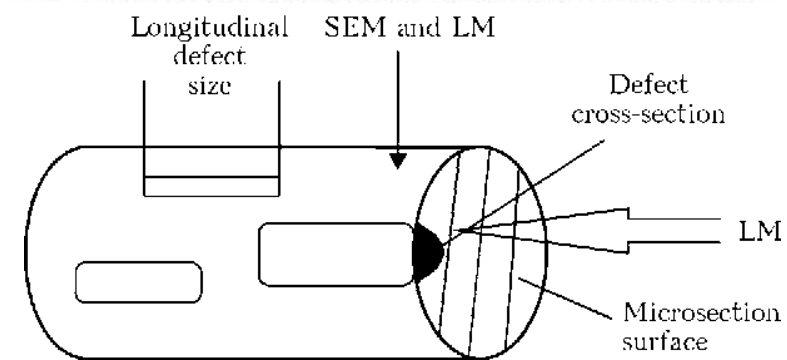

Figure 1. Schematic of object filming

$30^{\circ}$ angle (angle lap) with the axis. $4 \% \mathrm{HNO}_{3}$ solution in alcohol was used as etchant.

Cylindrical surfaces were studied in scanning electron microscope (SEM) in reflected and secondary electrons. In some points (electron probe diameter of approximately $50 \mathrm{~nm}$ ) X-ray spectral probe microanalysis (RSPMA) was used to perform complete chemical analysis. Micrographs were analyzed by the procedure described in [9].

Figure 1 shows the schematic of taking micrographs at examination by light microscopy (LM) and SEM methods.

Investigation results and their discussion. Figure 2 gives micrographs of copper coating surface, taken by LM method. The coating is nonuniform - regions, not having the colour characteristic for copper, are observed.

The low depth of resolution of light microscope does not allow a more detailed description of the observed layer defects. Electron micrographs of different coating regions (Figure 3 ) show a large quantity of surface defects of an elongated shape with the long axis coinciding with the direction of

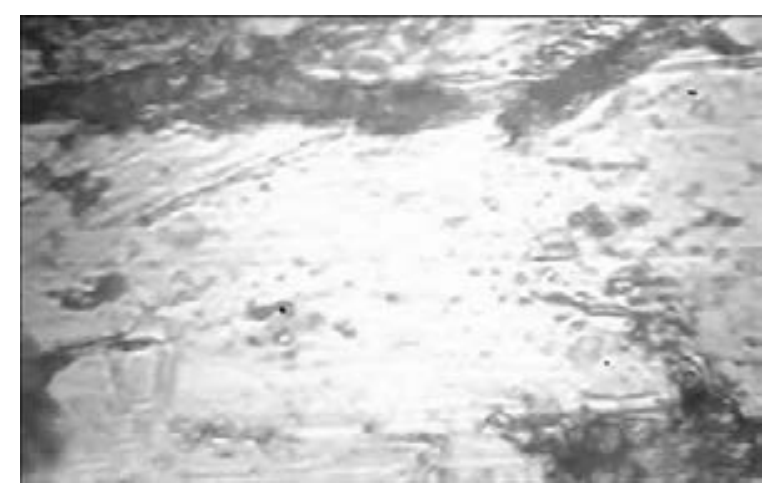

Figure 2. Micrograph $(\times 2000)$ of copper coating surface (LM)

wire drawing through the die. An essential difference in the contrast of micrographs taken in the secondary (Figure 3, $a, c$ ) and reflected electrons (Figure $3, b, d$ ) is attributable to the following features of the above procedures. At filming in reflected electrons a method of electron recording, minimizing the contrast topographic component, was realized. Thus, the composition (phase) contrast prevails in the above micrographs: micrograph brightest regions correspond to sample regions enriched in heavier elements (with greater atomic mass).

Therefore, the extensive light regions in $\mathrm{Fi}^{-}$ gure $3, b, d$ are the copper zones or steel surface. It is impossible to determine which regions correspond to copper or to iron, based on just the difference in contrast, because of the closeness of atomic masses of the above elements. Spots and grey film on the micrographs in Figure 3, $a$, $b$ are the remains of process lubricant used in
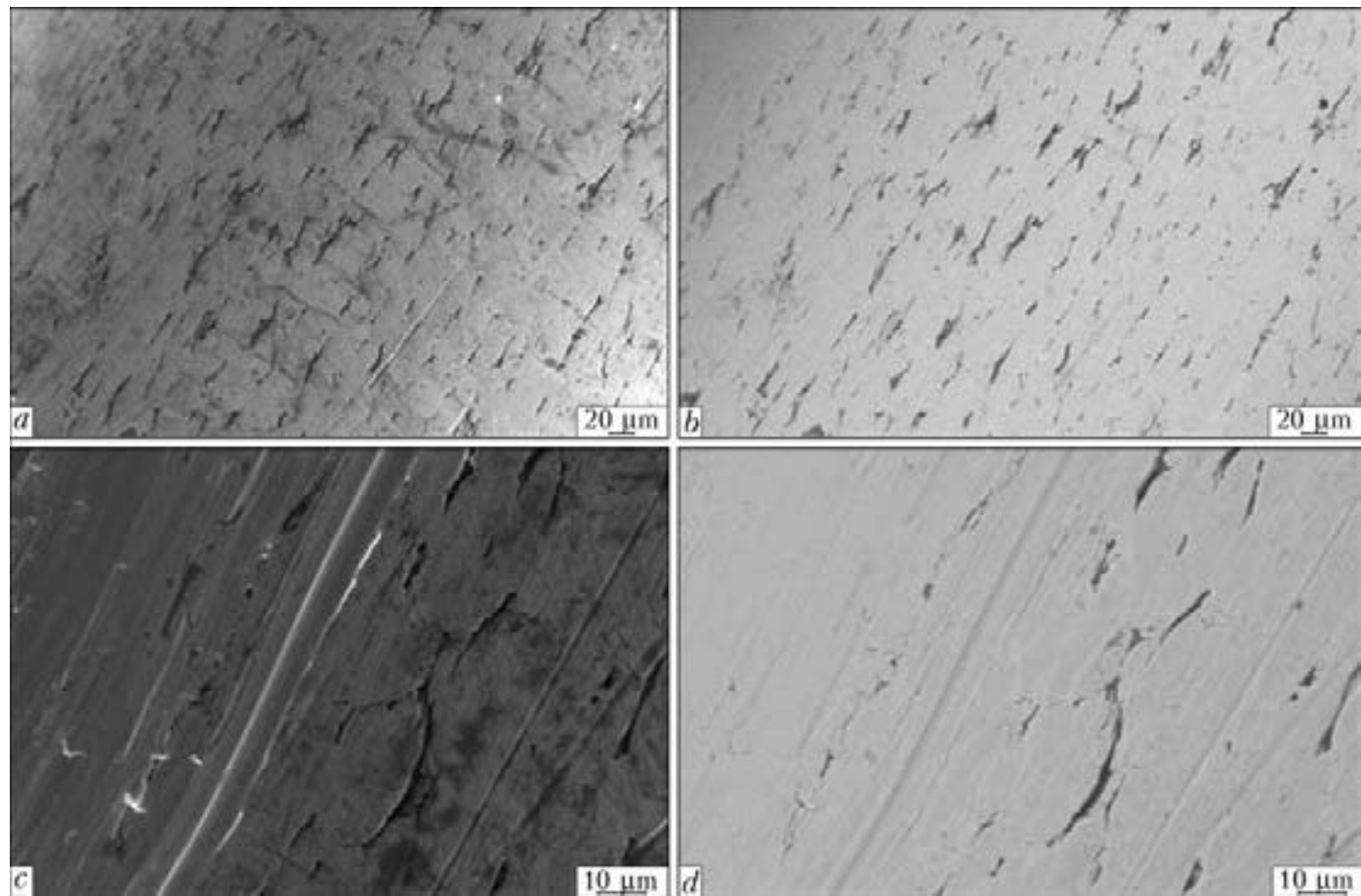

Figure 3. Electron micrographs of different sections of the copper coating: $a, c-$ in secondary; $b, d-$ in reflected electrons $(a, b-\times 500 ; c, d-\times 2000)$ 


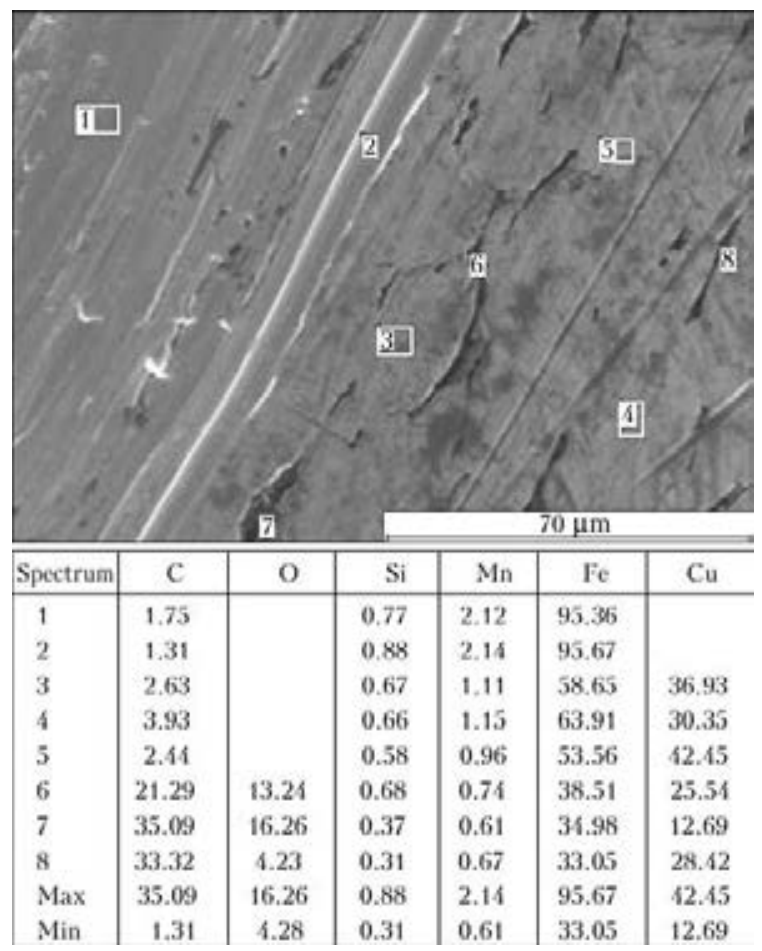

Figure 4. Results of X-ray spectral microprobe analysis of the composition of sections marked in the micrograph

drawing. RSPMA results of the composition of various regions of the sample (Figure 4) allow stating that a large part of volume defects are iron oxides, coated by a thin copper layer. $\mathrm{Fi}^{-}$ gure 5 gives a more visual representation of RSPMA results, from which it follows that the sample surface consists of two zones: region without coating traces taking $38 \%$ of the entire surface area, and coating region with coarse inclusions of iron oxides. Coating absence over a substantial surface area, in our opinion, is related to poor quality of wire surface treatment before coating deposition (incomplete removal of the lubricant, insufficient degreasing, etc.).

Weak adhesion of the coating in such regions leads to its removal (stripping off) during passage through the dies.

Let us analyze the possible causes for and mechanisms of iron oxide appearance in the wire surface layer. The first is that a hot-rolled billet has scale on its surface, which is pressed into the steel during drawing.

Phase composition of scale on rod wire from Sv-08G2S steel and methods to remove it were studied in [10]. It is shown that the oxide is removed completely, if mechanical removal of scale is performed at the temperature of wustite ( $\mathrm{FeO}$ ) existence, i.e. at $~ 950{ }^{\circ} \mathrm{C}$. This is exactly the technology of scale removal that was realized in the objects of this study. Considering the high drawing speed $(\sim 12 \mathrm{~m} / \mathrm{s})$, it can be assumed that the forces of friction in the point of billet contact with the tool result in heating up to high temperatures, that leads to wire surface oxidation.

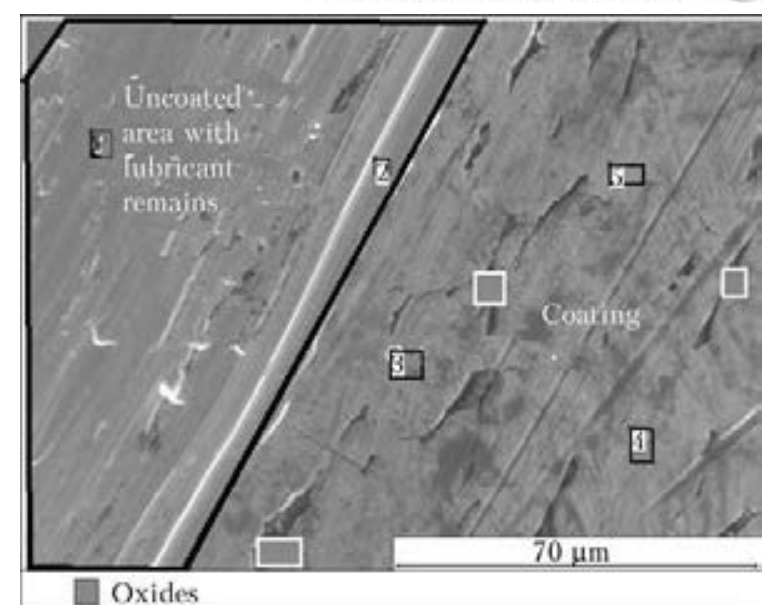

Figure 5. Electron micrograph of copper coating

Metallographic examination of transverse microsections confirmed that defects have considerable dimensions. Data in Figure 6 give an idea of defect depth and width.

It is clear that oxides of such dimensions could not have formed by the above mechanism. As shown by metallographic analysis of transverse microsections of $3 \mathrm{~mm}$ wire (Figure 7 ), oxides of the above dimensions are present in the steel inner volumes. Therefore, the initial billet contains iron oxides, located at different distance from the surface.

At passing through each die, oxides located near the billet surface become exposed ( $F i-$ gure 8), thus increasing their surface concentration. The suggested defect formation mechanism is confirmed by absence of plastic deformation traces, characteristic for steel drawing, on defect surface. Therefore, the die was in direct contact with the oxide.

Let us note in conclusion that polishing of final diameter wire, while essentially reducing the surface roughness (Figure 9), did not in any way
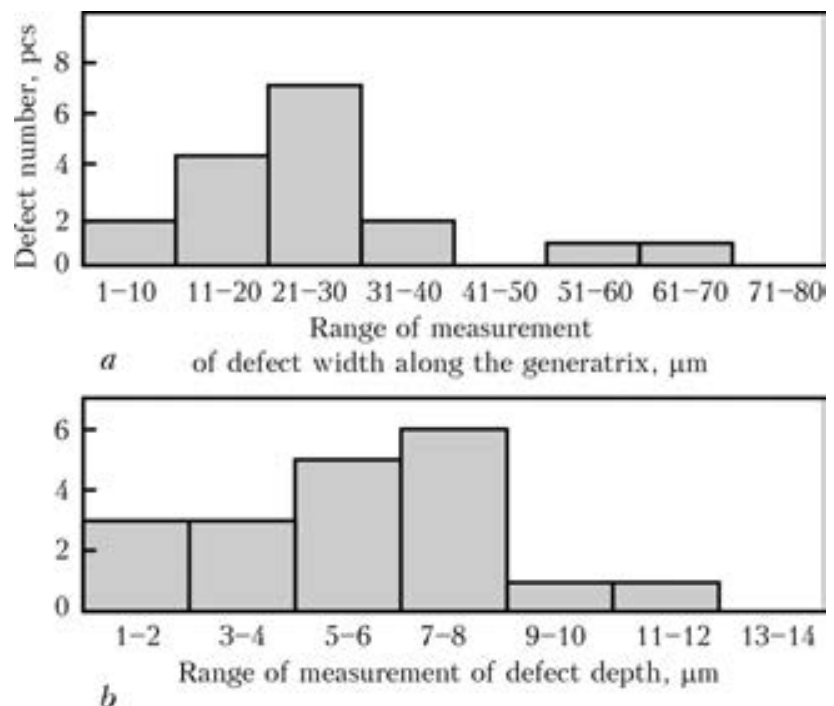

Figure 6. Histogram of linear defect dimensions: $a$ - width; $b$ - depth of surface defects 


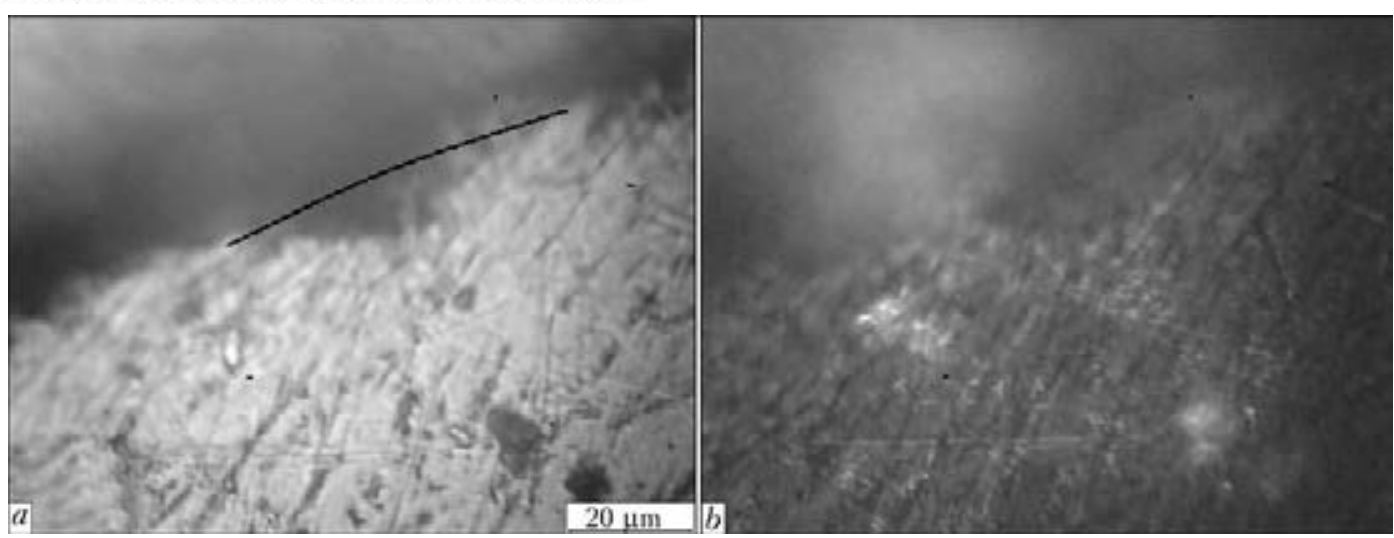

Figure 7. Micrographs of end surface of $3 \mathrm{~mm}$ wire in white $(a)$ and polarized $(b)$ light

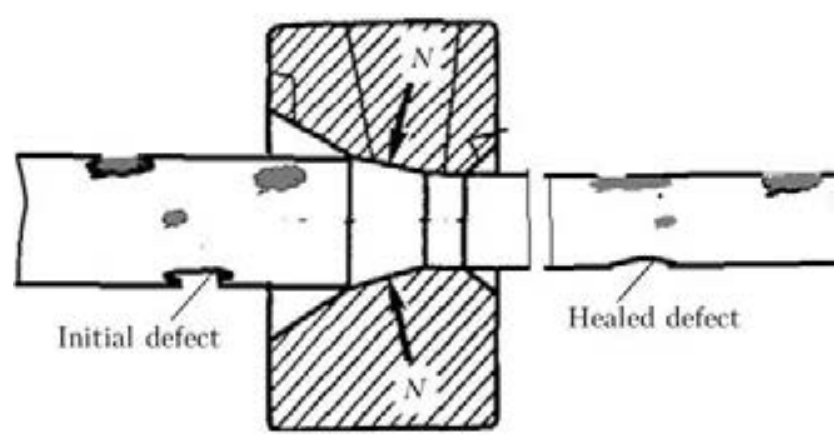

Figure 8. Schematic of defect formation on wire surface at drawing

affect the surface oxide concentration (Figure 10).

Analysis of the results of performed research showed that the copper coating, galvanically deposited on the steel welding wire Sv-08G2S, has a considerable number of defects, which are exactly the cause for metal spattering in welding.
Coating defects are due to two main causes insufficiently well treated surface of the wire before coating deposition, and large quantity of nonmetallic inclusions in its surface layer, their concentration changing in a broad range (from 20 up to $40 \%$ ). Oxide location depth is not more than 20-30 $\mu \mathrm{m}$.

High concentration of iron oxides on the surface of final diameter wire is accounted for by their successive exposure at passing through the dies. Wire polishing does not affect the surface iron oxide concentration.

Development of experimental equipment for laser treatment of welding wire. Experimental investigations related to welding wire treatment by laser radiation, were performed to assess the possibility of removing from its surface layer the nonmetallic inclusions present in it after the last drawing stage.

It is known that infrared radiation with $10.6 \mu \mathrm{m}$ wave length is poorly absorbed by metals
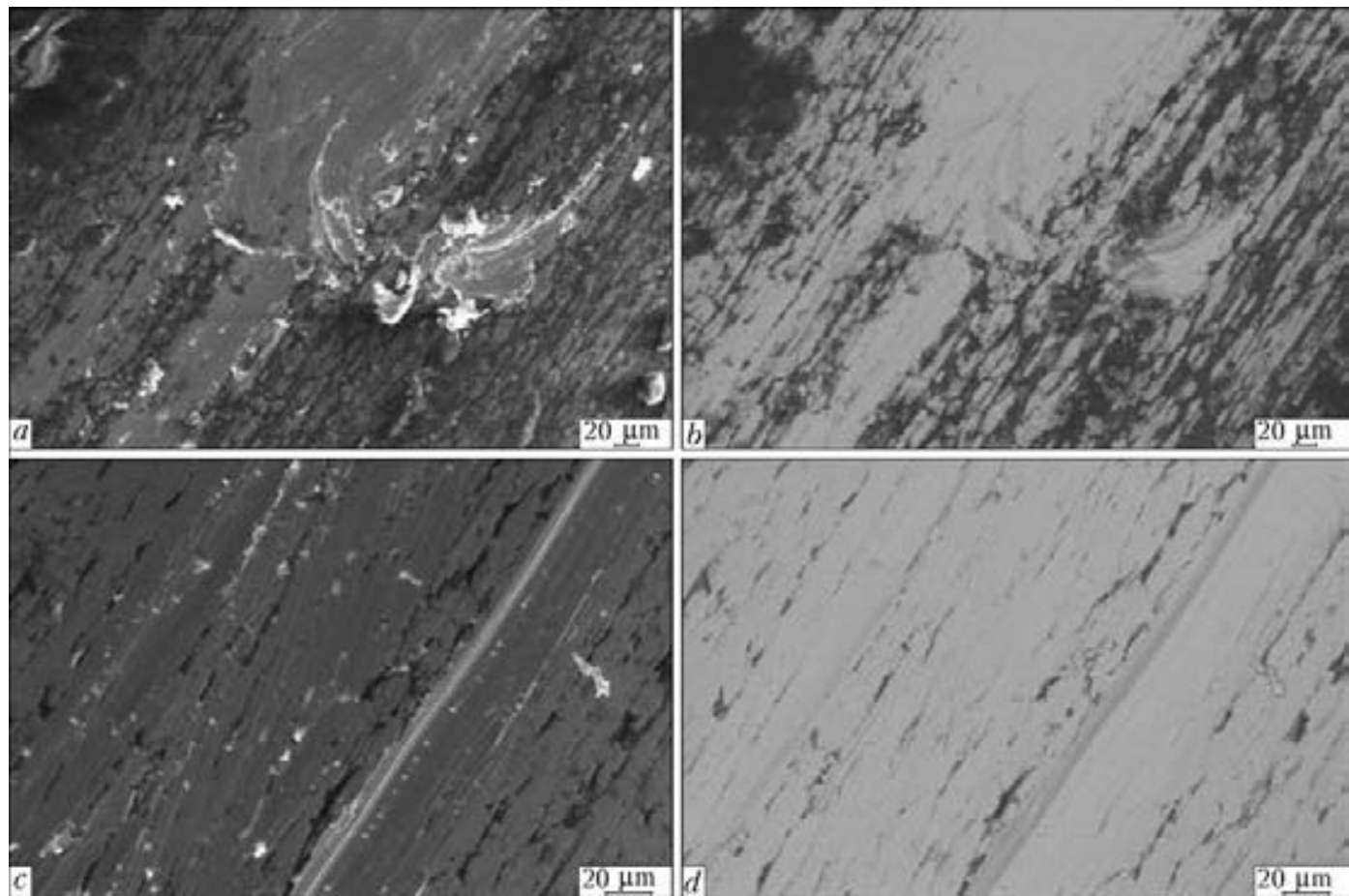

Figure 9. Electron micrographs of $1 \mathrm{~mm}$ wire surface after leaving the die $(a, b)$ and after subsequent polishing $(c, d)$ 
and readily absorbed by dielectrics (oxides). Therefore, for selective removal of oxide inclusions, the welding wire surface was treated by continuous radiation of $\mathrm{CO}_{2}$-laser system «Kometa-2» of $1200 \mathrm{~W}$ output power (Figure 11, $a$ ). Laser radiation with multimode distribution of intensity $\mathrm{TEM}_{20}$ was focused on the moving wire surface by a plane-spherical lens from $\mathrm{KCl}$ with $300 \mathrm{~mm}$ focal distance. Here, the diameter of the laser beam in the treatment plane was equal to $1 \mathrm{~mm}$. Shielding gas (argon) was fed into the zone of laser beam impact. A special device was developed for welding wire orientation and displacement relative to the laser beam, the schematic of which is given in Figure 11, $b$. The device consists of a metal case on four supports 1 , on which electric motor with reduction gear and receiving cassette 2 and mechanism for fixation of the cassette with wire displacement speed sensor 3 are mounted. Wire 4 is forcedly reeled off initial cassette 7 at preset speed, is directed by guide rollers and is fed into the inductor, where its heating up to tempering temperature is performed in inert gas atmosphere to relieve residual stresses. In the next stage, at wire passing through the next two roller pairs 5 , which orient it relative to the axis of the focused laser beam 6 , its irradiation is performed. As a result of selective absorption, oxide inclusions are removed from the wire surface through evaporation. To perform this operation, a system of laser radiation focusing based on torroidal mirror, should be built into the wire drawing machine.

Experimental studies were conducted in a somewhat simplified test facility, the general view of which and of welding wire guiding and rewinding device is shown in Figure 12.

Special brass dies were used for precise basing of wire surface relative to laser beam axis. To prevent oxidation of irradiated surface, shielding gas (argon) was fed into the laser beam impact zone. Special microscope with WEB-camera con-

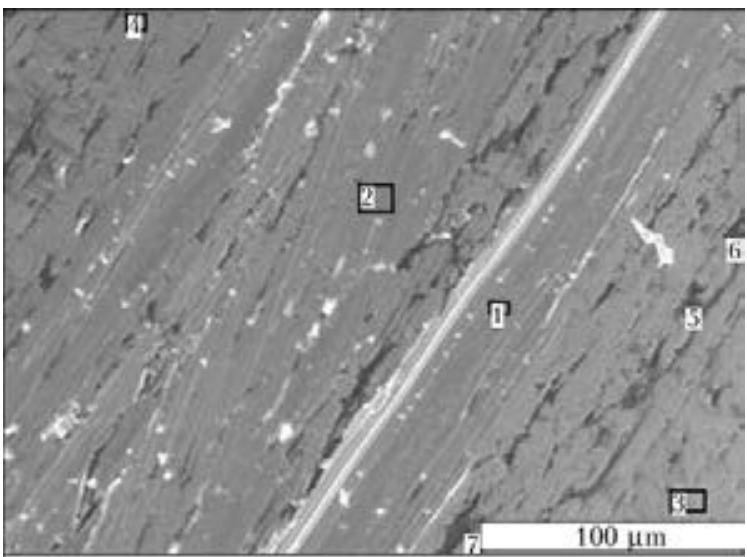

Element content in polished wire spectra, wt.\%

\begin{tabular}{l|c|c|c|c|c|c|c}
\hline Spectrum & $\mathrm{C}$ & $\mathrm{O}$ & $\mathrm{Na}$ & $\mathrm{Si}$ & $\mathrm{Ca}$ & $\mathrm{Mn}$ & $\mathrm{Fe}$ \\
\hline 1 & 1.40 & & & 0.80 & & 2.29 & 95.52 \\
2 & & & & 1.15 & & 1.99 & 96.86 \\
3 & 4.93 & & & 1.19 & & 1.80 & 92.08 \\
4 & 1.66 & & & 0.76 & & 1.85 & 95.73 \\
5 & 51.89 & 9.75 & 0.51 & 0.47 & 1.86 & 0.75 & 34.77 \\
6 & 48.07 & 8.43 & 0.36 & 0.47 & 1.33 & 0.72 & 40.62 \\
7 & 37.59 & 5.41 & 0.43 & 0.27 & 0.78 & 0.99 & 34.32 \\
Max & 51.89 & 9.75 & 0.51 & 1.19 & 1.86 & 2.29 & 96.86 \\
Min & 1.40 & 5.41 & 0.36 & 0.27 & 0.78 & 0.72 & 34.77
\end{tabular}

Figure 10. RSPMA results for $1 \mathrm{~mm}$ wire after polishing

nected to a computer, providing from 25- to 100fold magnification, was used for observation of laser treatment process. Laser radiation power was adjusted within 700 to $1200 \mathrm{~W}$. During laser treatment, the wire was rewound from passive spool onto drive spool. Speed of wire displacement relative to laser beam was varied in the range of 1.5 to $3.5 \mathrm{~m} / \mathrm{min}$.

Two samples of $1.2 \mathrm{~mm}$ welding wire each $10 \mathrm{~m}$ long were subjected to laser treatment. One sample was subjected to laser treatment from one side only, and the other was treated from two opposite sides. First one side was treated, then the wire was turned through $180^{\circ}$, and the other side was irradiated.

During laser treatment enhanced brightness flashes were continuously pulsing over the irra-
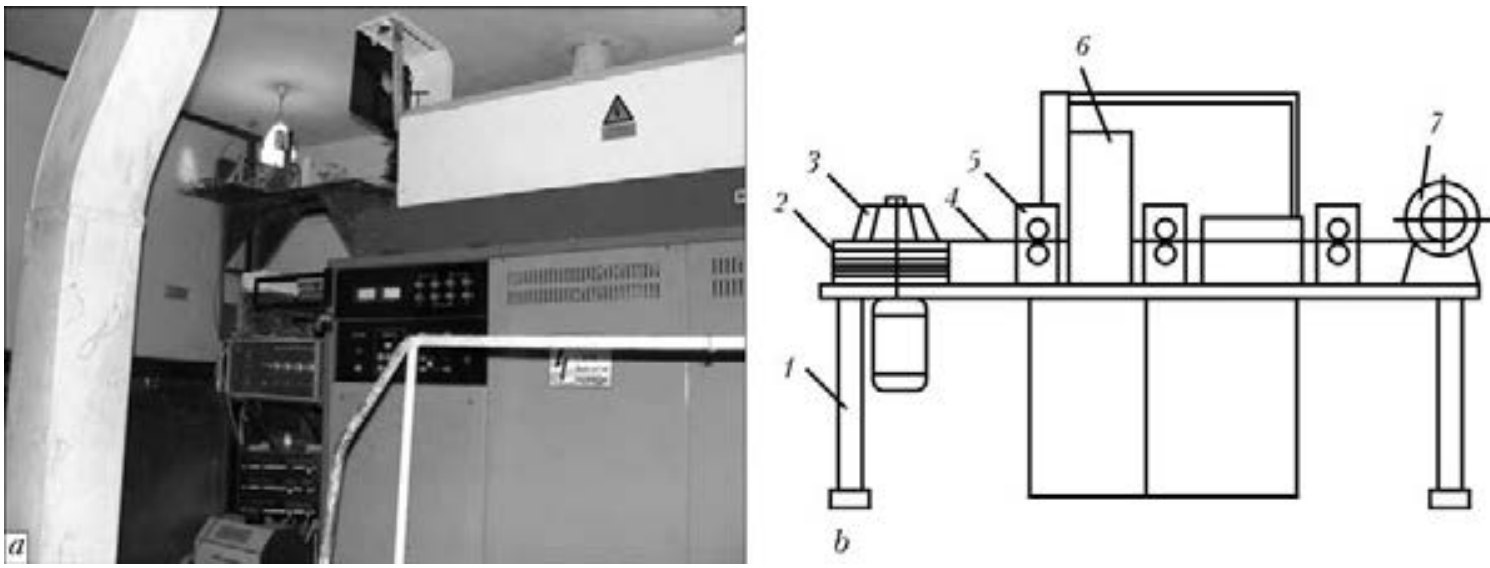

$b$

Figure 11. «Kometa-2» laser system $(a)$, and diagram of the device for welding wire guiding and rewinding relative to the laser beam $(b)$ (for designations see the text) 


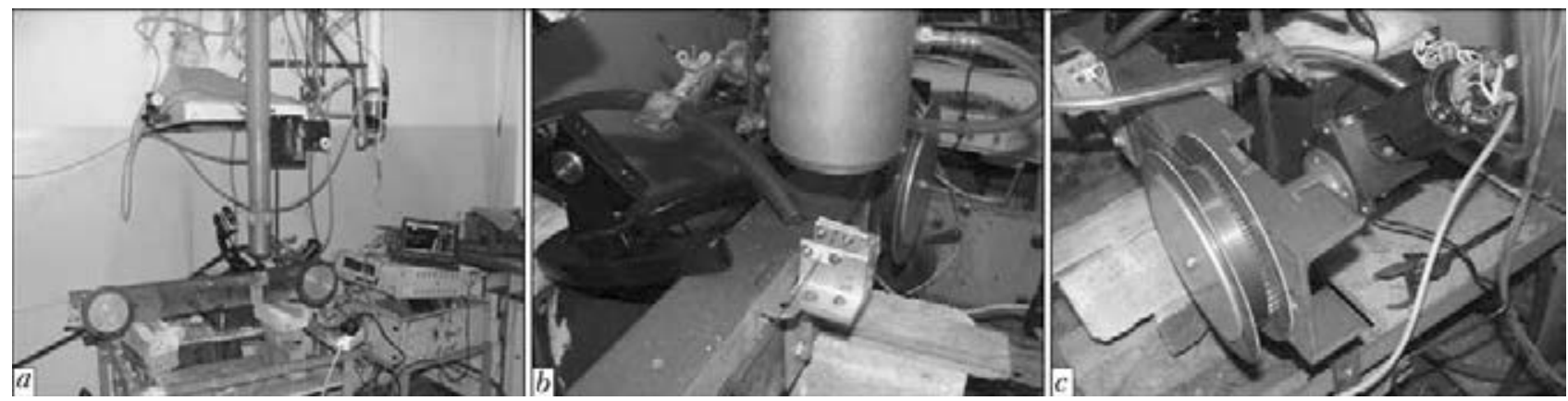

Figure 12. General view of the system $(a)$ and its individual devices designed for guiding $(b)$ and rewinding $(c)$ of welding wire at its surface treatment by $\mathrm{CO}_{2}$-laser radiation

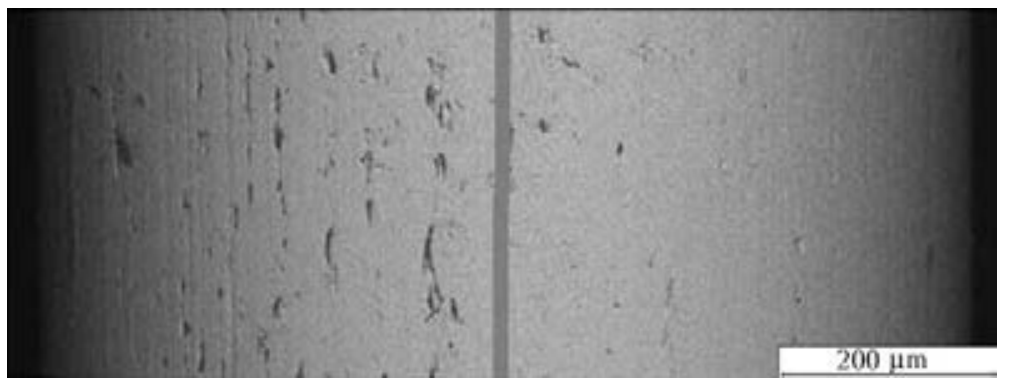

Figure 13. Electron micrograph of copper coating surface on the wire treated (right side) and untreated (left) by laser radiation

diated wire surface that is, probably, due to oxide evaporation.

After laser treatment samples were cut out from two wire types and were studied by the methods of light and scanning electron microscopy. Copper coating was applied onto the main part of two wire samples under production conditions.

Results of examination of the quality of copper coating on welding wire pretreated by laser. Figure 13 gives the electron micrograph of coating surface, including the zone treated by laser radiation, and zone not subjected to laser treatment. It is seen that laser pre-treatment of wire surface leads to formation of coating with much

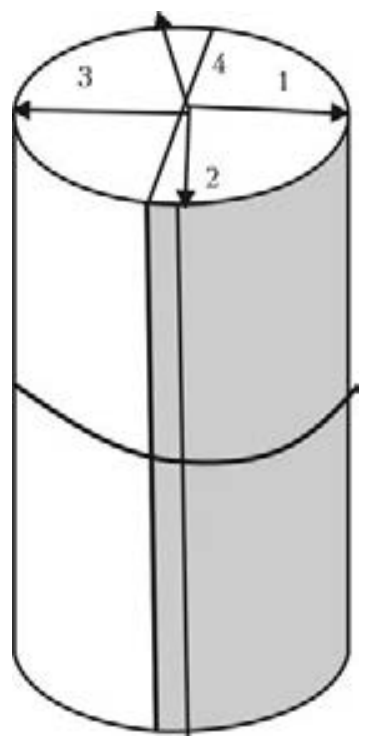

Figure 14. Schematic of defect location relative to the center of treated $(1$, gray $)$ and untreated $(3$, white) surface (for designations see the text) smaller number of defects. Their presence near the boundary line (see gray band in Figure 13, and zone 2 in Figure 14) on the treated side is attributable to non-uniform distribution of radiation power density over the wire cylindrical surface. The central part of its irradiated zone 1 (Figure 14) has practically no such inclusions. Such non-uniformity of inclusion distribution is readily removed by application of a laser beam with torroidal distribution of intensity.

Analyzing these results, it is rational to clarify the nature of defects in the treated zone, whether they contain oxide remains and whether there is coating on defects in both zones.

RSPMA of defects was performed to provide replies to the above questions. The object was revolving about the wire axis and after rotation through an angle of $\sim 90^{\circ}$, defect micrograph was taken and its composition was determined. Schematic of defect location on the wire is given in Figure 14, and their electron micrographs and element content are given in Figure 15. Results obtained in zone 4 are equivalent to zone 3 .

Examination of defects seldom found in the center of treated wire surface (Figure 15, $a$ ) showed that they contain a small amount of iron oxides, on the surface of which copper layer was deposited. Laser treatment of the wire peripheral surface by lower-intensity radiation leads to a certain increase of defect concentration and of oxide content level (Figure 15, b). In wire sections, not subjected to laser treatment, defect concentration was by an order of magnitude higher than in the center of irradiated surface. Oxide quantity in it changes in a very broad 

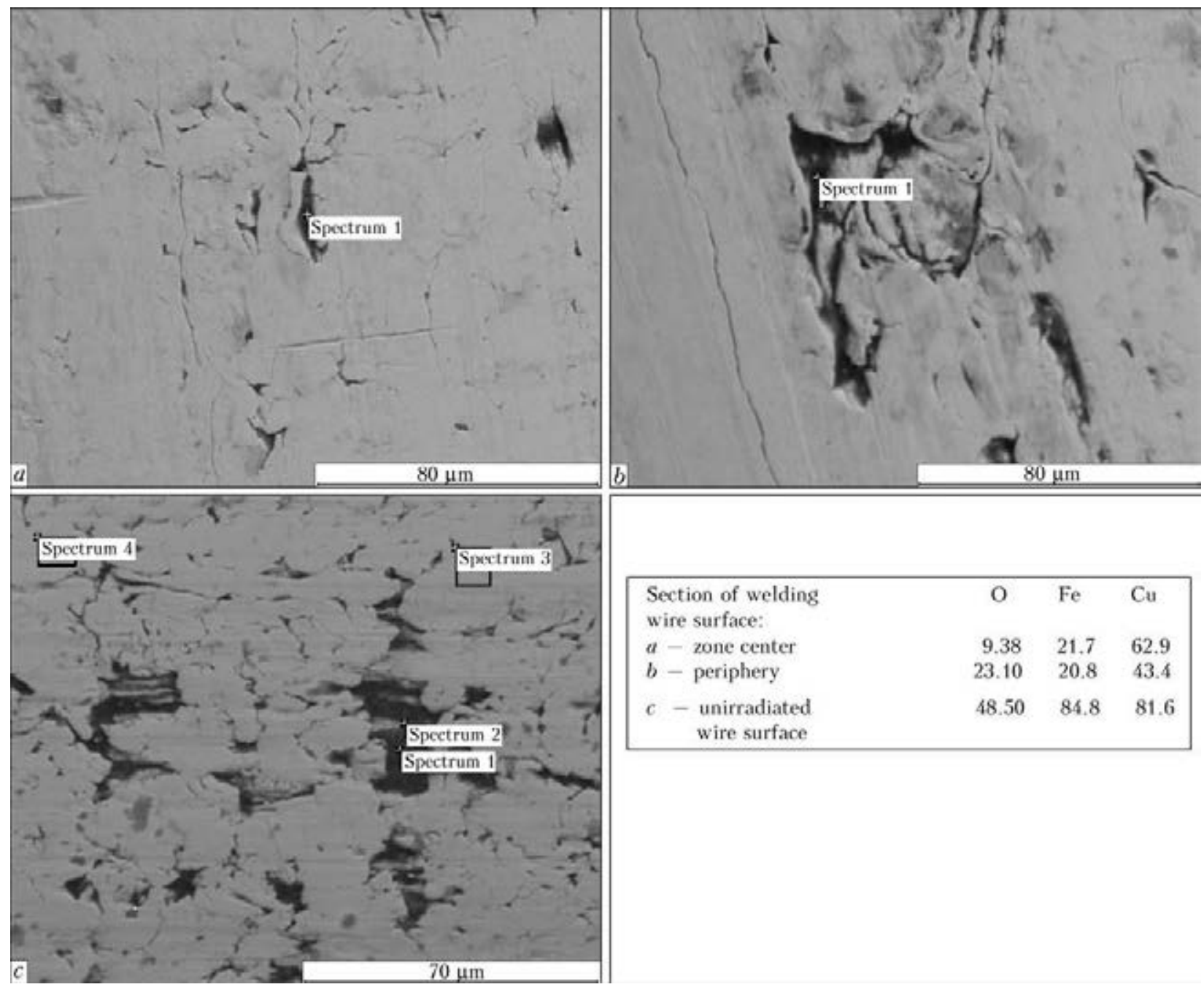

Figure 15. Electron micrographs of defects in zone 1 (center of wire irradiated surface) (a), in zone 2 (peripheral part of the zone) $(b)$ and in zone 3 (unirradiated surface) $(c)$

range (from 2 up to $48.55 \%$ ). Here, copper coating is practically absent in the majority of wire sections containing oxides. At two-sided laser treatment the number of wire sections with oxides, and, hence, without the copper coating, is essentially smaller. They, however, are present on the side surfaces.

\section{Conclusions}

1. Laser treatment of welding wire by continuous radiation with $10.6 \mu \mathrm{m}$ wave length significantly reduces the quantity of oxides in surface defects.

2. Volumes freed from oxides on welding wire surface are filled with copper at subsequent coating deposition.

3. Mechanism of oxide removal consists in a marked increase of their volume as a result of high-rate laser heating.

4. For uniform removal of oxides from the entire cylindrical surface of wire, it is rational to focus the laser radiation using a torroidal mirror.

1. Sychkov, A.B., Zhigarev, M.A., Zhukova, S.Yu. et al. (2008) Formation of optimal properties of scale on rolled wire surface. Bendery: Poligrafist.
2. Parusov, V.V., Sanyuk, A.N., Syckhov, A.B. (2004) Study of possibility of more complete removal of scale from rolled wire surface before drawing. Metallurg, 6, 6-28.

3. Parusov, V.V., Sychkov, A.B., Zhigarev, M.A. (2006) Study of possibility to remove the scale from the surface of rolled wire from Sv-08G2S steel. $M e^{-}$ tallurgich. $i$ Gornorudn. Promyshlennost, 5, 23-29.

4. Kozlov, E.I., Dekhtyaryov, V.G., Novikov, M.P. (1981) Electrochemical cleaning of Sv-08G2S wire surface. Avtomatich. Svarka, 9, 46-48.

5. Dalsky, A.M., Barsukova, T.M., Bukharkin, L.N. et al. (2004) Technology of structural materials: Manual for higher educational institution students of machine-building specialities. 5th ed. Moscow: Mashinostroenie.

6. (2002) Methods of manufacturing copper-coated welding wire. Svarochn. Proizvodstvo, 3, 41-43.

7. Medyushko, V.A., Razorenov, O.N. (2007) Some peculiarities of metallurgical processing and application of Sv-08G2S type wire in mechanized welding processes. Industriya, 32(5), 21-23.

8. www.spetechsoyuz.com. Technological properties of welding wire

9. Brandon, D., Kaplan, W. (2004) Microstructure of materials. Methods of examination and control. Moscow: Tekhnosfera.

10. Sychkov, A.B., Zhigarev, M.A., Zhukova, S.Yu. (2007) Ensuring scale removal from rolled wire surface before drawing. Metizy, 15(2), 48-54. 


\title{
STRUCTURE AND ABRASIVE WEAR RESISTANCE OF DEPOSITED METAL HARDENED WITH CARBIDES OF DIFFERENT TYPES
}

\author{
I.A. RYABTSEV ${ }^{1}$, A.I. PANFILOV ${ }^{2}$, A.A. BABINETS ${ }^{1}$, I.I. RYABTSEV ${ }^{1}$, \\ G.N. GORDAN ${ }^{1}$ and I.L. BABIJCHUK ${ }^{1}$ \\ ${ }^{1}$ E.O. Paton Electric Welding Institute, NASU \\ 11 Bozhenko Str., 03680, Kiev, Ukraine. E-mail: office@paton.kiev.ua

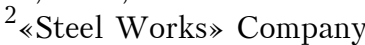

50 Mir Ave., of. 32, 50069, Krivoj Rog, Dnepropetrovsk Distr., Ukraine. E-mail: ogs@steel-work.net

\begin{abstract}
Wear resistance was studied at wearing by fixed and unfixed abrasive of metal deposited with PP-AN192 flux-cored wire (strengthened by titanium carbides) and by Hardface HC-O flux-cored wire (strengthened by chromium carbides). It is found that both the deposited metal types, despite the different total content of alloying elements (30\% for Hardface HC-O and $10 \%$ for PP-AN192), have approximately the same wear resistance. Structure of deposited metal of both the types consists of martensite, small quantity of residual austenite and carbides of different composition. Here, the high wear resistance of metal deposited with PP-AN192 flux-cored wire is attributable to the fact that titanium carbide contained in it is greatly superior in terms of hardness and wear resistance to chromium carbides, hardening the metal deposited with Hardface HC-O flux-cored wire. 10 Ref., 4 Tables, 6 Figures.
\end{abstract}

Ke y words: deposited metal, flux-cored wires, abra sive wear, wear resistance, microstructure, carbides

Strong carbide formers, namely chromium, titanium, vanadium, tungsten, etc., are used as the main alloying elements in surfacing materials, which are applied for reconditioning and hardening of parts exposed to different kinds of intensive abrasive wear in service [1-7]. They form hard phases such as carbides, carbonitrides, carboborides, etc. in the deposited metal structure. Being the hardest component of deposited metal, these phases largely determine its wear resistance [1-4]. Table 1 gives the composition, crystalline structure and some properties of carbides of above-mentioned metals [8].
Carbides can be primary or secondary, and can also form various carbide (boride) eutectics. These carbide precipitates solidify at different temperatures and are differently arranged in the deposited metal matrix, consisting of austenite and products of its transformation at cooling. Nature of forming carbides and their arrangement in the structure, in their turn, depend on deposited metal composition, as well as temperature of weld pool melt overheating and its cooling conditions. Carbide arrangement and their precipitate shape have a marked influence on material properties: their wear resistance, hardness and impact resistance.

At other equal conditions, the higher the carbide hardness, the higher the deposited metal

Table 1. Properties of carbides of the main carbide-forming metals [8]

\begin{tabular}{||c|l|c|c|c||}
\hline \hline Carbide & \multicolumn{1}{|c|}{ Crystalline lattice type } & Microhardness, $\mathrm{MPa}$ & Density, $\mathrm{g} / \mathrm{cm}^{3}$ & Melting temperature, ${ }^{\circ} \mathrm{C}$ \\
\hline $\mathrm{Fe}_{3} \mathrm{C}$ & Rhombic (orthorhombic) & $8400-8600$ & 7.62 & 1650 \\
\hline $\mathrm{Cr}_{3} \mathrm{C}_{2}$ & Orthorhombic & 22800 & 6.68 & 1895 \\
\hline $\mathrm{Cr}_{7} \mathrm{C}_{3}$ & Hexagonal (trigonal) & 22000 & 6.90 & 1780 \\
\hline $\mathrm{Cr}_{23} \mathrm{C}_{6}$ & Complex cubic & 16500 & 7 & 1520 \\
\hline $\mathrm{W}_{2} \mathrm{C}$ & Hexagonal & 30000 & 17.15 & 2850 \\
\hline $\mathrm{WC}$ & Hexagonal & 17000 & 15.70 & 2600 \\
\hline $\mathrm{VC}$ & FCC & 27000 & 5.36 & 2830 \\
\hline $\mathrm{TiC}$ & FCC & 32000 & 4.93 & 3100 \\
\hline $\mathrm{NbC}$ & FCC & 24000 & 7.78 & 3490 \\
\hline
\end{tabular}


Table 2. Deposited metal composition (wt.\%) and hardness

\begin{tabular}{|l|c|c|c|c|c|c||}
\hline \multicolumn{1}{|c|}{ Flux-cored wire } & $\mathrm{C}$ & $\mathrm{Mn}$ & $\mathrm{Si}$ & $\mathrm{Cr}$ & $\mathrm{Ti}$ & Mardness HRC \\
\hline Hardface HC-O & 3.60 & 1.32 & 1.47 & 25.90 & - & 0.30 \\
\hline PP-AN192 & 1.43 & 0.65 & 0.72 & 4.62 & 3.42 & 0.47 \\
\hline
\end{tabular}

wear resistance. If one and the same element forms several types of carbides, differing in their composition, hardness and crystalline structure, the properties of metal deposited with these carbides will differ.

Here, it is necessary to take into account the fact that surfacing materials are, as a rule, alloyed by several elements, leading to formation in the deposited metal of carbides, in which the main carbide former is substituted by other elements that may affect the forming carbide properties.

Structural condition of deposited metal matrix has a strong influence on its wear resistance. On the one hand, it should readily retain the hard phase particles, and should prevent their spalling during wearing. On the other hand, the matrix proper should have sufficiently high hardness and good wear resistance. Experience shows that highalloyed martensite-austenite matrix gives better results at intensive abrasive wear [1, 3, 7, 9].

Residual austenite content in the deposited metal structure depends on the intensity of shock loads which accompany wearing. Here, the higher the shock load intensity, the greater the quantity of residual austenite that should be present in the deposited metal structure, providing sufficient toughness and ductility to the latter [1]. By some data [9], carbides are more readily retained by the alloy matrix, if a coherent bond or strong conjugation develops between the carbide and matrix crystalline lattices on carbidematrix interface [10].

Thus, such a quantity of alloying elements and carbon should be added to the surfacing material, which ensures producing a strong and sufficiently ductile matrix of the deposited metal and the required content of the hard phase (carbides, carbonitrides, carboborides, etc.) in the latter.

In view of the above, the objective was set to evaluate the influence of structure and carbides of different type on deposited metal wear resistance at abrasive wear with fixed and unfixed abrasive.

Wear resistance and structure of two types of deposited metal designed for service under abrasive wear conditions was studied and compared. One was hardened with chromium carbides, the other - with titanium carbides and carboni- trides. Sample surfacing was performed with selfshielded flux-cored wires Hardface $\mathrm{HC}-\mathrm{O}$ of $1.6 \mathrm{~mm}$ diameter produced by Welding Alloys, and PP-AN192 of $2.0 \mathrm{~mm}$ diameter produced by PWI. Table 2 gives the deposited metal composition and hardness. As is seen from the Table, the total content of alloying elements in the metal deposited with Hardface $\mathrm{HC}-\mathrm{O}$ wire exceeds $30 \%$, and in the metal deposited with PP-AN192 wire it is on the level of $10 \%$.

To study the wear resistance, the above fluxcored wire grades were used to perform singleand two-layer surfacing of blanks from steel St3, from which $50 \times 50 \times 10 \mathrm{~mm}$ samples were cut out, in which the deposited surface was polished. Wear resistance studies were conducted by two procedures: at friction of surfaced samples on unfixed abrasive to GOST 23.208-79 and, for comparison, at friction on fixed abrasive.

During testing at friction on unfixed abrasive, sample 4 is pressed against rotating rubber disc 1 with its deposited surface with force $P$ ( Figure 1). Quartz sand 5 is fed onto rubber disc 1 from hopper 6 . At rotation the rubber disc entraps the sand which leads to wear of sample 4.

Quartz sand was dried before testing, resulting in its not more than $0.16 \%$ humidity. To remove sand particles embedded into the rubber disc, it was treated with sandpaper (Type 2 to GOST 6456-75) with \#8P grit (DSTU 3647-71)

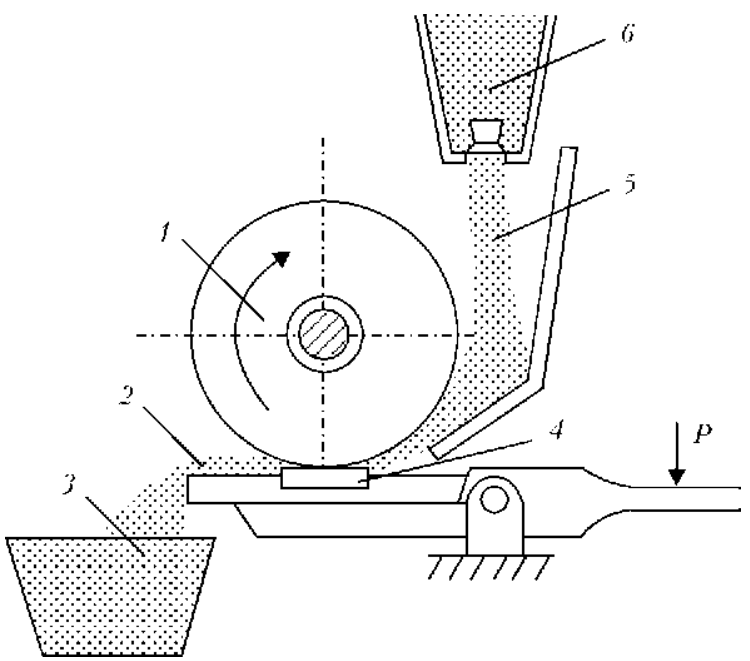

Figure 1. Block-diagram of the unit for studying abrasive wear by unfixed abrasive: 1 - rubber disc; 2 - used quartz sand; 3 - hopper for collection of used abrasive; 4 studied sample; 5 - fresh quartz sand; 6 - hopper with fresh quartz sand 


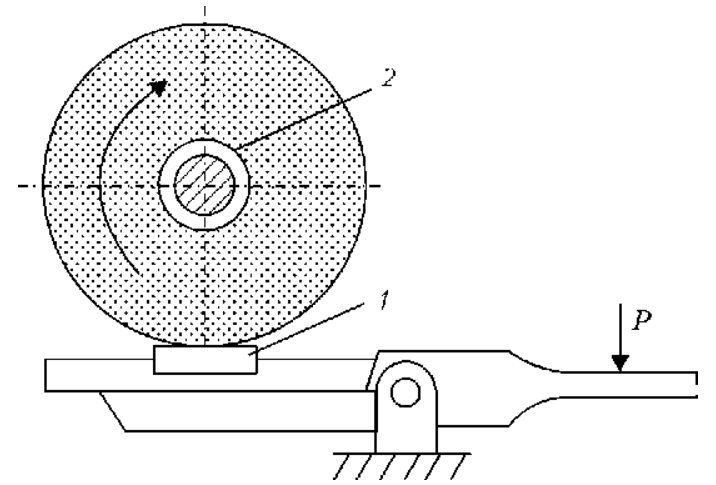

Figure 2. Block diagram of the unit for studying sample wear by rigidly fixed abrasive: 1 - sample; 2 - abrasive disc

before each test. The sandpaper was fixed in a holder in the form of a flat steel plate.

Rubber disc diameter was 48 to $50 \mathrm{~mm}$, its width was $15 \pm 0.1 \mathrm{~mm}$. Friction mode was as follows: hold-down pressure $P=2.4 \mathrm{~N}$, disc rotation speed of $25 \mathrm{~m} / \mathrm{min}$; quartz sand particle size was 200 to $1000 \mu \mathrm{m}$. Wear was evaluated by sample mass loss with up to $2 \cdot 10^{-4} \mathrm{~g}$ accuracy.

Comparative studies of wear at friction on fixed abrasive were conducted in the unit, the schematic of which is given in Figure 2. Disc of $150 \mathrm{~mm}$ diameter and $8 \mathrm{~mm}$ width from SM-2 electrocorundum of medium-soft hardness on 7K15 ceramic binder was used as wearing element. Electrocorundum grain size is equal to $250-315 \mu \mathrm{m}$, linear friction speed is $100 \mathrm{~m} / \mathrm{min}$ with $1.5 \mathrm{~N}$ load in the contact zone. Wear was evaluated by sample mass loss with up to $2 \cdot 10^{-4} \mathrm{~g}$ accuracy.

Results of testing by both the procedures are given in Table 3 .

As shown by the data given in Table 3, twolayer surfacing with both types of flux-cored wires provides a higher wear resistance. This is attributable to the fact that the first deposited layer composition differs from the optimum one as a result of mixing with the base metal. It should be noted that, despite the different alloying degree, wear resistance of deposited metal of both the types is at approximately the same level. Apparently, the wear resistance is influenced by deposited metal structure, content and properties of carbides forming in it.

Microstructure of deposited metal of two compositions and of transition zone on the deposited metal-base metal boundary (steel St3) was studied.

Sample etching was conducted in stages: first, electrolytically, in $20 \%$ solution of chromic acid. This reagent reveals the deposited metal structure. Then, chemical etching of samples in $4 \%$ nitric acid solution was performed to reveal the base metal structure.

Microstructure of metal deposited with Hardface HC-O flux-cored wire, consists of martensite-austenite matrix, primary carbides in the form of large «pencil-type» plates, secondary carbides with hexagonal faceting with clear-cut in-

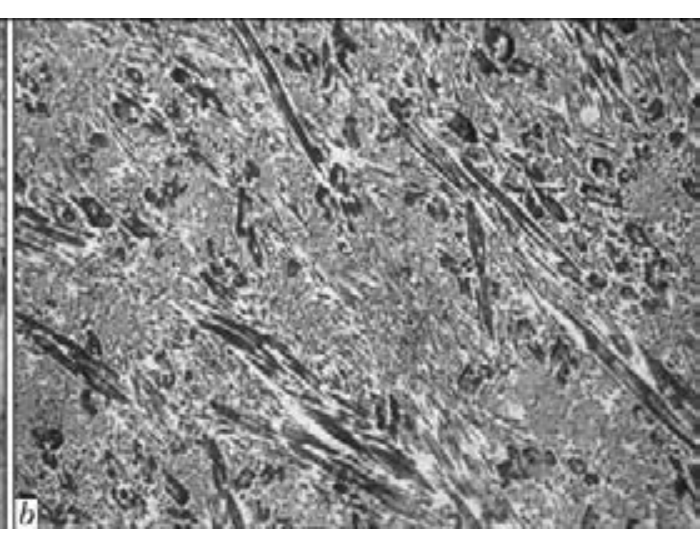

Figure 3. Microstructure of the transition zone $(a)$ and metal $(b)$ deposited by Hardface HC-O flux-cored wire

Table 3. Results of wear resistance testing of deposited metal at friction on unfixed and fixed abrasive

\begin{tabular}{||c|c|c|c|c|c||}
\hline \multirow{2}{*}{ Material grade } & \multirow{2}{*}{$\begin{array}{c}\text { Quantity of deposited } \\
\text { layers }\end{array}$} & \multicolumn{2}{|c|}{ Mass loss at wear, g } & $\begin{array}{c}\text { Wear resistance at } \\
\text { friction on unfixed } \\
\text { abrasive }\end{array}$ & $\begin{array}{c}\text { Wear resistance at } \\
\text { friction on fixed } \\
\text { abrasive }\end{array}$ \\
\cline { 2 - 6 } & Onf & 0.030 & 0.047 & 4.03 & 2.76 \\
\cline { 2 - 6 } Hardface HC-O & Two & 0.028 & 0.019 & 4.32 & 6.84 \\
\hline \multirow{2}{*}{ PP-AN192 } & One & 0.027 & 0.042 & 4.48 & 3.09 \\
\cline { 2 - 6 } & Two & 0.024 & 0.021 & 5.04 & 6.19 \\
\hline Reference - steel 40Kh & - & 0.121 & 0.130 & 1 & 1 \\
\hline
\end{tabular}


Table 4. Dimensions of carbides of different type in metal deposited with Hardface HC-O flux-cored wire

\begin{tabular}{|c|c|c|c||}
\hline \multirow{2}{*}{ Quantity of deposited layers } & \multicolumn{2}{|c|}{ Size of hexagonal carbide side, $\mu \mathrm{m}$} & \multicolumn{2}{c|}{ Length of «pencil» type carbides, $\mu \mathrm{m}$} \\
\cline { 2 - 5 } & At fusion line & In deposited layer center & \multicolumn{2}{|c|}{ At fusion line } \\
\hline One & $15-35$ & $5-15$ & $200-350$ \\
\hline Two & $10-12$ & $20-30$ & 200 \\
\hline
\end{tabular}

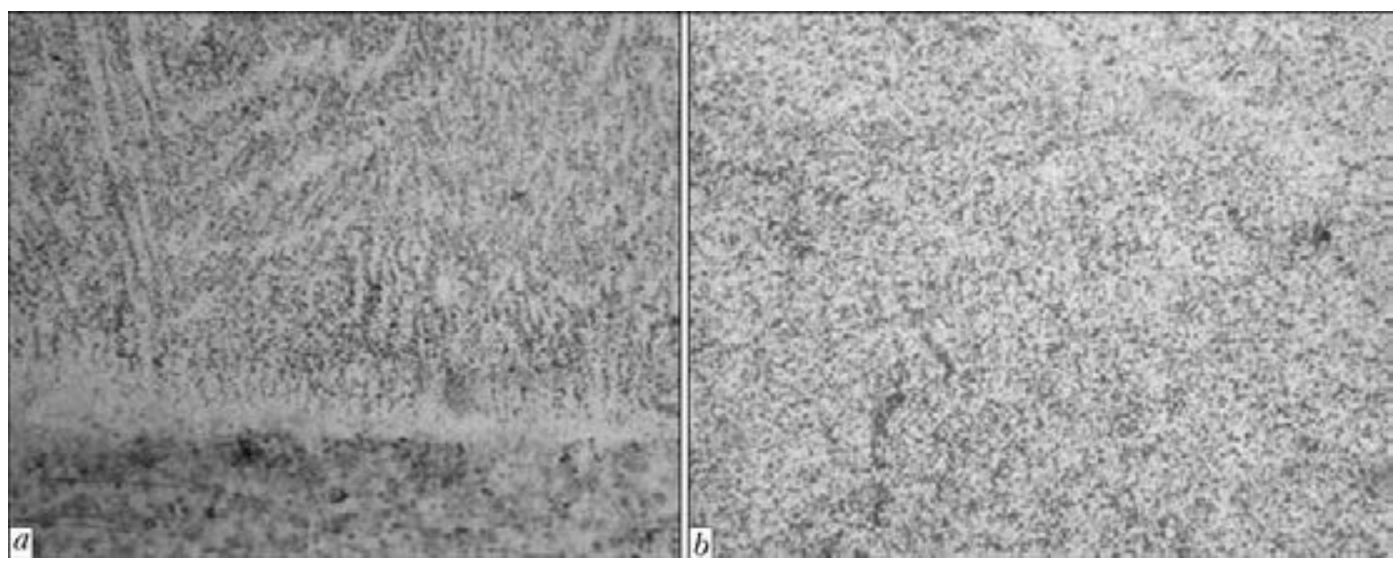

Figure 4. Distribution of iron, chromium, carbon $(a)$, manganese and silicon $(b)$ in the HAZ at surfacing of steel St3 sample with Hardface HC-O flux-cored wire

terface with the matrix, as well as carbide eutectics (Figure 3, $a, b$ ).

Carbide hardness is in the range of $H V 0.5-$ 10950-14130 MPa. Thus, in terms of hardness they can be classified as carbides of $\mathrm{Me}_{23} \mathrm{C}_{6}$ type (see Table 1). An unetchable white band from 5 to $10 \mu \mathrm{m}$ wide was detected along the joint line, the hardness of which is equal to $H V 0.5-3170-$ $3580 \mathrm{MPa}$. Deposited metal hardness in the layer
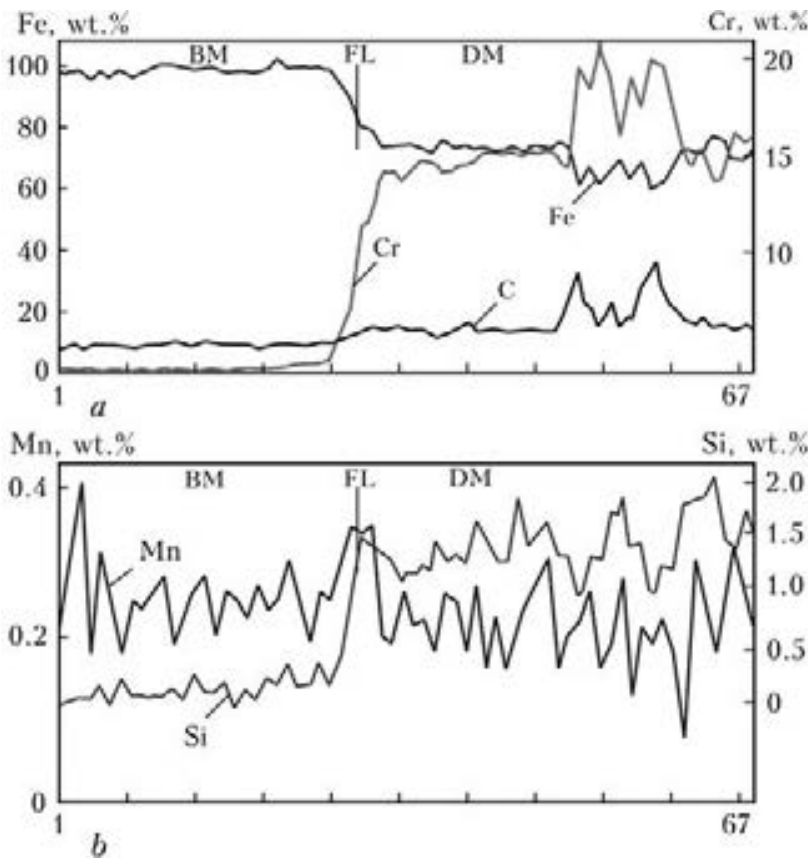

Figure 5. Distribution of iron, chromium, carbon $(a)$, manganese and silicon $(b)$ in the HAZ at surfacing of steel St3 sample with Hardface HC-O flux-cored wire center is equal to $H V 10-7420 \mathrm{MPa}$, being somewhat lower at the fusion line ( $H V 10-6730 \mathrm{MPa})$.

Median of «pencil-type» carbides and faces of hexagonal-shaped carbides was also measured (Table 4). «Pencil-type» carbides have considerable size that may lead to their spalling at wear.

Microstructure of metal, deposited with PPAN192 wire, consists of martensite and residual austenite with precipitates of very fine titanium carbides and carbonitrides (Figure 4, $a$ ). Here, in the deposited metal subsurface layers carbide
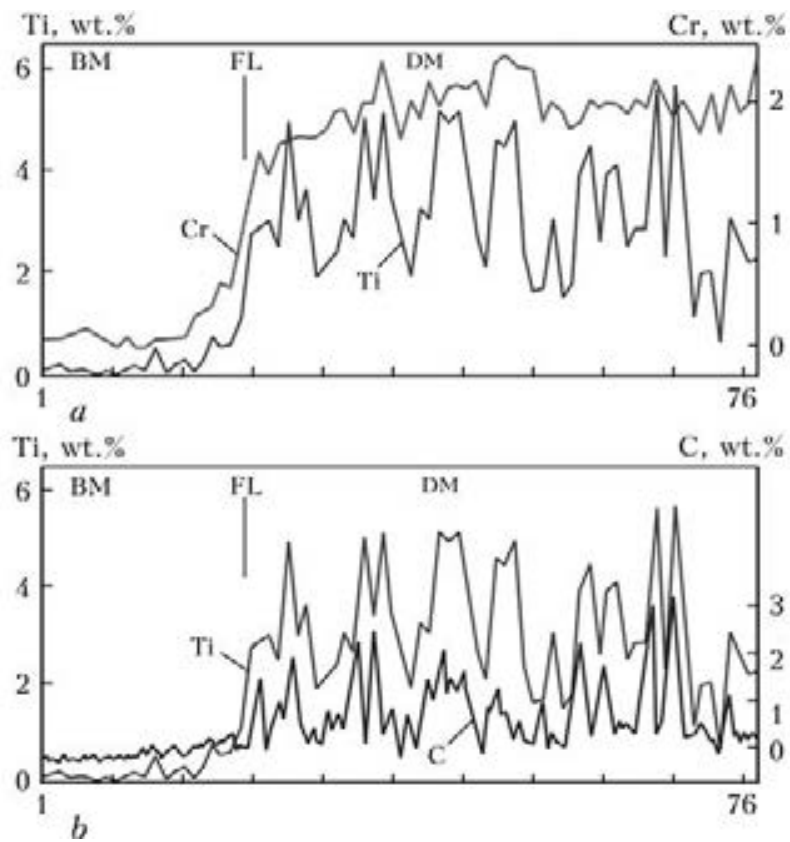

Figure 6. Distribution of chromium, titanium $(a)$, carbon and titanium $(b)$ in the HAZ in surfacing of St3 steel sample by PP-AN192 flux-cored wire 
precipitates are coarser and their quantity is greater than at the fusion line. A weakly-etching band from 5 to $20 \mu \mathrm{m}$ wide of hardness $H V 0.5-$ $3100 \mathrm{MPa}$ forms along the line of fusion with base metal. Deposited metal hardness is equal to $H V 0.5-5020-5090 \mathrm{MPa}$ at the fusion line, and to $H V 0.5-5490 \mathrm{MPa}$ in the deposited layer center, that is somewhat lower than in the metal deposited with Hardface HC-O wire. Carbide hardness could not be measured, because of their small size.

X-ray spectral microanalyzer was used to study the distribution of the main alloying elements in the fusion zone at surfacing with Hardface $\mathrm{HC}-\mathrm{O}$ (Figure 5, $a$ ) and PP-AN192 wires (Figure 6).

As is seen from Figure 5, in the metal deposited with Hardface HC-O wire chromium is partially bound into carbides, and partially alloys the matrix. In the metal deposited with PP-AN192 wire practically all the titanium is bound into carbides in 4:1 ratio with carbon. Chromium mainly alloys the deposited metal matrix (see Figure 6).

In terms of hardness, titanium carbide is greatly superior to all the three types of chromium carbides (see Table 1). More over, chromium carbides are much coarser than titanium carbides and they can spall during wear, because of their relatively low strength. Apparently, in view of these circumstances, the metal deposited with PP-AN192 wire is not inferior to metal deposited with Hardface HC-O wire in terms of wear resistance, despite the lower overall content of alloying elements.

\section{Conclusions}

1. Wear resistance at wearing by fixed and unfixed abrasive of metal deposited with Hardface
HC-O and PP-AN192 flux-cored wires was studied. It is established that both the types of deposited metal, despite the different total content of alloying elements (30\% in Hardface HC-O and $10 \%$ in PP-AN192), have approximately the same wear resistance.

2. High wear resistance of metal, deposited with PP-AN192 flux-cored wire, is attributable to the fact that titanium carbides contained in it are superior in terms of hardness and wear resistance to chromium carbides, which strengthen the metal deposited with Hardface HC-O fluxcored wire.

1. Livshits, L.S., Grinberg, N.A., Kurkumelli, E.G. (1969) Principles of alloying of deposited metal. Abrasive wear. Moscow: Mashinostroenie.

2. Khrushchov, M.M., Babichev, M.A. (1970) Abrasive wear. Moscow: Nauka.

3. Khrushchov, M.M., Babichev, M.A., Berkovich, E.S et al. (1971) Wear resistance and structure of hard deposits. Moscow: Mashinostroenie.

4. Ryabtsev, I.A., Senchenkov, I.K. (2013) Theory and practice of surfacing works. Kiev: Ekotekhnologiya.

5. Pereplyotchikov, E.F., Ryabtsev, I.A., Vasiliev, V.G. et al. (2003) Structure and properties of high-carbon high-vanadium iron-base alloys for surfacing. Metallovedenie i Termich. Obrab. Metallov, 5, 36-40.

6. Ryabtsev, I.A., Kondratiev, I.A., Zhudra, A.P. et al. (2002) Flux-cored wires for surfacing developed in PWI. Svarshchik, 2, 34-35

7. Ryabtsev, I.A., Kondratiev, I.A., Vasiliev, V.G et al. (2002) Wear resistance of deposited metal of Fe$\mathrm{C}-\mathrm{Cr}-\mathrm{Ti}-\mathrm{Mo}$ alloying system. The Paton Welding J., 4, 45-48.

8. Kiffer, R., Benezowsky, F. (1971) Hard alloys. Moscow: Metallurgiya.

9. Frumin, I.I., Ryabtsev, I.A., Golovashchuk, A.I. (1974) Influence of structural transformations on wear resistance of U25Kh6T4M carbide steel. Avtomatich. Svarka, 9, 23-25.

10. Palatnik, L.S., Papirov, I.I. (1964) Oriented crystallization. Moscow: Metallurgiya. 


\title{
FLUX-CORED WIRES PROVIDING DEPOSITED METAL WITH HIGH RESISTANCE TO ADHESION WEAR
}

\author{
V.V. OSIN \\ E.O. Paton Electric Welding Institute, NASU \\ 11 Bozhenko Str., 03680, Kiev, Ukraine. E-mail: office@paton.kiev.ua
}

\begin{abstract}
PWI developed flux-cored wires providing deposited metal with sulphide or graphite inclusions, which have the role of solid lubricant and prevent adhesion wear. Comparative studies of heat- and wear resistance at metal-to-metal friction at room and elevated temperatures showed that PP-Np-20Kh5M3FS(S) flux-cored wire can be recommended for welding parts operating under the conditions of increased mechanical loads and moderate cyclic thermal loads. PP-Np-50Kh9S3G(S) flux-cored wire providing deposited metal with high adhesion wear resistance at room temperature can be successfully used for surfacing parts of heavy-duty friction pairs. Having relatively low cost, but requiring application of complex surfacing technology, PP-Np-150S2Yu flux-cored wire can find limited application in surfacing friction pair parts operating at high mechanical loads in the case, if it is cost-effective. 13 Ref., 4 Tables, 5 Figures.
\end{abstract}

Keywords: arc surfacing, flux-cored wires, adhesion wear, wear resistance, thermal stability

Machines and mechanisms having heavy-duty parts in their design are operating practically in all the national economy industries. These are tools and fixtures for hot and cold working of metals, various rollers, shafts, axles, pulleys, crane wheels, etc.

One of the main causes for these parts failures is adhesion wear (Figure 1) [1]. This kind of wear is characterized by the processes of establishing of bonds (seizure points) between two friction surfaces at molecular level and subsequent mechanical breaking up of these bonds. B.I. Kostetsky [2] proposed differentiating between adhesion wear of first and second kind. Adhesion wear of the first kind is observed at sliding friction and low speeds, temperatures and specific pressures, while adhesion wear of the second kind is found at sliding friction at high speeds, great specific pressures and higher temperatures. Currently available surfacing materials, as a rule, do not provide deposited metal resistant to adhesion wear, and lubricant application remains to be the only method to prevent it.

This work is the generalization of PWI experience on development of flux-cored wires, which provide deposited metal with inclusions, having the role of solid lubricant and preventing adhesion wear [3-6].

Steels alloyed with sulphur, as well as graphitized steels were used as surfacing material prototypes. It is known that in both types of these materials, free inclusions of sulphides or graphite improve machinability and lower the friction coefficient [7-9].

Investigations resulted in development of three flux-cored wires, two of which provided deposited metal with sulphide inclusions (PPNp-20Kh5M3FS(S) and PP-Np-50Kh9S3G(S) wires), and one - with graphite inclusions (PP$\mathrm{Np}-150 \mathrm{~S} 2 \mathrm{Yu}$ wire).

The prototype of PP-Np-20Kh5M3FS(S) flux-cored wire was the known wire PP-Np$25 \mathrm{Kh} 5 \mathrm{FMS}$, which is widely applied for reconditioning and strengthening of tools for hot working [10]. From alloying elements in this wire the main attention was given to molybdenum, which forms $\mathrm{MoS}_{2}$ disulphide. By the data of [11], this disulphide is the most effective as the solid lubricant. It has a layered structure, these layers are quite strong, and can move relative to each other, resulting in improvement of tribotechnical characteristics of friction pairs.

Steel 50Kh9S3G, known under «silchrome» trade name, is applied for manufacturing tools for metal cold working, in particular, for cold deep drawing dies, as well as for heavy-duty parts of some friction pairs. These parts service is characterized by minimum thermal loads at considerable mechanical loads, and they most often fail as a result of adhesion wear of the first kind. Considering that thermal stability of steels of this type is minimal, their application under these conditions is quite justified.

For repair surfacing of cold drawing dies, PWI developed PP-Np-50Kh9S3G flux-cored wire, providing deposited metal of composition similar to base metal [10]. This steel has no molybdenum,
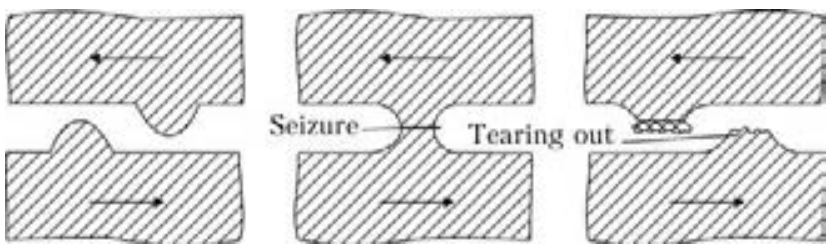

Figure 1. Scheme of adhesion wear of two rubbing metal surfaces 
INTERNATIONAL CONFERENCE «SURFACING»

Table 1. Optimum composition and hardness of metal deposited with PP-Np-20Kh5M3FS(S), PP-Np-50Kh9S3G(S) and PP-Np150S2Yu flux-cored wires

\begin{tabular}{||l|c|c|c|c|c|c|c|c||}
\hline \multirow{2}{*}{ Flux-cored wire grade } & \multicolumn{9}{|c|}{ Element mass fraction, \% } & \multicolumn{2}{c|}{ Hardness } \\
\cline { 2 - 10 } & $\mathrm{C}$ & $\mathrm{Mn}$ & $\mathrm{Si}$ & $\mathrm{Cr}$ & $\mathrm{Mo}$ & $\mathrm{V}$ & Other & HRC \\
\hline PP-Np-20Kh5M3FS(S) & 0.25 & 0.63 & 0.92 & 4.72 & 2.98 & 0.54 & $0.78 \mathrm{~S}$ & $44-46$ \\
\hline PP-Np-50Kh9S3G(S) & 0.64 & 0.55 & 2.65 & 9.25 & - & - & $0.70 \mathrm{~S}$ & $56-58$ \\
\hline PP-Np-150S2Yu & 1.80 & 0.58 & 1.46 & - & - & - & $0.09 \mathrm{Al}$ & $41-44$ \\
& & & & & & & $0.02 \mathrm{Ca}$ & \\
\hline
\end{tabular}

and to avoid increase of flux-cored wire cost, the possibility of producing in the deposited metal sulphide inclusions of other alloying elements, which can improve the tribotechnical properties of deposited metal of this type, was studied [12].

$\mathrm{PP}-\mathrm{Np}-150 \mathrm{~S} 2 \mathrm{Yu}$ flux-cored wire provides deposited metal of graphitized steel type. Application of such materials is one of the methods of improving the tribotechnical characteristics of friction pair parts, graphite inclusions having the solid lubricant role. The main problem here is providing an optimum quantity of globular graphite inclusions without high-temperature heat treatment [6].

Table 1 gives the composition and hardness of metal deposited with PP-Np-20Kh5M3FS(S), PP-Np-50Kh9S3G(S) and PP-Np-150S2Yu fluxcored wires.

Deposited metal composition and wire charge composition, respectively, were selected in keeping with earlier research findings [4-6].

These investigations showed that to provide the required properties of $20 \mathrm{Kh} 5 \mathrm{M} 3 \mathrm{FS}(\mathrm{S})$ and 50Kh9S3G(S) deposited metal, the volume content of complex sulphides of the main alloying elements should be equal to $1.5-2.0 \%$, while their dimensions should not exceed $0.02 \mathrm{~mm}(\mathrm{Fi}-$ gure $2, a, b)$. To satisfy these conditions, sulphur content in the deposited metal should be equal to $0.5-0.8 \%$, and the total content of the main alloying elements (molybdenum, chromium, vanadium, manganese) should be 8 to $10 \%$ [4, 5].

Volume content of graphite inclusions (1.0$1.3 \%$ ) in the deposited metal structure, which provides minimum wear of deposited metal of the type of graphitized steel $150 \mathrm{~S} 2 \mathrm{Yu}$ was also experimentally determined. To produce such a quantity of graphite inclusions, the deposited metal should contain, \%: 1.35-1.50 C, 1.5$2.0 \mathrm{Si}, 0.1-0.2 \mathrm{Al}$ and $0.02-0.05 \mathrm{Ca}$, and surfacing should be conducted with preheating up to $400{ }^{\circ} \mathrm{C}$ and tempering immediately after surfacing at the same temperature [6]. It should noted that this is exactly the preheating temperature that is required to avoid cracking in high-carbon deposited metal 150S2Yu. Figure 2, $c$ gives the structure of deposited metal of this type.

Comparative evaluation of wear resistance of deposited metal of this type at sliding friction of metal on metal without lubrication at room temperature, was conducted in friction machine, described in [13]. Testing was performed by crater wear method by «shaft-plane» scheme without any additional lubricant feeding into friction zone. Samples cut out of deposited metal upper layers for tribotechnical testing had the dimensions of $3 \times 17 \times 20 \mathrm{~mm}$. Wearing proceeded over $3 \times 20 \mathrm{~mm}$ plane. The counterbody of $40 \mathrm{~mm}$ diameter and $12 \mathrm{~mm}$ height was made from quenched steel 45 of hardness HRC 42.

At sample testing, deposited metal wear was determined by worn crater volume. Volume of worn crater on the surfaced sample was calculated by known formulas by average width of worn crater, using toolmaker's microscope with not more than $0.01 \mathrm{~mm}$ error. Total error of sample wear determination did not exceed $1 \%$. Counterbody wear was determined by its mass loss with not more than $0.0001 \mathrm{~g}$ error.

Proceeding from the results of earlier research, the following test mode was selected: slip velocity of $1 \mathrm{~m} / \mathrm{s}$, load of $30 \mathrm{~N}$, test duration of $600 \mathrm{~s}$,
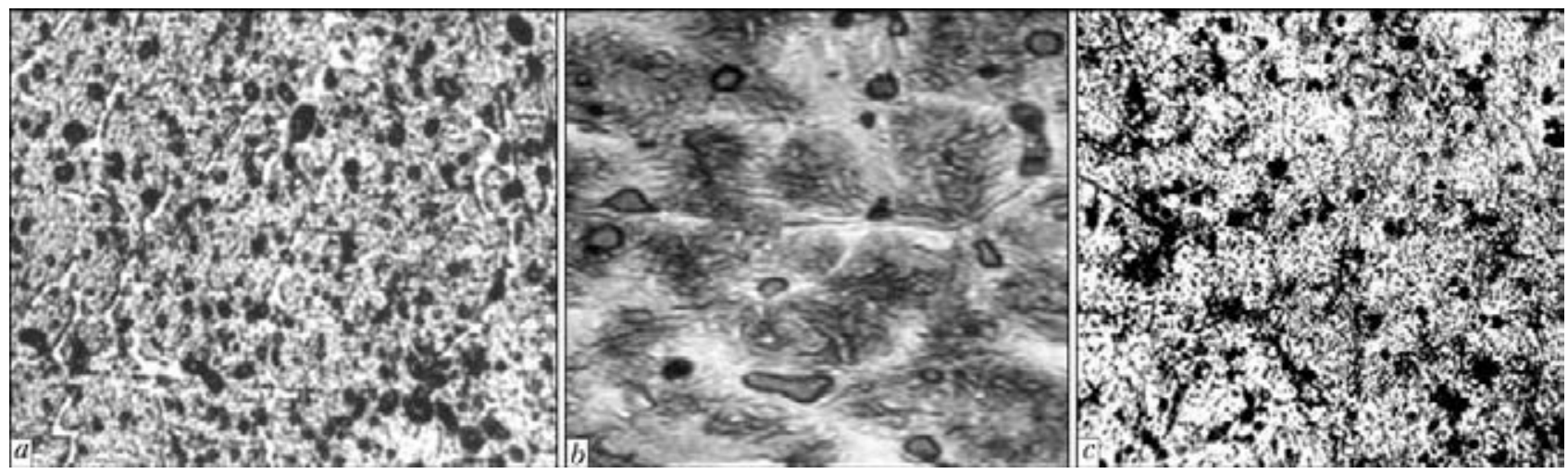

Figure 2. Microstructure of 20Kh5M3FS $(a), 50 \operatorname{Kh} 9 \mathrm{~S} 3 \mathrm{G}(\mathrm{S})(b)$ and $150 \mathrm{~S} 2 \mathrm{Yu}(c)$ deposited metal $(a, c-\times 500 ; b-$ $\times 1000)$ 
Table 2. Wear resistance of metal deposited by PP-Np20Kh5M3FS(S), PP-Np-50Kh9S3G(S) and PP-Np-150S2Yu fluxcored wires at room temperature

\begin{tabular}{||l|c|c||}
\hline \multicolumn{1}{|c|}{ Deposited metal } & $\begin{array}{c}\text { Sample wear, } \\
\mathrm{mm}^{2} / \mathrm{m}\end{array}$ & $\begin{array}{c}\text { Counterbody wear, } \\
\mathrm{g} / \mathrm{m}\end{array}$ \\
\hline 20Kh5M3FS(S) & 0.0017 & 0.0046 \\
\hline 50Kh9S3G(S) & 0.0026 & 0.0035 \\
\hline 150S2Yu & 0.0020 & 0.0031 \\
\hline Steel 45 (reference) & 0.0076 & 0.0037 \\
\hline
\end{tabular}

which ensured stabilization of tribotechnical characteristics of all the studied samples. Application of positioning system allowed testing of each sample to be repeated not less than 3 times on a new section of sample friction surface and on a new friction groove of the same counterbody.

Table 2 gives the results of wear resistance evaluation for three types of deposited metal and reference sample from quenched steel 45 by the same procedure. Data on wear of counterbody from quenched steel 45 are also given there.

As can be seen from the given data, the studied types of deposited metal can be arranged as follows by wear resistance level (in descending order): 20Kh5M3FS(S), 150S2Yu, 50Kh9S3G(S). Counterbody wear resistance changes as follows (depending on contacting sample): 150S2Yu, 50Kh9S3G(S), 20Kh5M3FS(S).

Investigation of wear resistance of metal deposited with PP-Np-20Kh5M3FS(S) and PP-Np150S2Yu flux-cored wires at metal-on-metal friction at higher temperatures was performed for the case of tools for hot working of metals and alloys. As was noted above, testing of samples surfaced with PP-Np-50Kh9S3G(S) wire by this procedure was not performed, as this wire is not designed for surfacing parts, exposed to high temperatures in service. Investigations were performed by «shaft-plane» scheme without additional feeding of lubricant into the friction zone. Surfaced blanks were used to prepare samples of $40 \times 10 \times 17 \mathrm{~mm}$ dimensions with $10 \times 40 \mathrm{~mm}$ size of friction plane. Deposited layer thickness was equal to $8-10 \mathrm{~mm}$.

Abrading ring was heated by gas-oxygen flame. Owing to precisely determined flow rate of natural gas and oxygen, abrading ring-counterbody temperature was maintained at a constant level of 950 to $980{ }^{\circ} \mathrm{C}$, that was periodically controlled by optical pyrometer.

Wear testing at metal-on-metal friction at higher temperatures was conducted for $1 \mathrm{~h}$ at $17.5 \mathrm{~kg}$ load; speed of ring-counterbody revolution was $30 \mathrm{rpm} ; 120 \mathrm{~mm}$ diameter rings from quenched steel 45 were used as counterbodies. Tested sample surface temperature in the abrasion zone was equal to about $600{ }^{\circ} \mathrm{C}$. During testing, the sample makes reciprocal motions in the vertical plane: $20 \mathrm{~mm}$ oscillation amplitude, $62 \mathrm{~min}^{-1}$ oscillation frequency (Figure 3) [13]. Reference samples were those deposited with PP-

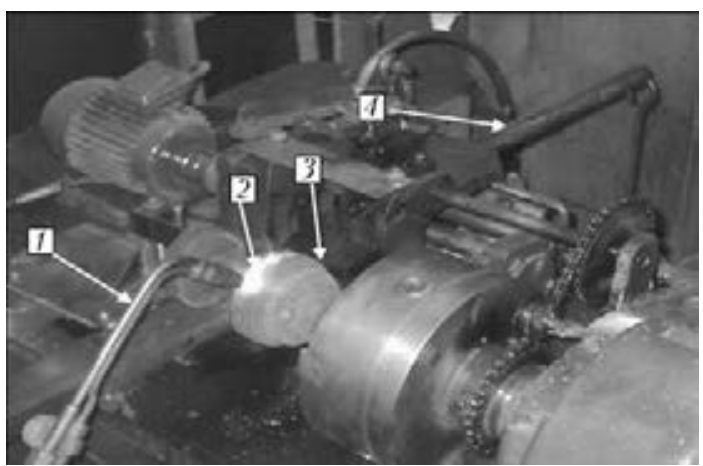

Figure 3. Testing of wear resistance of surfaced samples at higher temperatures: 1 - gas cutter for heating the abrading ring-counterbody; 2 - abrading ring-counterbody; 3 tested sample; 4 - lever for suspending the load

Np-25Kh5MFS flux-cored wire. Test results (averaged over three samples) are given in Table 3.

Sulphur addition to 25Kh5MFS deposited metal practically did not affect the surfaced sample wear, but considerably reduced counterbody wear. Wear of samples surfaced with PP-Np-150S2Yu wire was greater. Wear of ring-counterbodies tested in a pair with these samples was also high.

Analysis of worn surfaces of samples of 20Kh5M3FS(S) deposited metal with 0.02 ( Figure $4, a$ ) and $0.78 \% \mathrm{~S}$ (Figure $4, b$ ) content shows that the sulphides prevent adhesion wear and the worn surface of samples is smoother without seizure traces.

Thermal stability is one of the most important indices for materials, designed for reconditioning and strengthening of tools for hot working of metals. Testing of surfaced sample thermal stability was conducted by the following procedure: sample dimensions of $30 \times 40 \times 40 \mathrm{~mm}$, heating of deposited polished sample surface by gas cutter up to $800{ }^{\circ} \mathrm{C}$ (heated spot of $15 \mathrm{~mm}$, sample surface of $40 \times 40 \mathrm{~mm}$ size is heated), heated surface cooling by water jet to $60{ }^{\circ} \mathrm{C}$. Coolingheating cycles were repeated up to appearance of crazing visible to a naked eye (Figure 5). Thermal stability evaluation was conducted by the number of heating-cooling cycles up to appearance of the first cracks and reaching a certain degree of cracking - appearance of crazing.

Thermal stability testing of samples surfaced with PP-Np-20Kh5M3FS(S) and PP-Np150S2Yu flux-cored wires was performed. Tested as reference samples were those surfaced by standard PP-Np-25Kh5MFS flux-cored wire.

Table 3. Wear resistance of metal deposited by PP-Np20Kh5M3FS(S), PP-Np-150S2Yu and PP-Np-25Kh5FMS fluxcored wires at higher temperatures

\begin{tabular}{||l|c|c||}
\hline \multicolumn{1}{|c|}{ Deposited metal } & $\begin{array}{c}\text { Sample wear, } \\
\mathrm{kg} / \mathrm{m} \cdot 10^{-4}\end{array}$ & $\begin{array}{c}\text { Counterbody } \\
\text { wear, } \mathrm{kg} / \mathrm{m} \cdot 10^{-4}\end{array}$ \\
\hline 20Kh5M3FS(S) & 27.31 & 26.24 \\
\hline 150S2Yu & 31.60 & 59.48 \\
\hline 25Kh5FMS (reference) & 26.23 & 70.24 \\
\hline
\end{tabular}




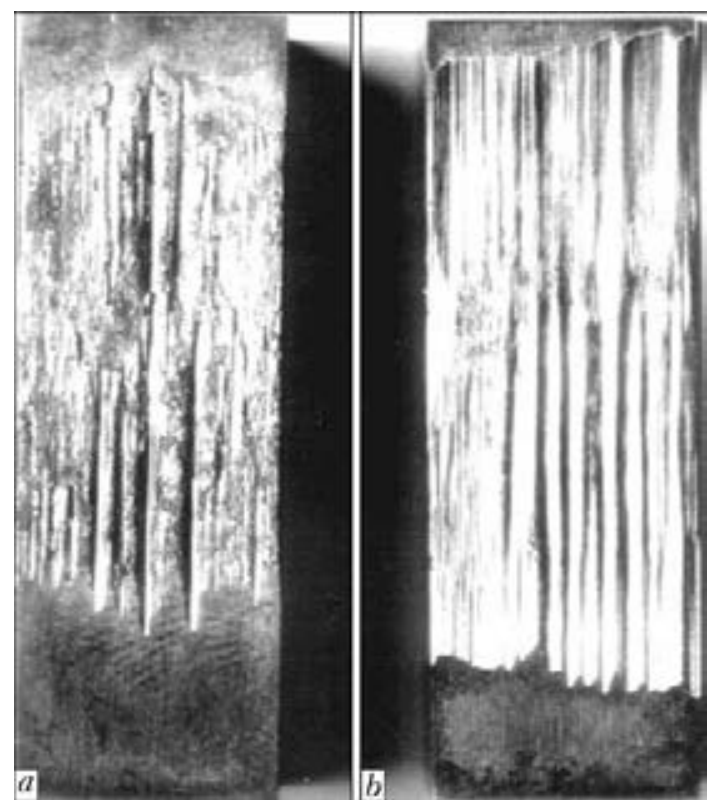

Figure 4. Worn surface of samples of 20Kh5M3FS(S) deposited metal with $0.02(a)$ and $0.76(b) \% \mathrm{~S}$

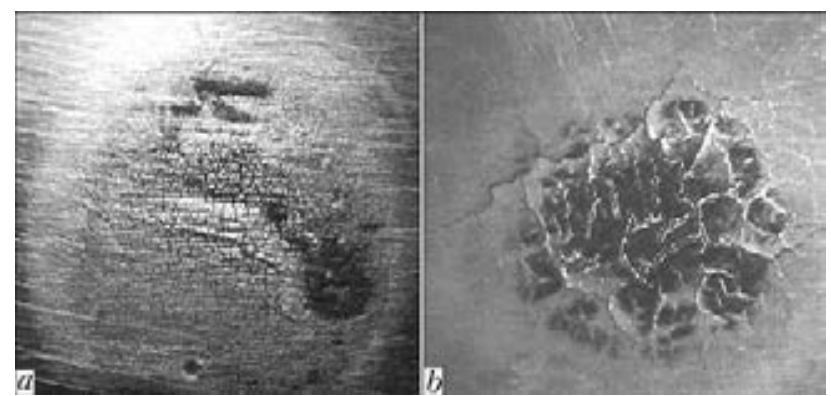

Figure 5. Sample surface after thermal stability testing: $a-20 \operatorname{Kh} 5 \mathrm{M} 3 \mathrm{FS}(\mathrm{S}) ; b-150 \mathrm{~S} 2 \mathrm{Yu}$ deposit

Test results (averaged over three to five samples of each type) are given in Table 4.

Sulphur lowered the thermal stability of deposited metal of 25Kh5MFS type, although its level was still quite high. By this index, 20Kh5M3FS(S) deposited metal alloyed by sulphur, is not inferior to metal deposited by known PP-Np-35V9Kh3FS flux-cored wire [10].

Thermal stability of 150S2Yu deposited metal is not sufficiently high, as the first thermal fatigue cracks appear in the deposited metal already after the first heating-cooling cycles. Here the depth of crazing cracks reached $1.5 \mathrm{~mm}$, whereas in the deposited metal of 20Kh5M3FS(S) type crazing crack depth did not exceed $0.5 \mathrm{~mm}$.

Thus, comparative studies of wear resistance and thermal stability of metal, deposited with flux-cored wires developed at PWI, confirmed that sulphide or graphite inclusions can have the role of solid lubricant and prevent adhesion wear.
Table 4. Thermal stability of samples surfaced by PP-Np20Kh5M3FS(S), PP-Np-150S2Yu and PP-Np-25Kh5FMS fluxcored wires

\begin{tabular}{||l|c|c||}
\hline \multirow{2}{*}{\multicolumn{1}{|c|}{ Deposited metal }} & \multicolumn{2}{|c|}{ Thermal stability, cycle number } \\
\cline { 2 - 3 } & $\begin{array}{c}\text { Appearance of } \\
\text { first cracks }\end{array}$ & $\begin{array}{c}\text { Appearance of } \\
\text { crazing }\end{array}$ \\
\hline 20Kh5M3FS(S) & 25 & 125 \\
\hline 150S2Yu & 4 & 100 \\
\hline 25Kh5MFS (reference) & 67 & 180 \\
\hline
\end{tabular}

Based on these studies, PP-Np-20Kh5M3FS(S) wire can be recommended for surfacing parts, exposed to increased mechanical loads and moderate cyclic thermal loads in service. PP-Np50Kh9S3G(S) wire providing deposited metal with higher adhesion wear resistance at room temperature can be successfully applied for surfacing parts of heavy-duty friction pairs. Having relatively low cost, but requiring complex surfacing technology, PP-Np-150S2Yu wire can find limited application in surfacing of friction pair parts operating at increased mechanical loads, provided it is cost-effective.

1. Ryabtsev, I.A., Senchenkov, I.K. (2013) Theory and practice of surfacing works. Kiev: Ekotekhnologiya.

2. Kostetsky, B.I. (1975) Reliability and life of machines. Kiev: Tekhnika.

3. Osin, V.V., Ryabtsev, I.A. (2004) Effect of sulphur on properties of iron-base alloys and prospects of its application in surfacing materials. The Paton Welding $J ., 10,18-21$

4. Osin, V.V., Ryabtsev, I.A., Kondratiev, I.A. (2006) Study of sulfur effect on properties of deposited metal of Kh5MFS type. Ibid., 12, 12-15.

5. Kondratiev, I.A., Ryabtsev, I.A., Bogajchuk, I.L. et al. (2008) Structure of deposited metal of the type of graphitized hypereutectoid steels. Ibid., 7, 15-18.

6. Ryabtsev, I.A., Kondratiev, I.A., Osin, V.V. et al (2011) Wear- and heat resistance of deposited metal of graphitized steel type. Ibid., 8, 33-36.

7. Goudremont, E. (1959) Special steels. Vol. 1, 2. Moscow: GNTI.

8. Khimushin, F.F. (1963) Stainless steels. Moscow: Metallurgizdat.

9. Zubkova, E.N. (2002) Sulfur effect on structure and properties of deposited high-speed steel. Metallovedenie $i$ Termich. Obrab. Metallov, 9, 27-30.

10. Ryabtsev, I.A., Kondratiev, I.A. (1999) Mechanized electric arc surfacing of metallurgical equipment parts: Refer. book. Kiev: Ekotekhnologiya.

11. Samsonov, G.V., Barsegyan, Sh.E., Tkachenko Yu.G. (1973) On mechanism of lubricating action of sulfides and selenides of refractory metals. Fiz.Khimich. Mekhanika Materialov, 9(1), 58-61.

12. Osin, V.V. (2014) Tribotechnical properties of deposited metal of 50Kh9S3G type with increased sulphur content. The Paton Welding J., 12, 8-10.

13. Rvabtsev, I.I., Chernyak, Ya.P., Osin, V.V. (2004) Block-modular unit for testing of deposited metal. Svarshchik, 1, 18-20. 


\title{
STRUCTURE AND PROPERTIES OF METAL DEPOSITED BY FLUX-CORED WIRE WITH CHARGE OF USED METAL-ABRASIVE WASTES
}

\author{
I.P. LENTYUGOV and I.A. RYABTSEV \\ E.O. Paton Electric Welding Institute, NASU \\ 11 Bozhenko Str., 03680, Kiev, Ukraine. E-mail: office@paton.kiev.ua
}

\begin{abstract}
The technology of recycling the grinding wastes of metal cutting tool was developed using electroslag remelting, allowing producing a master alloy of the certain chemical composition. The structure and wear resistance of metal of the similar chemical composition deposited using two pilot flux-cored wires was investigated. A charge of one of the wires was prepared of the master alloy produced after wastes recycling, a charge of the second one was prepared of the appropriate ferroalloys. The investigations showed that the metal deposited using both flux-cored wires had similar structures and approximately the same wear resistance. It was established that the master alloy produced by utilization of grinding wastes production can be successfully used as a charge in surfacing flux-cored wires. 4 Ref., 3 Tables, 3 Figures.
\end{abstract}

Keywords: metal-abrasive wastes, wastes recycling, flux-cored wires, surfacing materials, structure of deposited metal, wear resistance

Recycling of wastes, formed during abrasive machining of metal cutting tool or during high-speed grinding of ingots of high alloyed steels, is one of the challenging trends in the modern industrial production. These wastes are composed of oxidized metallic microchips mixed with abrasive particles and remnants of cutting fluid [1,2]. In addition, metal microchips contain the important alloying elements like chromium, tungsten, vanadium, molybdenum, etc. and their recycling and utilization represent interest not only from the ecological point of view. In particular, the recycling products of such wastes may be used as a charge in surfacing flux-cored wires [3].

At the E.O. Paton Electric Welding Institute the technology of recycling wastes from grinding of metal cutting tool was developed using electroslag remelting [3]. To remove the cutting fluid the calcination of metal abrasive wastes at the temperature of $200-400{ }^{\circ} \mathrm{C}$ is provided. In the process of calcination the wastes may be pelletized, therefore after calcination it is necessary to perform crushing of the formed lumps. The subsequent magnetic separation allows sorting out the metallic component of wastes.
Electroslag remelting of metallic component of wastes was performed in a copper mould using non-consumable graphite electrode. As a result of remelting the ingots of master alloy of a certain chemical composition were produced. At practicing the technology it was established that to provide stability of electroslag remelting process and the maximum output of quality master alloy the specific power should be at least $100 \mathrm{~W} / \mathrm{cm}^{2}$, and the feed rate of slime should be in the range of $2-3 \mathrm{~kg} / \mathrm{min}$.

Table 1 shows chemical composition of wastes at every stage of their recycling.

A high concentration of silicon in wastes is explained by the fact that silicon carbide penetrates them from abrasive discs. Preliminary magnetic separation of wastes can significantly reduce the silicon content. After electroslag remelting the content of silicon in master alloy is reduced to minimum. It is known that silicon carbide can recover oxides of a majority of other metals included into the composition of wastes, as a result of which silicon dioxide is formed, which is easily removed into slag during electroslag remelting.

Conducted were the comparative investigations of microstructure and tribological properties of metal, deposited using two flux-cored wires: in a charge of one of the wires a pilot

Table 1. Chemical composition of metal-abrasive wastes and master alloy produced of them, wt. \%

\begin{tabular}{||l|c|c|c|c|c|c|c|c||}
\hline \multicolumn{1}{|c|}{ Material } & $\mathrm{C}$ & $\mathrm{Si}$ & $\mathrm{Cr}$ & $\mathrm{Mo}$ & $\mathrm{V}$ & $\mathrm{W}$ & $\mathrm{Co}$ & $\mathrm{S}$ \\
\hline Metal-abrasive wastes & 1.8 & 15.60 & 1.4 & 0.8 & 0.85 & 5.89 & 0.32 & 0.039 \\
\hline Wastes after separation & 1.7 & 8 & 3.2 & 1.2 & 1 & 8 & 0.30 & 0.034 \\
\hline Master alloy & 4.9 & 0.23 & 2.7 & 2.6 & 0.63 & 9.88 & 0.20 & 0.080 \\
\hline
\end{tabular}


INTERNATIONAL CONFERENCE «SURFACING»

Table 2. Chemical composition of metal deposited using pilot flux-cored wires, wt.\%

\begin{tabular}{|c|c|c|c|c|c|c|c|c|c|}
\hline Flux-cored wire & $\mathrm{C}$ & $\mathrm{Si}$ & $\mathrm{Cr}$ & Mo & V & W & Co & $\mathrm{S}$ & Hardness \\
\hline PP-Op-01 & 1.68 & 0.50 & 1.52 & 0.85 & 0.2 & 3.0 & 0.13 & 0.012 & $50-52$ \\
\hline PP-Op-02 & 1.80 & 0.67 & 1.75 & 1.07 & 0.3 & 3.2 & Traces & 0.015 & $50-53$ \\
\hline
\end{tabular}

master alloy was used produced of metal-abrasive wastes; a charge of the second wire consisted of the appropriate ferroalloys. It was assumed that chemical composition and hardness of metal, deposited using both types of flux-cored wires, should be similar enough.

To perform this task a master alloy was melted of metal-abrasive wastes formed during grinding of tools of steel R6M5, according to the technology described above (for its chemical composition see Table 1).

The produced master alloy was crushed, refined and its powder was used as a charge in the pilot flux-cored wire with symbolic name PPOp-1. Using this wire under flux AN-26 the specimens were deposited and chemical analysis of the deposited metal was carried out (Table 2). According to the results of chemical analysis the second pilot flux-cored wire was manufactured, the charge of which was prepared of ferroalloys (PP-Op-2). The chemical composition of metal deposited using this wire under flux AN-26 is also given in Table 2 .

The specimens for investigation of microstructure were cut out from semi-products (steel St3), deposited in four layers using pilot flux-cored wires $\mathrm{PP}-\mathrm{Op}-1$ and $\mathrm{PP}-2-\mathrm{Op}-2$. The structure of deposited and base metal was revealed by chemical etching in $4 \%$ alcohol solution of nitric acid $\left(\mathrm{HNO}_{3}\right)$.

The investigations were carried out in the microscopes «Neophot-32» and «Polyvar». Microhardness of metal was measured on the LECO microdurometer M-400 at the loading of $100 \mathrm{~g}$. The investigations were conducted in accordance with GOST 5639-82 «Steels and alloys. Methods

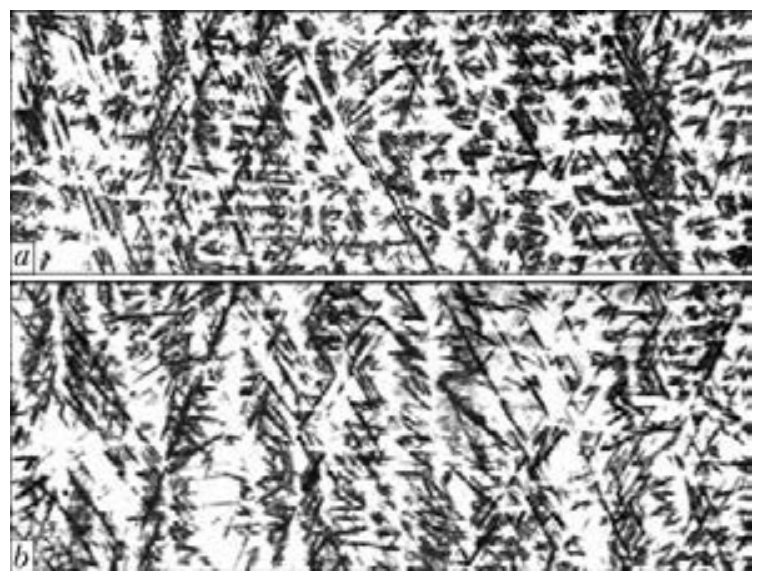

Figure 1. Microstructure $(\times 400)$ of metal deposited using flux-cored wire PP-Op-1 at the center $(a)$ and at the upper edge $(b)$ of deposited layer for detection and determination of grain size» and GOST 1778-70 «Steel. Metallographic methods for determination of non-metallic inclusions». Digital imaging of microstructures was obtained by the camera «Olympus».

The structure of metal, deposited using PPOp-1 wire with charge of master alloy, at the center of deposited layer represents martensite with coarse and fine needles of different etching and residual austenite (Figure 1, $a$ ). The hardness of martensite is $H V 1-542-606$, and that of residual austenite $H V 1-442-525$. At the upper edge the amount of residual austenite is not much increased, the size of needles of martensite is somewhat reduced (Figure 1, b). The hardness of martensite is $H V 1-530-542$, and that of residual austenite $H V 1-464-498$. The hardness of structural components along the entire height of deposited layer differs slightly. The characteristic structure of cast metal is also preserved along the entire height of deposited layer.

The structure of metal deposited using PPOp-2 wire with charge of ferroalloys is approximately the same as in metal deposited using wire PP-Op-1. At the center of the deposited layer the structure is composed of martensite and residual austenite (Figure 2, $a$ ), the needles of martensite have a large size. The hardness of martensite is $H V 1-542-606$, that of austenite $H V 1-442-468$. At the upper edge of deposited layer the structure is finer (Figure $2, b$ ), the hardness of martensite is $H V 1-514-572$, that of austenite $H V 1-416-442$. Also in this case the hardness of structural components along the height of deposited layer differs slightly. It is

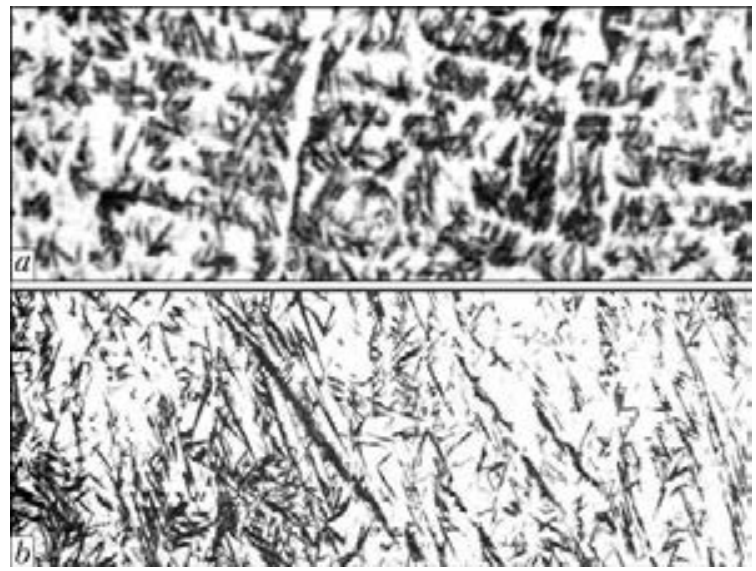

Figure 2. Microstructure $(\times 400)$ of metal deposited using flux-cored wire PP-Op-2 at the center $(a)$ and at the upper edge (b) of deposited layer 


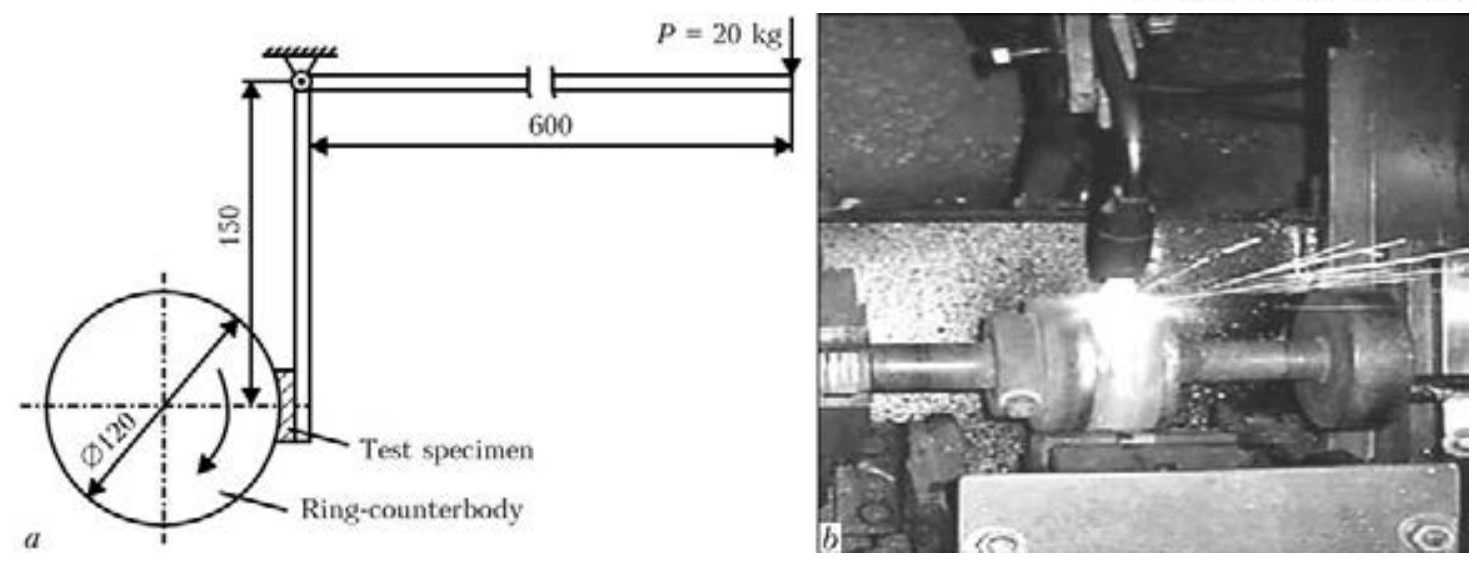

Figure 3. Principal scheme $(a)$, and process of testing wear resistance at metal-on-metal friction at elevated temperatures (b)

also close to the hardness of structural components of metal deposited using PP-Op-1 wire.

In both types of deposited specimens the pores in the lower layer of deposited metal were detected. At the same time in the specimen deposited using wire PP-Op-2 there is more pores and they are larger. The same concerns non-metallic inclusions, the number and size of which were studied on the polished non-etched specimens. In the investigated specimens the sulfides and oxysulfides, oxides and slag inclusions of finer sizes were detected. A number of non-metallic inclusions is higher in the specimen deposited using wire PP-Op-2. Obviously, the use of master alloy as a charge produced using electroslag remelting, allows decreasing the amount of non-metallic inclusions in the deposited metal.

The wear resistance of both types of deposited metal was investigated at a dry friction of metal on metal according to the scheme «shaft (ring)plane» at the high temperatures (Figure 3 ). The tests were carried out in the installation for complex investigations of properties of deposited metal [4]. The ratio of shoulders of lever mechanism with load of $20 \mathrm{~kg}$ (Figure 3, a) provides pressing of specimen to the abrasive ring with force equal to $800 \mathrm{~N}$.

The specific pressure in this case is approximately $100 \mathrm{MPa}$, that corresponds to the pressure which is undergone by the tool for hot deformation under industrial conditions. The heating of ring abrading the specimen is performed using a gas cutter. The temperature at the surface of specimen in the contact zone is about $650{ }^{\circ} \mathrm{C}$.

To carry out tests using pilot wires $\mathrm{PP}-\mathrm{Op}-01$ and $\mathrm{PP}-\mathrm{Op}-02$ in five or six layers the templates were deposited, of which the specimens with dimensions of $40 \times 10 \times 17 \mathrm{~mm}$ were manufactured. The thickness of deposited layer after machining was $8-10 \mathrm{~mm}$.
Table 3. Wear resistance of deposited specimens and counterbodies contacting with them at metal-on-metal friction at high temperatures

\begin{tabular}{||c|c|c||}
\hline \multirow{2}{*}{ Flux-cored wire } & \multicolumn{2}{|c|}{ Loss of mass, $\mathrm{g} / \mathrm{km}$} \\
\cline { 2 - 3 } & Deposited specimen & Counterbody of steel 45 \\
\hline PP-Op-01 & 0.0454 & 2.3905 \\
\hline PP-Op-02 & 0.0509 & 2.5064 \\
\hline
\end{tabular}

The tests on wear in friction of metal on metal at the elevated temperatures were carried out under the following conditions: load $800 \mathrm{~N}$; speed of rotation of ring-counterbody $30 \mathrm{rpm}$; oscillation amplitude of the specimen in vertical plane $20 \mathrm{~mm}$, oscillation frequency $62 \mathrm{~min}^{-1}$; temperature of specimen in the zone of abrasion $600-650{ }^{\circ} \mathrm{C}$; testing time was $1 \mathrm{~h}$. As a counterbody the rings of hardened steel 45 of $120 \mathrm{~mm}$ diameter were used. The test results (average values on three tested specimens) are given in Table 3.

As is seen from the data in Table 3, the wear resistance of specimens, deposited using pilot flux-cored wires and that of the bodies contacting with them, is at the same level. Thus, the master alloy produced by utilization of grinding wastes production can be successfully used as a charge in surfacing flux-cored wires.

1. Kiparisov, S.S., Padalko, O.V. (1993) Resource-saving and natural potential of powder materials and technologies: Realization in the field of secondary resource processing. Poroshk. Metallurgiya, 6, 1-4.

2. Gabrielov, I.P., Kerzhentseva, L.F. (1985) Properties of powder made from metal-abrasive waste of highspeed steel. Ibid., 9, 133-136.

3. Lentyugov, I.P., Ryabtsev, I.A., Kuzmenko, O.G. et al. (2008)' Metal-abrasive grinding wastes, methods of their processing and experience of application in surfacing materials. The Paton Welding J., 9, 34-38.

4. Ryabtsev, I.I., Chernyak, Ya.P., Osin, V.V. (2004) Block-modular unit for testing of deposited metal. Svarshchik, 1, 18-20. 


\title{
NEW ELECTRODES FOR REPAIR SURFACING OF DAMAGED LINING OF IMPELLER CHAMBER OF HES HYDROPOWER UNITS
}

\author{
K.A. YUSHCHENKO, Yu.N. KAKHOVSKY, A.V. BULAT, V.I. SAMOJLENKO and N.Yu. KAKHOVSKY \\ E.O. Paton Electric Welding Institute, NASU \\ 11 Bozhenko Str., 03680, Kiev, Ukraine. E-mail: office@paton.kiev.ua

\begin{abstract}
New electrodes of ANV-70BG grade were developed. Relationship of structural and chemical inhomogeneity in transition zone between low-carbon steel and highly-alloyed deposited metal depending on type of the latter and value of welding current was investigated. 4 Ref., 4 Tables, 3 Figures.
\end{abstract}

$\boldsymbol{K} \boldsymbol{e} \boldsymbol{y} \boldsymbol{w} \boldsymbol{o r d} \boldsymbol{s}:$ coated-electrode manual arc surfacing, low-carbon steel, highly-alloyed deposited metal, transition zone, structural and chemical inhomogeneity, cracks, corrosion

Welded joints from dissimilar steels are widely used in chemical and power machine building. Their serviceability to significant extent is determined by condition of metal of transition zone (its structure and chemical inhomogeneity), which undergoes degradation in zone of fusion with base metal at structure operation as a result of effect of increased temperature and pressure, cyclic mechanical loadings, thermal cycling and aggressive media.

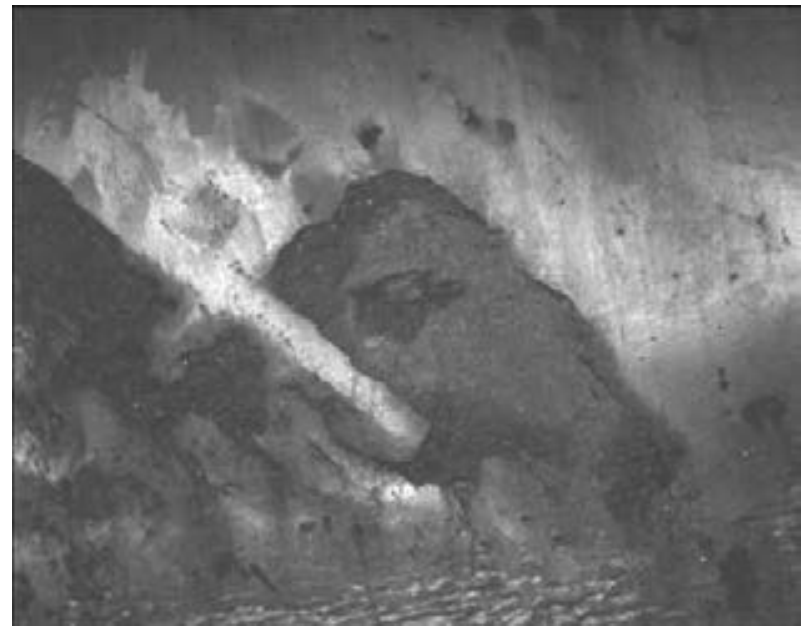

Figure 1. View of damaged metal of impeller chamber lining from St3sp steel
Different methods of arc welding are used by acting enterprises of petrochemical industry and power engineering for repair performance. Thus, repair of damaged lining from stainless steel of impeller chamber (IC) from St3sp steel is carried out in hydropower engineering for providing unit capacity. Reconstruction of its design sizes and further surfacing of highly-alloyed cavitation and corrosion resistance layer of metal on operating surface are used. Lining surfacing is often carried out by TsL-11 electrodes of E-08Kh20N9G2B type.

Examinations of fragments of metal of IC lining in one of hydropower units showed that fracture of corrosion-resistant layer deposited by TsL-11 electrodes takes place through formation of cracks, delaminations as well as corrosion in it (Figure 1). Table 1 gives chemical composition of the base and deposited metal.

The main dependencies determining inhomogeneity of chemical composition and structure in fusion zone of dissimilar metals are related with appearance of zones having conventional designation «solidification interlayers» [1-4]. Present study is dedicated to investigation of possibilities for minimizing structural inhomogeneities in $\mathrm{fu}^{-}$ sion zone due to varying composition of deposited metal and value of welding current.

One-layer deposits were made using pilot electrodes of E-10Kh28N14G2 type of $3 \mathrm{~mm}$ diameter over low-carbon steel (St3sp) plates varying welding current in 80-140 A range. Metal-

Table 1. Chemical composition of base and deposited metal, wt.\%

\begin{tabular}{||l|c|c|c|c|c|c||}
\hline \multicolumn{1}{|c|}{ Material } & $\mathrm{Cr}$ & $\mathrm{Ni}$ & $\mathrm{Mn}$ & $\mathrm{Si}$ & $\mathrm{C}$ & $\mathrm{Nb}$ \\
\hline St3sp steel base metal & 0.05 & 0.04 & 0.5 & 0.179 & 0.16 & - \\
\hline Metal deposited by E-08Kh20N9G2B type electrodes & 19.50 & 9.20 & 1.0 & 0.95 & 0.07 & 1.38 \\
\hline
\end{tabular}


Table 2. Effect of welding current on structure and microhardness of fusion zone and deposited metal, produced by E-10Kh28N14G2 electrodes over St3sp steel

\begin{tabular}{||c|c|c|c|c||}
\hline \multirow{2}{*}{$I_{\mathrm{w}}, \mathrm{A}$} & \multicolumn{3}{|c|}{ Microhardness, MPa } & \multirow{2}{*}{ Deposit microstructure } \\
\cline { 2 - 5 } & Fusion zone & Middle part of deposit & Upper part of deposit & \\
\hline $80-90$ & $1595-2580$ & $1688-1760$ & $1875-1940$ & Austenite + ferrite \\
\hline $110-130$ & $1942-3840^{*}$ & $1900-2120$ & $1900-2200$ & Austenite (in fusion zone) + martensite \\
\hline${ }^{*}$ Martensite of transition zone.
\end{tabular}

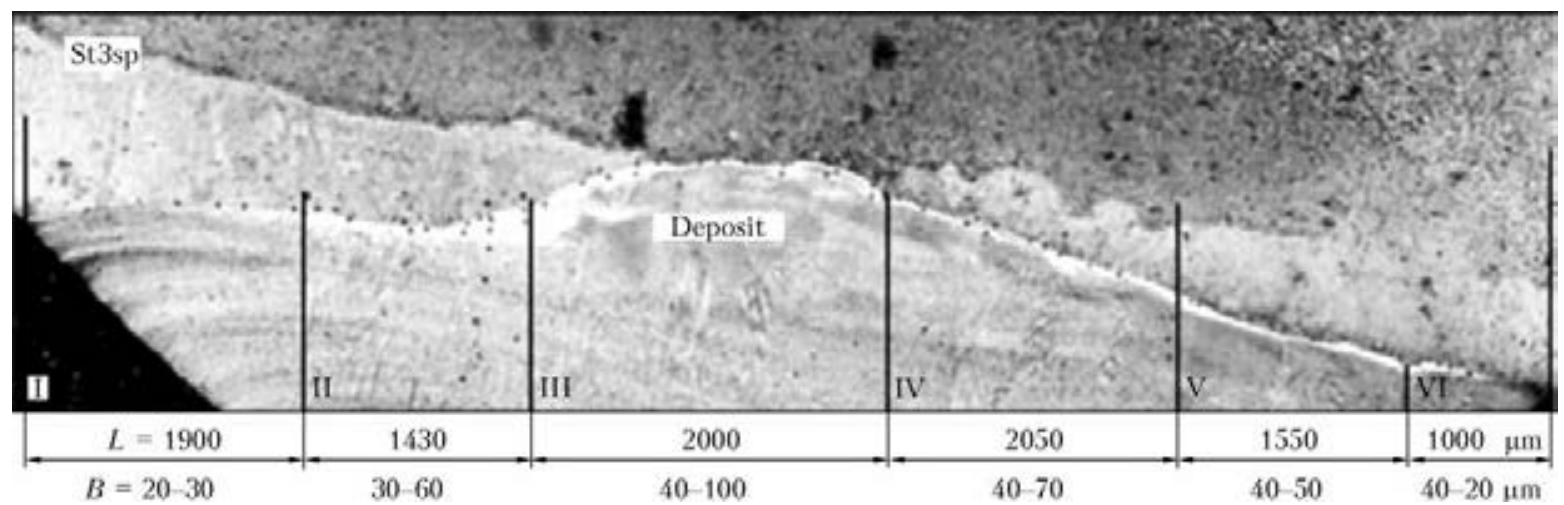

Figure 2. Panoramic sight $(\times 50)$ of transition zone of deposits produced using pilot electrodes of E-10Kh28N14G2 type over St3sp steel at $I_{\mathrm{w}}=80-90$ A: $L-$ length; $B-$ width

lographic examinations were carried out on microsections with evaluation of microhardness of structural constituents. Quantity of magnetic phase in high-alloyed metal was determined using FERRITGEHALT-MESSER 1.053 ferrite meter. The microstructure of deposited metal was examined at «Neophot-32» microscope.

Microhardness (GOSTs 9450-76 and 1071175) was determined at $100 \mathrm{~g}$ loading for evaluation of structural inhomogeneity in the transition zone. Data on chemical composition of metal of transition zone were obtained using energy dispersive X-ray microanalyzer of «Camscan» microscope. Metallographic examinations determined absence of cracks in fusion zone and weld metal deposited by pilot electrodes.

Table 2 shows the changes of microhardness of deposited metal depending on welding current. The transition zone includes an interface between base and highly-alloyed metal of alternating composition (Figure 2). Profile of transition zone was determined using combined chemical and ele-

Table 3. Data of X-ray spectrum analysis of transition zone (3rd area) between steel St3sp and metal deposited by E10Kh28N14G2 type electrodes (wt.\%) at $I_{\mathrm{w}}=80-90 \mathrm{~A}$

\begin{tabular}{|c|c|c|c|c|c||}
\hline No. & $\mathrm{Si}$ & $\mathrm{Cr}$ & $\mathrm{Mn}$ & $\mathrm{Fe}$ & $\mathrm{Ni}$ \\
\hline 1 & 0.16 & 0.67 & 0.36 & 98.81 & - \\
\hline 2 & 0.50 & 15.16 & 1.47 & 75.01 & 7.85 \\
\hline 3 & 0.76 & 18.75 & 2.46 & 67.09 & 10.93 \\
\hline 4 & 0.98 & 26.67 & 2.75 & 53.51 & 16.09 \\
\hline
\end{tabular}

crolythic etching of base low-carbon metal and highly alloyed deposit. It was determined that its width varies in $2-100 \mu \mathrm{m}$ range.

As can be seen from Table 2, microhardness of all areas of transition zone at $I_{\mathrm{w}}=80-90$ A made 1595-2580 MPa, except for one (3rd area) where it reached $3050 \mathrm{MPa}$. In this connection, energy dispersive analyzer was used for determination of content of alloying elements (Tables 3 and 4) in increased hardness area (see Figure 2). Concentration of nickel close to fusion line made 7.85 and that of chromium was 15.16 wt.\%. Microstructure of transition zone of deposited metal in surfacing at $I_{\mathrm{w}} \sim 80-90$ A represents itself austenite $+\sim 3-5 \%$ of ferrite. At that, chromium content nearby the fusion line made 15.214.9 wt. $\%$, that provides for sufficient metal corrosion resistance.

Increase of microhardness up to 1942$3840 \mathrm{MPa}$ is observed from the side of highlyalloyed metal at welding current increase to 100130 A. Metal of transition zone has the following

Table 4. Data of X-ray spectrum analysis of transition zone between steel St3sp and metal deposited by E-10Kh28N14G2 type electrodes (wt.\%) at $I_{\mathrm{w}}=130 \mathrm{~A}$

\begin{tabular}{|c|c|c|c|c|c||}
\hline No. & $\mathrm{Si}$ & $\mathrm{Cr}$ & $\mathrm{Mn}$ & $\mathrm{Fe}$ & $\mathrm{Ni}$ \\
\hline 1 & 0.15 & - & 0.61 & 99.24 & - \\
\hline 2 & 0.45 & 12.44 & 1.51 & 78.74 & 6.86 \\
\hline 3 & 0.64 & 19.69 & 1.71 & 66.14 & 11.81 \\
\hline 4 & 0.44 & 24.09 & 2.76 & 60.15 & 11.19 \\
\hline
\end{tabular}




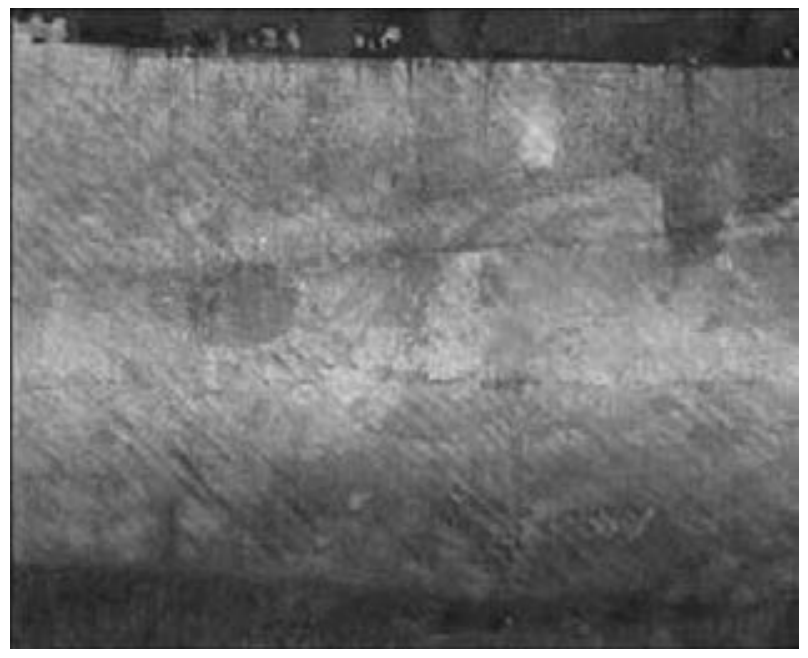

Figure 3. View of part of lining after repair surfacing using ANV-70BG electrodes and polishing of deposited metal

content of alloying elements, wt.\%: $12.44 \mathrm{Cr}$, $6.86 \mathrm{Ni}, 1.51 \mathrm{Mn}$, i.e. phase with martensite constituent is formed in the metal of transition zone together with austenite.

Thus, increase of welding current above $90 \mathrm{~A}$ rises structural and chemical inhomogeneity of metal of transition zone, that can promote for reduction of corrosion resistance and further initiate metal fracture during operation.

Recommendations of optimum modes and methods of welding using new special electrodes of E-10Kh28N14G2 type, providing higher repair quality and long-run serviceability than TsL-11 electrodes, were made as result of carried investigations during repair surfacing of corrosion- and cavitation-resistant layers of metal over operating surface of IC lining of hydropower units.

Testing of specimens of metal deposited using ANV-70BG (Figure 3) and TsL-11 electrodes, carried out at testing benches of laboratory of hydro-gas systems of the National Aviation University, showed that cavitation-wear resistance of metal deposited using ANV-70BG electrodes are 2 times higher than that made by TsL-11 electrodes and hydroabrasive-wear resistance rises by $10 \%$.

TU U 28.7-05416923-099 is registered for ANV-70BG electrodes and technology of their manufacture is mastered at the PWI Pilot Plant of Welding Consumables. The first industrial batches of electrodes were used in repair of IC lining of hydropower units at Kremenchug and Kakhovka HES.

\section{Conclusions}

1. Fracture of metal deposited using TsL-11 electrodes of E-08Kh20N9G2B type over operating surface of IC lining of hydropower units from St3sp steel is caused by formation of martensite phase in the transition zone, promoting corrosion, cracking and delamination of highly-alloyed layer.

2. Risk of formation of martensite in the transition zone and further fracture of deposited layer can be prevented using E-10Kh28N14G2 type electrodes at limitation of electrode diameter and value of welding current.

3. New welding electrodes ANV-70BG of E10Kh28N14G2 type were developed for repair surfacing of corrosion- and cavitation-resistant layer of metal over operating surfaces of lining from St3sp steel of IC of hydropower units. They provide for high corrosion and cavitation resistance of deposited metal.

1. Gotalsky, Yu.N. (1981) Welding of dissimilar steels. Kiev: Tekhnika.

2. Zemzin, V.N. (1966) Welded joints of dissimilar steels. Moscow: Mashinostroenie.

3. Frolov, K.V., Paton, B.E., Belyanin, P.N. (2006) Machine-building: Encyclopedia, Vol. 3, 4. Moscow: Mashinostroenie.

4. Pavlov, I.V., Antonets, D.P., Gotalsky, Yu.N. (1980) To problem of mechanism of transition layer formation in fusion zone of dissimilar steels. Avtomatich. Svarka, 7, 5-7.

Received 25.03.2015 


\title{
MATERIALS AND EQUIPMENT FOR SURFACING OF METAL HOT CUTTING KNIVES
}

\author{
A.P. ZHUDRA ${ }^{1}$, A.P. VORONCHUK ${ }^{1}$, A.A. FOMAKIN ${ }^{1}$ and S.I. VELIKY ${ }^{2}$ \\ ${ }^{1}$ E.O. Paton Electric Welding Institute, NASU \\ 11 Bozhenko Str., 03680, Kiev, Ukraine. E-mail: office@paton.kiev.ua \\ ${ }^{2}$ EDTB of the E.O. Paton Electric Welding Institute \\ 11 Bozhenko Str., 03680, Kiev, Ukraine. E-mail: office@paton.kiev.ua
}

\begin{abstract}
Analysis of operation conditions of knives for hot cutting of metal was performed and the main types of their working edge wear were determined. Self-shielded flux-cored strip PL-Np-40Kh2N6G2S2M2FB (PLAN183) and specialized machine UD-298M were developed for automatic surfacing of blooming mill hot cutting knives. Process automation is conducted through application of SU-360 control system, which is based on modern components. Application of the new flux-cored strip and specialized surfacing machine allowed 2 to 3 times increase of surfacing efficiency. Here, surfaced knife resistance increased 1.5 to 2 times. This development has been successfully introduced at Company «Arselor Mittal Krivoj Rog». 5 Ref., 2 Figures.
\end{abstract}

Keywords: surfacing, surfacing technology, flux cored strip, knives for hot cutting, deposited metal, surfacing machine, wear resistance

Knives for hot cutting of metal in blooming mill shears are an important element in the technology of rolled blanks production. Their resistance is largely dependent on operating efficiency of the mill as a whole. Earlier, and in some enterprises even up to now, the knives for hot cutting of metal were made from $6 \mathrm{KhV} 2 \mathrm{~S}$ steel that is not cost-effective because of the high consumption of expensive metal.

Later on the technology of manufacturing knives from steel 45 has become widely applied, in which their working edges are surfaced by submerged-arc process with PP-Np-35V9Kh3SF flux-cored wire [1]. Good results were also obtained at surfacing by electric arc and electroslag processes with sintered electrode strips LS25Kh5FMS and LS-20Kh5FMS [2].

Surfacing is performed in three layers with blank preheating up to $670-720 \mathrm{~K}$, usually, in batch-produced equipment. After surfacing, the knife is placed into a thermostat for delayed cooling. Before polishing of working surfaces, the surfaced knife is subjected to high-temperature tempering at $900-930 \mathrm{~K}$.

This technology is quite practicable, but it has a number of disadvantages: low surfacing efficiency, absence of specialized equipment and insufficient resistance of surfaced knives.

All that necessitated performance of work on development of new surfacing materials, technology and equipment.

(c) A.P. ZHUDRA, A.P. VORONCHUK, A.A. FOMAKIN and S.I. VELIKY, 2015
Development of surfacing materials was based on analysis of knife operating conditions and kinetics of their working edge wear in operation. Knives for hot cutting of metal are operated under the conditions of metal-on-metal friction at high specific contact loads with abrupt temperature variations. In particular, at the moment of cutting the knife working edges contact the metal heated up to $1400-1500 \mathrm{~K}$, and the coolant is water. Cutting time is 5 to $9 \mathrm{~s}$, and the overall working cycle varies from 45 to $90 \mathrm{~s}$.

The process of wearing of knife working edges can be divided into three stages. Wear starts from fracture of small metal volumes at the cutting edge tip, when its shape is violated as a result of shearing and tearing out of microvolumes heated up to high temperatures. The leading factor here is plastic and diffusion interaction with the metal being cut.

The second wear stage is characterized by thermal and force action on the cutting edge and, consequently, by its rounding-off. The leading factor in this case is crushing with shear of cutting edge surface macrolayers that greatly promotes formation of thermal cracks in it. This period can be classified as mechanical wear under plastic deformation.

At the third stage, after reaching more than $6 \mathrm{~mm}$ rounding-off radius of cutting edge, working surface wear is due to breaking up of oxidized surface layer, its further corrosion and cracking, as well as contacting surface seizure in microlocal volumes at greatly changed pattern of thermal and force impact. The determinant aspect in this 


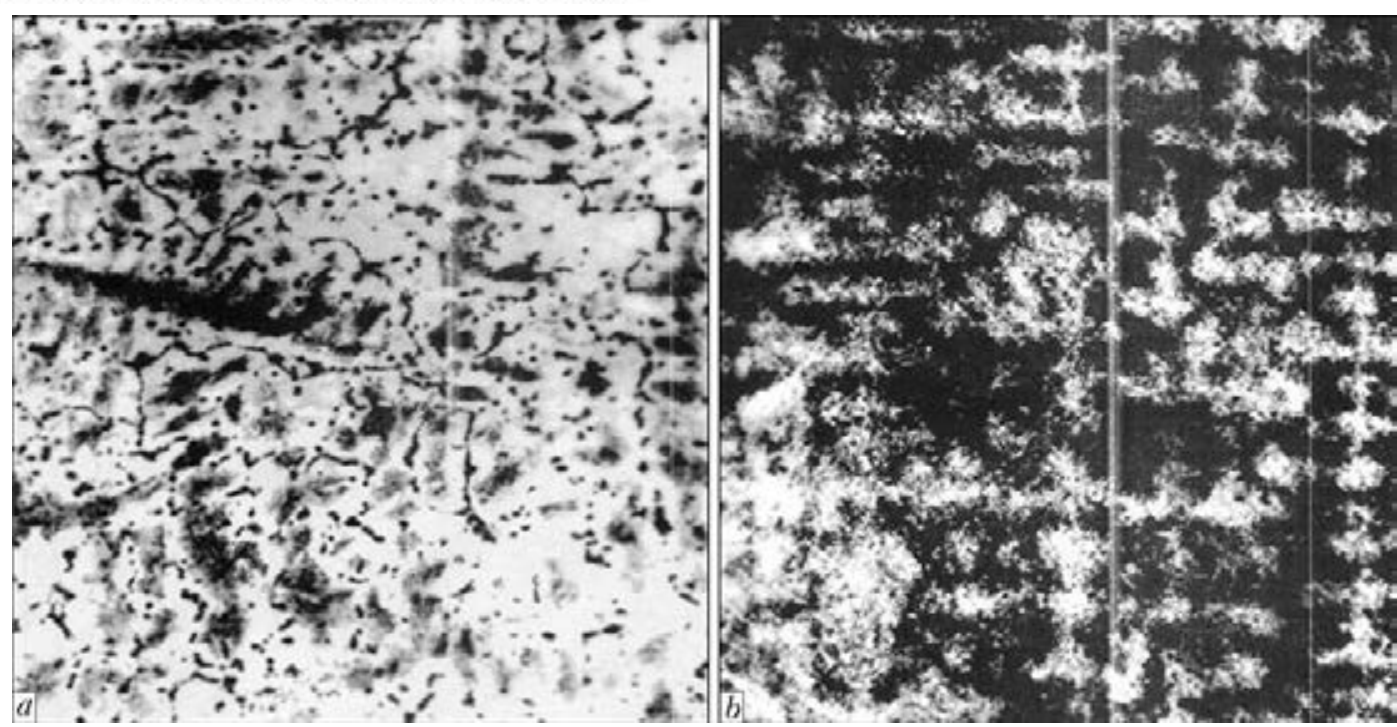

Figure 1. Microstructure $(\times 320)$ of $40 \mathrm{KhN6G2S2M} 2 \mathrm{FB}$ deposited layer before $(a)$ and after $(b)$ heat treatment

period, most probably, is corrosion-mechanical wearing.

Thus, the deposited metal should have good thermal resistance, as well as thermal shock resistance, ability to preserve its structure at heating and hardness, required to provide the working edge serviceability. It is known that heat-resistant tool steels have such a set of properties [3].

In development of new electrode material for surfacing hot cutting knives several types of deposited metal, namely 20Kh4V2M2, 30Kh4V2M2G2BFST, 40Kh2N6G2S2M2FB and 40Kh2N6K6M2G2SF were tested under the pilot-production conditions. Derived service and cost indices were the basis for selection of 40Kh2N6G2S2M2FB deposited metal. To obtain deposited metal of this type, self-shielded flux-

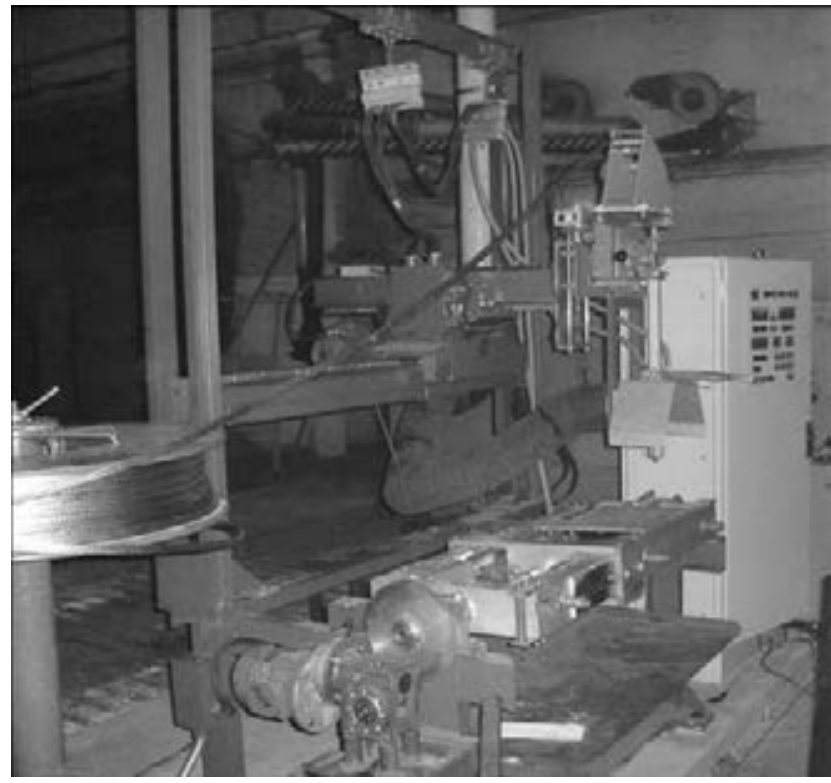

Figure 2. UD-298M machine for surfacing hot cutting knives cored strip was developed, which was later on named PL-AN183 [4, 5].

Structure of metal deposited with this fluxcored strip (Figure 1, $a$ ) consists of fine-needled martensite, residual austenite with a considerable quantity of excess phases in the form of carbides and intermetallics oriented, mainly, along the boundaries of grains $\left(H_{\mu}-550-610\right)$. After heat treatment (annealing-quenching-tempering) the deposited metal acquires the structure given in Figure 1, $b$. Deposited metal hardness after heat treatment is equal to $H R C$ 47-54.

An essential advantage of the proposed technology of open-arc surfacing with flux-cored strip is the high efficiency of process due to increase of parameters and reduction of the amount of deposited metal per knife. At surfacing of one of the typesizes of knives flux-cored wire consumption is $25 \mathrm{~kg}$ per knife, and at surfacing with self-shielded flux-cored strip PL-AN183 the same characteristic did not exceed $15 \mathrm{~kg}$. This was achieved due to more favourable formation of the deposited layer that enabled a marked reduction of allowances for further machining. Higher efficiency is also promoted by reduction of working time consumption for auxiliary operations, as operations related to slag crust removal, flux collection and sieving, were eliminated completely. All that on the whole allowed 2 to 3 times reduction of the time of one knife surfacing.

Technological advantages of flux-cored strip are the most completely implemented at application of specialized equipment - UD-298M surfacing machine (Figure 2) [4]. Process automation is performed due to application of SU-360 control system.

System of surfacing process control is based on modern components and consists of the following main parts: 
- programmable controller OMRON of CQM1H type with software for surfacing process control;

- frequency electric drives OMRON-YASKAWA for asynchronous motors (machine displacement and electrode feeding).

\section{Specification of UD-298M machine}

Rated mains voltage ( $50 \mathrm{~Hz}$ frequency), V

Maximum welding current, A ............ not more than 1000 Arc voltage, $\mathrm{V}$..................................... 26-38

Electrode strip feed rate, $\mathrm{m} / \mathrm{h}$............. not more than 40

Speed of surfacing head horizontal displacement

along the weld (smooth adjustment), $\mathrm{m} / \mathrm{h}$ $10-30$

Speed of surfacing head transverse displacement,

$\mathrm{m} / \mathrm{h}$

$2-100$

Maximum horizontal displacement of

surfacing head, mm ..................... not more than 1125

Maximum transverse displacement of

surfacing head, $\mathrm{mm} \ldots \ldots \ldots \ldots \ldots \ldots \ldots$ not more than 550

Maximum vertical displacement of surfacing

head, $m m$................................ not more than 300

Height of deposit center from floor level, mm ....... 800 820

Consumed power, kV.A ................. not more than 40

Surfaced knife dimensions, $\mathrm{mm}$ :

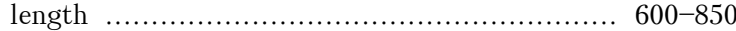

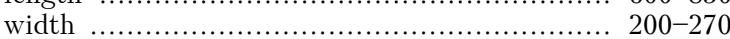

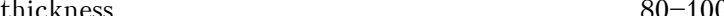

Weight of repaired knife, $\mathrm{kg}$.............. not more than 150

Machine overall dimensions, $\mathrm{mm}$ :

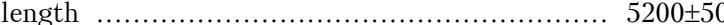

width ...................................... 2300 \pm 50

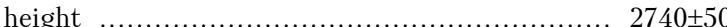

Weight, kg, not more than:

surfacing machine

740

control cabinet

Thus, the developed technology of open-arc surfacing of metal hot cutting knives with flux- cored strip, in combination with new equipment, allows hardening knife working edges in the automatic mode. Surfacing process efficiency is markedly increased. Time for surfacing a knife of average typesize $700 \mathrm{~mm}$ long is equal to about $2 \mathrm{~h}$, including auxiliary operations. Four working edges, each in three layers, are surfaced. Application of flux-cored strip PL-AN183 increases the hardened part resistance by 1.5 to 2 times, compared to knives surfaced by PP-Np-35V9Kh3SF wire. This development has been successfully introduced at Company «Arselor Mittal Krivoj Rog».

1. Paton, B.E. (1974) Technology of fusion electric welding of metals and alloys. Moscow: Mashinostroenie.

2. Malikin, V.L., Oparin, L.I. (1984) Service properties of metal of 5X4V2M2FS and 25X5FMS type deposited by electric arc and electroslag methods with sintered electrode strips. In: New processes of surfacing, properties of deposited metal and transition zone, 48-53. Kiev: PWI.

3. Geller, Yu.A. (1983) Tool steels. Moscow: Metallurgiya.

4. Zhudra, A.P., Voronchuk, A.P. (2010) Wear-resistant cladding by flux-cored strips. Svarshchik, 6, 6-9.

5. Zhudra, A.P., Voronchuk, A.P. (2012) Cladding flux-cored strips (Review). The Paton Welding J., 1, $34-38$.

Received 20.03.2015 


\title{
STRUCTURE AND PROPERTIES OF RAILWAY WHEEL SURFACE AFTER RESTORATION SURFACING AND SERVICE LOADING
}

\author{
L.I. MARKASHOVA, V.D. POZNYAKOV, A.A. GAJVORONSKY, \\ E.N. BERDNIKOVA and T.A. ALEKSEENKO \\ E.O. Paton Electric Welding Institute, NASU
}

11 Bozhenko Str., 03680, Kiev, Ukraine. E-mail: office@paton.kiev.ua

\begin{abstract}
Presented are the investigations of effect of composition of surfacing consumables on structure and phase composition of deposited metal of surfacing zones (surface, fusion line, HAZ) in restoration of railway wheels from grade 2 steel. Information received at different structural layers (from grain to dislocation) was used for analytical estimations of effect of parameters of forming structures on mechanical properties $\left(\sigma_{0.2}, K_{1 c}\right)$ of railway wheels, reconstructed by surfacing, before and after operation. Role of structural factors in change of level of local internal stresses $\tau_{\text {l.in }}$, i.e. sources of crack formation in subsurface layers of deposited metal, was investigated. It is determined that surfacing consumables of bainite and bainitemartensite classes provide for high indices of mechanical properties and crack resistance of railway wheels after restoration repair and operation. 9 Ref., 1 Table, 5 Figures.
\end{abstract}

$\boldsymbol{K} \boldsymbol{e} \boldsymbol{y} \boldsymbol{w} \boldsymbol{o} \boldsymbol{r} \boldsymbol{s}:$ surfacing, railway wheels, deposited metal, heat-affected zone, structure, phase composition, mechanical properties, crack resistance

Today problem of increase of service reliability and life of machines, mechanisms, parts etc. becomes more and more relevant. This problem is particularly critical for separate heavy loaded basic parts and mechanisms of running gear of cars and engines, main element of which is a wheel having direct contact with rail. Surface of wheel flange is subjected to the most significant wear in process of operation. Regardless different technological developments of restoration repair, problem of strength, reduction of wear level and crack resistance of railway wheels [1-3] is still relevant.

In relation to restoration surfacing of surface of wheel flange, the authors carried out preliminary examinations of structural-phase changes in metal close to the roll surface of railway wheels [4]. Role of each of structural factors (phase constituents, grain, subgrain and dislocation structures, phase precipitates etc.) in change of strength and crack resistance of metal of railway wheels was investigated based on obtained results. The results of experimental investigations, received at different structural levels, i.e. from macro (grain) to micro (dislocation), made a basis for performance of analytical estimation of specific (differential) input of separate structural-phase factors and parameters in change of general (integral) value of mechanical charac- teristics, namely strength $\sigma_{0.2}$, crack resistance $K_{1 c}$ as well as local internal stresses $\tau_{\text {l.in }}$ being a potential source of nucleation and propagation of cracks in investigated structural microareas [4-7].

As a result after operation of railway wheels, dispersed structures (ferrite-carbide mixture), band structures with their reorientation along metal depth (Figure 1, $a$ ) and rolled nonmetallic inclusions (NMI) (Figure 1, b) was formed in metal close to the roll surface (zones $1 \mathrm{R}-4 \mathrm{R}$, Figure $1, d$ ), in particular in 3R zone (transfer from roll area to wheel flange). Increased dislocation density (up to $(3-4) \cdot 10^{11} \mathrm{~cm}^{-2}$ ) is observed along the boundaries of these structural elements in zones of reorientation bands at the boundaries of cementite/ferrite $(\mathrm{C} / \mathrm{F})$ connection in pearlite constituent as well as in zones of «rolling» of NMI. This results in rise of local internal stresses along the boundaries of these structural elements up to $\tau_{1 . \text { in }} \sim 5200-7000 \mathrm{MPa}$ (makes $\left.(0.67-0.90) \tau_{\text {theor }}\right)$, which are potential sources of crack formation (Figure 1,c).

It was shown that the most significant structural changes in metal take place in transient zone from roll surface to flange with maximum change by depth to $200-300 \mu \mathrm{m}$, which result in significant strengthening (1.7-2.3 times) of subsurface layers and reduction of fracture toughness level (by $50 \%$ ) and noticeable increase (3-4 times) of local internal stresses in comparison 

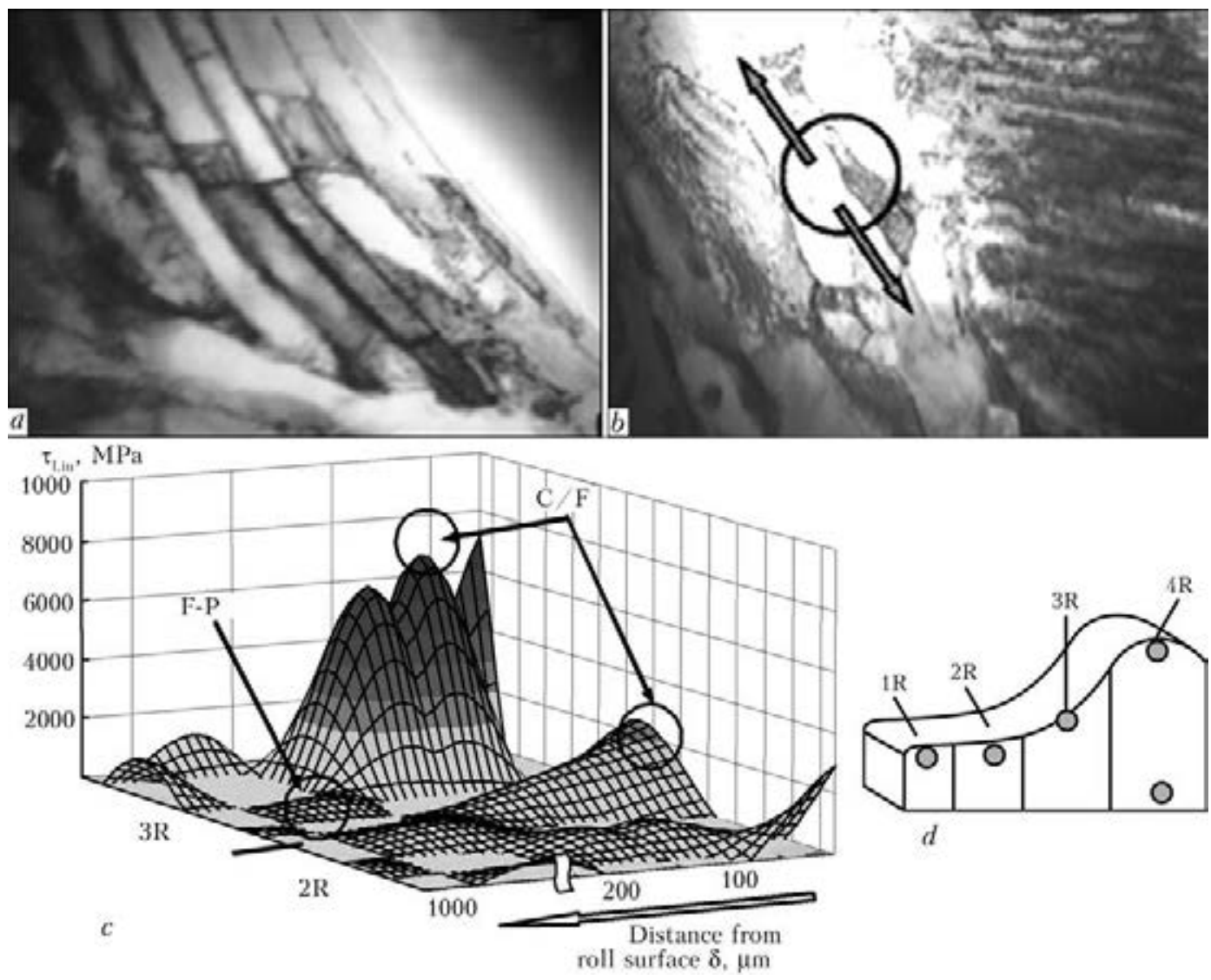

Figure 1. Fine structure $(a, b-\times 30000)$ of metal of roll zone, and local internal stresses $\tau_{\text {l.in }}(c)$ forming in subsurface layers at $\delta=0-200 \mu \mathrm{m}$ in metal of wheels in zones of roll surface $2 \mathrm{R}$ and 3R $(d)$ and their changes in moving from roll surface

with initial metal. This is explained by presence of microcracks in metal of subsurface layers. Increase of reliability of the wheel subjected to surfacing restoration requires preliminary removal of subsurface layer of metal in the place of planned surfacing in order to eliminate formation of subsurface cracks.

Next investigations of reasons of railway wheel fracture were carried out after their restoration surfacing depending on composition of welding wires, providing production of welds with ferrite-pearlite (F-P) and bainite-martensite (B-M) structures [8, 9]. Surfacing was carried out by mechanized method in $\mathrm{CO}_{2}$ using Sv-08G2S (F-P weld) and PP-AN180MN (B-M weld) wires. Chemical composition of produced weld metal is given in the Table.

Comparison of structural changes and phase composition of deposited metal and HAZ from point of view of effect on indices of strength, plasticity and crack resistance showed the following. Using PP-AN180MN wire promotes for formation of the most optimum B-M structure, which provides for absence of rapid gradients on size of structural constituents and microhardness, uniform phase composition and noticeable refin- ing of structure of deposited metal (in comparison to F-P weld).

The results of calculation estimations of fracture toughness $K_{1 c}$ for F-P and B-M welds as well as analysis of combination of $K_{1 c}$ and strength properties $\sigma_{\mathrm{y}}$ showed the following. Value of $K_{1 c}$ is somewhat higher (on average by $20 \%$ ) in surfacing using PP-AN180MN (B-M weld), that is promoted by formation of $\mathrm{M}-\mathrm{B}$ structure, refinement of grain, formation of substructure and uniform distribution of dislocations (Figure 2, b). High level of strength (Figure 2, a) is also observed at that. This indicates good combination of strength and plasticity characteristics of the deposited metal. Low $K_{1 c}$ index is typical for F-P weld, that is related with formation of gradient on sizes of grain structure and coarse grain pearlite constituent (Figure 2,c).

Aim of further investigations lied in examination of structure and mechanical properties of railway wheels, being repaired by restoration surfacing after operation, as well as analysis of effect of structural factors on their mechanical properties and crack resistance.

The work was carried out on welded joints of wheel steel 2 with, wt.\%: $0.55-0.65 \mathrm{C}$; $0.5-$ $0.9 \mathrm{Mn} ; 0.22-0.45 \mathrm{Si} ; \leq 0.1 \mathrm{~V}$, not more than 
Chemical composition of weld metal, wt.\%

\begin{tabular}{||l|c|c|c|c|c|c|c||}
\hline \multicolumn{1}{|c|}{ Wire grade } & $\mathrm{C}$ & $\mathrm{Mn}$ & $\mathrm{Si}$ & $\mathrm{Cr}$ & $\mathrm{Ni}$ & $\mathrm{V}$ & Mo \\
\hline Sv-08G2S & 0.10 & 2.10 & 0.95 & - & - & - & - \\
\hline Sv-08KhM & 0.12 & 1.36 & 0.60 & 0.60 & - & - & 0.42 \\
\hline Sv-08KhMF & 0.12 & 1.25 & 0.62 & 0.61 & - & 0.10 & 0.36 \\
\hline PP-AN180MN & 0.12 & 1 & 0.35 & 0.67 & 0.80 & 0.10 & 0.40 \\
\hline
\end{tabular}

$0.03 \mathrm{P}$ and $0.035 \mathrm{~S}$ (GOST 10791-89). Welding wires Sv-08KhMF, SV-08KhM (bainite-ferrite class) and PP-AN180MN (bainite-martensite class) were used as surfacing consumables (see the Table).

Structural-phase, concentration changes, nature of distribution and density of defects of crys-
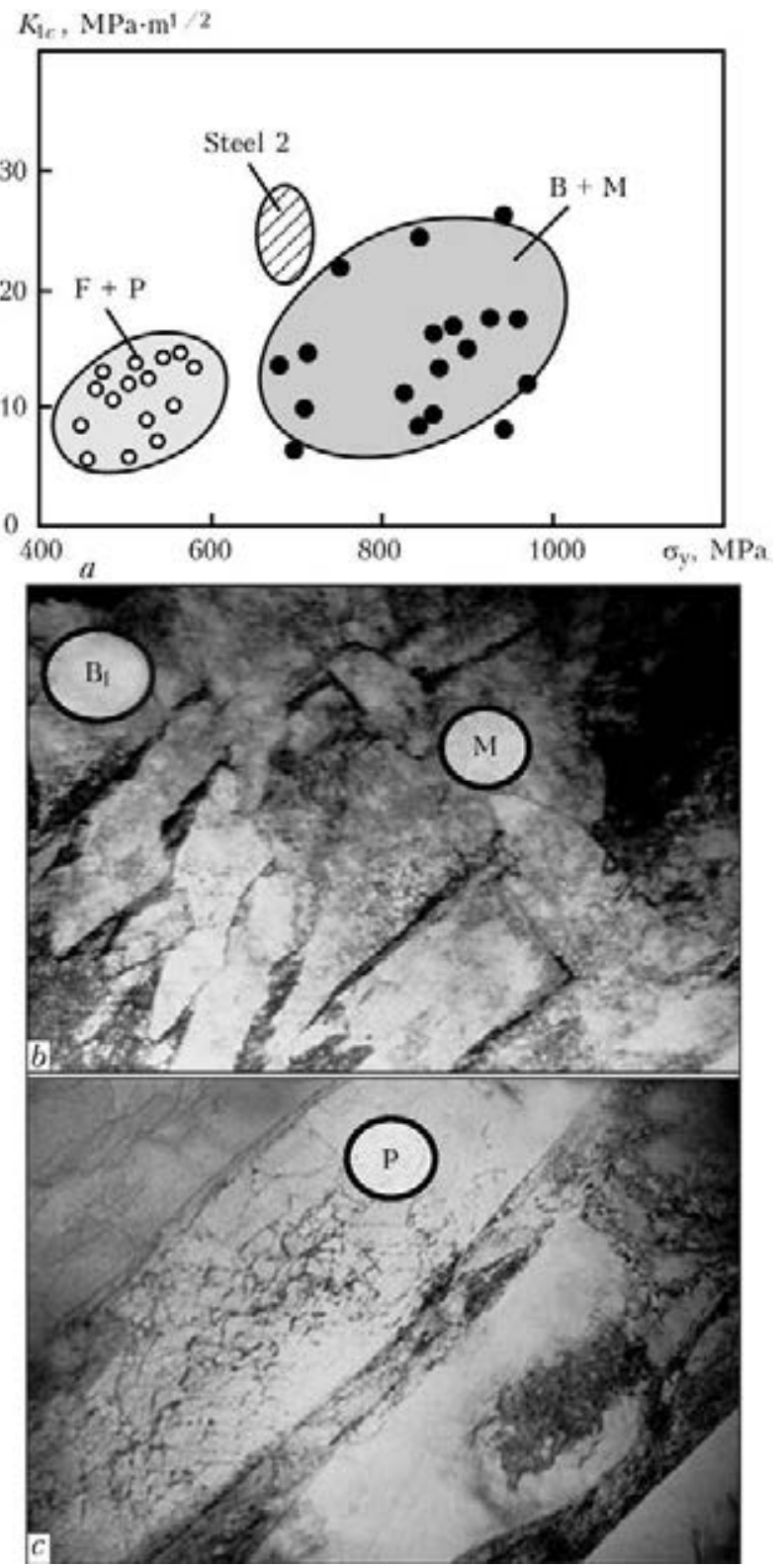

Figure 2. Comparison $(a)$ of calculation indices of mechanical properties of deposited metal and corresponding finegrain structure $(b)$ of lower bainite and martensite, and coarse-grain pearlite constituent $(c-\times 20000)$ talline lattice in different zones of welded joints were studied using complex of methods, including optical metallography, Philips analytical scanning electron microscopy SEM-515 and JEOL transmission electron microscopy JEM200CX.

The following was determined as a result of examination of NMI structure, their size and distribution, phase constituents (ferrite $\mathrm{F}$, pearlite $\mathrm{P}$, upper $\mathrm{B}_{\mathrm{u}}$ and lower $\mathrm{B}_{1}$ bainite), their volume fraction $\mathrm{V}, \%$, grain size $D_{\mathrm{g}}$ as well as changes of microhardness $H \mathrm{~V}$ along the zones of welded joint, namely deposited metal, fusion line (FL) and HAZ at depth $\delta$ from external surface of wear.

Using Sv-08KhMF and Sv-08KhM produce deposited metal having typical B-F structure; preferably silicate NMI with $d_{\mathrm{nmi}} \sim 15-20 \mu \mathrm{m}$ (separate) and dispersed $\left(d_{\mathrm{nmi}} \leq 2 \mu \mathrm{m}\right)$ with volume fraction up to $20 \%$ are formed. In the case of Sv-08KhM, 1.5 times increase of volume fraction of dispersed NMI in comparison to $\mathrm{Sv}^{-}$ $08 \mathrm{KhMF}$ is observed at $\delta \sim 0-50 \mu \mathrm{m}$. Using PPAN-180MN provides for formation of M-B structure along depth of the deposited metal at reduction of crystalline size approximately in 1.4 times, increase of $H V$ around by $5-15 \%$ in comparison to B-F welds in presence of mainly dispersed NMI with $d_{\mathrm{nmi}} \leq 1 \mu \mathrm{m}$.

The following can be observed for all investigated types of deposited metal, i.e. dispersion of structure at increase of its microhardness per 10-25 \% (in F-P welds) and per 5-10 \% (in B-M weld), formation of elongated bands of deformation with $\kappa \sim 5-12$ (F-P welds) and $\kappa \sim 6-8$ (B-F welds) oriented at $\sim 20-30^{\circ}$ angle relatively to external surface.

It is determined that the most optimum structure of deposited metal (from point of view of uniform increase of microhardness, refinement of structure, dispersion of NMI and their uniform distribution) is formed in the case of PPAN180MN application. Metal of such welds is characterized by absence of rapid gradients in microhardness as well as size of structural constituents. Microhardness of structural constituents at its uniform increase in further HAZ areas rises by $12 \%$ at transfer into wheel steel in coarsegrain area. Such structural changes, obviously, should provide for uniform increase of strength properties in railway wheels repaired using surfacing.

Methods of scanning electron microscopy were applied for examination of peculiarities of change of fine structure (width of laths, size of substructure, nature of dislocation structure). Band struc- 

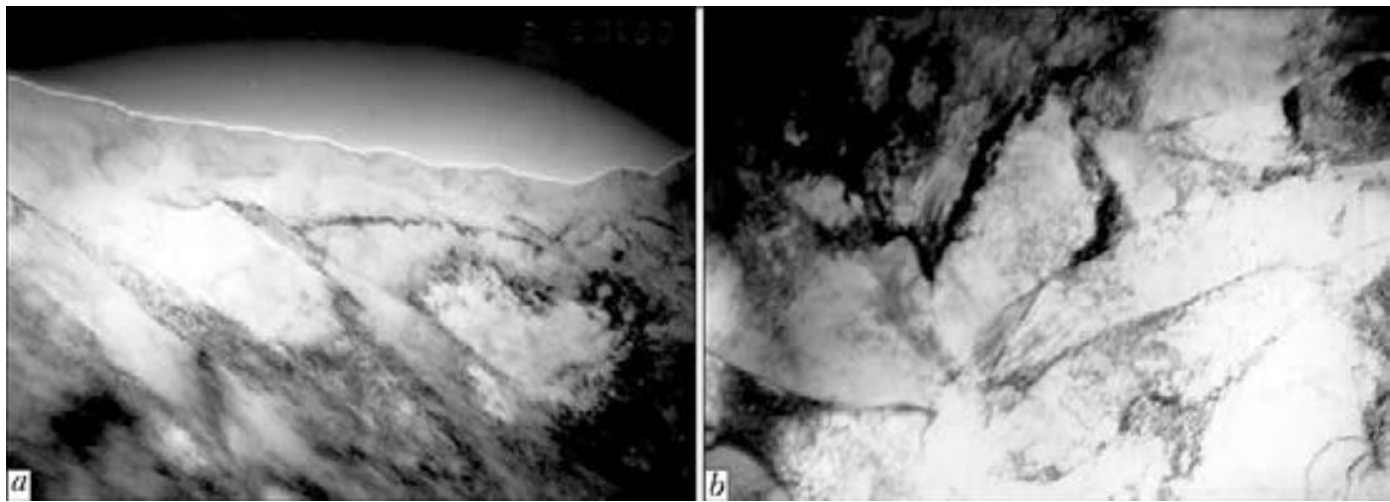

Figure 3. Fine structure $(\times 30000)$ of deposited metal near wear surface in surfacing using PP-AN180MN wire: $a-$ band structures; $b-$ lower bainite fragmentation at $\delta \sim 200 \mu \mathrm{m}$

tures are formed (Figure 3, a) at $\delta \sim 0-100 \mu \mathrm{m}$ distance (PP-AN180MN) from external surface after service loading. Structure fragmentation is also observed, i.e. width of deformation bands of $\sim 0.15-0.5 \mu \mathrm{m}$, size of fragments (or substructure) $d_{\mathrm{s}} \sim 0.3-0.5 \mu \mathrm{m}$ at increase of dislocation density up to $\rho \sim(1-2) \cdot 10^{11} \mathrm{~cm}^{-2}$ (Figure $3, b$ ). Fragmented structure of lower bainite with width of bainite lath of $\sim 0.2-0.6 \mu \mathrm{m}$ is formed at transfer to FL (at $\delta \sim 0-200 \mu \mathrm{m}$ from it). Size of subgrains of ferrite constituent is around $d_{\mathrm{s}}$ $\sim 0.5-1 \mu \mathrm{m}$. Dislocation density in weld metal makes $\rho \sim(4-6) \cdot 10^{10} \mathrm{~cm}^{-2}$.

HAZ metal at transfer into wheel steel consists of pearlite, ferrite, ferrite fringes of $\sim 0.5-1.2 \mu \mathrm{m}$ thickness, size of cementite and ferrite plates in pearlite was $\sim 0.02-0.03 \mu \mathrm{m}$ and $\sim 0.07-0.1 \mu \mathrm{m}$, respectively. Size of subgrain of ferrite constituent rises on average in 1.3 times and makes $d_{\mathrm{s}} \sim$ $\sim 0.5-1.5 \mu \mathrm{m}$. Dislocation densityof $\mathrm{HAZ}$ in area I makes $\rho \sim(2-4) \cdot 10^{10} \mathrm{~cm}^{-2}$.

Thus, refining of substructure (in 2 times) at uniform 2-3 times increase of dislocation density takes place in the deposited metal from the side of wear surface at $\delta \sim 0-100 \mu \mathrm{m}$ distance from external surface. Such structural changes (dis-

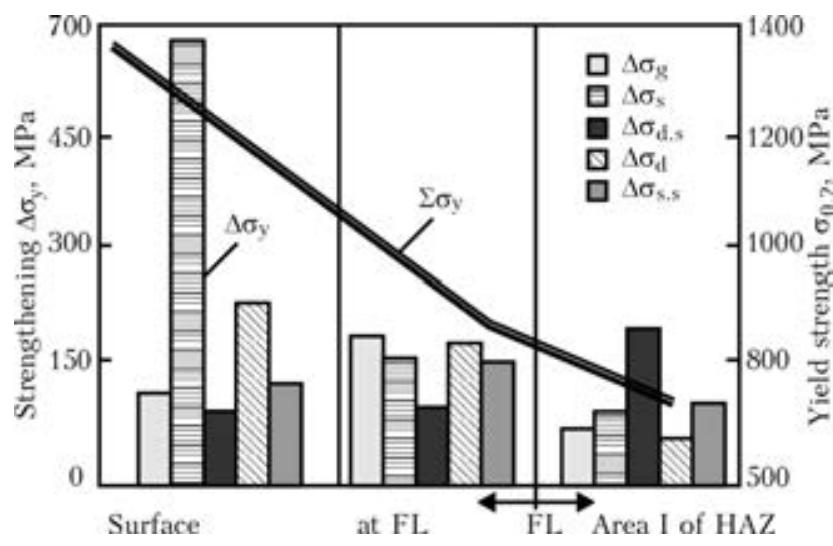

Figure 4. Diagrams reflecting input of grain $\Delta \sigma_{g}$, subgrain $\Delta \sigma_{\mathrm{s}}$, dispersed $\Delta \sigma_{\mathrm{d} . \mathrm{s}}$, dislocation $\Delta \sigma_{\mathrm{d}}$ and solid solution $\Delta \sigma_{\mathrm{s} . \mathrm{s}}$ strengthening in change of yield strength in deposited (PPAN180MN) metal and HAZ area I persion of structure at uniform distribution of dislocation density), obviously, should not promote for formation of local concentrators of internal stresses and reduction of metal crack resistance.

Comparison of strengthening effect of all structures forming in examined welds after service loading shows increase of general level of strength in surface layers of deposited metal. Dispersion of structure $\left(\Delta \sigma_{\mathrm{s}} \sim 682 \mathrm{MPa}\right)$ and uniform increase of dislocation density $\left(\Delta \sigma_{d} \sim 200-\right.$ $283 \mathrm{MPa}$ ) provide for increase of general level of strengthening on average by $60 \%\left(\Sigma \sigma_{0.2}=\right.$ $=1383 \mathrm{MPa}$ in comparison to weld metal, where $\Sigma \sigma_{0.2}=845 \mathrm{MPa}$ at $\delta \sim 0-200 \mu \mathrm{m}$ (PP-AN180MN, Figure 4). At that, values of $K_{1 c}$ in surface layers (at $\delta \sim 0-200 \mu \mathrm{m}$ ) of the deposited metal after service wear are approximately at one level. However, higher level of strength (by $16 \%$ higher in comparison to $\mathrm{Sv}-08 \mathrm{KhMF}$ ) is observed in the case of PP-AN180MN. It indicates good combination of mechanical characteristics of the deposited metal after wear.

Results of calculation estimations of local internal stresses $\tau_{1 . \text { in }}$ in comparison of their values with theoretical strength of material, given in

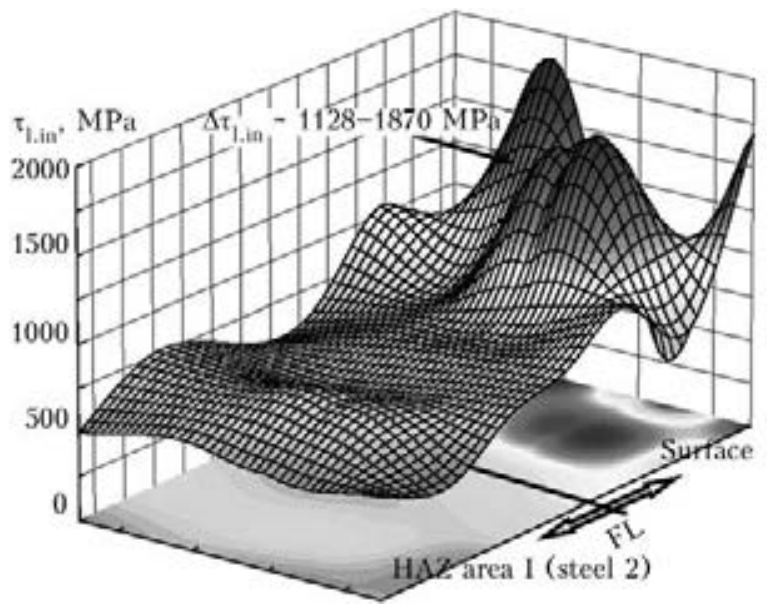

Figure 5. Level of local internal stresses forming in deposited (PP-AN180MN) metal after wear 
Figure 5, show the following. $\tau_{1 . \text { in }} \sim 740-$ $1100 \mathrm{MPa}$, making $(0.09-0.13) \tau_{\text {theor }}$, and uniformly distributed along weld metal are observed in the deposited metal. Level of forming internal stresses achieves $\tau_{\text {l.in }} \sim 1870 \mathrm{MPa}\left(0.22 \tau_{\text {theor }}\right)$ due to 2 times increase of dislocation density from $\rho \sim(4-6) \cdot 10^{10}$ up to $\rho \sim(1-2) \cdot 10^{11} \mathrm{~cm}^{-2}$ in approaching to external surface at $\delta \sim 0-200 \mu \mathrm{m}$ distance.

Thus, from point of view of strength indices, plasticity and crack resistance, the most optimum structure of deposited metal after wear is formed in PP-AN180MN application.

1. Pavlov, N.V., Kozubenko, I.D., Byzova, N.E. et al. (1993) Hardfacing of flanges of car wheel pair. $Z h$. D. Transport, 7, 37-40.

2. Sarzhevsky, V.A., Gajvoronsky, A.A., Gordonny, V.G. et al. (1996) Influence of technological factors on structure and properties of HAZ metal in repairrestoration hardfacing of flanges of car solid-rolled wheels. Avtomatich. Svarka, 3, 22-27, 33.
3. Gudkov, A.V., Lozinsky, V.N. (2008) New technological and technical solutions in field of railway transport welding. Vestnik VNIIZhT, 6, 3-9.

4. Markashova, L.I., Poznyakov, V.D., Gajvoronsky, A.A. et al. (2011) Evaluation of strength and crack resistance of railway wheel metal after long-term service. Fiz.-Khimichna Mekhanika Materialiv, 6, 73-79.

5. Goldshtejn, M.I., Litvinov, V.S., Bronfin, B.M. (1986) Physics of metals of high-strength alloys. Moscow: Metallurgiya.

6. Romaniv, O.N. (1979) Fracture toughness of structural steels. Moscow: Metallurgiya.

7. Gordienko, L.K. (1973) Ultrafine grain in metals. Moscow: Metallurgiya.

8. Gajvoronsky, A.A., Poznyakov, V.D., Markashova, L.I. et al. (2012) Influence of deposited metal composition on structure and mechanical properties of reconditioned railway wheels. The Paton Welding J., 8, 16-22.

9. Markashova, L.I., Poznyakov, V.D., Berdnikova, E.N. et al. (2014) Effect of structural factors on mechanical properties and crack resistance of welded joints of metals, alloys and composite materials. Ibid., 6/7, 22-28. 


\title{
COBALT-BASED ALLOYS FOR SURFACING
}

\author{
R. ROSERT \\ RCT GmbH, Dresden, Germany. E-mail: reinhard.rosert@gmx.de
}

\begin{abstract}
Many modern steel structures are characterized by high mechanical properties of joints, as well as good corrosion resistance of the applied materials. Coating of base materials with selected mechanical properties using surfacing by flux-cored wire based on cobalt is a reliable way to obtain the desired combination of properties, such as corrosion and wear resistance. The advantages of flux-cored wires by providing a diverse chemical composition of the deposited metal, reliability and high efficiency are proved in many industrial applications. This article describes examples of using Co-based flux-cored wires in two different welding processes (surfacing using TIG and MIG method). Different slag systems of wires and their properties are presented. Moreover a comparison with other arc surfacing processes is made. On the specific examples the diversity of applications of flux-cored wire based on cobalt is shown. The influence of different parameters on surfacing process is discussed. 11 Ref., 4 Tables, 10 Figures.
\end{abstract}

Keywords: arc surfacing, metal flux-cored wire, cobalt base, production, alloying, standardization, properties, application

Production of Co-based flux-cored wires for surfacing. Flux-cored wires based on cobalt for surfacing are rolled. So far only the flux-cored wires with overlapping strip are known ( $\mathrm{Fi}^{-}$ gure 1).

Production of cobalt flux-cored wires of seamless type is not possible so far due to a lower degree of filling. The flux-cored wires based on cobalt are metal powdered ones (M-type). Unlike medium- and highly-alloyed flux-cored wires for surfacing of corrosion- and wear-resistant layers, which mainly consist of non-alloyed strip and highly-alloyed filling, the high-quality alloyed flux-cored wires based on cobalt are composed of pure cobalt and filler containing alloying elements, deoxidizers, elements for stabilization of arc and slag-forming ones.

To achieve the accurate roundness of wire before its winding on the coil in manufacture after rolling stages the drawing is applied using accurate diamond dies. The principle of wire manufacture is shown in Figure 2.

The metal flux-cored wires provide a very finedrop metal transfer in surfacing and are characterized by absence of slag on the surface. The particles of manganese and silicate oxides located on the surface of the weld are easily removed. Except of high deposition rate using wires of M-type a significant penetration of base metal is achieved. These flux-cored wires can be used in all spatial positions. The use of pulsed technique is preferable. In general, the wires of M-type are surfaced in shielding gases according to the stand- ard DIN EN ISO 14175. Here, gases of the class 11 or M1x are applied. Cobalt flux-cored wires are also applied as a filler material in surfacing using non-consumable tungsten electrode (TIG method). In this case the wire feed can be realized in cold or preheated conditions. Moreover, fluxcored wires based on cobalt can be surfaced without shielding gas. In this case, the flux-cored wires belong to the type $U$. They are used for single and multipass surfacing in flat position. Filling of such wires consists of alloying elements, stabilizers of arc and also gas-forming elements, as well as slag-forming addition is possible.

Alloying groups. In Table 1 the conventional welding processes used for corrosion-resistant surfacing by cobalt flux-cored wires, types of protection and positions of surfacing are shown.

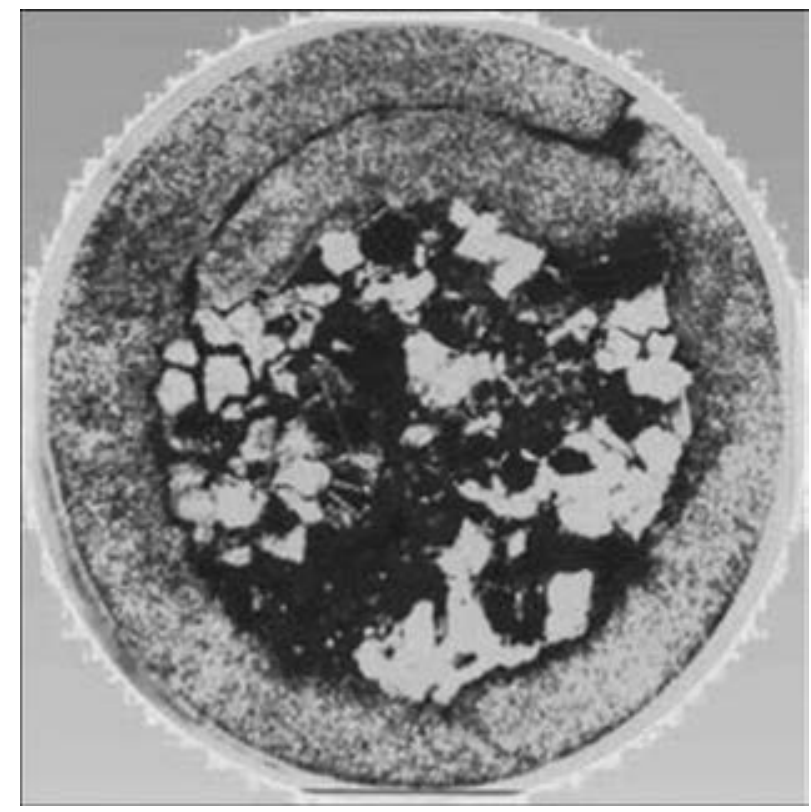

Figure 1. Rolled flux-cored wire with strip overlapping 


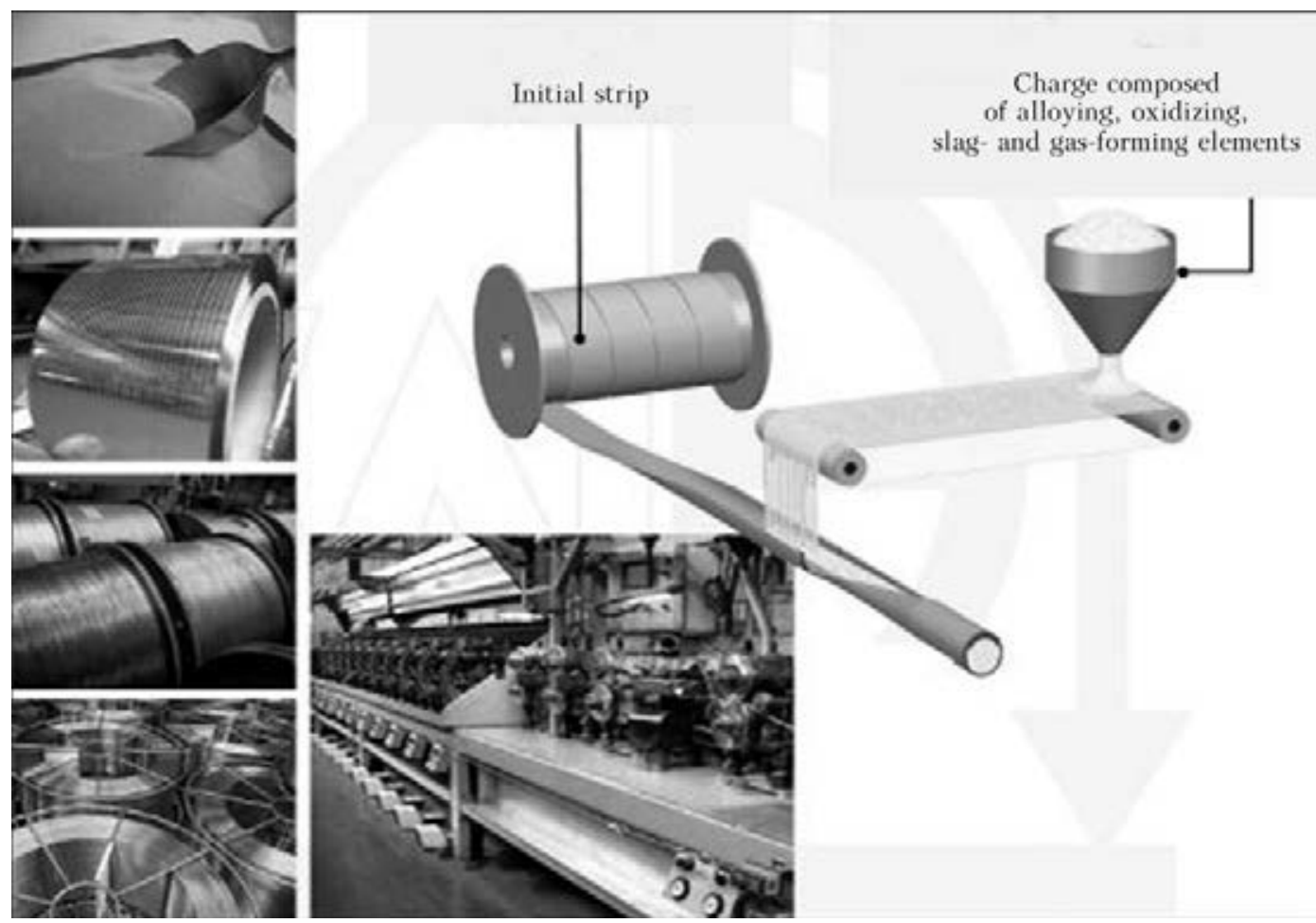

Figure 2. Production of Co-based flux-cored wires

Standard alloys. Table 2 the typical alloys are illustrated with hardness values of weld metal at the room temperature and up to $800^{\circ} \mathrm{C}$. Further the main fields of their application are shown. Today alloys 21 and 6 are among those, which are going to find the widest application in industry, in particular for surfacing of valve seats and sealing surfaces in oil or gas industry. These alloys possess an optimum combination of resistance to abrasion, corrosion and impact effects, at that, deposits have no cracks at strictly controlled surfacing parameters.

State-of-the-art of standardization. The international standardization (EN and ISO standards) as well as national regulations allows clas-

Table 1. Alloying groups

\begin{tabular}{||l|c|c||}
\hline \multicolumn{1}{|c|}{ Alloying group } & \multicolumn{2}{c||}{ Cobalt base } \\
\hline \multirow{2}{*}{ WA Cored Wires TM } & \multicolumn{2}{c||}{ STELLOY } \\
\cline { 2 - 3 } & $\mathrm{G}$ & $\mathrm{O}$ \\
\hline $\begin{array}{l}\text { Welding process acc. to } \\
\text { N ISO 4063 }\end{array}$ & 139 & 114 \\
\hline Welding process acc. to AWS & FCAW-G & FCAW \\
\cline { 2 - 3 } & FCAW-P & - \\
\hline AWS classification: & ERCCoxxx \\
Filler type & Eetal powder & Self-shielding \\
\cline { 2 - 3 } & M & U \\
\hline Welding position & PA & PA \\
\hline $\begin{array}{l}\text { Shielding gas acc. to } \\
\text { ISO 14175 }\end{array}$ & I1, M1x & - \\
\hline
\end{tabular}

sifying filler materials for surfacing. However, over flux-cored wires there is a special situation. Not for each alloying system the standard is available. Table 3 provides overview of state-of-theart of classification standards for arc surfacing.

Properties of surfacing coatings. Cobalt flux-cored wires are classified in the frames of materials for surfacing according to EN 14700 and in ASME II C SFA 5.21 even the standard materials for surfacing based on cobalt can be found.

Influence of technological parameters. Arc surfacing using flux-cored wire usually has a higher efficiency (up to $10 \mathrm{~kg} / \mathrm{h}$ or $0.4 \mathrm{~m}^{2} / \mathrm{h}$ ) as compared to solid wire electrodes, but has no their disadvantages in surfacing.

The penetration profile is similar to the profile in arc surfacing using electrodes. However the penetration depth can be reduced. In surfacing using cobalt flux-cored wires it is possible to control the penetration and thereby the iron content in the deposited layer (Figures 3 and 4).

It requires optimization of process parameters for surfacing using cobalt flux-cored wires.

The influence of technological parameters in arc surfacing using flux-cored wire can be described as follows:

- welding current: width and bead reinforcement as well as penetration are increased with increase in current strength;

- rate of surfacing: width and bead reinforcement are decreased with increase in welding 
Table 2. Typical standard alloys

\begin{tabular}{|c|c|c|c|c|c|c|c|}
\hline \multirow{2}{*}{ Type } & 1 & $6 \mathrm{BC}$ & 6 & $6 \mathrm{HC}$ & 12 & 21 & 25 \\
\hline & \multicolumn{7}{|c|}{ Wire diameter, mm } \\
\hline Stelloy-G MIG & $\begin{array}{l}1.2,1.6 \\
2.4\end{array}$ & $\begin{array}{l}1.2,1.6 \\
\quad 2.4\end{array}$ & $1.2,1.6,2.4$ & $1.2,1.6,2.4$ & $1.2,1.6,2.4$ & $1.2,1.6,2.4$ & $1.2,1.6$ \\
\hline Stelloy arc welding electrodes & $2.5-5.0$ & $\mathrm{~N} / \mathrm{A}$ & $2.5-5.0$ & $\mathrm{~N} / \mathrm{A}$ & $2.5-5.0$ & $2.5-4.0$ & $2.5-4.0$ \\
\hline Stelloy TIG wire & $\mathrm{N} / \mathrm{A}$ & $1.2-1.6$ & $1.2-1.6$ & $1.2-1.6$ & $\mathrm{~N} / \mathrm{A}$ & $1.2-1.6$ & $\mathrm{~N} / \mathrm{A}$ \\
\hline EN 14700 & TCo3 & $\mathrm{TCo} 2$ & TCo2 & TCo2 & TCo2 & TCo1 & TZCo1 \\
\hline $\begin{array}{l}\text { Typical chemical composition } \\
\text { of weld metal, wt. } \%\end{array}$ & $\begin{array}{c}\text { C } 2.3 \\
\text { Cr } 29 \\
\text { W } 12 \\
\text { Mn } 1.0 \\
\text { Si } 1.0 \\
\text { Fe } 4.0 \\
\text { Co - } \\
\text { base }\end{array}$ & $\begin{array}{c}\text { C } 0.9 \\
\text { Cr } 28.5 \\
\text { W } 4.5 \\
\text { Mn } 1.0 \\
\text { Si } 1.0 \\
\text { Fe } 4.0 \\
\text { Co }- \text { base }\end{array}$ & $\begin{array}{c}\text { C } 1.05 \\
\text { Cr } 28.5 \\
\text { W } 4.5 \\
\text { Mn } 1.0 \\
\text { Si } 1.0 \\
\text { Fe } 4.0 \\
\text { Co }- \text { base }\end{array}$ & $\begin{array}{c}\text { C } 1.2 \\
\text { Cr } 28.5 \\
\text { W } 4.5 \\
\text { Mn } 1.0 \\
\text { Si } 1.0 \\
\text { Fe } 4.0 \\
\text { Co }- \text { base }\end{array}$ & $\begin{array}{c}\text { C } 1.5 \\
\text { Cr } 30 \\
\text { W } 7.5 \\
\text { Mn } 1.0 \\
\text { Si } 1.0 \\
\text { Fe } 4.0 \\
\text { Co }- \text { base }\end{array}$ & $\begin{array}{c}\text { C } 0.25 \\
\text { Cr } 28 \\
\text { Mo } 5.5 \\
\text { Mn } 1.0 \\
\text { Ni } 3.0 \\
\text { Si } 1.0 \\
\text { Co }- \text { base }\end{array}$ & $\begin{array}{c}\text { C } 0.15 \\
\text { Cr } 20 \\
\text { W } 14 \\
\text { Mn } 1.5 \\
\text { Ni } 9.5 \\
\text { Si } 1.0 \\
\text { Fe } 4.0 \\
\text { Co }- \text { base }\end{array}$ \\
\hline $\begin{array}{l}\text { Hardness } H R C \text { of weld metal } \\
\text { at } 20{ }^{\circ} \mathrm{C} \\
\text { Hardness } H B \text { at } \\
200^{\circ} \mathrm{C} \\
400^{\circ} \mathrm{C} \\
600{ }^{\circ} \mathrm{C} \\
800{ }^{\circ} \mathrm{C}\end{array}$ & $\begin{array}{c}53 \\
495-560 \\
465 \\
420 \\
370 \\
330 \\
\end{array}$ & $\begin{array}{c}38 \\
350-380\end{array}$ & $\begin{array}{l}\text { Work hardens } \\
42 \\
380-415 \\
370 \\
320 \\
255 \\
240 \\
\end{array}$ & $\begin{array}{c}44 \\
410-430\end{array}$ & $\begin{array}{c}45 \\
415-455 \\
410 \\
370 \\
315 \\
275 \\
\end{array}$ & $\begin{array}{c}\text { Work hardens } \\
33 \\
300-340 \\
280 \\
255 \\
235 \\
220 \\
\end{array}$ & $\begin{array}{c}21 \\
210-260 \\
180 \\
145 \\
130 \\
120 \\
\end{array}$ \\
\hline Resistance to cracking & * & $* * * *$ & $* * *$ & $* *$ & $* *$ & $* * * *$ & $* * * *$ \\
\hline Impact toughness & $*$ & $* * *$ & $* * *$ & $* *$ & $* *$ & $* * * *$ & $* * * *$ \\
\hline Metal-to-metal wear & $* * *$ & $* * *$ & $* * *$ & $* * *$ & $* * *$ & $* * * *$ & $* * * *$ \\
\hline Corrosion & $* * * *$ & $* * * *$ & $* * * *$ & $* * * *$ & $* * * *$ & $* * * *$ & $* * * *$ \\
\hline Wear in the cold state & $* * * *$ & $* *$ & $* * *$ & $* * *$ & $* * * *$ & $* *$ & $* *$ \\
\hline Wear in the hot state & $* * * *$ & $* *$ & $* * *$ & $* * *$ & $* * * *$ & $* *$ & $* * *$ \\
\hline Machining of the material & $* * * *$ & $* *$ & $* *$ & $* *$ & $* *$ & $* * * *$ & $* * * *$ \\
\hline
\end{tabular}

speed, penetration depth and degree of mixing with base metal are increased with increase in welding speed;

- arc length: penetration depth and degree of mixing with base metal are decreased with increase in length of the arc;

- torch position: with inclination of torch forward the penetration depth, degree of mixing with base metal and bead reinforcement are increased; with increasing the inclination angle of torch this effect is intensified, and width of the weld is reduced;

Table 3. Classification of standards for flux-cored wires

\begin{tabular}{|c|c|c|c|c|c|c|c|}
\hline \multirow[b]{2}{*}{ Standard } & \multicolumn{7}{|c|}{ Material } \\
\hline & $\begin{array}{l}\text { Low carbon and } \\
\text { low alloyed steels }\end{array}$ & $\begin{array}{l}\text { High strength } \\
\text { steels }\end{array}$ & $\begin{array}{l}\text { Heat-resistant } \\
\text { steels }\end{array}$ & $\begin{array}{l}\text { Stainless and } \\
\text { heat-resistant } \\
\text { steels }\end{array}$ & Nickel alloy & Cast iron & Hard alloys \\
\hline DIN & 8559 & - & - & - & - & 8573 & 8555 \\
\hline EN & 758 & 12535 & 12071 & 12073 & - & 1071 & $14700^{*}$ \\
\hline ISO & $17632^{*}$ & $18276^{*}$ & $17634^{*}$ & $17633^{*}$ & 12153 & $1071^{*}$ & - \\
\hline
\end{tabular}

- preheating: penetration depth, degree of mixing with base metal and weld width are increased with increase in preheating temperature, and bead reinforcement is reduced;

- shielding gas: the higher is content of $\mathrm{CO}_{2}$ in shielding gas, the greater is penetration depth and degree of mixing with base metal. The degree of mixing is increased by applying gases (without helium) in the following order: I1 < M13 < $<\mathrm{M} 12<\mathrm{M} 20<\mathrm{M} 21<\mathrm{CO}_{2}$.

Comparison of gas arc surfacing using cobalt flux-cored wire with other processes of surfac- 


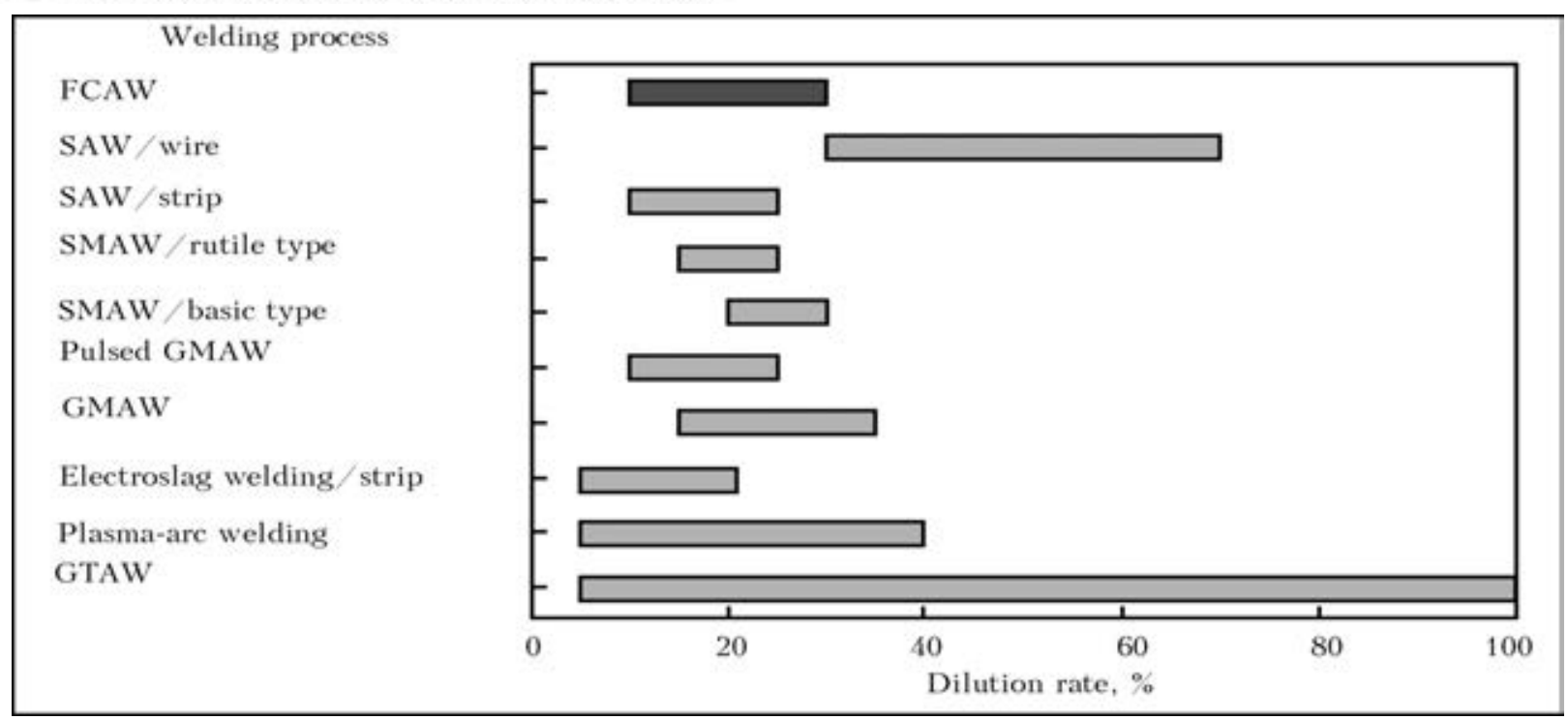

Figure 3. Penetration depth depending on method of surfacing

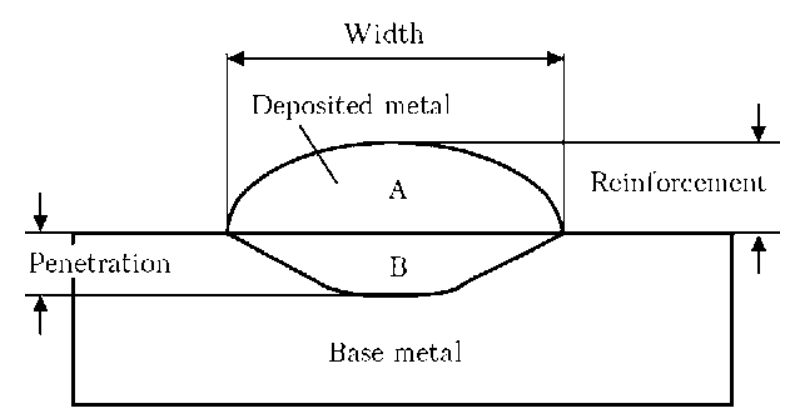

Stirring $[\%]=[\mathrm{B} /(\mathrm{A}+\mathrm{B})] \cdot 100$

Figure 4. Determination of penetration coefficient

ing. The arc surfacing using flux-cored wire has several advantages as compared to other processes of arc surfacing. They include low heat input; low deformation; poor mixing with base metal; possibility of single-layer surfacing; presence of great diversity of possible chemical compositions of deposited metal; possibility of surfacing in different spatial positions; low volume of further treatment.

Table 4 reflects the important distinctive criteria for different methods of surfacing. High purity of deposited metal using flux-cored wire based on cobalt is shown in Figure 5. This imaging shows the corresponding microstructure.

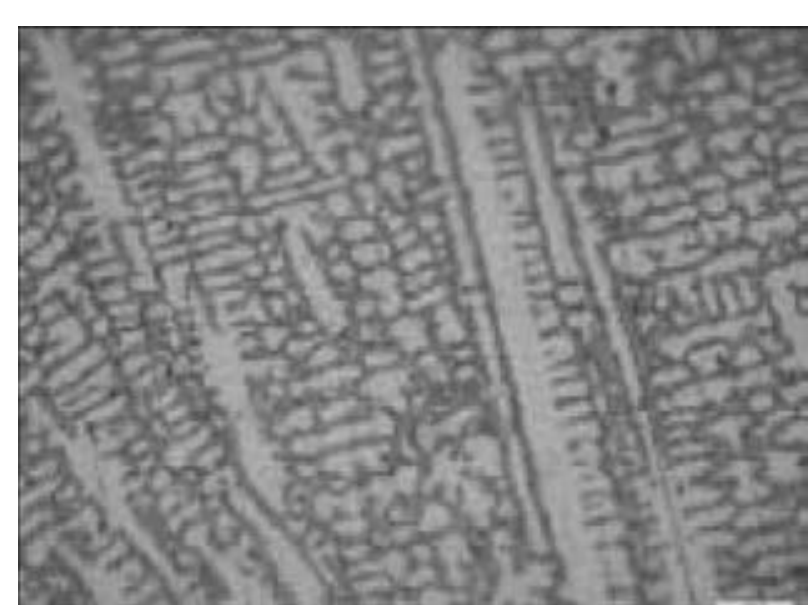

Figure 5. Microstructure of metal deposited using wire Stelloy $1-G$

Here it is noteworthy that dendritic structure is characterized by a very high purity.

Examples of application. The following examples demonstrate the variety of flux-cored wires based on cobalt. The alloys based on cobalt are used at high temperatures, where there is a high wear and corrosion resistance, for example, for high pressure sealing surfaces, screw conveyors of extruders in production of plastics, moulds in ceramic industry, tools in forge industry, hot

Table 4. Comparison of different surfacing methods

\begin{tabular}{|c|c|c|c|c|c|c|}
\hline Process & Automation & $\begin{array}{c}\text { Efficiency of } \\
\text { melting, } \mathrm{kg} / \mathrm{h}\end{array}$ & Investments & Welding positions & Advantages & Restrictions \\
\hline GTAW / hot wire & + & $1-2$ & High & All & High quality & Sizes/expenses \\
\hline GTAW / FCW & + & $3-5$ & Medium & All & Same & Efficiency \\
\hline GTAW / solid wire & + & $1-2$ & Same & $1 G / 3 G(P A, P G)$ & Cost & Quality \\
\hline SMAW & - & $0.5-2$ & Low & All & Flexibility & $\begin{array}{c}\text { Possibility of } \\
\text { automation }\end{array}$ \\
\hline ESW & + & Up to 25 & High & $1 \mathrm{G}(\mathrm{PA})$ & $\begin{array}{c}\text { Price / kg of } \\
\text { deposited metal }\end{array}$ & Sizes \\
\hline
\end{tabular}




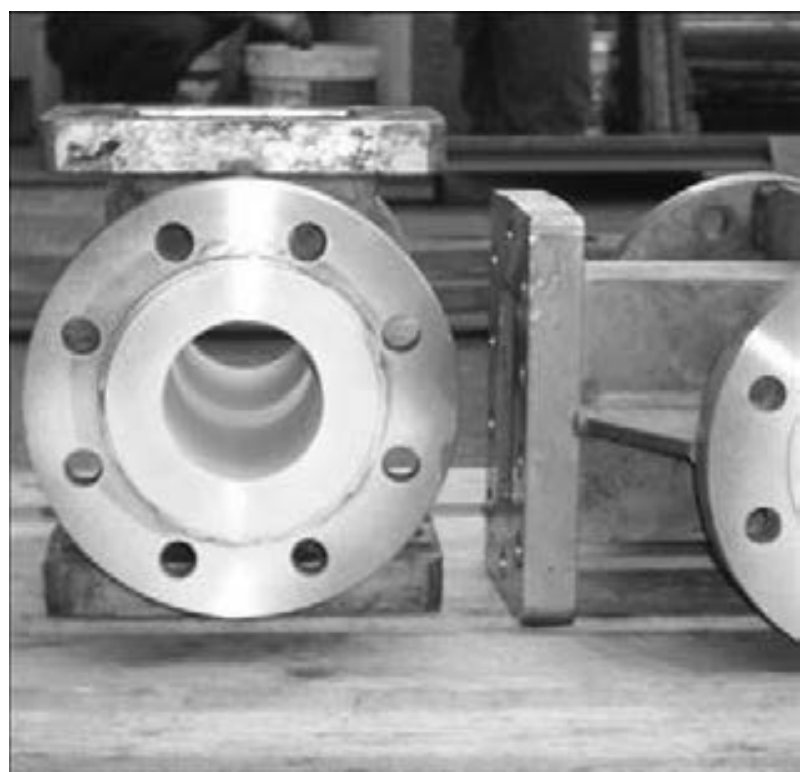

Figure 6. One-layer Hastelloy 6 coating produced using TIG method

shears or valves. For various alloys the corresponding flux-cored wires can be manufactured. They can be deposited using arc surfacing with or without using the pulsed technique. It is preferable to use pure argon as a shielding gas. In TIG surfacing as a shielding gas argon or mixture $\mathrm{Ar}+\mathrm{He}$ can be used.

Figure 6 shows TIG surfacing with Hastelloy 6 on valve seat. For a buffer layer in this case steel of 309L type can be used. Figure 7 shows MIG surfacing with Hastelloy G-6 for ceramic mould. Figure 8 shows single-layer arc surfacing using cobalt flux-cored wire of type Stelloy 21-G on the motor valve surface.

Another example of application of high-cobalt alloys can be brought from the steel industry. Hot knives cut steel rods and slabs at the temperature of $800{ }^{\circ} \mathrm{C}$. Due to a long contact with hot material the knives are exposed to thermal fatigue and it is necessary to protect them. Fi-

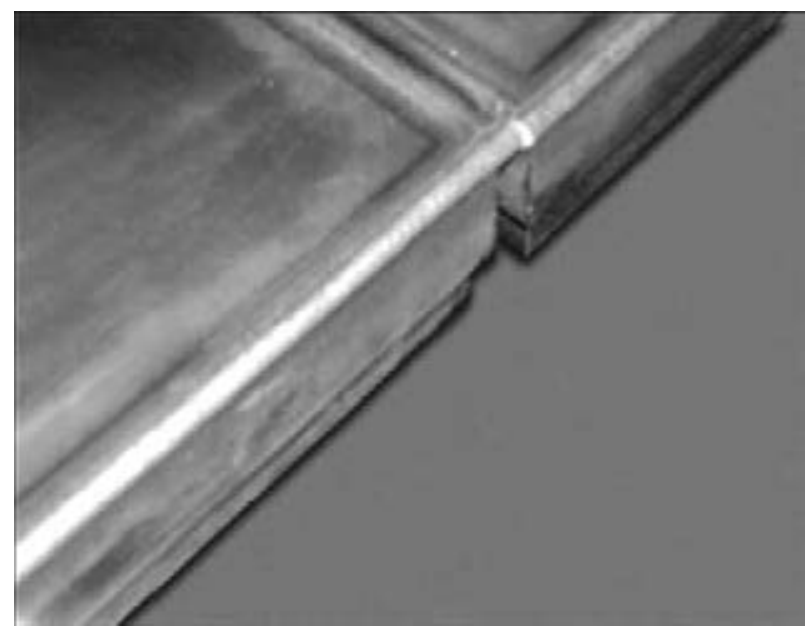

Figure 7. Surfacing of edges with alloy Hastelloy G-6

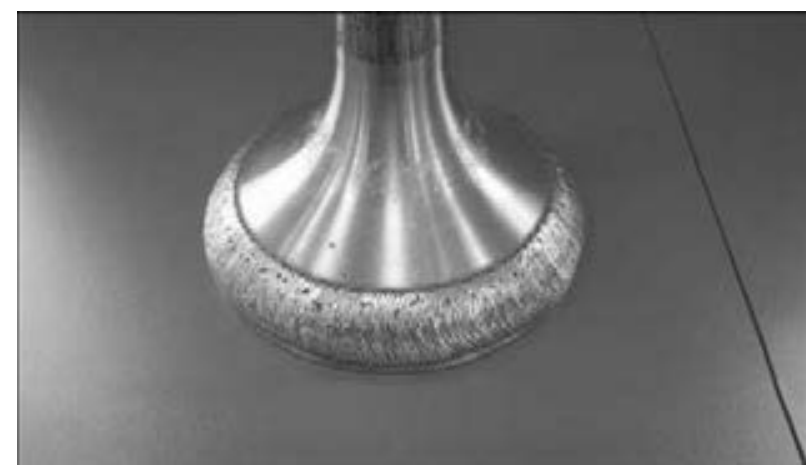

Figure 8. Surfacing of valve with alloy Stelloy 21-G

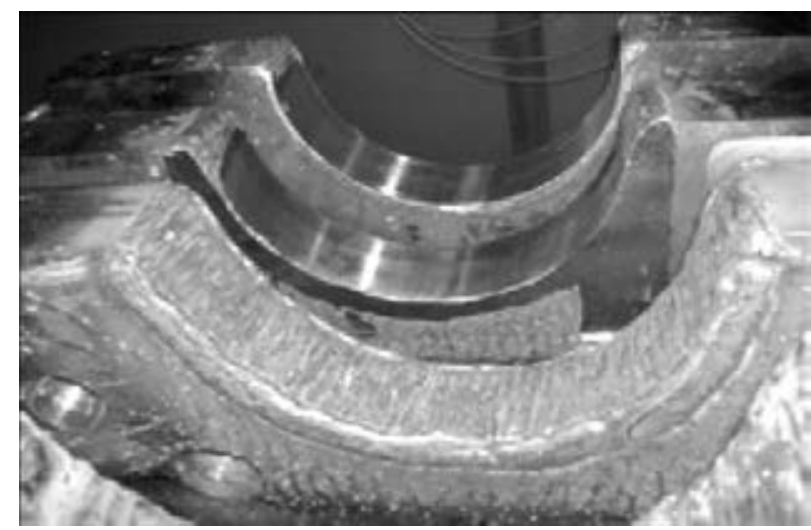

Figure 9. Multilayer surfacing of knife blade for hot cutting

gure 9 shows a typical multi-layered surfacing on hot cutting knife. After surfacing the heat treatment and subsequent machining are carried out.

Thermal conditions in surfacing using cobalt flux-cored wires. In most cases, the main criterion for producing high quality coating of $\mathrm{Co}^{-}$ based alloy is producing of deposits without cracks and with high hardness. The hardness of pure metal is in the range $H R C 21-53$ for standard alloys (see Table 2). At such a high hardness it is necessary to provide special measures to control heat input. First of all, the temperature of preliminary and interlayer heating must be strictly controlled and constantly maintained. The preheating depends on the type of base material, number of layers, thickness of walls.

As a rule, cobalt flux-cored wires of type 6 are deposited with preheating of not less than

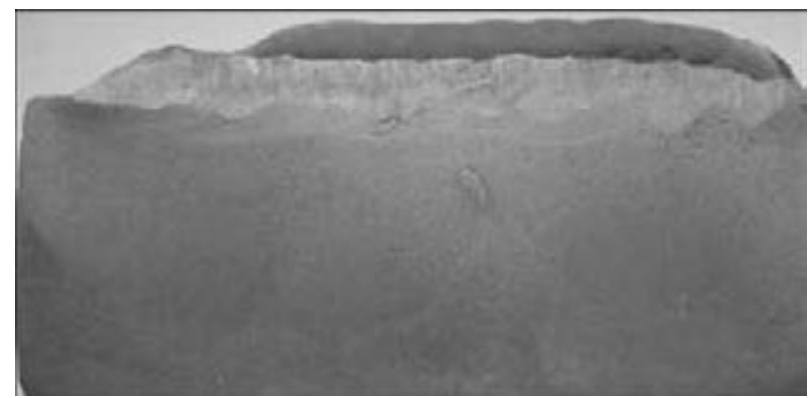

Figure 10. Macrosection of Hastelloy 6-G deposit with steel 309L buffer layer 
$200{ }^{\circ} \mathrm{C}$ in single-layer surfacing. Preheating can be increased to $400{ }^{\circ} \mathrm{C}$ in some cases.

The cooling rate of cobalt deposits is also an important criterion. In many cases martensite transformation in base metal steel leads to local stresses, which can overload the brittle deposited metal and result in cracking.

Buffer layers. The use of buffer layers allows decreasing the temperature of preheating for the coatings sensitive to cracking. As a rule, the steels based on iron, such as 309L or nickel alloys like Inconel 625, can be used for this purpose. Figure 10 shows macrosection of the cobalt-based alloy deposit with buffer layer of steel 309L produced using cobalt flux-cored wire Hastelloy 6-G.

The method of application of buffer layers affects hardness of deposited layer, therefore the control of technology is required. The selection of alloy for buffer layer depends also on need in the subsequent heat treatment.

Trends for the future. Nowadays the majority of cobalt flux-cored wires are surfaced using arc method with consumable electrode. Another method of surfacing is using the automated TIG process. Striving for higher quality and efficiency of TIG surfacing resulted in using the technology with hot wire. For this purpose the compositions of charges of flux-cored wires are optimized only for TIG process. For standard alloys, such as alloys 6 and 21, the cobalt flux-cored wires for TIG welding of $1.2 \mathrm{~mm}$ diameter already exist.

\section{Conclusion}

Today cobalt flux-cored wires have many possibilities of application in the field of surfacing of corrosion- and wear-resistant layers. High qual- ity types of deposited metal, high efficiency, economy of expenses, flexibility of compositions of alloys and excellent welding characteristics are the main arguments for their application.

1. Bouquin, B., Penning, O., Bonnel, J.-M. (2010) Herstellung von korrosionsbestaendigen Plattierungen durch Auftragschweissen mit Fuelldrahtelektroden. In: Grosse Schweisstechnische Tagung.

2. Bonnel, J.-M., Pease, N.C. (2006) Cored wires for corrosion resistant alloys: Status report 2006. In: IIW Congress Proc. (8-10.03.2006, Stellenbosch, South Africa).

3. Bonnel, J.-M, Pease, N.C. (2006) Duplex and superduplex cored wires: modern consumables for modern steel. Ibid.

4. Bonnel, J.-M., Vass, N., Pease, N.C. (2001) Fils tubulaires pour le soudage d'aciers inoxydables. In: Soudage Automatique. Applications Industrielles $d u$ Soudage avec Fil Fourre (Institut de Soudure, 11.12.2001).

5. Bonnel, J.-M. (2002) Fils fourres a poudre metallique - Journee d'etude. In: Soudage et mise en ниvre de l'acier inoxydable (Institut Belge de la Soudure, 28.11.2002).

6. Penning, O., Bonnel, J.-M., Muehlbauer, H. (2008) Basische Fuelldraehte fuer Edelstahl und Nickel-Basis-Legierungen. Das fehlende Bindeglied. In: Gross Schwesstechnische Tagung.

7. Bonnel, J.-M., Cordari, A., Desir, J.L. (2004) Fils fourres base nickel. In: SWI Seminaire Soudure (10.03.2004, Yverdon-les-Bains).

8. Bonnel, J.-M., Bouquin, B., Cordari, A. (2009) Cored wires for high quality welding of corrosion resistant alloys. In: Eurojoin 7-GNS5 (Venetia).

9. Bonnel, J.-M. Gevulde draad $M I G / M A G$ en onderpoederdek lassen van austenitisch en duplex roestvast staal.

10. (2001) Welding alloys. In: Seminarie Belgisch Instituut voor Lastechniek (Stivak en De Nayer Instituut).

11. Bouquin, B., Muehlbauer, H. (2014) Kobalt Basislegierungen in der technischen Anwendung (Verschleissschutztagung Halle).

Received 12.05.2014 


\title{
PECULIARITIES OF TECHNOLOGY OF MANUFACTURE AND APPLICATION OF FLUX-CORED STRIPS FOR SURFACING
}

\author{
A.P. VORONCHUK, A.P. ZHUDRA, V.O. KOCHURA, A.V. PETROV and V.V. FEDOSENKO \\ E.O. Paton Electric Welding Institute, NASU \\ 11 Bozhenko Str., 03680, Kiev, Ukraine. E-mail: office@paton.kiev.ua
}

\begin{abstract}
The paper deals with the problems of homogeneity of flux-cored strip charge at its mixing in double-cone mixers. Optimum mixing time for mixers of different volume was determined experimentally. Equipment for manufacturing flux-cored strips was optimized and a new design of withdrawal-roll set using pressure sensors was developed, that allows determination and adjustment of press-down force of withdrawal rolls of the mill. The paper gives the results of studying the influence of the degree of charge compaction on welding-technological properties of flux-cored strips. It is found that increase degree of compaction leads to a noticeable increase of the coefficient of electrode material melting. Insufficient or excessive degree of compaction adversely affects the welding-technological properties of flux-cored strips - spattering is increased and process stability deteriorates. 4 Ref., 1 Table, 7 Figures.
\end{abstract}

Keywords: surfacing, flux-cored strip, charge, mixer, mixing, homogeneity, complex-alloyed powders, degree of compaction, spattering

Flux-cored strips are widely applied in surfacing large-sized parts in metallurgical, mining, power and other industries. This is, primarily, related to high efficiency of surfacing with flux-cored strip reaching up to $30 \mathrm{~kg}$ of deposited metal per hour at application of one strip. Flux-cored strip is simple to manufacture, and its design features allow obtaining the filling coefficient of 60 to $70 \%$, that enables an essential increase of the degree of deposited metal alloying [1].

Technology of flux-cored strip manufacturing has several features, associated with preparation of charge materials, as well as process of strip forming, compacting and rolling.

The paper deals with two problems that may have an essential influence on flux-cored strip quality - this is mixing of charge materials and degree of their compaction during rolling. Considering the fact that the composition of many grades of flux-cored strips, as a rule, includes from 4 to 12 and more components, differing by their composition, granulation and physico-mechanical properties, their sound mixing is an important factor, providing surfacing material of the required composition and properties.

The objective of the process of charge material mixing is making a product with as homogeneous as possible distribution of particles of the charge individual components and, therefore, possibly also more similar properties in any part of the produced mixture.

Two-cone mixers are the most often used for charge material mixing, which have a number of advantages, namely:

- they practically do not change the shape and dimensions of mixed material particles;

- ensure complete sealing;

- are readily cleaned, etc.

As shown by numerous studies, rotating mixers, operating in the optimum mode, are characterized by rather short mixing periods. If satisfactory blending of the charge is not achieved within 5 to $20 \mathrm{~min}$, further mixing is not rational and the cause preventing mixture blending should be sought. D. Kaufman [2] believes that 50 to 250 revolutions of the mixer (tentatively 10 to $25 \mathrm{~min}$ ) are enough to produce an equilibrium mixture, and $\mathrm{M}$. Ashton and F. Valentin [3] believe that the optimum period of mixture blending is within 1.2 to $18 \mathrm{~min}$.

By an established tradition, the time for blending the charge materials for flux-cored wires and strips is equal to $40-60 \mathrm{~min}$.

Influence of the time of charge material mixing on homogeneity of the charge for surfacing flux-cored strip PL-Np-500Kh40N40S2GRTs was studied. Experiments on charge mixing were conducted in a two-cone laboratory mixer of $7 \mathrm{dm}^{3}$ volume (charge mass of $3.35 \mathrm{~kg}$ ); two-cone industrial mixer of $150 \mathrm{dm}^{3}$ volume (charge mass of $100 \mathrm{~kg}$ ); two-cone industrial mixer of $600 \mathrm{dm}^{3}$ volume (charge mass of $419.42 \mathrm{~kg}$ ). Time of mix- 
Sampling time at mixing in mixers of different volume

\begin{tabular}{||c|c|c|c||}
\hline \multirow{2}{*}{ Batch number } & \multicolumn{3}{|c|}{ Mixing time, min, at mixer volume, $\mathrm{dm}^{3}$} \\
\cline { 2 - 4 } & 7 & 150 & 600 \\
\hline 1 & 5 & 5 & 5 \\
\hline 2 & 10 & 10 & 10 \\
\hline 3 & 15 & 15 & 15 \\
\hline 4 & 20 & 20 & 20 \\
\hline 5 & 30 & 30 & 30 \\
\hline 6 & 60 & 60 & 45 \\
\hline 7 & 120 & 120 & 60 \\
\hline 8 & 180 & 180 & 90 \\
\hline 9 & 240 & 240 & 120 \\
\hline 10 & - & - & 150 \\
\hline
\end{tabular}

ing and taking samples of individual charge batches are given in the Table.

24 samples for assessment of mixing quality were taken from each charge batch after mixing, by the method of quartering (at checking $7 \mathrm{dm}^{3}$ capacity mixer) or with a probe from different locations (at checking industrial mixers of 150 and $600 \mathrm{dm}^{3}$ volume). Two tablets were pressed from each odd sample. Sample analysis was performed in the ORTEC X-ray fluorescent analyzer Tefa.

Degree of charge component blending was evaluated by mean-root-square deviations of intensities by four elements: aluminium, silicon, chromium and iron. Obtained results are presented in Figure 1.

Analyzing the obtained results, a certain cyclicity of variation of mean-root-square deviations of intensities by all the elements, can be noted. Apparently, the phenomena of rather uniform blending of the charge composition alternate with segregation phenomena during manyhour processing in the mixer. The optimum mixing time, depending on mixer volume, is given in Figure 2.

The smallest mean-root-square deviation of intensities by most of the elements is observed in the mixer of $7 \mathrm{dm}^{3}$ volume after $10 \mathrm{~min}$ of mixing, in the mixer of $150 \mathrm{dm}^{3}$ - after 13 to $20 \mathrm{~min}$ of mixing, and in the mixer of $600 \mathrm{dm}^{3}-$ after $30 \mathrm{~min}$ of mixing that fully confirms the correctness of recommendations and data in published sources. These data show the principal possibility
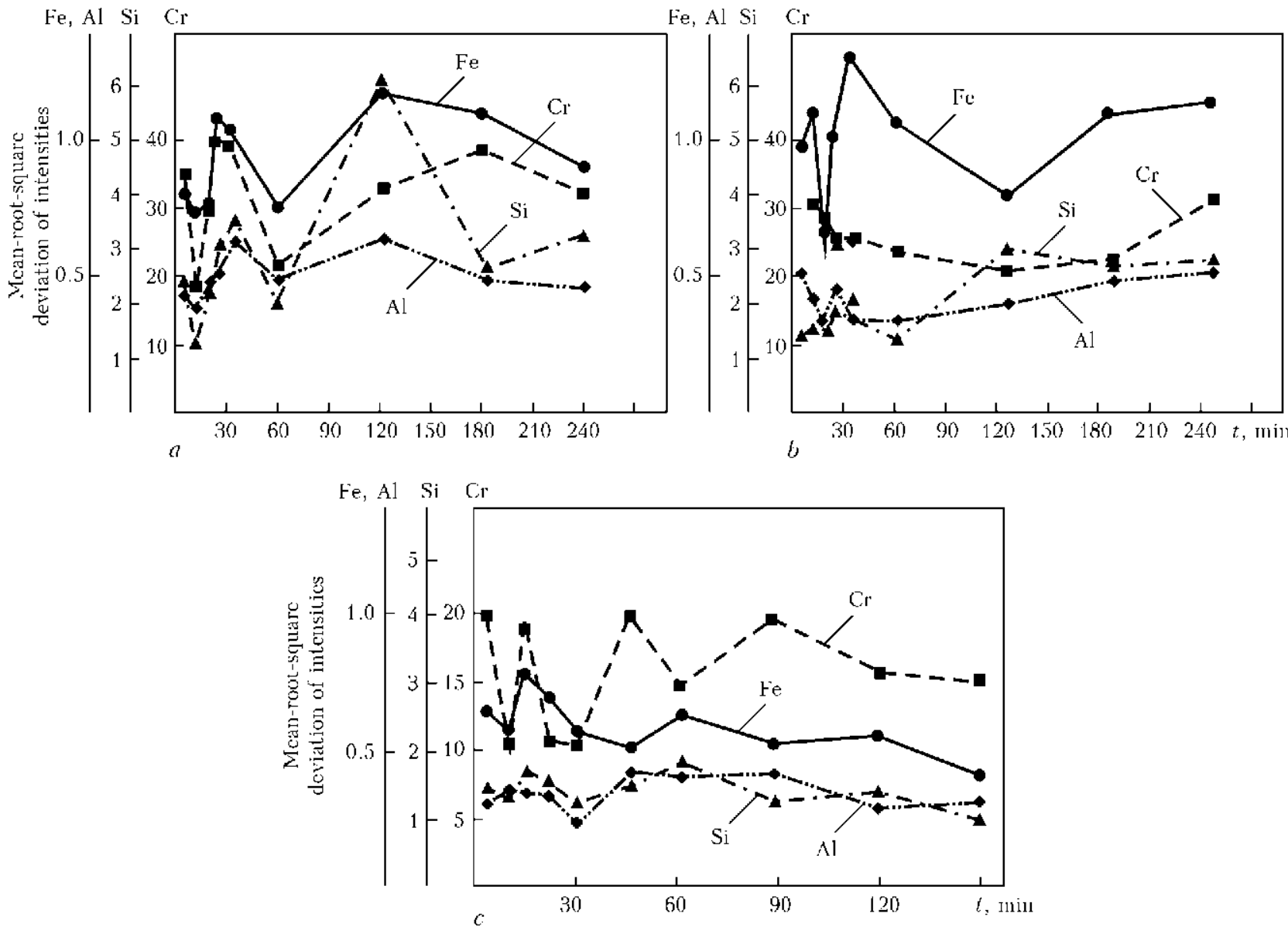

Figure 1. Influence of time $t$ of component mixing on mean-root-square deviation of intensities by individual elements: $a-$ for $7 \mathrm{dm}^{3}$ mixer; $b-150 \mathrm{dm}^{3} ; c-600 \mathrm{dm}^{3}$ 


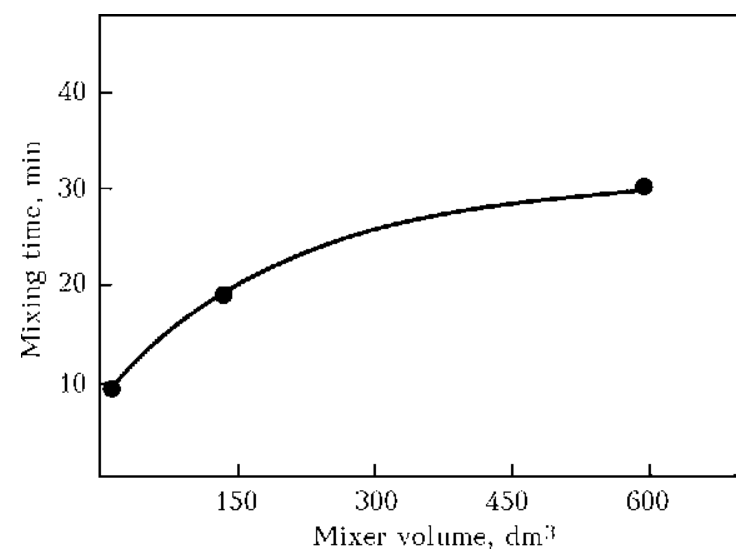

Figure 2. Optimum mixing time depending on mixer volume

of an abrupt shortening of operating time of twocone mixers that will greatly improve their efficiency.

It should be also noted that the composition of flux-cored strip or wire charge can be averaged not only due to their mechanical mixing, but also at application of complex-alloyed powders. The process of producing such powders was developed at PWI. Ingots of the specified composition are first melted from a mixture of ferroalloys and other alloying components with their subsequent plasma-arc thermocentrifugal atomization in an inert medium [4]. Obtained powder has spherically-shaped granules of the same composition, that essentially simplifies the process of surfacing material preparation, improves their weldingtechnological properties, as well as promotes an increase of deposited metal performance through reduction of its inhomogeneity.

The quality of flux-cored strip and its welding-technological properties, respectively, essentially depend on the degree of charge compaction during strip manufacture. Practical experience shows that insufficient compaction of the charge or its excessive compaction lead to lowering of welding-technological properties of flux-cored strip, in particular, to significant increase of spattering losses.

At present there is no objective characteristic of the quality of filler-powder compaction at flux-cored strip manufacture, and this parameter is totally dependent on operator experience.

Attempts at application of hydraulic load cell, built into the withdrawal-roll set of OB-2121 and OB-2240 mills, were unsuccessful. This engineering solution did not allow measuring the press-down force with the required accuracy, and also demonstrated the low reliability at operation under production conditions.

A new design of withdrawal-roll set was developed, which allows conducting continuous monitoring of withdrawal roll press-down force

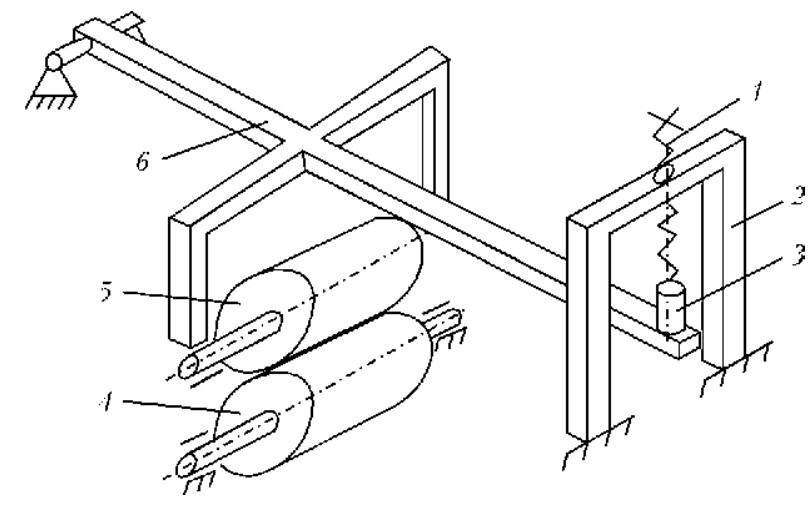

Figure 3. Kinematic scheme of withdrawal-roll set: 1 screw; 2 - stationary support; 3 - pressure sensor; 4 stationary roll; 5 - upper moving roll; 6 - lever; 7 axle

during flux-cored strip manufacture, as well as determining the optimum degree of filler-powder compaction (Figure 3). Press-down force is adjusted by screw 1 and is controlled by sensor 3, and the result is displayed on digital electronic indicator panel. The lever is designed so that the pressure is transmitted in two points to both the races of upper roll bearing through adjusting screws. This allows eliminating the roll non-parallelism, and, therefore, preventing flux-cored strip camber.

Influence of the degree of compaction on welding-technological properties of PL-Np400Kh20B7 M7B2F (PL-AN179) flux-cored strip was studied. Charge from one batch of stable composition was used to produce all the test fluxcored strips. Flux-cored strip filling coefficient was also constant. During flux-cored strip production just the withdrawal roll press-down force was varied. All the other parameters of mill adjustment remained unchanged, including fluxcored strip drawing speed.

At flux-cored strip production the withdrawal roll press-down force was set within the follow-

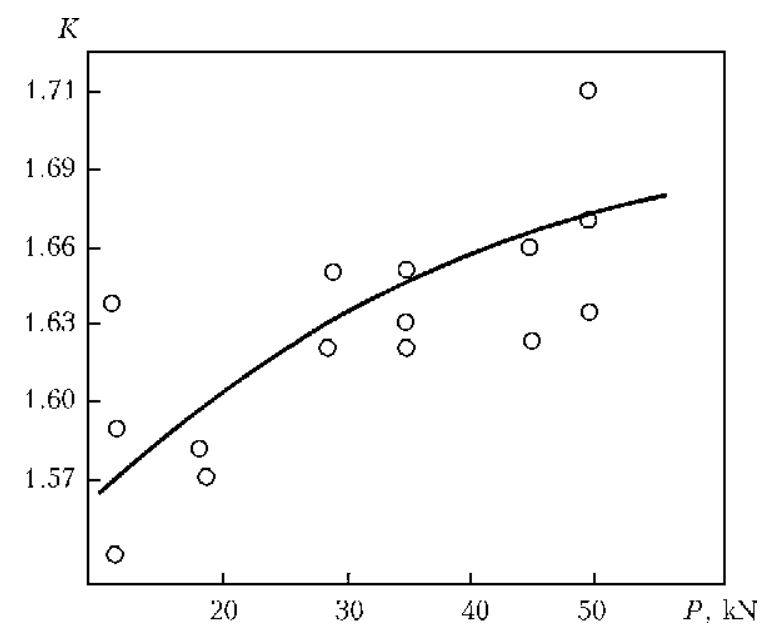

Figure 4. Degree of filler-powder compaction 


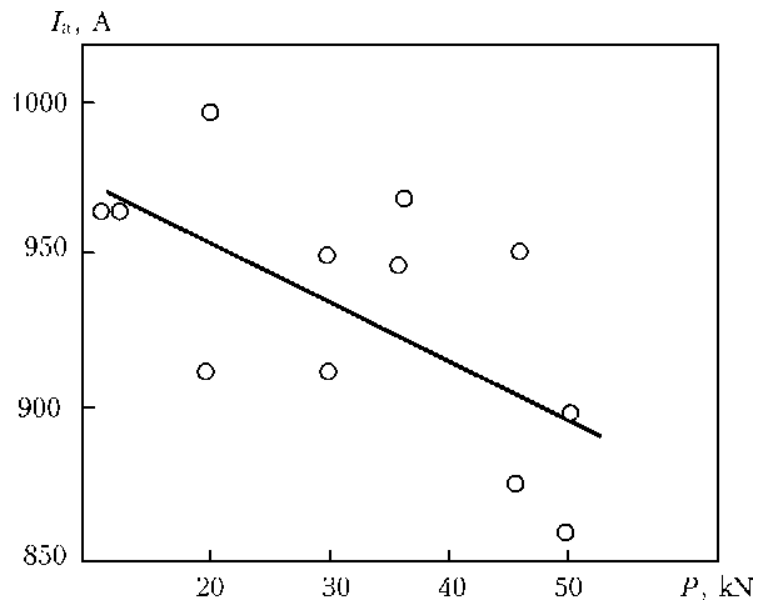

Figure 5. Surfacing current depending on roll press-down force

ing ranges, $\mathrm{kN}: 2.5-3.5 ; 15-20 ; 36-40 ; 48-53$; $66-72 ; 75-81$.

Degree of charge compaction in flux-cored strips was determined, depending on withdrawal roll press-down force. It was assessed as the ratio of apparent density of filler-powder after its mixing to density of filler-powder in the flux-cored strip by the following formula (Figure 4):

$$
K=\rho_{1} / \rho_{2},
$$

where $\rho_{1}$ is the apparent density of the charge after component mixing; $\rho_{2}$ is the charge density in the flux-cored strip.

Degree of charge compaction increases proportionally to increase of roll press-down force, and at press-down force of $60 \mathrm{kN}$ it is equal to 1.66. When studying the electrode material welding-technological properties, surfacing with test flux-cored strips was performed in A-874N apparatus with DC power source VDU-1201. Surfacing modes were as follows: voltage of $29 \pm 1 \mathrm{~V}$; flux-cored strip feed rate of $41 \pm 1 \mathrm{~m} / \mathrm{h}$; surfacing

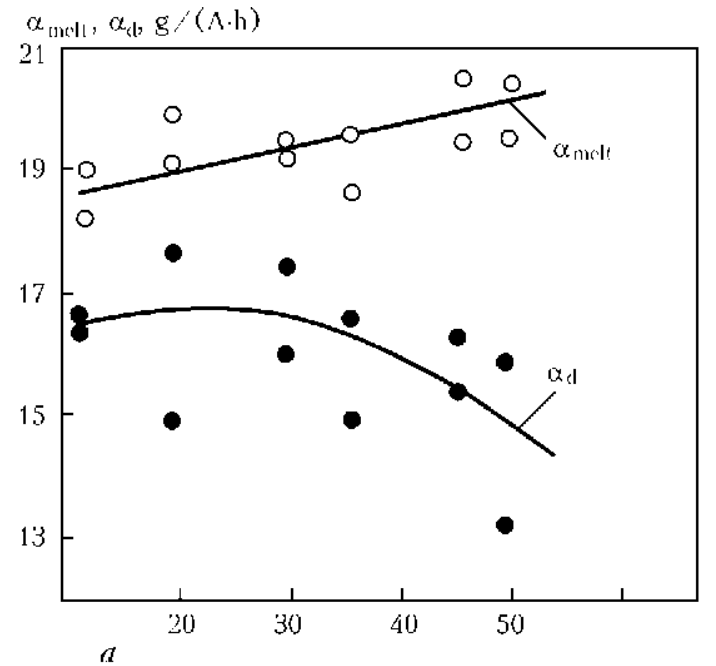

speed of $19 \pm 1 \mathrm{~m} / \mathrm{h}$; electrode extension of $50 \pm$ $\pm 5 \mathrm{~mm}$; at reverse polarity.

Surfacing was performed on St3 steel plates of $20 \times 45 \times 300 \mathrm{~mm}$ size. During surfacing by each of test flux-cored strips average current and voltage were recorded, and coefficients of current and voltage variation were determined. ANP-2 information-measurement system based on «Elektronika-60M» microcomputer was used to obtain these data.

Coefficients of melting, deposition and metal losses for evaporation and spattering were determined by the following dependencies.

Melting coefficient $\alpha_{\text {melt }}$ :

$$
\alpha_{\text {melt }}=\frac{3600\left(m_{\mathrm{str}}-m_{\mathrm{str}}^{\prime}\right)}{I t},
$$

where $m_{\text {str }}, m_{\text {str }}^{\prime}$ are the strip mass before and after surfacing, respectively; $I$ is the surfacing current, $\mathrm{A} ; t$ is the surfacing time, s.

Deposition coefficient $\alpha_{d}$ :

$$
\alpha_{\mathrm{d}}=\frac{3600\left(m_{\mathrm{pl}}-m_{\mathrm{pl}}^{\prime}\right)}{I t}
$$

where $m_{\mathrm{pl}}, m_{\mathrm{pl}}^{\prime}$ is the plate mass before and after surfacing, $g$.

Coefficient of losses for evaporation and spattering $K_{1}$ :

$$
K_{1}=\frac{\left(m_{\mathrm{str}}-m_{\mathrm{str}}^{\prime}\right)-\left(m_{\mathrm{pl}}-m_{\mathrm{pl}}^{\prime}\right)}{m_{\mathrm{str}}-m_{\mathrm{str}}^{\prime}} .
$$

Losses for spattering:

$$
K_{\mathrm{sp}}=\frac{m_{\mathrm{sp}}}{m_{\mathrm{str}}-m_{\mathrm{str}}^{\prime}},
$$

where $m_{\mathrm{sp}}$ is the collected spatter mass.

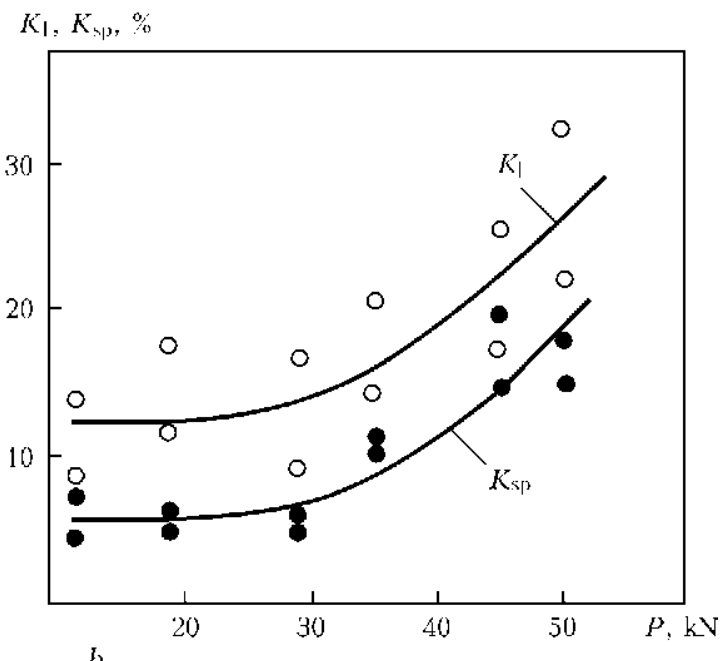

Figure 6. Dependence of coefficients of melting and surfacing $(a)$ and coefficients of losses and spattering (b) on roll press-down force 

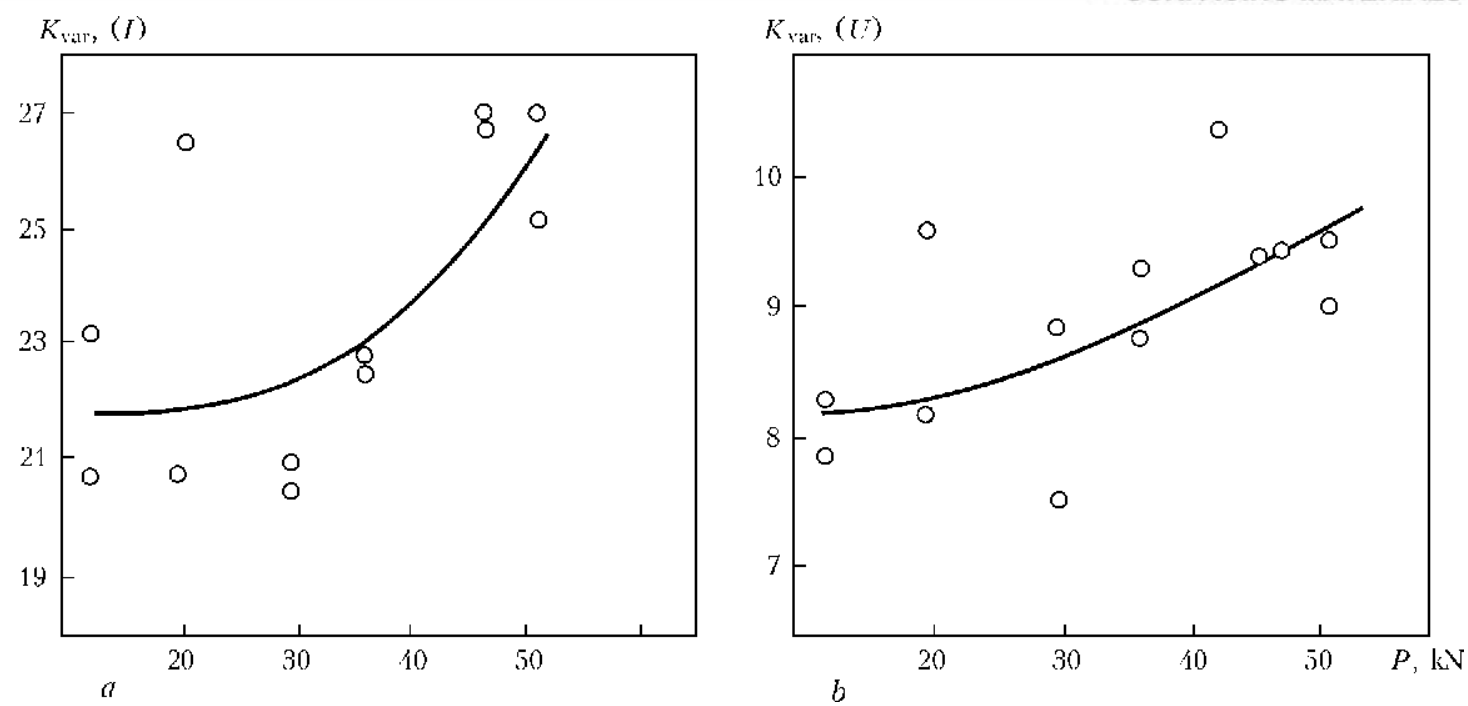

Figure 7. Coefficient of variation of current $(a)$ and voltage $(b)$ depending on roll press-down force

With increase of the degree of charge compaction, current decreases at unchanged rate of fluxcored strip feed, i.e. at the same arc voltage, the arc power consumed for melting of one and the same quantity of electrode material, becomes smaller (Figure 5).

This leads to increase of melting coefficient, but deposition coefficient decreases at roll press-down forces above $40 \mathrm{kN}$ (Figure 6, $a$ ). Decrease of deposition coefficient is attributable to an abrupt increase of spattering losses (Figure 6, $b$ ).

Increase of the coefficients of variation of current and voltage is also observed in the same range (press-down force from 40 to $80 \mathrm{kN}$ ) ( $\mathrm{Fi}$ gure $7, a, b)$.

Thus, increase of the degree of compaction of flux-cored strip charge leads to increase of electrode material melting rate, but this positive effect is completely neutralized by an abrupt increase of spattering losses.

Optimum welding-technological properties of flux-cored strip in the considered case were obtained only at roll press-down force in the range of 20 to $40 \mathrm{kN}$. At press-down forces below $20 \mathrm{kN}$, the result repeatability is low, that is, obviously, related to insufficient degree of flux-cored strip charge compaction.

Increase of electrode material melting rate is attributable to the change of electric resistance of flux-cored strip, that is, apparently, associated with the change of strip-sheath resistance due to work hardening and change of the cross-section at its deformation, because of imprints of withdrawal rolls of specified configuration on its surface.

Increase of spattering with increase of the degree of charge compaction, in our opinion, is associated with the change of charge heat conductivity and lowering of its electric resistance.

Conducted studies were the basis for improvement of technological manual for manufacturing of this grade of flux-cored strip, that allowed stabilization of manufactured product quality and reducing its losses at surfacing.

Application of the new technology of fluxcored strip manufacture allowed an essential reduction of equipment overall dimensions and several times lowering the electrode material power consumption.

\section{Conclusions}

1. It is established that the optimum time of mixing the components of flux-cored strip core charge depends on mixer volume and varies in the range of 10 to $30 \mathrm{~min}$. Increase of mixing time above these limits lowers the charge homogeneity.

2. A system was developed for determination of press-down force of rolls in withdrawal-roll set of flux-cored strip manufacturing mill. Optimum ranges of compaction of flux-cored strip charge were determined. Insufficient degree of compaction, or its increased value adversely affect the welding-technological properties of electrode material. This leads to greater spattering and lower stability of flux-cored strip melting.

3 . Obtained investigation results were implemented in the technology and equipment for manufacturing flux-cored strips.

1. Zhudra, A.P., Voronchuk, A.P. (2012) Cladding flux-cored strips (Review). The Paton Welding J., 1, 34-38.

2. Kaufman, J.J. et al. Ultrasonic bone-therapy apparatus and method. Pat. 5547459 U.S. Publ. Aug. 20, 1996.

3. Ashton, M.D., Valentin, F.H. (1986) The mixing of powders and particles in industrial mixers. Transact. of Inst. Chem. Engrs., 44(5), 166-169.

4. Zhudra, A.P., Krivchikov, S.Yu., Dzykovich, V.I. (2014) Application of complex-alloyed powders produced by thermocentrifugal sputtering in flux-cored wires. The Paton Welding J., 12, 36-40. 


\title{
EFFECT OF ALLOYING ON PHYSICO-MECHANICAL PROPERTIES OF FUSED TUNGSTEN CARBIDES
}

\author{
A.I. BELY ${ }^{1}$, A.P. ZHUDRA ${ }^{1}$, A.I. ROSLYAKOV ${ }^{1}$, V.V. PETROV ${ }^{1}$ and P.I. LOBODA ${ }^{2}$ \\ ${ }^{1}$ E.O. Paton Electric Welding Institute, NASU \\ 11 Bozhenko Str., 03680, Kiev, Ukraine. E-mail: office@paton.kiev.ua \\ ${ }^{2}$ NTUU «Kiev Polytechnic Institute» \\ 37 Pobeda Ave., 03056, Kiev, Ukraine. E-mail: mail@KPI.ua
}

\begin{abstract}
Studies of fused tungsten carbide alloying by $\mathrm{NbC}, \mathrm{Cr}_{3} \mathrm{C}_{2}, \mathrm{~B}_{4} \mathrm{C}, \mathrm{VC}, \mathrm{TiB}_{2}, \mathrm{Mo}$, and of their influence on alloy physico-mechanical properties have been performed. It is shown that the alloy properties largely depend on dimensions and quantity of the reinforcing phase, which can change in a broad range during solidification, depending on melt composition and thermal conditions of solidification. It is established that the high values of physico-mechanical properties of fused carbides are achieved at alloy structures, which are a matrix of one of the refractory compounds, reinforced by fibres of the second refractory compound. Increase of microhardness of the alloy spherical particles by $30-40 \%$, as well as of strength and wear resistance, particularly at alloying with molybdenum, is found. 6 Ref., 7 Figures.
\end{abstract}

Keywords: fused tungsten carbide, alloying, spherical particles, microhardness, microstructure, strength, wear resistance

Modern level of operation of machines and mechanisms requires continuous improvement of their performance, hence the constant need for development of new, more efficient materials. Considering the need to enhance gas production in the country, we can anticipate a significant increase of the volume of drilling operations that, in its turn, will require large numbers of drilling tools and equipment strengthened by new highefficient surfacing materials.

The most widely accepted material for strengthening, primarily drilling tools, as well as a whole range of rapidly-wearing parts in mechanical engineering and mining equipment, are materials for deposition of composite alloys based on cast tungsten carbide (relite). Relite is an eutectic alloy of tungsten mono- and semicarbide $\mathrm{WC}-\mathrm{W}_{2} \mathrm{C}\left(20-22 \% \mathrm{WC}+78-80 \% \mathrm{~W}_{2} \mathrm{C}\right)[1$, 2]. Relite melting temperature is $2735{ }^{\circ} \mathrm{C}$, carbon content is $3.6-4.12 \%$, microhardness $H V 100$ is 2200-2400.

Alloy microstructure consists of a matrix of tungsten semicarbide $\mathrm{W}_{2} \mathrm{C}$, pierced by elongated WC tungsten carbide grains, and largely similar in terms of microstructure to quasibinary composite materials with ceramic matrix and singlecrystal ceramic fibres [3].

It should be noted that with all the positive properties of fused tungsten carbide, it also has several disadvantages. This, primarily, is the high brittleness inherent to materials of this class.

Fused tungsten carbides have been produced for a long time in Tamman tipping furnaces. The thus obtained ingots are crushed with subsequent sieving into the respective fractions which were applied in the respective surfacing technologies and materials. Powder particles have cracks and preserve the characteristic casting defects: pores, cavities, compositional inhomogeneity, looseness, etc. that adversely affects the alloy wear resistance.

PWI method of thermo-centrifugal atomization of relite ingots allowed producing powder particles of a spherical shape, and, owing to their high cooling rate, greatly increase their quality. Particles acquired a more dispersed structure, higher microhardness and strength. Wear resistance of composite alloys based on spherical relite increased, accordingly (Figure 1). Thus, positive effect of increased rate of relite melt cooling on its service properties was established.

More over, it is shown in $[3,4]$ that mechanical properties greatly depend on dimensions and quantity of the reinforcing phase, which can vary in a broad range during solidification, depending on the melt chemical composition and thermal conditions of solidification. In this connection, it is proposed to further improve the properties of fused tungsten carbides through formation of solid solutions of other refractory metals by relite alloying with them. 

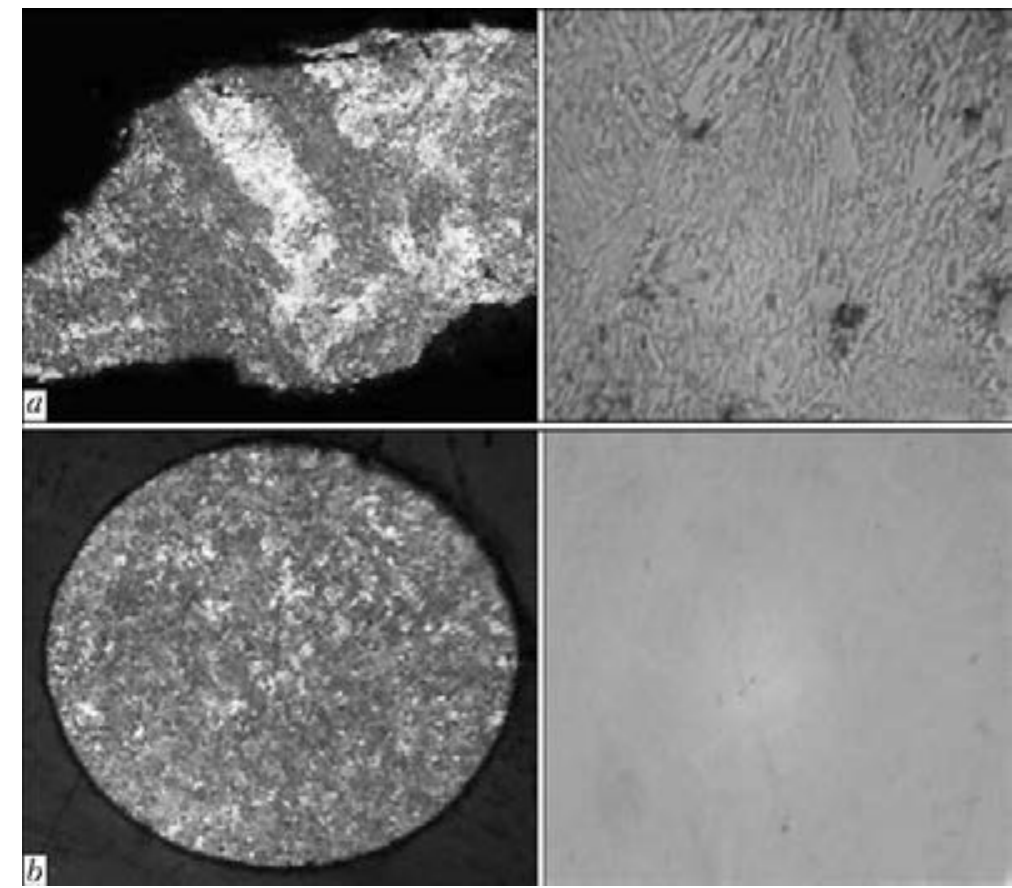

Figure 1. Macro- and microstructure $(\times 100)$ of crushed $(a)$ and spherical $(b)$ relite particles

Performed experimental work on producing test alloys doped with $\mathrm{NbC}, \mathrm{Cr}_{3} \mathrm{C}_{2}, \mathrm{~B}_{4} \mathrm{C}, \mathrm{VC}$, $\mathrm{TiB}_{2}$ showed that the degree of alloying of the above material is limited to $5-7 \mathrm{wt} \%$, depending on the kind of added element. Exceeding the above limits leads to disturbance of melting process, intensive melt boiling, and material splashing, right up to interruption of melting. Considering these technological features, alloy doping was limited to $5 \mathrm{wt} . \%$ of alloying component.

Obtained samples were subjected to mechanical crushing and thermo-centrifugal atomization for producing spherical particles, filling and preparation of microsections for metallographic analysis and determination of microhardness as one of the main quality indices.

Analysis of composite alloy structures obtained at different cooling rates shows that fragmented particle structure is more defective. Alloying by $\mathrm{Cr}_{3} \mathrm{C}_{2}$ and Mo leads to the most considerable refinement of relite phase components and prevailing dissolution of alloying component in semicarbide phase. By the nature of microstructure, spherical particles produced as a result

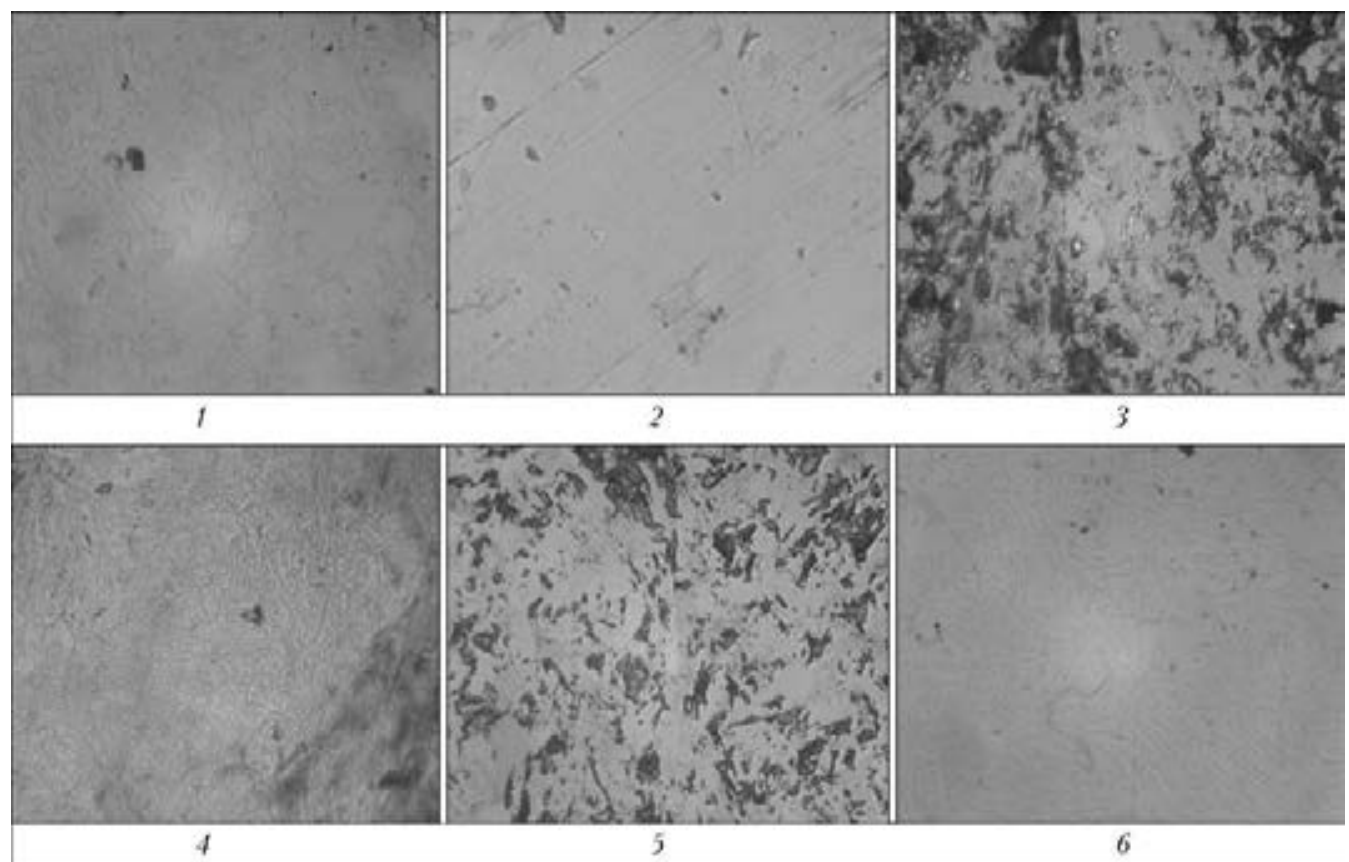

Figure 2. Microstructure $(\times 100)$ of alloyed crushed particles: $1-5 \mathrm{NbC}+\mathrm{WC}-\mathrm{W}_{2} \mathrm{C} ; 2-5 \mathrm{Cr}_{3} \mathrm{C}_{2}+\mathrm{WC}^{-} \mathrm{W}_{2} \mathrm{C} ; 3-$ $3 \mathrm{~B}_{4} \mathrm{C}+\mathrm{WC}-\mathrm{W}_{2} \mathrm{C} ; 4-5 \mathrm{VC}+\mathrm{WC}-\mathrm{W}_{2} \mathrm{C} ; 5-5 \mathrm{TiB}_{2}+\mathrm{WC}-\mathrm{W}_{2} \mathrm{C} ; 6-5 \mathrm{Mo}+\mathrm{WC}-\mathrm{W}_{2} \mathrm{C}$ 


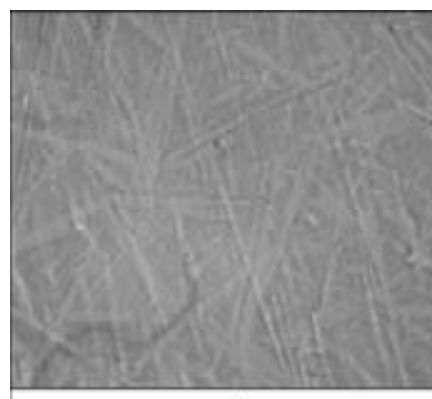

t

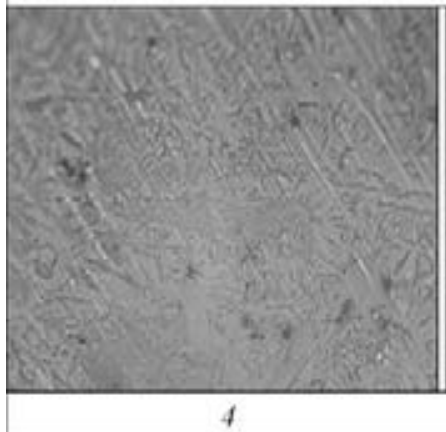

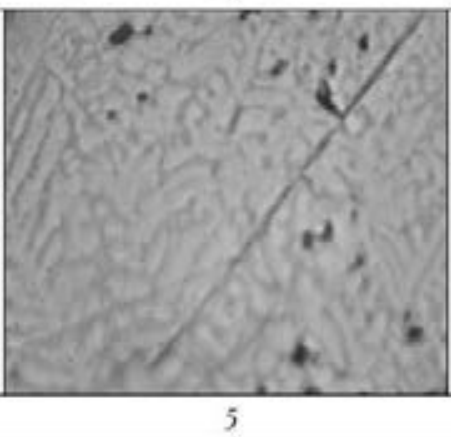

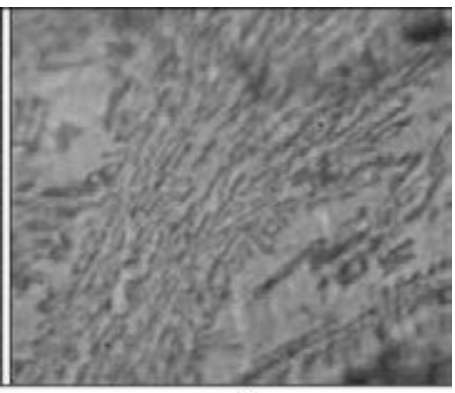

3

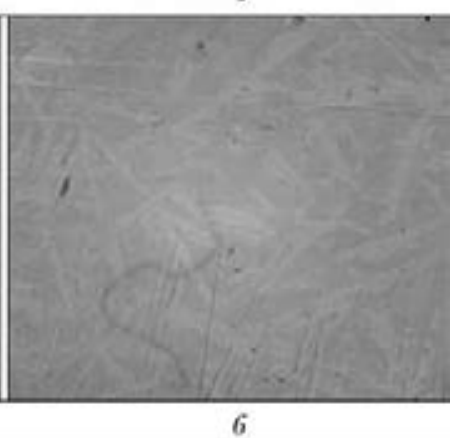

Figure 3. Microstructure $(\times 100)$ of alloyed spherical particles: $1-5 \mathrm{NbC}+\mathrm{WC}-\mathrm{W}_{2} \mathrm{C} ; 2-5 \mathrm{Cr} 3 \mathrm{C}_{2}+\mathrm{WC}^{-} \mathrm{W}_{2} \mathrm{C} ; 3-$ $3 \mathrm{~B}_{4} \mathrm{C}+\mathrm{WC}-\mathrm{W}_{2} \mathrm{C} ; 4-5 \mathrm{VC}+\mathrm{WC}-\mathrm{W}_{2} \mathrm{C} ; 5-5 \mathrm{TiB}_{2}+\mathrm{WC}-\mathrm{W}_{2} \mathrm{C} ; 6-5 \mathrm{Mo}+\mathrm{WC}-\mathrm{W}_{2} \mathrm{C}$

of thermo-centrifugal atomization, consist of a matrix of tungsten semicarbide, alloyed by additive component. Microstructure of promising alloyed crushed and spherical particles is given in Figures 2 and 3.

Results of microhardness studies are given in Figure 4.

Note the high nonuniformity of classical composition particles and those alloyed, for instance, by $5 \% \mathrm{TiB}_{2}$, in terms of microhardness, and high stability of microhardness of particles alloyed with 5 wt.\% Mo (Figure 5). This, in our opinion, is due to volume ratio of system components, as grains of refractory compounds present in eutectic melt are separated by grains of different nature.

The process of thermo-centrifugal atomization improves the uniformity of structure of fused tungsten carbide particles, that has a positive effect on their strength. The force required for destruction of grains was determined in MP machine. The particles were placed between two polishing plates and were statically loaded. Test-

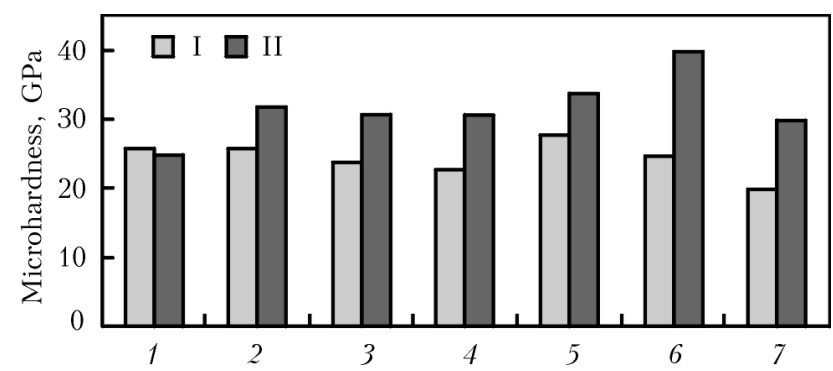

Figure 4. Microhardness of crushed I and spherical II particles: $1-5 \mathrm{NbC}+\mathrm{WC}-\mathrm{W}_{2} \mathrm{C} ; 2-5 \mathrm{Cr}_{3} \mathrm{C}_{2}+\mathrm{WC}-\mathrm{W}_{2} \mathrm{C}$; $3-3 \mathrm{~B}_{4} \mathrm{C}+\mathrm{WC}-\mathrm{W}_{2} \mathrm{C} ; 4-5 \mathrm{VC}+\mathrm{WC}-\mathrm{W}_{2} \mathrm{C} ; 5-5 \mathrm{TiB}_{2}+$ $\mathrm{WC}-\mathrm{W}_{2} \mathrm{C} ; 6-5 \mathrm{Mo}+\mathrm{WC}-\mathrm{W}_{2} \mathrm{C} ; 7-\mathrm{WC}^{-\mathrm{W}_{2} \mathrm{C}}$ ing was performed on forty particles of 100$250 \mu \mathrm{m}$ size of each composition (Figure 6).

Thus, investigation of spherical particle strength also showed the good prospects for tungsten carbide alloying by molybdenum.

Studies of microstructure of fused tungsten carbides of classical composition, compared to microstructure of alloys doped by molybdenum, revealed that classical relite has a fine-grained
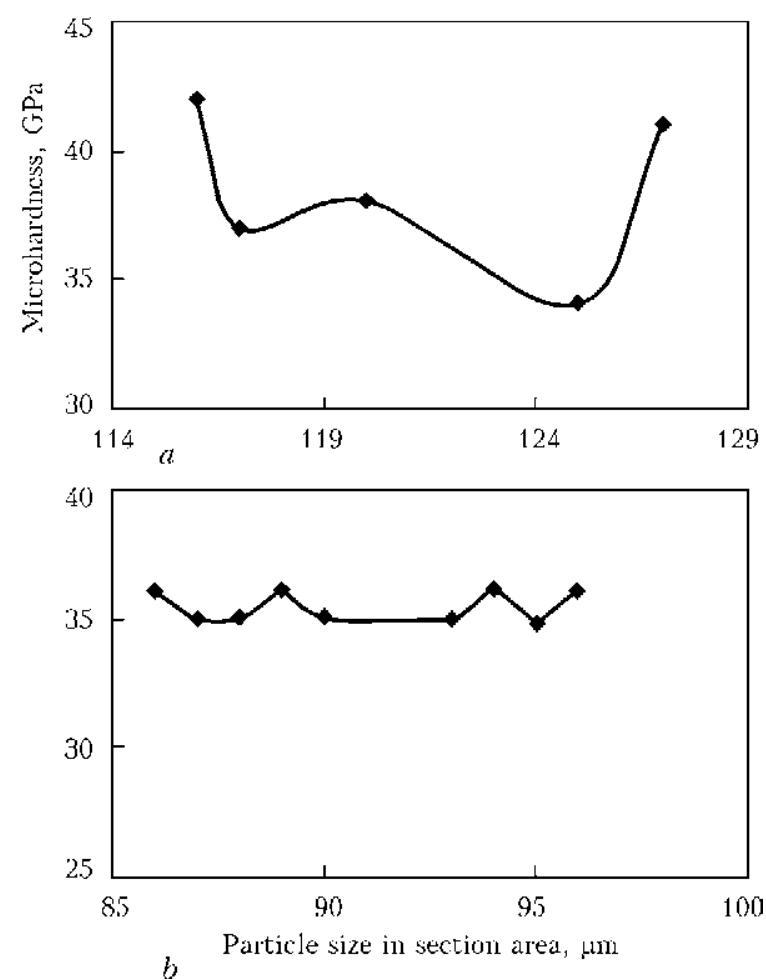

Figure 5. Microhardness of spherical alloyed relite particles of 100-250 $\mu \mathrm{m}$ size: $a-5 \mathrm{TiB}_{2} ; b-5 \mathrm{Mo}$ 


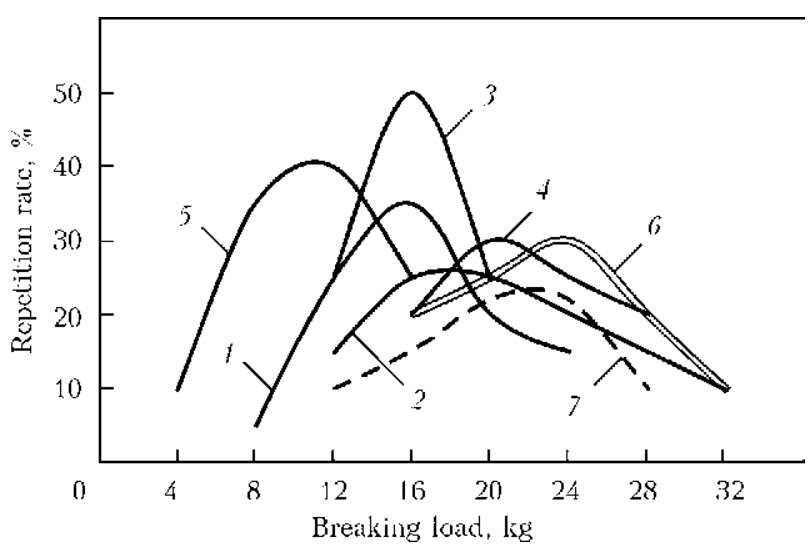

Figure 6. Strength of 100-250 $\mu \mathrm{m}$ spherical particles of alloyed tungsten carbides: $1-5 \% \mathrm{NbC} ; 2-5 \% \mathrm{TiB}_{2}$; $3-5 \% \mathrm{VC} ; 4-3 \% \mathrm{~B}_{4} \mathrm{C} ; 5-5 \% \mathrm{Cr}_{3} \mathrm{C}_{2} ; 6-5 \% \mathrm{Mo}$ $7-\mathrm{WC}-\mathrm{W}_{2} \mathrm{C}$

structure, while relite alloyed by molybdenum, has a plate-like structure. The high values of physico-mechanical properties of fused carbides are achieved at alloy structures, which consist of a matrix of one refractory compound, which is reinforced by fibres of the second refractory compound. Analysis of tungsten carbide microstructures, alloyed by molybdenum, confirms formation of a reinforcing lattice, which consists of complex W-Mo carbide.

Wear resistance of alloyed spherical particles was studied by testing for abrasive wear in NK-M machine [5, 6]. Abrasive was quartz sand of 0.05$0.50 \mathrm{~mm}$ granulation. Used as samples were cylinders of $10 \mathrm{~mm}$ diameter, which were made as follows. Reinforcing grains of crushed or spherical tungsten carbides were loosely charged into a graphite mould of $10 \mathrm{~mm}$ diameter. A portion of matrix alloy from MNMts 60-20-20 was placed on top of the grains. The mould was closed by a graphite lid and intensively heated by plasma arc. The matrix alloy impregnated the reinforcing grains and after cooling it was subjected to machining by diameter and height. Wear was evaluated by mass loss. Sample area was equal to $78.5 \mathrm{~mm}^{2}$, specific load was $0.5 \mathrm{~Pa}$, friction speed was $0.58 \mathrm{~m} / \mathrm{s}$. Friction path was $3500 \mathrm{~m}$.

It was found that fused tungsten carbide alloying by niobium, vanadium and molybdenum improves wear resistance of spherical particles produced by thermo-centrifugal atomization. Alloying with molybdenum in the amount of $5 \%$ is the most effective (Figure 7).

\section{Conclusions}

1. Studies showed the good prospects for and rationality of alloying fused tungsten carbides

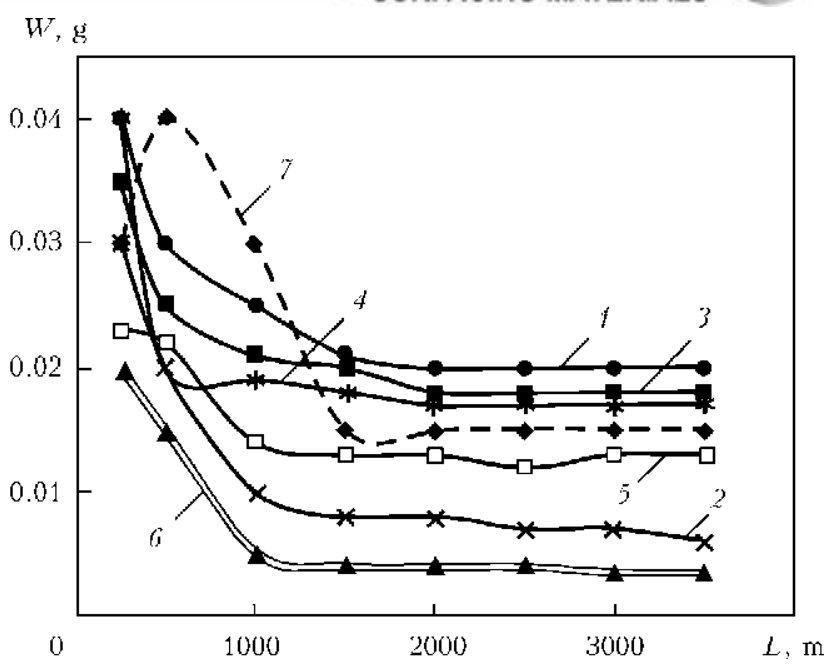

Figure 7. Wear resistance of spherical particles of alloyed tungsten carbides of less than $180 \mu \mathrm{m}$ size compared to unalloyed particles of similar size (same designations as in Figure 6)

by refractory metals, that provides 30 to $40 \%$ increase of microhardness. Alloying is particularly effective when producing spherical relite by centrifugal atomization that ensures higher rates of alloy solidification.

2. Studying the strength of tungsten carbide particles produced by different methods showed that spherical tungsten carbides alloyed with molybdenum have the highest strength.

3. Fused tungsten carbides alloying with niobium, tungsten and molybdenum improves wear resistance of spherical particles produced by thermo-centrifugal atomization. Alloying with molybdenum in the amount of $5 \%$ is the most effective.

1. Umansky, Ya.S. (1947) Carbides of hard alloys. Moscow: Metallurgizdat.

2. Samsonov, G.V., Umansky, Ya.S. (1957) Hard joints of hard metals. Moscow: Metallurgizdat.

3. Loboda, P.I. (2004) Physical-chemical principles of creation of new boride materials for electronic engineering and development of ceramic cathode assemblies with higher efficiency: Syn. of Thesis for Dr. of Sci. (Eng.) Degree. Kiev: KPI

4. Bogomol, I., Vasylkiv, O., Sakka, Y. et al. (2010) Mechanism of nucleation and growth of directionally crystallized alloys of the $\mathrm{B}_{4} \mathrm{C}-\mathrm{MeB}_{2}$ system. J. $A \dot{l}$ loys and Compounds, 490(1/2), 557-561.

5. Yuzvenko, Yu.A. (1978) Study and development of materials and technology of mechanized open-arc surfacing: Syn. of Thesis for Dr. of Sci. (Eng.) Degree. Kiev: PWI.

6. Yuzvenko, Yu.A., Zhudra, A.P., Frumin, E.I. (1973) Abrasive wear of composite alloys. Avtomatich. Svarka, 7, 62-63. 


\title{
DOUBLE-LAYER SURFACING COMPOSITIONS BASED ON FILLING MATERIAL OF $\mathrm{Cr}-\mathrm{Ti}-\mathrm{C}$ ALLOYING SYSTEM
}

\author{
E.V. SUKHOVAYA \\ Oles Gonchar Dnepropetrovsk National University \\ 72 Gagarin Ave., 49010, Dnepropetrovsk, Ukraine. E-mail: sukhovaja@ukr.net
}

\begin{abstract}
It was proposed in the work to use the method of furnace surfacing to produce double-layer macroheterogeneous compositions. It consists in successive impregnation of hard filler-alloy particles by two metal binder-alloys having different melting points. As a filler the $\mathrm{Cr}-\mathrm{Ti}-\mathrm{C}$ alloy is used, as binders the dispersion-hardening alloy of grade MNMts20-20 and hypoeutectic $\mathrm{Fe}-\mathrm{B}-\mathrm{C}$ alloy are used. As a result of impregnation a double-layer composition is produced, the layers of which are hardened by particles of the same filler, but having different composition of binder-alloy. It is shown that after furnace impregnation almost defect-free structure of double-layer compositions is formed, the porosity of which does not exceed 5-7\%. The comparison of dissolution rate of primary and peritectic phase of filler-alloy in melts based on copper and iron was made. Determined were the mechanical properties of layers of surfacing composition intended for hardening the parts operating under the conditions of non-uniform distribution of temperatures, stresses and deformations. 5 Ref. 3 Tables, 6 Figures.
\end{abstract}

Key words: furnace surfacing, double-layer surfacing compositions, interphase interaction, dissolution rate, mechanical properties

The surfacing composite materials are rather widely applied for hardening the surface of parts operating under the conditions of intensive abrasive wear. Among the existing methods for producing composite deposited layers the best known is the method of furnace impregnation developed by the specialists of the E.O. Paton Electric Welding Institute [1]. This technology is distinguished by simplicity, sufficiently high efficiency and relatively low power consumption. In addition, it allows producing double- and multi-layer surfacing compositions [2].

The surfacing composite material is composed of particles of hard filler-alloy and metal binderalloy. Moreover, the binder-alloy should produce a good wetting of particles of hard filler-alloy and surface of the part being surfaced. Due to macroheterogeneous structure the deposited layer acquires new operational properties, which are not inherent to each of its separate initial materials. As fillers in composite surfacing alloys the carbides, borides, nitrides and also crushed alloys of VK and TK type are used [3]. A challenging filler of composite materials is alloy $70 \%$ $\mathrm{Cr}-20 \% \mathrm{Ti}-10 \% \mathrm{C}$ with high mechanical properties [4], which in case of right selection of the binder-alloy should provide a strong bonding with filler.

Therefore, the aim of this work was the study of structure of interfaces between the structural

(C) E.V. SUKHOVAYA, 2015 components of double-layer macroheterogeneous compositions, mechanical properties of deposited composite layers produced by furnace surfacing, where as filler the alloy $70 \% \mathrm{Cr}-20 \% \mathrm{Ti}-10 \% \mathrm{C}$ is used, and as binder-alloys the manganese nickel silver of grade MNMts 20-20 and alloy Fe-3.1\% B- $0.05 \%$ C were used.

Experiment procedure. For surfacing of double-layer composition into the form repeating surface of deposited part with a gap equal to thickness of deposited layer, filler granules $70 \mathrm{Cr}-$ $20 \mathrm{Ti}-10 \mathrm{C}$ of $0.2-2.5 \mathrm{~mm}$ were poured and compacted. Atop the granules the binder-alloys were placed separated by a partition.

Heating of form in the furnace during impregnation was carried out in two stages. At first it was heated to the temperature by $50{ }^{\circ} \mathrm{C}$ higher than melting point of more easily melted binderalloy MNMts 20-20 and soaked for $15 \mathrm{~min}$. Then, temperature in the furnace was increased by $50{ }^{\circ} \mathrm{C}$ higher than melting point of more refractory binder-alloy $\mathrm{Fe}-\mathrm{B}-\mathrm{C}$ and again soaked at this temperature for $15 \mathrm{~min}$. At the end of impregnation the form was cooled together with the furnace. After removal of the form a doublelayer composition was produced, the layers of which were hardened by the same filler but with different composition of binder-alloy.

The microstructure of deposited layers was studied in optical microscopes Neophot, GX-51 and Epytype-2. The quantitative metallographic examinations were carried out in diffraction analyzer Epiquant. The identification of phase components was performed using X-ray diffraction 


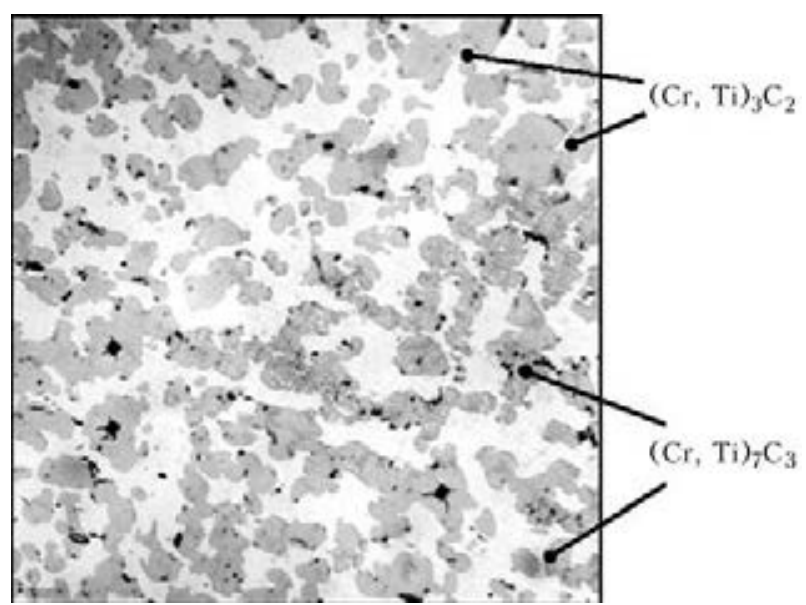

Figure 1. Microstructure $(\times 300)$ of carbide $\mathrm{Cr}-\mathrm{Ti}-\mathrm{C}$

analysis by filming the powder diffraction patterns in devices DRON-UM1 and HZG-4A in the filtered $K_{\alpha}$-iron and copper radiation. The examinations using method of X-ray spectral microanalysis (XSMA) were performed in devices MS-46 with four channels of recording the intensity of radiating elements and in scanning microscopes-microanalyzers REMA $102-02 \mathrm{M}$ and Camebax. As an adapter device the latter was equipped with semiconductor detector LINK 860, series II. The linear rate of phases dissolution of filler in the molten metal was evaluated as the ratio of width of contact interaction areas $(3 \mathrm{kV})$, formed at the interfaces, to the impregnation duration.

The experiment results. Before impregnation, filler-alloy $\mathrm{Cr}-\mathrm{Ti}-\mathrm{C}$ has two-phase structure consisting of dark-colored carbide crystals $(\mathrm{Cr}$, Ti ${ }_{3} \mathrm{C}_{2}$ on the background of bright carbide crystals $(\mathrm{Cr}, \mathrm{Ti})_{7} \mathrm{C}_{3}$ (Figure 1). Before impregnation, binder-alloy $\mathrm{Fe}-3.1 \mathrm{~B}-0.05 \mathrm{C}$ has hypoeutectic structure, where at room temperature the crystals $\alpha-\mathrm{Fe}$ and eutectic $\mathrm{Fe}-\mathrm{Fe}_{2}(\mathrm{~B}, \mathrm{C})$ are observed

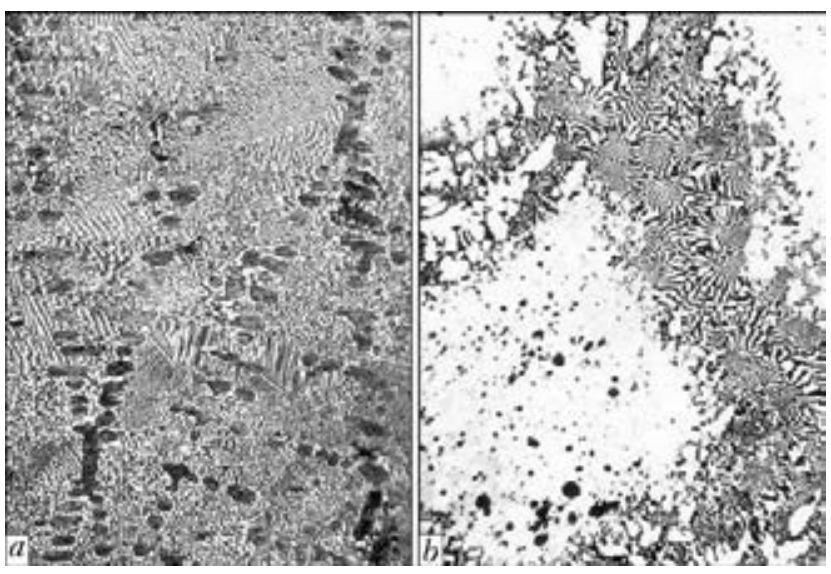

Figure 2. Microstructure $(\times 200)$ of binder-alloy $\mathrm{Fe}-3.1 \%$ $\mathrm{B}-0.05 \% \mathrm{C}(a)$ and layer of composition $(\mathrm{Cr}-\mathrm{Ti}-\mathrm{C}) /(\mathrm{Fe}-$ $\mathrm{B}-\mathrm{C})(b)$

(Figure $2, a$ ). In the structure of manganese nickel silver MNMts 20-20 a solid solution of manganese and nickel on copper base is formed, in which the dispersed inclusions of intermetallic phase NiMn are present [5].

After furnace impregnation the structure of deposited layers is characterized by a uniform distribution of filler granules $\mathrm{Cr}-\mathrm{Ti}-\mathrm{C} \quad(\mathrm{Fi}-$ gure $2, b)$. The average filler content is $60 \pm 2 \%$. At the interface between layers the defects of lack of fusion type are absent. This is confirmed by the results of porosity determination in the compositions, which is not higher than $5-7 \%$.

In layer $(\mathrm{Cr}-\mathrm{Ti}-\mathrm{C}) /(\mathrm{Fe}-\mathrm{B}-\mathrm{C})$ at the interfaces between carbide $\mathrm{Cr}-\mathrm{Ti}-\mathrm{C}$ and Fe-based binder the zones of coarse inclusions (ZCI) occur characterized by the presence of carbide inclusions $(\mathrm{Cr}, \mathrm{Ti})_{3} \mathrm{C}_{2}$ and $(\mathrm{Cr}, \mathrm{Ti})_{7} \mathrm{C}_{3}$ in eutectic $\mathrm{Fe}^{-}-\mathrm{Fe}_{3}(\mathrm{C}, \mathrm{B})$ alloyed with chromium and titanium (Figure 3, Table 1). According to the results of XSMA after wetting with melt $\mathrm{Fe}-3.1 \mathrm{~B}-$ $0.05 \mathrm{C}$ the iron content in the surface layer of

Table 1. Structure and width of ZCI formed between the filler $\mathrm{Cr}-\mathrm{Ti}-\mathrm{C}$ and binders based on copper and iron

\begin{tabular}{|c|c|c|c|c|}
\hline \multirow{2}{*}{ Binder } & \multirow{2}{*}{ Initial structure of binder } & \multicolumn{2}{|c|}{ Structure of interfaces on the side of } & \multirow{2}{*}{$\begin{array}{c}\text { Width of ZCI, } \\
\qquad \mu \mathrm{m}\end{array}$} \\
\hline & & matrix & filler & \\
\hline $\mathrm{Fe}-3.1 \% \mathrm{~B}-0.05 \% \mathrm{C}$ & $\begin{aligned} & \alpha-\mathrm{Fe} \\
\text { eutectic } & \mathrm{Fe}-\mathrm{Fe}_{2}(\mathrm{~B}, \mathrm{C})\end{aligned}$ & $\alpha-\mathrm{Fe}, \mathrm{Fe}-(\mathrm{Fe}, \mathrm{Cr}, \mathrm{Ti})_{2}(\mathrm{~B}, \mathrm{C})$ & $\begin{array}{c}(\mathrm{Cr}, \mathrm{Ti})_{3} \mathrm{C}_{2},(\mathrm{Cr}, \mathrm{Ti}, \mathrm{Fe})_{7} \mathrm{C}_{3} \\
\mathrm{Fe}^{-}(\mathrm{Fe}, \mathrm{Cr}, \mathrm{Ti})_{3}(\mathrm{C}, \mathrm{B})\end{array}$ & $75-80$ \\
\hline MNMts 20-20 & $\begin{array}{l}\text { Solid solution } \\
(\mathrm{Cu}, \mathrm{Ni}, \mathrm{Mn})\end{array}$ & $\begin{array}{c}\text { Solid solution } \\
(\mathrm{Cu}, \mathrm{Ni}, \mathrm{Mn}, \mathrm{Cr}, \mathrm{Ti}, \mathrm{C})\end{array}$ & $\begin{array}{l}\text { Solid solution of } \mathrm{Ni}, \mathrm{Mn}, \mathrm{Cu} \\
\text { in }(\mathrm{Cr}, \mathrm{Ti})_{7} \mathrm{C}_{3},(\mathrm{Cr}, \mathrm{Ti})_{3} \mathrm{C}_{2}\end{array}$ & $7-10$ \\
\hline
\end{tabular}

Table 2. Results of determination of microhardness ( $\mathrm{GPa}$ ) of structural components of deposited layers with filler $\mathrm{Cr}-\mathrm{Ti}-\mathrm{C}$ and binders based on copper and iron before and after impregnation

\begin{tabular}{|c|c|c|c|c|c|c|c|}
\hline \multirow{3}{*}{ Binder } & \multicolumn{2}{|c|}{ Matrix } & \multicolumn{5}{|c|}{ Filler } \\
\hline & \multirow{2}{*}{ Initial alloy } & \multirow{2}{*}{ Interface } & \multicolumn{2}{|c|}{ Initial alloy } & \multicolumn{3}{|c|}{ Interface } \\
\hline & & & $(\mathrm{Cr}, \mathrm{Ti})_{7} \mathrm{C}_{3}$ & $(\mathrm{Cr}, \mathrm{Ti})_{3} \mathrm{C}_{2}$ & $(\mathrm{Cr}, \mathrm{Ti})_{7} \mathrm{C}_{3}$ & $(\mathrm{Cr}, \mathrm{Ti})_{3} \mathrm{C}_{2}$ & $\mathrm{Fe}^{-}-\mathrm{Fe}_{3}(\mathrm{C}, \mathrm{B})$ \\
\hline $\mathrm{Fe}-3.1 \% \mathrm{~B}-0.05 \% \mathrm{C}$ & $4.7 \pm 0.1$ & $5.8 \pm 0.1$ & $19.5 \pm 0.5$ & $25.1 \pm 0.6$ & $17.8 \pm 0.4$ & $25.0 \pm 0.5$ & $8.1 \pm 0.3$ \\
\hline MNMts $20-20$ & $0.73 \pm 0.4$ & $0.97 \pm 0.2$ & $19.5 \pm 0.5$ & $25.1 \pm 0.6$ & $18.9 \pm 0.3$ & $24.7 \pm 0.7$ & - \\
\hline
\end{tabular}



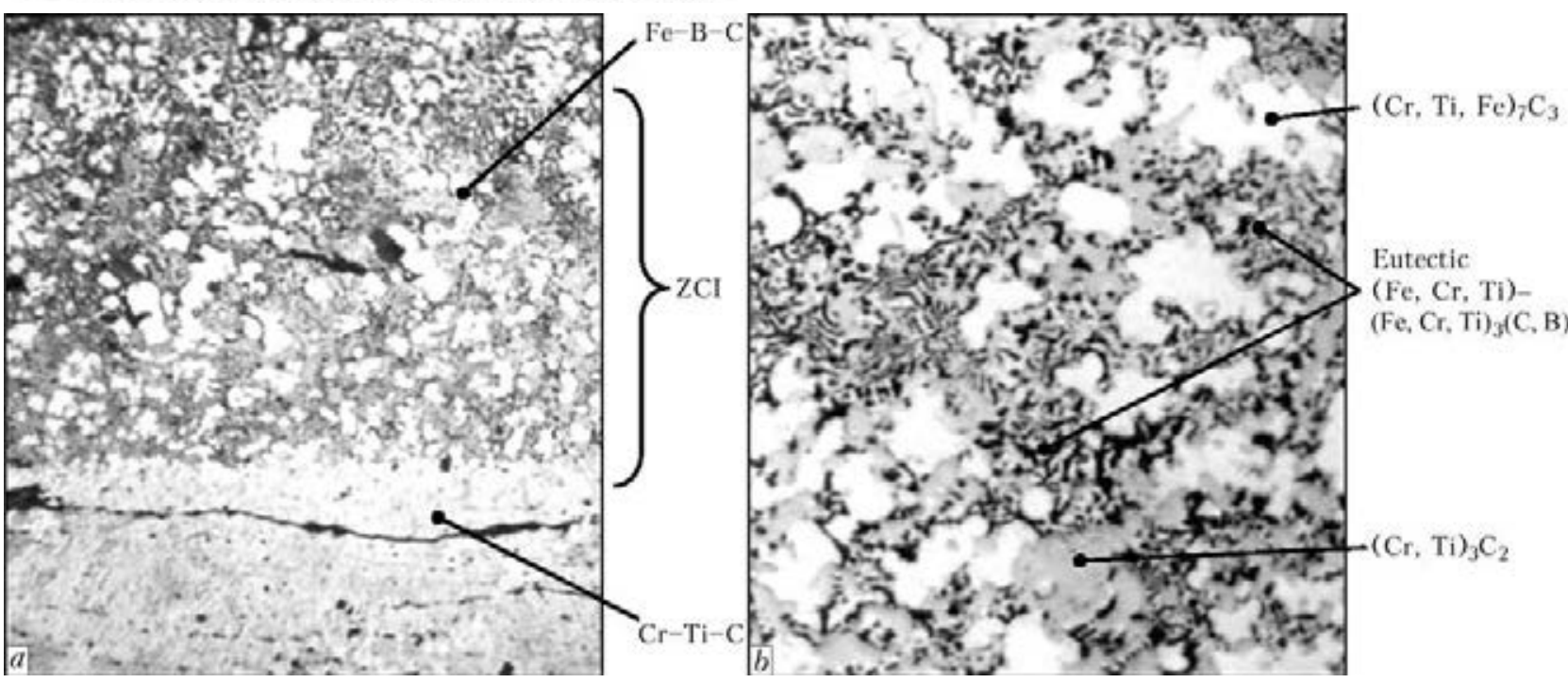

Figure 3. Microstructure of ZCI between the carbide $\mathrm{Cr}-\mathrm{Ti}-\mathrm{C}$ and binder-alloy $\mathrm{Fe}-3.1 \% \mathrm{~B}-0.05 \% \mathrm{C}: a-\times 300 ; b-$ $\times 1000$

carbides $(\mathrm{Cr}, \mathrm{Ti})_{7} \mathrm{C}_{3}$ increases up to $1.3 \%$ (Figure 4). The composition of carbides $(\mathrm{Cr}, \mathrm{Ti})_{3} \mathrm{C}_{2}$ corresponds to the initial one.

In the crystallized matrix in the vicinity of interface $0.2 \% \mathrm{Cr}$ and about $0.1 \% \mathrm{Ti}$ are additionally present. The concentration of chromium in carbides $(\mathrm{Cr}, \mathrm{Ti})_{3} \mathrm{C}_{2}$ and especially in carbides $(\mathrm{Cr}, \mathrm{Ti})_{7} \mathrm{C}_{3}$, observed in the structure of $\mathrm{ZCI}$ on the side of filler, is decreased, while that of iron is increased (see Figure 4). During moving the probe towards the filler the content of chromium in carbide phases is gradually increased whereas concentration of iron is decreased. At removal from ZCI towards the matrix the iron content is increased. The matrix of composite materials has structure of eutectic $\mathrm{Fe}-\mathrm{Fe}_{3}(\mathrm{C}, \mathrm{B})$ alloyed with chromium and titanium, which differs from the initial structure of binder, where $\alpha$-Fe and eutectic $\mathrm{Fe}_{2}(\mathrm{~B}, \mathrm{C})$ were present. Microhardness of matrix of composite materials is $4.7-5.8 \mathrm{GPa}$ depending on the content of alloying elements $(\mathrm{Ta}-$ ble 2). In the vicinity of interface the microhardness of carbides $(\mathrm{Cr}, \mathrm{Ti})_{7} \mathrm{C}_{3}$, additionally alloyed with iron, is reduced as compared to this characteristic of carbides of initial alloy $\mathrm{Cr}-\mathrm{Ti}-\mathrm{C}$. The microhardness of carbides $(\mathrm{Cr}, \mathrm{Ti})_{3} \mathrm{C}_{2}$ is not almost changed.

At the contact interaction of $\mathrm{Cr}$ - $\mathrm{Ti}$ carbide with the melt based on iron the processes of strong chemical interaction are observed at the interface, characterized by carbides $(\mathrm{Cr}, \mathrm{Ti})_{7} \mathrm{C}_{3}$ dissolution in the molten metal. The molten metal penetrates mainly along the grain boundaries of carbides $(\mathrm{Cr}, \mathrm{Ti})_{7} \mathrm{C}_{3}$, the diffusion of iron at-

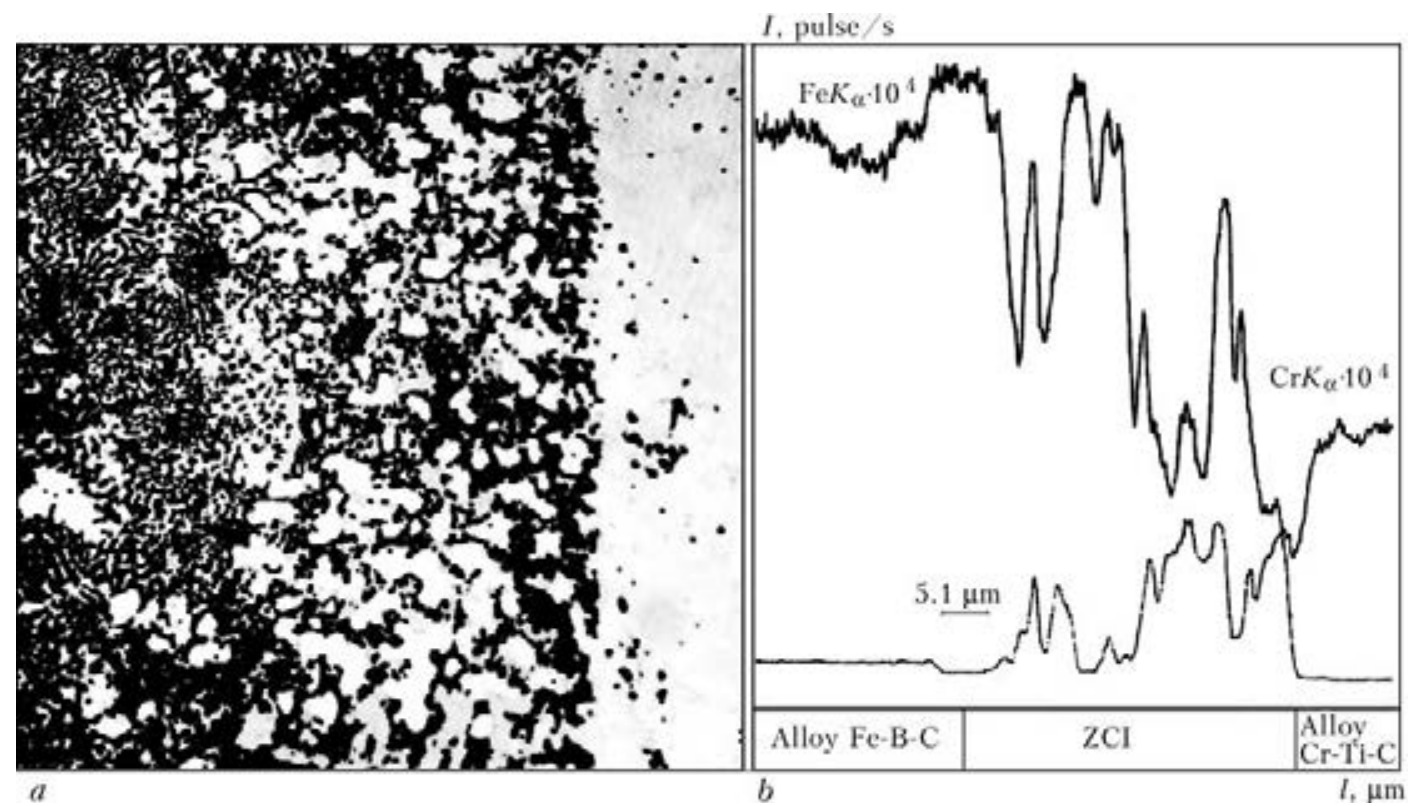

Figure 4. Microstructure $(a-\times 300)$ and diagram of distribution of radiation intensity of elements during moving the probe across the area of boundary interface $(\mathrm{Cr}-\mathrm{Ti}-\mathrm{C}) /(\mathrm{Fe}-\mathrm{B}-\mathrm{C})(b)$ 
Table 3. Results of determination of mechanical properties of deposited layers

\begin{tabular}{||c|c|c|c|}
\hline Layer & $\begin{array}{c}\text { Hardness } \\
H R C\end{array}$ & $\begin{array}{c}\text { Total micro- } \\
\text { hardness, } \\
\text { GPa }\end{array}$ & $\begin{array}{c}\text { Compression } \\
\text { strength, } \\
\mathrm{MPa}\end{array}$ \\
\hline$(\mathrm{Cr}-\mathrm{Ti}-\mathrm{C}) / \mathrm{MNMts} 20-20$ & $43 \pm 3$ & $8.1 \pm 0.3$ & $3105 \pm 5$ \\
\hline$(\mathrm{Cr}-\mathrm{Ti}-\mathrm{C}) /(\mathrm{Fe}-\mathrm{B}-\mathrm{C})$ & $60 \pm 2$ & $10.8 \pm 0.4$ & $2240 \pm 10$ \\
\hline
\end{tabular}

oms along which is facilitated. Dissolution of carbide $(\mathrm{Cr}, \mathrm{Ti})_{7} \mathrm{C}_{3}$ alloyed with iron occurs at rate of $2.0-2.5 \mu \mathrm{m} / \mathrm{min}$ in a short period of time. Rapid dissolution of carbides $(\mathrm{Cr}, \mathrm{Ti})_{7} \mathrm{C}_{3}$ may be also facilitated by transformation of carbide $(\mathrm{Cr}, \mathrm{Ti})_{7} \mathrm{C}_{3}$ into lower carbide $(\mathrm{Cr}, \mathrm{Ti})_{23} \mathrm{C}_{6}$, caused by loss of carbon in diffusion.

Carbide $(\mathrm{Cr}, \mathrm{Ti})_{3} \mathrm{C}_{2}$ is dissolved in the molten matrix at rate of $0.4-0.7 \mu \mathrm{m} / \mathrm{min}$. Moreover, penetration of iron atoms from the melt to this carbides is almost absent. Carbides $(\mathrm{Cr}, \mathrm{Ti})_{3} \mathrm{C}_{2}$ are preserved almost unchanged during impregnation and are present in the form of dark inclusions in eutectic $\mathrm{Fe}^{-} \mathrm{Fe}_{3}(\mathrm{C}, \mathrm{B})$ alloyed with chromium and titanium.

In the structure of layer $(\mathrm{Cr}-\mathrm{Ti}-\mathrm{C}) / \mathrm{MNMts}$ 20-20 at the interfaces with matrix the surface of hard alloy particles does not change ( $\mathrm{Fi}^{-}$ gure 5). However, XSMA and microdurometric measurements confirm the formation of ZCI between the filler and matrix (see Tables 1 and 2). Titanium and chromium from Cr-Ti carbide penetrate into nickel silver melt (Figure 6). Nickel and manganese diffuse from the molten metal into the hard alloy mainly along the grain boundaries. In presence of these elements the diffusion of copper into carbide is also facilitated. At the interfaces the processes of weak chemical interactions occur, which include the stage of $\mathrm{Cr}-\mathrm{Ti}$ carbide dissolution in nickel silver at a rate of $0.2-0.6 \mu \mathrm{m} / \mathrm{min}$.

At the interface between the layers of surfacing composition on the side of binder MNMts 20-20 crystals of Fe-based phase alloyed with copper and nickel appear additionally. The structure of eutectic binder is almost unchanged. In the transition from the layer with alloy-binder MNMts 20-20 to the layer with binder-alloy $\mathrm{Fe}^{-}$ $\mathrm{B}-\mathrm{C}$ the general microhardness is 1.3 times increased, hardness is increased by 1.4 times, and the compression strength is reduced by 1.4 times (Table 3).

Discussion of the results. The sequence of processes occurring during impregnation of filler $\mathrm{Cr}-\mathrm{Ti}-\mathrm{C}$ with melts on copper and iron base in a generalized way can be presented in the following way. At first the molten binder penetrates

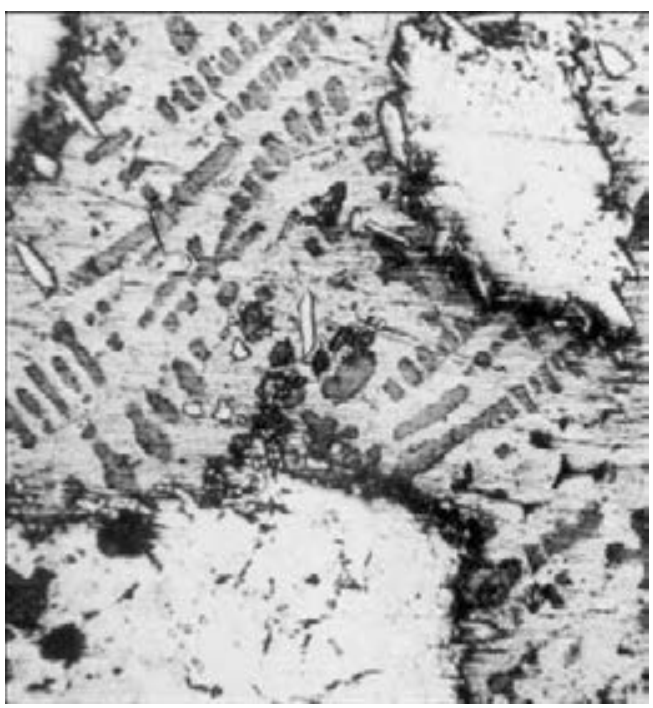

Figure 5. Microstructure $(\times 200)$ of layer of composition ( $\mathrm{Cr}-\mathrm{Ti}-\mathrm{C}) /$ MNMts $20-20$

into the gaps between the freely poured filler particles, fills the pores, cracks and other defects. Then, mutual diffusion of binder and filler components occurs. In case of wetting $\mathrm{Cr}$-Ti carbide with molten nickel silver, penetration of filler components into the binder is mainly observed.
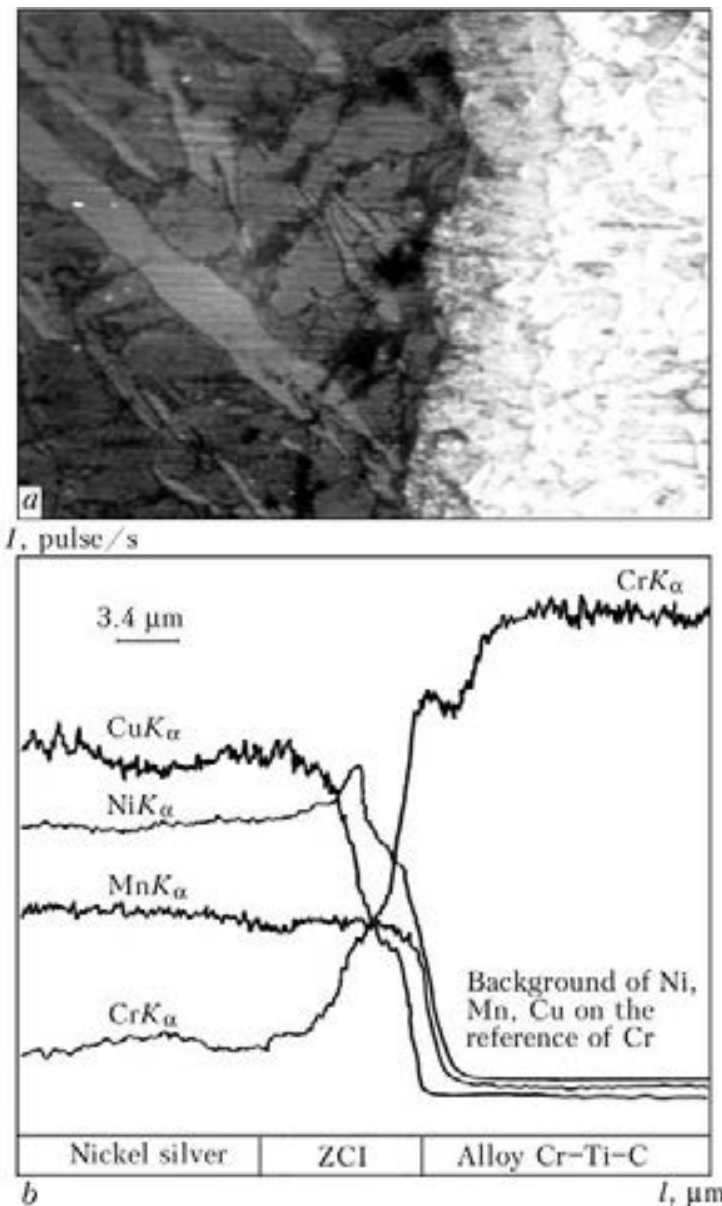

Figure 6. Microstructure $(\times 200)(a)$, and diagram of distribution of radiation intensity of elements during moving the probe across the area of interface $(\mathrm{Cr}-\mathrm{Ti}-\mathrm{C}) / \mathrm{MNMts}$ 20-20(b) 
The filler phases are dissolved in nickel silver at owest rate. Therefore, after solidification of composite materials with $\mathrm{Cu}$-based matrix at the interfaces the changes in structure are absent, and only using XSMA method it is possible to detect the presence of filler elements in the matrix, and vice versa.

The limit of mutual saturation by binder and filler components during wetting with Fe-based melts is not achieved during the impregnation process. In this case, the binder components penetrate into the hard alloy in a much larger quantity. The solubility of iron in phase $(\mathrm{Cr}, \mathrm{Ti})_{7} \mathrm{C}_{3}$ of $\mathrm{Cr}$-Ti carbide is 10 times higher than that of nickel and manganese, which diffuse from the nickel silver binder. Moreover, as compared to nickel silver, the molten iron binder penetrates along the grain boundaries of the carbide $(\mathrm{Cr}$, $\mathrm{Ti})_{7} \mathrm{C}_{3}$ to a greater depth and almost completely dissolves carbides $(\mathrm{Cr}, \mathrm{Ti})_{7} \mathrm{C}_{3}$, which are present in the surface layer of filler. Carbides $(\mathrm{Cr}, \mathrm{Ti})_{3} \mathrm{C}_{2}$ are dissolved in the molten metal at a much slower rate.

In the liquid state at the surfaces between the filler and matrix the diffusion processes occur. During subsequent cooling due to the limited solubility of components, carbide crystals $(\mathrm{Cr}$, $\mathrm{Ti})_{7} \mathrm{C}_{3}$ alloyed with iron are precipitated from the melt. Their origination is facilitated on the surface of non-dissolved phase $(\mathrm{Cr}, \mathrm{Ti})_{7} \mathrm{C}_{3}$. The remaining liquid is crystallized with formation of eutectic $\mathrm{Fe}^{-} \mathrm{Fe}_{3}(\mathrm{C}, \mathrm{B})$ alloyed with chromium and titanium, along the grain boundaries as a result of enrichment of the melt, corresponding to composition of initial eutectic $\mathrm{Fe}-\mathrm{Fe}_{2}(\mathrm{~B}, \mathrm{C})$, with carbon, chromium and titanium during dissolution of $\mathrm{Cr}$-Ti carbide.
At the interfaces between the layers of double-layer composite coating also dissolution and diffusion processes occur. New phases appear only in the transition zone between the layers on copper and iron base. They represent Fe-based solid solution formed during cooling due to the limited solubility of components in copper.

In conclusion it may be noted that the method of furnace impregnation can be used for surfacing of double-layer compositions hardened by filler of the same composition but having different composition of matrix. The investigations of physical and chemical processes occurring during formation of interfaces between the filler and matrix in the structure of deposited layers show prospects in application of alloy $\mathrm{Cr}-\mathrm{Ti}-\mathrm{C}$ as a filler, and metal alloys MNMts 20-20 and $\mathrm{Fe}^{-}$ $3.1 \% \mathrm{~B}-0.05 \% \mathrm{C}$ as a binders in double-layer composition. It is characterized by almost defectfree structure and presence of mechanical properties gradient along the cross section. It allows using the proposed composition for strengthening the surface of parts operating under non-uniform temperature distributions, stresses, deformations, etc.

1. Netesa, I.V., Dudko, D.A., Maksimovich, B.I. et al. Method of wear-resistant surfacing. USSR author's cert. 562393. Int. Cl. B 23K 9/04, B 22 D $19 / 08$. Fil. 18.07.75. Publ. 08.06.1977.

2. Sukhova, O.V., Spyrydonova, I.M., Butenko, V.F. et al. Method for production of composite material. Pat. 96921 UA. Int. Cl. B23K 35/00, C23C $28 / 00$, C22C 29/08. Publ. 26.12.2011.

3. Spiridonova, I.M., Panasyuk, A.D., Sukhovaya, E.V. et al. (2011) Stability of composite materials. Dnepropetrovsk: Svidler.

4. Kosolapova, T.Ya. (1969) Carbides. Moscow: Metallurgiya.

5. Zakharov, A.M. (1980) Commercial alloys of nonferrous metals. Moscow: Metallurgiya. 


\title{
EFFECT OF MAGNETIC-PULSED TREATMENT OF FILLER MATERIALS ON DEPOSITED METAL STRUCTURE
}

Yu.M. KUSKOV, G.N. GORDAN, L.T. EREMEEVA, I.L. BOGAJCHUK and T.V. KAJDA

E.O. Paton Electric Welding Institute, NASU

11 Bozhenko Str., 03680, Kiev, Ukraine. E-mail: office@paton.kiev.ua

\begin{abstract}
Effect of magnetic-pulsed treatment on structure of surfacing filler material, i.e. shot from high-chromium cast iron, was investigated. Effect of magnetic-pulsed treatment on refining of structure of shot metal, quantitative composition of phases and parameters of their crystal lattice was determined. New properties of the shot received as a result of magnetic-pulsed treatment are not inherited by deposited metal. 5 Ref., 2 Tables, 3 Figures.
\end{abstract}

Keywords: electroslag surfacing, current-carrying mold, shot, deposited metal, magnetic-pulsed treatment

The E.O. Paton Electric Welding Institute developed a method of electroslag surfacing and remelting in current-carrying mold [1]. Compact (large section electrodes - rods, bars, plates; wires, strips etc.), discrete (shot, powder, chip etc.) and liquid surfacing consumables can be used with this method.

Practice and theoretical investigations showed that application of discrete materials is perspective for electroslag process. Shot is the most widespread discrete material, which has found industrial application in surfacing [2]. Its can be produced using different technological schemes [3]. The main condition of possibility of its application as surfacing filler is optimum size and form of granules, their low gas-saturation and high metal density.

Electroslag process as a result of melting of surfacing consumables promotes for formation of liquid metal pool, which on volume is more comparable with pool volume in casting than, for example, with weld pool forming in fusion arc welding. Therefore, number of points referring to behavior of liquid metal in casting can be related to electroslag process with sufficient level of approximation.

In particular, it is referred to determined in casting practice fact of effect of properties of charge materials on properties of liquid metal and, as a result, on quality of produced castings. This interconnection was termed «inheritance» and now present research direction is actively developed by school of V.I. Nikitin and his colleagues [4]. Authors of this direction think that the «guided effect on structure of charge metals can help to caught a response (trace) of structural or another information at different stages of casting production, after passing liquid state» is the main peculiarity of structural inheritance.

Different ways can be used for introduction such information in the charge materials. One of such methods based on classification of V.I. Nikitin is solid-phase treatment, which allows receiving non-equilibrium structures, saturated by dislocations, with thin mosaic structure. Heat treatment, pressure treatment, electrolytic treatment and physical treatment, i.e. magnetic, ultrasonic, laser etc., can be referred to it.

Investigations on evaluation of effect of special treatment of discrete surfacing consumable, i.e. shot, on structural changes of granules as well as deposited metal produced at their melting in slag pool were carried out in present work.

Magnetic-pulsed treatment (MPT) was taken as a method of influence on discrete filler.

Selection of such treatment was caused by the investigations [5], carried in Bauman Moscow State Technical University and Moscow State Mining University, which showed significant increase of efficiency of some traditional methods of strengthening and protection of surfaces of machine parts at additional application of MPT.

\begin{tabular}{|c|c|}
\hline \multirow{2}{*}{\multicolumn{2}{|c|}{$\begin{array}{c}\text { Comparative evaluation of traditional methods } \\
\text { of strengthening of machine parts using MPT, \% }\end{array}$}} \\
\hline & \\
\hline Phosphatizing & 120 \\
\hline Chroming ...... & 140 \\
\hline Borating. & .. 126 \\
\hline Plasma spraying & 167 \\
\hline Diffusion chroming .. & .. 142 \\
\hline Explosion treatment & \\
\hline Rolling ................. & 156 \\
\hline Cold work $. . . \ldots \ldots . .$. & .. 120 \\
\hline
\end{tabular}




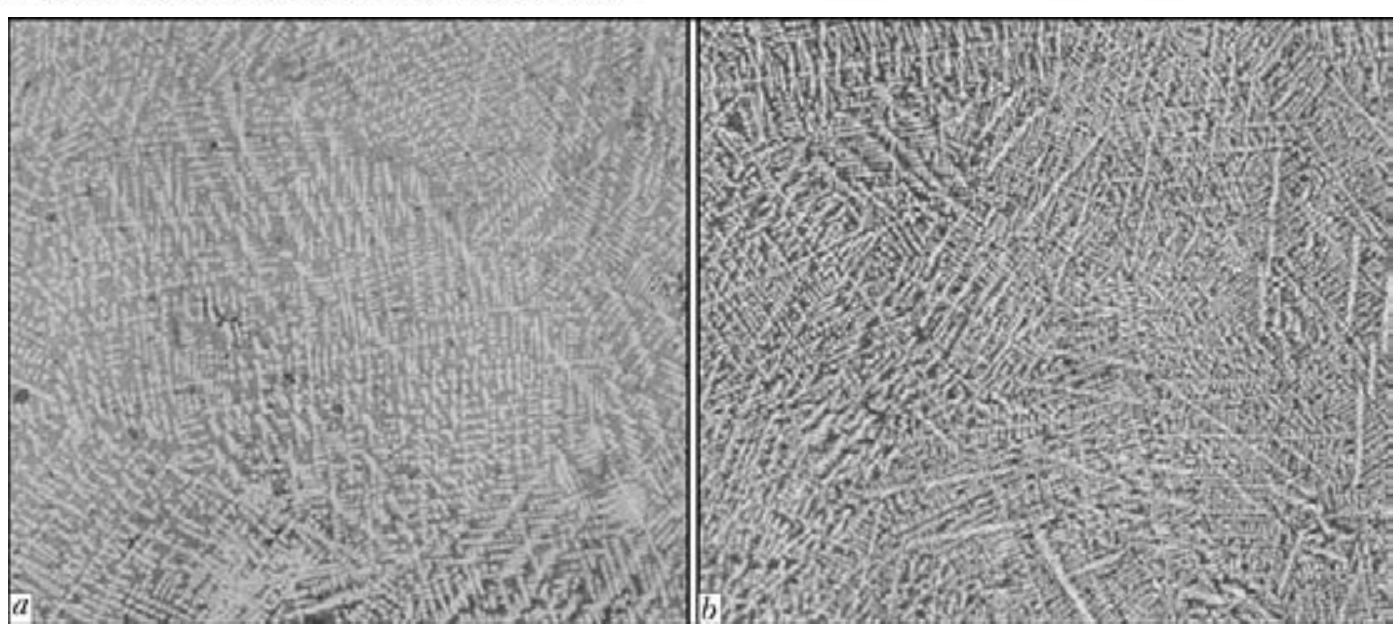

Figure 1. Microstructure $(\times 400)$ of shot metal in initial state $(a)$ and after MPT $(b)$

Isothermal quenching ................................. 136

Step-by-step quenching …....................................... 128

Quenching with cold treatment at $-270{ }^{\circ} \mathrm{C}$............. 150

Thermomechanical treatment .............................. 170

Shot from high-chromium cast iron (25$28 \% \mathrm{Cr}$ ), produced by air spraying of jet of liquid metal [3], was used for surfacing in currentcarrying mold of $180 \mathrm{~mm}$ diameter. Fractional composition of shot was $0.8-2.5 \mathrm{~mm}$. Surfacing was carried out using two batches of shot, namely one untreated, and the second was subjected to MPT using Moscow State Mining University technology* Technological parameters of surfacing in both cases were similar.

Shots of both batches as well as deposited metal, produced with their application, were examined with the help of optical metallography, $\mathrm{X}$-ray spectrum and X-ray structural analysis.

The following equipment was used: X-ray spectrum analysis - Camebax SX-50; X-ray structural analysis - DRON Um-1; optical metallography - Neophot-32 and Versamet microscopes; and LECO hardness meter H-400.

Results of metallographic investigations of shot metal. Metallographic examinations and MXSA determined that shots, treated by MPT as well as not treated, have dendrite structure. The dendrites were formed by austenite grains, and martensite constituent of the structure was

Table 1. Phase composition and parameters of crystal lattices of shot metal in initial state and after MPT

\begin{tabular}{|c|c|c|c|c|}
\hline \multirow{2}{*}{ Phase } & \multicolumn{2}{|c|}{ Without MPT } & \multicolumn{2}{|c|}{ After MPT } \\
\hline & wt.\% & parameter, $\AA$ & wt.\% & parameter, $\AA$ \\
\hline Austenite & 69.74 & $a: 3.6253$ & 53.49 & $a: 3.6126$ \\
\hline Martensite & 29.31 & $\begin{array}{l}a: 2.8976 \\
c: 2.9092\end{array}$ & 45.51 & $\begin{array}{l}a: 2.8967 \\
c: 2.9043\end{array}$ \\
\hline
\end{tabular}

\footnotetext{
${ }^{*}$ MPT was carried out under the leadership of Dr. V.G. Ivakhnik.
}

located interdendritic space. MPT treatment results in refining of shot metal structure on average by $50 \%$ (Figure 1). It follows from visual evaluation as well as measurement of dendrite parameter (distance between the axes of the second order was 7.59 and $4 \mu \mathrm{m}$, respectively), performed by linear method using Versamet microscope. Some difference is observed in indices of microhardness of untreated and treated metal (HV0.1-5500 and $5960 \mathrm{MPa}$, respectively). Distribution of alloying elements over shot section and their metal chemical composition before and after treatment remain virtually unchanged.

$\mathrm{X}$-ray structural analysis allowed determining quantitative composition of phases of metal of surfacing filler before and after its treatment by MPT, as well as calculating parameters of their crystal lattices. According to received results MPT gave rise to change of these indices ( $\mathrm{Ta}-$ ble 1).

Results of examination of deposited metal. Microstructure of metal, deposited using both types of shot, represents itself austenite matrix with carbides $(\mathrm{CrFe})_{7} \mathrm{C}_{3}$ located in it at longitudinal as well as transverse directions, and chromium-carbide eutectics (Figure 2).

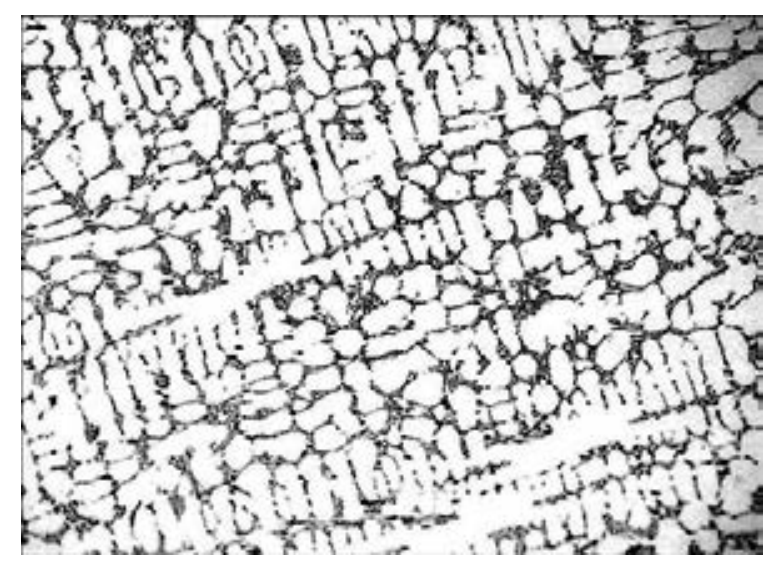

Figure 2. Microstructure $(\times 200)$ of deposited high-chromium cast iron 
Table 2. Phase composition of metal, deposited by untreated and MP-treated

\begin{tabular}{||l|c|c|}
\hline \multirow{2}{*}{\multicolumn{1}{|c|}{ Phase }} & Without MPT & After MPT \\
\cline { 2 - 3 } & wt.\% & wt.\% \\
\hline$\gamma$-Fe & 65.63 & 66.54 \\
\hline$\alpha-\mathrm{Fe}$ & 20.97 & 22.80 \\
\hline Carbide $(\mathrm{CrFe})_{7} \mathrm{C}_{3}$ & 13.40 & 10.65 \\
\hline
\end{tabular}

Distribution of alloying elements (Figure 3) and phase composition (Table 2) of metal, deposited by shot, in initial condition and after MPT does not virtually change.

Thus, though magnetic-pulsed treatment changes for better the properties of discrete surfacing filler in form of shot, but these changes are not preserved in the deposited metal.

It is seems that metal, which has passed temperature of Curie point and being further melted, loses all positive changes determined by magnetic effect on filler metal. It should be noted that earlier work [4] represented magnetic treatment of charge as theoretically possible without verification of positive effect of this method on charge at casting of real products. Obtained examination results allowed recommending MPT for deposited metal. Relevance of such technological solution is justified by investigations carried in work [5].

\section{Conclusions}

1. It is determined that MPT allows significant changing of properties of surfacing discrete filler, but these changes are not preserved in the deposited metal.

2. It can be interesting to investigate other methods (not magnetic ones) of effect on filler in order to improve deposited metal quality.
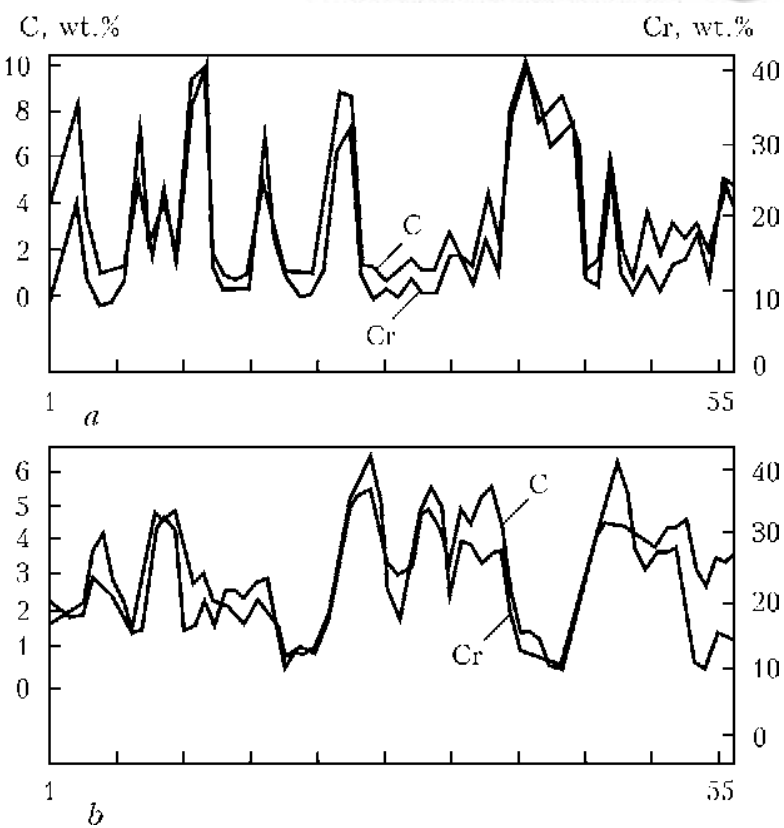

Figure 3. Distribution of chromium and carbon in metal, deposited by shot: $a$ - in initial state; $b-$ subjected to MPT

3. Obtained investigation results allow recommending MPT for deposited metal. Relevance of such technological solution is justified by investigations carried in work [5].

1. Kuskov, Yu.M. (2003) A new approach to electroslag welding. Welding J., 4, 42-45.

2. Ksyondzyk, G.V., Kuskov, Yu.M. (1978) Cast-iron shot - a new type of filler material for electroslag surfacing. In: Theoretical and technological principles of surfacing. Surfacing materials, 80-82. Ed. by I.I. Frumin. Kiev: PWI.

3. Zatulovsky, S.S., Mudruk, L.A. (1988) Production and application of metal shot. Moscow: Metallurgiya.

4. Nikitin, V.I., Nikitin, K.V. (2005) Inheritance in cast alloys. 2nd ed. Moscow: Mashinostroenie.

5. Kantovich, L.I., Malygin, B.V., Pervov, K.M. (2007) Increase in resource of tool and parts of mining machines by magnetic treatment method. Gornoe Oborud. i Elektromekhanika, 1, 13-16.

Received 20.03.2015 


\title{
EFFECT OF TECHNOLOGICAL PARAMETERS OF LASER AND LASER-PLASMA ALLOYING ON PROPERTIES OF 38KhN3MFA STEEL LAYERS
}

\author{
L.I. MARKASHOVA, V.D. SHELYAGIN, O.S. KUSHNARYOVA and A.V. BERNATSKY \\ E.O. Paton Electric Welding Institute, NASU \\ 11 Bozhenko Str., 03680, Kiev, Ukraine. E-mail: office@paton.kiev.ua
}

\begin{abstract}
The results of investigations of structural-phase conditions in surface layers of structural steel 38KhN3MFA and their changes under different modes of strengthening by laser and laser-plasma alloying are given. Experimental investigations were used as a basis for analytical evaluation of differential input of all structures being formed in strengthening and their parameters (chemical composition, grain and subgrain structures, dislocation density, volume fraction of phase precipitates etc.) in change of strength characteristics of alloyed layers, conditions of crack formation promoted by formation of local internal stress concentrators, i.e. zones of nucleation and propagation of cracks, as well as mechanisms for relaxation of such type of stresses. 12 Ref., 6 Figures.
\end{abstract}

Key words: structural steel, working surface, laser and laser-plasma surface alloying, structure, substructure, phase precipitates, dislocation density, service properties of surfaces

One of the main tasks in manufacture of parts of machines and mechanisms is providing of their service properties, that, as a rule, depend on conditions of their operation and corresponding properties of materials, from which these parts are manufactured [1]. As for the structures with specific properties of their surfaces, then their working capacity and increase of life of such types of structures can be provided, first of all, by corresponding technologies for surface layer strengthening. Today, laser and laser-plasma methods of treatment are referred to them [2].

It should be noted that conditions of operation of indicated technologies provide for appearance of problems related to significant extent with accumulation of local internal stresses in treated surfaces, that is the main reason of reduction of crack resistance and, respectively, reduction of properties of the whole structure.

It should be noted that virtually all properties, including material crack resistance, are determined by their structural-phase condition. Investigation of nature of structures and their changes in surface layers of metal under conditions of different technological treatments in combination with further evaluation of effect of forming structures on their service properties is a relevant task. Such an experimental-analytical approach gives a possibility for providing necessary service properties of hardened surfaces due to optimization of surface structures [3-5].
Experimental information on structure-phase condition of alloyed layers of structural steel $38 \mathrm{KhN} 3 \mathrm{MFA}$ (surface of circular specimens $187 \times 125 \times 30 \mathrm{~mm})$ and its changes was received for conditions of laser and laser-plasma alloying [6] using mechanical mixture of powders of 0 $40 \mu \mathrm{m}$ fraction of the following composition, wt.\%: 46( $\left.\mathrm{WC}-\mathrm{W}_{2} \mathrm{C}\right)+46 \mathrm{Cr}+4 \mathrm{Al}+4 \mathrm{Si}$ (laser alloying) and $48\left(\mathrm{WC}-\mathrm{W}_{2} \mathrm{C}\right)+48 \mathrm{Cr}+4 \mathrm{Al}$ (laser-plasma alloying). Following modes of treatment were used at that: power $P=3.5-4.4 \mathrm{~kW}$; alloying speed $v=400-750 \mathrm{~mm} / \mathrm{min}$ at radiation defocusing $\Delta F=+(30-45) \mathrm{mm}$ at laser alloying method. Laser-plasma alloying was performed at constant $P=3 \mathrm{~kW}$, varying $v=500-$ $750 \mathrm{~mm} / \mathrm{min}$ with overlaying of different number of paths.

The following was determined using complex examinations at all structural levels from macro (grain) to micro (dislocation) one [7] using light (Versamet-2), analytical scanning (Philips SEM515) as well as transmission microdiffraction electron microscopy (JEOL JEM-200CX).

Surface alloyed layer at all investigated methods of treatment has obvious crystalline structure. However, modes of laser-plasma treatment are characterized by reduction of sizes and prevailing of more globular (cell) nature of structures forming in surface layers (Figure 1). The most problematic defective zones for all investigated surfaces (at laser as well as laser-plasma alloying) are areas of microcracks, in which rapid increase of chromium concentration (up to $25 \%$ ) is observed (Figure 2). However, if cracks are observed not only in alloyed layer, but also in fusion zone and base metal under conditions of 

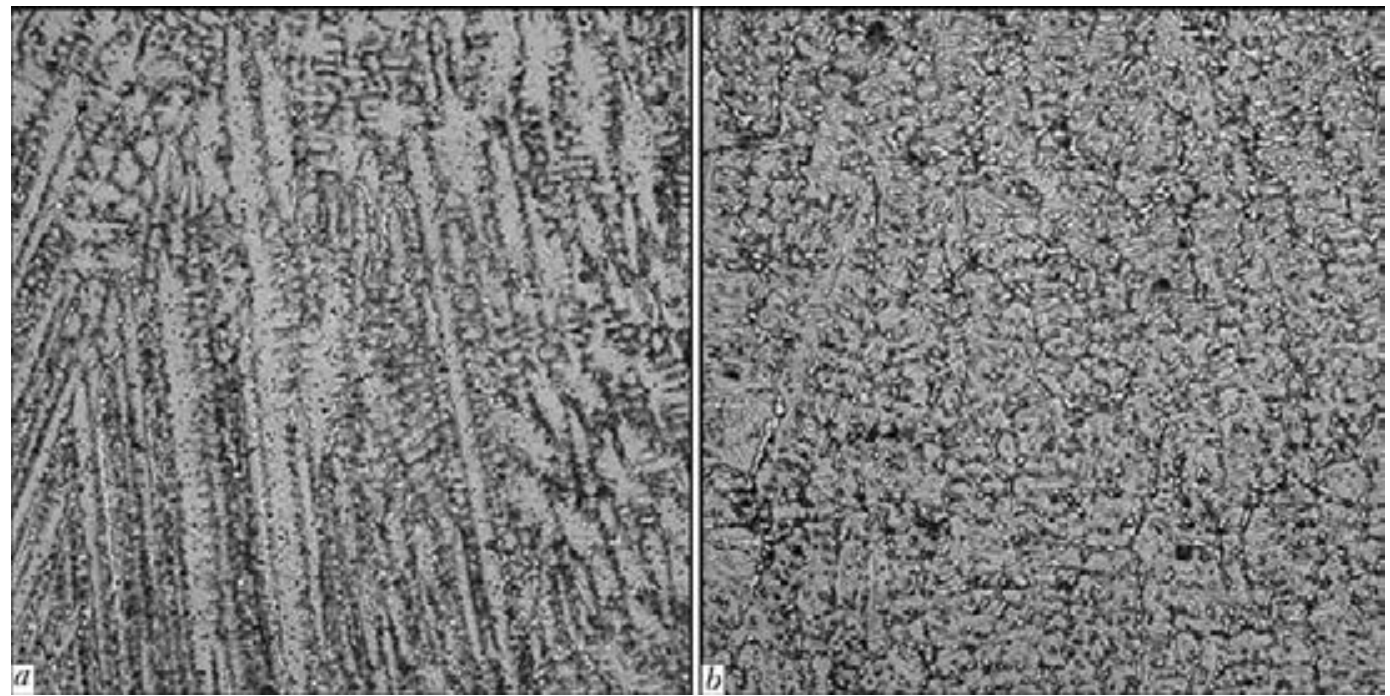

Figure 1. Microstrucutre $(\times 500)$ of surface of structural steel 38KhN3MFA under conditions of laser $(a)$ and laser-plasma (b) alloying

laser treatment, then areas of crack propagation are significantly reduced under laser-plasma alloying. No cracks are found in fusion zone and, moreover, in base metal [6]. More detailed parallel investigations were carried out using specimens produced at optimum technological modes (absence of cracks or their minimum quantity) and at deviations from optimum mode (conditions of formation of significant quantity of cracks) for detection of reasons of crack formation appearing under specific technological modes of surface treatment.

It was determined that laser alloying at $P=$ $=4.4 \mathrm{~kW}, v=400 \mathrm{~mm} / \mathrm{min}$ (deviation from optimum mode) provides for formation in treated surface layers of the structure differing by increased indices of microhardness ( $H V$-4830$5720 \mathrm{MPa}$ ). Their values exceed corresponding indices of base metal ( $H V-3760-3820 \mathrm{MPa})$, i.e. gradient of microhardness $\Delta H V$ from surface to base metal makes around 1070-850 $\mathrm{MPa}$. Besides, insignificant microporosity (volume fraction up to $V_{\mathrm{fr}} \sim 1 \%$ ) is typical for treated surfaces. As for type of forming structures and their size, then investigations showed that indicated modes of treatment provides for formation in alloyed surface layers of structures of mainly acicular type, including martensite, as well as structures of upper and lower bainite saturated with elongated $(h \times l=(0.06-0.10) \times(1.0-1.6 \mu \mathrm{m}))$ carbides of grain boundary type (Figure $3, a$ ). Coarse grain acicular structures $(h \times l$ up to $\sim 15 \times$ $\times 150 \mu \mathrm{m})$ with coefficient of grain shape up to $\kappa \sim 10$ should be noted at that. It indicates extension of structures forming in surface layers.

Examinations of concentration changes as well as presence and distribution of particles of phase formations of different compositions, being introduced in treatment together with powder mixture, showed comparatively uniform distribution of inclusions of size up to $\sim 25 \mu \mathrm{m}$ in internal volumes of grains of alloyed layers under indicated treatment. They mainly consist of tungsten carbides $\left(\mathrm{WC}+\mathrm{W}_{2} \mathrm{C}\right)$ of $V_{\mathrm{fr}} \sim 1 \%$. Formation of local zones of increase chromium concentration (up to $\sim 20-25 \%$ ), which are distributed, as a rule, along intergrain boundaries, is also observed. Areas of such type are clearly registered

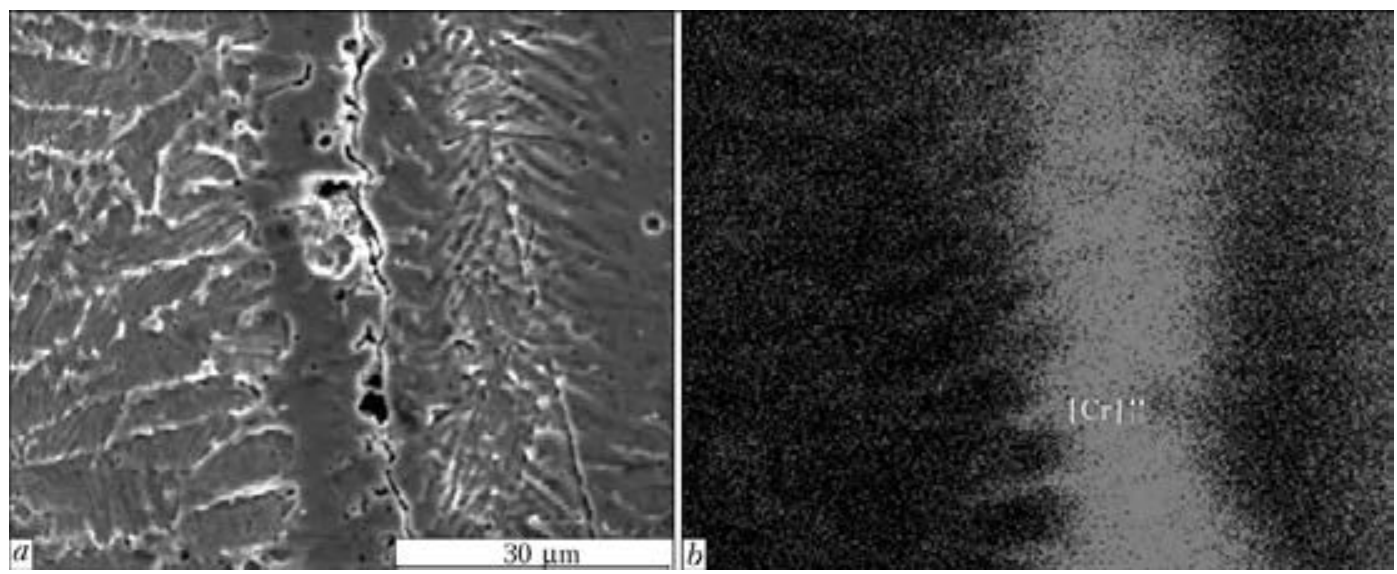

Figure 2. Image of microcracks in area of surface alloyed layer $(a)$, and distributon of chromium along this crack (b) 

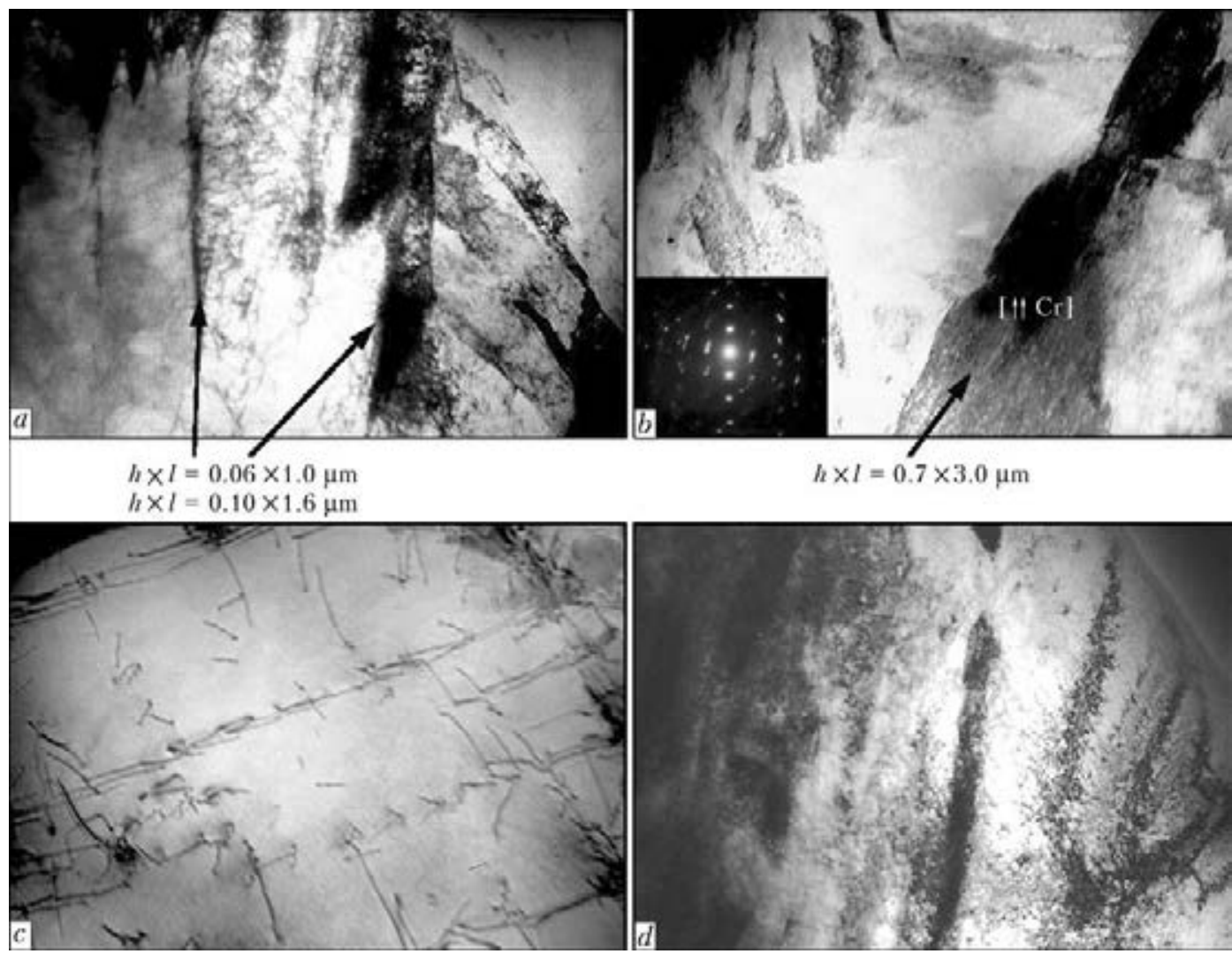

Figure 3. Fine structure of surface layer produced by laser alloying at $P=4.4 \mathrm{~kW}, v=400 \mathrm{~mm} / \mathrm{min}: a-$ gradient of distribution of dislocations along phase precipitates in internal volumes of crystalline particles $(\times 37,000) ; b-$ internal strturture of phase precipitates $(\times 30,000)$; and at $P=3.5 \mathrm{~kW}, v=500 \mathrm{~mm} / \mathrm{min}: c-$ uniform distribution of dislocation density in austenite structure $(\times 20,000) ; d-$ martensite structure $(\times 30,000)$

on maps of chemical elements distribution during corresponding examinations.

In the case of investigated modes of laser alloying, metal layers within thin (dislocation structure) is characterized by uniform distribution of dislocation density differing by rapid increase (mainly along intergrain boundaries) of dislocation density up to $\rho \sim 9 \cdot 10^{11}-1 \cdot 10^{12} \mathrm{~cm}^{-2}$ values that is significantly higher than the values of intergrain dislocation density $\left(\rho \sim 8 \cdot 10^{8}-2 \cdot 10^{10} \mathrm{~cm}^{-2}\right)$. Elongated dense dislocation accumulations of such type are, as a rule, interlocked with sufficiently high near-boundary concentration distributions of chromium, and, respectively, formation in this zone (along intergrain boundaries) of Cr-containing carbide phases $\left(\mathrm{Cr}_{23} \mathrm{C}_{6}\right.$ type) (see Figure $\left.2, b\right)$.

Radical changes of structure-phase conditions of treated surfaces are observed in the case of optimum mode of laser alloying $(P=3.5 \mathrm{~kW}$, $v=500 \mathrm{~mm} / \mathrm{min})$ in comparison to mode with deviation from optimum one. The surfaces are characterized by formation of more fine-grain martensite-austenite structure (Figure 3,c,d) (grain size $h \times l$ is reduced to $40 \times 125 \mu \mathrm{m}$ ) at significant decrease of grain shape coefficient $(\kappa \sim 3)$. It indicates not only fine gran structure, but equiaxial surface structure under conditions of optimum modes of treatment.
Distribution of chemical elements being entered at optimum treatment appears to be relatively uniform, i.e. for instance, if chromium and tungsten content in grain volumes is registered at the level of $\sim 6$ and $7 \%$, respectively, then increase of such types of concentrations is insignificant (up to $\sim 8$ and $9 \%$ ) in near-boundary areas. The latter shows absence of significant gradient in distribution of chemical elements entered by treatment in metal surface areas. Besides, it should be noted that surface layers contain minimum quantity of pores as well as rapid $(\sim 1 \%)$ reduction of quantity of cracks and insignificant change of microhardness in surface-base metal zone.

Peculiarities of formation of dislocation structure in surface layers are indicative for optimum modes of laser surface treatment: more uniform distribution of dislocations at general reduction of their density $\left(\rho \sim(2-4) \cdot 10^{9} \mathrm{~cm}^{-2}\right)$ (Figure 3, $c)$ are typical for these alloying cases. Relative uniformity should be noted in connection to size and distribution of particles of phase precipitates which are more disperse (their sizes of about 0.04$1.2 \mu \mathrm{m})$ and have comparatively uniform distribution mainly in internal grain volumes in surface layers under conditions of optimum laser treatment. Moreover, entered coarse particles of tungsten carbide $\left(\mathrm{WC}+\mathrm{W}_{2} \mathrm{C}\right)$ are virtually absent. 

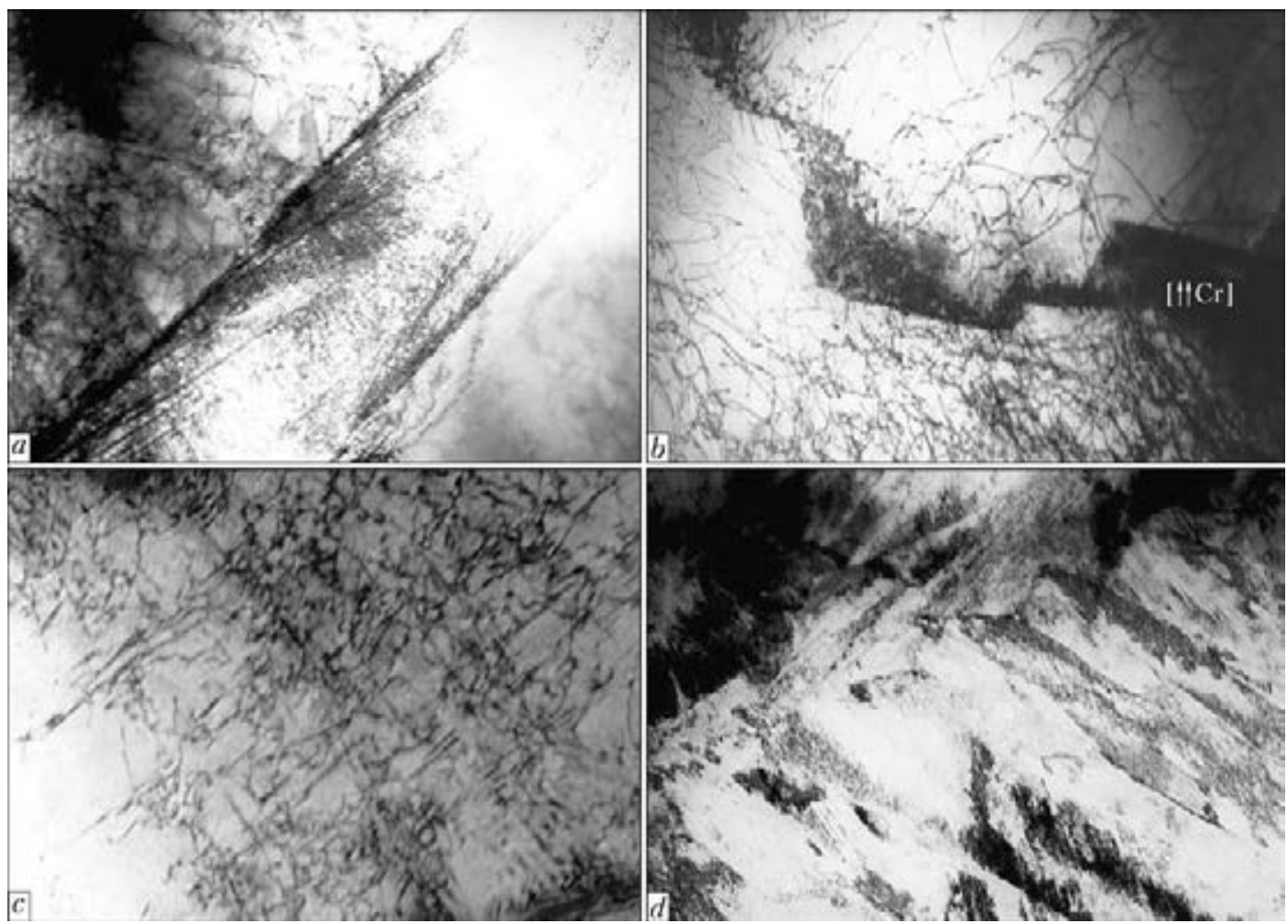

Figure 4. Fine structure of laser-plasma alloyed layer at $P=3 \mathrm{~kW}, v=500 \mathrm{~mm} / \mathrm{min}$ with overlaying of four paths: rapid gradient in distribution of dislocation density in crystalline particles volume $(a-\times 30,000)$ as well as along the boundaries $(b-\times 20,000)$; and at $P=3 \mathrm{~kW}, v=500 \mathrm{~mm} / \mathrm{min}$ with overlaying of one path: uniform distribution of dislocation density and phase precipitates $(c, d-\times 30,000)$ in metal of alloyed layer

The following is typical under conditions of laser-plasma alloying in the case of deviation from optimum mode $(P=3 \mathrm{~kW}, v=$ $=500 \mathrm{~mm} / \mathrm{min}$ with overlaying of four paths) for treated alloyed layers of metal: formation of acicular type structure, but with grain size coarsening ( $h \times l$ up to $20 \times 150 \mu \mathrm{m})$ and coefficient of their shape $(\kappa \sim 8)$; increase of quantity (to $\sim 10 \%$ ) of coarse inclusions ( $\left.\mathrm{WC}+\mathrm{WC}_{2}\right)$ of up to $50-230 \mu \mathrm{m}$ size; rise of surface microhardness $H V$ and porosity (to $\sim 20 \%$ ) as well as significant enough increase of quantity of cracks (to $30 \%$ ) in surface layers.

Besides, quite considerable changes of chromium concentration in specific structural zones are also determined, i.e. increase (to $17 \%$ and more) of chromium is observed mainly along the zones of intergrain boundaries and fusion line. Clear localization of processes of crack formation along the fusion line is also typical for indicated modes. They differ by the largest gradient in chromium concentration $(\Delta \mathrm{Cr} 15 \%)$ and formation of elongated dislocation clusters with high density (to $\rho \sim 8 \cdot 10^{11} \mathrm{~cm}^{-2}$ ) (Figure $3, a, b$ ).

Optimum mode of laser-plasma alloying $(P=$ $=3 \mathrm{~kW}, v=500 \mathrm{~mm} / \mathrm{min}$ with one path) provides for following typical moments for metal of alloyed layers: some increase of surface layer hardness, but without gradient in comparison with base metal; significant dispersion of marten- site structure, carbide phases and inclusions (WC $+\mathrm{W}_{2} \mathrm{C}$ ); uniform distribution (in volumes as well as along the grain boundaries) of such chemical elements as chromium and tungsten as well as complete absence of porosity and cracks. General reduction of dislocation density (to $\rho \sim 8 \cdot 10^{8}$ $1 \cdot 10^{9} \mathrm{~cm}^{-2}$ ) at uniform their distribution along whole volume of surface layer (Figure $4, c, d$ ) is also characteristic for optimum mode of laserplasma treatment.

Carried complex of experimental investigations allowed performing analytical estimations of differential input of different structural-phase constituents and their parameters, forming in investigated layers under different modes of alloying, as well as concentration of alloying elements in change of the most significant service characteristics of treated surfaces, namely, strength and crack resistance. Analytical estimations of integral value of yield strength $\Sigma \sigma_{\mathrm{y}}$ were carried out using known dependence [8-11]:

$$
\Sigma \sigma_{\mathrm{y}}=\Delta \sigma_{0}+\Delta \sigma_{\mathrm{s} . \mathrm{s}}+\Delta \sigma_{\mathrm{g}}+\Delta \sigma_{\mathrm{s}}+\Delta \sigma_{\mathrm{d}}+\Delta \sigma_{\mathrm{d} . \mathrm{s}}
$$

including $\Delta \sigma_{0}$ - the resistance of metal lattice to movement of free dislocations (lattice friction stress or Peirels-Nabarro stress); $\Delta \sigma_{\text {s.s }}-$ the strengthening of solid solution by alloying elements and additives (solid-solution strengthening); $\Delta \sigma_{\mathrm{g}}, \Delta \sigma_{\mathrm{S}}-$ the strengthening due to change 


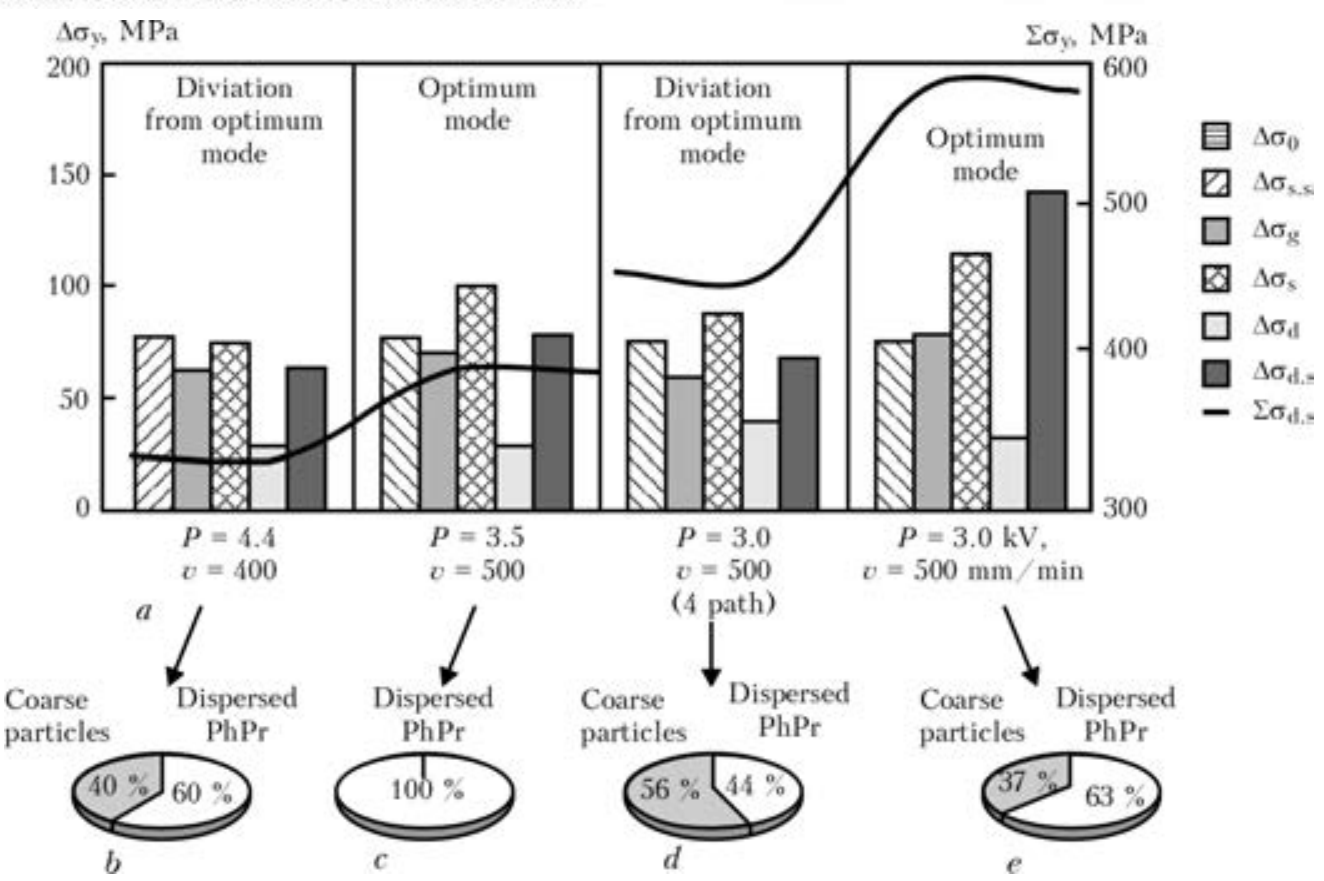

Figure 5. Histogram $(a)$ of differential input of structural constituents in total calculated value of yield strength (integral $\Sigma \sigma_{\mathrm{y}}$ ) of surface alloyed by laser and laser-plasma method; $b-e-$ pie chart of percent relationship of input of disperse and coarse phase precipitates in $\Sigma \sigma_{\mathrm{y}}$

of grain and subgrain value (by Hall-Petch dependence for grain-boundary and subgrain strengthening); $\Delta \sigma_{d}-$ the dislocation strengthening caused by interaction between dislocations; and $\Delta \sigma_{\text {d.s }}-$ the strengthening due to particles of phase transformations by Orowan (dispersion strengthening).

The results of evaluation showed that the highest total values of yield strength $\Sigma \sigma_{y}$ in treated surfaces are provided at optimum modes of laser alloying $\left(\Sigma \sigma_{\mathrm{y}}=406 \mathrm{MPa}\right)$ as well as laser-plasma alloying $\left(\Sigma \sigma_{\mathrm{y}}=591 \mathrm{MPa}\right)$ (Figure 5, a). Moreover, the largest input in increase of yield strength in laser alloying (optimum mode) is provided due to substructure refining $\left(\Delta \sigma_{\mathrm{s}}=\right.$ $=115 \mathrm{MPa})$ that under these conditions makes around $28 \%$ of total $\Sigma \sigma_{\mathrm{y}}$ value. In laser-plasma allying (optimum mode) the maximum input in increase of $\Sigma \sigma_{\mathrm{y}}$ is provided by substructure refining $\left(\Delta \sigma_{\mathrm{s}}=176 \mathrm{MPa}\right.$, i.e. $30 \%$ of $\left.\Sigma \sigma_{\mathrm{y}}\right)$ and effect of phase precipitates $\left(\Delta \sigma_{\text {d.s }}=196 \mathrm{MPa}\right.$, i.e. $33 \%$ of $\Sigma \sigma_{\mathrm{y}}$ ) (Figure $5, a, e$ ). It should be noted that rise of level of dispersion strengthening $\Delta \sigma_{\mathrm{d} . \mathrm{s}}$ in the latter case takes place to significant extent due to input of dispersed phases $(\sim 63 \%)$ and less significant contribution from coarse inclusions based on tungsten carbide $(\sim 37 \%$ ) (Figure $5, e)$.

The results of investigations at all structural levels allowed carrying also evaluation of such quite considerable indices of mechanical properties as indices of crack resistance of alloyed layers of surfaces being treated under different investigated modes. Analysis of crack resistance indices was carried out considering distribution of dislocation density based on evaluation of level of local internal stresses according to dependence [12] $\tau_{1 . \text { in }}=G b h \rho /[\pi(1-v]$, where $G$ is the shear modulus; $h$ is the foil thickness; $v$ is the Poisson's ratio. Conditions when $\tau_{1 . \text { in }}$ value in specific area approaches to value of theoretical strength $\tau_{\text {theor }}$ of material, this area (with specific structuralphase condition) is a zone of nucleation and propagation of cracks.

It shown as a result that sharp changes of dislocation density in specific zones of metal, where it varied from $\rho=9 \cdot 10^{11}-1 \cdot 10^{12}$ to $8 \cdot 10^{8}$ $2 \cdot 10^{10} \mathrm{~cm}^{-2}$, are typical for surface layers forming under conditions of laser alloying at $P=4.4 \mathrm{~kW}$, $v=400 \mathrm{~mm} / \mathrm{min}$ (deviation from optimum mode). Present of such type of zones is a basis for formation in these areas of alloyed layers with sharp gradients in value of local internal stresses being the concentrators of internal stresses and, respectively, factors, promoting crack formation and rapid deterioration of surface quality. In this case $\Delta \tau_{1 . i n}$ values vary from $18500\left(G / 4.5 \cdot 10^{3}\right.$ corresponds to $\left.2.2 \tau_{\text {theor }}\right)$ to $14.9 \mathrm{MPa}\left(G / 5.7 \cdot 10^{3}\right.$ corresponds to $0.0018 \tau_{\text {theor }}$ ) (Figure 6 ).

The main reason providing non-uniformity in distribution of dislocation density and so local internal stresses, as can be seen from comparison of investigation results, is significant local increase (preferably along the intergrain boundaries) of concentration of such chemical elements as chromium, as well as formation in this zone of elongated Cr-containing phases $\left(\mathrm{Cr}_{23} \mathrm{C}_{6}\right)$. 
Reduction of dislocation density to $\sim 4 \cdot 10^{9} \mathrm{~cm}^{-2}$ and their uniform distribution are observed in treated surfaces in the case of laser alloying at decrease $P=3.5 \mathrm{~kW}$ and increase $v=$ $=500 \mathrm{~mm} / \mathrm{min}$ (optimum mode). This, respectively, results not only to reduction, but optimum (uniform) distribution of local internal stresses to $\tau_{\text {l.in }} \sim 55.4 \mathrm{MPa}\left(G / 9 \cdot 10^{2}-0.007 \tau_{\text {theor }}\right)$ in alloyed layer, that, as a result, develops conditions for formation of zones of nucleation and propagation of cracks. It is typical that in this case no significant variations are observed in surface layers at distribution of concentrations of such chemical elements as chromium, promoting formation of local dislocation clusters.

Rapid gradient in distribution of dislocation density in crystalline particle volumes is observed in the sample after laser-plasma alloying $(P=$ $=3 \mathrm{~kW}, v=500 \mathrm{~mm} / \mathrm{min}$ with overlaying of four path, deviation from optimum mode). There increase of chromium concentration (to $17 \%$ ) is clearly evident, that is the main reason for formation of elongated internal stresses, i.e. spots of crack nucleation, where $\tau_{\text {l.in }}$ makes from $\sim 370 \mathrm{MPa}\left(G / 2.3 \cdot 10^{2}-0.04 \tau_{\text {theor }}\right)$ to $14000 \mathrm{MPa}\left(G / 6-1.8 \tau_{\text {theor }}\right)$. In the case of laser-plasma alloying at $P=3 \mathrm{~kW}, \quad v=$ $=500 \mathrm{~mm} / \mathrm{min}$ (optimum mode), presence of discrete on size and uniformly distributed on volume grains of phase precipitates at accompanying low dislocation density (without rapid gradients in its distribution) indicates the absence of structural conditions for formation of internal stress concentrators.

At that, $\tau_{1 . \text { in }}$ values are reduced and make 2148-370 $\left(G / 5.7 \cdot 10^{2}-G / 2.3 \cdot 10^{2}-(0.018-\right.$ $0.04) \tau_{\text {theor }}$ (Figure 6 ). The latter helps to characterize structural condition of surface as optimum and verifies practical absence of cracks.

Thus, experimental-analytical investigations determined effect of structural-phase condition of metal of alloyed layers, forming at different modes of strengthening, on change of strength characteristics and crack resistance of treated surfaces. It is shown that modes of laser-plasma alloying promote for increase of strength (on average by $20 \%$ ) in comparison with laser alloying by irradiation with Gaussian distribution of beam intensity, and phase precipitates (27\%) and substructure (25\%) make the largest input in strengthening at optimum mode. Laser-plasma alloying $(P=3 \mathrm{~kW}, v=500 \mathrm{~mm} / \mathrm{min}$ with overlaying of one path) provides for the maximum crack resistance of alloyed layers. It is promoted by absence of zones of nucleation and propagation of cracks, caused by uniform distribution of dis-

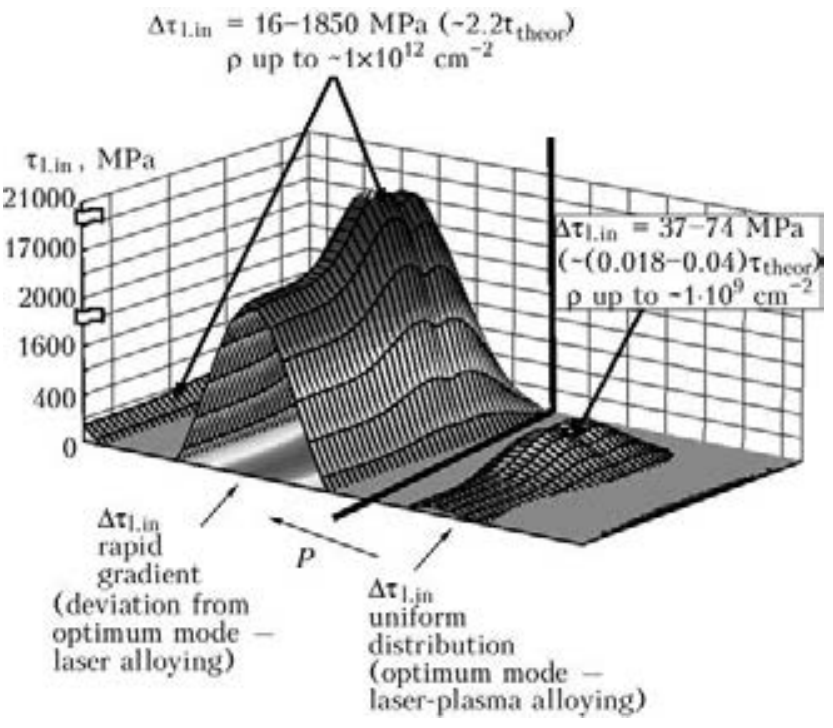

Figure 6. Diagram of distribution of local internal stresses $\tau_{l} /$ in in alloyed layer depending on nature of forming structures and dislocation density

location density without its rapid gradients. Crack formation in laser and laser-plasma strengthening of alloyed layers of structural steel, as a rule, is related with formation of dense and elongated dislocation clusters (mainly along the intergrain boundaries), that provides for nonuniformity in distribution of such chemical elements as chromium.

1. Kurdyumov, V.Ya., Ryazanov, V.P. (1973) Repair of building machines by methods of welding and surfacing. Moscow: Strojizdat

2. Teregulov, N.G., Sokolov, B.K., Varbanov, G. et al. (1993) Laser technologies at machine-building plant. Ufa: AN RB.

3. Markashova, L.I., Ishchenko, A.Ya., Kushnaryova, O.S. et al. (2012)' Effect of structural-phase transformations in aluminium-lithium alloy 1460 joints on physical-mechanical properties. The Paton Welding J., 5, 17-25.

4. Markashova, L.I., Poznyakov, V.D., Gaivoronskii A.A. et al. (2012) Estimation of the strength and crack resistance of the metal of railway wheels after long-term operation. Materials Sci., 47(6), 799-806.

5. Markashova, L.I. Kushnaryova, O.S. (2012) Welded joints of complexly-alloyed aluminium-lithium alloys. Structure and service properties. In: Building. Materials science. Machine-building: Transact., 64, 7580. Dnepropetrovsk: PGASA.

6. Shelyagin, V.D., Markashova, L.I., Khaskin, V.Yu. et al. (2014) Laser and laser-microplasma alloying of surface of $38 \mathrm{KhN} 3 \mathrm{MFA}$ steel specimens. The Paton Welding J., 2, 24-30.

7. Honeycomb, R. (1972) Plastic deformation of metals. Moscow: Mir.

8. Gordienko, L.K. (1973) Ultrafine grain in metals. Moscow: Metallurgiya.

9. Petch, N.J. (1953) The cleavage strength of polycrystalline. J. Iron and Steel Inst., 173(1), 25-28.

10. Orowan, W. (1954) Dislocation in metals. New York: AIME.

11. Kelly, A., Nickolson, R. (1966) Precipitation hardening. Moscow: Metallurgiya.

12. Markashova, L., Kushnareva, O. (2014) Effect of structure on the mechanical properties of the metal of welded joints of aluminium alloys of the $\mathrm{Al}-\mathrm{Cu}-\mathrm{Li}$ system. Materials Sci., 49(5), 681-687. 


\title{
STRUCTURAL SCHEME OF PROCEDURE FOR CALCULATION OF STRESS-STRAIN STATE OF PARTS DURING SURFACING AND FURTHER SERVICE
}

\author{
I.K. SENCHENKOV ${ }^{1}$, I.A. RYABTSEV ${ }^{2}$ and E. TURYK ${ }^{3}$ \\ ${ }^{1}$ S.P. Timoshenko Institute of Mechanics, NASU \\ 3 Nesterov Str., 03057, Kiev, Ukraine. E-mail:ang@inmex.kiev.ua \\ ${ }^{2}$ E.O. Paton Electric Welding Institute, NASU \\ 11 Bozhenko Str., 03680, Kiev, Ukraine. E-mail: office@paton.kiev.ua \\ ${ }^{3}$ Welding Institute \\ 16-18 B. Czeslaw Str., 44100, Gliwice, Poland. E-mail: eugeniusz.turyk@glivice.pl
}

\begin{abstract}
Structural scheme of calculation procedure for estimation of stress-strain and microstructural state of parts during surfacing process and further operation is presented. The procedure is based on the following mathematical models: initial condition, including stress-strain and structural state in process of production surfacing; evolution of service and structural parameters in process of operation; accumulation of damageability and reduction of fatigue life; reconstruction surfacing. In comparison with experimental methods, mathematical modelling allows evaluating stress-strain and structural state of the parts in process of surfacing and further operation with lower expenses and more efficient. 20 Ref., 3 Figures.
\end{abstract}

Keywords: surfacing, stress-strain state, microstructural state, mathematical modelling, calculation procedure

Development of procedure for calculation of stress-strain and microstructural state (SSMSS) of parts in process of surfacing and operation requires consideration of number of factors. Current development of mathematical apparatus and computer technologies allow eliminating number of limitations on using in calculation procedures of such characteristics of complex behavior of metal as plasticity, creep, isotropic and directed hardening, dependence of material yield strength on deformation rate, structural transformations etc. This increases safety and reliability of calculations to significant extent. As a result, experimental methods for investigation of processes of manufacture and operation of different parts of machines and mechanisms give way to more efficient and less expensive methods of mathematical modelling.

Procedures for calculation of SSMSS of parts should provide for reliable description of material behavior in area of elastic and inelastic deformation depending on time or rate of deformation. Current experimental and theoretical investigations show that models of viscoplastic behavior of materials, using concept of varying states, are the most suitable for such description. Besides, these models are convenient for computer programs [1]. As a result, deeper analysis of SSMSS

(๑) I.K. SENCHENKOV, I.A. RYABTSEV and E. TURYK, 2015 of parts based on more realistic mathematical models provides for more proved evaluation of reliability of parts and safety of their operation $[2,3]$.

Modelling of technological processes. Uniform viscoplastic models of technological processes are more favorable in comparison with models based on separate application of plasticity and creep theory, since single system of equations can describe plasticity, creep and relaxation in a wide interval of temperatures depending on type and rate of external loading. This property is important in modelling of technological processes of manufacture of parts and their further operation. Obtained model of material behavior should be suitable for application in computer, in particular, fine-element programs.

In contrast to particular models of viscoplasticity, current models, applying varying states, describe all main phenomena such as creep, isotropic and directed hardening, dependence of material yield strength on deformation rate, relaxation etc.

This is the reason why such approaches are widely used in present time for simulation of stressstrain state of parts in welding, surfacing and other technological processes, as well as simulation of processes in deposited parts at their further operation. In particular, uniform Bodner-Partom model can be referred to such models.

Modelling of thermomechanical processes. Material of the part in thermomechanical processes can have different temperature histories in 
manufacture and operation. Initial structure constituents of the material, in particular, steel, are transformed in austenite at the stage of sufficiently high heating. The latter can decay for pearlite, bainite and martensite during cooling. These transformations are accompanied by physical-mechanical characteristics, latent heat, change of volume, appearance of thermal-phase deformations etc. Figure 1 shows model of interaction of thermal-mechanical processes in manufacture and operation of the part.

Figure 2 shows block diagram of monitoring of the part state at all stages of its existence. This scheme can be a basis for development of mathematical models and procedures for calculation of SSMSS of the parts in process of surfacing and further operation at different types of wear and loading. The following models are presented in the block diagram.

Model of part initial state. «Initial state» block includes initial characteristics of the deposited part when it comes into operation. These characteristics can be divided for two parts.

The first one includes actual dimensions of part and its separate layers $\left\{h_{k}\right\}$, their mechanical and thermal-physical characteristics, namely elasticity $E$, Poisson's ratio $v$, heat conduction and heat capacity coefficients $k$ and $c$ etc.

The second part is the parameters with which part is entered into operation. Values of these parameters are determined by manufacturing technology and being specified experimentally or by means of mathematical modelling.

The set of following parameters determine initial state for the deposited part:

$$
\Pi^{0}=\left\{\varepsilon_{i j}^{0}, \sigma_{i j}^{0}, C_{\xi}^{0}, K^{0}, \beta_{i j}^{0}, w^{0}, h_{k}^{0}\right\},
$$

where $\varepsilon_{i j}^{0}$ and $\sigma_{i j}^{0}$ are the residual deformations and stresses; $C_{\xi}^{0}$ is the volumetric concentration of phases: $\xi=a$ (austenite); $\xi=p$ (pearlite); $\xi=$ $=b$ (bainite); $\xi=m$ (martensite) etc.; $K^{0}, \beta_{i j}^{0}$ are the parameters of isotropic and kinematics hardening; $w^{0}$ is the damageability parameter; $h_{k}^{0}, k=1,2,3$ are the initial dimension of part.

Model of SSMSS of parts in surfacing. The calculation simulates thermal-mechanical processes in surfacing of parts using elements of theory of growing thermal viscoplastic bodies [4-7] in combination with numerical finite element method (FEM). Thermal-kinetic diagrams of austenite decay for corresponding steels [8,9] are used in phase calculation. Thermal-mechanical behavior of materials is described using modified Bodner-Partom flow model [10-13].

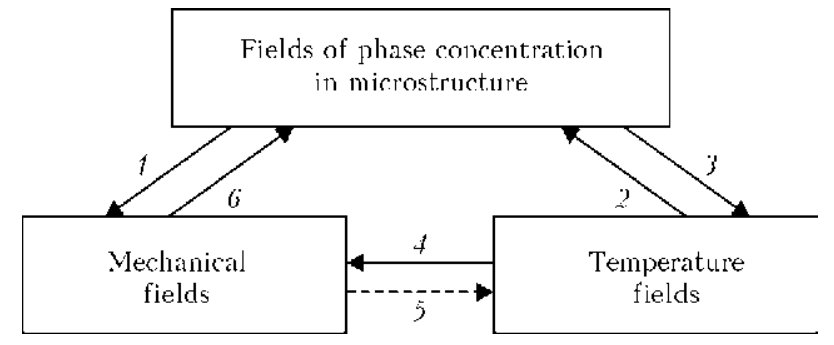

Figure 1. Relation between temperature, mechanical state and evolution of microstructure in process of manufacture and operation of part: 1 - dependence of mechanical properties on phase concentration; volumetric changes due to phase transformations; plasticity caused by phase transformations; 2 - microstructural evolution based on temperature history; 3 - microstructural evolution effecting temperature field via latent heat, and properties of materials depending on microstructure; 4 - interaction through heat expansion and properties of materials depending on temperature; 5 - mechanical heating; 6 - effect of stresses on microstructure transformations

Model of evolution of service parameters. Two aspects can be outlined in this case, namely geometry and strength. The geometry parameter, as a service factor, is related with part wearing. The strength aspect is related with damageability accumulation in places of stress concentration and can result in exhaust of part functions due to fracture. The proposed model as service parameters takes a set of critical dimensions of the parts $h_{k}, k=1,2,3$, or parameter of damageability $w$, or service life $N_{f}$. They are designated by $\Omega=\left\{h_{k}, w, \ldots\right\}$ symbol in sum form.

Model describing structural transformations. Accurate description of structure transformations plays an important role in analysis of thermal elastoplastic stress-strain state of part in surfacing (welding) and operation [14]. Results received at that also effect evaluation of possibility of part wear resistance and cyclic loading. Today, two methods for investigation of structure transformations are used. The first one applies information from diagrams of isothermal transformation of austenite, as well as in SchaefflerDelong diagrams [15]. The second uses thermalkinetic diagrams also termed as CCT-diagrams (Continuous Cooling Transformation) [16, 17]. They describe austenite decay in continuous cooling mode.

Recently, synthetic models, combining advantages and results of both approaches, became widespread. Typical in this sense is a model developed in work [18].

Model of part wearing. Wearing is a process of continuous change of part dimensions taking place in friction, and wear is a result and quantitative measure of wearing.

Wearing result is loss of functional properties of the part as well as its service life due to change 


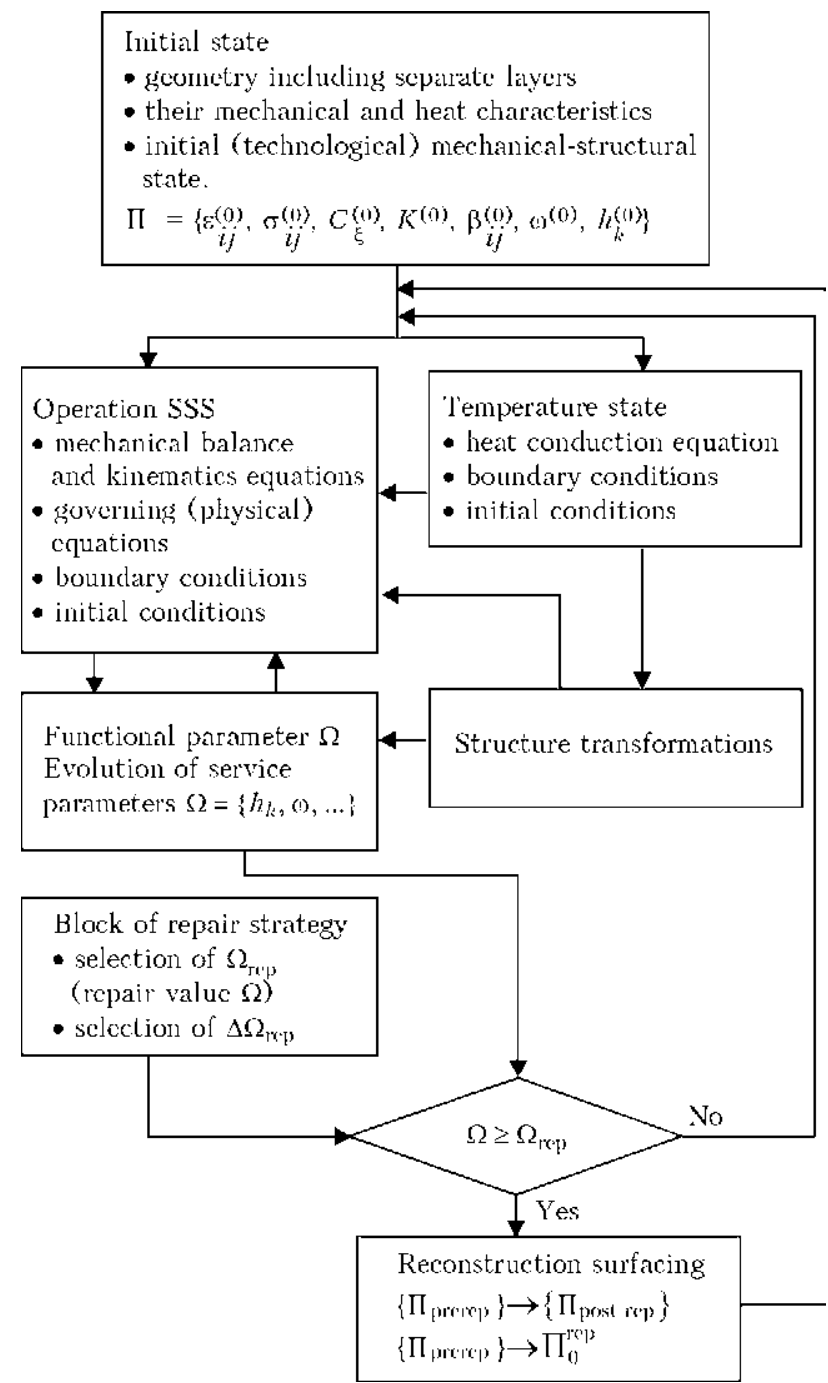

Figure 2. Scheme for monitoring of part state in process of its manufacture, operation and reconstruction surfacing

of part size, formation of stress concentrators in places of wearing, fatigue microcracks etc.

Intensity of wearing is often used for process characterization:

$$
I_{h}=\Delta h / \Delta s=\dot{h} / v,
$$

where $\dot{h}$ is the rate of change of part linear size; $v$ is the slip velocity.

Model of damageability accumulation. Concept of damageability introduced by Kachanov [19] simulates acceleration of creep in metals which results in material fracture. At more general approach, the damageability reflects defects in material such as microdefects and microcracks. When these microdefects are uniformly distributed and have random orientation, then the damageability can be considered as scalar quantity. If orientation of the damageability defects is important then the latter is treated as tensor parameter [20].

Model of reconstruction surfacing. Change of $\Omega$ service parameter (see Figure 2 ) is controlled

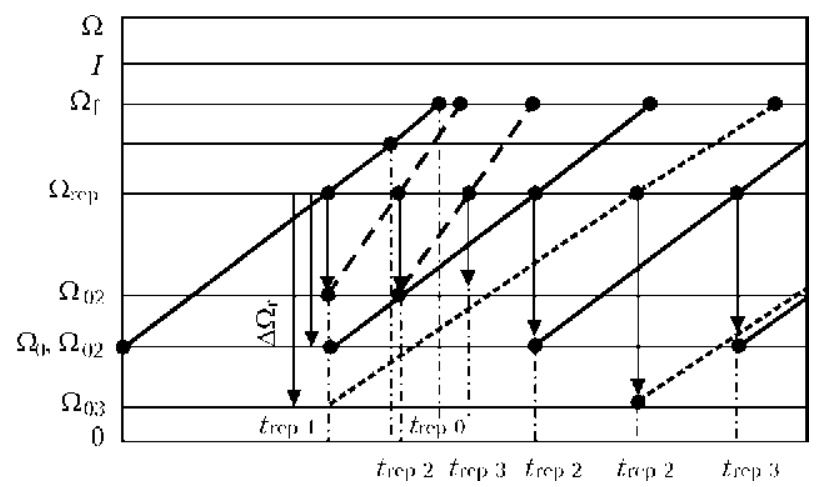

Figure 3. Change of $\Omega$ service parameter (SP) in process of operation and reconstruction by different schemes: $\Omega_{\mathrm{f}}-$ SP value in part fracture; $\Omega_{\text {rep }}-$ «repair» value of SP reaching of which determines necessity of part surfacing; $\Omega_{0}-$ SP value before operation start; $\Omega_{0 n}-$ SP value after $n$-th surfacing; $\Delta \Omega_{\mathrm{r}}-$ change of SP as a result of surfacing; $t_{\text {rep } 0}$ - time during which part works before fracture; $t_{\text {rep }} 1$ - time of part operation before first repair surfacing; $t_{\text {rep } n}$ - time before $n$-th surfacing

by simulation of time process of part operation. At each time step it is compared with some «repair» value, reaching which the part is transferred from operation step in reconstruction (repair) surfacing step. From point of view of mathematical modelling, the repair is a transformation of set of pre-repair parameters $\Pi_{\text {prerep }}$ in a set of after repair parameters:

$$
\Pi_{\text {prerep }}^{n} \rightarrow \Pi_{\text {post rep }}^{n},
$$

where $n=1,2,3$ are the repair numbers.

Graphical interpretation of reconstruction surfacing is given by curves of $\Omega$ parameter change in time (Figure 3).

The first stage of part operation is finished when $\Omega$ parameter reaches $\Omega_{\text {rep }}$ value at moment of time $t=t_{\mathrm{rep} 1}$. Stepwise change of $\Omega$ parameter by $\Delta \Omega_{\mathrm{r}}$ value corresponds to reconstruction stage. There are three types of reconstruction surfacing from point of view of quality:

- identical on quality, at which $\Omega$ falls to initial value of $\Omega_{01}=\Omega_{0}$, and after surfacing $\Omega$ rises with the same rate as before it;

- low on quality, at which $\Omega$ falls to $\Omega_{02}>$ $\Omega_{0}$ value and further increases faster then at initial stage;

- high on quality, which results in achievement of $\Omega_{03}$ value being lower then $\Omega_{01}$ and it rises lower in after surfacing operation.

Surfacing of more wear-resistant material or additional strengthening of deposited metal correspond to the latter case.

\section{Conclusion}

Procedure for calculation of stress-strain and microstructural state of parts during surfacing process and further operation was developed. The 
procedure is based on the following mathematical models, initial condition including SSMSS in process of production surfacing; evolution of service and structural parameters in process of operation; accumulation of damageability and reduction of fatigue life; reconstruction surfacing. In comparison with experimental methods, mathematical modelling allows evaluating SSMSS of the parts in process of surfacing and further operation with lower expenses and more efficient.

1. Krempl, E. (2000) Viscoplastic models for high temperature applications. Int. J. Solids and Structures, 37, 279-291.

2. Nix, W.D., Gibeling, J.C., Hughes, D.A. (1985) Time-dependent behavior of metals. Met. Transact. $A, \mathbf{1 6}, 2216-2226$.

3. Makhnenko, V.I. (2006) Safety life of welded joints and assemblies in modern structures. Kiev: Naukova Dumka.

4. Senchenkov, I.K., Turyk, E., Ryabtsev, I.A. et al (2003) Modeling of nonisothermic growing of physically nonlinear bodies and technological appendices. Teor. i Prikl. Mekhanika, Issue 38, 109-114.

5. Senchenkov, I.K., Tabieva, G.A., Ryabtsev, I.A. et al. (2004) Numerical modeling of residual stresses and strains in multilayer surfacing of cylindrical parts. In: Proc. of 2nd Int. Conf. on Mathematical Modelling and Information Technologies in Welding and Related Processes (13-17 Sept. 2004, Katsiveli, Ukraine), 237-242. Kiev: PWI.

6. Senchenkov, I.K. (2005) Thermomechanical model of growing cylindrical bodies from physically nonlinear materials. Prikl. Mekhanika, 41(9), 118-126.

7. Senchenkov, I.K., Chervinko, O.P., Turyk, E. et al. (2007) Investigation of thermomechanical state of cylindrical parts deposited by austenitic and martensitic steel layers. Svarochn. Proizvodstvo, 8, 6-13.

8. Popov, A.A., Popova, L.E. (1961) Handbook of heat-treater. Isothermal and thermokinetic diagrams of overcooled austenite decomposition. MoscowSverdlovsk: GNTI Mashinostr. Lit.

9. Leblond, J.B., Mottet, G., Devaux, J.C. (1986) A theoretical and numerical approach to the plastic behavior of steel during phase transformation. Pt 1: Derivation of general relations. J. Mech. Phys. Solids, 34(4), 395-409.

10. Bodner, S.R. (1984) Evolution equations for anisotropic hardening and damage of elastic-viscoplastic materials. Plasticity today: Modelling methods and applications. In: Elsevier Applied Sci., 471-482.

11. Bodner, S.R. (2000) Unified plasticity - An engineering approach (Final report). Haifa: Isr.IT.

12. Bodner, S.R. (2005) Plasticity over a wide range of strain rates and temperatures. Archives of Mechanics, $57(2 / 3), 73-80$

13. Senchenkov, I.K., Tabieva, G.F. (1996) Determination of parameters of Bodner-Partom model of thermoviscoplastic deformation of materials. Prikl. $\mathrm{Me}$ khanika, 32(2), 64-72.

14. Shorshorov, M.Kh., Belov, V.V. (1972) Phase transformations and changes of properties during welding: Atlas. Moscow: Nauka.

15. Henwood, C., Bibby, M., Goldak, J. et al. (1988) Coupled transient heat transfer - microstructure weld computations (Pt B). Acta Metall., 36(11), 3037-3046.

16. Makhnenko, V.I., Velikoivanenko, E.A., Kravtsov, T.G. et al. (2001) Numerical studies of thermomechanical processes in surfacing of shafts of ship mechanisms. The Paton Welding J., 1, 2-10.

17. Sheng, I.C., Chen, Y. (1992) Modelling welding by surface heating. J. Eng. Materials and Techn., 114, 439-449.

18. Ueda, Y., Murakawa, H., Luo, Y.A. (1995) Computational model of phase transformation for welding processes. Transact. of JWRI, 24(1), 95-100.

19. Kachanov, L.M. (1958) On the time of failure under creep conditions. Izvestiya AN SSSR, 8, 26-31.

20. Krajeinovic, D. (1996) Damage mechanics. Amsterdam: Elsevier.

Received 20.04.2015 


\title{
CALCULATION OF FATIGUE LIFE OF CYLINDRICAL PARTS AT MULTILAYER SURFACING AND SERVICE CYCLIC THERMOMECHANICAL LOADING
}

\author{
I.K. SENCHENKOV ${ }^{1}$, O.P. CHERVINKO ${ }^{1}$ and I.A. RYABTSEV ${ }^{2}$ \\ ${ }^{1}$ S.P. Timoshenko Institute of Mechanics, NASU \\ 3 Nesterov Str., 03057, Kiev, Ukraine \\ ${ }^{2}$ E.O. Paton Electric Welding Institute, NASU \\ 11 Bozhenko Str., 03680, Kiev, Ukraine. E-mail: office@paton.kiev.ua
}

\begin{abstract}
Procedure was developed for calculation of residual stress-strain and microstructural state of cylindrical part at multilayer surfacing aver lateral surface as well as calculation of its thermomechanical state and fatigue life in further service cyclic thermomechanical loading. The procedure was developed in scope of common mathematical model based on theory of growing bodies, current model of viscoplastic non-isothermic flow, thermokinetic diagrams of decay of austenite, deposited and base metals considering residual stressstrain and structural state in single- and multilayer surfacing of parts by layers of different chemical composition, structure and thickness. It allows evaluating the fatigue life of deposited parts depending on value and relationship of service cyclic thermal and mechanical loads and on consumables applied for sublayer and wear-resistant layer. 21 Ref., 7 Figures.
\end{abstract}

Key $\boldsymbol{w} \boldsymbol{o r d} \boldsymbol{s}:$ multilayer surfacing, numerical simula tion, residual surfacing stresses, cyclic thermomechanical loading, fatigue life

Hot rolls, continuous casting machine rollers, stamps for metal hot working etc. are subjected to multilayer surfacing and further cyclic service thermomechanical loading $[1,2]$ in manufacture or repair.

Methods for numerical simulation of thermomechanical processes are used in evaluation of stress-strain and microstructural state of deposited parts and their fatigue life in operation. The nature of surfacing process lies in deposition of molten metal on surface of part being strengthened or repaired. Such processes from point of view of mechanics of deformed solid body are described in scope of nonclassical models of such called growing bodies [3]. Such models applicable to surfacing and related technologies are represented in works [4-7].

Surfacing process is realized in a wide interval of homological temperatures, in which thermal viscoelastoplastic properties of material become apparent. Experimental and theoretical investigations showed that governing equations for inelastic deformation are developed based on unified models [8]. Bodner-Partom [9] model is one of them. It is well grounded by experiments and widely used in practice. Adapting of this model to processes, typical for surfacing, is given in work [10].

(C) I.K. SENCHENKOV, O.P. CHERVINKO and I.A. RYABTSEV, 2015
Structure of part material can be changes in manufacture and operation in thermomechanical processes. Structural changes are accompanied by change of physical-mechanical characteristics, latent heat of each of used materials, changes of volume, appearance of thermal-phase deformations etc. Thermokinetic diagrams of decay of overcooled austenite [11] in combination with Koistinen-Marburger equation [12] are used in calculation of kinetic of phase concentration.

Finite-element (FE) procedure combined with implicit time-based step schemes of integration of nonstationary equations as well as iteration methods of solving nonlinear boundary thermomechanic problems at each time step were developed for finding solution of considered class of problems in works [5-7, 13]. In whole, current level of numerical simulation of studied processes is registered in works [2, 14, 15].

Calculation of residual and current service stress-strain and microstructural state is an important, but not a final stage of problem solving. The determining is evaluation of life of deposited element of structure and its connection with selection of surfacing consumables and technological parameters of surfacing.

This work represents a procedure for evaluation of fatigue life of cylindrical parts, deposited over lateral surface, under effect of service cyclic thermomechanical loading.

An object of investigation is a hot roll ( $\mathrm{Fi}-$ gure 1, a) from 50KhFA steel, deposited by sublayer of low-carbon steel 08kp (solid wire 
Sv-08A) and outer layer of martensite steel 25Kh5FMS (flux-cored wire PP-Np25Kh5FMS) (Figure 1, $b$ ). Diameter of roll body makes $1435 \mathrm{~mm}$. After surfacing the roll is subjected to service cyclic thermomechanical loading. It is assumed that the roll is supported by backup roll and does not suffer from bending deformation.

Problem of spiral (helical) surfacing and further cyclic loading of roll is a three-dimension (3D-problem). Such formulation can not be effective for practical calculations at present stage of computer development.

The following approach is proposed for problem solving considering double-stage nature of the process, i.e. surfacing and operation as well as axial length of bead:

1. Surfacing stage is simulated in scope of axial-symmetric problem formulation.

2. Operation stage, characterizing by highlylocalized contact temperature-mechanical loads, is described in scope of problem on flat deformation for axial $A-A$ section of cylinder (see $\mathrm{Fi}^{-}$ gure $1, a)$.

At that problem formulation for stage 2 should consider residual deformations $\left(\varepsilon_{z z} \neq 0\right)$ formed at surfacing stage. In this aspect, such a formulation differs from classical problem of flat deformation, in which residual stresses are absent $\left(\varepsilon_{z z}=0\right)$.

Mechanical behavior of the material is described by Bodner-Partom model [9] which includes the following relationships in cylindrical coordinate system $O_{r z}$ :

- law of flow and equation of plastic incompressibility

$$
\dot{\varepsilon}_{k k}=\dot{\varepsilon}_{i j}^{p}+\dot{\varepsilon}_{i j}^{e}, \quad \dot{\varepsilon}_{k k}=0, \quad i, j=r, z, \varphi ;
$$

- Prandtl-Reuss law of flow

$$
\dot{\varepsilon}_{i j}^{p}=\frac{D_{0}}{J_{2}^{1 / 2}} \exp \left[-\frac{1}{2}\left(\frac{K_{0}+K}{\sqrt{3 J_{2}}}\right)^{2 n}\right] s_{i j},
$$

where $J_{2}=\frac{1}{2} s_{i j} s_{i j} ; s_{i j}=\sigma_{i j}-\frac{1}{3} \delta_{i j} \sigma_{k k}$;

- equation of evolution for parameter of isotropic strengthening

$$
\dot{K}=m_{1}\left(K_{1}-K\right) \dot{W}_{p}, \quad K(0)=0,
$$

where $\dot{W}_{p}=\sigma_{i j} \dot{\varepsilon}_{i j}^{p} ; D_{0}, K_{0}, K_{1}, m_{1}, n$ are the parameters of model;

- Hook's law

$$
\begin{gathered}
\sigma_{k k}=3 K_{v}\left(\varepsilon_{k k}-3 \alpha\left(\theta-\theta_{0}\right)\right), \\
s_{i j}=2 G\left(e_{i j}-e_{i j}^{p}\right), \quad e_{i j}=\varepsilon_{i j}-\frac{1}{3} \varepsilon_{k k} \delta i j,
\end{gathered}
$$
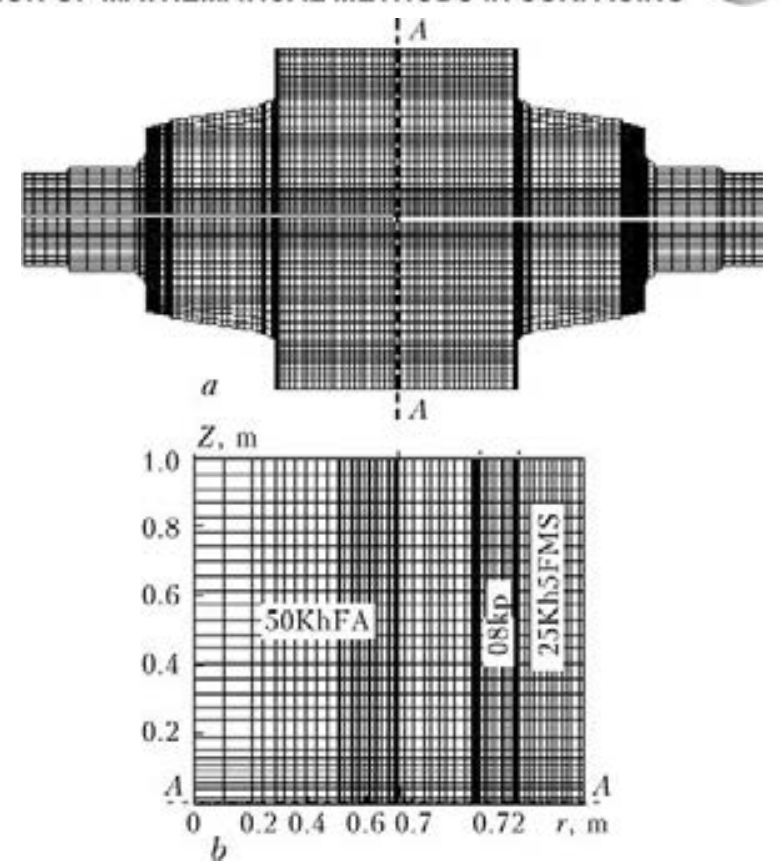

Figure 1. Finite-element layout of forming roll $(a)$ and deposited roll body $(b)$

where $G, K_{v}, \alpha$ are the moduli of shear, compression and coefficient of linear heat expansion.

The relationships are supplemented with universal equilibrium quasi-static equation and equation of heat conduction for axial-symmetric problem:

$$
\begin{gathered}
\frac{\partial \sigma_{r r}}{\partial r}+\frac{1}{3}\left(\sigma_{r r}-\sigma_{\varphi \varphi}\right)+\frac{\partial \sigma_{r z}}{\partial z}=0, \\
\frac{\partial \sigma_{r z}}{\partial r}+\frac{1}{r} \sigma_{r z}+\frac{\partial \sigma_{z z}}{\partial z}=0, \\
c_{V} \dot{\theta}=\frac{1}{3} \frac{\partial}{\partial r}\left(\lambda \frac{\partial \theta}{\partial r}\right)-\frac{\partial}{\partial z}\left(\lambda \frac{\partial \theta}{\partial z}\right)+Q,
\end{gathered}
$$

where $c_{V}$ and $\lambda$ are the coefficients of volumetric heat capacity and heat conduction; $Q$ is the heat source; $\theta=\partial \theta / \partial t$, as well as boundary and initial (for temperature) conditions:

$$
\begin{gathered}
\sigma_{r r}=\sigma_{r z}=0, \quad-\lambda \frac{\partial \theta}{\partial r}=\alpha\left(\theta-\theta_{\mathrm{a}}\right)+c c_{0}\left(T^{4}-T_{\mathrm{a}}^{4}\right) \\
r=R, \quad R+h, \quad 0<z<L, \quad t \neq t_{1}^{*}, 2 \\
\sigma_{z z}=\sigma_{r z}=0, \quad \pm \lambda \frac{\partial \theta}{\partial r}=\alpha\left(\theta-\theta_{\mathrm{a}}\right)+c c_{0}\left(T^{4}-T_{\mathrm{a}}^{4}\right) \\
z=0, \quad r=R, \quad R+\tilde{h}, \quad t>0 \\
\theta=\theta_{\mathrm{a}}, \quad t=0,
\end{gathered}
$$

where $\tilde{h}=h_{1} ; h_{1}+h_{2} ; h_{1,2}$ are the thicknesses of first and second layers being deposited; $t_{1,2}^{*}$ is the time of overlaying of layers being deposited; $\lambda$ is the heat conduction coefficient; $c$ is the emissivity factor; $c_{0}$ is the Boltzmann constant; $\alpha$ is the coefficient of heat exchange; $\theta_{\mathrm{a}}$ is the temperature of ambient atmosphere. 
Let's consider surfacing process $\left(t=t_{1,2}^{*}\right)$ and modification of (2)-(4) relationships taking into account build-up process. The problem is solved by FE method. The process of build-up is controlled, i.e. speed of build-up and final body configuration are known. The configuration of body being built-up is covered by fixed FE-mesh. The FE-mesh covers body being built-up in initial configuration as well as all further build-up layers. Thus, mesh (quantity of nodes) does not change in process of numerical simulation.

Properties of area, taken by initial body, are determined by body material properties. Buildup material initially receives properties of «emptiness» material which is considered as thermoelastic with $E=0, v=0, \alpha=\alpha_{f}$ characteristics, where $E$ is the Young modulus, $v$ is the Poisson's coefficient; $\alpha_{f}$ is the coefficient of thermal expansion of the build-up material. Thermophysical properties of «emptiness» are taken the same as of material, which is built-up. Therefore, the element is «empty» only from point of view of mechanics. During filling, which is considered as a process developing in time, «empty» elements of the FE-mesh will be filled by build-up material. It should be taken into account that the whole FE-mesh, covering initial body as well as adjacent to body «empty» elements, are deformed in process of filling of the element (build-up).

It is assumed that in moment of filling $t^{*}$ a certain empty element of the mesh $\Delta V\left(t^{*}\right)$ has $\varepsilon_{i j}^{*}$ deformation, and it is filled by material having temperature $\theta^{*}$. It is supposed that material of layer being built-up is unstressed up to the moment of contact with the body surface:

$$
\sigma_{r r}=\sigma_{\varphi \varphi}=\sigma_{z z}=\sigma_{r z}=0 \text { at } t=t^{*} .
$$

Studied model of build-up contains filling of the element, which has preliminary deformation

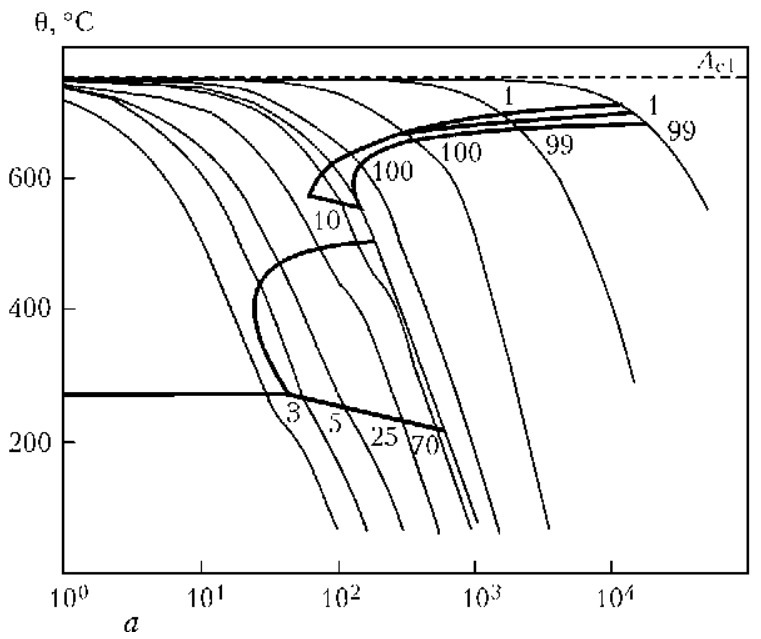

$\varepsilon_{i j}^{*}$, by build-up material of $\theta^{*}$ temperature. Thus, conditions (9), basically, mean that

$$
\sigma_{i j}\left(\varepsilon_{i j}^{*}, \theta^{*}\right)=0 \text { in } \Delta V\left(t^{*}\right) .
$$

In order to match the governing equations of build-up material (2), (4) with condition (9), (10), it is necessary and quite enough to modify equations (2) and (4) in the following way:

$$
\begin{gathered}
s_{i j}=2 G_{j}\left(e_{i j}-\varepsilon_{i j}^{p}-e_{i j}^{*}\right), \\
\sigma_{k k}=3 K_{j}\left(\varepsilon_{k k}-\varepsilon_{k k}^{*}-3 \alpha_{f}\left(\theta-\theta^{*}\right)\right) ; \quad t>t^{*}, \\
\varepsilon_{i j}^{p}\left(t^{*}\right)=0, \quad K_{0}\left(t^{*}\right)=K_{0 f^{\prime}}\left(\theta^{*}\right) .
\end{gathered}
$$

In this case, lower index $f$ shows that parameters refer to material of build-up volume. Thus, in order to fulfill build-up condition (9), all elements, which are built-up, will have the governing equations, individualized by specific values of deformation $\varepsilon_{i j}^{*}$ and temperature $\theta^{*}$, at which their filling has taken place. Therefore, condition $\left(\varepsilon_{i j}^{*}, \theta^{*}\right)$ can be interpreted as «own», since it does not promote stresses.

Thermokinetic diagrams (TKD) are used for calculation of microstructural condition of metal. Figure 2 gives TKD for steel 50KhFA and 25Kh5FMS [11]. They represent transformations in steel at cooling caused by austenite decay $(\xi=$ $=\mathrm{A})$ in ferrite $(\xi=\mathrm{F})$, pearlite $(\xi=\mathrm{P})$, bainite $(\xi=\mathrm{B})$ and martensite $(\xi=\mathrm{M})$. Thick lines limit the transformation areas, and thin ones correspond to cooling curves. Digits show volume per cent of decayed austenite in the output of transformation areas.

Law of new phase $\xi$ accumulation in corresponding areas along the cooling path is represented by phenomenological Koistinen-Marburger equation [12]:

$$
p_{\xi}=\left[1-\exp \left(-k \frac{\theta_{\mathrm{s}}-\theta}{\theta_{\mathrm{s}}-\theta_{\mathrm{e}}}\right)\right] p_{\xi e}
$$

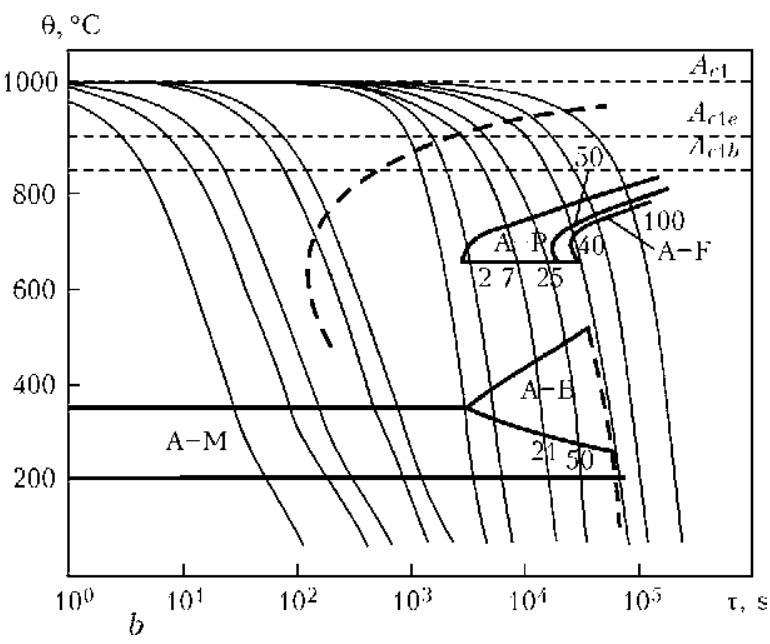

Figure 2. Thermokinetic diagrams for steels 50KhFA ( $a$ ) and 25Kh5FMS (b) 
where $\theta_{\mathrm{s}}, \theta_{\mathrm{e}}$ are the temperatures of start and ending of transformation; $p_{\xi}=C_{\xi} \cdot 100 \% ; p_{\xi e}$ is the maximum value of new phase for given path; $C_{\xi}$ is the volumetric fraction of phase; $0 \leq C_{\xi} \leq$ $\leq 1 ; \sum_{\xi} C_{\xi}=1$.

The properties of each phase $Y_{\xi}$ are calculated considering dependence on temperature $Y_{\xi}=$ $=Y_{\xi}(\theta)$. Linear rule of mixtures is used for calculation of $Y$ macrocharacteristics for random phase composition. The general formula looks like

$$
Y(\theta, t)=\sum_{\xi} C_{\xi}(\theta, t) Y_{\xi}(\theta) .
$$

Physical values, calculated by rule of mixtures, are as follows: $c_{V}$ is the coefficient of volumetric heat capacity; $k$ is the heat conduction; $E$ is the Young modulus; $\alpha$ is the coefficient of linear thermal expansion; $v$ is the Poisson's coefficient. The rule of mixtures (13) for wide interval of temperatures is used and matched with experiments described in [5, 15, 16].

Manson-Birger model [17] is used for evaluation of fatigue life. The following is received at asymmetric cycle of loading considering Goodman equation [18]:

$$
\begin{aligned}
& \Delta \varepsilon=\left(\ln \frac{1}{1-\psi}\right)^{0.6} N^{-0.6}+ \\
& +\frac{2 \sigma_{-1}}{E}\left(1-\frac{\sigma_{\mathrm{m}}}{\sigma_{\mathrm{t}}}\right)\left(\frac{N}{N_{0}}\right)^{k},
\end{aligned}
$$

where $\psi$ is the plasticity at fracture; $\sigma_{-1}$ is the fatigue limit; $E$ is the Young modulus; $\sigma_{\mathrm{m}}$ is the mean value of stress in the cycle; $\sigma_{t}$ is the tensile strength; $N_{0}$ is the base for determining fatigue limit; $k$ is the parameter, determining slope of fatigue curve.

The first summand in (14) can be neglected in absence of cyclic plastic deformation $\Delta \varepsilon^{p}=0$.

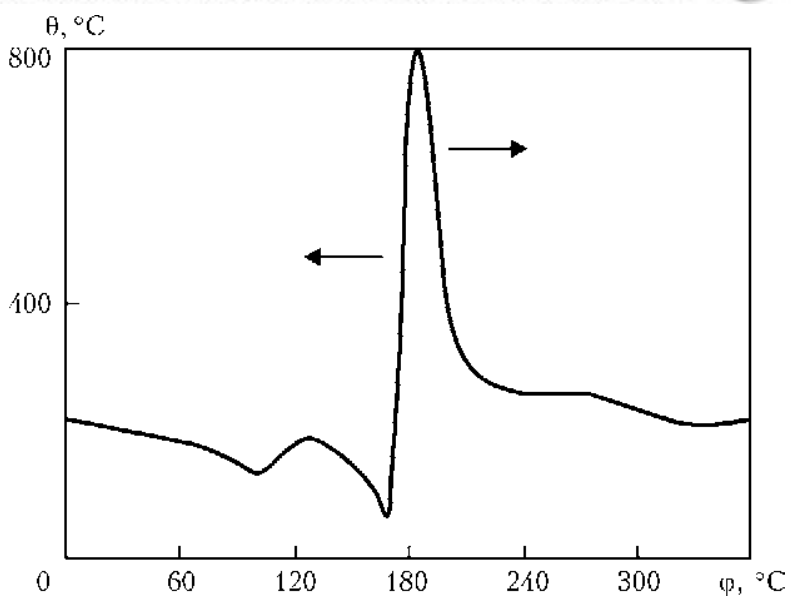

Figure 3. Distribution of temperature along circumferential coordinate on roll surface at $\theta_{\max }=800{ }^{\circ} \mathrm{C}$

Then $\Delta \varepsilon=\Delta \sigma / E$ and $\Delta \sigma=2 \sigma_{\mathrm{amp}}$ are received as a result considering relationships:

$$
\ln N=\frac{1}{k} \lg \left[\frac{\sigma_{-1}}{\sigma_{\mathrm{t}}}\left(\frac{\sigma_{\mathrm{t}}-\sigma_{\mathrm{m}}}{\sigma_{\mathrm{amp}}}\right)\right] \text {, }
$$

where $\sigma_{\text {amp }}$ is the amplitude value of stress in the cycle.

Transfer from uniaxial equation (15) to multiaxial stressed state is performed using equivalent stress $\sigma_{1}=\sqrt{3} s_{i}=\left(2 / 3 s_{i j} s_{i j}\right)^{1 / 2}[17]$.

Taking into account $\sigma_{i \mathrm{amp}}=\sqrt{3} s_{i \mathrm{a}}$ and $\sigma_{\mathrm{m}}=$ $=3 s_{i \mathrm{~m}}$ relationships, the following is received after several transformations:

$$
\ln N=\frac{1}{k} \lg \left[\chi\left(\frac{\sigma_{\mathrm{t}}-\sqrt{3 s_{i \mathrm{~m}}}}{s_{i \mathrm{a}}}\right)\right],
$$

where

$$
\chi=\frac{\sigma-1}{\sigma_{\mathrm{t}}} \frac{N_{0}^{k}}{\sqrt{3}}
$$

Values $\sigma_{\mathrm{t}}=\sigma_{\mathrm{t}}(\theta), \sigma_{-1}=\sigma_{-1}(\theta), N_{0}(\theta)$ and $k(\theta)$ for each material were taken from reference literature [18-21], and $s_{i \mathrm{a}}, s_{i \mathrm{~m}}$ and $\theta$ values were
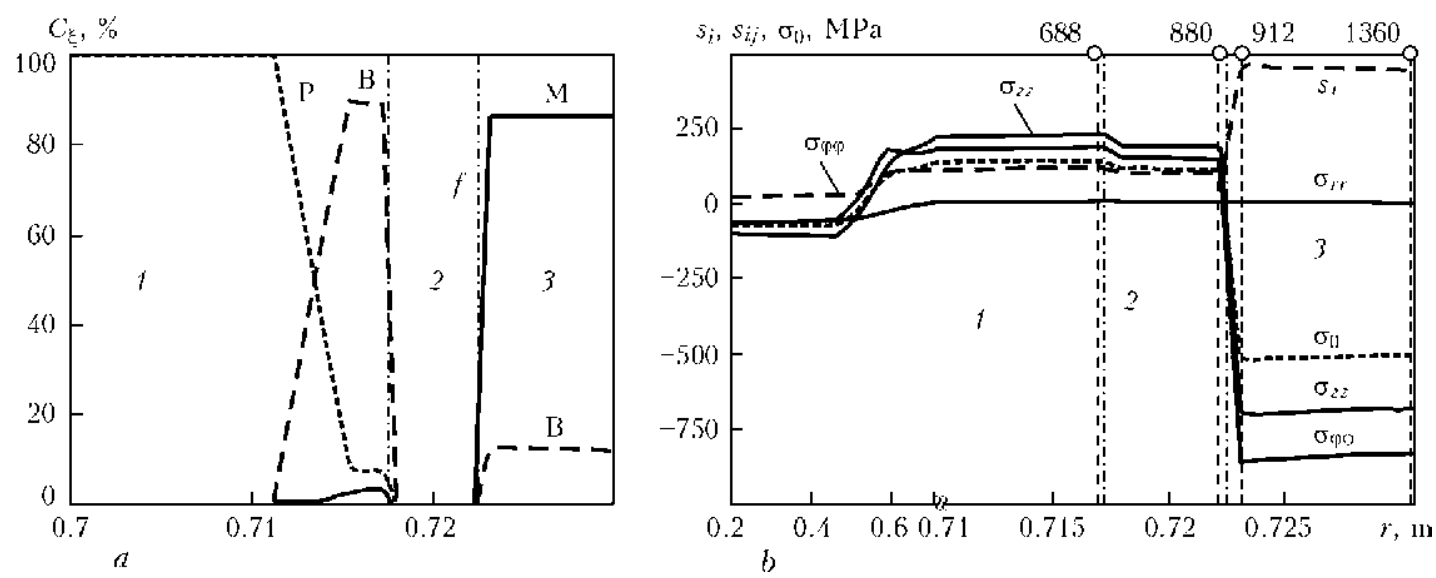

Figure 4. Residual microstrucutural $(a)$ and stress-strain $(b)$ state of deposited cylinder: 1 - base layer; 2 - deposited sublayer; 3 - deposited wear-resistant layer (digits in upper part of Figure $4, b$ correspond to numbers of points in Figure $\left.5, b ; \sigma_{0}=1 / 3 \sigma_{k k}\right)$ 

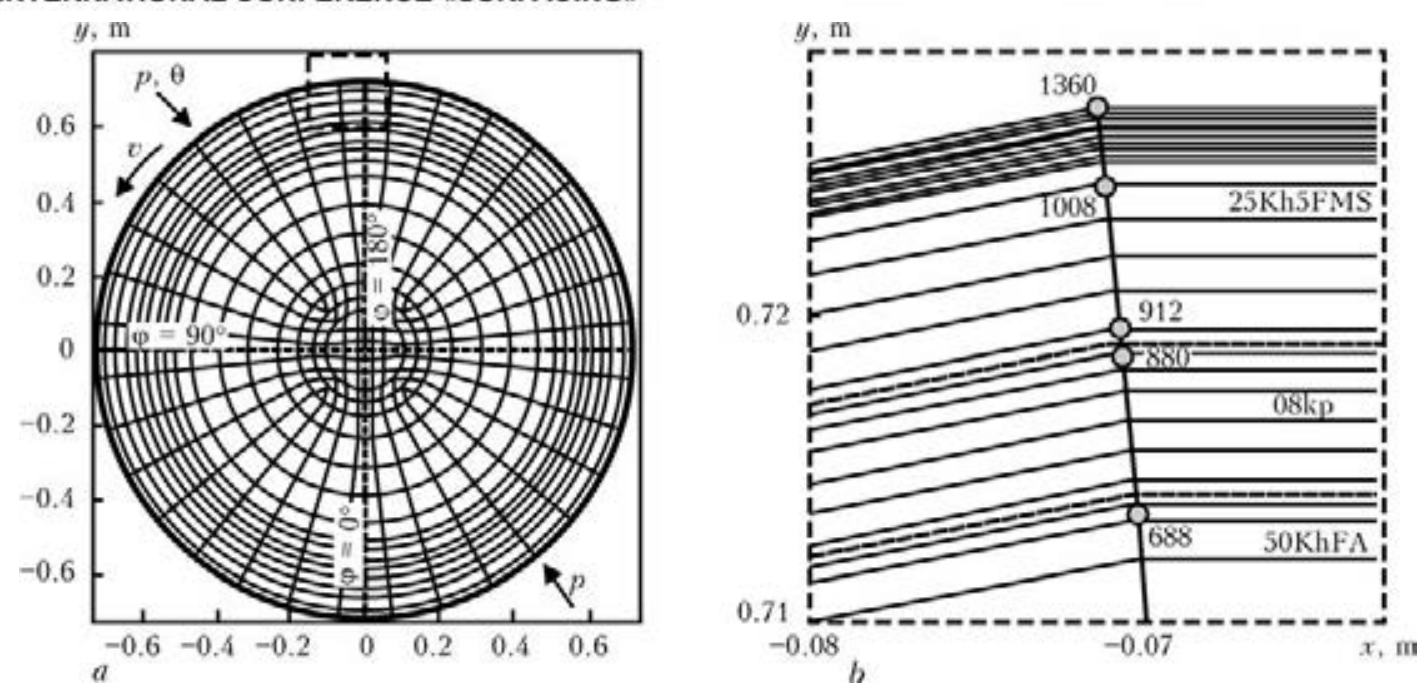

Figure 5. FE-mesh and scheme of roll loading: $a$ - full circle; $b$ - fragment of circle and numbers of points

calculated using numerical methods in each point of cylinder.

The following assumptions were used for specification of relationship $(16): \sigma_{-1}(\theta) / \sigma_{t}(\theta)=$ const, $k$ = const, $N_{0}=$ const for all temperatures; $\sigma_{\mathrm{t}}$ depends on temperature and in relationship (16) is calculated for maximum value of temperature in the cycle. Indicated assumptions result in some generalization of multicycle variant of Manson universal equation. Values of parameters in (16) and (17) are given below.

Problem of service loading of the cylinder is formulated in scope of flat deformation for middle section $z=L / 2$. In polar coordinate system $O_{r \varphi}$ the typical distribution of temperature and pressure in involute $\varphi^{*}=\varphi-\omega t$ (where $\omega$ is the circular frequency of roll rotation) is shown in Figure 3.

Boundary conditions are taken in the following form in area of contact with hot strip:

$$
\sigma_{r r}=\sigma\left(\varphi^{*}\right), \quad \sigma_{r z}\left(\varphi^{*}\right)=0, \quad\left|\varphi^{*}\right|<\varphi_{0}^{*} .
$$

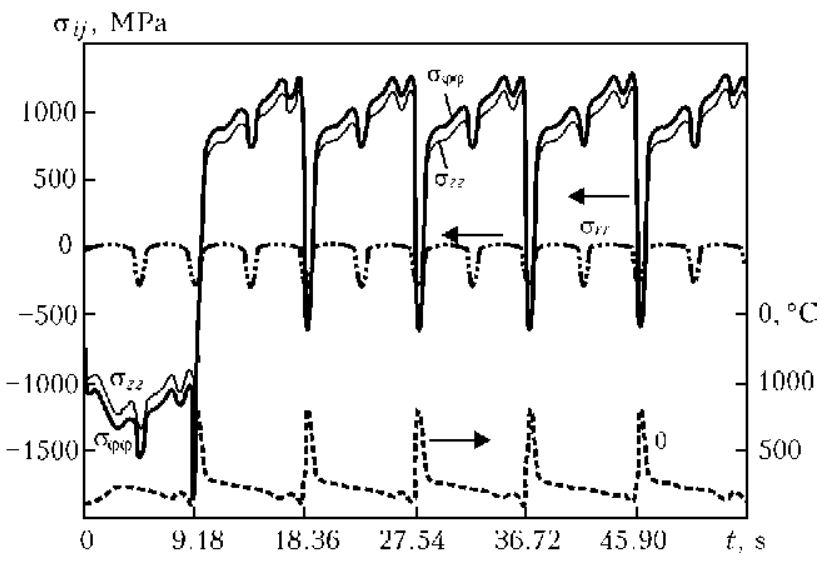

Figure 6. Operating stress-strain state in point 1360 in external deposited layer at $p_{0}=300 \mathrm{MPa}$ and $\theta_{\max }=800{ }^{\circ} \mathrm{C}$
In this case $\varphi^{*}=\varphi-\omega t ; \theta(\varphi)$ distribution is given in Figure $3 ; \sigma\left(\varphi^{*}\right)=p_{0} \sqrt{1-\left(\varphi^{*} / \varphi_{0}^{*}\right)^{2}}$ (where $2 \varphi_{0}^{*}$ is the area of loading effect).

Calculation of residual stresses. Simplified scheme of instantaneous surfacing by layers was realized in the following mode. Surface of the roll body was heated up to $1800{ }^{\circ} \mathrm{C}$ during $2.8 \mathrm{~s}$, then the first layer of steel $08 \mathrm{kp}$ (sublayer) of $h_{1}=5 \mathrm{~mm}$ thickness was deposited on it. After

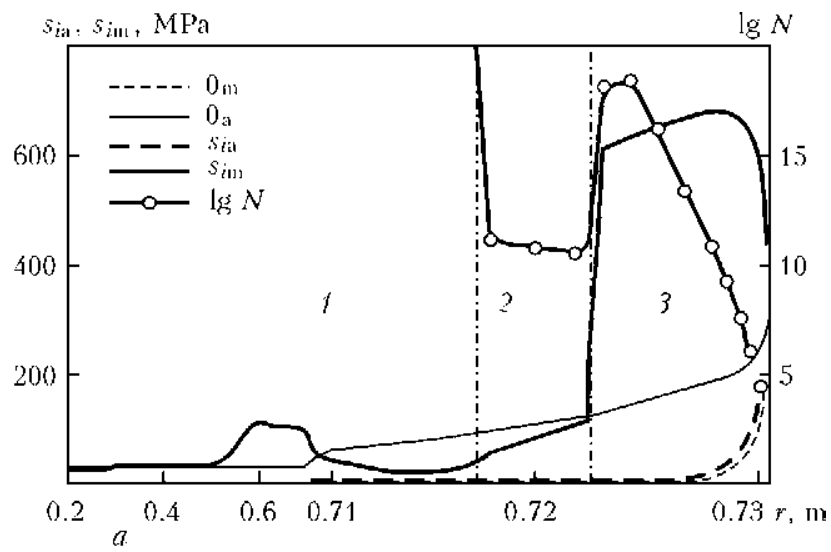
$\lg N$

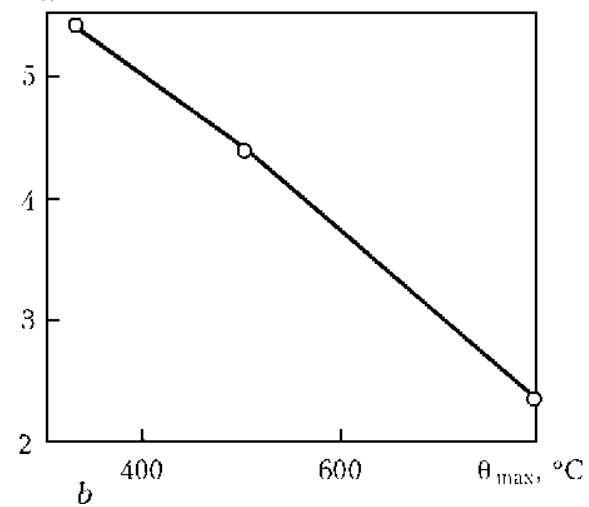

Figure 7. Radial distribution of life $\lg N$, mean $s_{i m}$ and amplitude $s_{i}$ values of stress intensity $s_{i}$ for $p_{0}=0, \theta_{\max }=$ $=500{ }^{\circ} \mathrm{C}$ cycle $(a)$, and dependence of life of external deposited layer on temperature $(b): 1$ - base layer; 2 deposited sublayer; 3 - deposited wear-resistant layer 
part cooled to $300{ }^{\circ} \mathrm{C}$ its surface was again heated up to $1800{ }^{\circ} \mathrm{C}$ during $2.8 \mathrm{~s}$, and the second layer of $h_{2}=8 \mathrm{~mm}$ thickness from steel 25Kh5FMS was deposited. Then part cooled to room temperature $20{ }^{\circ} \mathrm{C}$.

Figure 4 shows microstructural and stress-strain state of the deposited cylinder. Dashed lines indicate boundaries of the layers. It is seen that structure of external layer is mainly martensite, and near-boundary zones of the base metal is bainite. Since the martensite phase has maximum volume, then residual stresses in the external layer are compressive ones and that in sublayer and base metal are tensile ones (Figure $4, b$ ).

Calculation of service stresses. Figure $5, a$ shows the FE-mesh of cylinder section $z=L / 2$ (section $A-A$ in Figure 1), and Figure $5, b$ is the mesh fragment, extracted in Figure 5, $a$ by dashed square. Digits in this case as in Figure 4 show numbers of points, for which indices of stressstrain state were calculated. Arrows show mobile loading, $v$ is the linear speed of surface points.

Figure 6 shows the time dependencies of components of stresses and temperature for point 1360 close to cylinder surface at $v=0.5 \mathrm{~m} / \mathrm{s}$. It is seen that stresses in surface layer of roll in area of contact with hot strip $\left(\theta=\theta_{\max }\right)$ are compressive ones and in cooling they transform into tensile ones. Calculations show that effect of mechanical constituent of loading is insignificant at $p_{0}<300 \mathrm{MPa}$ and stress-strain state is formed due to heat loading.

Life evaluation. Life is calculated by formula (16), (17) in each point of cylinder section (see Figure $5, b$ ). Figure $7, a$, as an example, shows a radial distribution of life $\lg N$ as well as mean $s_{i \mathrm{~m}}$ amplitude $s_{i \mathrm{amp}}$ values of stress intensity $s_{i}$ for $p_{0}=0, \theta_{\max }=500{ }^{\circ} \mathrm{C}$ cycle. It can be seen that surface layers of external deposited layer of the roll has minimum life $N \approx 10^{4}$. At that, life of the surface layer significantly depends on temperature (Figure $7, b$ ). Sublayer and base metal under these conditions have fundamentally higher life.

\section{Conclusions}

1. Procedure was proposed for calculation of residual stress-strain and microstructural state of cylindrical part (of forming roll) in multilayer surfacing over lateral surface, as well as calculation of its fatigue life in further service cyclic thermomechanical loading.

2. Developed procedure allows evaluating fatigue life of deposited parts depending on value and relationship of service cyclic thermal and mechanical loads and on surfacing consumables applied for sublayer and wear-resistant layer.

1. Ryabtsev, I.A. (2004) Surfacing of machine and mechanism parts. Kiev: Ekotekhnologiya.

2. Ryabtsev, I.A., Senchenkov, I.K. (2013) Theory and practice of surfacing works. Kiev: Ekotekhnologiya.

3. Arutyunyan, N.Kh., Drozdov, A.D., Naumov, V.E. (1987) Mechanics of growing viscoelastoplastic bodies. Moscow: Nauka.

4. Senchenkov, I.K., Lobanov, L.M., Chervinko, O.P. et al. (1998) Principles of relative longitudinal displacements of plates in butt electric welding. Doklady NANU, 66-70.

5. Senchenkov, I.K. (2005) Thermomechanical models of growing cylindrical bodies from physically nonlinear materials. Prikl. Mekhanika, 41(9), 118-126.

6. Senchenkov, I.K., Chervinko, O.P., Banyas, M.V. (2013) Modeling of thermomechanical process in growing viscoplastic bodies with accounting of microstructural transformation: Encyclopedia of Thermal Stresses. Springer Ref., Vol. 6, 3147-3157.

7. Senchenkov, I., Chervinko, O., Turyk, E. et al. (2008) Examination of the thermomechanical state of cylindrical components deposed with layers of austenitic and martensitic steels. Welding Int., 22(7), 457-464.

8. Krempl, E. (2000) Viscoplastic models for high temperature applications. Int. J. Solids and Structures, 37, 279-291.

9. Bodner, S.R. (2000) Unified plasticity - an engineering approach (Final report). Haifa: IIT.

10. Senchenkov, I.K., Zhuk, Ya.A., Tabieva, G.A. (1998) Thermodynamically consistent modifications of generalized models of thermoviscoplasticity. Prikl. Mekhanika, 34(4), 53-60.

11. Senchenkov, I.K., Chervinko, O.P., Dolya, E.V. (2014) Modeling of residual stress-strain and microstructural state of cylinder in growing along lateral surface with melted metal layers. Teoriya $i$ Prikl. Mekhanika, Issue 8(54), 34-44.

12. Popov, A.A., Popova, L.E. (1961) Handbook of heat-treater. Isothermal and thermokinetics diagrams of overcooled austenite decay. M.-S.: GNTI Mashinostrit. L-ry.

13. Koistinen, D.R., Marburger, R.E. (1959) A general equation prescribing the extent of austenite-martensite transformation in pure iron-carbon alloys and carbon steel. Acta Metall., 7, 56-60.

14. Radaj, D. (2003) Welding residual stresses and distortion: Calculation and measurement. Dusseldorf: DVS.

15. Makhnenko, V.I. (2006) Safety life of welded joints and assemblies of modern structures. Kiev: Naukova Dumka.

16. Inone, T. (2011) Mechanics and characteristics of transformation plasticity and metallo-thermo-mechanical process simulations. Proced. Eng., 10, 3793-3798.

17. Dulnev, P.A., Kotov, P.I. (1980) Thermal fatigue of metals. Moscow: Mashinostroenie.

18. Troshchenko, B.T., Sosnovsky, L.A. (1987) Fatigue resistance of metals and alloys: Refer. Book, Pt 1. Kiev: Naukova Dumka.

19. Bezukhov, N.I., Bazhanov, V.L., Goldenblat, I.I. et al. (1965) Calculations of strength, stability and vibration under high-temperature conditions. Moscow: Mashinostroenie.

20. (2003) Reference book on grades of steels and alloys. Ed. by A.S. Zubchenko. Moscow: Mashinostroenie.

21. Johnson, K.L. (1989) Contact mechanics. Moscow: Mir. 


\title{
EFFECT OF SURFACING ON STRESS-STRAIN STATE OF ROLLERS OF MACHINES FOR CONTINUOUS CASTING OF BILLETS
}

\author{
A.P. GOPKALO and V.V. KLIPACHEVSKY \\ G.S. Pisarenko Institute for Problems of Strength, NASU \\ 2 Timiryazevskaya Str., 01014, Kiev, Ukraine. E-mail: postmaster@ipp.adam.kiev.ua
}

\begin{abstract}
The effect of ratio of physical and mechanical properties of the base and deposited metal on stress-strain state of rollers of machines for continuous casting of billets was considered using numerical modeling. It is shown that by varying the ratio of the coefficient of linear expansion and coefficient of thermal conductivity of base and deposited metals and their mechanical properties it is possible to control the value and sign of thermal stresses on the surface of rollers. 2 Ref., 2 Figures.
\end{abstract}

Key words: roller, surfacing, temperature, stresses, deformation

In engineering practice to increase the life of rollers of machines for continuous casting of billets (MCCB) a metal with higher characteristics of resistance to thermomechanical loading is deposited on their surface [1]. In this work, numerical simulation of estimation of influence of differences in physical and mechanical properties of the base and deposited metals on formation of stress-strain state (SSS) of MCCB rollers was carried out.

Figure 1 shows comparison of calculations of thermal stresses in monolithic (without deposit) MCCB roller of steel $25 \mathrm{Kh} 1 \mathrm{M} 1 \mathrm{~F}$ in elastic (curve 1) and elastic-plastic variants at the temperature dependence of physical characteristics and mechanical properties (curve 2), and also at their fixed $\left(T=20^{\circ} \mathrm{C}\right)$ values (curve 3$)$. As it follows

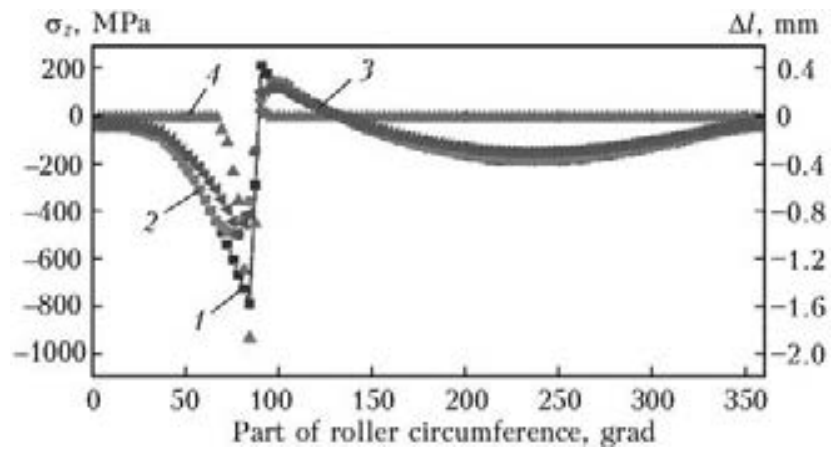

Figure 1. Distribution of calculation thermal stresses $\sigma_{z}$ along the surface of MCCB roller of steel $25 \mathrm{Kh} 1 \mathrm{M} 1 \mathrm{~F}$ contacting with slab in elastic (1) and elastic-plastic variants at the temperature dependence of physical characteristics [2] and mechanical properties (2), and at their fixed $(T=$ $=20^{\circ} \mathrm{C}$ ) values $(3)$, and distribution of plastic deformations $\Delta l$ around the roller circumference (4) from these data, consideration of temperature dependence of thermophysical and mechanical characteristics affects the character of diagram of thermal stresses relatively to the diagram obtained at their fixed values (compare curves 2 and 3). Estimation of SSS of the roller in elastic-plastic variant showed that in the area before contact of roller with slab the plastic compression deformations occur (curve 4), and in the contact zone of roller with slab the tensile deformations occur.

Figure 2 shows diagrams of thermal stresses on the surface of roller circumference part near the contact zone with slab, which were obtained

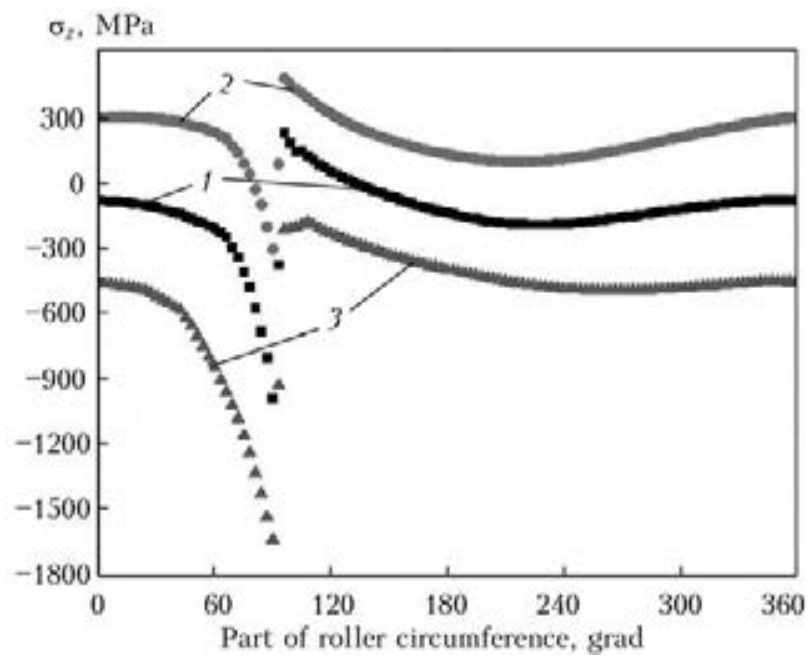

Figure 2. Effect of ratios of CLE of base and deposited metals on distribution of thermal stresses along the surface of MCCB roller (outer diameter of roller $D=300 \mathrm{~mm}$, thickness of deposit layer $\left.t_{1}=15 \mathrm{~mm}\right): 1-\alpha_{1}=\alpha_{2}=$ $=1.35 \cdot 10^{-1} ; c_{1}=c_{2}=45$ (without deposit) $; 2-\alpha_{1}=$ $=1.8 \cdot 10^{-5} ; \alpha_{2}=0.9 \cdot 10^{-5} ; c_{1}=65 ; c_{2}=25 ; 3-\alpha_{1}=0.9 \cdot 10^{-5}$; $\alpha_{2}=1.8 \cdot 10^{-5} ; c_{1}=65 ; c_{2}=25$ (where $c_{1}-$ CTC of base; $c_{2}-$ of deposit; $\alpha_{1}-$ CLE of base; $\alpha_{2}-$ of deposit) 
by calculation in the elastic variant at varying of physical and mechanical characteristics of base and deposited metal. It is considered that at equality of physical and mechanical characteristics of deposited and base metals the roller is monolithic. In this example, the influence of ratios of coefficient of linear expansion (CLE) of base metal and that of deposit on SSS of the roller at the same values of coefficient of thermal conductivity (CTC) is considered. The increase of CLE values of deposited metal by 2 times respectively to base metal causes increase in values of thermal compression stresses in the most loaded zone before the contact of roller with slab (curve 3) by 1.65 times as compared to the corresponding stresses for monolithic roller (curve 1 ). Moreover, on the surface of contact area of roller with slab the thermal compression stresses also occur unlike the monolithic roller, which is characterized by the thermal tensile stresses. The use of metal for surfacing with CLE values by 2 times lower than that for the base metal resulting in 3 times reduction in thermal compression stresses in the contact of roller with slab (2) relatively to the corresponding thermal stresses in the monolithic roller (curve 1). At the same time on surface of the contact area of roller with slab the thermal tensile stresses occur, which are 2.2 times higher than those in the monolithic roller.

Thus, by varying of CLE and CTC ratios of base and deposited metals and their mechanical properties it becomes possible to control the value and sign of thermal stresses on the roller surface. The calculation optimization of these ratios, taking into account the operational mechanical loads can serve as a basis for development of technical solutions not only for recovery of service properties of surface layers of MCCB rollers, but also to increase their life.

1. Bulanov, L.V., Korzunin, L.G., Parfenov, E.P. et al. (2004) Machines for continuous casting of billets. In: Theory and calculation. Kazan: Ural center Marat.

2. (1967) Physical properties of steels and alloys applied in power engineering: Refer. Book. Ed. by B.E. Nejmark. Moscow-Leningrad: Energiya.

Received 29.04.2015 


\title{
MODELING OF PROCESS OF MELTING OF ELECTRODES WITH EXOTHERMAL MIXTURE IN COATING DURING REPAIR WELDING AND SURFACING
}

\author{
A.M. KUSHCHY and A.F. VLASOV \\ Donbas State Machine Building Academy \\ 72 Shkadinov Str., 84313, Kramatorsk, Donetsk region, Ukraine. E-mail: dgma@dgma.donetsk.ua
}

\begin{abstract}
Application of high-production electrodes in welding-up of casting defects and repair of stands is still relevant up to present moment. Efficiency of surfacing process can be increased by using exothermal mixtures in coating. The work studies the possibility of optimizing fusion of electrode coating with iron powder containing scale of rolling industry and aluminum powder. Statistical model was proposed allowing optimizing content of exothermal mixture in coating for minimizing loss of electrode metal. 6 Ref., 6 Figures.
\end{abstract}

Keywords: arc welding and surfacing, repair, coated electrodes, exothermal mixture, electrode melting, simulation

Coated-electrode arc welding and surfacing is one of the efficient methods of repair in welding-up of casting defects and cracks of stands of metalworking machines. At that, entering up to $70 \%$ of iron powder in electrode coating composition at simultaneous increase of its thickness can result in rise of efficiency. Introduction of significant amount of iron powder in electrode coatings promotes for reduction of their plasticity and process complication due to non-uniform fusion of rod and coating, formation of such called nose, which results in unsatisfactory weld formation and arc extinction.

Uniformity of fusion of electrode rod and coating can be reasonably provided by application of effect of exothermal reactions [1]. Thermit welding is tending to reach higher temperatures, therefore, thermit mixtures are manufactured based on iron oxide. Results of calculation of temperature of scale and its constituents during reaction with aluminum powder showed that using roll scale instead of scale of forge-and-press production at small difference in heat emission promotes for reduction of larger amount of iron. This has positive effect not only on uniformity of fusion of electrode coating and rod, but also on quality of deposited metal and allows selecting scale of rolling production and aluminum powder as base components for exothermal reaction [2].

Aim of preset work is optimizing parameters of fusion of electrode coating with exothermal mixture consisting of scale of rolling production and aluminum powder.

Simulation of fusion process is carried out using Statistica 6 [3-6] software complex. Experimental realizing of the designs is performed by means of determination of coefficient of deposition and loss of electrode metal. Parameters being varied are the content of exothermal mixture in

\begin{tabular}{|c|c|c|c|c|c|c|}
\hline \multirow[b]{2}{*}{ Factor } & \multicolumn{6}{|c|}{$\begin{array}{l}\text { Regr. Coefficients; Var.:AH; R-sqi=,93047; Adj; ,39357 (Spreadsheet9) } \\
2 \text { factors, } 1 \text { Blocks, } 10 \text { Runs; MS Residual=2,487993 } \\
\text { DV: AH }\end{array}$} \\
\hline & \begin{tabular}{|c|} 
Regressn \\
Coeff.
\end{tabular} & Std.Err. & $t(4)$ & $p$ & $\begin{array}{c}-95, \% \\
\text { Cnf.Limt } \\
\end{array}$ & $\begin{array}{c}+95, \% \\
\text { Cnf.Limt }\end{array}$ \\
\hline Mean/interc. & 6,91111 & 3,160179 & 1,71089 & 0,016227 & $-3,36734$ & 14,18079 \\
\hline (1)Q(L) & 0,13958 & 0,158751 & 0,65771 & 0,044665 & $-0,33635$ & 0,54517 \\
\hline$Q(Q)$ & $-0,00083$ & 0,002399 & 0,21521 & 0,008401 & $-0,00614$ & 0,00718 \\
\hline (2)D(L) & 1,02500 & 3,175017 & 2,35885 & 0,007776 & $-1,32586$ & 16,30466 \\
\hline $\mathrm{D}(\mathrm{Q})$ & $-0,01603$ & 0,959621 & $-1,80210$ & 0,014588 & $-4,39367$ & 0,93500 \\
\hline $1 \mathrm{~L}$ by $2 \mathrm{~L}$ & 0,00901 & 0,039433 & $-2,50422$ & 0,006647 & $-0,20823$ & 0,01073 \\
\hline
\end{tabular}

Figure 1. Analysis of experiment design-matrix (model 1) 


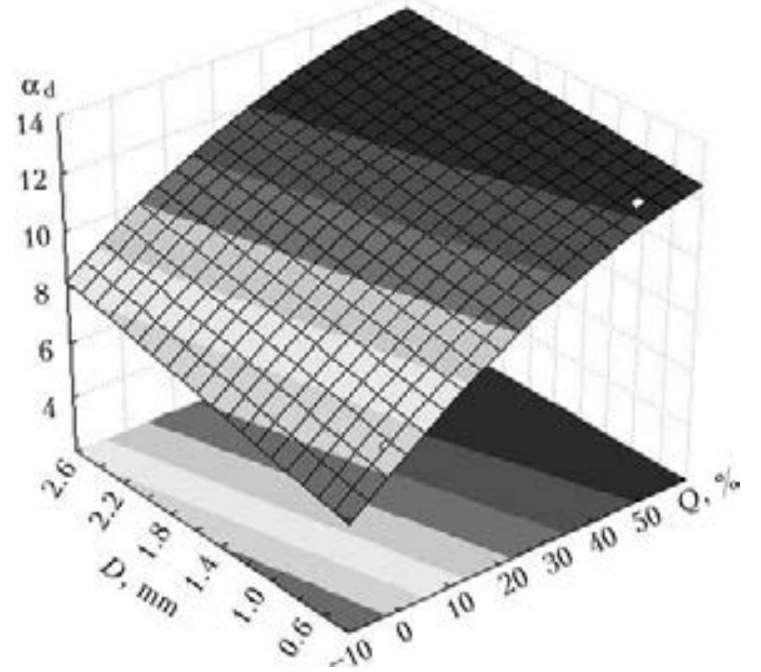

Figure 2. Dependence of deposition coefficient $\alpha_{\mathrm{d}}$ on amount of exothermal mixture $Q$ and thickness of electrode coating $D$

the coating of electrodes $N_{\text {ex.m }}$, amount of scale portion in relation to portion of aluminum pow$\operatorname{der} A$ and thickness of electrode coating $D$.

Experiments with factors varying at two levels, i.e. experiments of $2^{k}$ type, have found the largest distribution. Rise of number of factors and variation levels sharply increases number of experiments, therefore, orthogonal designs of the second order $2^{2}$ were used [6]. Mathematical models were designed describing effect of the following pairs of factors on deposition coefficient and electrode metal loss coefficient. They are content of exothermal mixture in electrode coating $N_{\text {ex.m }}$ and thickness of electrode coating $D$, amount of scale portion in relation to portion of aluminum powder $A$ and thickness of electrode coating $D$.

Model 1. Factors: amount of exothermal mixture $Q$ and thickness of electrode coating $D$. Response is the deposition coefficient $\alpha_{\mathrm{d}}$. Figure 1 shows analysis of experiment plan-matrix.

It is seen from Figure 1 that all members of the model have statistically significant effects (level $p<0.05$ ). It also gives value of approxi-

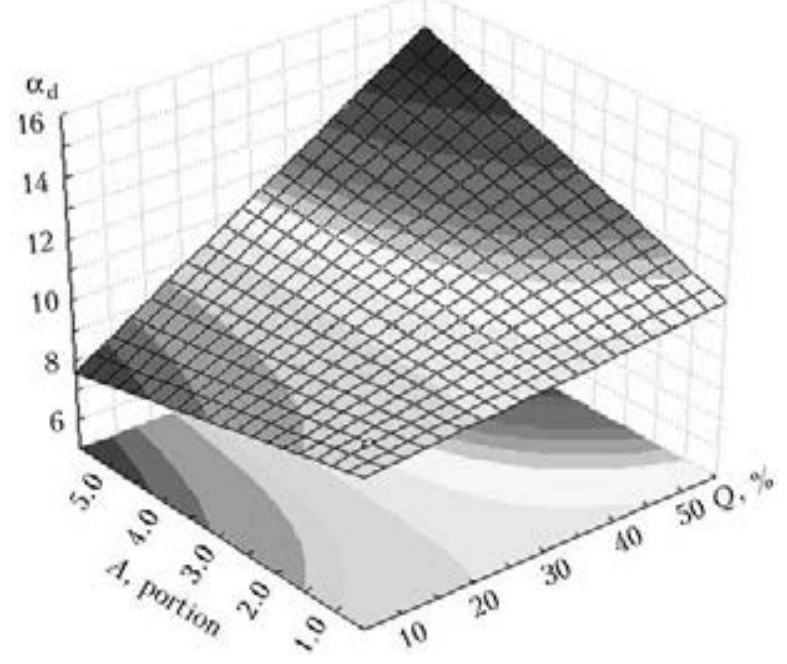

Figure 4. Dependence of surfacing coefficient $\alpha_{\mathrm{d}}$ on amount of exothermal mixture $Q$ and amount of scale portion $A$

mation reliability $R$-sqr $=0.93047-$ general quality of the model is good. Calculation of coefficients of regression is represented in the first column; $t$ (4) is the observed values of Student's criterion; $p$ is the significance of coefficients on Student's criterion; two last columns are the intervals for coefficients.

Regression equation looks like:

$$
\begin{gathered}
\alpha_{d}=6.911111+0.139500 Q-0.000827 Q^{2}+ \\
+1.025000 D-0.016667 D^{2}-0.009000 Q D .
\end{gathered}
$$

Figure 2 shows response surface.

Model 2. Factors: amount of exothermal mixture $Q$ and amount of scale portion in relation to aluminum $A$; response is the deposition coefficient $\alpha_{d}$. Figure 3 shows analysis of experiment plan-matrix.

It is seen from Figure 3 that all members of the model have statistically significant effects (level $p<0.05$ ). It also gives value of approximation reliability $R$-sqr $=0.98857-$ general quality of the model is good. Calculation of coefficients of regression is represented in the first column; $t(3)$ is the observed values of Student's criterion; $p$ is the significance of coefficients on

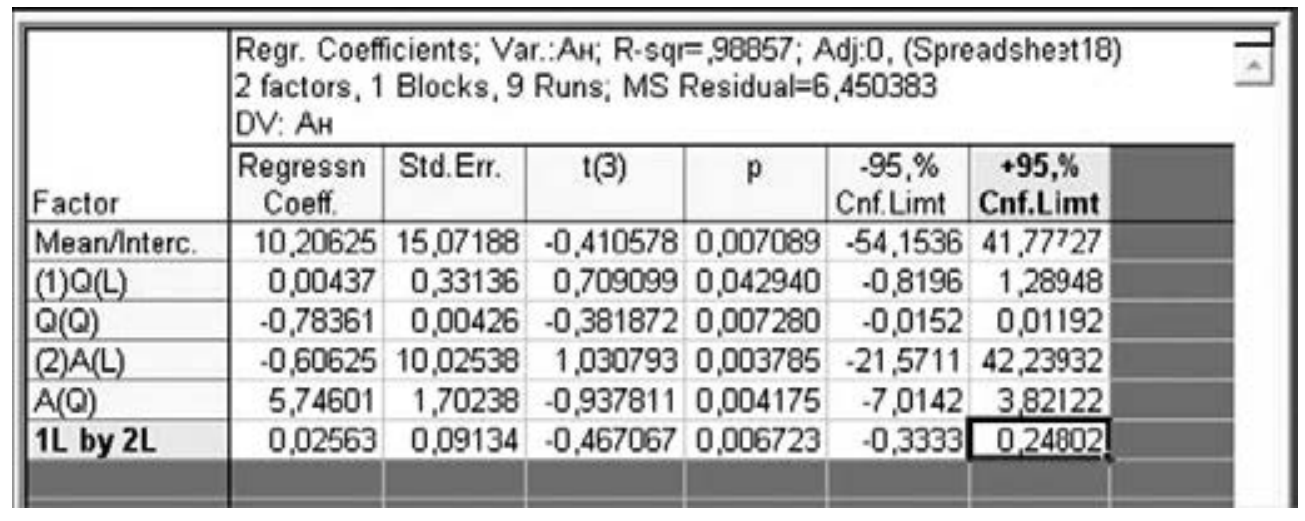

Figure 3. Analysis of experiment design-matrix (model 2) 


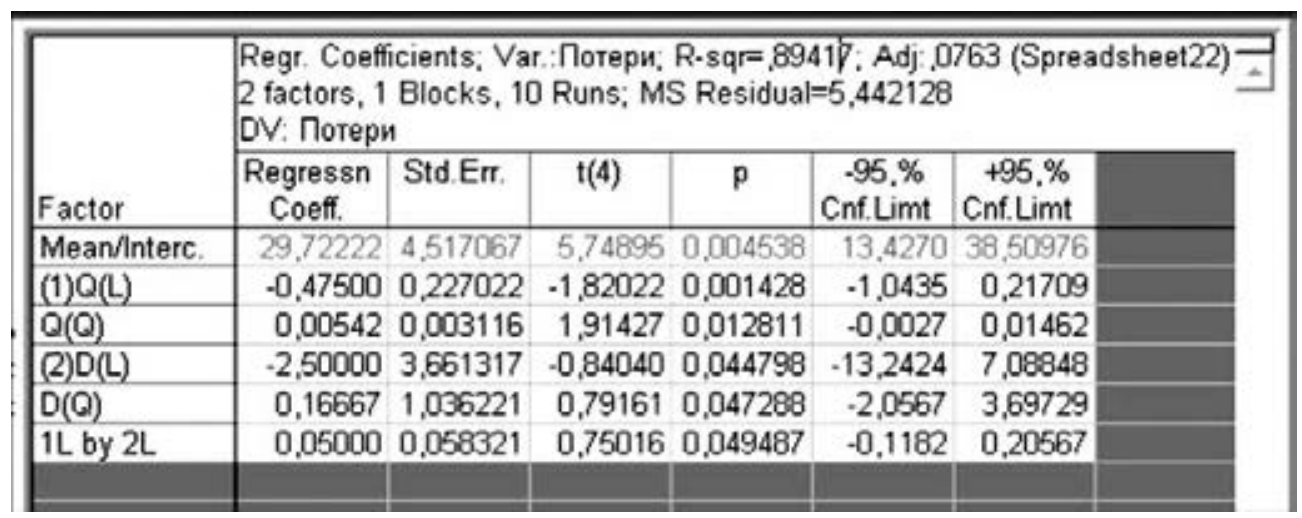

Figure 5. Experiment design-matrix and its realizing (model 3)

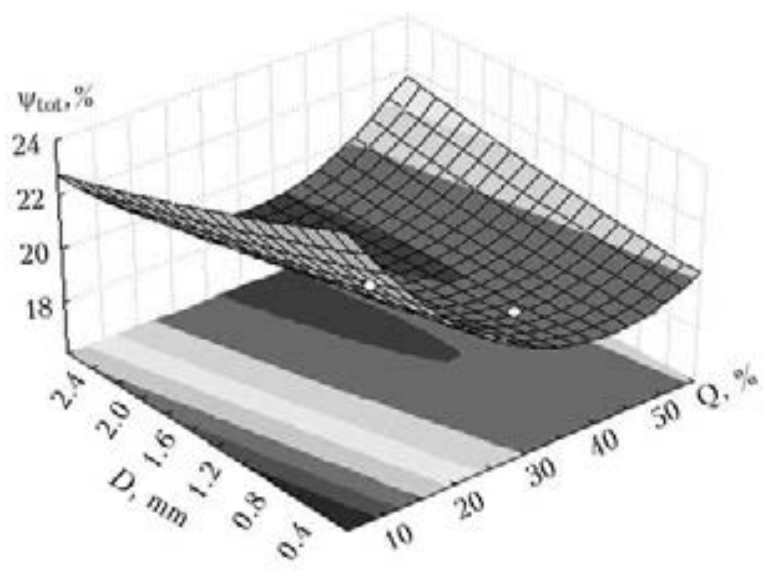

Figure 6. Dependence of coefficient of electrode metal loss $\psi$ tot on thickness of electrode coating $D$ and amount of exothermal mixture $Q$

Student's criterion; two last columns are the intervals for coefficients.

Regression equation looks like:

$$
\begin{gathered}
\alpha_{d}=10.20625+0.00437 Q-0.78361 Q^{2}- \\
-0.60625 A+5.7460 A^{2}+0.02563 A Q .
\end{gathered}
$$

Figure 4 shows response surface.

Model 3. Factors: amount of exothermal mixture $Q$ and thickness of electrode coating $D$; response is the loss coefficient $\psi_{\text {tot }}$. Figure 5 shows analysis of experiment plan-matrix.

It is seen from Figure 5 that all members of the model have statistically significant effects (level $p<0.05$ ). It also gives value of approximation reliability $R$-sqr $=0.89417-$ general quality of the model is good. Calculation of coefficients of regression is represented in the first column; $t(4)$ is the observed values of Student's criterion; $p$ is the significance of coefficients on Student's criterion; two last columns are the intervals for coefficients.

Regression equation looks like:

$$
\begin{gathered}
\psi_{\text {tot }}=29.72222-0.47500 Q+0.00542 Q^{2}- \\
-2.50000 \delta+0.16667 \delta^{2}+0.05000 Q \delta .
\end{gathered}
$$

Figure 6 shows response surface.

Analysis of obtained models showed that the optimum one is content of exothermal mixture in the amount of $35-40 \%$ at coating thickness $1.6 \mathrm{~mm}$ per side and scale to aluminum powder relationship 3:1. Such parameters provide for the lowest value of coefficient of electrode metal loss and deposition coefficient corresponds to set value in calculation of optimum content of exothermal mixture.

\section{Conclusion}

Statistical model is proposed. Its analysis shows that content of exothermal mixture in the amount of $35-40 \%$ is the optimum one at coating thickness $1.6 \mathrm{~mm}$ per side and 3:1 scale to aluminum powder relationship. Such parameters promote for the lowest value of coefficient of electrode metal loss and deposition coefficient corresponds to set value in calculation of optimum content of exothermal mixture.

1. Vlasov, A.F., Makarenko, N.A., Kushchy, A.M. (2014) Heating and melting of electrodes with exothermic mixture in coating. The Paton Welding J., $6 / 7,147-150$.

2. Vlasov, A.F., Kushchy, A.M. (2013) Improvement of high-efficient electrodes for manual arc welding and surfacing. In: Proc. of Int. Sci.-Techn. Conf. on University Science (Mariupol, GVUZ PGTU, 2013).

3. Yashcheritsyn, P.I. (1985) Planning of experiment in machine-building. Moscow: Mashinostroenie.

4. Spiridonov, A.A. (1981) Planning of experiment in examination of technological processes. Moscow: Mashinostroenie.

5. Zarubin, V.S. (2001) Mathematical modeling in technique: Manual for higher education institutions. Ed. by V.S. Zarubin, A.P. Krishchenko. Moscow: MGTU.

6. Borovikov, V.P. (2001) Statistica: Art of computer data analysis. For professionals. St.-Petersburg: Piter. 